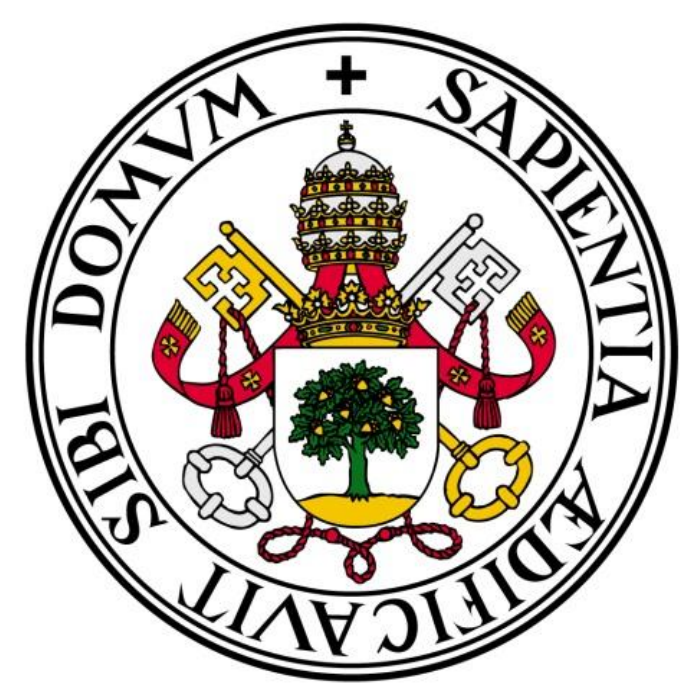

Universidad de Valladolid. Facultad de Medicina. Hospital Clínico Universitario de Valladolid.

\title{
METABOLISMO ÓSEO-MINERAL Y CALCIFICACIÓN VASCULAR EN EL TRASPLANTADO RENAL.
}

Tesis presentada para la obtención del grado de Doctor en Medicina por:

Armando Coca Rojo

Dirigida por el Profesor:

Jesús Bustamante Bustamante

Valladolid, Enero 2016. 

A mis padres Armando y Mạ Concepción y a mi tía Irenea.

A Marta. 



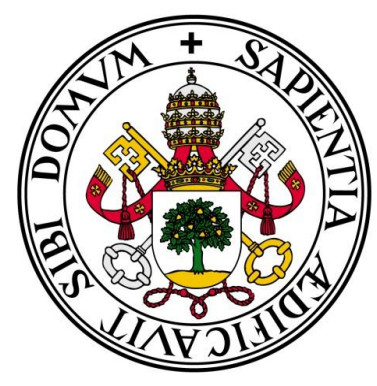

Jesús Bustamante Bustamante, Profesor Emérito de la Facultad de Medicina de la Universidad de Valladolid

\section{CERTIFICA:}

Que ha dirigido el trabajo titulado "METABOLISMO ÓSEO-MINERAL Y CALCIFICACIÓN VASCULAR EN EL TRASPLANTADO RENAL" realizado por Armando Coca Rojo y que lo consideran apto para su defensa pública como tesis doctoral.

Para que conste donde convenga firman en Valladolid a 16 de Diciembre de 2015.

Prof. Jesús Bustamante Bustamante 



\section{AGRADECIMIENTOS.}

Me gustaría expresar mi más sincero agradecimiento a todas aquellas personas que han contribuido en el terreno profesional al desarrollo de esta tesis doctoral y a aquellas personas que me han ofrecido su apoyo incondicional en el ámbito personal. De manera especial,

Al Prof. D. Jesús Bustamante Bustamante, Catedrático de Nefrología de la Universidad de Valladolid, director de este trabajo, por sus explicaciones, su continuo asesoramiento y colaboración en la realización de esta tesis.

A la Profa Dña. Alicia Mendiluce Herrero, por su apoyo, confianza y disponibilidad en todo momento. Por sus enseñanzas y buenos consejos a lo largo de mi residencia en el Servicio de Nefrología del Hospital Clínico Universitario de Valladolid.

Al Dr. Jesús Mạ Núñez García, por su ayuda y consejos a lo largo de estos años y sus magistrales lecciones sobre el metabolismo óseo-mineral en el enfermo renal y muchos otros temas.

Al Prof. Dr. Najaty S. Jabary, por su apoyo y confianza, y por haberme guiado en mis primeros pasos en la realización de éste y otros trabajos.

Al Prof. Dr. Jose Ma Monfá Bosch, por su ayuda y colaboración durante la elaboración de este estudio.

Al personal de enfermería, en especial a Dña. Mạ Rita Pons Martín, enfermera de la Unidad de Trasplante Renal del HCUV y Dña. Mã Jesús Rollán De la Sota, supervisora de enfermería del Servicio de Nefrología del HCUV, por su ayuda desinteresada en todo momento. 
Al Dr. Vicente Pérez Díaz, a la Dra. Mạ Victoria Oviedo Gómez, del Servicio de Nefrología del Hospital Río Carrión de Palencia y a la Dra. Luisa Sánchez García, del Servicio de Nefrología del Hospital Río Hortega de Valladolid, por su ayuda en la realización de este trabajo.

A la Dra. Ana Revilla, del Servicio de Cardiología del Hospital Clínico Universitario de Valladolid, al Dr. Israel Sánchez Lite, del Servicio de Radiología del Hospital Clínico Universitario de Valladolid y a los Dres. Azael J. Herrero y Héctor Menéndez del Centro de Investigación en Discapacidad Física (CIDIF) por su colaboración en la realización de las diferentes pruebas de imagen.

A mis compañeros del Servicio de Nefrología del Hospital Clínico Universitario de Valladolid, por su apoyo personal y profesional a lo largo de todos los años que hemos compartido juntos.

Finalmente a los pacientes trasplantados que han colaborado de forma altruista en la realización de este trabajo.

A todos ellos, gracias. 


\section{ABREVIATURAS:}

1,25[OH]2D: 1,25-dihidroxi-vitamina D.

BGP: Proteína GLA ósea.

BMP: Proteína morfogenética ósea.

CBFA1: Factor de fijación de núcleos A1.

CAC: Calcificación en arterias coronarias.

CAA: Calcificación en aorta abdominal.

CML: Células musculares lisas.

Cols: Colaboradores.

Cr: Creatinina.

CV: Calcificaciones vasculares.

DEXA: Absorciometría de rayos $\mathrm{X}$ de energía dual.

DMO: Densidad mineral-ósea,

ECV: Enfermedad cardiovascular.

ERC: Enfermedad renal crónica.

FRCV: Factores de riesgo cardiovascular.

FG: Filtrado glomerular.

FGF: Factor de crecimiento de fibroblastos.

FGFR1: Receptor 1 de FGF-23.

GIM: Grosor íntima-media.

HbA1c: Hemoglobina glicosilada.

HDL: Lipoproteina de alta densidad.

HTA: Hipertensión arterial.

HVI: Hipertrofia ventricular izquierda.

IGF: Factor de crecimiento semejante a insulina.

IL: Interleukina.

LDL: Lipoproteína de baja densidad.

LRP5: Proteína 5 relacionada con el receptor de lipoproteínas.

M-CSF: Factor estimulador de colonias de macrófagos.

MOM: Metabolismo óseo-mineral.

NFAT: Factor nuclear de células T activadas. 
NTI: Nefropatía túbulo-intersticial.

OPG: Osteoprotegerina.

PCR: Proteína C Reactiva.

PTH: Hormona paratiroidea.

PTHi: Hormona paratiroidea intacta.

PTH-R1: Receptor 1 de PTH 1.

PTHrP: Proteína asociada a PTH.

RANK: Ligando del receptor activado de NFkB.

RCa: Receptor sensible al calcio.

Rs: Rho de Spearman.

Rx: Radiografía.

TA: Tensión arterial.

TAC: Tomogragía axial computerizada.

TEFG: Tasa estimada de filtrado glomerular.

TNF: Factor de necrosis tumoral.

TRS: Terapia Renal Sustitutiva.

Tto: Tratamiento.

Tx: Trasplante.

VD: Vitamina D.

VDR: Receptor de vitamina D.

VLDL: Lipoproteína de muy baja densidad. 


\section{ÍNDICE}

INTRODUCCIÓN

1.1: METABOLISMO MINERAL EN CONDICIONES NORMALES .......................................... 2

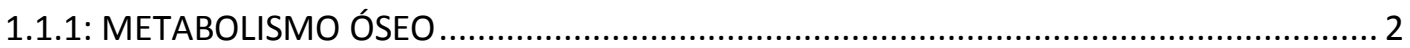

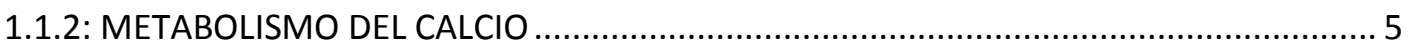

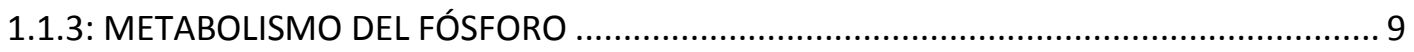

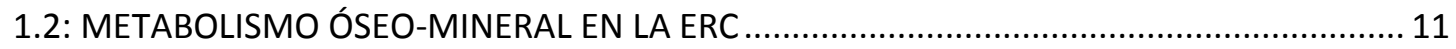

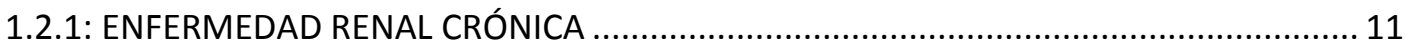

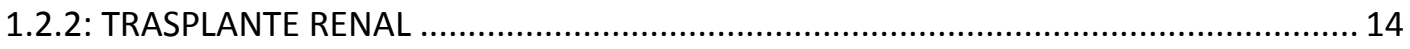

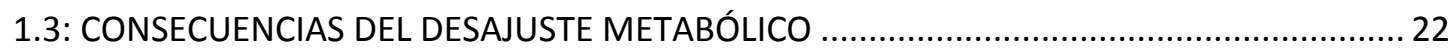

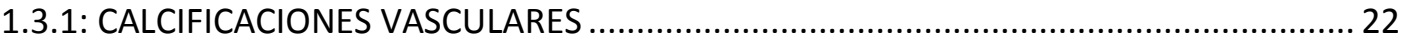

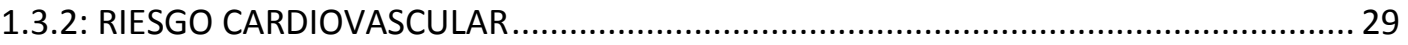

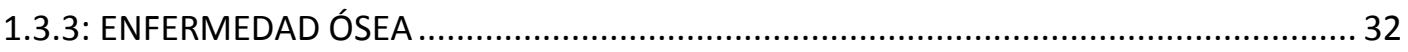

1.3.4: CONSECUENCIAS DEL DESAJUSTE METABÓLICO EN EL TRASPLANTE ........................ 34

1.4: MÉTODOS PARA LA EVALUACIÓN DEL MOM .............................................................. 40

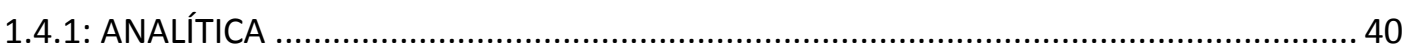

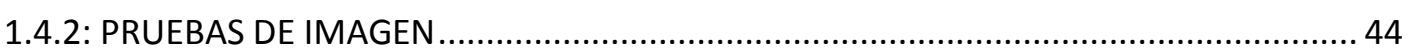

1.5: ESTUDIOS REALIZADOS EN ESPAÑA SOBRE MOM Y ERC ............................................... 53

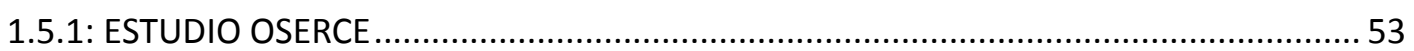

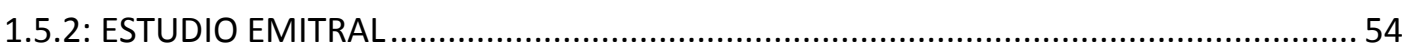

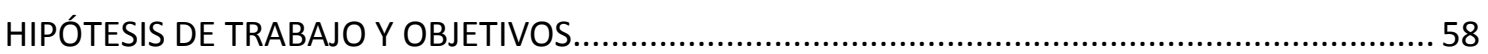

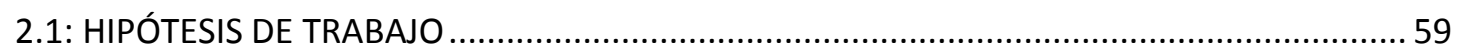

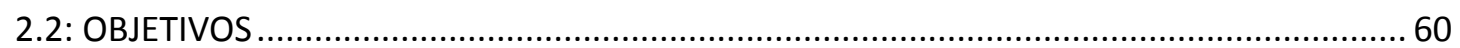

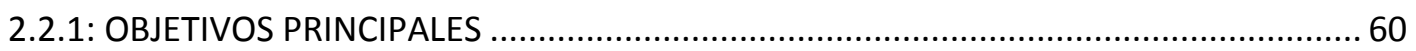

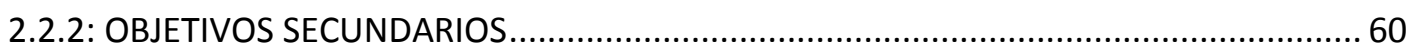

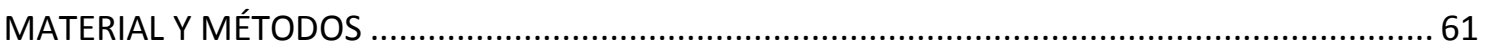

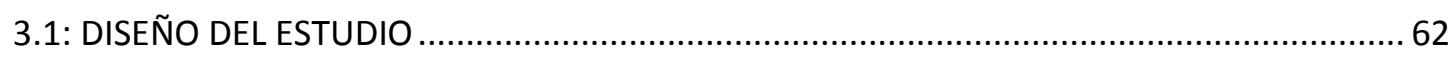

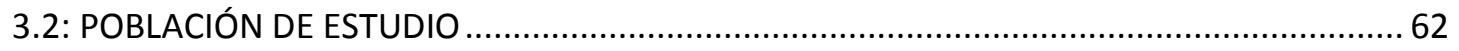

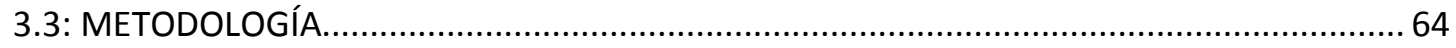

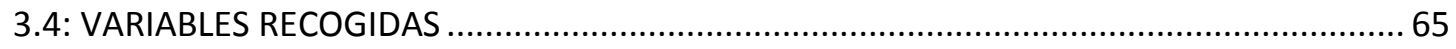

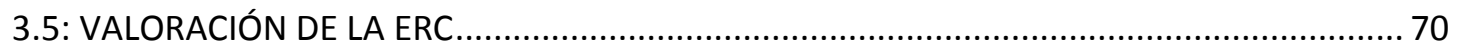

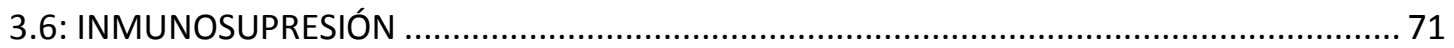

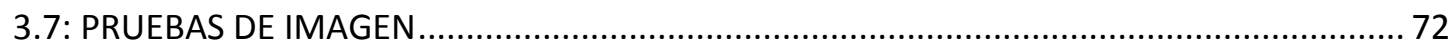

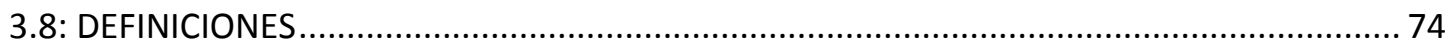

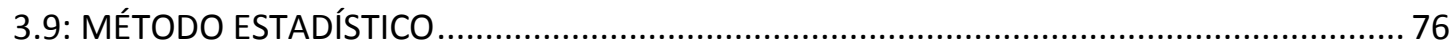

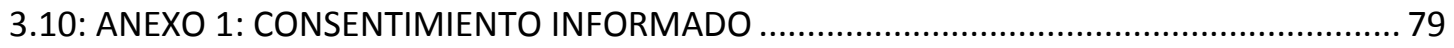


3.12: ANEXO 2: COMITÉ ÉTICO DE INVESTIGACIÓN CLÍNICA .82

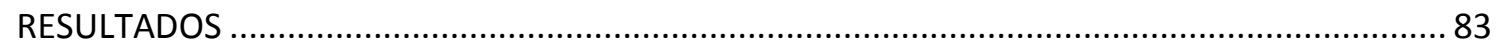

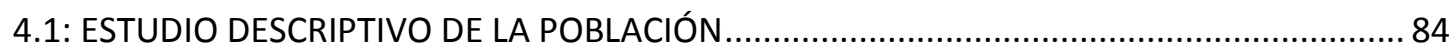

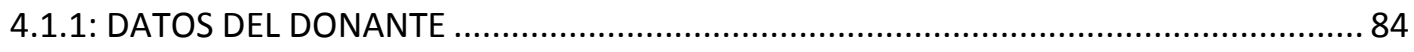

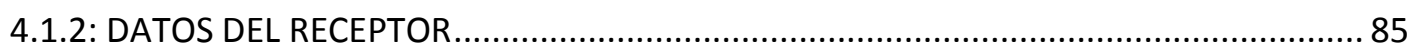

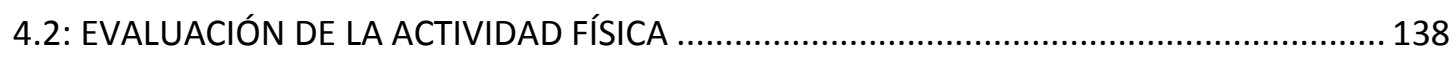

4.3: EVALUACIÓN DEL GRADO DE CALCIFICACIÓN VASCULAR Y ÓSEA.................................. 139

4.3.1: CUANTIFICACIÓN DEL CALCIO EN ARTERIAS CORONARIAS ..................................... 139

4.3.2: GROSOR ÍNTIMA-MEDIA EN ARTERIA CARÓTIDA ................................................... 83

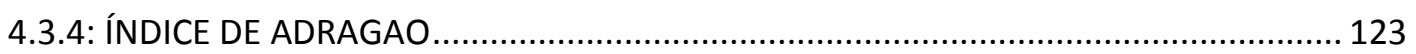

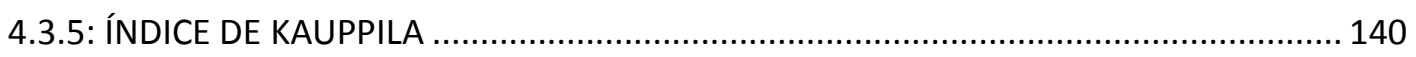

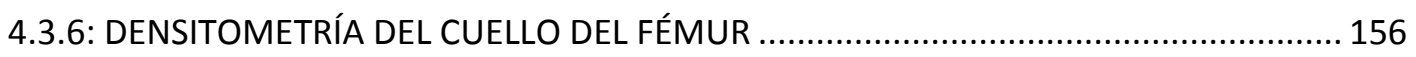

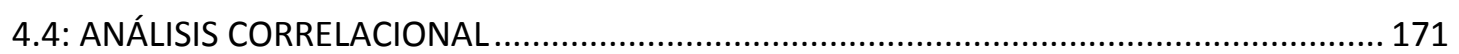

4.5: ESTUDIO DE LA SENSIBILIDAD Y ESPECIFICIDAD DIAGNÓSTICA .................................... 178

4.6: MODELO DE REGRESIÓN PARA PREDECIR EL GOLD STANDARD ................................... 179

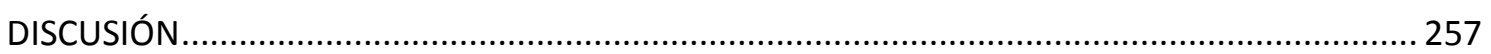

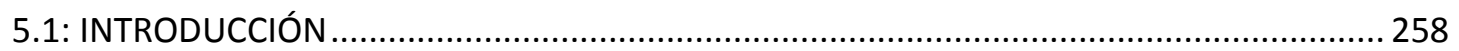

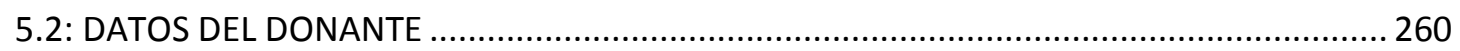

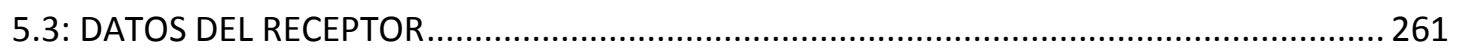

5.3.1: ANTECEDENTES Y FACTORES DE RIESGO CARDIOVASCULAR ................................264

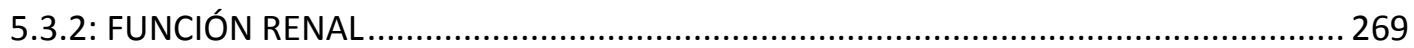

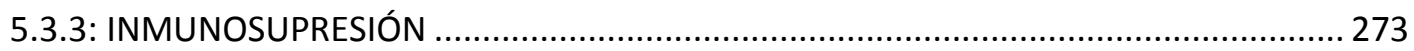

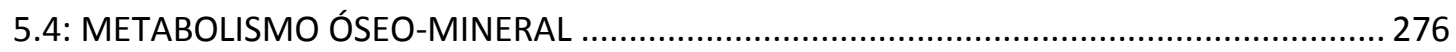

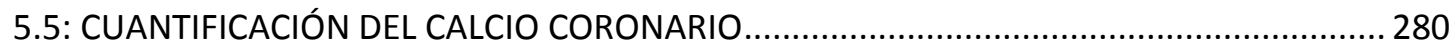

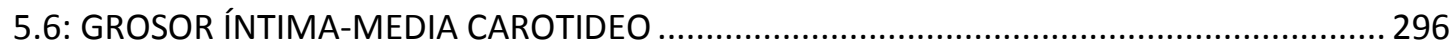

5.7: CALCIFICACIÓN VASCULAR EVALUADA MEDIANTE ÍNDICES RADIOGRÁFICOS ................306

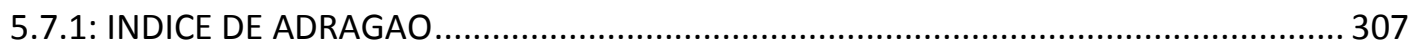

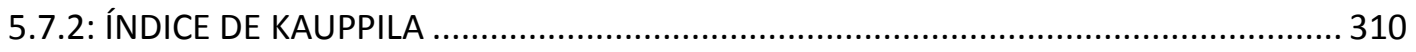

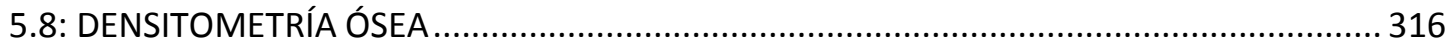

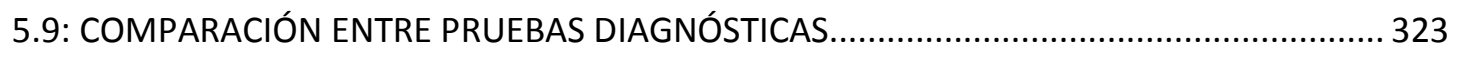

5.10: MODELO PREDICTIVO DEL GRADO DE CALCIFICACIÓN CORONARIA.............................325

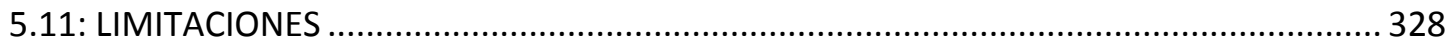

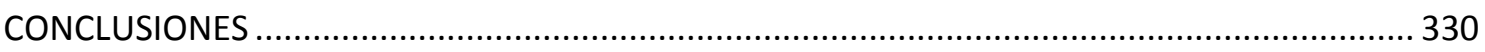

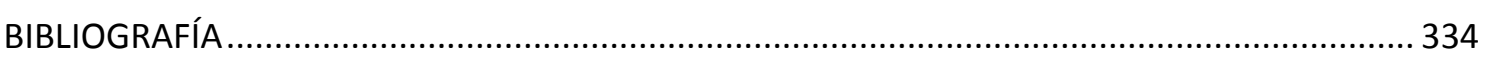


INTRODUCCIÓN

\section{INTRODUCCIÓN}




\section{1: METABOLISMO MINERAL EN CONDICIONES NORMALES}

\subsection{1: METABOLISMO ÓSEO}

El hueso se compone, a grandes rasgos, de dos tipos de tejido: el hueso cortical, mayoritariamente calcificado y localizado principalmente en la diáfisis de los huesos largos y en la superficie de los huesos planos, suponiendo aproximadamente el $85 \%$ del hueso total, y el hueso trabecular, propio de las regiones epifisarias y metafisarias de los huesos largos y de los huesos cortos, en su mayor parte no calcificado y que supone el $15 \%$ restante $(\mathbf{1})$.

El esqueleto se encuentra muy vascularizado, recibiendo casi el 10\% del gasto cardiaco. Desde el punto de vista funcional, el hueso trabecular posee una mayor vascularización, porosidad y superficie, cumpliendo una importante función metabólica y mecánica, mientras que el hueso cortical cumple fundamentalmente una función mecánica y protectora. Además, el hueso constituye un importante almacén de calcio, fósforo, magnesio, sodio y otros iones de suma importancia $(2,3)$. Tanto el hueso cortical como el hueso trabecular están formados por dos componentes, celular y extracelular. La porción extracelular del tejido óseo consta de una fase mineral sólida ligada a una matriz orgánica constituida principalmente por colágeno tipo I, junto con otras proteínas como la albúmina, la osteopontina, la fibronectina o proteínas fijadoras del calcio como la osteocalcina o la proteína GLA de la matriz (3). La fase mineral, formada por calcio y fosfato se deposita en relación con las fibrillas de colágeno, en una disposición ideada para resistir las fuerzas mecánicas (2).

El remodelado óseo supone anualmente el recambio de un $10 \%$ del tejido total del esqueleto y se produce gracias a la actividad de dos tipos celulares: los osteoblastos, encargados de la producción de la matriz ósea, y los osteoclastos, encargados de su resorción. Los osteoblastos son células de origen mesenquimatoso encargadas de 


\section{INTRODUCCIÓN}

sintetizar y secretar la matriz orgánica. Localizados en la superficie del hueso en formación, progresivamente se ven enterrados en la matriz orgánica sintetizada por ellos mismos, que se calcifica y los aísla, convirtiéndolos en osteocitos. La mineralización de la matriz ósea se prolonga en el tiempo durante semanas. La actividad de la fosfatasa alcalina, secretada por los osteoblastos y encargada de hidrolizar factores inhibidores de la mineralización, así como las concentraciones de calcio y fósforo se encargan de regular el proceso $(\mathbf{1}, \mathbf{3})$.

Existen varios genes que controlan el desarrollo de los osteoblastos. El factor de fijación de núcleos $A 1$ (CBFA1) es un factor de transcripción que se expresa tanto en progenitores como en osteoblastos maduros y que regula la expresión de varias proteínas como la osteopontina, la osteocalcina, la sialoproteína ósea o el ligando del receptor activador de NFKB (RANK). La ausencia de CBFA1 se traduce en una ausencia de osteoblastos (1). Otra importante molécula de señalización paracrina es la Indian Hedgehog, implicada también en el desarrollo de los osteoblastos (4). Existen asimismo otros factores destacables como la proteína 5 relacionada con el receptor de lipoproteínas (LRP5), los factores de crecimiento de fibroblastos 2 y 18 (FGF2 y FGF18), los factores de crecimiento semejantes a insulina (IGF) I y II y algunas hormonas, como la hormona paratiroidea (PTH) o la 1,25-dihidroxivitamina $\mathrm{D}\left(1,25[\mathrm{OH}]_{2} \mathrm{D}\right)$.

La resorción ósea es llevada a cabo por los osteoclastos, células multinucleadas producto de la fusión de células derivadas del precursor de osteoclastos y macrófagos. A través de diversos factores los osteoblastos regulan la actividad osteoclástica. El factor estimulador de colonias de macrófagos (M-CSF) facilita la fusión de células progenitoras de osteoclastos para permitir la formación de osteoclastos activos. El ligando de RANK también participa en este proceso de activación y diferenciación a través de la unión con su receptor. Otras moléculas, como la osteoprotegerina (OPG) inhiben la diferenciación y proliferación de los osteoclastos y dificultan el proceso de reabsorción del hueso (5). La actividad osteoclástica también se ve afectada por la presencia de diversos factores de crecimiento y citocinas como TNF- $\alpha$, IL-1, IL-6 o IL-11, actuando mayoritariamente de forma indirecta, a través de M-CSF y del ligando de $\operatorname{RANK}(6,7)$. Respecto a la acción 


\section{INTRODUCCIÓN}

hormonal, tanto PTH como $1,25[\mathrm{OH}]_{2} \mathrm{D}$ aumentan el número y la actividad de los osteoclastos, mientras que los estrógenos o la calcitonina inhiben dicha actividad.

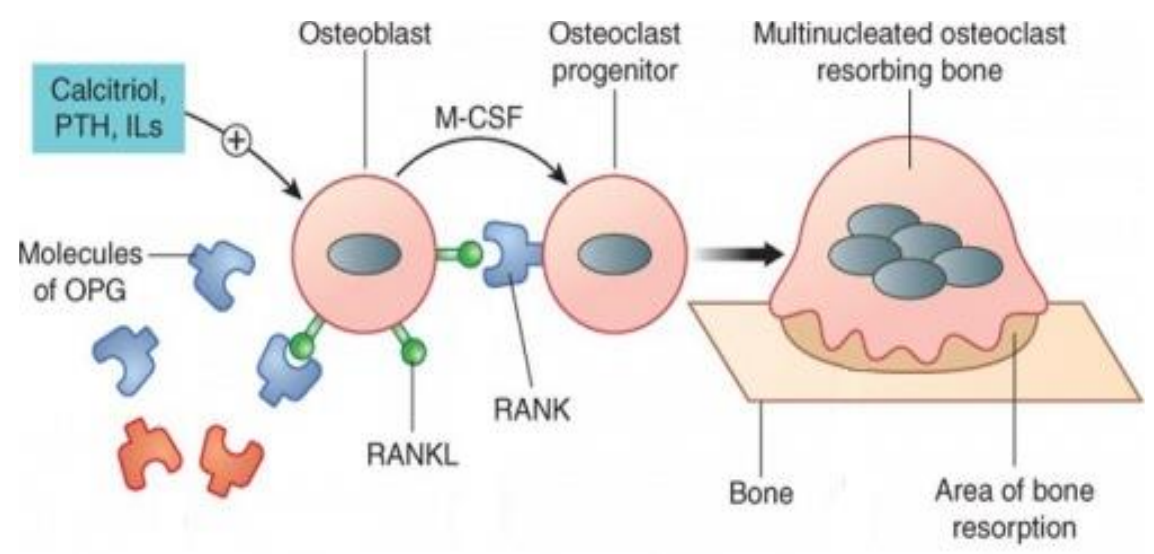

Diagrama 1: Activación del osteoclasto. Adaptado de Rang \& Dale’s Pharmacology, Churchill Livingstone 6a edición (2007).

Para llevar a cabo la resorción ósea los osteoclastos activados se fijan a través de una integrina a ciertos componentes de la matriz ósea, secretando protones, cloro y proteinasas hacia un espacio cerrado. La membrana celular del osteoclasto emplea una ATPasa para secretar ácido y solubilizar la fase mineral del hueso. La anhidrasa carbónica y diversas proteinasas facilitan el proceso creando un ambiente ácido en el que solubilizar la matriz ósea (2).

El hueso nuevo, denominado "entretejido" se caracteriza por presentar fibras de colágeno dispuestas en haces que se entrecruzan de forma aleatoria, mientras que el hueso más maduro, denominado "laminar" presenta los haces de fibras dispuestos de forma paralela o concéntrica. El crecimiento en longitud depende principalmente de la proliferación del cartílago, mientras que el crecimiento en amplitud y espesor se produce gracias a una formación y resorción combinadas a nivel de periostio y endostio.

En los individuos adultos, pese a que el crecimiento longitudinal queda detenido al cerrarse las placas de cartílago, el remodelado óseo continúa durante toda la vida. Este ciclo se activa siguiendo las líneas de fuerza generadas por la tensión mecánica. El proceso se lleva a cabo mediante una activación de precursores de osteoclastos, que 


\section{INTRODUCCIÓN}

una vez activados llevan a cabo la resorción de la matriz ósea existente, permitiendo posteriormente a los macrófagos "limpiar" la cavidad reabsorbida para, finalmente, dejar paso a los osteoblastos que regenerarán el tejido óseo destruido (2).

\subsection{2: METABOLISMO DEL CALCIO}

Un individuo adulto contiene aproximadamente entre 1 y $2 \mathrm{~kg}$ de calcio, que se almacena en un $99 \%$ en el tejido óseo, otorgándole estabilidad mecánica a la vez que cumple con funciones de depósito. Asimismo, el calcio localizado en el hueso permite regular y mantener constantes las concentraciones de dicho ion en el líquido extracelular (2).

El calcio posee un importante papel en múltiples funciones celulares, como procesos de secreción y transducción de señales o en la actividad neuromuscular. Los valores normales de calcio iónico se sitúan entre 4.6 y $5.1 \mathrm{mg} / \mathrm{dl}$, unas 10000 veces superiores a los encontrados a nivel intracelular. En plasma, los niveles de calcio se sitúan normalmente entre 8.5 y $10.5 \mathrm{mg} / \mathrm{dl}$, de los que aproximadamente el 50\% se encuentra en forma ionizada, mientras que la parte restante se encuentra unida a proteínas, especialmente albúmina e inmunoglobulinas $(2, \mathbf{8})$.

Las alteraciones de las concentraciones séricas de proteínas pueden trastornar los niveles de calcio, así como la acidosis, que disminuye la unión del ión a proteínas. Los niveles de calcio extracelular son regulados a través del control de su absorción a nivel intestinal y su eliminación a través de los riñones. Ambos procesos dependen de forma directa de las concentraciones plasmáticas de dos hormonas: PTH y $1,25[\mathrm{OH}]_{2} \mathrm{D}$.

La hormona paratiroidea o PTH es una hormona secretada a nivel de las células principales de las glándulas paratiroides. Se trata de un polipéptido compuesto por 84 aminoácidos, con un peso molecular de 9.4 kDa y una semivida de aproximadamente 4 minutos. Las concentraciones séricas normales de PTH están entre 10 y 60 pg/ml. La función principal de PTH es aumentar los valores plasmáticos de calcio, efecto que 


\section{INTRODUCCIÓN}

consigue actuando a varios niveles a través de la unión con el receptor de PTH 1 (PTH-

R1) $(2,8)$ :

- Hueso: PTH a nivel óseo realiza un aumento indirecto de la actividad osteoclástica. Esta estimulación se produce gracias a la unión de PTH con PTHR1 a nivel osteoblástico, lo que conduce a la inhibición de la síntesis de OPG y al aumento de la expresión del ligando de RANK.

- Riñón: PTH aumenta la reabsorción de calcio y magnesio en el túbulo distal.

- Intestino delgado: PTH aumenta la absorción de calcio en intestino de forma indirecta, gracias a una estimulación de la producción de vitamina D en su forma

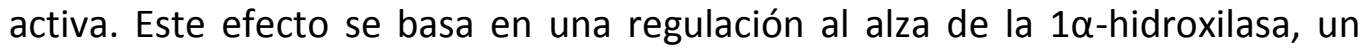
enzima localizado en el riñón encargado de la transformación de 25[OH]D en $1,25[\mathrm{OH}]_{2} \mathrm{D}$, la forma activa de la vitamina $\mathrm{D}$.

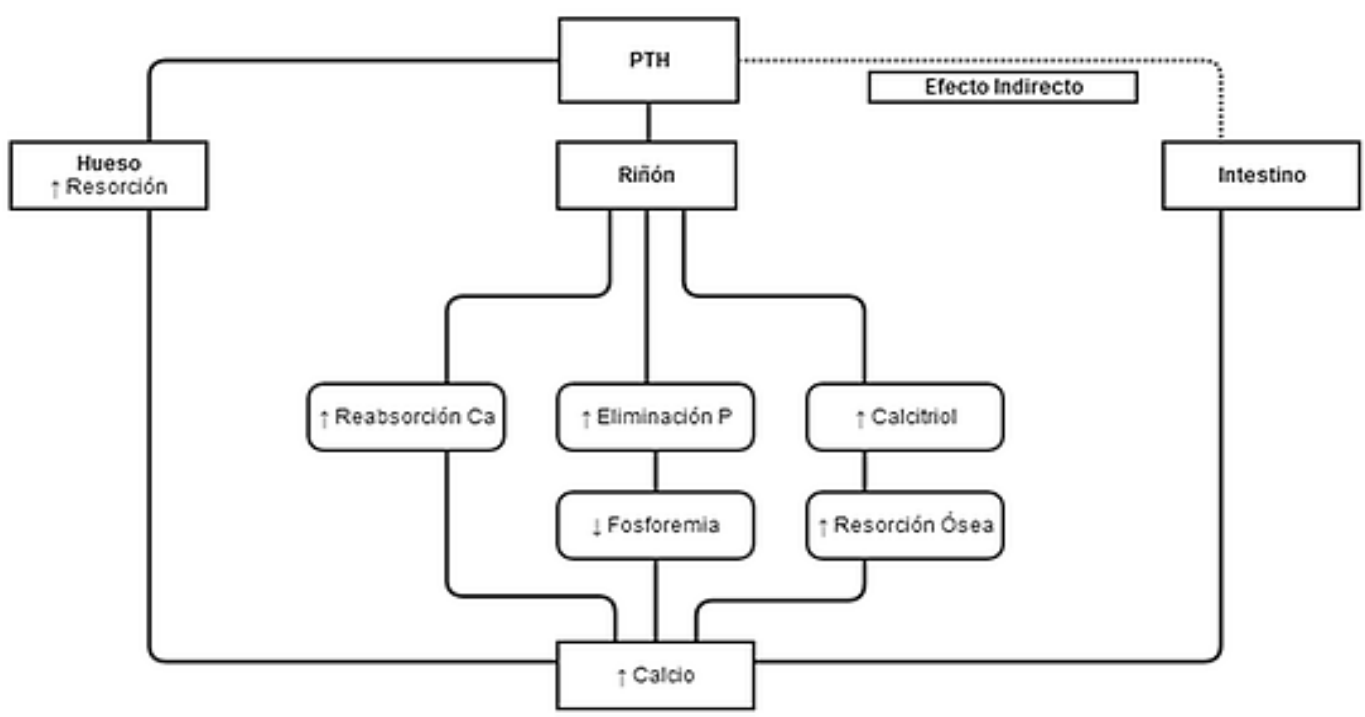

Diagrama 2: Actividad de la Hormona Paratiroidea. Adaptado de Nefrología Clínica. Hernando Avendaño, Editorial Médica Panamericana (2008).

La secreción de PTH se encuentra regulada por los niveles plasmáticos de calcio. Cuando los niveles de calcio en plasma aumentan se produce una activación de receptores sensibles al calcio en la superficie de las células principales de las glándulas paratiroides. 


\section{INTRODUCCIÓN}

Esta activación desencadena una cascada de señales intracelulares que desemboca en el aumento de la concentración de calcio a nivel intracelular, que a su vez inhibe la liberación de PTH preformada y almacenada en vesículas intracelulares (2).

A nivel paratiroideo, es el magnesio el encargado de facilitar la liberación de las vesículas que contienen PTH, por lo que una hipomagnesemia podría producir una forma de hipoparatiroidismo reversible. El aumento de los niveles de fósforo también estimula la liberación de PTH de forma indirecta. Esto se debe a que en situaciones de hiperfosforemia aumenta la producción de compuesto calcio-fósforo, disminuyendo de esta forma los niveles de calcio sérico libre y su capacidad para activar los receptores sensibles al calcio en el tejido paratiroideo (2).

La vitamina $D$ es una hormona de la familia de los secosteroides. Existen diversas formas de vitamina $D$, siendo las principales el ergocalciferol, de origen vegetal, y el colecalciferol, de origen animal. Todas las formas de vitamina D precisan de la radiación ultravioleta para su síntesis. En el caso de los mamíferos, el colecalciferol se produce a nivel cutáneo gracias a la reacción de 7-dehidrocolesterol en presencia de radiación UV, aunque también puede absorberse procedente de la dieta. El colecalciferol es transformado en 25-hidroxicolecalciferol en el interior de los hepatocitos y sufre una segunda hidroxilación a nivel renal para transformarse en 1,25-OH-colecalciferol, la forma activa de la vitamina $D$ (8). Esta última hidroxilación depende de la actividad de la $1 \alpha$-hidroxilasa renal, que a su vez está condicionada por la masa renal funcional y por ende, la activación final de la vitamina $\mathrm{D}$ depende de la tasa de filtrado glomerular. Otro factor estimulador de la síntesis de calcitriol es la prolactina, mientras que cifras elevadas de fósforo sérico y el factor de crecimiento de fibroblastos 23 (FGF-23) actúan como inhibidores de su producción $(2,8)$.

La función principal del calcitriol es incrementar los niveles séricos de calcio. Para llevar a cabo su función el calcitriol debe unirse con el receptor de vitamina D (VDR). Este receptor se expresa en la mayoría de los órganos. El complejo formado por calcitriol y VDR actúa en el núcleo como factor de transcripción, regulando la expresión de numerosos genes y aumentando los niveles de calbindina, una proteína transportadora 


\section{INTRODUCCIÓN}

de calcio que permite su absorción en el tubo digestivo. El aumento de la absorción de calcio se acompaña de un incremento de la absorción de fósforo con el objetivo de conservar la electroneutralidad. Además, VDR también participa en procesos de proliferación y diferenciación celular.

El aporte de calcio normal en la alimentación es muy variable y sus cifras fluctúan entre 10 y $37 \mathrm{mmol} /$ día. La absorción intestinal de calcio implica mecanismos activos (transcelulares) y pasivos (paracelulares) (2). La absorción pasiva de calcio, que supone un $5 \%$ del calcio absorbido con la ingesta, no es regulable. El transporte activo de calcio sucede principalmente en las primeras porciones del intestino delgado, duodeno y yeyuno, ya que depende de la existencia de un medio ácido para su realización. Este transporte depende también del contenido en calcio de la dieta, ya que cifras elevadas de calcio provocarán un feedback negativo sobre la liberación de calcitriol, disminuyendo finalmente el efecto de la vitamina $D$ sobre el tubo digestivo y reduciendo el grado de absorción. La absorción neta diaria de calcio en el intestino es de 200-400 $\mathrm{mg} /$ día (2).

Los niveles plasmáticos de calcio iónico regulan asimismo la eliminación de calcio renal. Diariamente se filtran por el glomérulo entre 8 y $10 \mathrm{~g}$ de calcio, de los que se excretan finalmente entre un 2 y un 3\%. La mayor parte del calcio filtrado por el glomérulo (65\%) es reabsorbido en el túbulo proximal de forma pasiva, asociado a la reabsorción de cloruro sódico. Un $20 \%$ es reabsorbido en la rama ascendente gruesa del asa de Henle, gracias a la acción de una proteína transportadora de calcio, la paracelina-1, cuya actividad depende de los niveles de calcio en plasma. La regulación de la actividad de la paracelina-1 depende directamente de las cifras séricas de calcio y no precisa de la mediación de PTH o calcitriol (2).

Finalmente, un $10 \%$ del calcio filtrado se reabsorbe a nivel de los túbulos contorneados distales, a través de un mecanismo transcelular. El calcio que alcanza el túbulo contorneado distal es introducido al citoplasma de las células tubulares a través de canales de calcio específicos en la membrana. Una vez en el citoplasma, el calcio es transportado por una calbindina para finalmente ser bombeado de forma activa a 


\section{INTRODUCCIÓN}

exterior gracias a la acción de una ATPasa $\mathrm{Na}+\mathrm{Ca} 2+$. Este proceso está controlado directa e indirectamente por la acción de PTH (2).

En aquellos casos en los que el aporte nutricional de calcio es insuficiente para mantener los niveles séricos, la actividad de PTH y calcitriol conduce a la liberación de calcio de sus depósitos en hueso, generando un balance negativo del mismo y la pérdida progresiva de masa ósea.

En situaciones de aporte excesivo de calcio en la dieta, el transporte pasivo a nivel intestinal continúa aportando calcio al plasma, pese a una regulación a la baja máxima del transporte activo, lo que podría conducir a situaciones de hipercalciuria grave, nefrocalcinosis o insuficiencia renal.

\subsection{3: METABOLISMO DEL FÓSFORO}

El contenido de fósforo de una persona adulta ronda los $600 \mathrm{~g}$, de los cuales el $85 \%$ se encuentran almacenados en el hueso (9). El fósforo cumple un importante papel a nivel intracelular, como componente de diversas moléculas como proteínas, enzimas, factores de transcripción, reservas energéticas o ácidos nucleicos. El fósforo orgánico se encuentra principalmente en forma de compuestos de fosfato, especialmente en el compartimento intracelular. A nivel plasmático, un $12 \%$ del fósforo circula unido a proteínas (2).

El fósforo se absorbe de forma eficaz en el tubo digestivo en situaciones basales, alcanzando un $65 \%$ del contenido del mismo en la ingesta. Este porcentaje puede incrementarse mediante mecanismos de transporte activo regulados por calcitriol que implican un cotransportador específico denominado (NaPi)-IIb (10), alcanzando tasas de absorción de entre un 85 y un 90\%. En general, la cantidad diaria de fósforo procedente de la dieta ronda entre 500-1000 mg/día. Los niveles séricos normales de fósforo se sitúan entre 2.7 y $4.6 \mathrm{mg} / \mathrm{dl}$ y pueden variar, dependiendo tanto del fósforo procedente de la dieta como de un ritmo circadiano. 


\section{INTRODUCCIÓN}

Los niveles séricos dependen también de la tasa de eliminación renal. Diariamente se filtran por los glomérulos entre 4 y $6 \mathrm{~g}$ de fósforo sérico. La excreción fraccionaria de fosfatos ronda entre un 10 y un $15 \%$ y depende de un cotransportador de sodio y fosfato en la membrana apical de las células del túbulo proximal denominado (NaPi)-Ila (11). La acción de PTH disminuye la expresión y la actividad de dicho cotransportador, produciendo fosfaturia con el objeto de mantener estables las cifras séricas de fósforo tras la liberación del mismo de su almacén óseo mediada por la hormona.

FGF-23 disminuye también la reabsorción tubular del fósforo filtrado a nivel glomerular. FGF-23 es un factor de crecimiento de fibroblastos que se libera como respuesta a elevaciones en los niveles plasmáticos de calcitriol y fósforo (12) así como de otros compuestos como los estrógenos (13).

FGF-23 es una proteína de 32 kDa constituida por 251 aminoácidos, producida por osteoblastos y osteocitos en el hueso. FGF-23 se une a su receptor FGFR1, que únicamente es funcional si se encuentra unido a su vez al complejo Klotho, provocando una supresión de la expresión del cotransportador sodio-fosfatos en el túbulo proximal y disminuyendo la actividad de la $1 \alpha$-hidroxilasa a nivel renal, a la vez que aumenta la acción de la 24-hidroxilasa $(\mathbf{1 4}, \mathbf{1 5})$. Esto se traduce en una disminución de la reabsorción tubular de fósforo, con la consiguiente fosfaturia, y en una reducción de los niveles de calcitriol circulantes, lo que conlleva una menor absorción de fósforo en intestino. La ausencia tanto de FGF-23 como de Klotho conllevaría una hiperfosforemia y un aumento excesivo de los niveles de calcitriol que conducirían al desarrollo de importantes calcificaciones.

FGF-23 es capaz también de actuar a nivel paratiroideo, dónde el complejo FGF-Klotho reduce la secreción de PTH (16-18) a través de una disminución de la proliferación de las células paratiroides y de un aumento en la expresión de los genes responsables de los receptores sensibles a calcio y calcitriol, actuando de forma indirecta sobre la liberación de fósforo en hueso y sobre su absorción en el tubo digestivo. 


\section{INTRODUCCIÓN}

La hipofosforemia puede producirse por una absorción insuficiente de fósforo en el aparato digestivo, por una excreción renal excesiva o por una rápida distribución del fósforo plasmático hacia los tejidos de depósito. Por el contrario, la hiperfosforemia se suele deber a alteraciones de la filtración glomerular, el hipoparatiroidismo o el aporte excesivo de fosfatos hacia el medio extracelular, bien sea desde el aparato digestivo o liberado desde sus depósitos en hueso.

\section{2: METABOLISMO ÓSEO-MINERAL EN LA ERC}

\subsection{1: ENFERMEDAD RENAL CRÓNICA}

En los pacientes con enfermedad renal crónica (ERC), el descenso de la tasa estimada de filtrado glomerular (TEFG), la incapacidad para eliminar de forma adecuada el fósforo, la hipocalcemia y las dificultades para obtener calcitriol inducen el desarrollo de hiperparatiroidismo secundario. Los estadios iniciales de la ERC se caracterizan por un manejo inadecuado del fósforo debido a la pérdida de masa renal, especialmente en situaciones de sobrecarga de este elemento procedente de la dieta (19). Sin embargo esta situación no se traduce en una hiperfosforemia objetivable en el análisis bioquímico gracias a una mayor eliminación urinaria de fósforo inducida por la elevación de FGF-23.
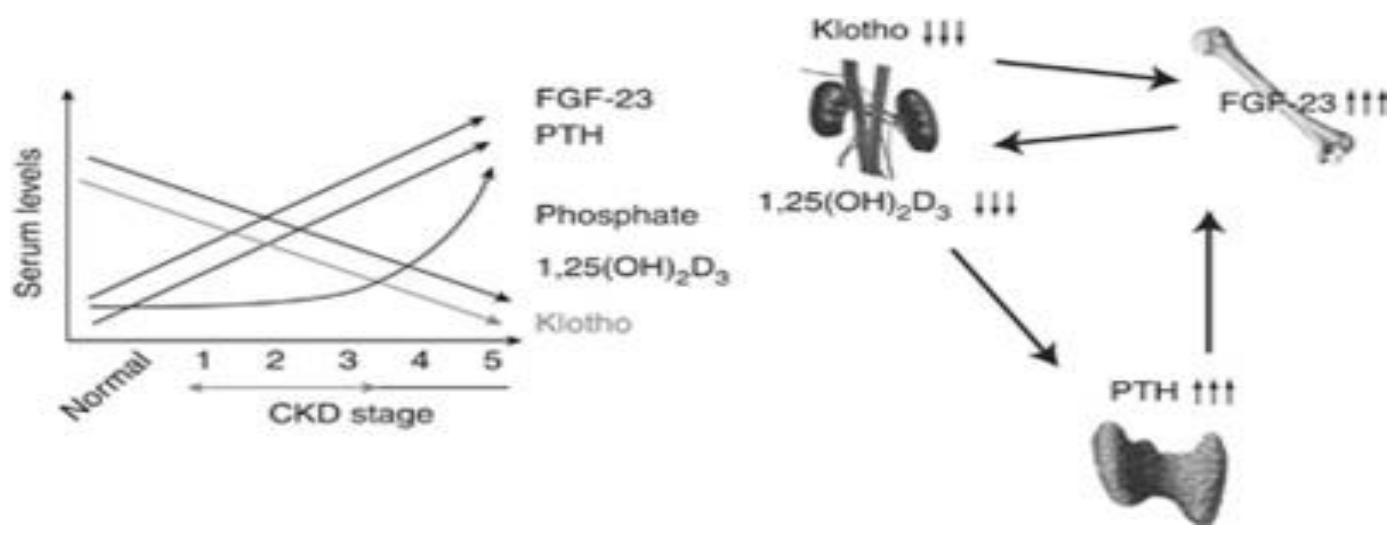

Diagrama 3: Evolución de la concentración sérica de los diferentes factores implicados en la enfermedad óseo-mineral característica de la ERC. Adaptado de Kuro-O M et al. Kidney Int Suppl (2011). 


\section{INTRODUCCIÓN}

Otra de las alteraciones del metabolismo óseo-mineral que se produce de forma precoz es el descenso en los niveles de calcitriol, debido a la pérdida progresiva de masa renal funcional, lo que conlleva una menor actividad de la $1 \alpha$-hidroxilasa, el descenso del filtrado glomerular, lo que supone una menor llegada de calcidiol al túbulo contorneado distal para su activación final, y una retención de fósforo, que disminuye la síntesis de calcitriol al estimular la liberación de FGF-23. Como consecuencia del descenso de la actividad de calcitriol se produce una absorción deficitaria de calcio a nivel del tubo digestivo, lo que se traduce en hipocalcemia.

En las glándulas paratiroides existen dos tipos de receptores, el receptor de vitamina D (VDR) y el receptor sensible a calcio (RCa). VDR es un receptor citosólico para calcitriol. La uremia dificulta la síntesis del VDR, reduciendo su número y dificultando su mecanismo de acción en las células paratiroideas. RCa es un receptor de membrana sensible a las concentraciones de calcio séricas y cuyo número desciende también en estados de uremia.

Todos estos factores provocan un aumento de la proliferación celular en las glándulas paratiroides que conducirá en los últimos estadios a una hiperplasia de las mismas (20). La hiperplasia de las paratiroides puede adoptar varios patrones: hiperplasia difusa policlonal, crecimiento nodular monoclonal con componente policlonal e hiperplasia monoclonal difusa, también conocida como adenoma o hiperparatiroidismo autónomo terciario.

Inicialmente, la hiperplasia es difusa y policlonal, desarrollando progresivamente una hiperplasia nodular monoclonal en estadios avanzados. Aparentemente el desarrollo de hiperplasia de las células paratiroides produce una regulación a la baja de la expresión de RCa y VDR (21). A esta regulación a la baja podrían contribuir los bajos niveles séricos de calcio y vitamina $D$ propios de la enfermedad renal crónica, junto con una interdependencia entre ellos, ya que se ha observado que el empleo de calcimiméticos (moléculas activadoras del receptor sensible a calcio) provocan un aumento de la expresión del receptor de vitamina $D$ independiente de los niveles de calcio sérico. Estudios recientes han comprobado que ciertos polimorfismos de nucleótido simple que 


\section{INTRODUCCIÓN}

afectan al RCa pueden condicionar cifras plasmáticas más elevadas de fósforo y glucosa (22).

La hiperplasia paratiroidea tiene como consecuencia una elevación de la concentración de PTH, que estimula los osteoclastos y desencadena un aumento del recambio óseo, que se traducirá en la aparición de osteítis fibrosa quística, patología caracterizada por la existencia de tejido osteoide anormal, estructurado de forma irregular, fibrosis y formación de quistes, disminución del hueso cortical y de la resistencia ósea y aumento del riesgo de fracturas. La acción de PTH a nivel óseo puede desencadenar también la aparición de hipercalcemia e hiperfosforemia. Además, el tejido paratiroideo que sufre los estadios más avanzados de hiperplasia nodular tiende a perder su capacidad de respuesta frente a los niveles plasmáticos de calcio y calcitriol (23).

En algunos casos, el tratamiento de estas alteraciones en la enfermedad renal crónica produce una supresión excesiva de la síntesis de PTH, lo que conduce a una pérdida del número de osteoclastos y osteoblastos y a una disminución de la actividad de estos últimos, acompañada de acumulación de matriz ósea no mineralizada en la denominada osteomalacia o enfermedad ósea adinámica. Estos pacientes presentan un importante riesgo de fracturas óseas, incluso mayor que aquellos que padecen osteítis fibrosa quística.

FGF-23 juega un papel importante en los estadios iniciales del hiperparatiroidismo secundario. La síntesis de FGF-23 en los osteocitos y osteoblastos es estimulada por incrementos de la concentración sérica de fósforo y calcitriol. FGF-23 actúa sobre su receptor FGFR1 activando el complejo FGFR1-Klotho, disminuyendo la reabsorción de fósforo a nivel del túbulo proximal (23). Asimismo, FGF-23 produce de forma directa una disminución de la síntesis de PTH, mientras que genera indirectamente una estimulación de la misma a través de la reducción de los niveles de calcitriol circulante. En los primeros estadios de la ERC, los pacientes presentan cifras de calcio y fósforo séricos dentro de la normalidad, con sólo pequeñas elevaciones de PTH. Los niveles de fósforo y calcio sérico se controlan inicialmente gracias a la hiperactividad de FGF-23, aunque el estímulo que desencadena el aumento de la actividad de FGF-23 en estos estadios no 


\section{INTRODUCCIÓN}

está aclarado. Sobre paratiroides normales, FGF-23 es capaz de disminuir la síntesis de PTH y la proliferación celular, así como aumentar la expresión de RCa y VDR en dichas poblaciones (24). Este efecto está ausente en glándulas con hiperplasia (24, 25), posiblemente en relación con una disminución de la expresión de FGFR1-Klotho, lo que se traduce en una pérdida de capacidad de acción de FGF-23 (24).

\subsection{2: TRASPLANTE RENAL}

El trasplante renal constituye hoy en día el tratamiento renal sustitutivo de primera elección en todos aquellos individuos con ERC en los que no exista una contraindicación para su ejecución, con tasas de supervivencia del paciente superiores al $90 \%$ al primer año (26). Tras la realización de un trasplante renal funcional, el incremento del filtrado glomerular permite la corrección total o parcial de muchas de las alteraciones metabólicas propias de la enfermedad renal.

Sin embargo, es habitual observar tanto en etapas tempranas como tardías de la evolución de los pacientes trasplantados la existencia de cifras elevadas de PTH y calcio y disminuidas de fósforo, aunque su prevalencia, progresión e influencia sobre la morbimortalidad del paciente no son bien conocidas. El metabolismo óseo-mineral en el paciente trasplantado se ve alterado tanto por factores propios de su insuficiencia renal, como la evolución de la osteodistrofia renal previa al trasplante, como por factores inherentes al trasplante, como el uso de medicación inmunosupresora o trastornos de tipo hormonal (27).

\subsubsection{1: EVOLUCIÓN DEL MOM TRAS EL TRASPLANTE RENAL}

La evolución de los trastornos del metabolismo óseo-mineral en el post-trasplante depende del momento evolutivo del mismo (28). Tras la realización del trasplante renal, los niveles de hormona paratiroidea se mantienen por debajo de los existentes antes de 


\section{INTRODUCCIÓN}

la cirugía (29-33), con un descenso entre un 19 y un 71\% según diversos estudios. La evolución de los valores plasmáticos de PTH es variable en el post-trasplante más inmediato, produciéndose un descenso significativo de sus cifras en los primeros 6 meses tras la cirugía y no presentando cambios de importancia posteriormente. Entre los 6 y los 12 meses tras el trasplante existen resultados contradictorios, observando un descenso aún mayor en algunos estudios mientras que otros autores recogen incrementos de los valores séricos. La evolución posterior, entre los meses 12 y 24 tras la cirugía, es mínima, observando únicamente cambios mínimos en la cifras de hormona paratiroidea $(34,35)$.

Se ha comprobado como las cifras de PTH persisten por encima de la normalidad en más del $50 \%$ de los pacientes trasplantados entre los 2 y los 5 años tras el trasplante (36-38). La concentración de PTH plasmática dependerá directamente de la función renal residual del injerto, aunque algunos autores han descrito una prevalencia de hasta un 43\% de hiperparatiroidismo en trasplantados renales de larga evolución con valores séricos de creatinina por debajo de $1,5 \mathrm{mg} / \mathrm{dl}$ (39). Los factores de riesgo más importantes para la persistencia del hiperparatiroidismo post-trasplante son el tiempo en diálisis, el tamaño de las paratiroides y el desarrollo de hiperplasia paratiroidea nodular y/o monoclonal (40).

Los valores séricos de calcio se mantienen en el rango superior de la normalidad en la mayoría de los casos tras el trasplante $(\mathbf{3 3}, \mathbf{3 4})$, aunque persiste un porcentaje de pacientes con hipercalcemia. Durante las primeras dos semanas tras el trasplante se ha observado una disminución transitoria de los niveles plasmáticos de calcio, presentando posteriormente un aumento entre las semanas 2 y 26 , para después estabilizarse al alcanzar los 6 meses (30). Más adelante, entre los meses 6 y 12 la variación de los niveles de calcio es menor del 5\%, porcentaje que se reduce aún más entre los meses 12 y 24. Aparentemente no existe una relación clara entre la función renal residual del injerto y los valores de calcio plasmático $(\mathbf{4 1}, \mathbf{4 2})$. La aparición de hipercalcemia post-trasplante se debe al efecto de PTH sobre el riñón, estimulando la síntesis de calcitriol, lo que incrementa la absorción intestinal de calcio y la liberación de este elemento desde sus depósitos en hueso. La corrección de la uremia anula la resistencia del esqueleto a la 


\section{INTRODUCCIÓN}

acción de PTH, permitiendo la liberación de calcio a través de un proceso de resorción ósea (43). La existencia de hipercalcemia en los tres primeros meses post-trasplante se ha llegado a cuantificar en un 52\% de los enfermos (35) y es especialmente frecuente en enfermos que presentaban un severo hiperparatiroidismo pretrasplante.

Las cifras de fósforo sérico, que se mantienen normalmente elevadas en los pacientes con ERC previa al trasplante sufren un importante descenso tras la cirugía, hasta situarse en el rango inferior de la normalidad o incluso por debajo durante el primer mes tras el trasplante (34). Posteriormente los niveles de fósforo parecen estabilizarse, con cambios por debajo del $10 \%$ entre los meses 6 y 12 y por debajo del $2 \%$ entre los meses 12 y 24. La incidencia de hipofosforemia en los primeros meses tras el trasplante es importante, con cifras situadas entre el 1,6 y el $39 \%$ tras 6 meses $(34,44)$.

Las cifras de fósforo plasmático no parecen depender del grado de función renal residual del injerto y su descenso precoz en el post-trasplante inmediato parece asociarse a un aumento de la eliminación urinaria debido a una disfunción tubular del injerto y a la persistencia del hiperparatiroidismo, junto con el efecto de diuréticos e inmunosupresores administrados (45).

La elevación persistente de los niveles de FGF-23 tras el trasplante también parece guardar relación con la hipofosforemia post-trasplante y con la supresión de la actividad de la $1 \alpha$-hidroxilasa renal (46-48). Dicha elevación y la actividad fosfatúrica inducida por FGF-23 sufre un descenso progresivo a lo largo del primer año tras el trasplante, lo que ayuda a estabilizar la concentración sérica de fósforo (49). Este descenso en la concentración plasmática de FGF-23 llega a alcanzar en algunas series el 97\%, mostrando una clara correlación inversa con el fósforo sérico, mientras que a largo plazo, la asociación entre fósforo y PTHi no parece tan clara (50).

Respecto al calcitriol, sus niveles plasmáticos se sitúan por debajo de la normalidad antes de la cirugía, con un lento ascenso tras la misma para alcanzarla hacia el mes 12 tras el trasplante $(\mathbf{3 4 - 3 5 , 5 1 )}$. Aun así, un porcentaje importante de los enfermos mantiene cifras de calcitriol por debajo de la normalidad. 


\section{INTRODUCCIÓN}

\subsubsection{2: INFLUENCIA DEL TRATAMIENTO INMUNOSUPRESOR EN EL METABOLISMO ÓSEO-MINERAL}

\subsubsection{1: GLUCOCORTICOIDES}

La administración de glucocorticoides durante un periodo de tiempo superior a 6 meses induce la aparición de osteoporosis en aproximadamente el $50 \%$ de los pacientes que reciben dicho tratamiento, con una tasa de incidencia de fracturas de entorno al $34 \%$ (3). La gravedad de la osteoporosis viene determinada tanto por la dosis de esteroides administrada como por la duración del tratamiento (52).

El grado de osteoporosis es directamente proporcional a la dosis de esteroides que recibe el paciente. Se considera que a partir de $7,5 \mathrm{mg} /$ día se produce un aumento exponencial de la pérdida de masa ósea y del riesgo de fracturas patológicas. La posibilidad de sufrir una fractura patológica alcanza su valor máximo dentro de los primeros 6 meses de tratamiento con esteroides, pudiendo disminuir si se interrumpe el tratamiento (3). Ciertas situaciones, cómo una masa ósea disminuida previa a la administración de esteroides pueden mantener elevado el riesgo de fracturas pese a la interrupción del tratamiento. Los esteroides afectan tanto al hueso trabecular como al cortical, induciendo un aumento de la resorción ósea secundario a una mayor proliferación y actividad de los osteoclastos, mientras que disminuyen la capacidad de formación del hueso al dificultar la proliferación y diferenciación de los osteoblastos, induciendo su apoptosis, impidiendo la síntesis de diversos componentes de importancia estructural en el hueso. Se ha comprobado como los esteroides actúan sobre el eje OPG-RANKL, inhibiendo el primero y estimulando la actividad del segundo (53). Poseen además otros efectos que alteran el metabolismo del hueso; reducen la absorción de calcio a nivel digestivo y aumentan su eliminación por vía renal, favoreciendo el mantenimiento del hiperparatiroidismo secundario (54-56). 


\section{INTRODUCCIÓN}

\subsubsection{2: ANTICALCINEURÍNICOS}

Los anticalcineurínicos, incluyendo tanto ciclosporina A como tacrólimus, inducen una forma de enfermedad ósea de alto remodelado caracterizada por un incremento de la formación y resorción de hueso, con un predominio de ésta última. Este cuadro metabólico se acompaña además de un aumento de osteocalcina y calcitriol. Este proceso parece estar mediado por la acción de los linfocitos T, aunque su papel no está del todo aclarado (57). La acción ósea de los anticalcineurínicos se caracteriza por una disminución del área trabecular con pérdida de masa ósea, siempre acompañada de una cifra elevada de linfocitos T. Actúan sobre la calcineurina ósea, que regula la diferenciación de osteoblastos y osteoclastos. In vitro, esta acción se traduce en una inhibición de la osteoclastogénesis y la resorción ósea. Sin embargo, los efectos observados in vivo tienen un signo opuesto, favoreciendo la aparición de osteoporosis. La explicación para este fenómeno aún no está aclarada (3). Estos fármacos influyen también sobre el eje OPG-RANKL a través de los linfocitos T. Además, producen una inhibición del factor nuclear de células T activadas (NFAT), que a su vez juega un importante papel en la diferenciación de los osteoclastos.

\subsubsection{3: OTROS INMUNOSUPRESORES}

No se han observado efectos perjudiciales a nivel óseo relacionados con la administración de everólimus, sirólimus, rapamicina o micofenolato mofetil. En el caso de everólimus y rapamicina, algunos estudios indican una posible acción protectora a nivel óseo $(\mathbf{5 8}, \mathbf{5 9})$. 


\section{INTRODUCCIÓN}

\subsubsection{3: RESÚMEN DE LAS GUÍAS SOBRE EL MOM EN EL TX}

\subsubsection{1: GUÍAS KDOQI}

Las guías KDOQI, publicadas en 2003 (54), realizan las siguientes recomendaciones relativas al manejo del metabolismo óseo-mineral en receptores de trasplante renal:

- Deben monitorizarse los niveles de calcio, fósforo, CO2 total y PTH intacta plasmática como parte del seguimiento del trasplante renal (Opinión).

- La frecuencia de dichas medidas de calcio y fósforo séricos, CO2 total y PTH intacta plasmática queda recogida en la siguiente tabla (Opinión):

\begin{tabular}{|l|c|c|}
\hline Parámetro & Primeros $\mathbf{3}$ meses Post-Tx & Entre $\mathbf{3}$ y $\mathbf{1 2}$ meses Post-Tx \\
\hline Calcio & Cada 2 semanas & Mensual \\
\hline Fósforo & Cada 2 semanas & Mensual \\
\hline PTHi & Mensual & Cada 3 meses \\
\hline CO2 Total & Cada 2 semanas & Mensual \\
\hline
\end{tabular}

Posteriormente, la periodicidad de las determinaciones se basará en la función renal del paciente:

\begin{tabular}{|l|c|c|}
\hline Tasa de Filtrado Glomerular & Valoración $\mathbf{P T H}$ & Valoración Ca y $\mathbf{P}$ \\
\hline $30-59 \mathrm{ml} / \mathrm{min} / 1,73 \mathrm{~m} 2$ & Cada 12 meses & Cada 12 meses \\
\hline $15-29 \mathrm{ml} / \mathrm{min} / 1,73 \mathrm{~m} 2$ & Cada 3 meses & Cada 3 meses \\
\hline$<15 \mathrm{ml} / \mathrm{min} / 1,73 \mathrm{~m} 2$ o diálisis & Cada 3 meses & Mensual \\
\hline
\end{tabular}




\section{INTRODUCCIÓN}

Durante la primera semana tras el trasplante, los niveles de fósforo sérico deben ser evaluados diariamente. Los receptores de trasplante renal que desarrollen niveles bajos de fósforo sérico $(<2,5 \mathrm{mg} / \mathrm{dl})$ debería recibir tratamiento con suplementos de fósforo (Opinión).

- Para minimizar la pérdida de masa ósea y el grado de osteonecrosis tras el trasplante, el tratamiento inmunosupresor deberá ajustarse con el objetivo de conseguir la dosis mínima eficaz de glucocorticoides (Evidencia).

- Respecto a los valores séricos de calcio, fósforo y PTHi: Los valores de calcio sérico deberán mantenerse en el rango de normalidad definido por el laboratorio, siendo preferente el margen inferior de dicho rango cuando se trate de individuos en estadio 5 de su ERC.

En cuanto al fósforo, En pacientes con estadios 3-4 de ERC, sus valores séricos deberán mantenerse por encima de 2,7 mg/dl (Evidencia), sin llegar a superar 4,6 mg/dl (Opinión). En pacientes con ERC estadio 5 los valores de fósforo deberán situarse entre 3,5 y $5,5 \mathrm{mg} / \mathrm{dl}$ (Evidencia).

- Los valores de PTHi deberán mantenerse dentro de los siguientes rangos:

\begin{tabular}{|l|c|}
\hline Tasa de Filtrado Glomerular & PTHi sérica según estadio ERC \\
\hline $30-59 \mathrm{ml} / \mathrm{min} / 1,73 \mathrm{~m} 2$ & $35-70 \mathrm{pg} / \mathrm{ml}$ (Opinión) \\
\hline $15-29 \mathrm{ml} / \mathrm{min} / 1,73 \mathrm{~m} 2$ & $70-110 \mathrm{pg} / \mathrm{ml}$ (Opinión) \\
\hline$<15 \mathrm{ml} / \mathrm{min} / 1,73 \mathrm{~m} 2$ & $150-300 \mathrm{pg} / \mathrm{ml}$ (Evidencia) \\
\hline
\end{tabular}




\section{INTRODUCCIÓN}

\subsubsection{2: GUÍAS SEN}

Las guías de la Sociedad Española de Nefrología para el manejo de las alteraciones del metabolismo óseo-mineral en pacientes con enfermedad renal crónica (19) hacen las siguientes recomendaciones de cara al seguimiento de trasplantados.

- En pacientes trasplantados renales, el control de las cifras plasmáticas de calcio y fósforo se realizará en cada revisión (1B). La determinación de PTHi se realizará anualmente, salvo en aquellos casos en los que se encuentre elevada, en los que deberá ser vigilada al menos cada 6 meses (2C). Por último, los niveles de $25 \mathrm{OH}$ vitamina $D$ se realizarán cada 6-12 meses $(2 C)$.

- Respecto a los valores plasmáticos adecuados en pacientes trasplantados, las cifras de calcidiol se situarán por encima de $30 \mathrm{ng} / \mathrm{ml}$ en todos los estadios (2B). El calcio deberá encontrarse entre 8,4 y $9,5 \mathrm{mg} / \mathrm{dl}$, mientras que el fósforo se controlará entre 2,5 y $4,5 \mathrm{mg} / \mathrm{dl}$, en ambos casos para todos los estadios.

- La regulación de los niveles de PTHi se realizará con el objetivo de mantenerla entre 35 y $70 \mathrm{pg} / \mathrm{ml}$ para estadio 3, entre 70 y $110 \mathrm{pg} / \mathrm{ml}$ para estadios 4 y 5 y entre 150 y $300 \mathrm{pg} / \mathrm{ml}$ para pacientes en diálisis.

- La estrategia diagnóstica de las lesiones secundarias a la alteración del metabolismo óseo-mineral se realizará de la siguiente forma:

- Rx Simple: se recomienda la realización de Rx lateral de columna dorsolumbar, radiografía AP de abdomen o simple de manos, con el fin de detectar calcificaciones vasculares o ante el riesgo o la sospecha del padecimiento de fracturas vertebrales.

- Densitometría ósea: Basal y bienal, en mujeres por encima de los 50 años y en varones por encima de los 65 años. También en pacientes con riesgo elevado por consumo de esteroides o antecedentes de fracturas. En el 


\section{INTRODUCCIÓN}

caso de que el enfermo reciba tratamiento con bifosfonatos se recomienda la realización de un estudio densitométrico anual.

\section{3: CONSECUENCIAS DEL DESAJUSTE METABÓLICO}

Las alteraciones del metabolismo óseo-mineral provocan lesiones en diferentes órganos y tejidos, siendo el esqueleto y el aparato cardiovascular los más afectados. El desarrollo de calcificaciones a nivel vascular es una de las consecuencias de la alteración del MOM. Existen varias modalidades de calcificación vascular. La arteriosclerosis calcificante, también conocida como enfermedad de Möckeberg, afecta a la capa media de las arterias, mientras que la aterosclerosis calcificante sitúa las lesiones en la capa íntima de las arterias. En la enfermedad renal crónica se pueden observar otros tipos de calcificaciones, como las localizadas en válvulas cardiacas o en tejidos blando, denominada en este último caso calcifilaxis (61).

\subsection{1: CALCIFICACIONES VASCULARES}

Existe una elevada mortalidad cardiovascular asociada a la enfermedad renal crónica, hasta 30 veces mayor que la población general $(62,63)$, que no puede ser explicada únicamente mediante la existencia de los tradicionales factores de riesgo cardiovascular (FRCV), como la edad, la hipertensión arterial, la diabetes mellitus o la dislipemia, sino debido a la interacción de otra serie de factores como el estrés oxidativo, la inflamación crónica, la hiperfosforemia o las calcificaciones vasculares (CV).

El desarrollo de CV en pacientes con enfermedad renal crónica es una complicación habitual del estado urémico y se debe, entre otros factores, a la alteración del metabolismo óseo-mineral, caracterizado por una elevación de los niveles séricos de fósforo junto con aumentos puntuales de la calcemia (64). El incremento de los valores séricos de estos dos elementos induce cambios adaptativos en el fenotipo de las células 


\section{INTRODUCCIÓN}

de músculo liso que forman los vasos $(\mathrm{CML})$, provocando un aumento de rigidez de los mismos debido a la calcificación de las capas íntima y media de las arterias (65). El empleo de ciertas estrategias terapéuticas dirigidas a controlar el hiperparatiroidismo secundario característico de la ERC, como la administración de dosis elevadas de vitamina $D$ o quelantes cálcicos de fósforo puede contribuir al desarrollo de calcificaciones.

La calcificación vascular se produce debido al depósito de fosfato cálcico en forma de cristales de hidroxiapatita tanto en vasos sanguíneos como en válvulas cardiacas (66). La calcificación de la capa íntima arterial se asocia al desarrollo de placas de ateroma (67) relacionándose con un aumento en el depósito de lípidos y células inflamatorias, mientras que la calcificación de la capa media se asocia al proceso de envejecimiento, la diabetes mellitus o el padecimiento de enfermedad renal crónica (68) implicando un cambio fenotípico de las CML. Ambos procesos parecen íntimamente ligados, ya que se ha observado que la aparición de calcificación lineal vascular y el desarrollo de placas de ateroma están fuertemente relacionados (69). La combinación de calcificación vascular y el incremento de la rigidez arterial limitan la capacidad elástica de las arterias, lo que se traduce en un incremento de la presión de pulso y de la velocidad de onda de pulso. Estos factores contribuyen a la disfunción e hipertrofia del ventrículo izquierdo (70). Esta hipertrofia ventricular izquierda se caracteriza por un desorden de los miocitos a nivel cardiaco con un alto grado de fibrosis intersticial (71).

Los niveles elevados de calcio, fósforo y el producto calcio-fósforo promueven la formación y el crecimiento de los cristales de hidroxiapatita (72). La incubación in vitro de CML con altas concentraciones de calcio o fósforo induce el depósito de hidroxiapatita en la matriz extracelular, comprobando un efecto sinérgico cuando la incubación se produce en presencia de ambos elementos (73). In vitro, el fósforo es capaz de precipitar de forma espontánea incluso en ausencia de células, en un proceso de depósito "físico-químico" dependiente del pH del medio, punto sobre el que actúan diversas proteínas con capacidad inhibidora del proceso de calcificación (74). El proceso de calcificación arterial inducido por el fósforo se debe a un cambio adaptativo de las CML vasculares, que pasan de mostrar un fenotipo contráctil a uno osteo/condrogénico. 


\section{INTRODUCCIÓN}

Este cambio se caracteriza por la formación de vesículas matriz con contenido citoplasmático y membrana celular intacta, capaces de concentrar calcio en su interior, la regulación a la baja de moléculas inhibidoras de la mineralización y la elaboración de una matriz que favorezca el proceso de calcificación (75). Se ha demostrado como la exposición a niveles elevados de fósforo induce in vitro la sobreexpresión de genes responsables de proteínas osteogénicas como RUNX2, osteopontina o fosfatasa alcalina (76) en las CML. RUNX2 es un factor de transcripción implicado en la expresión de importantes componentes de la matriz ósea como el colágeno de tipo I o la osteocalcina.

Los pirofosfatos son moléculas inhibidoras del proceso de calcificación. Cifras normales de pirofosfato son suficientes para impedir la producción de las mismas (77). En pacientes con ERC terminal en diálisis, los niveles de pirofosfato se encuentran anormalmente descendidos y se asocian de forma inversa con el grado de calcificación vascular. Esto se debe, en parte, a la actividad enzimática de la fosfatasa alcalina. La fosfatasa alcalina es una proteína reguladora de la matriz ósea encargada de inactivar diversos inhibidores de la mineralización mientras que simultáneamente libera fósforo de sus depósitos en hueso (78). La pérdida de la actividad de CD73 resulta también en un aumento de la actividad de la fosfatasa alcalina y por tanto del desarrollo de calcificaciones (79).

Las alteraciones de la matriz vascular extracelular facilitan el cambio fenotípico de las CML vasculares. Las metaloproteinasas (MMP) favorecen el proceso de calcificación al degradar componentes de la matriz (80). La pérdida de fibras de elastina también se asocia a la progresión del proceso de calcificación a nivel arterial (81). Pese a que la degradación de la elastina se ha demostrado en modelos experimentales de ERC (82), este fenómeno no ha sido demostrado en vasos de pacientes con ERC (83).

Estos cambios fenotípicos se traducen en la aparición en la superficie de las CML de vesículas que contienen apatita y fibras de colágeno calcificado (84) que actúan como núcleos de calcificación. Además, los cristales de hidroxiapatita formados a partir de las vesículas pueden inducir cambios ulteriores en el fenotipo de las células musculares lisas de los vasos (85). Otro de los factores que inducen este cambio y que se asocia a la 


\section{INTRODUCCIÓN}

hiperfosforemia es la producción de especies reactivas del oxígeno, implicadas también en feedback positivo sobre RUNX2 (86). Además, el fósforo puede facilitar la calcificación vascular a través de la inducción de la apoptosis de las CML, gracias a la regulación a la baja de la expresión del complejo Gas6-Axl (87). Este complejo se encarga de impedir el desencadenamiento del proceso de apoptosis de la célula y su ausencia facilita la activación de proteínas como la caspasa-3 que inducen la muerte celular (88). In vivo, las CML están rodeadas de una compleja matriz extracelular compuesta por colágeno, elastina, fibronectina, heparan-sulfato y proteoglicanos. La hiperfosforemia produce la acumulación de depósitos lineales de mineral a lo largo de la lámina elástica de la arteria, en un proceso denominado elastocalcinosis $(\mathbf{8 2}, \mathbf{8 9}-\mathbf{9 0})$. La degradación de la elastina permite el crecimiento de los depósitos de hidroxiapatita por agregación de calcio (91).

Pese a que gran parte del conocimiento sobre el mecanismo de producción de las calcificaciones vasculares en los pacientes renales se centra en el papel del fósforo, es evidente la importancia de los niveles de calcio en dicho proceso (92). La adición de niveles elevados de calcio a un ambiente con sobrecarga de fósforo produce efectos sinérgicos sobre el grado de calcificación vascular $(93,94)$. Se ha observado que la combinación de calcio y fósforo tiene un efecto sinérgico sobre la expresión de RUNX, en parte debido a que el calcio es capaz de producir un proceso de calcificación a través de vías diferentes de las utilizadas por el fósforo (95), razón por la cuál es capaz de potenciar el efecto calcificante de éste último.

El aumento de los niveles plasmáticos de calcio aumenta la capacidad de formación de núcleos de calcificación, además de inducir la apoptosis de las CML de forma sinérgica con el fósforo (94) y de facilitar la liberación de vesículas calcificantes (96). El calcio es capaz de promover cambios en las vesículas calcificantes, modificando su contenido en fosfolípidos y anexinas, facilitando la formación de núcleos sobre los que se agregarán los cristales de hidroxiapatita (96). Aunque se ha observado como el calcio podría inducir la producción de algunos inhibidores de la calcificación como la proteína gla de la matriz ósea como parte de una respuesta adaptativa (97), la estimulación continuada de este sistema provoca una disregulación y una pérdida de este mecanismo de protección. La 


\section{INTRODUCCIÓN}

proteína gla de la matriz fue el primer inhibidor de la calcificación identificado. Se trata de una proteína dependiente de vitamina $\mathrm{K}$ que se expresa en $\mathrm{CML}$, pero su expresión se ve reducida en arterias calcificadas (98).

Sin embargo, algunos estudios señalan la posibilidad de que la administración de vitamina $D$ acelere la progresión de las calcificaciones vasculares (99-101). Los cambios inducidos por la vitamina $D$ parecen, en algunos casos, ser reversibles al menos parcialmente tras suspender el aporte exógeno de calcitriol.

El calcitriol incrementa la absorción intestinal de calcio y fósforo, causando hiperfosforemia, lo que induce al desarrollo de calcificaciones. Esto sucede en ausencia de la capacidad fosfatúrica e inhibidora de la síntesis de calcitriol propia del complejo FGF-23/Klotho. La acción calcificante a nivel vascular de calcitriol parece, en gran medida, estar mediada por el fósforo, comprobando en modelos animales con ausencia de FGF-23 y una dieta pobre en vitamina D como la elevación del fósforo inducía calcificación independientemente de los valores de calcitriol. Aun así, un efecto promotor directo de calcitriol sobre el proceso de calcificación no ha sido descartado hasta el momento. Los hallazgos de Shroff y cols postularon que cifras tanto bajas como altas de calcitriol en plasma en enfermos pediátricos en diálisis conducen al desarrollo de calcificación vascular en un proceso mediado por el grado de inflamación (102).

El suero de los pacientes con enfermedad renal crónica parece contener otras sustancias estimulantes de la calcificación (103). Existe un amplio número de factores de la uremia capaces de inducir la transformación osteoblástica y la secreción de proteínas de la matriz ósea, como el factor de necrosis tumoral, la fibronectina, el colágeno tipo I o el 25-hidroxicolesterol (104-106). 


\section{INTRODUCCIÓN}

\begin{tabular}{|c|c|}
\hline Promotores de la Calcificación & Inhibidores de la Calcificación \\
\hline BMP-2, 4 y 6 & OPG \\
\hline BGP & PTHrP \\
\hline Colágeno tipo II & Osteopontina \\
\hline RANKL & Osteonectina \\
\hline Sialoproteína Ósea & Klotho \\
\hline Osteocalcina & BMP-7 \\
\hline Citoquinas inflamatorias & Fetuína \\
\hline Estrés oxidativo & Pirofosfatos \\
\hline MMP2, 3 y 7 & \\
\hline
\end{tabular}

Tabla 1: Promotores e inhibidores de la calcificación vascular.

El FGF-23, juega un papel fundamental en el proceso de calcificación vascular. Sus niveles séricos se elevan de forma precoz en la enfermedad renal, marcando la existencia de un balance positivo de fósforo aun cuando los niveles séricos de dicho elemento no muestren variaciones.

En modelos animales se ha comprobado como el incremento en los valores de FGF-23 en sujetos con función renal normal actuaba como factor protector frente al desarrollo de CV gracias a su capacidad fosfatúrica e inhibidora de la PTH y el calcitriol, reduciendo la absorción de calcio y fósforo a nivel intestinal y consiguiendo por tanto un balance negativo de dicho elemento $(\mathbf{1 0 7}, \mathbf{1 0 8})$. Esta relación parece mantenerse en modelo exvivo, siempre que existan niveles adecuados de su receptor, la proteína transmembrana Klotho, como para responder adecuadamente a la acción de FGF-23. El déficit de Klotho parece facilitar el desarrollo de calcificaciones arteriales en parte debido a la pérdida de los efectos protectores a nivel vascular de FGF-23 (109).

Un trabajo reciente ha demostrado como en pacientes con enfermedad cardiovascular (ECV) pero libres de ERC, la correlación entre la concentración sérica de FGF-23 y el desarrollo de eventos cardiovasculares dependía directamente de la intensidad de la respuesta fosfatúrica a nivel renal (110). En una muestra de 178 enfermos con ERC 


\section{INTRODUCCIÓN}

estadio 3-4 se comprobó como en estos pacientes el desarrollo de calcificaciones en aorta abdominal, cuantificadas según el índice de Kauppila, se correlacionaba con el deterioro de la respuesta fosfatúrica a FGF-23 (111). El incremento de FGF-23 se asocia, en enfermos renales con estadios 2-4, a una mayor incidencia de eventos cardiovasculares, especialmente insuficiencia cardiaca crónica (112).

Sin embargo, existe cierta controversia acerca de la capacidad de FGF-23 de modificar el desarrollo de calcificaciones vasculares independientemente de las concentraciones de fósforo en estadios iniciales de ERC. El FGF-23 parece tener la capacidad de inducir el desarrollo de calcificaciones vasculares a través de mecanismos independientes del grado de fosfaturia, especialmente facilitando el desarrollo de hipertrofia ventricular izquierda (113). Otros estudios señalan que en estadios 2-4 de ERC el FGF-23 no se correlaciona con el grado de calcificación en arterias coronarias y aorta torácica, por lo que podría no participar en la génesis de las calcificaciones vasculares, aunque podría facilitar su progresión (114). El descenso en las cifras séricas de Klotho en pacientes con ERC se ha asociado también con un aumento de la rigidez arterial determinada por la velocidad de onda de pulso (115).

En pacientes en estadios más avanzados de ERC y en diálisis se ha demostrado como el mantenimiento de niveles séricos elevados de FGF-23 se relaciona con la calcificación

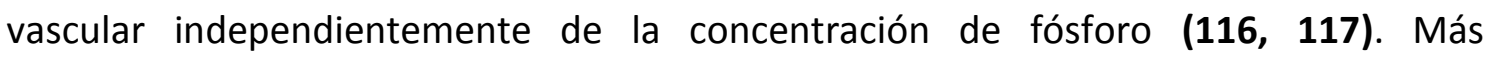
específicamente, Ozkok y cols han demostrado como en pacientes en hemodiálisis, los niveles séricos de FGF-23 se relacionaban de forma directa con la progresión del score de calcificación de arterias coronarias, independientemente de los niveles de fósforo (118).

La precipitación del calcio y del fósforo en el organismo se ve contrarrestada por una serie de factores que inhiben dicho proceso. La fetuína A es una proteína plasmática de origen hepático perteneciente a la superfamilia de las cistatinas (119). Modelos animales han establecido la capacidad de la fetuína A de inhibir el desarrollo de calcificaciones ectópicas (120). El déficit de esta proteína agrava las lesiones calcificadas ya existentes, asociándose en pacientes en hemodiálisis con el grado de inflamación y 


\section{INTRODUCCIÓN}

mortalidad $(\mathbf{1 2 1}, \mathbf{1 2 2})$. La fetuína A dificulta la producción de calcificaciones a través de la eliminación de partículas calcio-proteicas promotoras de la calcificación y del bloqueo de factores facilitadores del proceso como BMP-2, BMP-4 y BMP-6 $(\mathbf{1 2 3}, \mathbf{1 2 4})$.

La osteoprotegerina constituye un receptor soluble para RANKL, impidiendo la unión de éste a RANK. De esta forma se impide la activación de los osteoclastos y por tanto el proceso de resorción ósea (125). La proteína GLA de la matriz, cuya actividad depende de la vitamina $\mathrm{K}$, inhibe el crecimiento de los cristales de calcio que actúan como núcleos de calcificación, bloqueando además factores favorecedores de la calcificación como BMP-2 o BMP-4 (126). La osteopontina es una fosfoproteína extracelular con afinidad por la hidroxipatita gracias a su carga electronegativa. La osteopontina inhibe el crecimiento de los cristales de calcio y estimula la actividad osteoclástica (127).

\subsection{2: RIESGO CARDIOVASCULAR}

Las complicaciones cardiovasculares constituyen la principal causa de muerte en pacientes con enfermedad renal crónica y son el resultado de un proceso de remodelado cardiaco que conduce a la hipertrofia del ventrículo izquierdo (HVI) y del desarrollo de aterosclerosis que afecta tanto a la capa íntima como a la capa media de las arterias (128). Los factores de riesgo implicados en la aparición de HVI y de la enfermedad arteriosclerótica son diferentes aunque comparten algunos aspectos en común (129).

La relación entre la enfermedad cardiovascular y la enfermedad renal es doble. La disminución del filtrado glomerular implica un mayor riesgo cardiovascular, al que puede sumarse la proteinuria, que actúa como un factor de riesgo cardiovascular independiente del filtrado glomerular (130). Según datos procedentes de población estadounidense, sólo un $25 \%$ de los pacientes con un filtrado glomerular estimado por debajo de $60 \mathrm{ml} / \mathrm{min} / 1.73 \mathrm{~m}^{2}$ presentan proteinuria, mientras que un porcentaje similar de pacientes con proteinuria presentan una tasa estimada de filtrado glomerular por debajo de dicha cifra (131). 


\section{INTRODUCCIÓN}

La prevalencia de la patología cardiovascular en la enfermedad renal crónica depende del grado de evolución de la misma. En algunos estudios se ha observado como el 19\% de los individuos con enfermedad renal crónica leve padecen enfermedad cardiovascular (132), mientras que para aclaramientos de entre 20 y $50 \mathrm{ml} / \mathrm{min} / 1,72 \mathrm{~m}^{2}$ existe una prevalencia de infarto agudo de miocardio y de infarto cerebral isquémico del $27,2 \%$ y del 6,8\% respectivamente, valores que triplican los recogidos en la población general (133). Otros trabajos cifran la prevalencia de enfermedad coronaria en pacientes que comienzan terapia renal sustitutiva en torno al $25 \%$, con una prevalencia de infarto agudo de miocardio del 9,4\% y de enfermedad cerebro-vascular de un 9,7\% (134), datos que parecen subestimar la prevalencia real de estas enfermedades. Algunos autores calculan que la mortalidad cardiovascular de los enfermos en diálisis es entre 10 y 100 veces superior a la presente en población general de la misma edad y sexo (135).

La epidemiología de la enfermedad cardiovascular es diferente en los enfermos renales respecto a la población general, siendo más frecuente el fallecimiento por fallo cardiaco o muerte súbita cardiaca en los enfermos renales, mientras que la principal causa de fallecimiento de tipo cardiovascular en la población general suele ser el infarto agudo de miocardio o el ictus (136).

La elevada prevalencia de enfermedad cardiovascular en los enfermos renales se debe a la concurrencia de factores de riesgo cardiovascular clásicos, como pueden ser la hipertensión arterial, la dislipemia, la diabetes mellitus, el tabaquismo o la inactividad física junto con otros relacionados con la disfunción renal, como las alteraciones hidroelectrolíticas, la hiperhomocisteínemia, la proteinuria, el aumento del volumen extracelular y el mismo tratamiento con diálisis (137-140).

La hipertensión arterial constituye un factor de riesgo de nuevos eventos cardiovasculares o recurrencia de los mismos desde los estadios más tempranos de la ERC (141). La relación de la HTA con la patología cardiovascular se modifica, sin embargo, en los pacientes en diálisis, adoptando una morfología en " $U$ ", en la que cifras tanto bajas como elevadas de tensión arterial conllevan una mayor mortalidad (142). De 


\section{INTRODUCCIÓN}

igual forma, el padecimiento de diabetes mellitus comporta una elevación del riesgo cardiovascular en todos los estadios de la enfermedad renal (143).

La dislipemia es una patología común en pacientes con ERC y se caracteriza en esta población por presentar niveles plasmáticos elevados de triglicéridos y colesterol VLDL, reducidos de colesterol HDL y cifras normales o reducidas de colesterol LDL (144). En diálisis, la relación entre el colesterol y la mortalidad cardiovascular depende del grado de inflamación: mientras que en los pacientes sin evidencia de elevación de parámetros inflamatorios el aumento de colesterol se correlaciona con la mortalidad, cuando hay constancia de la existencia de un estado inflamatorio, caracterizado por el incremento de los valores séricos de interleukina-6 o PCR, la relación adquiere una forma de "U", lo que sugiere que cifras reducidas de colesterol total podrían ocultar una malnutrición subyacente, lo que conllevaría un grado mayor de inflamación (145). De forma similar y al contrario que lo habitual en población general, en diálisis la obesidad se asocia a supervivencias más prolongadas (146). El tabaquismo, sin embargo, constituye un factor de riesgo cardiovascular para todos los estadios de ERC, incluyendo diálisis.

Las alteraciones del metabolismo óseo-mineral son un importante factor de riesgo cardiovascular propio de los enfermos renales. Se ha demostrado una relación directa entre los niveles séricos de fósforo, PTHi y producto calcio-fósforo con la mortalidad en pacientes en diálisis $(\mathbf{1 4 7}, \mathbf{1 4 8})$. Este proceso, que sucede de forma independiente al desarrollo de placas de ateroma, no depende únicamente de las concentraciones en plasma de calcio y fósforo, sino también del resto de factores promotores e inhibidores implicados en el proceso, que regulan el cambio morfológico de las células musculares lisas propias de la pared de los vasos en células osteoblásticas que inician el proceso de mineralización de la pared vascular.

La anemia es otro de los factores de riesgo cardiovascular propios de la ERC y su padecimiento facilita el desarrollo de cardiomiopatía e hipertrofia ventricular izquierda (149). El comportamiento de la anemia en los pacientes con ERC sigue también un patrón en "U", no objetivándose beneficios a nivel renal, cardiovascular o en calidad de vida derivados de una corrección intensiva de la anemia, según los resultados del 


\section{INTRODUCCIÓN}

estudio TREAT. El desarrollo de HVI depende de factores como la sobrecarga de volumen propia de los estadios terminales de la enfermedad renal, la HTA o la rigidez vascular y constituye un factor de riesgo de mortalidad independiente (150).

La inflamación es un factor de riesgo para el desarrollo de lesiones ateroscleróticas tanto en población general como en pacientes con ERC. Múltiples circunstancias pueden colaborar al mantenimiento del estado pro-inflamatorio propio de la ERC como complicaciones derivadas de la diálisis, exposición a toxinas, aclaramiento deficitario de factores pro-inflamatorios o infección clínica o subclínica. La inflamación en estos pacientes se relaciona directamente con una mayor mortalidad global y cardiovascular (151). Los estados procoagulantes, comunes en los enfermos renales pese a su elevado riesgo de sangrado, constituyen otros factores de riesgo de cardiopatía isquémica e infarto agudo de miocardio.

La proteinuria se asocia con un peor pronóstico tanto cardiovascular como renal, acelerando la progresión de la ERC hacia sus estadios más avanzados. Su papel como factor de riesgo cardiovascular independiente del daño endotelial preexistente parece claro (152). El bloqueo del eje renina-angiotensina-aldosterona parece tener utilidad más allá de facilitar el control de las cifras tensionales, permitiendo mejorar la función endotelial y reducir de esta forma el nivel de inflamación y las cifras de microalbuminuria y proteinuria (153). El aumento del estrés oxidativo y la hiperhomocisteinemia son otros factores característicos de la enfermedad renal que juegan un papel importante en la génesis de la enfermedad cardiovascular.

\subsection{3: ENFERMEDAD ÓSEA}

La persistencia de niveles séricos elevados de PTH induce una forma particular de enfermedad a nivel óseo, característica de la enfermedad renal crónica: la osteítis fibrosa. Esta enfermedad se caracteriza por una aceleración en la formación y reabsorción de hueso debido a un aumento en el número y actividad de osteoblastos y osteoclastos, y a un incremento de la fibrosis de la médula ósea. El grado de desarrollo 


\section{INTRODUCCIÓN}

de la osteítis fibrosa depende directamente de la intensidad y duración de la elevación de PTH.

En estadios precoces de la enfermedad, el grado de alteración del metabolismo mineral es bajo y el hueso conserva gran parte de su fuerza. En estadios avanzados, la pérdida de hueso se produce de forma tan rápida que no es posible una correcta mineralización posterior, aumentando la cantidad de hueso desmineralizado y provocando una alineación irregular del colágeno, que favorece la formación de complejos amorfos de calcio y fosforo, dando como resultado un hueso con tendencia a las fracturas $(3, \mathbf{8})$.

El hallazgo clínico habitual en los pacientes es la existencia de dolores óseos y articulares, en parte provocados por el depósito periarticular de calcio en forma de calcificaciones metastásicas. Los hallazgos radiológicos de la osteítis fibrosa son característicos de la enfermedad en fase avanzada, estando ausentes en estadios precoces. La radiografía de manos permite apreciar con especial intensidad el efecto de la osteítis fibrosa, en particular a nivel de la cara radial de la segunda y tercera falanges, así como en la punta de las mismas. También pueden observarse signos característicos de la enfermedad en otros huesos como el cráneo (imagen de cráneo en "sal y pimienta") y en ciertos huesos largos como el fémur $(3,8)$.

En ocasiones, el tratamiento médico o quirúrgico del hiperparatiroidismo secundario a la enfermedad renal crónica provoca la aparición de un cuadro distinto, la enfermedad por bajo remodelado, que comprende a su vez la enfermedad ósea adinámica y la osteomalacia. La enfermedad ósea adinámica se caracteriza por una disminución del número de osteoblastos y osteoclastos, lo que se traduce en una baja o nula actividad de formación de hueso. En el caso de la enfermedad ósea adinámica la cantidad de osteoide (hueso desmineralizado) es normal o incluso está disminuida. En analítica, la enfermedad ósea adinámica se caracteriza por presentar cifras de PTH sérica por debajo de $100 \mathrm{pg} / \mathrm{ml}$, disminución de los niveles de fosfatasa alcalina y discretas elevaciones del calcio iónico en plasma $(3,8)$. 


\section{INTRODUCCIÓN}

Algunos individuos son más susceptibles de padecer enfermedad ósea adinámica, como es el caso de diabéticos, ancianos y mujeres. Además de la existencia de cifras bajas de PTH sérica, este tipo de lesión ósea también puede ser generada por la intoxicación por aluminio, aunque esta causa es cada día más infrecuente. La enfermedad ósea adinámica se asocia con un riesgo aumentado de fracturas, aún mayor que en el caso de la osteítis fibrosa, cursando además en ocasiones con hipercalcemia y calcificaciones en el árbol vascular y otros tejidos $(3,8)$.

La osteomalacia es también una forma de enfermedad ósea por bajo remodelado, pero se diferencia de la enfermedad ósea adinámica en la existencia de grandes cantidades de osteoide en hueso. Esta forma de enfermedad ósea, asociada en la población general a un déficit importante de vitamina $D$, aparecía a menudo en enfermos renales tratados con aluminio, debido a la capacidad inhibidora de este elemento sobre la mineralización del hueso y sobre la síntesis de PTH. La mejora en el tratamiento del agua depurada para las unidades de diálisis, así como un menor empleo de hidróxido de aluminio como quelante de fósforo ha permitido reducir drásticamente la prevalencia de enfermedad ósea asociada al aluminio en los enfermos renales $(2-3,8)$.

\subsection{4: CONSECUENCIAS DEL DESAJUSTE METABÓLICO EN EL TRASPLANTE}

Los pacientes que han recibido un trasplante renal presentan, pese a la existencia de un injerto renal funcional, una elevada morbimortalidad de origen cardiovascular, fruto de la conjunción de factores de riesgo clásicos junto con otros factores específicos de la enfermedad renal o del trasplante, como la inmunosupresión, las infecciones o la disfunción del injerto (154). Las enfermedades cardiovasculares suponen la primera causa de fallecimiento en pacientes trasplantados, especialmente a partir del primer año, cuándo pueden llegar a suponer hasta un $50 \%$ del total de fallecimientos (155-158). Comparado con un enfermo en hemodiálisis o diálisis peritoneal, la mortalidad de un trasplantado es de una cuarta o una sexta parte, y a su vez supone aproximadamente el doble que la de un individuo de la misma edad y sexo de la población general. Si 


\section{INTRODUCCIÓN}

consideramos únicamente el riesgo de muerte por un evento cardiovascular, éste es 10 veces superior en un paciente trasplantado comparado con un sujeto sin enfermedad renal de su misma edad y sexo (135). Dado que la mayoría de individuos trasplantados fallece con un injerto normofuncional, la patología cardiovascular se ha convertido en una de las causas principales de pérdida del injerto $(9,159)$.

La prevalencia de calcificaciones vasculares en pacientes trasplantados es elevada (160, 161). La evaluación del grado de calcificación a nivel de arterias coronarias y del grosor íntima-media carotideo son de gran importancia. Estos marcadores estratifican el avance de la aterosclerosis en pacientes con enfermedad renal crónica, mostrándose elevados en trasplantados comparados con población general y disminuidos al compararlos con los valores obtenidos en pacientes en diálisis, posiblemente por una regresión de la afectación del vaso posterior al trasplante $(160,161)$.

El trasplante renal tiene un efecto beneficioso sobre el riesgo cardiovascular de los pacientes con enfermedad renal crónica. En población trasplantada, la prevalencia de patología cardiovascular varía entre un 6 y un 15\% $(162,163)$, dependiendo del tamaño muestral, la prevalencia de diabetes mellitus o el tiempo de seguimiento. Valdés y cols observaron en una cohorte de 1729 pacientes trasplantados en España un 22,2\% de eventos cardiovasculares, registrando como factores predisponentes la edad del receptor, la diabetes, la obesidad, la presencia de hipertrofia ventricular izquierda y el tabaquismo en el momento del trasplante (164). Asimismo se ha postulado que tanto la existencia de cardiopatía isquémica pre-trasplante como una fracción de eyección por debajo del $40 \%$ objetivada mediante ecocardiograma previo al trasplante pueden actuar como factores predictores de mortalidad cardiovascular (165). Este mismo trabajo encontró un mayor riesgo de presentar un evento cardiovascular en pacientes con cardiopatía isquémica que habían sido revascularizados frente a los no revascularizados. La realización de un estudio morfológico y funcional cardiovascular es de especial interés. En este sentido, algunos autores (166) parecen conferir una mayor importancia a la fracción de eyección como predictor de supervivencia del paciente que a las pruebas de perfusión y anatomía coronaria. Además, un injerto renal funcional facilita la 


\section{INTRODUCCIÓN}

disminución de la masa ventricular izquierda con regreso de la hipertrofia del mismo $(167,168)$.

La prevalencia de factores de riesgo cardiovascular, tanto clásicos como propios de la enfermedad renal crónica es elevada en la población trasplantada.

La hipertensión arterial (HTA) es una patología muy frecuente en el enfermo trasplantado, con una prevalencia que ronda entre el 60 y el 85\% (169-174). La existencia de HTA se debe a múltiples factores en esta población, tanto pretrasplante, como la enfermedad renal de base como post-trasplante, como función del injerto deteriorada, rechazo agudo, estenosis de arteria renal del injerto, enfermedades renales

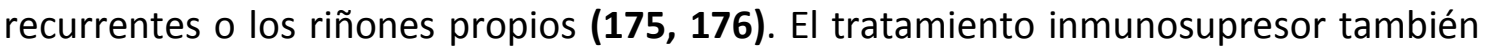
juega un importante papel en el mantenimiento de cifras elevadas de tensión arterial. Los inhibidores de la calcineurina inducen $\operatorname{HTA}(177,178)$ al provocar la vasoconstricción de la arteriola aferente en el glomérulo, estimulando el sistema renina-angiotensinaaldosterona. Aumentan además la liberación de citoquinas vasoconstrictoras y reducen la actividad del óxido nítrico y otras sustancias vasodilatadoras.

La elevación de los niveles plasmáticos de colesterol total, triglicéridos y LDL son también comunes en trasplantados renales, afectando a un 50-60\% de los enfermos $(\mathbf{1 7 9}, \mathbf{1 8 0})$. La dislipemia se asocia al avance de enfermedad cardiovascular tanto en población general como en los enfermos renales (180). Entre los factores presentes en los receptores de trasplante renal que favorecen el desarrollo de la dislipemia destaca el sobrepeso, el deterioro de la función del injerto, la proteinuria, o el uso de betabloqueantes, diuréticos y ciertos inmunosupresores como ciclosporina, corticoides o sirólimus (181).

Respecto a la prevalencia de diabetes mellitus en la población trasplantada, esta oscila entre el 7 y el $28 \%(9,162,182-186)$, siendo un factor de riesgo cardiovascular independiente en la mayoría de los estudios realizados. Tras el trasplante renal, la incidencia de diabetes de novo depende de la pauta de inmunosupresión utilizada, con una prevalencia variable entre el 3,6 y el 18\% (179). La diabetes de novo puede verse 


\section{INTRODUCCIÓN}

precedida por un estado de intolerancia a la glucosa mantenido a lo largo del tiempo. La diabetes mellitus de novo en población trasplantada se asocia tanto a pérdida del injerto como a una mayor mortalidad con injerto funcionante $(\mathbf{1 8 7}, \mathbf{1 8 8})$. El riesgo de padecer eventos CV tanto mortales como no mortales en pacientes que desarrollan diabetes de novo es entre 2 y 3 veces superior al resto de trasplantados $(189,190)$. Entre los factores de riesgo para el desarrollo de diabetes de novo en población trasplantada destaca tener un donante cadáver, la edad avanzada, el sexo masculino, la obesidad, la ganancia de peso tras el trasplante, la hiperuricemia, la hipertrigliceridemia o el empleo de inhibidores de la calcineurina, corticoides o sirólimus $(188,191-192)$.

La obesidad es una complicación frecuente en el paciente trasplantado, llegando a afectar aproximadamente al $60 \%$ de los receptores de trasplante renal estadounidenses (193). La obesidad supone un factor de riesgo CV independiente, aumentando además las probabilidades de padecer HTA, diabetes mellitus o dislipemia. Tanto el tratamiento prolongado con corticoides como la eliminación de las restricciones dietéticas que se realiza tras el trasplante favorecen la ganancia de peso. El tabaquismo aumenta el riesgo cardiovascular tanto en población general como en trasplantados renales.

La proteinuria se observa también frecuentemente en pacientes trasplantados, apareciendo entre un 9 y un 45\% de los enfermos (194-196). La presencia de proteinuria transitoria en el post-trasplante inmediato, pese a relacionarse con episodios de rechazo agudo no suele tener significado pronóstico (197), mientras que la proteinuria persistente presente en fases avanzadas se ha relacionado con una peor supervivencia del injerto (198). La presencia de proteinuria en la población general supone un factor de riesgo cardiovascular, especialmente en hipertensos y diabéticos (199) y en población trasplantada también se ha mostrado como un factor independiente de riesgo cardiovascular (200). La anemia constituye otro importante factor de riesgo CV, tanto en población trasplantada como no trasplantada (201-203).

La hiperhomocisteinemia, definida como una concentración de homocisteína superior a $11 \mathrm{mmol} / \mathrm{l}$, es otro factor de riesgo presente en la enfermedad renal crónica (204). Los niveles de homocisteína se reducen tras el trasplante de una forma menor a lo esperado, 


\section{INTRODUCCIÓN}

posiblemente debido a la interferencia de los inmunosupresores y a la existencia de una función renal deficitaria $(205,206)$. La elevación de la proteína $C$ reactiva es un factor de riesgo independiente para el padecimiento de eventos CV (207).

Disponemos de datos recientes acerca de la morbimortalidad del trasplante renal de cadáver en una población de enfermos procedente la Unidad de Trasplante Renal del Servicio de Nefrología del Hospital Clínico Universitario de Valladolid (208). En este trabajo se observó una incidencia de eventos cardiovasculares del 16,5\% en una muestra de 139 trasplantados renales a lo largo de 5 años de evolución, con 4 fallecimientos a causa de los mismos. Todos ellos fueron de causa cardiaca, representando la cardiopatía isquémica un $69,6 \%$ de los eventos, seguida de la insuficiencia cardiaca con un $21,7 \%$. Su distribución en el tiempo tuvo dos picos, a los 6 meses tras el trasplante y transcurridos 4 años.

Respecto a la prevalencia de factores de riesgo cardiovascular en esta muestra, la HTA fue el factor de riesgo más frecuente, con una prevalencia previa al trasplante de $74,8 \%$, alcanzando el 78,9\% tras 5 años. Un 11,5\% de los pacientes padecía diabetes mellitus, con una incidencia de diabetes de novo tras el trasplante del 9,6\%. Respecto a la prevalencia de dislipemia, un $23 \%$ de los pacientes la padecía previamente al trasplante, cifra que se elevó al 57,8\% a los 5 años. La obesidad afectó a un 10,1\% de pacientes antes del trasplante, aumentado al $24,8 \%$ a los 5 años, mientras que el consumo de tabaco, que admitieron el $28 \%$ de los pacientes antes de la cirugía se redujo al $16,5 \%$ una vez transcurrido 5 años. Una función renal del injerto deteriorada, estimada mediante MDRD-4 como inferior a $60 \mathrm{ml} / \mathrm{min}$ comportaba un aumento significativo del riesgo de desarrollo de un episodio cardiovascular.

En los pacientes trasplantados se ha observado una rápida pérdida de masa ósea durante los primeros 6 meses tras el trasplante, en torno a un 7-10\%, que afecta especialmente al hueso trabecular. La masa ósea parece estabilizarse e incluso tiende a la recuperación en torno a los 12 meses post-trasplante (209-211). La pérdida de masa ósea inicial se ha cuantificado en torno a un $1.6 \%$ mensual a nivel de columna lumbar durante los primeros 5 meses tras el trasplante, mientras que en fémur se observó una 


\section{INTRODUCCIÓN}

disminución de un 3.6\% en los primeros 3 meses en los pacientes varones mientras que

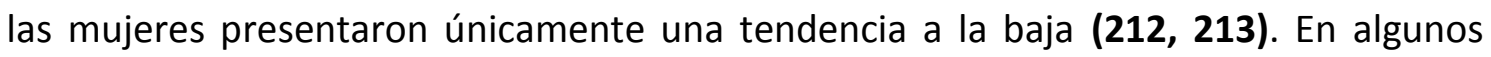
estudios a largo plazo se observa estabilidad e incluso ligeros incrementos de la densidad mineral-ósea mientras que en otros se han observado pérdidas que llegan a cuantificar en torno a 1-2\% anual, dato que parece dependiente del consumo de corticoides.

La pérdida de masa ósea que se produce en el post-trasplante inmediato condiciona una alta prevalencia de fracturas, entre el 7 y el $20 \%(3,214-215)$, sucediendo generalmente en el post-trasplante tardío y con localización preferente en pies y tobillos $(215,215)$ y conllevando un incremento del riesgo de dolor y necrosis ósea. Los trasplantados renales presentan un mayor riesgo de fracturas respecto a la población general de la misma edad y sexo (216), debido a la disminución de la masa ósea producida principalmente en los primeros 6 meses tras el trasplante. Entre los factores de riesgo de fractura en la población trasplantada destacan la edad superior a 60 años, el sexo femenino, los antecedentes de fracturas, la existencia de un hiperparatiroidismo persistente, la diabetes y el tratamiento previo con corticoides (27). El padecimiento de diabetes mellitus tipo 1 multiplica más de tres veces la prevalencia de fracturas respecto a los no diabéticos (216). Este incremento tiene una etiología multifactorial, ya que a una menor masa ósea secundaria al efecto de la diabetes sobre el hueso se une la retinopatía y neuropatía diabéticas, que provocan un mayor número de caídas por inestabilidad y problemas visuales. Respecto a los factores de riesgo para desarrollar una enfermedad ósea post-trasplante señalaremos el empleo de análogos de vitamina D antes de la cirugía, inmunosupresores, corticoides o anticonvulsivantes, inmovilización, malnutrición o uso continuado de diuréticos del asa. 


\section{4: MÉTODOS PARA LA EVALUACIÓN DEL MOM}

\subsection{1: ANALÍTICA}

\subsubsection{1: CALCIO SÉRICO}

Los niveles normales de calcio plasmático se sitúan entre 8,4-10,2 mg/dl. El calcio circula como calcio libre (fracción ionizada) o unido a proteínas. La cifra obtenida como resultado de los análisis estándar suele cuantificar el calcio total, suma de ambas fracciones (8). La proporción de calcio unido a proteínas depende de la concentración de albúmina, por lo que, en situaciones de hipoalbuminemia debe corregirse el calcio total obtenido de los datos de laboratorio según la siguiente fórmula

Calcio Corregido (mg/dl): Calcio total + 0,8 * [4-Alb (g/dl)]

Las cifras recomendadas de calcio en receptores de un trasplante renal son las mismas que en sujetos sanos.

\subsubsection{2: FÓSFORO SÉRICO}

Los niveles normales de fósforo sérico se sitúan entre 2,7 y 4,6 mg/dl, aconsejando valores ligeramente superiores a los mencionados en pacientes en diálisis (8). En pacientes trasplantados los valores recomendados de fósforo deben situarse en el rango de la normalidad.

La hiperfosforemia en enfermos renales crónicos se correlaciona con el desarrollo de progresión de la enfermedad renal (217), y con un aumento de la hipertrofia ventricular (218) y de la mortalidad cardiovascular (219). 


\section{INTRODUCCIÓN}

\subsubsection{3: FOSFATASA ALCALINA}

La fosfatasa alcalina puede proceder de diversas fuentes, entre las que destacan el hueso, el hígado, el intestino o el riñón. Suele estar elevada en pacientes con enfermedad renal crónica debido a la existencia de un hiperparatiroidismo que condiciona la aparición de osteítis fibrosa. Existe una variante, la fosfatasa alcalina específica de hueso, que se emplea cuando existen dudas acerca de la procedencia de la molécula. Tanto la fosfatasa alcalina total como la específica de hueso se elevan en el hiperparatiroidismo (8).

\subsubsection{4: PTH}

La hormona paratiroidea es un péptido de 84 aminoácidos cuya porción $\mathrm{N}$-terminal es imprescindible para la activación de su receptor, mientras que la porción más larga, denominada C-terminal, no lo es. Los fragmentos de PTH se eliminan por vía renal, y tienden a acumularse en estados de insuficiencia renal, pero muchos de ellos carecen de capacidad para activar el receptor de PTH, debido a la pérdida de la porción Nterminal (8).

La determinación de PTH intacta o PTHi (1-84) permite eliminar parcialmente las interferencias generadas por dichos fragmentos de la hormona a través del empleo de dos anticuerpos que se fijan en la zona media y en la región $\mathrm{N}$-terminal. De esta forma se cuantifican tanto la PTHi como un fragmento de gran tamaño (7-84), que llega a suponer el $48 \%$ de la PTH total, presente en los enfermos renales. En la actualidad disponemos además de una nueva técnica que emplea anticuerpos que se unen a los primeros aminoácidos de la molécula. Esta técnica, denominada determinación de PTHbi (biointacta) permite la determinación exclusiva de la molécula completa (1-84).La cuantificación de PTHbi supone aproximadamente un 55\% del valor de PTHi. El uso de esta prueba no se ha generalizado debido a sus limitaciones y requisitos técnicos (8). 


\section{INTRODUCCIÓN}

Los valores séricos de PTHi en la población general se sitúan entre 10 y 65 pg/ml. Las recomendaciones actuales para enfermos en diálisis son mantener las cifras de PTHi entre 150 y 300 pg/ml. Niveles de PTHi por encima de $400-500$ pg/ml son indicativos de la presencia de una enfermedad ósea por alto remodelado, con gran frecuencia osteítis fibrosa o formas mixtas. Valores plasmáticos de PTHi por debajo de 100-120 pg/ml indican la presencia de una enfermedad por bajo remodelado (enfermedad ósea adinámica u osteomalacia) (8). No se ha establecido una correlación entre los niveles de PTHi y el desarrollo de lesiones cardiovasculares aunque si se ha observado un aumento del riesgo de mortalidad, especialmente cardiovascular, con cifras elevadas o disminuidas de PTH.

\subsubsection{5: VITAMINA D}

La medición de $25-\mathrm{OH}$ vitamina D es la forma más habitual de cuantificar las reservas orgánicas de la vitamina. Los valores séricos normales de $25-\mathrm{OH}$ vitamina $\mathrm{D}$ se sitúan entre 30 y $74 \mathrm{ng} / \mathrm{ml}$. La existencia de unos niveles deficitarios de vitamina $D$ suele deberse a la restricción de la ingesta de derivados lácteos, la baja exposición a la radiación solar o la prevalencia de población de raza negra, así como en pacientes con enfermedad renal crónica.

La concentración plasmática de $25-\mathrm{OH}$ vitamina $\mathrm{D}$ se encuentra especialmente reducida en los pacientes que presentan enfermedad renal crónica. Se demostró como en una muestra de 390 pacientes españoles con enfermedad renal crónica aproximadamente un $80 \%$ de ellos presentaban unas cifras de $25-\mathrm{OH}$ vitamina D sérica inferiores a $30 \mu \mathrm{g} / \mathrm{I}$ (Luño y cols, 2011).

La carencia de unos niveles adecuados de vitamina $D$ constituye asimismo un factor de riesgo para el desarrollo de HTA y enfermedad cardiovascular. En una población de más de 11000 individuos, con un periodo de seguimiento de más de 10 años se comprobó que la existencia de niveles plasmáticos de vitamina $D$ inferiores a $15 \mathrm{ng} / \mathrm{ml}$ aumentaba 6 veces el riesgo de padecer HTA (220). Se obtuvieron resultados similares al 


\section{INTRODUCCIÓN}

correlacionar el déficit severo de vitamina $D$ con el desarrollo de enfermedad cardiovascular (221).

\subsubsection{6: $\underline{\text { FGF-23 }}$}

El factor de crecimiento de fibroblastos 23 o FGF-23 es una proteína compuesta por 251 aminoácidos implicada en la regulación del metabolismo óseo mineral. La unión de FGF23 con su receptor induce la eliminación de fósforo a través de la orina (efecto fosfatúrico), además de suprimir la síntesis de calcitriol a nivel renal al inhibir el enzima $1 \alpha$-hidroxilasa encargado de transformar $25-\mathrm{OH}$ vitamina $\mathrm{D}$ en $1,25-\mathrm{OH}$ vitamina $\mathrm{D}$ y estimular la 24-hidroxilasa, que inactiva el calcitriol. En individuos sanos, los valores séricos de FGF-23 se sitúan por debajo de los $50 \mathrm{pg} / \mathrm{ml}$. El aumento de los niveles de FGF-23 se observa en los estadios iniciales de la enfermedad renal crónica como respuesta a una disminución del filtrado glomerular que comporta un manejo inadecuado del fósforo (12). 


\section{INTRODUCCIÓN}

\subsection{2: PRUEBAS DE IMAGEN}

\subsubsection{1: TOMOGRAFÍA AXIAL COMPUTERIZADA CON DETERMINACIÓN DE CAC}

La cuantificación de calcio coronario mediante tomografía axial computerizada con haz de electrones o tomografía computerizada multicorte constituye una herramienta no invasiva de gran utilidad para evaluar la existencia de enfermedad coronaria, con un alto valor predictivo negativo y cuyos resultados se han comprobado tanto en población general (222) como en enfermos renales crónicos (223). La realización de la cuantificación de calcio coronario es un proceso relativamente seguro, con una duración reducida, de aproximadamente 15 minutos, y que no precisa de la administración de contraste yodado. La cuantificación de calcio a nivel coronario se basa en la evaluación del área calcificada, la densidad media de la calcificación y el número de placas existentes (224).

La presencia y la extensión de calcificaciones vasculares a nivel de las arterias coronarias se ha demostrado como un importante predictor de mortalidad, tanto de origen cardiovascular como por otras causas en la población general $(\mathbf{2 2 5}, \mathbf{2 2 6})$, así como en pacientes con enfermedad renal crónica terminal $(\mathbf{2 2 7}, \mathbf{2 2 8})$ y pacientes trasplantados renales (229-233). Existe también una correlación entre la aparición y el grado de calcificación de arterias coronarias objetivado por tomografía computerizada y la presencia de estenosis en dichos vasos objetivada mediante angiografía coronaria (234), aunque la existencia de calcificación en arterias coronarias no indica necesariamente la estenosis de dichos vasos.

El grado de calcificación tanto a nivel coronario como aórtico en enfermos renales depende de diversos factores (235), como la edad, el tiempo en diálisis, el padecimiento de diabetes mellitus o el grado de inflamación representado por los niveles plasmáticos de PCR. No se ha observado correlación, sin embargo, entre el grado de calcificación y los niveles plasmáticos de lípidos, calcio, fósforo, producto calcio-fósforo, IL-6, TNF- $\alpha$ o 


\section{INTRODUCCIÓN}

el hábito tabáquico. El papel del FGF-23 en el desarrollo de calcificaciones coronarias no ha sido aclarado. Pese a que hasta el momento no existen pruebas de una toxicidad vascular directa mediada por FGF-23 algunos autores sugieren esta posibilidad (236) mientras que otros estudios no han demostrado relación alguna (237).

En cuanto a la población trasplantada, el porcentaje de pacientes que padece un grado de calcificación coronaria moderada o grave se sitúa entre el 44 y el $66 \%$ según diferentes series (231, 238-239). Se han identificado en pacientes trasplantados diversos factores de riesgo para la existencia de calcificación en arterias coronarias: edad avanzada, sexo masculino, tiempo en diálisis, diabetes mellitus, glucosa sérica elevada, hipercolesterolemia, hipertrigliceridemia o presentar valores por debajo de la normalidad de $\operatorname{HDL}(\mathbf{2 2 9}, \mathbf{2 4 0})$. En el caso de la diabetes mellitus, los estudios realizados hasta el momento muestran una clara asociación entre el padecimiento de la misma antes del trasplante y la presencia de calcificaciones coronarias. Sin embargo, el desarrollo de diabetes post-trasplante no parece asociarse con el grado de calcificación coronaria, probablemente por una menor evolución de la enfermedad (240).

La influencia de la tasa de filtrado glomerular sobre el grado de calcificación coronaria no parece clara, ya que algunos autores han encontrado una fuerte correlación inversa entre ambos factores en pacientes con enfermedad renal crónica (241) mientras que en otros estudios realizados con pacientes trasplantados (240) no se ha observado relación entre ellos. El ritmo de progresión de las calcificaciones en arterias coronarias en pacientes trasplantados parece depender de ciertos factores como el grado de calcificación coronaria basal, la hipertensión arterial post-trasplante, la tasa de filtrado glomerular, el índice de masa corporal o la raza caucásica (242). Otros agentes, como el grado de inflamación representado por parámetros analíticos como la PCR se relacionan estrechamente con la presencia de calcificaciones coronarias aunque según recientes estudios no parecen influir en el desarrollo de las mismas (229). 


\section{INTRODUCCIÓN}

\subsubsection{2: ECOGRAFÍA CAROTIDEA Y GROSOR ÍNTIMA-MEDIA}

La ecografía carotidea permite determinar el grado de aterosclerosis preclínica a través de la medición del grosor íntima-media (GIM) y de la demostración de la existencia de placas de ateroma, permitiendo la estratificación del riesgo cardiovascular de los enfermos (243). La medición del GIM es una prueba no invasiva, fácilmente reproducible y de bajo coste. El GIM medido en arteria carótida es un marcador consolidado de enfermedad cardiovascular subclínica y presenta una fuerte correlación con los factores de riesgo cardiovascular clásicos. Sirve además para estudiar la localización de la placa de ateroma o la presencia de calcificaciones situadas en la lámina elástica interna del vaso.

El GIM se produce también como respuesta a la sobrecarga hídrica y el mantenimiento de cifras tensionales elevadas, así como al desarrollo de insulino-resistencia y de intolerancia a la glucosa, produciendo una disfunción endotelial que incrementa el estrés al que quedan sometidas las paredes del vaso $(\mathbf{2 4 4}, \mathbf{2 4 5})$. EI GIM se asocia además, en la población con ERC, a otros factores como el producto calcio/fósforo, los niveles de PTHi, el grado de inflamación sistémica o el tiempo en diálisis (244). El tipo de tratamiento renal sustitutivo no influye en el aumento del GIM (161).

Comparados con pacientes en diálisis, los enfermos trasplantados presentan un GIM significativamente inferior (160). EI GIM en pacientes trasplantados disminuye acompañando el descenso en las cifras de PTH que se produce tras la cirugía, que alcanzan su mínimo entre los meses 6 y 12 tras el trasplante. El GIM depende de forma significativa de los niveles plasmáticos de PTH, mientras que no presenta en estos pacientes relación aparente con la función renal residual del injerto o con los niveles séricos de calcio o fósforo (33). Algunos autores señalan que el descenso del GIM que se produce tras el trasplante es muy rápido (244), lo que podría indicar que el mantenimiento de éste no dependería tanto de la existencia de placas de ateroma en la íntima arterial sino de la persistencia de una sobrecarga de volumen que se soluciona con el trasplante. Otro factor cuya influencia parece importante en el aumento del GIM es la existencia de niveles plasmáticos elevados de ácido úrico, siendo su corrección tras 


\section{INTRODUCCIÓN}

el trasplante un factor predictor independiente de la disminución del GIM (244). Asimismo, aquellos pacientes trasplantados que padecen alteraciones del metabolismo de la glucosa presentan un mayor GIM, aumentando el porcentaje de aterosclerosis preclínica $(\mathbf{2 4 6}, \mathbf{2 4 7})$. La peroxidación lipídica también parece estar presente en pacientes trasplantados durante las fases más precoces, asociando niveles mayores de glucemia y un mayor GIM carotideo (248).

\subsubsection{3: ÍNDICES RADIOGRÁFICOS}

\subsubsection{1: ÍNDICE DE KAUPPILA}

El índice de Kauppila es una sencilla herramienta de bajo coste económico que emplea una radiografía lateral de columna lumbar para evaluar el grado de calcificación en aorta a su paso por dicha región. Este índice se subdivide en dos componentes; en primer lugar se evalúa el grado de calcificación de las paredes anterior y posterior de la aorta a nivel de L1, L2, L3 y L4 (249). El grado de calcificación se obtiene valorando cada una de las paredes, otorgando 3 puntos si está calcificada en su totalidad, 2 puntos si presenta calcificación en al menos $2 / 3$ de su longitud, 1 punto si presenta calcificación en 1/3 de su longitud y 0 puntos si no presenta calcificaciones. De esta forma, la evaluación de las calcificaciones aórticas valorará 8 regiones, con una puntuación que se situará entre 0 y 24 puntos. En un segundo paso, se valora globalmente los 4 sectores de aorta lumbar, con 1 punto si presentan algún grado de calcificación y 0 puntos si no es así, otorgando una puntuación entre 0 y 4 puntos (249).

Existen varios estudios que emplean este índice en pacientes en hemodiálisis. En una muestra de 933 pacientes en hemodiálisis se objetivaron calcificaciones en los cuatro segmentos de aorta lumbar en el $51 \%$ de los individuos, con depósitos en al menos uno, dos o tres segmentos en un 30\% de los pacientes. Un 19\% de los enfermos no presentó calcificaciones objetivables en aorta lumbar en ningún nivel (249). La localización 


\section{INTRODUCCIÓN}

preferente de las calcificaciones fueron los segmentos $L 3$ y L4, descendiendo en segmentos superiores. Esta localización es similar a la observada en población general, aunque más prematura y de mayor extensión (249). La edad de los individuos, la existencia de antecedentes de enfermedad cardiovascular y el tiempo en diálisis son tres factores con una importante correlación con el grado de calcificación en aorta lumbar, mientras que no se observó relación entre el grado de calcificación y las cifras de presión arterial sistólica o diastólica, el calcio y fósforo plasmáticos, el producto calcio-fósforo, los lípidos o la PCR (249). En un reciente estudio con pacientes en hemodiálisis, sólo la edad supuso un factor predictor de calcificación aórtica (235). Se ha observado además como el desarrollo de calcificaciones en aorta abdominal constituyen un factor predictor de mortalidad general y de eventos cardiovasculares no fatales en pacientes en hemodiálisis (250).

\subsubsection{2: ÍNDICE DE ADRAGAO}

El score radiográfico de Adragao es un índice que evalúa de forma sencilla el grado de calcificación vascular existente a partir de radiografías simples de pelvis y manos (251). La estratificación de las calcificaciones vasculares se realiza dividiendo ambas imágenes en cuatro cuadrantes; en el caso de la radiografía simple de pelvis se obtienen los cuadrantes trazando dos líneas imaginarias, una vertical, que atraviese la porción central de los cuerpos vertebrales y una horizontal, que roce el extremo superior de las cabezas femorales. Para la radiografía simple de manos, los cuadrantes se consiguen trazando una línea horizontal que roce el borde proximal de los huesos del metacarpo. Se valorará con 1 punto la presencia de calcificaciones lineales en cada uno de los cuadrantes de cada imagen, otorgando un 0 si no existen dichas lesiones. Por tanto, la puntuación del índice de Adragao se encontrará entre 0 (ausencia de calcificaciones) y 8 puntos (calcificaciones lineales en todos los cuadrantes). El score de Adragao permite de esta forma valorar el grado de calcificación a nivel de varias arterias musculares: iliaca, femoral, radial e interdigital (251). 


\section{INTRODUCCIÓN}

El score de Adragao se ideó como una herramienta sencilla para valorar el grado de calcificación vascular en pacientes en diálisis $(\mathbf{1 9 8 , 2 5 1 )}$. En esta población se ha encontrado una fuerte asociación entre el desarrollo de enfermedad coronaria y enfermedad vascular periférica con la existencia de un score $\geq 3$ (251). Aquellos pacientes en diálisis que presentaron un score de Adragao igual o superior a 3 presentaron un aumento del riesgo de mortalidad cardiovascular de 3,9 respecto al resto de enfermos en diálisis, con un incremento del número de hospitalizaciones por causa cardiovascular en 2,8 y un aumento del riesgo de eventos cardiovasculares de 2,3. El índice de Adragao se correlaciona asimismo con la presión de pulso y la velocidad de la onda de pulso, ambos factores de riesgo independientes de mortalidad cardiovascular $(\mathbf{2 5 1}, \mathbf{2 5 2})$. En una muestra de pacientes en diálisis peritoneal se comprobó como el índice de Adragao se correlaciona con unos valores más bajos de densidad mineral ósea cuantificada mediante DEXA a nivel del cuello femoral (253).

Respecto a los parámetros analíticos, no se ha observado correlación entre los niveles séricos de calcio, fósforo y PTHi y la presencia de calcificaciones y el score de Adragao. Por otro lado la edad, el sexo masculino, el padecimiento de diabetes mellitus, el tiempo en diálisis y los valores de presión arterial media se relacionaban con un score de Adragao $\geq 3$ (251).

\subsubsection{4: ÍNDICE TOBILLO-BRAZO}

El índice tobillo-brazo (ITB) es una herramienta sencilla para valorar la existencia de enfermedad arterial periférica. Para la realización de esta medición es necesaria la utilización de un equipo Doppler continuo con sonda de 8-9 Mhz y un esfigmomanómetro convencional con brazalete de $12 \mathrm{~cm}$ de ancho. La realización del ITB implica la medición de la presión arterial sistólica en arteria braquial y tibial posterior/dorsal del pie, calculando el ITB mediante la siguiente fórmula:

ITB: PAS (tibial posterior/dorsal del pie) / PAS (braquial) 


\section{INTRODUCCIÓN}

Se define como normal un ITB comprendido entre 0,9 y 1,3 . Un ITB reducido $(<0,9)$ indica la existencia de patología obstructiva a nivel arterial y se correlaciona, por ejemplo, con fallo del acceso vascular en pacientes en diálisis, mientras que un ITB aumentado $(>1,3)$ es debido a la existencia de un endurecimiento de los vasos arteriales distales, en relación con la presencia de calcificación vascular. Valores tanto elevados como reducidos del ITB se han relacionado con una mayor mortalidad en enfermos tanto en hemodiálisis como diálisis peritoneal (254-256). En una muestra de pacientes en hemodiálisis, Adragao y col. encontraron un ITB normal en un 40\% de los pacientes, aumentado en un $19 \%$ y disminuido en un $41 \%$ (257).

Tanto las cifras elevadas como reducidas de ITB se correlacionaron con una mayor mortalidad cardiovascular y por todas las causas en los enfermos estudiados. La edad supone un factor de riesgo independiente para la existencia de un ITB fuera de la normalidad. Además se observó una asociación entre la existencia de un ITB $<0,9$ y la presencia de calcificaciones en arteria aorta, iliacas y femorales, mientras que un ITB > 1,3 se asoció a la presencia de calcificaciones en vasos distales (257). Los datos referentes a prevalencia de enfermedad arterial periférica subclínica en población trasplantada son limitados, pero recientemente se ha estudiado dicha patología en una muestra de 304 receptores de trasplante renal, observando un ITB $<0,9$ en un $8 \%$ de los individuos, mientras que tan sólo un 0,3\% presentaron un ITB $>1,3$. La existencia de antecedentes de eventos ateroscleróticos fue el único factor de riesgo independiente para el desarrollo de enfermedad arterial periférica subclínica en dicha muestra de pacientes trasplantados (258).

\subsubsection{5: DENSITOMETRÍA ÓSEA}

La densitometría ósea o absorciometría de rayos $\mathrm{X}$ de energía dual (DEXA) es un método de estudio no invasivo para cuantificar la pérdida de masa ósea, constituyéndose como método de elección para realizar el diagnóstico, evaluar la severidad y realizar el seguimiento de las alteraciones óseo-metabólicas (3). El fundamento técnico de la DEXA 


\section{INTRODUCCIÓN}

se basa en analizar la atenuación que presenta un haz de radiación de baja energía al atravesar los tejidos.

Esta exploración analiza los cambios en el contenido mineral del hueso, ofreciendo una valoración precisa de la masa ósea en regiones anatómicas de especial interés minimizando la radiación recibida por el paciente, permitiendo el diagnóstico precoz de la pérdida de masa ósea, antes de que aparezcan las fracturas. Los lugares estudiados habitualmente mediante DEXA son el cuello del fémur y la región lumbar de la columna vertebral (3). Los resultados se expresan mediante los valores de T-score y Z-score, que representan respectivamente la desviación de los resultados de la DEXA frente a los valores medios de esta exploración en adultos jóvenes (T-score) o en una población de características similares al individuo estudiado (Z-score) (3). Se ha comprobado que cada disminución de una desviación estándar del T score aumenta entre 2 y 2,5 veces el riesgo de fractura ósea (259). El Z score, por otro lado, permite, al comparar los resultados con una población de características similares al individuo estudiado, realizar un diagnóstico diferencial de la osteopenia/osteoporosis y averiguar si existe influencia de factores externos o se debe únicamente al envejecimiento del paciente (3).

Existen dos regiones específicas dónde se suele realizar el estudio mediante DEXA: el tercio proximal del fémur y la columna lumbar. La valoración de la densidad mineral ósea en el tercio próximal del fémur permite predecir el riesgo de fractura de cadera, constituyendo asimismo un importante factor predictor del riesgo de fracturas en el resto de huesos del esqueleto $(3,259)$. En columna lumbar, la región de interés abarca L1, L2, L3 y L4 y debido a su mayor superficie y vascularización, esta región del esqueleto es más sensible a los efectos de hormonas y medicamentos. Sin embargo, la densidad mineral ósea de la columna lumbar puede aumentar en pacientes ancianos, fruto de cambios degenerativos. En pacientes trasplantados renales, la asociación entre los resultados de la DEXA y el riesgo de fracturas está en entredicho $(\mathbf{2 1 4}, \mathbf{2 6 0})$.

La densitometría ósea ha demostrado ser una prueba de gran utilidad para el seguimiento de la evolución de la masa ósea tras el trasplante (19). El hallazgo de una densidad ósea disminuida (T-score $<-2.5$ ) en trasplantados renales es frecuente, 


\section{INTRODUCCIÓN}

afectando en algunas series al $53 \%$ de los pacientes estudiados y con una prevalencia de fracturas óseas en un $44 \%(44,261)$.

A nivel de cuello femoral se encontró una prevalencia de osteoporosis en torno al $22 \%$ en pacientes con trasplante renal. En general, los valores de densidad ósea mineral descienden durante los primeros tres meses post-trasplante con una pérdida de rigidez y de resistencia a las fracturas $(\mathbf{2 6 0}, \mathbf{2 6 2})$, estabilizándose hacia el sexto mes y aumentando discretamente hacia el mes 12 tras la cirugía. Algunos autores han encontrado una relación entre el sexo de los pacientes estudiados y el punto anatómico en el que se producen los mayores cambios de densidad mineral ósea, situado en los varones en el tercio proximal del fémur, mientras que en las mujeres los cambios de mayor cuantía se observan en columna lumbar (212).

Las cifras de PTH producen un impacto negativo sobre la densidad mineral-ósea. Parece existir una correlación inversa entre los niveles séricos de PTH y la densidad ósea cuantificada mediante DEXA $(\mathbf{4 2}, \mathbf{2 6 3})$. La persistencia de un hiperparatiroidismo secundario tras el trasplante se traduce en un adelgazamiento del hueso cortical con resorción intracortical. El hueso trabecular, por otra parte, es más susceptible al efecto de los glucocorticoides, cuyas dosis normalmente se encuentran lo suficientemente elevadas durante los primeros meses tras el trasplante como para inhibir la formación ósea (260). La pérdida de densidad ósea parece depender también de la localización, el sexo y el tiempo del trasplante, mientras que no parece presentar relación con la función renal residual o el tiempo en diálisis previo al trasplante (31), aunque esta última relación no está aclarada completamente.

\subsubsection{6: BIOPSIA ÓSEA}

El estudio histológico del hueso mediante biopsia ósea es la herramienta más fiable a la hora de evaluar detalladamente las alteraciones estructurales del esqueleto, sirviendo como método de referencia para validar otras formas no invasivas de estudio. Sin embargo, su carácter cruento limita sus aplicaciones en la práctica clínica habitual (3). La cresta iliaca es el lugar más utilizado a la hora de obtener muestras para su estudio. 


\section{INTRODUCCIÓN}

La punción se realiza con un trócar de 6-8 $\mathrm{mm}$ de diámetro de borde serrado. Una vez extraída, la muestra se fija en un medio de sostén, habitualmente resinas, que posibilitan su corte en micrótomos. Además del estudio estático, el empleo de tetraciclinas permite obtener información dinámica sobre el grado de avance del proceso de mineralización ósea (3).

En pacientes trasplantados, las series de biopsia ósea realizadas muestran formas tanto de alto como de bajo remodelado óseo, con predominio de las formas adinámicas, constituyendo un fiel reflejo del estado del esqueleto previo a la realización del trasplante renal. Evolutivamente se ha comprobado cómo durante los primeros 6 meses tras el trasplante se produce una rápida pérdida de masa ósea, especialmente de hueso trabecular, debido al efecto de los corticoides que generan una importante disfunción de los osteoblastos. El grado de pérdida de masa ósea se ha correlacionado directamente con el nivel de hiperparatiroidismo existente antes del trasplante (3).

\section{5: ESTUDIOS REALIZADOS EN ESPAÑA SOBRE MOM Y ERC}

\subsection{1: ESTUDIO OSERCE}

El estudio OSERCE es un estudio multicéntrico y transversal que analizó las alteraciones clínicas y bioquímicas del metabolismo óseo-mineral en pacientes con enfermedad renal crónica no en diálisis, así como el cumplimiento de las guías K/DOQI. En este estudio se excluyeron aquellos pacientes que habían recibido un trasplante previo (264).

Se incluyeron 634 pacientes con filtrado glomerular por debajo de $60 \mathrm{ml} / \mathrm{min} / 1,73 \mathrm{~m}^{2}$, excluyendo pacientes con insuficiencia renal aguda, trasplantados renales, con enfermedad grave o con una esperanza de vida inferior a un año. En 409 pacientes se realizó una analítica que incluía calcio, fósforo, PTH y 25-OH vitamina D (264). 


\section{INTRODUCCIÓN}

La edad media de los pacientes de la muestra se situó en torno a los 68 años, con un porcentaje de diabetes del 33\%. Con un valor medio de filtrado glomerular de 26 $\mathrm{ml} / \mathrm{min} / 1,73 \mathrm{~m}^{2}$ según la ecuación de MDRD, los pacientes presentaron los siguientes valores séricos medios: Calcio: 9,4 mg/dl, Fósforo: $4 \mathrm{mg} / \mathrm{dl}$ y PTHi: $177 \pm 145$. Respecto al tratamiento, el $34 \%$ de los pacientes recibía quelantes de fósforo, el 29\% eran tratados con vitamina $D$ en su forma activa y un $0,8 \%$ recibían calcimiméticos.

Por último, el cumplimiento de las guías KDOQI respecto a los niveles de PTHi se situaba en torno al $30 \%$ con más de la mitad de los valores por encima del límite superior. El grado de incumplimiento fue similar en todos los estadios de ERC. Asimismo, el 64,7\% de los pacientes revisados presentaban niveles inadecuados de calcitriol $(<22 \mathrm{pg} / \mathrm{ml})$, porcentaje que aumentaba según disminuía la tasa estimada de filtrado glomerular (264).

EI estudio OSERCE-II buscó ampliar estos resultados, estudiando la presencia de calcificaciones vasculares detectadas mediante la realización de radiografías simples y del índice tobillo-brazo y su relación con alteraciones bioquímicas propias del hiperparatiroidismo, incluyendo algunas exploraciones adicionales como ecocardiografía o medición del grosor íntima-media carotideo (265).

\subsection{2: ESTUDIO EMITRAL}

El estudio EMITRAL fue diseñado específicamente para estudiar las alteraciones del metabolismo óseo-mineral en la población trasplantada (266).

Se trata de un estudio multicéntrico transversal en que se estudiaron 729 pacientes con al menos un año de evolución desde su trasplante renal (69,2 $\pm 30,6$ meses). Un $55 \%$ de los pacientes presentó una tasa estimada de filtrado glomerular inferior a 40 $\mathrm{ml} / \mathrm{min} / 1,73 \mathrm{~m} 2$. Como parte del estudio bioquímico de los pacientes se analizaron los valores plasmáticos de calcio, fósforo, albúmina, PTH, 25-OH vitamina $D$, fosfatasa alcalina y su isoforma específica de hueso (266). 


\section{INTRODUCCIÓN}

El cumplimiento de las guías KDOQI y SEN respecto al control de dichos parámetros en cada estadio fue del 49,7\% (calcio), 86,2\% (fósforo) y 99,3\% (CaxP). En el caso de PTH, un $71,9 \%$ de los pacientes presentaron valores superiores a los recomendados. Los niveles de $25 \mathrm{OH}$ vitamina $\mathrm{D}$ resultaron insuficientes en el $69,4 \%$ de los enfermos y se correlacionaron de manera inversa con las cifras de PTH. Un 37,2\% de los pacientes recibían aportes de vitamina $\mathrm{D}$ (nutricional, calcitriol o paricalcitol) mientras que un $10 \%$ eran tratados con calcimiméticos (266). Se realizaron además estudios radiográficos centralizados (índice de Kauppila). El 3\% presentó antecedentes de fracturas óseas previas, mientras que un $27 \%$ presentaban fracturas óseas prevalentes en columna vertebral. Un 67,3\% de los pacientes mostraba además calcificaciones a nivel aórtico (266). 
HIPÓTESIS DE TRABAJO Y OBJETIVOS 
HIPÓTESIS DE TRABAJO Y OBJETIVOS

\section{HIPÓTESIS DE TRABAJO Y OBJETIVOS}




\section{HIPÓTESIS DE TRABAJO Y OBJETIVOS}

\section{1: HIPÓTESIS DE TRABAJO}

El avance de la investigación, tanto básica como clínica, en el campo del trasplante de órganos sólidos ha sido incuestionable en los últimos años. La mejoría progresiva de los regímenes de inmunosupresión ha conseguido una mejor tolerancia inmunológica al injerto, lo que ha conllevado una importante reducción de las tasas de rechazo hiperagudo y agudo del injerto y ha permitido incrementar de forma notable la supervivencia del mismo.

Sin embargo, estas mejoras introducidas han destapado una serie de problemas asociados a la realización de un trasplante renal que comprometen seriamente tanto la supervivencia del injerto como la del individuo. El mayor de estos problemas en la actualidad es, sin lugar a dudas, el elevado riesgo cardiovascular al que están sometidos estos enfermos. Una mejor caracterización de las alteraciones cardiovasculares propias del receptor de trasplante renal nos permitiría ajustar y emplear con la mayor eficiencia las herramientas diagnósticas de las que disponemos y planificar estrategias terapéuticas que nos conduzcan a mejorar tanto el pronóstico como la calidad de vida de estos enfermos.

Estudiamos las características tanto clínicas como analíticas de las alteraciones del metabolismo óseo-mineral, así como prevalencia de lesiones a nivel cardiovascular y óseo en una muestra de pacientes que han recibido un trasplante renal de cadáver en el Servicio de Nefrología del Hospital Clínico Universitario de Valladolid durante los últimos 6 años. Analizamos asimismo la relación existente entre los parámetros analíticos y las lesiones a nivel cardiovascular objetivadas mediante diversas pruebas de imagen, con el fin de describir el estado del metabolismo óseo-mineral en dichos pacientes. 


\section{HIPÓTESIS DE TRABAJO Y OBJETIVOS}

\section{2: OBJETIVOS}

El objetivo del presente estudio es caracterizar el estado del metabolismo óseo-mineral en pacientes trasplantados y valorar las consecuencias del desajuste del mismo en los diferentes órganos diana como arterias coronarias, vasos arteriales y sistema óseo, con el fin de poder detectar y tratar de forma precoz estas lesiones.

Nuestro protocolo incluye la realización de un estudio analítico ampliado, la cuantificación de calcio en arterias coronarias (CAC) mediante tomografía axial computerizada, la medición del grosor íntima-media en arteria carótida mediante ecografía, la realización de una densitometría ósea de fémur y el estudio de calcificaciones macroscópicas en vasos de gran tamaño mediante radiografía estándar.

\subsection{1: OBJETIVOS PRINCIPALES}

1.- Estudiar las características del metabolismo óseo-mineral de los enfermos tras la realización de un trasplante renal, comparando su estado previo y posterior al trasplante y analizando su evolución a lo largo del tiempo.

2.- Determinar las consecuencias que la alteración del metabolismo óseo-mineral comporta en el árbol vascular y en los huesos, analizando la prevalencia de enfermedad cardiovascular y ósea.

\subsection{2: OBJETIVOS SECUNDARIOS}

1.- Estudiar la relación existente entre la función renal del injerto, la medicación inmunosupresora y otros factores influyentes y el desarrollo post-trasplante del metabolismo óseo-mineral. 


\section{HIPÓTESIS DE TRABAJO Y OBJETIVOS}

2.- Determinar la correlación existente entre las diversas pruebas de imagen para el diagnóstico de la lesión cardiovascular secundaria a la alteración del metabolismo óseomineral. 
MATERIAL Y MÉTODOS

\section{MATERIAL Y MÉTODOS}




\section{MATERIAL Y MÉTODOS}

\section{1: DISEÑO DEL ESTUDIO}

El presente estudio fue planteado como un estudio observacional y transversal en las condiciones de la práctica clínica habitual, sin ningún tipo de intervención terapéutica.

El estudio se ha basado en las directrices definidas en la declaración de la iniciativa STROBE para estudios observacionales $(\mathbf{2 3 9}, \mathbf{2 4 0})$. La declaración STROBE es un documento de consenso que determina una serie de recomendaciones orientadas a mejorar la calidad de la divulgación científica relativa a los estudios epidemiológicos observacionales.

El protocolo y objetivos del estudio fueron remitidos a la Comisión de Ética y Ensayos Clínicos del Hospital Clínico Universitario de Valladolid, obteniendo su consentimiento para la investigación.

\section{2: POBLACIÓN DE ESTUDIO}

Se seleccionaron todos aquellos pacientes que recibieron un trasplante renal de cadáver en el Hospital Clínico Universitario de Valladolid entre el 30 de Julio de 2005 y el 12 de Noviembre de 2012 procedentes del Hospital Clínico Universitario de Valladolid, del Hospital Universitario Río Hortega y del Hospital General Río Carrión y que continuasen en la actualidad siendo revisados por la Unidad de Trasplante Renal del Hospital Clínico de Valladolid. Se informó a todos los pacientes acerca del protocolo y los objetivos del estudio, obteniendo su consentimiento informado por escrito. La muestra final fue de 43 receptores de trasplante renal.

A la hora de incluir al paciente en lista de espera para trasplante renal se empleó el protocolo de inclusión de la Unidad de Trasplante Renal del Servicio de Nefrología del Hospital Clínico Universitario de Valladolid. Dicho protocolo admite como incluido a 


\section{MATERIAL Y MÉTODOS}

cualquier paciente con insuficiencia renal crónica terminal que no cumpla con ninguno de los criterios de exclusión. Estos criterios son:

- Negativa del paciente a ser incluido en el programa de trasplante.

- Presencia de tumor maligno activo. Dependiendo de la etiología del tumor, se considerará al paciente libre de la enfermedad cuando haya transcurrido un periodo de tiempo entre 2 y 5 años tras la curación.

- Presencia de criterios sugestivos de infección activa.

- Insuficiencia cardiaca severa irreversible.

- Insuficiencia pulmonar severa irreversible.

- Cirrosis hepática no susceptible de ser tratada.

- Enfermedad vascular periférica severa que dificulte o impida la realización técnica de la anastomosis vascular necesaria para el trasplante.

- Incumplimiento terapéutico, adicción a drogas o padecimiento de enfermedad psiquiátrica que afecte a la capacidad del paciente de comprender en que consiste y que conlleva la realización de un trasplante o que comprometa su capacidad para seguir las órdenes médicas.

Con el fin de elegir el receptor más adecuado para el órgano donado se siguen una serie de criterios médicos en busca de la mayor idoneidad. Entre estos criterios figuran la compatibilidad $A B 0$, la compatibilidad $H L A$, el resultado negativo de la prueba cruzada de IgG del posible receptor frente a los linfocitos $T$ del donante, el tiempo en lista de espera, el título de anticuerpos reactivos contra el panel, la edad y el peso tanto de 


\section{MATERIAL Y MÉTODOS}

donante como de receptor y la existencia de otros motivos que determinen un grado especial de urgencia para el trasplante.

Se realizó un seguimiento de los pacientes desde el momento del trasplante hasta la actualidad. Las fuentes de información fueron una entrevista clínica específica, los datos presentes en la historia clínica de los pacientes recogidos tanto en revisiones ordinarias como extraordinarias durante la visita del enfermo a la consulta médica de la Unidad de Trasplante Renal, así como las bases de datos tanto analíticas como relativas a las pruebas de imagen procedentes del sistema de información clínica informatizado del Hospital. Además, la información referente a los resultados de la densitometría ósea y la ecografía carotidea se recogieron directamente en el momento de realizar dichas pruebas.

Todos los datos relativos al estudio fueron almacenados en una base de datos informatizada.

Para los objetivos de este trabajo se recogieron datos relativos al periodo pretrasplante así como de la revisión en el momento actual. Se completaron de esta forma dos puntos de control para cada uno de los participantes en el estudio, junto con una referencia antropométrica y analítica adicional referente al post-trasplante inmediato, con datos procedentes del día 15 tras el Tx para proveer de un punto de referencia adicional.

\section{3: METODOLOGÍA}

El paciente acude al hospital a las 08:30 horas, en ayunas, momento en el que se extrae muestras para analítica de sangre y orina. Las extracciones se realizaron por personal de enfermería del Servicio de Nefrología, siendo remitidas posteriormente al Laboratorio Central del Hospital Clínico Universitario de Valladolid, sección de bioquímica, donde se realizan las determinaciones analíticas convencionales de sangre y orina. 


\section{MATERIAL Y MÉTODOS}

Las determinaciones analíticas como urea sérica, creatinina sérica, triglicéridos, colesterol, glucosa o proteínas totales se realizan con el método fotométrico turbidimétrico de Roche $^{\circledR}$. La hemoglobina o el hematocrito se determinan con la técnica de citometría de flujo de Roche ${ }^{\circledR}$.

En la revisión actual se realizó una revisión clínica del paciente, recogiendo su presión arterial, peso y talla. A continuación se realizó una anamnesis y exploración clínica, además de la realización de un cuestionario estandarizado sobre su actividad física.

\section{4: VARIABLES RECOGIDAS}

Características demográficas y clínicas del receptor.

- Fecha de nacimiento.

- Sexo.

- Raza.

- Etiología de la enfermedad renal crónica.

- Glomerulonefritis.

- Nefroangioesclerosis.

- Nefropatía diabética.

- Poliquistosis renal del adulto.

- Nefropatía túbulo-intersticial.

- No filiada.

- Tiempo en diálisis (meses).

- Modalidad de diálisis.

○ Hemodiálisis.

○ Diálisis peritoneal.

- Peso.

- Talla.

- Índice de masa corporal.

- Número de trasplantes renales previos. 
Situación cardiovascular basal.

- Factores de riesgo cardiovascular pre-trasplante:

○ Hipertensión arterial (HTA).

- Diabetes Mellitus (DM).

○ Dislipemia.

○ Obesidad.

- Consumo de tabaco.

- Ecocardiografía transtorácica.

- Enfermedad cardiovascular pre-trasplante.

- Cardiopatía isquémica.

$\circ$ Angina.

- Infarto agudo de miocardio.

- Revascularización coronaria.

- Insuficiencia cardiaca.

- Accidente cerebrovascular agudo.

- Patología vascular periférica.

- Claudicación intermitente.

○ Amputación.

Situación del metabolismo óseo-mineral basal.

- Realización de paratiroidectomía previa al trasplante.

- Presencia de calcificaciones radiográficas pre-trasplante.

- Tratamiento farmacológico relacionado.

- Calcitriol.

- Agonistas del receptor de vitamina D.

- Calcimiméticos.

- Quelantes de fósforo.

- Quelantes cálcicos.

- Quelantes no cálcicos.

- Quelantes con aluminio. 


\section{MATERIAL Y MÉTODOS}

Características del donante y de la cirugía.

- Edad del donante.

- Sexo del donante.

- Fecha del trasplante.

Controles

Se establecieron tres puntos de control: visita pre-trasplante, alta tras el trasplante y revisión actual, que se realizó entre Septiembre y Noviembre de 2013. En cada punto de control se registraron:

- Cifras de tensión arterial ( $\mathrm{mmHg})$.

- Talla (m).

- Peso (kg) e índice de masa corporal.

- Diuresis (ml).

Y también los siguientes parámetros analíticos.

- Hemoglobina (g/dl)

- Hematocrito (\%)

- Leucocitos $\left(\times 10^{3} / \mu \mathrm{l}\right)$

- Plaquetas $\left(\times 10^{3} / \mu \mathrm{l}\right)$

- Urea (mg/dl)

- Glucosa (mg/dl)

- Creatinina $(\mathrm{mg} / \mathrm{dl})$

- Triglicéridos (mg/dl)

- Colesterol (mg/dl)

- Fosfatasa alcalina (U/I)

- Proteínas totales (g/dl)

- Calcio $(\mathrm{mg} / \mathrm{dl})$

- Fósforo (mg/dl)

- $\mathrm{pH}$ 


\section{MATERIAL Y MÉTODOS}

- Bicarbonato.

- Hormona paratiroidea (pg/ml)

En la revisión actual se registraron asimismo las siguientes variables analíticas:

- $\quad$ VSG $(\mathrm{mm})$

- Magnesio (mg/dl)

- Ácido Úrico (mg/dl)

- Hemoglobina glicosilada (\%)

- $H D L(m g / d l)$

- $\quad \operatorname{LDL}(\mathrm{mg} / \mathrm{dl})$

- Índice de riesgo

- Cociente LDL/HDL

- Calcio iónico ( $\mathrm{mmol} / \mathrm{l})$

- Vitamina D (ng/ml)

- Proteína C reactiva $(\mathrm{mg} / \mathrm{l})$

- Interleukina-6 (pg/ml)

- $\quad \mathrm{FGF}-23(\mathrm{pg} / \mathrm{ml})$

- Microalbuminuria (mg/dl)

La cuantificación de FGF-23 intacto se realizó empleando un kit de inmunoensayo ELISA (USCN Life Science Inc., Wuhan, China). Se obtuvieron muestras de sangre que se almacenaron en tubos EDTA, procediendo a la separación de plasma y suero de forma inmediata y conservándolas a -70 으 C hasta su uso. El coeficiente de variación de este kit de inmunoensayo ELISA se sitúa en $<10 \%$ (intra-ensayo) y $<12 \%$ (inter-ensayo). La sensibilidad de la prueba se situó en $6,7 \mathrm{pg} / \mathrm{ml}$.

La revisión final se completó con los siguientes parámetros:

- Actividad física habitual: Este parámetro se determinó aplicando el cuestionario de actividad física IPAQ (International Physical Activity Questionnaire), 


\section{MATERIAL Y MÉTODOS}

determinando el número de METS (Metabolic equivalent of task) consumidos semanalmente.

$1 \mathrm{MET}=1 \mathrm{kcal} / \mathrm{kg} *$ hora.

- Función renal, estimada mediante la creatinina sérica y el empleo de cuatro ecuaciones diferentes: Cockroft-Gault (CG), MDRD-4, CKD-EPI y la ecuación de la Clínica Mayo (MQ) (269-273).

1) Creatinina sérica.

2) Cálculo del aclaramiento de creatinina mediante la fórmula de Cockroft-Gault:

Tasa estimada de aclaramiento de creatinina $=[(140-$ Edad $) *$ Peso $* 0,85($ si el paciente es una mujer)] / $72 *$ Creatinina sérica. La edad se expresa en años, el peso en kilogramos y la creatinina sérica en $\mathrm{mg} / \mathrm{dl}$.

3) Cálculo de la tasa estimada de filtrado glomerular por la fórmula MDRD-4 o fórmula abreviada (Modifications of Diet in Renal Disease):

Tasa estimada de filtrado glomerular $=186 *(\text { Creatinina sérica })^{-1,154} *(\text { Edad })^{-0,203}$ * 1,210 (si el paciente es de raza negra) * 0,742 (si el paciente es una mujer). La creatinina sérica se expresa en $\mathrm{mg} / \mathrm{dl}$ mientras que la edad se expresa en años.

4) Cálculo de la tasa estimada de filtrado glomerular por la fórmula Mayo Quadratic:

Tasa estimada de filtrado glomerular $=\exp \{1,911+(5,249 /$ Creatinina sérica $)-$ $\left(2,114 /\right.$ Creatinina sérica $\left.{ }^{2}\right)-(0,00686 *$ Edad $)-0,205$ (si el paciente es una mujer)\}. La creatinina sérica se expresa en $\mathrm{mg} / \mathrm{dl}$ y la edad en años. 


\section{MATERIAL Y MÉTODOS}

5) Cálculo de la tasa estimada de filtrado glomerular mediante la fórmula CKD-EPI (Chronic Kidney Disease Epidemiology Collaboration):

Tasa estimada de filtrado glomerular (hombres, $\mathrm{Cr} \leq 0,9 \mathrm{mg} / \mathrm{dl}$ ) $=141 *$ (Creatinina sérica/0,9)-0,411 *0,993 Edad.

Tasa estimada de filtrado glomerular (hombres, $\mathrm{Cr}>0,9 \mathrm{mg} / \mathrm{dl}$ ) $=141 *$ (Creatinina sérica/0,9)-1,209*0,993 Edad.

Tasa estimada de filtrado glomerular (mujeres, $\mathrm{Cr} \leq 0,7 \mathrm{mg} / \mathrm{dl}$ ) $=144 *$ (Creatinina sérica/0,7)-0,329*0,993 Edad.

Tasa estimada de filtrado glomerular (mujeres, $\mathrm{Cr}>0,7 \mathrm{mg} / \mathrm{dl}$ ) $=144 *$ (Creatinina sérica/0,7)-1,209*0,993 Edad.

La creatinina sérica se expresa en $\mathrm{mg} / \mathrm{dl}$ y la edad en años.

\section{5: VALORACIÓN DE LA ERC}

Los pacientes fueron estratificados en cada revisión de acuerdo a los estadios de enfermedad renal crónica propuestos por las guías K/DIGO (Kidney Disease: Improving Global Outcomes) (274), en función de la tasa de filtrado glomerular estimada mediante la ecuación MDRD-4.

- Estadio 1: Tasa estimada de filtrado glomerular mayor o igual a 90 $\mathrm{ml} / \mathrm{min} / 1,73 \mathrm{~m}^{2}$.

- Estadio 2: Tasa estimada de filtrado glomerular entre 60 y $90 \mathrm{ml} / \mathrm{min} / 1,73 \mathrm{~m}^{2}$.

- Estadio 3: Tasa estimada de filtrado glomerular entre 30 y $59 \mathrm{ml} / \mathrm{min} / 1,73 \mathrm{~m}^{2}$. 


\section{MATERIAL Y MÉTODOS}

- Estadio 4: Tasa estimada de filtrado glomerular entre 15 y $29 \mathrm{ml} / \mathrm{min} / 1,73 \mathrm{~m}^{2}$.

- Estadio 5: Tasa estimada de filtrado glomerular menor de $15 \mathrm{ml} / \mathrm{min} / 1,73 \mathrm{~m}^{2}$.

\section{6: INMUNOSUPRESIÓN}

Se utilizó el protocolo de inmunosupresión de la Unidad de Trasplante Renal del Hospital Clínico de Valladolid a la hora de establecer la pauta de tratamiento. Los pacientes recibieron:

- Tratamiento de inducción con anticuerpos monoclonales (basiliximab) en todos los casos.

- Corticoides.

- Inhibidor de la calcineurina (tacrólimus).

- Tratamiento coadyuvante en algunos pacientes con everólimus, sirólimus, micofenolato mofetilo o micofenolato sódico.

Las dosis administradas a los pacientes fueron las siguientes:

- Basiliximab: Primera dosis de 20 mg intravenosa previa a la cirugía. Segunda dosis de $20 \mathrm{mg}$ intravenosa a los 4 días tras el trasplante.

- Corticoides: Primera dosis de $250 \mathrm{mg}$ de 6-metilprednisolona intravenosa intraoperatoria, seguida de $40 \mathrm{mg}$ de metilprednisolona intravenosa cada 12 horas los 3 primeros días tras el trasplante. Posteriormente se administran 0,3 $\mathrm{mg} / \mathrm{kg} /$ día de prednisona vía oral durante 21 días, reduciendo la dosis progresivamente hasta suspender o hasta dejar una dosis mínima según la patología de base. 


\section{MATERIAL Y MÉTODOS}

- Tacrólimus: 0,2 mg/kg/día vía oral repartida en dos dosis administradas cada 12 horas de inicio. Más adelante dicha dosis se modifica para mantener niveles basales entre $15 \pm 2 \mathrm{ng} / \mathrm{ml}$ los primeros 15 días, de $10 \pm 2 \mathrm{ng} / \mathrm{ml}$ hasta el tercer mes y después entre 5 y $10 \mathrm{ng} / \mathrm{ml}$.

- Micofenolato mofetilo: Administrado conjuntamente con tacrólimus, la dosis inicial es de $1000 \mathrm{mg}$ diarios repartidos en dos tomas. Se administra en pacientes hiperinmunizados o con mayor riesgo inmunológico para desarrollar rechazo agudo, así como en aquellos pacientes que desarrollan una necrosis tubular aguda severa.

- Micofenolato sódico: Administrado conjuntamente con tacrólimus, la dosis inicial es de $720 \mathrm{mg}$ diarios repartidos en dos tomas. Se administra en pacientes hiperinmunizados o con mayor riesgo inmunológico para desarrollar rechazo agudo, así como en aquellos pacientes que desarrollan una necrosis tubular aguda severa.

- Sirólimus: Dosis de 2-6 mg/día para mantener niveles entre 5 y $10 \mathrm{ng} / \mathrm{ml}$, ajustando posteriormente según niveles valle.

- Everólimus: Dosis 1,5-3 mg/día repartidos en dos dosis para mantener niveles entre 3 y $12 \mathrm{ng} / \mathrm{ml}$, ajustando posteriormente según niveles valle.

\section{7: PRUEBAS DE IMAGEN}

Índice de calcio coronario: Para la realización del índice de calcio coronario, determinado por el score de Agatston y el percentil de calcio coronario se empleó un TC de 64 detectores General Electric LightSpeed VCR ${ }^{\circledR}\left(\mathrm{GE}^{\circledR}\right.$; Milwaukee, Wisconsin, Estados Unidos) con sincronización cardiaca. El análisis de las imágenes se realiza en una estación de trabajo (Advantage Work Station 4.4 ${ }^{\circledR}$, General Electric Medical System; Milwakee, Wisconsin, Estados Unidos) con software específico para el estudio cardiovascular 


\section{MATERIAL Y MÉTODOS}

(VolumeViewer ${ }^{\circledast}$ 7.6.29) y calcio coronario (Smart Score). El paciente fue colocado en posición de decúbito supino, colocando los receptores electrocardiográficos y solicitando que permaneciese en apnea durante el registro de las imágenes. El electrocardiograma se empleó para asegurar que la toma de imágenes se realizó en todos los casos durante el mismo ciclo cardiaco. Se realizaron una serie de imágenes en corte transversal de $3 \mathrm{~mm}$ de grosor abarcando la raíz aórtica y los senos coronarios y procediendo en dirección caudal para cubrir todo el árbol coronario. No se empleó ningún tipo de contraste radiográfico. La variabilidad inter-scan de la prueba se sitúa en un $8-10 \%$ (275).

La tomografía axial computerizada y el análisis de la imagen cardiaca fueron realizados en todos los pacientes por el mismo equipo, compuesto por un cardiólogo y un radiólogo. Este score se calcula analizando la densidad de calcificación más alta en arterias coronarias y multiplicándola por el área de la calcificación (276).

Grosor íntima-media carotideo: Para la medición del GIM carotideo se empleó un ecógrafo MyLab 25 con el software MyLab Desk 8.0 (Esaote, Génova, Italia) con sonda lineal (13-6 Mhz). Se realizaron 10 mediciones a nivel de arteria carótida común derecha e izquierda ( 5 mediciones por vaso) a una distancia de $1 \mathrm{~cm}$ del bulbo carotideo, obteniendo el valor medio de cada vaso y el resultado medio global de cada paciente. La realización de la ecografía carotidea empleada para determinar el grosor íntimamedia se realizó en todos los pacientes por el mismo investigador. Para ello se colocó al paciente en decúbito supino, orientando la cabeza lateralizada en un ángulo de 45은 hacia el lado contrario al que se pretende explorar y con el explorador en posición lateral.

Índice de Kauppila: Se calculó empleando una radiografía de columna lumbosacra lateral. Para calcular el índice se evalúa el grado de calcificación de las paredes anterior y posterior de la arteria aorta a nivel de los sectores vertebrales L1 a L4. De esta forma se valora con 0 puntos la ausencia de calcificaciones, con 1 punto si la calcificación abarca $1 / 3$ de la pared, con dos puntos si abarca $2 / 3$ y con tres puntos si la extensión de las calcificaciones abarca la práctica totalidad de la pared vascular en ese tramo. De esta 


\section{MATERIAL Y MÉTODOS}

forma tenemos 4 sectores vertebrales en los que analizar el grado de calcificación, dos zonas (anterior y posterior) por sector, y tres tercios a valorar en cada una. El score gradúa por tanto la calcificación aórtica abdominal de 0 (ausencia de calcificación en todos los sectores) a 24 puntos (calcificación total de la arteria) (278).

La valoración de la radiografía y el cálculo del score de Kauppila los realizó en todos los casos el mismo investigador.

Índice de Adragao: Se calculó empleando radiografías de pelvis y manos AP. Para realizar dicho score se dividieron ambas radiografías en dos mitades (izquierda y derecha) con dos regiones, superior e inferior delimitadas por la cabeza del fémur en la placa de pelvis y por el carpo en la placa de manos. En cada uno de los 8 cuadrantes resultantes se valoró como 0 puntos la ausencia de calcificaciones lineales en los vasos del territorio o 1 punto si dichos vasos mostraban calcificación. La puntuación variaba por tanto entre 0 (sin calcificación) y 8 puntos (calcificación en arterias iliacas, femorales, radiales e interdigitales de ambos lados) (251).

La valoración de las radiografías y el cálculo del índice de Adragao fue realizada en todos los casos por el mismo investigador.

Densitometría ósea: Se recogieron los valores de densidad mineral-ósea, T-score y Zscore en el cuello del fémur mediante el empleo de un densitómetro Norland XR-46 (Emsor, Madrid, España). Dichos parámetros se cuantificaron en ambas extremidades.

\section{8: DEFINICIONES}

Hipertensión arterial: Según el VII Report of the Joint National Comitee y las guías europeas para el manejo del paciente trasplantado renal, se define como aquellas cifras de tensión arterial sistólica mayores o iguales a $130 \mathrm{mmHg}$ y/o aquellas cifras de tensión arterial diastólica mayores o iguales a $85 \mathrm{mmHg}$, así como toma de medicación antihipertensiva(279). 


\section{MATERIAL Y MÉTODOS}

Diabetes Mellitus: Según los criterios de la ADA (American Diabetes Association) el padecimiento de diabetes mellitus queda definido por la presencia de glucemia en ayunas igual o superior a $126 \mathrm{mg} / \mathrm{dl}$ y/o hemoglobina glicosilada superior a 6,5\% (280).

Dislipemia: Según el Third Report of the Expert Panel in the National Cholesterol Education Program's NCEP, se define como dislipemia cifras de colesterol total sérico igual o mayor de $200 \mathrm{mg} / \mathrm{dl}$ y/o cifras de triglicéridos iguales o superiores a 150 y/o la toma de estatinas o fibratos (281).

Anemia: Definida según las guías KDOQI de anemia en la Enfermedad Renal Crónica como cifras de hemoglobina sérica inferiores a $11 \mathrm{~g} / \mathrm{dl}$ (282).

Índice de masa corporal: Peso/Talla².

- Bajo peso: $I M C<18 \mathrm{~kg} / \mathrm{cm}^{2}$.

- Normo peso: IMC $=18-25 \mathrm{~kg} / \mathrm{cm}^{2}$.

- Sobrepeso: $I M C \geq 25 \mathrm{~kg} / \mathrm{cm}^{2}$.

- Obesidad: IMC $\geq 30 \mathrm{~kg} / \mathrm{cm}^{2}$.

Sobrepeso: Índice de masa corporal igual o superior a $25 \mathrm{~kg} / \mathrm{cm}^{2}$.

Obesidad: Índice de masa corporal igual o superior a $30 \mathrm{~kg} / \mathrm{cm}^{2}$.

Tabaquismo: Se definió como tabaquismo el consumo habitual de tabaco por parte del enfermo en los últimos 10 años.

Osteopenia: Se define como osteopenia el grado de pérdida de densidad mineral-ósea caracterizado por un T-Score inferior a -1 DS y superior a -2,5 desviaciones estándar (283).

Osteoporosis: Se define como osteopenia el grado de pérdida de densidad mineral-ósea caracterizado por un T-Score inferior a -2,5 desviaciones estándar (283). 


\section{MATERIAL Y MÉTODOS}

\section{9: MÉTODO ESTADÍSTICO}

Para el estudio estadístico se utilizó el software IBM SPSS Statistics, versión 22. Las técnicas y test estadísticos empleados han sido:

- Tablas de frecuencias y porcentajes con intervalo de confianza al 95\% para variables categóricas.

- Descriptivos habituales para variables cuantitativas: media con intervalo de confianza al 95\%, mediana y desviación estándar. Asimismo se ha estudiado la forma de estas variables con los índices de asimetría y curtosis, junto al valor de la P-sig del test de bondad de ajuste de Shapiro-Wilk (indicado cuando $\mathrm{N}<50$ ) para determina la semejanza, o no, de la distribución de valores con el modelo de la curva normal de Gauss (se considera desvío grave con respecto al mismo, si $\mathrm{P}<.01$ ).

- Test de bondad de ajuste al modelo de la curva normal de Gauss.

- Test de diferencia de medias en muestras independientes: $T$ de Student y $U$ de Mann-Whitney.

- Tablas de contingencia con test $\mathrm{Chi}^{2}$, para el cruce de dos variables categóricas en grupos independientes.

- Coeficientes de correlación de Pearson y de Spearman.

- Estimación de sensibilidad, especificidad, valores predictivos y Kappa de Cohen.

- Regresión logística binaria, univariante y multivariante.

El nivel de significación fijado es el habitual 5\% (significativo si $\mathrm{P}<.05$ ) excepto en el test Kolmogorov-Smirnov de bondad de ajuste, donde se consideran significativas solo los desvíos graves del modelo, es decir al 1\% ( $\mathrm{P}<.01)$.

A la hora de establecer asociaciones entre las variables incluidas en el estudio y las variables resultado de las pruebas diagnósticas realizadas se ha optado por emplear la siguiente estrategia estadística. Las variables resultantes de las pruebas han sido dicotomizadas por un determinado punto de corte que en todas (con una excepción) genera dos subgrupos bastante equilibrados en cuanto al número de casos, aplicando posteriormente un test de contraste de diferencias entre medias. Es decir, se estableció 


\section{MATERIAL Y MÉTODOS}

en cada variable del grupo de pruebas diagnósticas dos grupos, comparando el valor medio del resto de variables en cada grupo.

Para realizar esta comparación de medias el estadístico más adecuado es la T de Student para muestras independientes entre sí. Dado que dicho estadístico exige el ajuste a la normalidad de la variable cuantitativa que se contrasta, en los casos en que no se cumple dicho ajuste emplearemos la alternativa no-paramétrica correspondiente, el Test U de Mann-Whitney. Hemos optado por aplicar ambos test con todas las variables, en todos los contrastes, como una forma de aumentar la fiabilidad estadística bajo la expectativa de que ambos van a generar resultados similares.

Una ventaja de la utilización de técnicas paramétricas radica en la posibilidad de calcular el tamaño del efecto. Éste es un índice que cuantifica la magnitud de los cambios observados en una escala adimensional que posibilita la comparación de efectos en variables medidas con diferentes instrumentos y por ello con diferentes escalas y unidades.

Para calcular este tamaño del efecto empleamos el coeficiente $R^{2} \cdot R^{2}$ tiene una escala cerrada $(0-1)$ con unas referencias interpretativas estándar: sobre .050 es bajo/muy bajo; sobre .100 es leve; sobre .150 moderado bajo; .200 moderado alto; mayor a .250 ya es elevado; mayor a .360 es grande y desde .450 en adelante muy grande.

El coeficiente $\mathrm{R}^{2}$ viene a ser una estimación de la proporción de los cambios observados en la variable medida que estarían explicados por su asociación con la variable independiente; es decir que su valor se vincula al de una correlación entre las variables (284).

En resumen, para el estudio de la asociación de cada variable del grupo de pruebas diagnósticas (score de Agatston, GIM, índices de Adragao y Kauppila, DMO y T-Score), dicotomizadas por el punto de corte indicado, con cada variable de los demás grupos mantenidas en su forma cuantitativa, se han utilizado: test T de Student de diferencia entre medias, test alternativo de Mann-Whitney y estimación del efecto mediante $R^{2}$. 


\section{MATERIAL Y MÉTODOS}

A continuación se exponen los resultados, organizados en tablas de resumen y ordenados en función de cada variable que se define como factor. Debido al elevado número de variables y para mayor claridad, las tablas de cada grupo se han fraccionado en varias partes. 


\title{
3.10: ANEXO 1: CONSENTIMIENTO INFORMADO
}

\author{
DOCUMENTO DE CONSENTIMIENTO INFORMADO PARA INVESTIGACIÓN \\ HOSPITAL CLÍNICO UNIVERSITARIO DE VALLADOLID \\ “EVALUACIÓN DEL METABOLISMO ÓSEO-MINERAL EN EL TRASPLANTE RENAL” \\ JESÚS BUSTAMANTE BUSTAMANTE
}

ALICIA MENDILUCE HERRERO

ARMANDO COCA ROJO

\section{SERVICIO DE NEFROLOGÍA}

\section{Finalidad y Objetivos:}

Para un adecuado avance en la investigación biomédica es necesario estudiar tanto muestras biológicas normales o patológicas de pacientes como los resultados de diversos métodos de estudio por imagen para conocer posibles alteraciones bioquímicas o de otro tipo que influyen en el desarrollo de las enfermedades y las consecuencias que acarrean. Los resultados de estos estudios ayudarán probablemente a diagnosticar y tratar de manera más precisa a los enfermos con una enfermedad como la suya.

El objetivo del presente estudio es caracterizar el estado del metabolismo óseo-mineral en pacientes que han recibido un trasplante renal, analizando las consecuencias de éste tanto en el esqueleto como en el árbol vascular con el fin de poder realizar un tratamiento precoz de las mismas.

\section{Descripción del proceso:}

Es importante que Vd., como potencial participante en este estudio, conozca que el proceso constará de las siguientes fases:

A) Se le informará sobre los objetivos del estudio y sobre el hecho de que la participación es totalmente voluntaria. Se le responderá a las dudas que pueda plantear.

B) El estudio comprenderá la realización de una serie de pruebas de imagen no invasivas ni cruentas que no requieren de preparación alguna. Estas pruebas son las siguientes:

- Tomografía computerizada de arterias coronarias.

- Ecografía carotidea.

- Densitometría ósea.

- Radiografías simples de columna lumbar, pelvis y manos.

Asimismo se recogerán ciertos parámetros antropométricos y se realizará una analítica sanguínea. Éste se remitirá, como ocurre habitualmente, a los servicios centrales correspondientes, donde se procederá a su diagnóstico.

\section{Otras consideraciones:}




\section{MATERIAL Y MÉTODOS}

D) No percibirá ninguna compensación económica o de otro tipo por las muestras donadas y éstas no tendrán valor comercial.

E) Los productos obtenidos de las muestras serán almacenados y custodiados en el Servicio de Nefrología y en la Unidad de Investigación Biomédica del Hospital Clínico Universitario de Valladolid. La persona responsable de la custodia es el director de la Unidad de Investigación, (Dr. Bermejo) y el Investigador Principal del Estudio (Dr. Coca).

F) La información obtenida se almacenará en una base de datos, en soporte informático, y registrada en la Agencia Española de Protección de Datos. Los datos registrados serán tratados estadísticamente de forma codificada. En todo momento el donante tendrá derecho de acceso, rectificación o cancelación de los datos depositados en la base de datos siempre que expresamente lo solicite. Los datos quedarán custodiados bajo la responsabilidad del Investigador Principal del Estudio (Dr. Coca).

G) Las muestras estarán codificadas de forma que la identidad del donante nunca estará disponible para los investigadores. Para todo lo previsto en este documento, se aplicará la legislación vigente sobre protección de datos de carácter personal (Ley Orgánica 15/1999), de 13 de diciembre) y cualquier otra que resultara aplicable.

H) No se empleará su muestra o información con fines distintos a los definidos en el apartado previo. En caso de que se plantee un uso diferente, deberá Vd. dar su consentimiento por escrito.

I) La falta de consentimiento o la revocación de este consentimiento previamente otorgado no supondrá perjuicio alguno en la asistencia sanitaria que Vd. recibe/recibirá.

\section{DECLARACIONES Y FIRMAS}

\section{Declaración del donante:}

He sido informado por el profesional de salud abajo firmante:

-Sobre las ventajas e inconvenientes de este procedimiento.

-Sobre el lugar de obtención, almacenamiento y el proceso que sufrirán los datos personales y las muestras.

-Que en cualquier momento puedo revocar mi consentimiento y solicitar la eliminación o anonimización de todos mis datos personales y muestras que permanezcan almacenadas 0 distribuidas. Esta eliminación no se extendería a los datos resultantes de las investigaciones que ya se hubieran llevado a cabo.

- Que en cualquier momento, yo, mi Representante Legal, ó Tutor, de conformidad con lo establecido en el artículo 4, punto 5 de la Ley 14/2007, de 3 de julio, puedo solicitar información sobre los datos que se obtengan a partir del análisis de las muestras donadas.

-Que he comprendido la información recibida y he podido formular todas las preguntas que he creído oportunas.

\section{Consiento en:}

- El fin para el que se utilizarán mis muestras y datos personales.

Nombre del Paciente. Firma:

Lugar: Valladolid Fecha: 


\section{MATERIAL Y MÉTODOS}

Declaración del profesional de salud médica de que ha informado debidamente al donante-

Nombre:

Firma:

APARTADO PARA LA REVOCACIÓN DEL CONSENTIMIENTO

Yo,

revoco el consentimiento de participación en el estudio,

arriba firmado, con fecha

Firma: 


\subsection{2: ANEXO 2: COMITÉ ÉTICO DE INVESTIGACIÓN CLÍNICA}
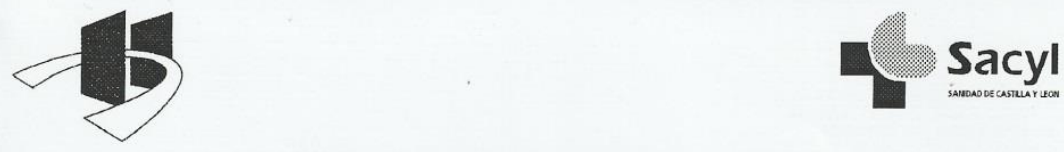

COMITÉ ÉTICO DE INVESTIGACIÓN CLÍNICA

ÁREA DE SALUD VALLADOLID - ESTE (CEIC-VA-ESTE-HCUV)

Valladolid a 26 de Septiembre de 2013

En la reunión del CEIC ÁREA DE SALUD VALLADOLID - ESTE del 26 de Septiembre de 2013, se procedió a la evaluación de los aspectos éticos del siguiente proyecto de investigación.

A continuación les señalo los acuerdos tomados por el CEIC ÁREA DE SALUD VALLADOLID - ESTE en relación a dicho Proyecto de Investigación:

\begin{tabular}{|l|l|l|}
\hline PI-13-86 & "EVALUACIÓN DEL METABOLISMO ÓSEO- & Investigador principal: \\
& MINERAL EN PACIENTES TRASPLANTADOS & ARMANDO COCA ROJO \\
& RENALES" & Equipo de investigadores: \\
& & ALICIA MENDILUCE, \\
& JESUS BUSTAMANTE \\
& NEFROLOGÍA \\
& Recibida la Autorización \\
& de la Comisión de \\
& Investigación del \\
& HCUV.:08-04-2013 \\
& Recibido: 09-05-2013 \\
\hline
\end{tabular}

Considerando que el Proyecto contempla los Convenios y Normas establecidos en la legislación española en el ámbito de la investigación biomédica, la protección de datos de carácter personal y la bioética, se hace constar el informe favorable y la aceptación del Comité Ético de Investigación Clínica del Área de Salud Valladolid Este para que sea llevado a efecto dicho Proyecto de Investigación.

Un cordial saludo.
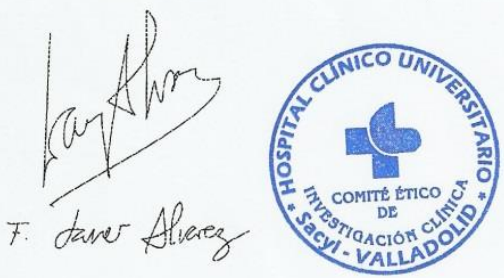

Dr. F. Javier Álvarez.

CEIC Área de Salud Valladolid Este - Hospital Clínico Universitario de Valladolid Farmacología

Facultad de Medicina,

Universidad de Valladolid,

c/ Ramón y Cajal 7,

47005 Valladolid

alvarez@med.uva.es

jalvarezgo@saludcastillayleon.es

tel: 983423077 
RESULTADOS

RESULTADOS 


\section{RESULTADOS}

\section{1: ESTUDIO DESCRIPTIVO DE LA POBLACIÓN}

\subsection{1: DATOS DEL DONANTE}

\section{Edad del donante}

Los 43 órganos trasplantados procedían de 42 donantes cuya la edad media fue de 46,42 \pm 16,03 años (IC 95\%: 41.48 - 51.35; con desviación estándar de \pm 16.03 años; rango 1980 años; mediana 50 años). (Figura 1).

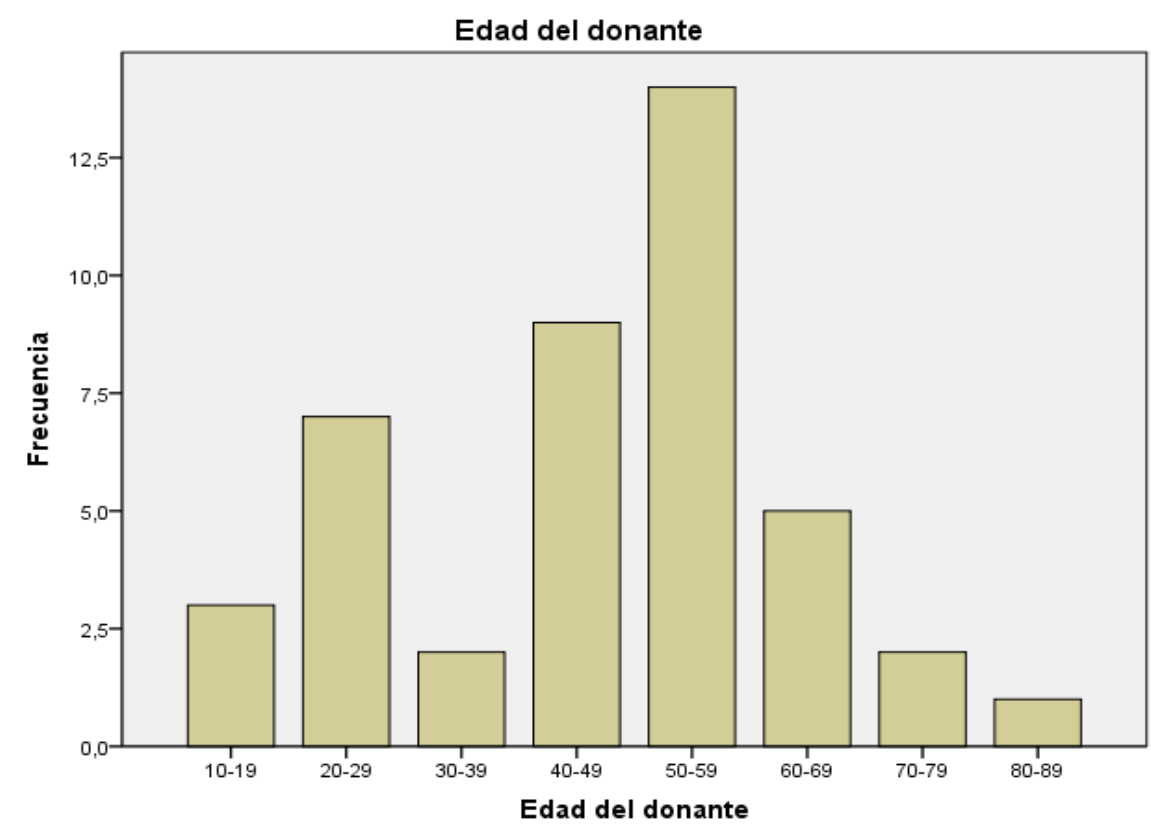

Figura 1: Distribución de la edad del donante.

\section{Sexo del donante}

El 79,1\% de los donantes fueron varones, frente al 20,9\% de mujeres (Figura 2). 


\section{RESULTADOS}

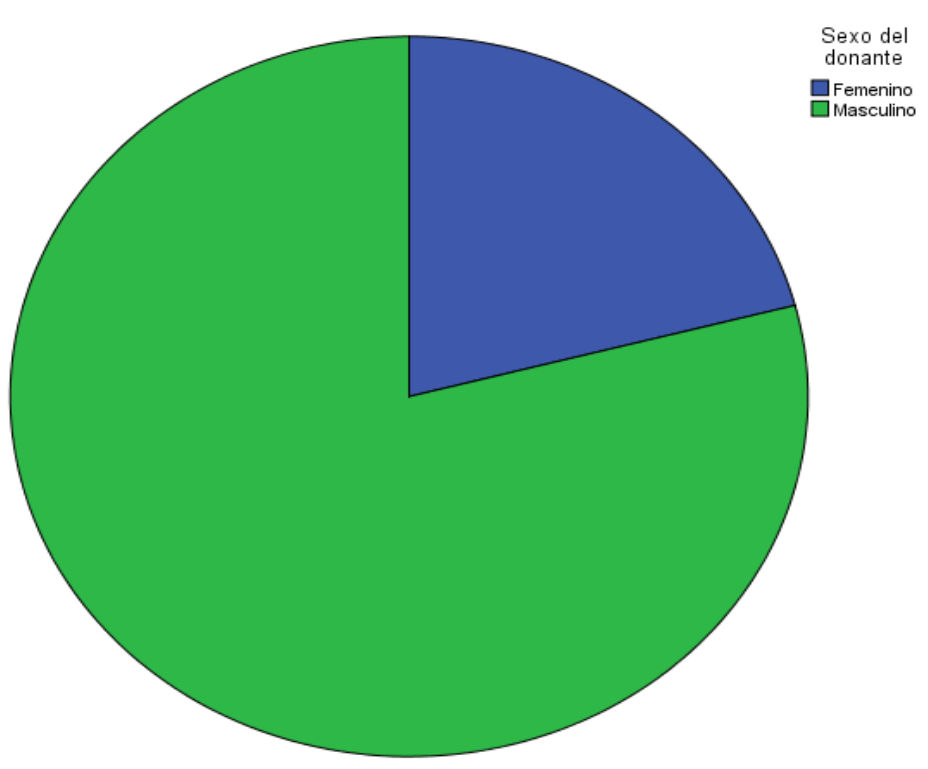

Figura 2: Distribución según el sexo del donante.

\subsection{2: DATOS DEL RECEPTOR}

\subsubsection{1: CARACTERÍSTICAS DEMOGRÁFICAS DE LOS RECEPTORES}

\section{Edad del Receptor}

La edad media de los receptores fue de 53,88 $\pm 12,29$ años, con un rango entre 30 y 81 años. El mayor porcentaje de receptores de trasplante se situó entre los 50 y los 69 años. La siguiente figura recoge la distribución de los receptores según su edad (Figura 3). 


\section{RESULTADOS}

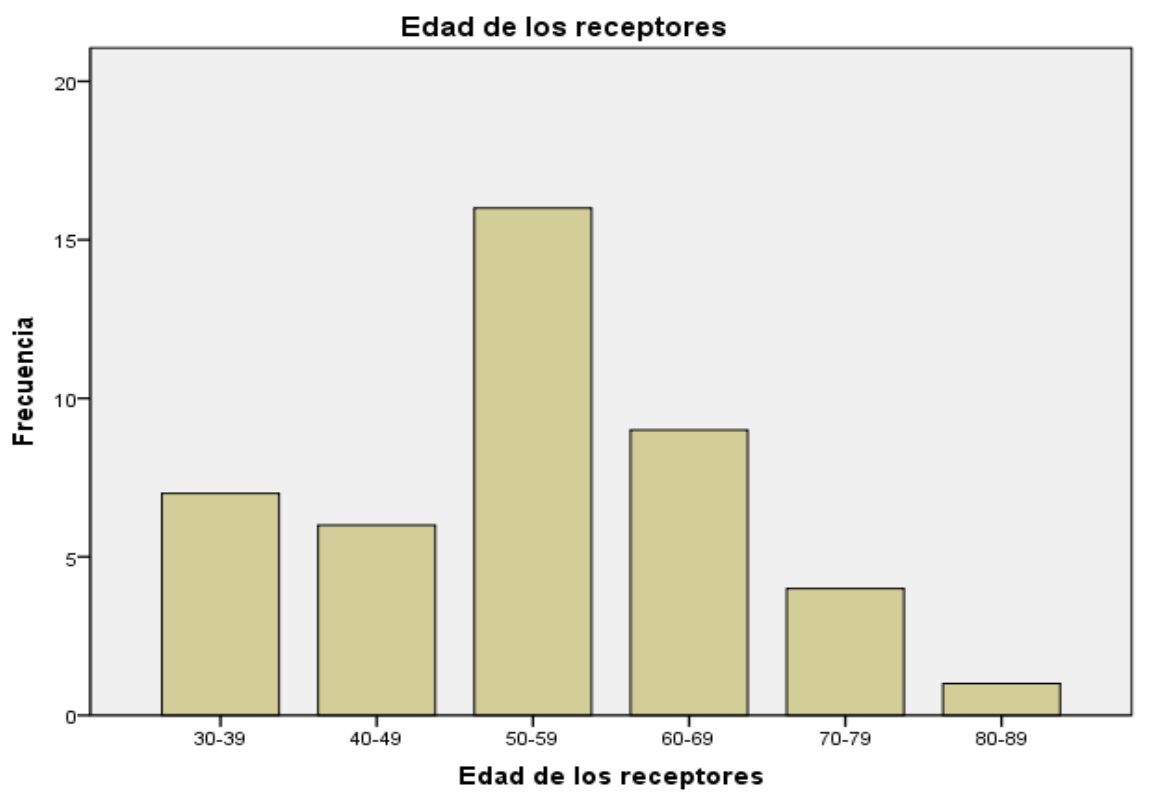

Figura 3: Edad de los receptores.

\section{Sexo del receptor}

De los pacientes estudiados, 31 individuos fueron varones $(72,1 \%)$ y 12 mujeres $(28,9 \%)$. La siguiente figura recoge la distribución de los receptores según su sexo (Figura 4).

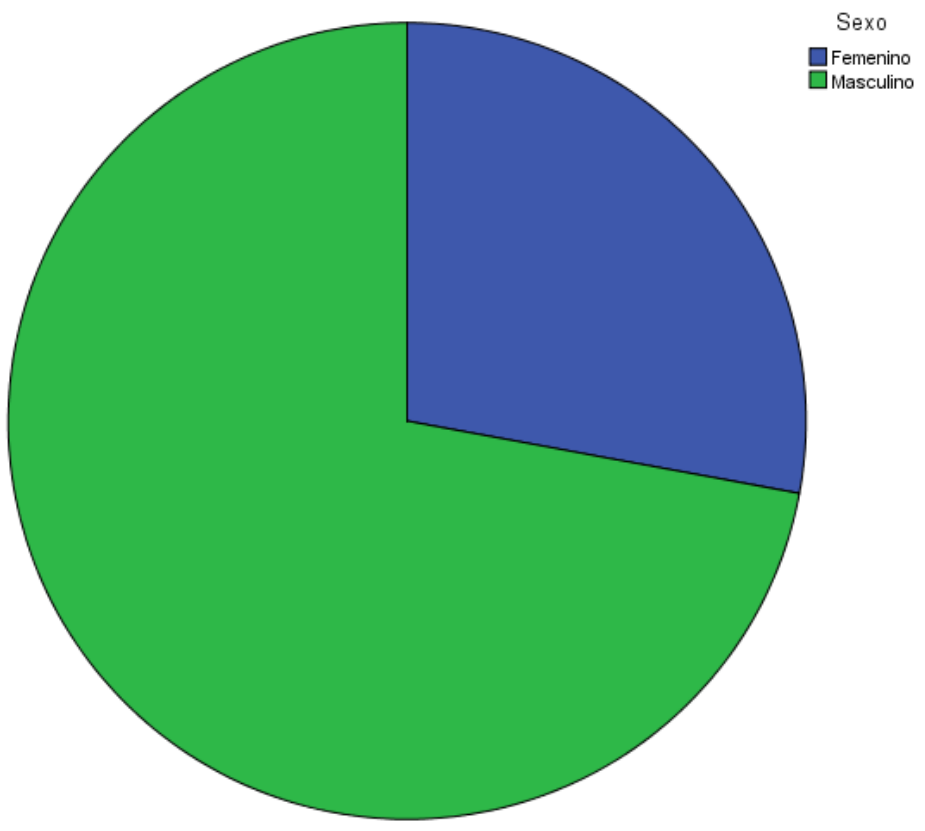

Figura 4: Sexo de los receptores. 


\section{RESULTADOS}

La edad media de los varones fue de $54 \pm 13,02$ años, resultando ligeramente superior a la edad media de las mujeres, que fue de 53,58 \pm 10,68 años. La distribución por edades, tanto en hombres como en mujeres, es similar a la observada en la muestra general (Figuras 5 y 6 ).

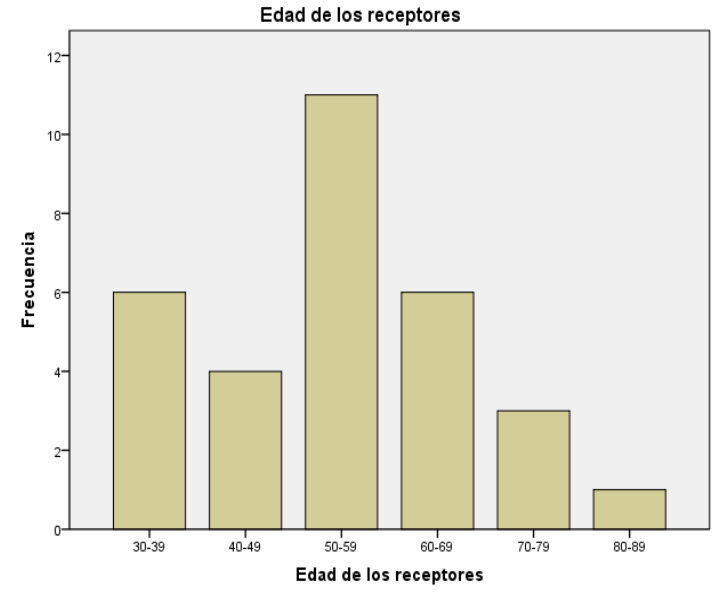

1

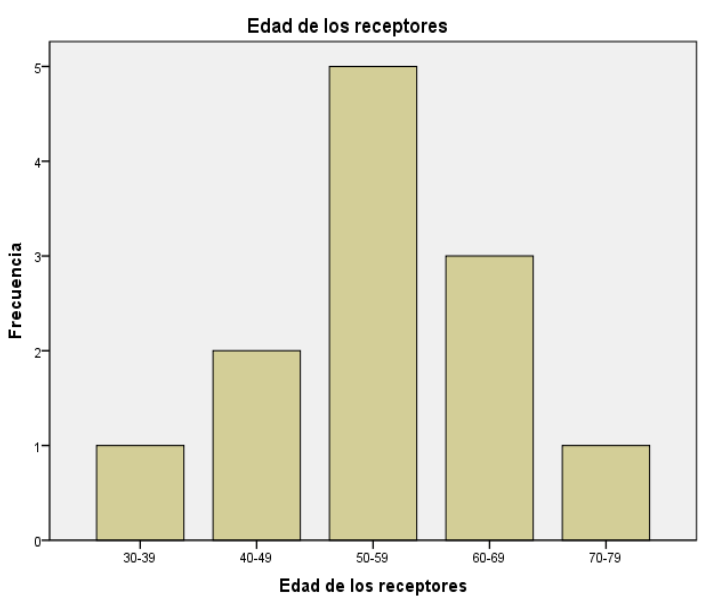

2

Figuras 5 y 6: Distribución de la edad en relación al sexo. (1) Hombres. (2) Mujeres.

\subsubsection{2: CARACTERÍSTICAS CLÍNICAS DE LOS RECEPTORES PRETRASPLANTE}

\section{Etiología de la enfermedad renal}

Las causas de la enfermedad renal terminal de los enfermos estudiados fueron, en orden decreciente: Nefropatía túbulo-intersticial, glomerulonefritis, poliquistosis renal, nefroangioesclerosis y nefropatía diabética. La etiología del fracaso renal terminal de un porcentaje considerable de los casos no se llegó a filiar (20,9\%) (Tabla 1). 


\section{RESULTADOS}

\begin{tabular}{|l|c|c|}
\hline ENFERMEDAD RENAL & N & $\%$ \\
\hline No filiada & 9 & 20,9 \\
\hline Nefropatía túbulo-intersticial & 10 & 23,3 \\
\hline Glomerulonefritis & 9 & 20,9 \\
\hline Poliquistosis renal & 9 & 20,9 \\
\hline Nefroangioesclerosis & 3 & 7 \\
\hline Nefropatía diabética & 3 & 7 \\
\hline Total & 43 & 100 \\
\hline
\end{tabular}

Tabla 1: Enfermedad renal de base.

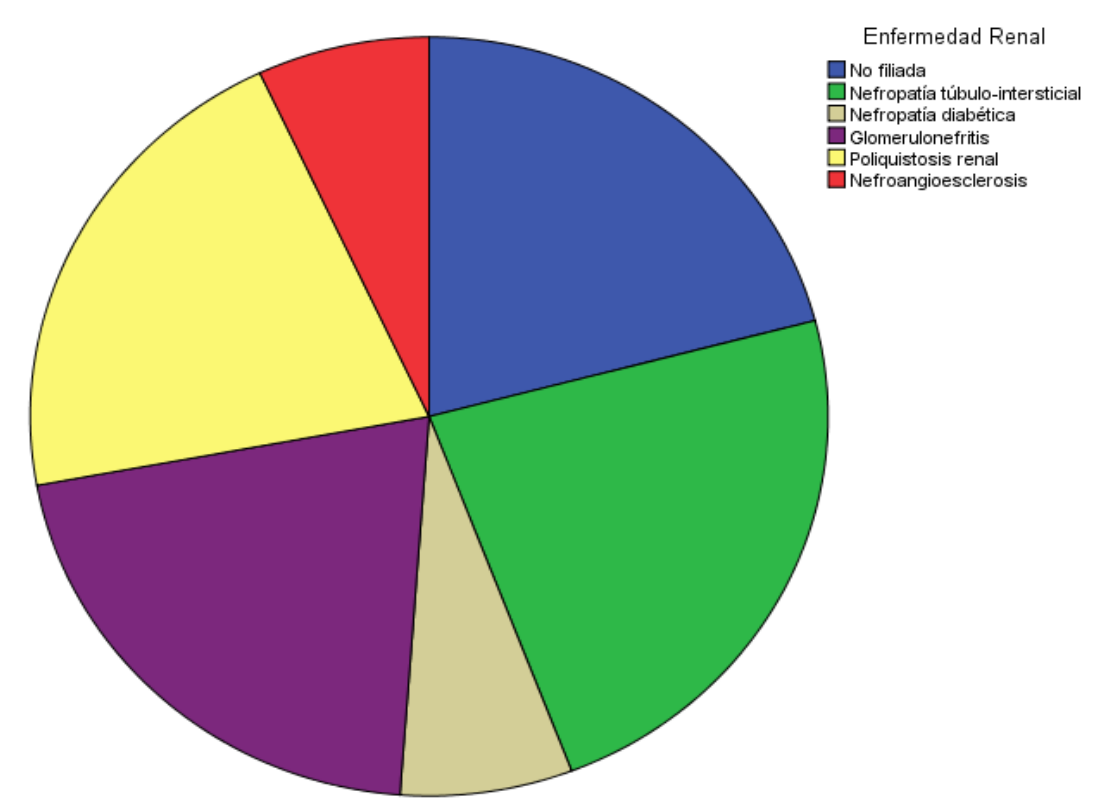

Figura 7: Distribución de la etiología de la enfermedad renal.

\section{Modalidad de diálisis}

El tratamiento renal sustitutivo del que eran subsidiarios los pacientes de la muestra en el momento previo al trasplante renal fue hemodiálisis periódica en 29 pacientes $(67,4 \%)$ y diálisis peritoneal en 14 pacientes (32,6\%) (Figura 8). 


\section{RESULTADOS}

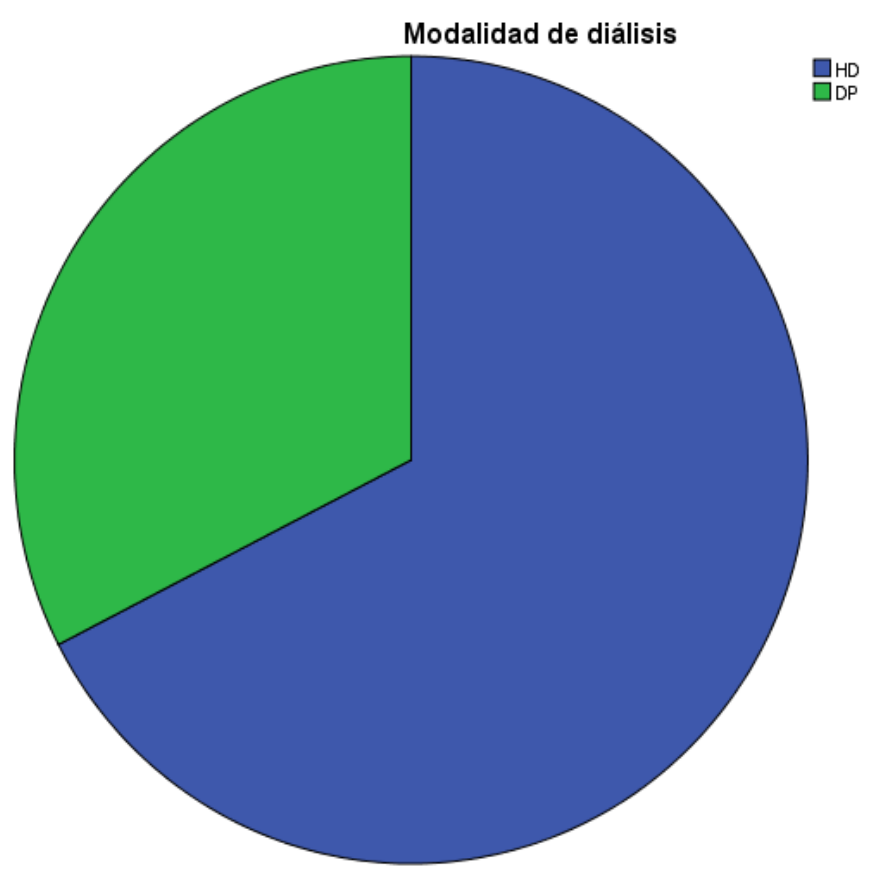

Figura 8: Tipo de terapia renal sustitutiva recibida.

El acceso vascular utilizado para la realización de hemodiálisis periódica fue una fístula arterio-venosa en 25 pacientes $(86,2 \%)$ o un catéter venoso central en 4 pacientes $(13,8 \%)$.

Tiempo en diálisis.

El tiempo medio de permanencia en diálisis fue de 38,69 meses. Mediana: 26 meses. Rango entre 6 y 344 meses.

\section{Características de la intervención.}

Todos los pacientes recibieron un trasplante renal simple. Para un $88,4 \%$ (38 pacientes) se trataba de un primer trasplante. Un 7\% (3 pacientes) recibió un segundo trasplante, mientras que para el 4,7\% (2 pacientes) se trataba de su tercer trasplante (Figura 9). 


\section{RESULTADOS}

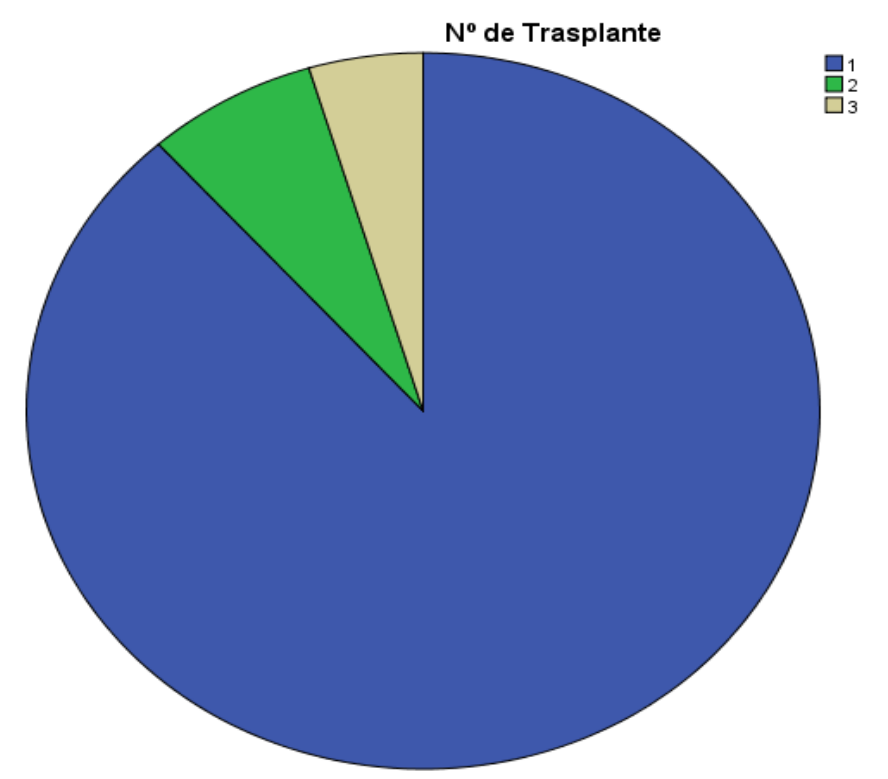

Figura 9: Número de trasplantes recibidos.

\section{Seguimiento tras el trasplante.}

El tiempo medio de seguimiento tras el trasplante en el momento de la revisión es de 48,41 meses. Mediana: 45 meses. Rango entre 11 y 99 meses (Figura 10).

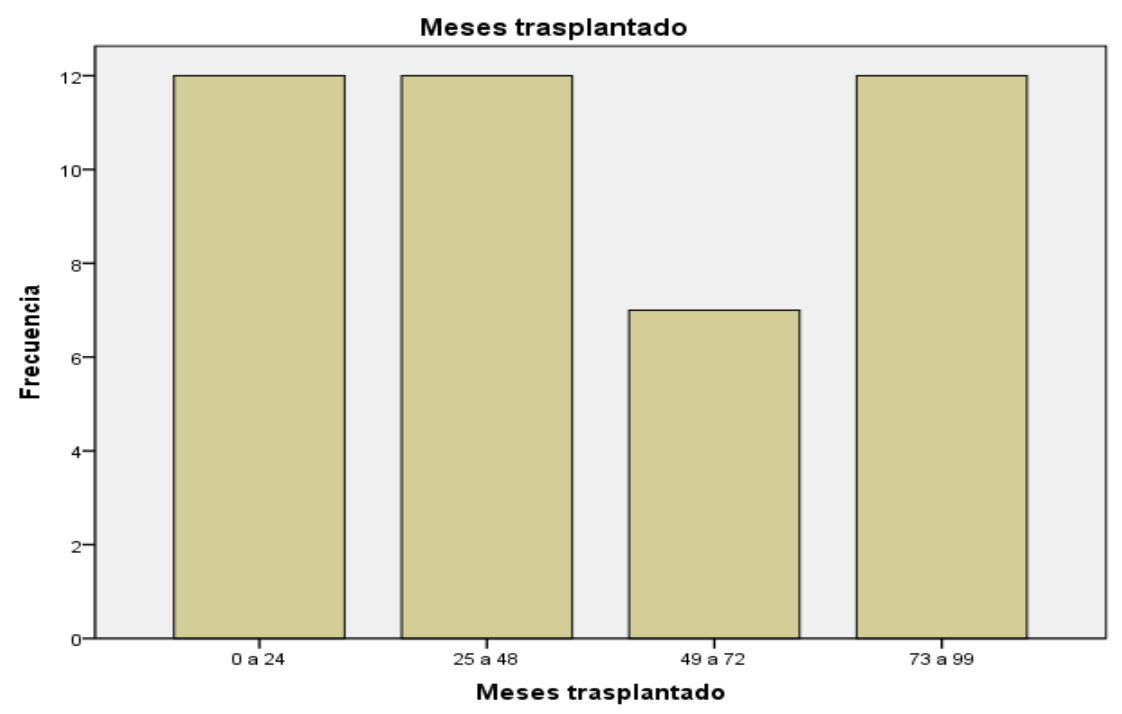

Figura 10: Distribución de frecuencias de Tiempo trasplantado (meses). 


\section{RESULTADOS}

\section{Perfil cardiovascular pretrasplante.}

Un 4,7\% (2 pacientes) de los enfermos de la muestra presentaba antecedentes de cardiopatía isquémica pretrasplante (angina inestable, infarto agudo de miocardio, enfermedad coronaria diagnosticada mediante angioplastia o revascularización coronaria).

El ecocardiograma transtorácico realizado como parte del protocolo para admisión en lista de trasplante informó de la existencia de hipertrofia ventricular izquierda leve en un $32,6 \%$ (14 pacientes), hipertrofia ventricular izquierda moderada en un $20,9 \%$ (9 pacientes) e hipertrofia ventricular izquierda grave en un 2,3\% (1 paciente). Un 44,2\% (19 pacientes) no presentaba signos de hipertrofia ventricular izquierda en la ecocardiografía pretrasplante (Figura 11).

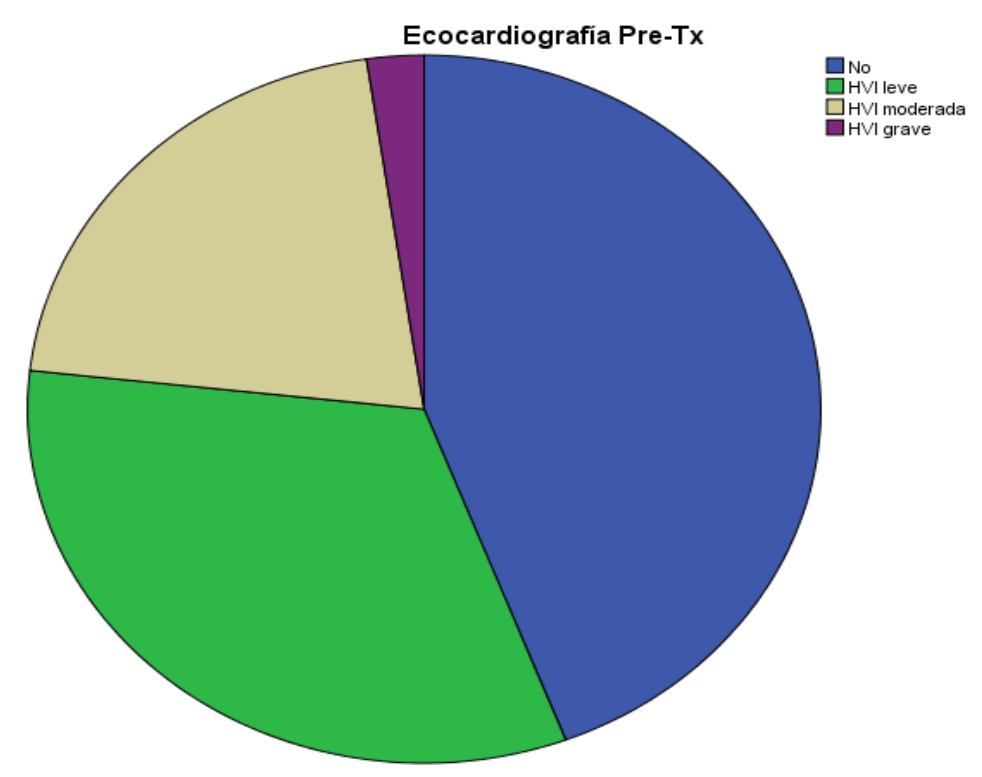

Figura 11: Resultado de la ecocardiografía previa al trasplante.

La fracción de eyección estimada por la electrocardiografía fue de $66,01 \pm 6,54$. Un $81,4 \%$ de los pacientes presentaba un riesgo cardiovascular bajo (FE $>50 \%$ ) según su fracción de eyección. 


\section{RESULTADOS}

Factores de riesgo cardiovascular.

Hipertensión arterial.

La hipertensión arterial fue el factor de riesgo cardiovascular principal en la evaluación pretrasplante, afectando al $88,4 \%$ de los pacientes. Se observó un descenso de las cifras de TAS y TAD tras la realización del Tx respecto a la evaluación pretrasplante, ascendiendo de nuevo a cifras similares en la revisión actual (Tabla 2 y Figura 12).

\begin{tabular}{|l|l|l|l|l|}
\hline & Media & DS & MAX & MIN \\
\hline TAS (1) & 146,13 & 25,54 & 210 & 103 \\
\hline TAD (1) & 84,16 & 12,86 & 118 & 57 \\
\hline TAS (2) & 137,64 & 23,6 & 183 & 79 \\
\hline TAD (2) & 78,48 & 13,71 & 105 & 50 \\
\hline TAS (3) & 144,37 & 17,93 & 189 & 100 \\
\hline TAD (3) & 84,74 & 8,87 & 104 & 66 \\
\hline
\end{tabular}

Tabla 2: (1) Pretrasplante. (2) Alta de trasplante. (3) Revisión actual.
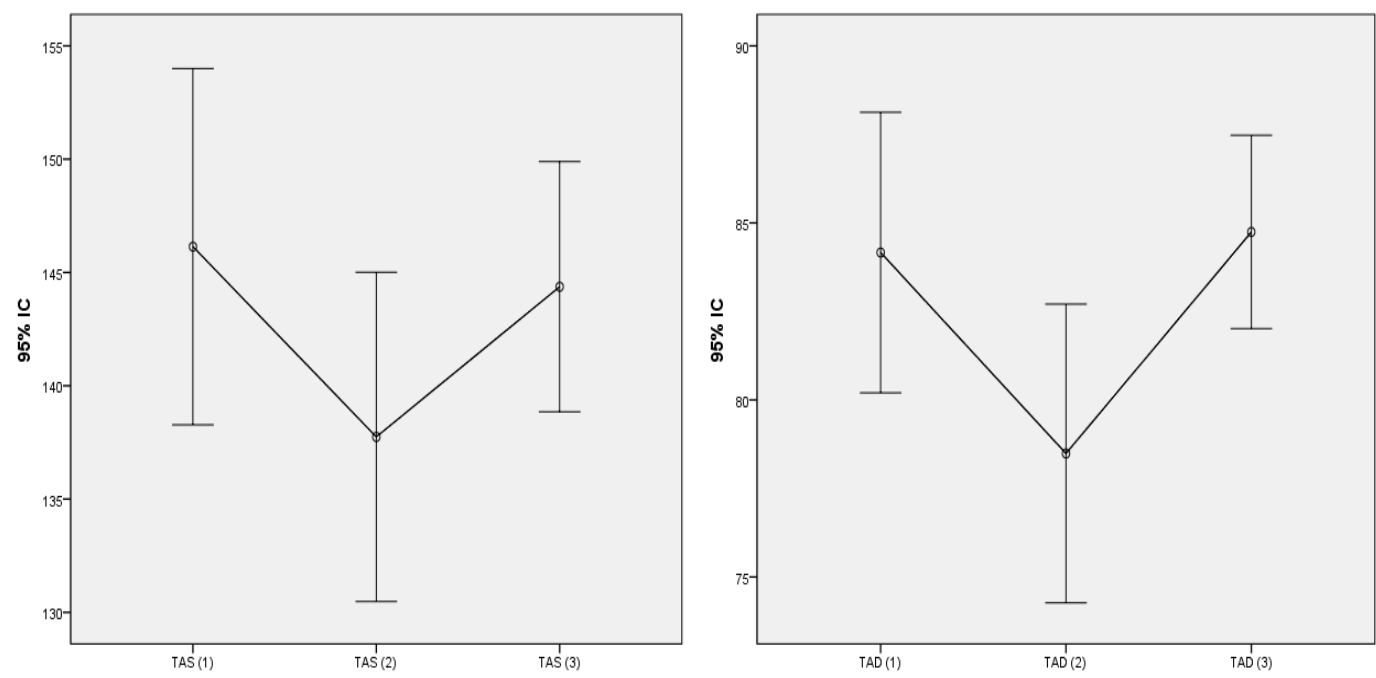

Figura 12: Evolución de las cifras de TAS y TAD a lo largo del seguimiento. (1) Pretrasplante. (2) Alta de trasplante. (3) Revisión actual. 


\section{RESULTADOS}

\section{Sobrepeso y Obesidad}

El sobrepeso (IMC $>25 \mathrm{~kg} / \mathrm{cm}^{2}$ ) supuso el segundo factor de riesgo cardiovascular de mayor importancia en la evaluación pretrasplante, presente en un 46,5\% (un 2,3\% eran obesos, IMC $\left.>30 \mathrm{~kg} / \mathrm{cm}^{2}\right)$. El IMC descendió inmediatamente $(-0,52)$ tras la realización del trasplante $(p=0,05)$ para aumentar posteriormente $(+1,85)$ hasta superar los valores pretrasplante en la revisión actual $(p<0,001)$ (Tabla 3 y Figura 13).

\begin{tabular}{|l|l|l|l|l|}
\hline & Media & DS & MAX & MIN \\
\hline Peso (1) & 70,88 & 11,72 & 105 & 44,5 \\
\hline IMC (1) & 24,95 & 2,96 & 32,05 & 20,04 \\
\hline Peso (2) & 69,29 & 11,59 & 104 & 41,6 \\
\hline IMC (2) & 24,43 & 3,25 & 31,75 & 18,74 \\
\hline Peso (3) & 74,63 & 13,21 & 125,8 & 44 \\
\hline IMC (3) & 26,28 & 3,5 & 38,4 & 19,73 \\
\hline
\end{tabular}

Tabla 3: Evolución del peso y del IMC. (1) Pretrasplante. (2) Alta de trasplante. (3) Revisión actual.
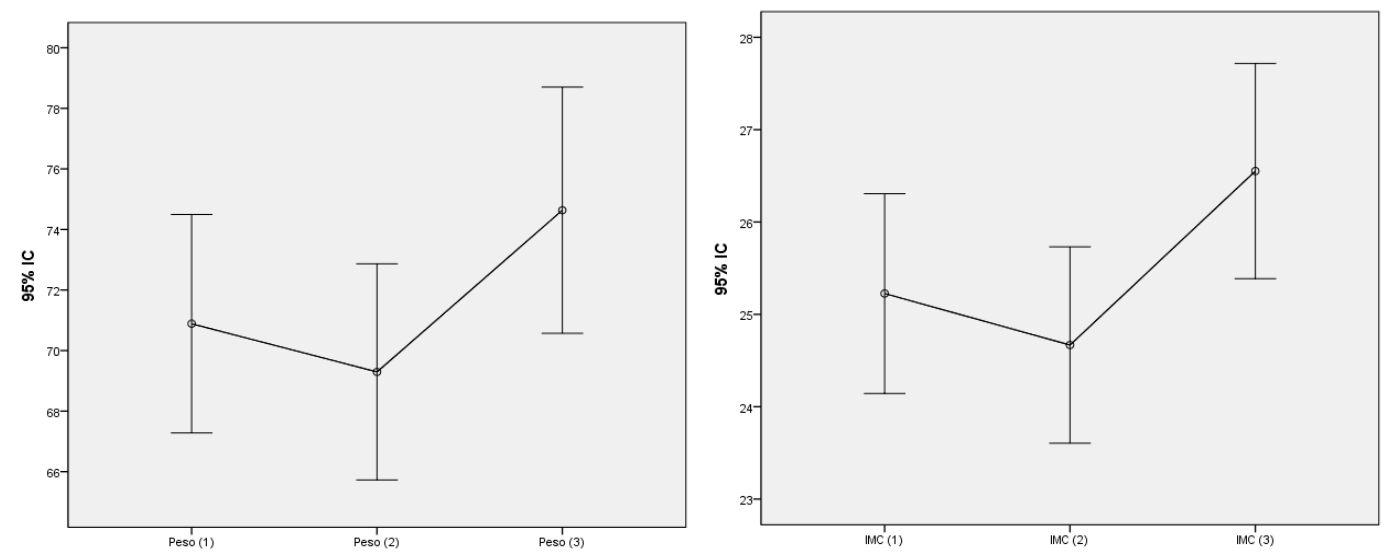

Figura 13: Evolución del peso y del IMC a lo largo del seguimiento. (1) Pretrasplante. (2) Alta del trasplante. (3) Revisión actual.

En el momento inmediato tras la realización del trasplante, un 32,6\% (14 pacientes) presentaban sobrepeso, mientras que un 4,7\% (2 pacientes) mostraba obesidad. En la revisión actual, un 53,5\% (23 pacientes) presenta sobrepeso, siendo un 9,3\% (4 


\section{RESULTADOS}

pacientes) obesos actualmente. El número de pacientes obesos en la revisión actual es significativamente mayor al observado en la evaluación pretrasplante $(p=0,04$, test de McNemar). No se observaron diferencias significativas en cuanto al número de pacientes con obesidad.

\section{Dislipemia.}

Un $44,2 \%$ de los pacientes presentaba un diagnóstico previo de dislipemia en la evaluación pretrasplante. La evolución de las cifras de colesterol total y triglicéridos a lo largo del seguimiento fue la siguiente (Tabla 4):

\begin{tabular}{|l|l|l|}
\hline & Media & DS \\
\hline Colesterol Total (1) & 168,88 & 51,89 \\
\hline Triglicéridos (1) & 117,13 & 41,14 \\
\hline Colesterol Total (2) & 184,69 & 50,03 \\
\hline Triglicéridos (2) & 146,11 & 68,74 \\
\hline Colesterol Total (3) & 184,04 & 39,7 \\
\hline Triglicéridos (3) & 122,2 & 63,83 \\
\hline
\end{tabular}

Tabla 4: Evolución de la concentración sérica de colesterol total y triglicéridos. (1) Pretrasplante. (2) Alta de trasplante. (3) Revisión actual. 


\section{RESULTADOS}
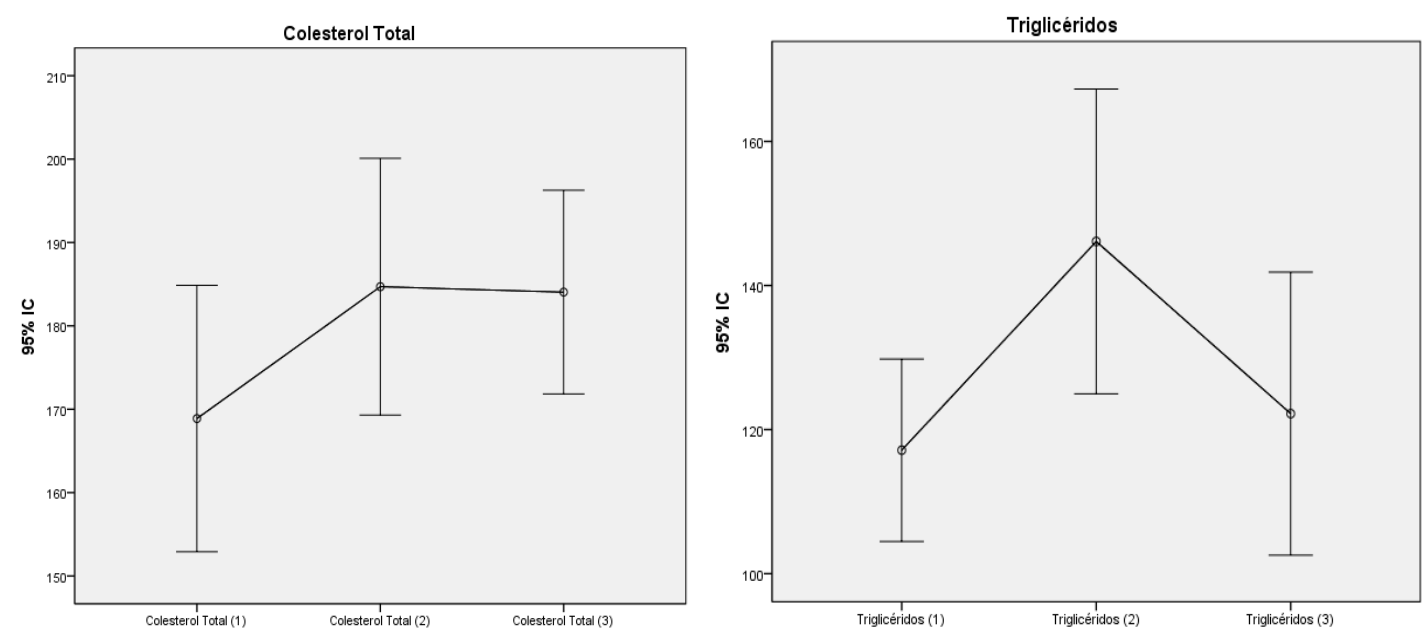

Figura 14: Colesterol total (mg/dl), Triglicéridos (mg/dl). (1) Pretrasplante. (2) Alta de trasplante. (3) Revisión Actual.

Se observó un incremento de las cifras de colesterol total tras la realización del trasplante respecto a la evaluación pretrasplante, tanto de forma inmediata $(p=0,07)$ como en la revisión actual $(p=0,04)$. Las cifras de triglicéridos aumentaron significativamente $(p=0,02)$ inmediatamente tras la cirugía respecto a la evaluación PreTx, para después descender de nuevo a valores similares a los previos al trasplante.

En el momento actual, los pacientes presentaron las siguientes cifras de colesterol LDL y HDL (Tabla 5):

\begin{tabular}{|l|l|l|}
\hline & Media & DS \\
\hline Colesterol LDL* & 58,83 & 32,39 \\
\hline Colestrol HDL* & 100,34 & 18,59 \\
\hline
\end{tabular}

Tabla 5: Concentración plasmática de colesterol HDL y colesterol LDL en la revisión actual. $* m g / d l$. 


\section{RESULTADOS}

Según los criterios NCEP ATP-III observamos la siguiente distribución (Tabla 6):

\begin{tabular}{|l|l|l|l|}
\hline & Óptimo/Casi óptimo & Ligeramente alto & Alto/Muy alto \\
\hline Col-LDL (mg/dl) & $76,7 \%$ (33 pacientes) & $20,9 \%$ (9 pacientes) & $2,3 \%$ (1 paciente) \\
\hline Col Total (mg/dl) & $11,6 \%$ (5 pacientes) & $18,6 \%$ (8 pacientes) & $69,8 \%$ (30 pacientes) \\
\hline Triglicéridos (mg/dl) & $67,4 \%$ (29 pacientes) & $11,6 \%$ (5 pacientes) & $20,9 \%$ (9 pacientes) \\
\hline & Bajo & Normal & Alto \\
\hline Col-HDL (mg/dl) & $16,3 \%$ (7 pacientes) & $44,2 \%$ (19 pacientes) & $39,5 \%$ (17 pacientes) \\
\hline
\end{tabular}

Tabla 6: Distribución de los pacientes según su metabolismo lipídico (NCEP ATP-III).

En la revisión actual, un 11,62\% (5 pacientes, 4 varones y una mujer) presentaban criterios diagnósticos de dislipemia aterogénica según la NCEP ATP-III (253), mientras que un $20,93 \%$ (9 pacientes, 8 varones y una mujer) cumplen los criterios diagnósticos de síndrome metabólico.

\section{Diabetes Mellitus}

La prevalencia de la diabetes en la evaluación pretrasplante fue de un 16,3\% (7 pacientes). En la revisión actual, y siguiendo los criterios ADA (252) se observó la prevalencia de diabetes en el 18,6\% (8 pacientes). Dicha diferencia entre la evaluación pretrasplante y la revisión actual no presentó significación estadística.

\section{Tabaquismo}

Un 20,9\% de los enfermos refirió consumo habitual de tabaco.

La tabla 7 resumen la prevalencia de los diferentes factores de riesgo cardiovascular clásicos en la muestra de trasplantados renales estudiada: 
RESULTADOS

\begin{tabular}{|l|c|c|}
\hline FACTORES DE RIESGO CV & N & $\%$ \\
\hline HTA & 38 & 88,4 \\
\hline Diabetes & 7 & 16,3 \\
\hline Dislipemia & 19 & 44,2 \\
\hline Tabaquismo & 9 & 20,9 \\
\hline Sobrepeso & 20 & 46,5 \\
\hline Obesidad & 2 & 4,7 \\
\hline
\end{tabular}

Tabla 7: Prevalencia de factores de riesgo cardiovascular.

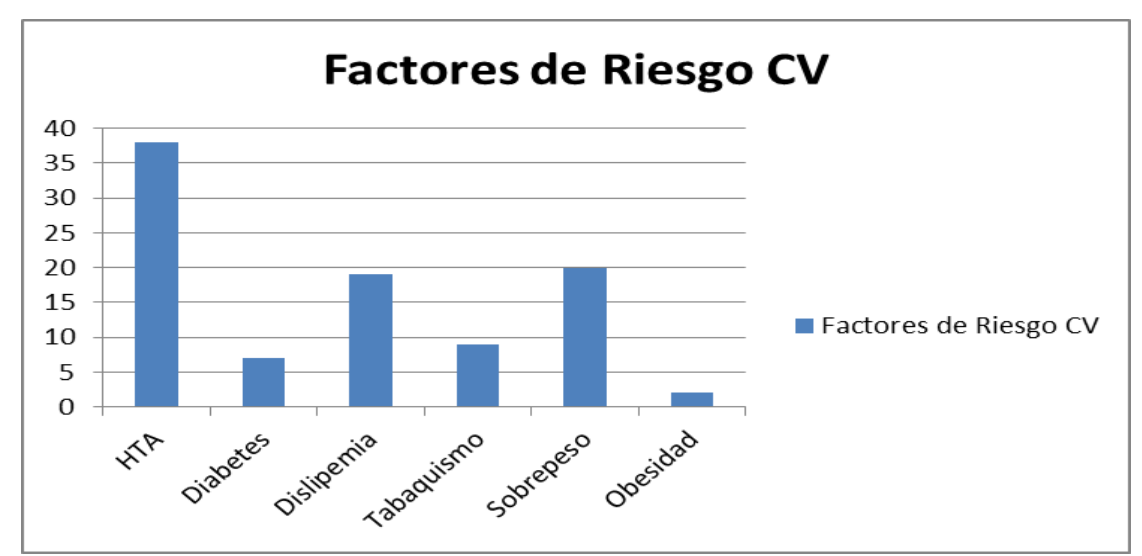

Figura 15: Prevalencia de FRCV clásicos pretrasplante.

\section{Evolución Post-trasplante.}

Sólo un paciente (2,3\%) precisó atención hospitalaria debido al desarrollo de cardiopatía isquémica (angina inestable, infarto agudo de miocardio, enfermedad coronaria diagnosticada mediante angioplastia o revascularización coronaria) tras la realización del trasplante renal.

Se recogió un cuestionario relativo a la sintomatología referida por el individuo desde la realización del trasplante (Tabla $\mathbf{8})$ : 
RESULTADOS

\begin{tabular}{|l|c|c|}
\hline Respuesta Afirmativa & Frecuencia & Porcentaje \\
\hline Dolor torácico tipo angor & 3 & $7 \%$ \\
\hline Disnea de esfuerzo & 2 & $2,3 \%$ \\
\hline Ortopnea & 1 & $2,3 \%$ \\
\hline Claudicación a la marcha & 1 & \\
\hline
\end{tabular}

Tabla 8: Prevalencia de síntomas sugestivos de ECV en la revisión actual.

\section{Tablas Resumen}

Tabla 9: Análisis descriptivo. Antecedentes personales (Variables Categóricas)

\begin{tabular}{|c|c|c|c|c|c|}
\hline \multirow[b]{2}{*}{ Variable } & \multirow[b]{2}{*}{ Categoría } & \multirow{2}{*}{$\begin{array}{l}\text { Núm. de } \\
\text { casos }\end{array}$} & \multirow{2}{*}{$\%$} & \multicolumn{2}{|c|}{ I.C. 95 \% } \\
\hline & & & & Lim. Inf. & Lim. Sup. \\
\hline \multirow[t]{2}{*}{ Sexo } & Hombres & 31 & 72.1 & 57.5 & 86.7 \\
\hline & Mujeres & 12 & 27.9 & 13.3 & 42.5 \\
\hline \multirow[t]{6}{*}{ Enf. renal de base } & Nefropatía túbulo-interst. & 10 & 23.3 & 9.5 & 37.0 \\
\hline & Glomerulonefritis & 9 & 20.9 & 7.6 & 34.3 \\
\hline & Poliquistosis renal & 9 & 20.9 & 7.6 & 34.3 \\
\hline & Nefropatía diabética & 3 & 7.0 & 1.5 & 19.1 \\
\hline & Nefroangioesclerosis & 3 & 7.0 & 1.5 & 19.1 \\
\hline & No filiada & 9 & 20.9 & 7.6 & 34.3 \\
\hline \multirow[t]{2}{*}{ Modalidad de diálisis } & Hemodiálisis & 29 & 67,4 & 52.3 & 82.6 \\
\hline & Diálisis Peritoneal & 14 & 32.6 & 17.4 & 47.7 \\
\hline \multirow[t]{3}{*}{ Acceso Vascular } & FAVI & 25 & 58.1 & 42.2 & 74.0 \\
\hline & Catéter peritoneal & 14 & 32.6 & 17.4 & 47.7 \\
\hline & Catéter venoso central & 4 & 9.3 & 2.6 & 22.1 \\
\hline Hipertensión arterial & $\mathrm{Si}$ & 38 & 88.4 & 74.9 & 96.1 \\
\hline Dislipemia & $\mathrm{Si}$ & 19 & 44.2 & 28.2 & 60.2 \\
\hline Tabaquismo & $\mathrm{Si}$ & 9 & 20.9 & 7.6 & 34.3 \\
\hline Diabetes & $\mathrm{Si}$ & 7 & 16.3 & 4.1 & 28.5 \\
\hline Cardiopatía isquémica & $\mathrm{Si}$ & 2 & 4.7 & 0.6 & 15.8 \\
\hline \multirow[t]{4}{*}{ Ecocardiografía Pre-Tx } & HVI leve & 14 & 32.6 & 17.4 & 47.7 \\
\hline & HVI moderada & 9 & 20.9 & 7.6 & 34.3 \\
\hline & HVI grave & 1 & 2.3 & 0.1 & 12.3 \\
\hline & No & 19 & 44.2 & 28.2 & 60.2 \\
\hline
\end{tabular}




\section{RESULTADOS}

Tabla 10: Análisis descriptivo. Antecedentes personales (Variables Cuantitativas)-

\begin{tabular}{|c|c|c|c|c|c|c|c|}
\hline & Variable & $\begin{array}{l}\text { Edad en el } \\
\text { trasplante }\end{array}$ & $\begin{array}{c}\text { Edad en la } \\
\text { revisión }\end{array}$ & $\begin{array}{c}\text { Meses de } \\
\text { diálisis }\end{array}$ & $\begin{array}{c}\text { Meses } \\
\text { desde } \\
\text { trasplante }\end{array}$ & $\begin{array}{c}\text { Fracción } \\
\text { de } \\
\text { eyección }\end{array}$ & $\begin{array}{c}\text { Estatura } \\
\text { (cms) }\end{array}$ \\
\hline & $\mathrm{N}$ válido & 43 & 43 & 43 & 43 & 35 & 43 \\
\hline \multicolumn{2}{|l|}{ Media } & 49.84 & 53.88 & 38.70 & 48.42 & 66.01 & 168.22 \\
\hline \multicolumn{2}{|c|}{ IC 95\%: límite inferior } & 46.07 & 50.10 & 21.87 & 39.74 & 63.80 & 165.43 \\
\hline \multicolumn{2}{|c|}{ IC 95\%: límite superior } & 53.60 & 57.67 & 55.52 & 57.10 & 68.23 & 171.01 \\
\hline \multicolumn{2}{|c|}{ Error típico de la media } & 1.87 & 1.87 & 8.34 & 4.30 & 1.09 & 1.38 \\
\hline \multicolumn{2}{|c|}{ Mediana } & 50.00 & 53.00 & 26.00 & 45.00 & 65.00 & 167.50 \\
\hline \multicolumn{2}{|l|}{ Mínimo } & 28.00 & 30.00 & 6.00 & 11.00 & 52.00 & 148.00 \\
\hline \multicolumn{2}{|l|}{ Máximo } & 77.00 & 81.00 & 344.00 & 99.00 & 77.00 & 185.00 \\
\hline \multicolumn{2}{|c|}{ Desviación estándar } & 12.24 & 12.29 & 54.66 & 28.21 & 6.45 & 9.06 \\
\hline \multirow[t]{3}{*}{ Forma: } & Asimetría & 0.12 & 0.01 & 4.53 & 0.25 & -0.12 & -0.12 \\
\hline & Curtosis & -0.48 & -0.41 & 24.01 & -1.39 & -0.48 & -0.42 \\
\hline & Test K-S (P-valor) & $.694^{\mathrm{NS}}$ & $.803^{\mathrm{NS}}$ & $.000 * *$ & $.002^{* *}$ & $.459^{N S}$ & .642 Ns \\
\hline
\end{tabular}

\subsubsection{3: TRATAMIENTO DE LAS ALTERACIONES DEL METABOLISMO OSEO MINERAL PRE-TRASPLANTE}

\section{1 $\alpha, 25$-dihidroxicolecalciferol.}

Un 39,5\% (17 pacientes) recibía calcitriol por vía oral o intravenosa como parte de su tratamiento previo al trasplante. La dosis media semanal de calcitriol fue de $1,88 \mu \mathrm{g}$, mediana de 1,75 $\mu \mathrm{g}(0,94-2 \mu \mathrm{g})$. La dosis media semanal de calcitriol oral fue de 1,54 $\mu \mathrm{g}$, mientras que la dosis media semanal de calcitriol intravenoso fue de 2,25 $\mu \mathrm{g}$. Ningún paciente recibió simultáneamente calcitriol por vía oral e intravenosa.

\section{Paricalcitol.}

Un 9,3\% (4 pacientes) recibía paricalcitol como parte de su pauta terapéutica. Ningún paciente recibió calcitriol y paricalcitol de forma simultánea pretrasplante. 


\section{RESULTADOS}

\section{Cinacalcet.}

Un 23,3\% (10 pacientes) recibía cinacalcet como parte de su tratamiento habitual pretrasplante. La dosis media de cinacalcet recibida fue de $39 \pm 14,5 \mathrm{mg} /$ día (dosis mínima $30 \mathrm{mg} /$ día, dosis máxima $60 \mathrm{mg} /$ día). Un 7\% (3 pacientes) de los pacientes de la muestra recibían tratamiento combinado con calcitriol y cinacalcet, mientras que un $4,7 \%$ (2 pacientes) recibían tratamiento combinado con paricalcitol y cinacalcet.

\section{Quelantes de fósforo.}

\section{Carbonato de lantano.}

Un 25,6\% (11 pacientes) recibían carbonato de lantano. La mediana de la dosis recibida por estos pacientes fue de $(2340 \pm 477,92) 2250 \mathrm{mg} /$ día (2000-3000 mg/día).

\section{Clorhidrato de sevelámer.}

Un 60,5\% (26 pacientes) recibían clorhidrato de sevelámer. La mediana de la dosis

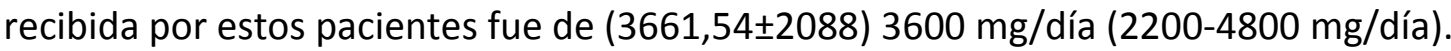

\section{Quelantes cálcicos.}

Un 37,2\% (16 pacientes) recibían acetato cálcico. La mediana de la dosis recibida por estos pacientes fue de 3,25 \pm 1,43 mg/día (3; 2-4 mg/día).

\section{Quelantes con aluminio.}

Un 7\% (3 pacientes) recibían quelantes de fósforo con aluminio. La dosis media recibida por estos pacientes fue de 543,67 $\pm 134 \mathrm{mg} /$ día (466; 466-0 mg/día). 


\section{RESULTADOS}

Resúmen de tratamiento con quelantes de fósforo.

\begin{tabular}{|l|c|c|}
\hline Tratamiento Recibido & Frecuencia & Porcentaje \\
\hline Sevelámer & 14 & 32,55 \\
\hline Lantano & 9 & 20,93 \\
\hline Acetato cálcico & 5 & 11,62 \\
\hline Sevelámer + Acetato cálcico & 9 & 20,93 \\
\hline Sevelámer + Aluminio & 2 & 4,65 \\
\hline Sevelámer + Lantano & 1 & 2,32 \\
\hline Lantano + Acetato cálcico & 1 & 2,32 \\
\hline Acetato cálcico + Aluminio & 1 & 2,32 \\
\hline Ninguno & 1 & 2,32 \\
\hline Total & 43 & 100 \\
\hline
\end{tabular}

Tabla 11: Empleo en monoterapia o uso combinado de quelantes del fósforo.

\section{Otros}

La dosis media de calcio presente en el baño de diálisis fue de 2,3 $\pm 0,47 \mathrm{mEq} / \mathrm{I}$. Al 4,7\% (2 pacientes) se les había practicado una paratiroidectomía pretrasplante debido a la existencia de adenomas paratiroideos. 


\section{RESULTADOS}

\section{Tablas Resumen}

Tabla 12: Análisis exploratorio y descriptivo. Tratamiento farmacológico previo

\begin{tabular}{lrrrrrrr}
\hline Variable & Rocatrol & Calcijex & Paricalcitol & Cinacalcet & $\begin{array}{c}\text { Carbonato } \\
\text { de lantano }\end{array}$ & $\begin{array}{c}\text { Clorhidrato de } \\
\text { sevelámer }\end{array}$ & $\begin{array}{c}\text { Quelantes } \\
\text { cálcicos }\end{array}$ \\
\hline No tiene (\%) & $79.1 \%$ & $81.4 \%$ & $90.7 \%$ & $76.7 \%$ & $74.4 \%$ & $39.5 \%$ & $62.8 \%$ \\
Sí tiene (\%) & $20.9 \%$ & $18.6 \%$ & $9.3 \%$ & $23.3 \%$ & $25.6 \%$ & $60.5 \%$ & $37.2 \%$ \\
N válido & 9 & 8 & -4 & 10 & 11 & 26 & 16 \\
Media & 0.222 & 2.25 & -- & 39.00 & 2340.91 & 3661.54 & 3.25 \\
IC 95\%: límite inferior & 0.129 & 0.93 & -- & 28.63 & 2019.84 & 2818.07 & 2.48 \\
IC 95\%: límite superior & 0.316 & 3.57 & -- & 49.37 & 2661.98 & 4505.01 & 4.02 \\
Error típico de la media & 0.040 & 0.56 & -- & 4.58 & 144.10 & 409.54 & 0.36 \\
Mediana & 0.250 & 2.00 & -- & 30.00 & 2250.00 & 3600.00 & 3.00 \\
Mínimo & 0.125 & 1.00 & -- & 30.00 & 1500.00 & 800.00 & 2.00 \\
Máximo & 0.500 & 6.00 & -- & 60.00 & 3000.00 & 7200.00 & 6.00 \\
Desviación estándar & 0.121 & 1.58 & -- & 14.49 & 477.92 & 2088.27 & 1.44 \\
Forma: Asimetría & 1.60 & 2.35 & -- & 1.04 & 0.20 & 0.32 & 0.73 \\
$\quad$ Curtosis & 3.19 & 6.22 & -- & -1.22 & -0.32 & -0.84 & -0.54 \\
$\quad$ Test K-S (P-valor) & $.006 * *$ & $.000 * *$ & -- & $.000 * *$ & .050 Ns & .027 Ns & $.001 * *$
\end{tabular}

NS = Desvío NO significativo $(P>.01)$ la variable sí se ajusta al modelo normal

** = Desvío significativo $(\mathrm{P}<.01)$ del modelo de la normal de Gauss

\subsubsection{4: DATOS ANALÍTICOS Y ANTROPOMÉTRICOS. EVOLUCIÓN DESDE EL TRASPLANTE.}

En las siguientes tablas se detalla la evolución de parámetros antropométricos como el peso, el índice de masa corporal, la presión arterial o el volumen de diuresis, junto con valores analíticos en tres puntos temporales: antes del trasplante, en el momento del alta (mediana de 13 días tras el trasplante) y en la revisión actual: 
RESULTADOS

a) Grupo 1: Datos antropométricos y analíticos previos al trasplante.

Tabla 13: Análisis exploratorio y descriptivo. Datos antropométricos y analíticos previos al trasplante -1-

\begin{tabular}{|c|c|c|c|c|c|c|c|c|c|}
\hline $\begin{array}{c}\text { Variable } \\
\text { medida }\end{array}$ & Peso & $I M C$ & TAS & $T A D$ & $\begin{array}{l}\text { Vol. de } \\
\text { diurésis }\end{array}$ & Hemoglobina & Hematocrito & Leucocitos & Plaquetas \\
\hline N válido & 43 & 43 & 43 & 43 & 43 & 43 & 43 & 43 & 43 \\
\hline Media & 70.89 & 24.95 & 146.14 & 84.16 & 1019.07 & 12.63 & 38.10 & 6710.23 & 188674.42 \\
\hline IC 95\%: & & & & & & & & & \\
\hline $\begin{array}{l}\text { límite } \\
\text { inferior }\end{array}$ & 67.28 & 24.04 & 138.028 & 80.20 & 714.28 & 12.13 & 36.52 & 6207.98 & 167424.31 \\
\hline IC 95\%: & & & & & & & & & \\
\hline $\begin{array}{l}\text { límite } \\
\text { superior }\end{array}$ & 74.49 & 25.87 & 154.00 & 88.12 & 1323.86 & 13.14 & 39.68 & 7212.49 & 209924.53 \\
\hline $\begin{array}{l}\text { Error típico } \\
\text { de la media }\end{array}$ & 1.79 & 0.45 & 3.89 & 1.96 & 151.03 & 0.25 & 0.78 & 248.88 & 10529.86 \\
\hline Mediana & 69.00 & 24.66 & 145.00 & 85.00 & 500.00 & 12.60 & 38.30 & 6790.00 & 178000.00 \\
\hline Mínimo & 44.50 & 20.04 & 103.00 & 57.00 & 0.00 & 9.40 & 29.00 & 3900.00 & 61000.00 \\
\hline Máximo & 105.00 & 32.05 & 21.00 & 118.00 & 3800.00 & 15.90 & 50.80 & 10690.00 & 371000.00 \\
\hline $\begin{array}{l}\text { Desviación } \\
\text { estándar }\end{array}$ & 11.72 & 2.97 & 25.54 & 12.86 & 990.36 & 1.65 & 5.13 & 1632.00 & 69048.89 \\
\hline $\begin{array}{l}\text { Forma: } \\
\text { Asimetría }\end{array}$ & 0.32 & 0.26 & 0.51 & 0.14 & 0.96 & -0.11 & 0.20 & 0.35 & 0.91 \\
\hline Curtosis & 1.04 & -0.57 & -0.08 & 0.30 & 0.03 & -0.57 & -0.29 & 0.16 & 0.86 \\
\hline $\begin{array}{l}\text { Test K-S (P- } \\
\text { valor) }\end{array}$ & .359 NS & $.568^{\mathrm{NS}}$ & .356 NS & $.588^{\mathrm{NS}}$ & $.000 * *$ & .461 NS & $.580 \mathrm{NS}$ & $.264^{\mathrm{NS}}$ & $.019^{\mathrm{NS}}$ \\
\hline
\end{tabular}

NS = Desvío NO significativo $(P>.01)$ la variable sí se ajusta al modelo normal

** = Desvío significativo $(\mathrm{P}<.01)$ del modelo de la normal de Gauss 


\section{RESULTADOS}

Tabla 14: Análisis exploratorio y descriptivo. Datos antropométricos y analíticos previos al trasplante -2-

\begin{tabular}{|c|c|c|c|c|c|c|c|c|c|}
\hline $\begin{array}{c}\text { Variable } \\
\text { medida }\end{array}$ & Urea & Glucosa & Creatinina & Triglicéridos & $\begin{array}{c}\text { Colesterol } \\
\text { total }\end{array}$ & $\begin{array}{c}\text { Proteínas } \\
\text { totales }\end{array}$ & Calcio & $\begin{array}{c}\text { Calcio } \\
\text { corregido }\end{array}$ & $\begin{array}{l}\text { Prod. } \\
\text { Calcio } \\
\text { fósforo }\end{array}$ \\
\hline $\mathrm{N}$ válido & 43 & 43 & 43 & 43 & 43 & 43 & 43 & 43 & 43 \\
\hline Media & 144.70 & 95.09 & 8.85 & 117.14 & 168.88 & 6.90 & 9.27 & 9.57 & 46.39 \\
\hline $\begin{array}{l}\text { IC 95\%: } \\
\text { límite } \\
\text { inferior }\end{array}$ & 133.98 & 88.00 & 8.02 & 104.48 & 152.91 & 6.73 & 9.00 & 9.30 & 43.17 \\
\hline $\begin{array}{l}\text { IC 95\%: } \\
\text { límite } \\
\text { superior }\end{array}$ & 155.41 & 102.19 & 9.67 & 129.80 & 184.85 & 7.07 & 9.53 & 9.84 & 49.61 \\
\hline $\begin{array}{l}\text { Error típico } \\
\text { de la media }\end{array}$ & 5.31 & 3.52 & 0.41 & 6.27 & 7.91 & 0.08 & 0.13 & 0.13 & 1.60 \\
\hline Mediana & 145.00 & 90.00 & 7.88 & 112.00 & 173.00 & 6.90 & 9.35 & 9.65 & 47.84 \\
\hline Mínimo & 88.00 & 72.00 & 5.20 & 51.00 & 68.00 & 5.30 & 6.00 & 6.60 & 18.26 \\
\hline Máximo & 219.00 & 206.00 & 15.10 & 228.00 & 308.00 & 7.90 & 10.80 & 11.50 & 71.40 \\
\hline $\begin{array}{l}\text { Desviación } \\
\text { estándar }\end{array}$ & 34.82 & 23.06 & 2.67 & 41.14 & 51.89 & 0.55 & 0.86 & 0.88 & 10.47 \\
\hline $\begin{array}{l}\text { Forma: } \\
\text { Asimetría }\end{array}$ & 0.26 & 3.41 & 0.63 & 0.67 & 0.54 & -0.41 & -1.11 & -0.50 & -0.35 \\
\hline Curtosis & -0.67 & 13.68 & -0.73 & 0.49 & 0.46 & 0.19 & 3.55 & 2.14 & 0.55 \\
\hline $\begin{array}{l}\text { Test K-S (P- } \\
\text { valor) }\end{array}$ & .172 NS & $.000 * *$ & $.006^{* *}$ & .108 NS & $.285^{\mathrm{NS}}$ & .293 NS & $.006^{* *}$ & $.115^{\text {NS }}$ & $.615^{\mathrm{NS}}$ \\
\hline
\end{tabular}

NS = Desvío NO significativo $(P>.01)$ la variable sí se ajusta al modelo normal

** = Desvío significativo $(\mathrm{P}<.01)$ del modelo de la normal de Gauss 


\section{RESULTADOS}

Tabla 15: Análisis exploratorio y descriptivo. Datos antropométricos y analíticos previos al trasplante -3-

\begin{tabular}{|c|c|c|c|c|c|c|c|c|c|}
\hline $\begin{array}{c}\text { Variable } \\
\text { medida }\end{array}$ & Fósforo & $\begin{array}{c}\text { Fosfatasa } \\
\text { alcalina }\end{array}$ & $\begin{array}{c}\text { Hormona } \\
\text { paratiroidea }\end{array}$ & $p H$ & Bicarbonato & $M D R D a$ & $\begin{array}{c}\text { Cockcroft } \\
\text { Gault }\end{array}$ & $\begin{array}{c}\text { Mayo } \\
\text { Quadratic }\end{array}$ & $C K D-E P I$ \\
\hline N válido & 43 & 43 & 42 & 43 & 43 & 43 & 43 & 43 & 43 \\
\hline Media & 5.00 & 101.00 & 357.56 & 7.37 & 23.68 & 6.95 & 10.34 & 9.14 & 6.42 \\
\hline $\begin{array}{l}\text { IC 95\%: } \\
\text { límite } \\
\text { inferior }\end{array}$ & 4.68 & 81.79 & 237.73 & 7.35 & 22.82 & 6.27 & 9.21 & 8.54 & 5.74 \\
\hline $\begin{array}{l}\text { IC 95\%: } \\
\text { límite } \\
\text { superior }\end{array}$ & 5.33 & 120.21 & $47 . .38$ & 7.39 & 24.54 & 7.64 & 11.47 & 9.74 & 7.10 \\
\hline $\begin{array}{l}\text { Error típico } \\
\text { de la } \\
\text { media }\end{array}$ & 0.16 & 9.52 & 5.35 & 0.01 & 0.43 & 0.34 & 0.56 & 0.30 & 0.34 \\
\hline Mediana & 4.90 & 77.00 & 194.50 & 7.37 & 23.30 & 6.74 & 9.81 & 8.90 & 5.98 \\
\hline Mínimo & 2.20 & 39.00 & 22.00 & 7.28 & 15.90 & 3.50 & 5.25 & 6.39 & 3.26 \\
\hline Máximo & 7.00 & 346.00 & 1715.00 & 7.50 & 28.50 & 12.18 & 22.17 & 14.38 & 11.92 \\
\hline $\begin{array}{l}\text { Desviación } \\
\text { estándar }\end{array}$ & 1.06 & 62.43 & 384.51 & 0.05 & 2.80 & 2.22 & 3.67 & 1.96 & 2.20 \\
\hline $\begin{array}{l}\text { Forma: } \\
\text { Asimetría }\end{array}$ & -0.07 & 2.09 & 2.24 & 0.32 & -0.28 & 0.41 & 1.27 & 0.77 & 0.55 \\
\hline Curtosis & -0.16 & 5.02 & 5.35 & 0.12 & 0.11 & -0.68 & 2.21 & -0.05 & -0.46 \\
\hline $\begin{array}{r}\text { Test } \\
\text { K-S (P-valor) }\end{array}$ & $.318^{\mathrm{NS}}$ & $.000 * *$ & $.000^{* *}$ & $.177^{\text {NS }}$ & .498 NS & .135 NS & $.002 * *$ & $.020^{N S}$ & $.065^{\mathrm{NS}}$ \\
\hline
\end{tabular}

NS = Desvío NO significativo $(P>01)$ la variable sí se ajusta al modelo normal

** = Desvío significativo $(\mathrm{P}<.01)$ del modelo de la normal de Gauss 


\section{RESULTADOS}

b) Grupo 2: Datos antropométricos y analíticos al alta tras el trasplante.

Tabla 16: Análisis exploratorio y descriptivo. Datos antropométricos y analíticos al alta tras el trasplante -1-

\begin{tabular}{|c|c|c|c|c|c|c|c|c|c|}
\hline $\begin{array}{r}\text { Variable } \\
\text { medida }\end{array}$ & Peso & $I M C$ & TAS & $T A D$ & $\begin{array}{l}\text { Vol. de } \\
\text { diurésis }\end{array}$ & Hemoglobina & Hematocrito & Leucocitos & Plaquetas \\
\hline $\mathrm{N}$ válido & 43 & 43 & 43 & 43 & 43 & 43 & 43 & 43 & 43 \\
\hline Media & 69.29 & 24.43 & 137.74 & 78.49 & 2438.49 & 10.72 & 32.71 & 9473.95 & 260674.42 \\
\hline $\begin{array}{l}\text { IC 95\%: límite } \\
\text { inferior }\end{array}$ & 65.73 & 23.43 & 130.48 & 74.27 & 2198.20 & 10.31 & 31.49 & 8327.43 & 225102.66 \\
\hline $\begin{array}{l}\text { IC 95\%: límite } \\
\text { superior }\end{array}$ & 72.86 & 25.44 & 145.01 & 82.71 & 2678.78 & 11.13 & 33.94 & 10620.47 & 296247.18 \\
\hline $\begin{array}{l}\text { Error típico de } \\
\text { la media }\end{array}$ & 1.77 & 0.50 & 3.60 & 2.09 & 119.07 & 0.20 & 0.61 & 568.12 & 17627.02 \\
\hline Mediana & 68.00 & 23.78 & 130.00 & 78.00 & 2300.00 & 10.40 & 32.00 & 9500.00 & 240000.00 \\
\hline Mínimo & 41.60 & 18.74 & 79.00 & 50.00 & 1050.00 & 8.50 & 27.00 & 1620.00 & 82000.00 \\
\hline Máximo & 104.00 & 31.75 & 183.00 & 105.00 & 5350.00 & 8.50 & 27.00 & 1620.00 & 606000.00 \\
\hline $\begin{array}{l}\text { Desviación } \\
\text { estándar }\end{array}$ & 11.60 & 3.26 & 23.60 & 13.71 & 780.78 & 1.33 & 3.99 & 3725.44 & 115588.09 \\
\hline $\begin{array}{l}\text { Forma: } \\
\text { Asimetría }\end{array}$ & 0.52 & 0.49 & -0.13 & 0.16 & 1.47 & 0.58 & 0.71 & 0.09 & 1.15 \\
\hline Curtosis & 1.09 & -0.59 & -0.49 & -0.49 & 3.61 & -0.26 & -0.05 & -0.23 & 1.50 \\
\hline S (P-valor) & .556 NS & .114 NS & .333 NS & $.308^{\mathrm{NS}}$ & $.001^{* *}$ & .144 NS & .036 NS & .860 NS & $.005^{* *}$ \\
\hline
\end{tabular}

NS = Desvío NO significativo $(P>.01)$ la variable sí se ajusta al modelo normal

** = Desvío significativo $(\mathrm{P}<.01)$ del modelo de la normal de Gauss 


\section{RESULTADOS}

Tabla 17: Análisis exploratorio y descriptivo. Datos antropométricos y analíticos al alta tras el trasplante -2-

\begin{tabular}{|c|c|c|c|c|c|c|c|c|c|}
\hline Variable medida & VSG & Urea & Glucosa & Creatinina & Triglicéridos & $\begin{array}{c}\text { Colesterol } \\
\text { total }\end{array}$ & $\begin{array}{l}\text { Proteínas } \\
\text { totales }\end{array}$ & Calcio & $\begin{array}{c}\text { Calcio } \\
\text { corregido }\end{array}$ \\
\hline $\mathrm{N}$ válido & & 43 & 43 & 43 & 43 & 43 & 43 & 43 & 43 \\
\hline Media & & 88.84 & 103.28 & 2.22 & 146.12 & 184.70 & 6.20 & 9.59 & 10.24 \\
\hline $\begin{array}{l}\text { IC 95\%: límite } \\
\text { inferior }\end{array}$ & & 76.99 & 93.57 & 1.79 & 124.96 & 169.30 & 6.02 & 9.32 & 9.99 \\
\hline $\begin{array}{l}\text { IC 95\%: límite } \\
\text { superior }\end{array}$ & & 100.68 & 112.99 & 2.64 & 167.27 & 200.10 & 6.37 & 9.85 & 10.49 \\
\hline $\begin{array}{l}\text { Error típico de la } \\
\text { media }\end{array}$ & & 5.87 & 4.81 & 0.21 & 10.48 & 7.63 & 0.09 & 0.13 & 0.12 \\
\hline Mediana & & 76.00 & 94.00 & 1.70 & 130.00 & 187.00 & 6.30 & 9.50 & 10.15 \\
\hline Mínimo & & 38.00 & 45.00 & 1.00 & 56.00 & 90.00 & 4.70 & 8.20 & 8.80 \\
\hline Máximo & & 221.00 & 224.00 & 7.10 & 385.00 & 327.00 & 7.60 & 12.40 & 13.00 \\
\hline $\begin{array}{l}\text { Desviación } \\
\text { estándar }\end{array}$ & & 38.49 & 31.55 & 1.38 & 68.75 & 50.03 & 0.57 & 0.87 & 0.80 \\
\hline $\begin{array}{l}\text { Forma: } \\
\text { Asimetría }\end{array}$ & & 1.47 & 2.09 & 2.32 & 1.56 & 0.31 & -0.21 & 0.78 & 1.06 \\
\hline Curtosis & & 2.69 & 5.46 & 5.29 & 2.93 & 0.22 & 0.49 & 1.57 & 2.51 \\
\hline $\begin{array}{l}\text { Test K-S } \\
\text { (P-valor) }\end{array}$ & & $.000 * *$ & $.000 * *$ & $.000 * *$ & $.000 * *$ & $.688^{\text {NS }}$ & $.861^{\mathrm{NS}}$ & .042 NS & .026 NS \\
\hline
\end{tabular}

NS = Desvío NO significativo $(P>.01)$ la variable sí se ajusta al modelo normal

${ }^{* *}$ = Desvío significativo $(\mathrm{P}<.01)$ del modelo de la normal de Gauss

Tabla 18: Análisis exploratorio y descriptivo. Datos antropométricos y analíticos al alta tras el trasplante -3-

\begin{tabular}{|c|c|c|c|c|c|c|c|}
\hline & Variable & $\begin{array}{c}\text { Prod. Calcio } \\
\text { fósforo }\end{array}$ & Fósforo & Magnesio & $\begin{array}{c}\text { Fosfatasa } \\
\text { alcalina }\end{array}$ & $\begin{array}{c}\text { Urea en } \\
\text { orina }\end{array}$ & $\begin{array}{l}\text { Creatinia } \\
\text { en orina }\end{array}$ \\
\hline & N válido & 43 & 43 & 43 & 43 & 43 & 43 \\
\hline \multicolumn{2}{|l|}{ Media } & 30.46 & 3.18 & 1.67 & 86.88 & 1209.57 & 51.67 \\
\hline \multicolumn{2}{|c|}{ IC 95\%: límite inferior } & 27.36 & 2.86 & 1.57 & 70.72 & 1071.34 & 49.94 \\
\hline \multicolumn{2}{|c|}{ IC 95\%: límite superior } & 33.57 & 3.50 & 1.77 & 103.05 & 1337.81 & 65.29 \\
\hline \multicolumn{2}{|c|}{ Error típico de la media } & 1.54 & 0.16 & 0.05 & 8.01 & 63.54 & 3.80 \\
\hline \multicolumn{2}{|l|}{ Mediana } & 69.68 & 3.10 & 1.60 & 75.00 & 1181.00 & 52.00 \\
\hline \multicolumn{2}{|l|}{ Mínimo } & 12.45 & 1.50 & 1.20 & 44.00 & 443.00 & 9.60 \\
\hline \multicolumn{2}{|l|}{ Máximo } & 71.61 & 7.70 & 2.60 & 369.00 & 2462.00 & 122.00 \\
\hline \multicolumn{2}{|c|}{ Desviación estándar } & 10.09 & 1.04 & 0.32 & 52.52 & 416.68 & 24.94 \\
\hline \multirow[t]{3}{*}{ Forma: } & Asimetría & 1.67 & 2.04 & 0.92 & 4.09 & 0.62 & 0.60 \\
\hline & Curtosis & 5.56 & 7.59 & 1.43 & 20.30 & 0.85 & -0.12 \\
\hline & Test K-S (P-valor) & $.000 * *$ & $.000 * *$ & $.009 * *$ & $.000 * *$ & .169 NS & $.095^{\mathrm{NS}}$ \\
\hline
\end{tabular}

NS = Desvío NO significativo $(P>.01)$ la variable sí se ajusta al modelo normal

** = Desvío significativo $(\mathrm{P}<.01)$ del modelo de la normal de Gauss 


\section{RESULTADOS}

Tabla 19: Análisis exploratorio y descriptivo. Datos antropométricos y analíticos al alta tras el trasplante -4-

\begin{tabular}{|c|c|c|c|c|c|c|c|}
\hline & Variable & $p H$ & Bicarbonato & $M D R D a$ & $\begin{array}{c}\text { Cockcroft } \\
\text { Gault }\end{array}$ & $\begin{array}{c}\text { Mayo } \\
\text { Quadratic }\end{array}$ & $C K D-E P I$ \\
\hline & $\mathrm{N}$ válido & 43 & 43 & 43 & 43 & 43 & 43 \\
\hline \multicolumn{2}{|l|}{ Media } & 7.35 & 21.08 & 35.12 & 39.88 & 39.90 & 35.08 \\
\hline \multicolumn{2}{|c|}{ IC 95\%: límite inferior } & 7.33 & 20.11 & 35.12 & 39.88 & 39.90 & 35.08 \\
\hline \multicolumn{2}{|c|}{ IC 95\%: límite superior } & 7.36 & 22.05 & 45.59 & 49.27 & 54.41 & 45.99 \\
\hline \multicolumn{2}{|c|}{ Error típico de la media } & 0.01 & 0.48 & 2.59 & 2.33 & 3.60 & 2.70 \\
\hline \multicolumn{2}{|c|}{ Mediana } & 7.36 & 21.30 & 43.05 & 45.98 & 51.31 & 44.78 \\
\hline \multicolumn{2}{|l|}{ Mínimo } & 7.17 & 14.00 & 7.34 & 10.78 & 8.86 & 7.04 \\
\hline \multicolumn{2}{|c|}{ Máximo } & 7.41 & 25.90 & 73.08 & 76.37 & 93.49 & 73.61 \\
\hline \multicolumn{2}{|c|}{ Desviación estándar } & 0.05 & 3.15 & 17.01 & 15.26 & 23.58 & 17.73 \\
\hline \multirow[t]{3}{*}{ Forma: } & Asimetría & -1.49 & -0.27 & -0.07 & -0.17 & 0.18 & -0.06 \\
\hline & Curtosis & 3.04 & -0.82 & -0.72 & -0.38 & -0.89 & -0.84 \\
\hline & Test K-S (P-valor) & $.000 * *$ & $.144^{\mathrm{NS}}$ & $.647^{N S}$ & $.886^{\mathrm{NS}}$ & .194 NS & $.427^{\mathrm{NS}}$ \\
\hline
\end{tabular}

NS = Desvío NO significativo $(P>$.01) la variable sí se ajusta al modelo normal

** = Desvío significativo $(\mathrm{P}<.01)$ del modelo de la normal de Gauss

c) Grupo 3: Datos antropométricos y analíticos en la revisión.

Tabla 20: Análisis exploratorio y descriptivo. Datos antropométricos y analíticos en la revisión -1-

\begin{tabular}{|c|c|c|c|c|c|c|c|c|c|}
\hline $\begin{array}{c}\text { Variable } \\
\text { medida }\end{array}$ & Peso & $I M C$ & TAS & $T A D$ & $\begin{array}{l}\text { Vol. de } \\
\text { diurésis }\end{array}$ & Hemoglobina & Hematocrito & Leucocitos & Plaquetas \\
\hline $\mathrm{N}$ válido & 43 & 43 & 43 & 43 & 43 & 43 & 43 & 43 & 43 \\
\hline Media & 74.63 & 26.29 & 144.37 & 84.74 & 2594.65 & 13.35 & 40.21 & 6863.72 & 190697.67 \\
\hline $\begin{array}{l}\text { IC 95\%: límite } \\
\text { inferior }\end{array}$ & 70.57 & 25.21 & 138.85 & 82.01 & 2348.20 & 12.76 & 38.61 & 6207.21 & 172668.34 \\
\hline $\begin{array}{l}\text { IC 95\%: límite } \\
\text { superior }\end{array}$ & 78.70 & 27.37 & 149.89 & 87.47 & 2841.11 & 13.94 & 41.81 & 7520.23 & 208727.01 \\
\hline $\begin{array}{l}\text { Error típico de } \\
\text { la media }\end{array}$ & 2.01 & 0.53 & 2.74 & 1.35 & 122.12 & 0.29 & 0.79 & 325.31 & 8933.90 \\
\hline Mediana & 72.30 & 26.00 & 141.00 & 85.00 & 2500.00 & 13.00 & 39.80 & 6540.00 & 182000.00 \\
\hline Mínimo & 44.00 & 19.73 & 100.00 & 66.00 & 1200.00 & 8.90 & 28.70 & 3450.00 & 61000.00 \\
\hline Máximo & 15.80 & 38.40 & 189.00 & 104.00 & 4300.00 & 18.90 & 54.20 & 12210.00 & 341000.00 \\
\hline $\begin{array}{l}\text { Desviación } \\
\text { estándar }\end{array}$ & 13.21 & 3.50 & 17.94 & 8.87 & 800.81 & 1.93 & 5.20 & 2133.23 & 58583.49 \\
\hline $\begin{array}{l}\text { Forma: } \\
\text { Asimetría }\end{array}$ & 1.24 & 0.86 & 0.25 & 0.05 & 0.24 & 0.48 & 0.47 & 0.52 & 0.57 \\
\hline Curtosis & 4.50 & 2.38 & 0.35 & -0.28 & -0.69 & 1.10 & 0.92 & -0.37 & 0.56 \\
\hline $\begin{array}{l}\text { Test K- } \\
\mathrm{S} \text { (P-valor) }\end{array}$ & $.002 * *$ & .060 NS & $.641^{\mathrm{NS}}$ & .906 Ns & $.407^{* *}$ & .179 Ns & .214 NS & .139 NS & .322 Ns \\
\hline
\end{tabular}

NS = Desvío NO significativo $(P>01)$ la variable sí se ajusta al modelo normal

** = Desvío significativo $(\mathrm{P}<.01)$ del modelo de la normal de Gauss 
RESULTADOS

Tabla 21: Análisis exploratorio y descriptivo. Datos antropométricos y analíticos en la revisión -2-

\begin{tabular}{|c|c|c|c|c|c|c|c|c|c|}
\hline Variable medida & VSG & Urea & Glucosa & Creatinina & $\begin{array}{l}\text { Ácido } \\
\text { úrico }\end{array}$ & Triglicéridos & $\begin{array}{c}\text { Colesterol } \\
\text { total }\end{array}$ & $\begin{array}{l}\text { Proteinas } \\
\text { totales }\end{array}$ & Calcio \\
\hline $\mathrm{N}$ válido & 43 & 43 & 43 & 43 & 43 & 43 & 43 & 43 & 43 \\
\hline Media & 16.50 & 68.51 & 103.33 & 1.57 & 8.77 & 122.21 & 184.05 & 6.81 & 9.60 \\
\hline $\begin{array}{l}\text { IC 95\%: límite } \\
\text { inferior }\end{array}$ & 12.02 & 59.44 & 93.53 & 1.41 & 5.08 & 102.83 & 171.83 & 6.66 & 9.43 \\
\hline $\begin{array}{l}\text { IC 95\%: límite } \\
\text { superior }\end{array}$ & 20.98 & 77.58 & 113.12 & 1.73 & 12.47 & 141.85 & 196.26 & 6.96 & 9.78 \\
\hline $\begin{array}{l}\text { Error típico de la } \\
\text { media }\end{array}$ & 2.22 & 4.49 & 4.85 & 0.08 & 1.83 & 9.73 & 6.05 & 0.07 & 0.09 \\
\hline Mediana & 10.00 & 59.00 & 96.00 & 1.40 & 7.00 & 104.00 & 190.00 & 6.90 & 9.50 \\
\hline Mínimo & 2.00 & 27.00 & 56.00 & 0.70 & 4.40 & 44.00 & 112.00 & 5.30 & 8.00 \\
\hline Máximo & 59.00 & 164.00 & 256.00 & 3.00 & 85.00 & 341.00 & 264.00 & 7.80 & 10.90 \\
\hline $\begin{array}{l}\text { Desviación } \\
\text { estándar }\end{array}$ & 14.56 & 29.47 & 31.82 & 0.52 & 11.99 & 63.83 & 39.70 & 0.49 & 0.58 \\
\hline $\begin{array}{l}\text { Forma: } \\
\text { Asimetría }\end{array}$ & 1.46 & 1.20 & 3.28 & 1.12 & 6.40 & 1.67 & -0.02 & -0.62 & -0.39 \\
\hline Curtosis & 1.61 & 1.56 & 13.37 & 0.91 & 41.61 & 3.15 & -0.74 & 1.83 & 1.42 \\
\hline (P-valor) $^{\text {Test K-S }}$ & $.000 * *$ & $.002^{* *}$ & $.000 * *$ & $.001 * *$ & $.000 * *$ & $.000 * *$ & .490 NS & $.037^{\mathrm{NS}}$ & $.082^{\mathrm{NS}}$ \\
\hline
\end{tabular}

NS = Desvío NO significativo $(P>.01)$ la variable sí se ajusta al modelo normal

** = Desvío significativo $(\mathrm{P}<.01)$ del modelo de la normal de Gauss

Tabla 22: Análisis exploratorio y descriptivo. Datos antropométricos y analíticos en la revisión -3-

\begin{tabular}{|c|c|c|c|c|c|c|c|c|c|}
\hline Variable medida & $\begin{array}{c}\text { Calcio } \\
\text { corregido }\end{array}$ & $\begin{array}{l}\text { Prod. } \\
\text { Calcio } \\
\text { fósforo }\end{array}$ & Fósforo & Magnesio & $\begin{array}{l}\text { Fosfatasa } \\
\text { alcalina }\end{array}$ & $\begin{array}{l}\text { Calcio } \\
\text { iónico }\end{array}$ & $P C R$ & Interleukina & PTH \\
\hline $\mathrm{N}$ válido & 43 & 43 & 43 & 43 & 43 & 43 & 43 & 43 & 43 \\
\hline Media & 9.95 & 30.62 & 3.20 & 1.84 & 76.98 & 1.27 & 3.16 & 7.08 & 107.63 \\
\hline $\begin{array}{l}\text { IC 95\%: límite } \\
\text { inferior }\end{array}$ & 9.79 & 28.76 & 2.99 & 1.76 & 68.96 & 1.25 & 2.19 & 1.52 & 90.40 \\
\hline $\begin{array}{l}\text { IC 95\%: límite } \\
\text { superior }\end{array}$ & 10.11 & 32.48 & 3.41 & 1.93 & 85.00 & 1.29 & 4.14 & 12.64 & 124.87 \\
\hline $\begin{array}{l}\text { Error típico de la } \\
\text { media }\end{array}$ & 0.08 & 0.92 & 0.10 & 0.04 & 3.97 & 0.01 & 0.48 & 2.75 & 8.54 \\
\hline Mediana & 10.00 & 31.02 & 3.10 & 1.80 & 75.00 & 1.27 & 2.00 & 3.00 & 93.50 \\
\hline Mínimo & 8.85 & 19.95 & 2.10 & 1.40 & 36.00 & 1.08 & 1.00 & 0.00 & 1.20 \\
\hline Máximo & 11.20 & 43.65 & 4.60 & 2.60 & 194.00 & 1.43 & 14.00 & 120.00 & 281.00 \\
\hline $\begin{array}{l}\text { Desviación } \\
\text { estándar }\end{array}$ & 0.52 & 6.04 & 0.67 & 0.28 & 26.06 & 0.06 & 3.18 & 18.06 & 56.00 \\
\hline $\begin{array}{l}\text { Forma: } \\
\text { Asimetría }\end{array}$ & 0.10 & 0.15 & 0.36 & 0.80 & 2.42 & -0.26 & 1.80 & 6.10 & 1.02 \\
\hline Curtosis & 0.05 & -0.92 & -0.79 & 0.62 & 9.30 & 1.85 & 2.84 & 38.73 & 1.35 \\
\hline (P-valor) & .981 NS & .268 NS & .108 NS & .015 NS & $.000 * *$ & .104 NS & $.000 * *$ & $.000 * *$ & $.017^{\mathrm{NS}}$ \\
\hline
\end{tabular}

NS = Desvío NO significativo $(P>.01)$ la variable sí se ajusta al modelo normal

${ }^{* *}=$ Desvío significativo $(\mathrm{P}<.01)$ del modelo de la normal de Gauss 
RESULTADOS

Tabla 23: Análisis exploratorio y descriptivo. Datos antropométricos y analíticos en la revisión -4-

\begin{tabular}{|c|c|c|c|c|c|c|c|}
\hline & Variable & $\begin{array}{l}\text { Hemoglobina } \\
\text { glicosilada }\end{array}$ & Vitamina $D$ & $\begin{array}{c}\text { Colesterol } \\
\text { HDL }\end{array}$ & $\begin{array}{c}\text { Colesterol } \\
\text { LDL }\end{array}$ & $p H$ & Bicarbonato \\
\hline & \multirow[t]{2}{*}{$\mathrm{N}$ válido } & 43 & 43 & 43 & 43 & 43 & 43 \\
\hline Media & & 5.95 & 18.50 & 58.84 & 100.35 & 7.33 & 22.40 \\
\hline \multicolumn{2}{|c|}{ IC 95\%: límite inferior } & 5.67 & 15.30 & 53.12 & 90.38 & 7.32 & 21.60 \\
\hline \multicolumn{2}{|c|}{ IC 95\%: límite superior } & 6.23 & 21.69 & 64.56 & 110.32 & 7.34 & 23.19 \\
\hline \multicolumn{2}{|c|}{ Error típico de la media } & 0.14 & 1.58 & 2.84 & 40.94 & 0.01 & 0.39 \\
\hline \multicolumn{2}{|c|}{ Mediana } & 5.60 & 16.10 & 53.00 & 96.80 & 7.32 & 22.30 \\
\hline \multicolumn{2}{|l|}{ Mínimo } & 5.10 & 4.99 & 32.00 & 40.00 & 7.27 & 17.40 \\
\hline \multicolumn{2}{|l|}{ Máximo } & 10.60 & 55.42 & 116.00 & 167.40 & 7.44 & 27.70 \\
\hline \multicolumn{2}{|c|}{ Desviación estándar } & 0.90 & 10.39 & 18.59 & 32.40 & 0.04 & 2.58 \\
\hline \multirow[t]{3}{*}{ Forma: } & Asimetría & 3.49 & 1.42 & 0.80 & 0.17 & 0.66 & 0.02 \\
\hline & Curtosis & 16.35 & 2.60 & 0.51 & -0.67 & 0.33 & -0.66 \\
\hline & Test K-S (P-valor) & $.000 * *$ & $.001 * *$ & .022 Ns & .626 NS & .079 NS & .764 NS \\
\hline
\end{tabular}

NS = Desvío NO significativo $(P>.01)$ la variable sí se ajusta al modelo normal

** = Desvío significativo $(\mathrm{P}<.01)$ del modelo de la normal de Gauss

Tabla 24: Análisis exploratorio y descriptivo. Datos antropométricos y analíticos en la revisión -5-

\begin{tabular}{|c|c|c|c|c|c|c|c|}
\hline & Variable & Microalbuminuria & $M D R D a$ & $\begin{array}{c}\text { Cockcroft } \\
\text { Gault }\end{array}$ & $\begin{array}{c}\text { Mayo } \\
\text { Quadratic }\end{array}$ & $C K D-E P I$ & FGF-23 \\
\hline & \multirow[t]{2}{*}{ N válido } & 43 & 43 & 43 & 43 & 43 & 43 \\
\hline Media & & 71.39 & 51.29 & 59.97 & 61.85 & 51.70 & 5.04 \\
\hline \multicolumn{2}{|c|}{ IC 95\%: límite inferior } & 27.57 & 45.73 & 52.45 & 53.96 & 45.63 & 1.03 \\
\hline \multicolumn{2}{|c|}{ IC 95\%: límite superior } & 115.21 & 56.85 & 67.49 & 69.75 & 57.77 & 9.06 \\
\hline \multicolumn{2}{|c|}{ Error típico de la media } & 21.71 & 2.76 & 3.73 & 3.91 & 3.01 & 1.99 \\
\hline \multicolumn{2}{|c|}{ Mediana } & 17.10 & 49.03 & 53.87 & 62.13 & 46.95 & 0.00 \\
\hline \multicolumn{2}{|l|}{ Mínimo } & 3.00 & 20.74 & 21.87 & 19.42 & 20.54 & 0.00 \\
\hline \multicolumn{2}{|c|}{ Máximo } & 760.00 & 94.14 & 138.43 & 113.29 & 99.24 & 66.18 \\
\hline \multicolumn{2}{|c|}{ Desviación estándar } & 142.38 & 18.08 & 24.44 & 25.65 & 19.74 & 13.05 \\
\hline \multirow[t]{3}{*}{ Forma: } & Asimetría & 3.49 & 0.20 & 1.00 & 0.08 & 0.33 & 3.74 \\
\hline & Curtosis & 13.79 & -0.58 & 1.24 & -0.91 & 0.46 & 14.49 \\
\hline & Test K-S (P-valor) & $.000^{* *}$ & .555 NS & .025 Ns & $.331^{\mathrm{NS}}$ & .403 NS & $.000^{* *}$ \\
\hline
\end{tabular}

NS = Desvío NO significativo $(P>$.01) la variable sí se ajusta al modelo normal

** = Desvío significativo $(\mathrm{P}<.01)$ del modelo de la normal de Gauss 


\section{RESULTADOS}

\subsubsection{5: EVOLUCIÓN DE PARÁMETROS RELATIVOS AL MOM}

\section{Calcio plasmático.}

La evolución de los valores de calcio plasmático fue la siguiente:

\begin{tabular}{|l|l|l|l|l|}
\hline & Media & DS & MAX & MIN \\
\hline Calcio Plasmático* (1) & 9,26 & 0,86 & 10,8 & 6 \\
\hline Calcio Corregido* (1) & 9,57 & 0,87 & 11,5 & 6,6 \\
\hline Calcio Plasmático* (2) & 9,58 & 0,87 & 12,4 & 8,2 \\
\hline Calcio Corregido* (2) & 10,23 & 0,8 & 13 & 8,8 \\
\hline Calcio Plasmático* (3) & 9,6 & 0,57 & 10,9 & 8 \\
\hline Calcio Corregido* (3) & 9,94 & 0,52 & 11,2 & 8,85 \\
\hline Calcio lónico** (3) & 1,26 & 0,06 & 1,43 & 1,08 \\
\hline
\end{tabular}

Tabla 25: Evolución de las cifras de calcio plasmático. ${ }^{*} \mathrm{mg} / \mathrm{dl} .{ }^{* *} \mathrm{mmol} / \mathrm{l}$. (1) Pretrasplante. (2) Alta de trasplante. (3) Revisión actual.

Las cifras de calcio total en plasma se incrementan tras la realización del trasplante. En el momento del alta se comprueba un aumento de $0,31 \mathrm{mg} / \mathrm{dl}$ no significativo $(p=0,078)$. En la revisión actual, las cifras de calcio total plasmático aumentan 0,34 $\mathrm{mg} / \mathrm{dl}$ respecto a la situación basal $(p=0,034)$. Desde el momento del alta hasta la revisión actual se registra un incremento de $0,016 \mathrm{mg} / \mathrm{dl}$, no significativo.

Los niveles de calcio corregido según proteínas totales presentan un aumento significativo tras la realización del trasplante. Dicho aumento es de 0,66 mg/dl $(p<0,001)$ y de $0,37 \mathrm{mg} / \mathrm{dl}(p=0,009)$ si comparamos la situación basal con el alta hospitalaria y la revisión actual respectivamente. Sin embargo, los niveles de calcio corregido según proteínas totales se reducen en la revisión actual respecto al momento del alta tras el trasplante, con una diferencia de $-0,29 \mathrm{mg} / \mathrm{dl}(p=0,025)$. 


\section{RESULTADOS}

El grado de cumplimiento de las guías SEN queda recogido en la siguiente tabla:

\begin{tabular}{|l|l|l|l|}
\hline & Ca $<8,4^{*}$ & Ca: $8,4-9,5^{*}$ & Ca $>9,5^{*}$ \\
\hline Pretrasplante. & $11,6 \%$ (5 pac.) & $55,8 \%(24$ pac.) & $32,6 \%$ (14 pac.) \\
\hline Alta tras el trasplante & $9,3 \%$ (4 pac.) & $41,9 \%(18$ pac.) & $48,8 \%$ (21 pac.) \\
\hline Revisión Actual & $4,7 \%$ (2 pac.) & $48,8 \%(21$ pac.) & $46,6 \%$ (20 pac.) \\
\hline
\end{tabular}

Tabla 26: Distribución de los pacientes respecto al Ca según las guías SEN. *mg/dl.

\section{Fósforo plasmático.}

La evolución de los valores séricos de fósforo fue la siguiente:

\begin{tabular}{|l|l|l|l|l|}
\hline & Media & DS & MAX & MIN \\
\hline Fósforo sérico* (1) & 5 & 1,05 & 7 & 2,2 \\
\hline Fósforo sérico* (2) & 3,17 & 1,04 & 7,7 & 1,5 \\
\hline Fósforo sérico* (3) & 3,2 & 0,66 & 4,6 & 2,1 \\
\hline
\end{tabular}

Tabla 27: Evolución de las cifras de fósforo plasmático. * $\mathrm{mg} / \mathrm{dl}$. (1) Pretrasplante. (2) Alta tras el trasplante. (3) Revisión actual.

Las cifras de fósforo plasmático disminuyen significativamente tras la realización del trasplante. En el momento del alta se comprueba un descenso de 1,82 mg/dl $(p<0,001)$. En la revisión actual, las cifras de calcio total plasmático muestran un descenso de 1,8 $\mathrm{mg} / \mathrm{dl}$ respecto a la situación basal $(\mathrm{p}<0,001)$. Desde el momento del alta hasta la revisión actual no hay cambios significativos en las concentraciones de fósforo sérico. 


\section{RESULTADOS}

El grado de cumplimiento de las guías SEN queda recogido en la siguiente tabla:

\begin{tabular}{|l|l|l|l|}
\hline & $\mathbf{P}<\mathbf{2 , 5 *}$ & $\mathbf{P : ~ 2 , 5}-\mathbf{4 , 5 *}$ & $\mathbf{P}>\mathbf{4 , 5 *}$ \\
\hline Pretrasplante. & $2,3 \%$ (1 pac.) & $30,2 \%$ (13 pac.) & $67,4 \%$ (29 pac.) \\
\hline Alta tras el trasplante & $20,9 \%$ (9 pac.) & $72,1 \%$ (31 pac.) & $7 \%$ (3 pac.) \\
\hline Revisión Actual & $11,6 \%$ (5 pac.) & $86 \%$ (37 pac.) & $2,3 \%$ (1 pac.) \\
\hline
\end{tabular}

Tabla 28: Distribución de los pacientes respecto al $\mathrm{P}$ según las guías $\mathrm{SEN}$. *mg/dl.

\section{Magnesio.}

La evolución de los valores plasmáticos de magnesio fue la siguiente:

\begin{tabular}{|l|l|l|l|l|}
\hline & Media & DS & MAX & MIN \\
\hline Magnesio sérico* (2) & 1,67 & 0,32 & 2,6 & 1,2 \\
\hline Magnesio sérico* (3) & 1,84 & 0,27 & 2,6 & 1,4 \\
\hline
\end{tabular}

Tabla 29: Evolución de las cifras de magnesio plasmático. *mg/dl. (2) Alta de trasplante.

(3) Revisión actual.

Las cifras de magnesio en suero se incrementan significativamente desde el momento del alta tras el trasplante hasta la revisión actual, aumentando $0,17 \mathrm{mg} / \mathrm{dl}(p=0,03)$

\section{Hormona Paratiroidea.}

La evolución de los valores séricos de hormona paratiroidea fue la siguiente:

\begin{tabular}{|l|l|l|l|}
\hline & Mediana & Percentil 25 & Percentil 75 \\
\hline PTHi* (1) & 194,5 & 145,5 & 476,38 \\
\hline PTHi* (3) & 93,5 & 68,32 & 139,2 \\
\hline
\end{tabular}

Tabla 30: Evolución de las cifras de PTHi plasmática. *pg/ml. (1) Pretrasplante. (3) Revisión actual. 


\section{RESULTADOS}

Las cifras de PTHi sufren una fuerte corrección con el trasplante. Observamos un descenso de $251,05 \mathrm{pg} / \mathrm{ml}(\mathrm{p}<0,001)$ en las cifras de PTHi en la revisión actual respecto a la situación basal.

El grado de cumplimiento de las guías SEN en la revisión actual queda recogido en la siguiente tabla:

\begin{tabular}{|l|l|l|l|}
\hline & PTH baja & PTH en rango & PTH elevada \\
\hline Estadio 2 ERC & $5,88 \%(1)$ & $29,41 \%(5)$ & $64,7 \%(11)$ \\
\hline Estadio 3 ERC & $4,54 \%(1)$ & $18,18 \%(4)$ & $77,27 \%(17)$ \\
\hline Estadio 4 ERC & $0 \%(0)$ & $0 \%(0)$ & $100 \%(4)$ \\
\hline
\end{tabular}

Tabla 31: Grado de cumplimiento de las guías SEN respecto al metabolismo óseomineral según el estadio ERC.

\section{Producto Calcio-Fósforo.}

La evolución del producto calcio-fósforo en los pacientes de la muestra queda recogida en la siguiente tabla:

\begin{tabular}{|l|l|l|l|l|}
\hline & Media & DS & MAX & MIN \\
\hline CaxP* (1) & 46,39 & 10,46 & 71,4 & 18,26 \\
\hline CaxP* (2) & 30,46 & 10,08 & 71,61 & 12,45 \\
\hline CaxP* (3) & 30,61 & 6,03 & 43,65 & 19,95 \\
\hline
\end{tabular}

Tabla 32: Evolución del producto calcio-fósforo. ${ }^{*} \mathrm{mg}^{2} / \mathrm{dl}^{2}$. (1) Pretrasplante. (2) Alta de trasplante. (3) Revisión actual.

Las guías KDOQI definen como patológicamente elevado un producto calcio-fósforo que igual o superior a $55 \mathrm{mg}^{2} / \mathrm{dl}^{2}$. Según dichas guías, $18,6 \%$ (8 pacientes) presentaba un producto CaxP elevado en el estudio pretrasplante. Dicho porcentaje se redujo al 2,3\% (1 paciente) en el momento del alta del trasplante. En el momento actual, ninguno de los 43 pacientes estudiado presenta un producto CaxP fuera de las guías. 


\section{RESULTADOS}

Equilibrio Calcio-Fósforo-Hormona paratiroidea.

Las siguientes tablas recogen las alteraciones del eje calcio-fósforo-PTHi de forma global en cada una de las revisiones analizadas.

Tabla 33: Situación Pretrasplante

\begin{tabular}{|c|c|c|c|}
\hline Desequilibrio & Porcentaje & Desequilibrio & Porcentaje \\
\hline Sin alteraciones & $20,93 \%$ (9 p.) & $\downarrow \mathrm{Ca}+\uparrow \mathrm{PTH}$ & 2,32\% (1 p.) \\
\hline 个Ca. & 9,3\% (4 p.) & $\downarrow \mathrm{Ca}+\downarrow \mathrm{PTH}$ & $2,32 \%$ (1 p.) \\
\hline$\uparrow \mathrm{Ca}+\uparrow \mathrm{PTH}$ & $2,32 \%$ (1 p.) & $\downarrow \mathrm{Ca}+\downarrow \mathrm{P}+\downarrow \mathrm{PTH}$ & $2,32 \%$ (1 p.) \\
\hline 个Ca+ 个P & $4,65 \%$ (2 p.) & $\uparrow P$ & 6,97\% (3 p.) \\
\hline$\uparrow \mathrm{Ca}+\downarrow \mathrm{PTH}$ & $13,95 \%$ (6 p.) & $\uparrow P+\uparrow P T H$ & $13,95 \%$ (6 p.) \\
\hline$\uparrow \mathrm{Ca}+\downarrow P+\downarrow P T H$ & $2,32 \%$ (1 p.) & 个PTH & $13,95 \%$ (6 p.) \\
\hline$\downarrow \mathrm{Ca}+\uparrow P$ & 2,32\% (1 p.) & $\downarrow$ PTH & 2,32\% (1 p.) \\
\hline
\end{tabular}

$\uparrow$ Valores por encima de los recomendados en las guías SEN.

$\downarrow$ Valores por debajo de los recomendados en las guías SEN.

Tabla 34: Situación al Alta de trasplante.

\begin{tabular}{|l|l|l|l|}
\hline Desequilibrio & Porcentaje & Desequilibrio & Porcentaje \\
\hline Sin alteraciones & $30,23 \%(13$ p.) & $\downarrow C a+\downarrow P$ & $4,65 \%(2$ p.) \\
\hline$\uparrow C a$ & $39,53 \%(17$ p.) & $\uparrow P$ & $4,65 \%(2$ p.) \\
\hline$\uparrow C a+\downarrow P$ & $9,3 \%(4$ p.) & $\downarrow P$ & $6,97 \%(3$ p.) \\
\hline$\downarrow C a$ & $4,65 \%(2$ p.) & & \\
\hline
\end{tabular}

$\uparrow$ Valores por encima de los recomendados en las guías SEN.

$\downarrow$ Valores por debajo de los recomendados en las guías SEN. 


\section{RESULTADOS}

Tabla 35: Situación en la Revisión actual

ERC-2

\begin{tabular}{|c|c|c|c|}
\hline Desequilibrio & Porcentaje & Desequilibrio & Porcentaje \\
\hline Sin alteraciones & $5,88 \%$ (1 p.) & $\uparrow C a+\downarrow P+\uparrow P T H$ & $11,76 \%$ (2 p.) \\
\hline 个Ca & $23,53 \%$ (4 p.) & 个PTH & $29,41 \%$ (5 p.) \\
\hline 个Ca + 个PTH & $17,64 \%$ (3 p.) & $\downarrow P+\uparrow P T H$ & $5,88 \%$ (1 p.) \\
\hline 个Ca $+\downarrow P T H$ & $5,88 \%$ (1 p.) & & \\
\hline
\end{tabular}

$\uparrow$ Valores por encima de los recomendados en las guías SEN.

$\downarrow$ Valores por debajo de los recomendados en las guías SEN.

ERC-3

\begin{tabular}{|c|c|c|c|}
\hline Desequilibrio & Porcentaje & Desequilibrio & Porcentaje \\
\hline 个Ca & $9,09 \%$ (2 p.) & 个P + 个PTH & $4,54 \%$ (1 p.) \\
\hline 个Ca + 个PTH & $27,27 \%$ (6 p.) & $\downarrow P+\uparrow P T H$ & 4,54\% (1 p.) \\
\hline 个Ca $+\downarrow P$ & 4,54\% (1 p.) & 个PTH & $36,36 \%$ (8 p.) \\
\hline$\downarrow \mathrm{Ca}$ & $4,54 \%$ (1 p.) & $\downarrow$ PTH & $4,54 \%$ (1 p.) \\
\hline$\downarrow \mathrm{Ca}+\uparrow \mathrm{PTH}$ & $4,54 \%$ (1 p.) & & \\
\hline
\end{tabular}

$\uparrow$ Valores por encima de los recomendados en las guías SEN.

$\downarrow$ Valores por debajo de los recomendados en las guías SEN.

ERC-4

\begin{tabular}{|l|l|}
\hline Desequilibrio & Porcentaje \\
\hline 个PTH & $75 \%(3$ p.) \\
\hline 个Ca + 个PTH & $25 \%(1$ p.) \\
\hline
\end{tabular}

$\uparrow$ Valores por encima de los recomendados en las guías SEN.

$\downarrow$ Valores por debajo de los recomendados en las guías SEN. 


\section{RESULTADOS}

\section{5-OH Vitamina D.}

En la revisión actual, la mediana de concentración de 25-OH-vitamina D en plasma en los pacientes de la muestra fue de $16,1 \mathrm{ng} / \mathrm{ml}$ con un rango intercuartílico de 11,4-24,64 $\mathrm{ng} / \mathrm{ml}$.

La distribución de los pacientes según niveles de $25-\mathrm{OH}$ vitamina $\mathrm{D}$ queda recogida en la siguiente tabla:

\begin{tabular}{|l|l|l|l|l|}
\hline & $>\mathbf{3 0} \mathbf{~ n g} / \mathbf{m l}$ & $\mathbf{2 0 - 3 0} \mathbf{~ n g / m l}$ & $\mathbf{1 0 - 2 0} \mathbf{~ n g} / \mathbf{m l}$ & $<\mathbf{1 0} \mathbf{~ n g} / \mathbf{m l}$ \\
\hline 25-OH Vitamina D & $13,95 \%(6$ p.) & $18,6 \%(8$ p.) & $46,51 \%(20$ p.) & $20,93 \%(9$ p.) \\
\hline
\end{tabular}

Tabla 36: Distribución de los pacientes según la concentración plasmática de 25-OH VD.

Respecto a los valores recomendados en las guías SEN para el manejo del metabolismo óseo-mineral en pacientes trasplantados (19), un 13,95\% (6 pacientes) presentaban niveles normales de $25-\mathrm{OH}$ vitamina $\mathrm{D}$ (por encima de $30 \mathrm{ng} / \mathrm{ml}$ ). Sin embargo, el 86,04\% restante (37 pacientes) presentaban hipovitaminosis $D$ de diferente magnitud.

Fosfatasa Alcalina.

La evolución de los valores plasmáticos de fosfatasa alcalina fue la siguiente:

\begin{tabular}{|l|l|l|l|l|}
\hline & Media & DS & MAX & MIN \\
\hline Fosfatasa Alcalina* (1) & 101 & 62,42 & 346 & 39 \\
\hline Fosfatasa Alcalina* (2) & 86,88 & 52,51 & 369 & 44 \\
\hline Fosfatasa Alcalina* (3) & 76,97 & 26,05 & 194 & 36 \\
\hline
\end{tabular}

Tabla 37: Evolución de la concentración sérica de fosfatasa alcalina. *U/I. (1) Pretrasplante. (2) Alta tras el trasplante. (3) Revisión actual.

Las cifras de fosfatasa alcalina presentan un descenso de $14,11 \mathrm{U} / \mathrm{I}(\mathrm{p}=0,044)$ y $24,03 \mathrm{U} / \mathrm{I}$ $(p=0,005)$ si comparamos la situación basal con el momento del alta y la revisión actual 


\section{RESULTADOS}

respectivamente. No se observan cambios significativos en las cifras de fosfatasa alcalina desde el alta tras el trasplante hasta el momento actual.

Metabolismo ácido-base.

La evolución del metabolismo ácido base a lo largo del seguimiento fue la siguiente:

\begin{tabular}{|l|l|l|l|l|}
\hline & Media & DS & MAX & MIN \\
\hline pH (1) & 7,37 & 0,05 & 7,5 & 7,28 \\
\hline Bicarbonato (1) & 23,67 & 2,79 & 28,5 & 15,9 \\
\hline pH (2) & 7,35 & 0,04 & 7,41 & 7,17 \\
\hline Bicarbonato (1) & 21,07 & 3,14 & 25,9 & 14 \\
\hline pH (3) & 7,33 & 0,04 & 7,44 & 7,27 \\
\hline Bicarbonato (1) & 22,39 & 2,58 & 27,7 & 17,4 \\
\hline
\end{tabular}

Tabla 38: Evolución del metabolismo ácido-base. (1)Pretrasplante. (2) Alta de trasplante. (3) Revisión actual.

\section{Microalbuminuria.}

En la revisión actual, la mediana de concentración de microalbuminuria en orina en los pacientes de la muestra fue de 17,1 mg/dl con un rango intercuartílico de 3-83 mg/dl.

\section{Calcificaciones pretrasplante.}

Como parte del estudio pretrasplante se realizaron radiografías de tórax y abdomen. En la radiografía de tórax se observó la presencia de signos sugerentes de calcificación aórtica en un 4,7\% ( 2 pacientes), mientras que un 9,3\% (4 pacientes) presentaba imágenes sugestivas de osteoporosis. En la radiografía abdominal, un 7\% (3 pacientes) mostraban signos de calcificación aórtica aislada, un 2,3\% (1 paciente) presentó signos de calcificaciones a nivel iliaco aisladas, mientras que un 4,7\% (2 pacientes) presentaba calcificaciones tanto a nivel aórtico como iliaco en la radiografía abdominal. 


\section{RESULTADOS}

Tras la realización del trasplante, sólo un paciente (2,3\%) sufrió una fractura ósea.

\subsubsection{6: EVOLUCIÓN DE LA FUNCIÓN RENAL}

\section{Creatinina sérica.}

Se observó un descenso progresivo de las cifras de creatinina a lo largo del seguimiento.

\begin{tabular}{|l|l|l|l|l|}
\hline & Media & DS & MAX & MIN \\
\hline Cr sérica (1) & 8,85 & 2,67 & 15,1 & 5,2 \\
\hline Cr sérica (2) & 2,22 & 1,38 & 7,1 & 1 \\
\hline Cr. Sérica (3) & 1,57 & 0,52 & 3 & 0,7 \\
\hline
\end{tabular}

Tabla 39: Evolución de la creatinina sérica a lo largo del seguimiento. ${ }^{*} \mathrm{mg} / \mathrm{dl}$. (1)

Pretrasplante. (2) Alta de trasplante. (3) Revisión actual.

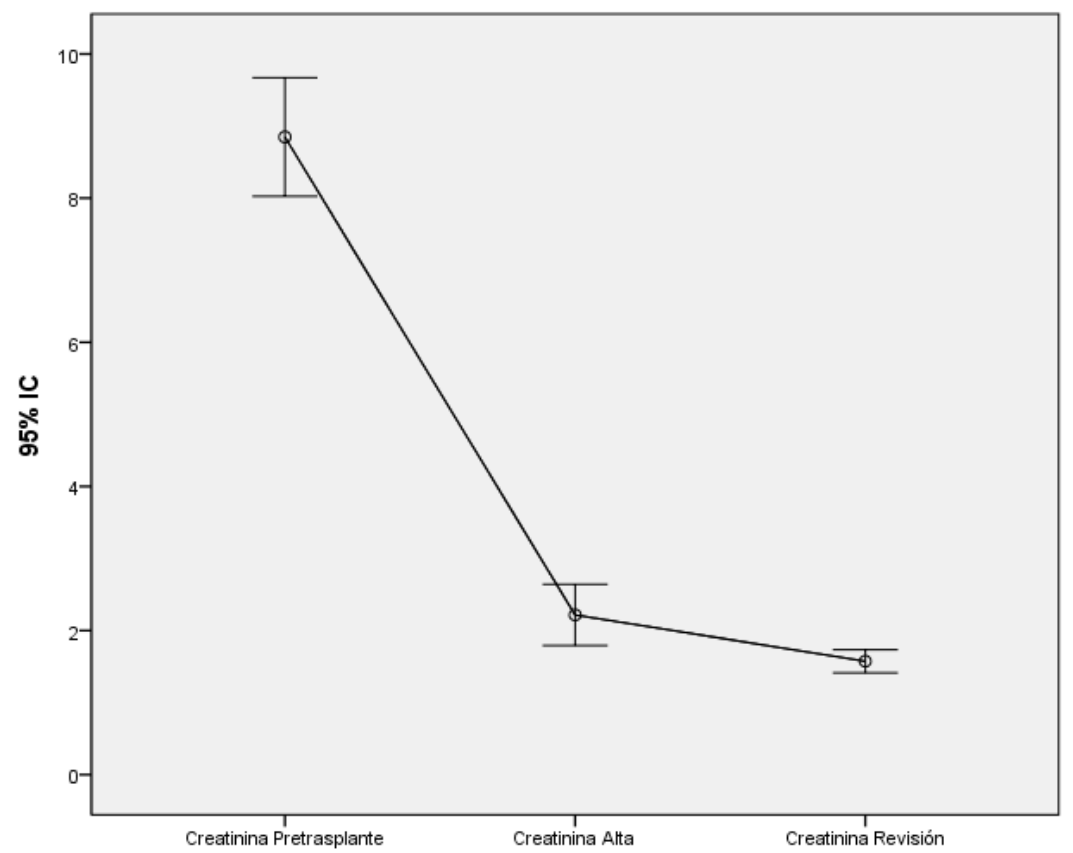

Figura 16: Evolución de las cifras de creatinina sérica.

Los niveles de creatinina plasmática presentan un descenso significativo tras la realización del trasplante. Dicha disminución es de 6,63 $\mathrm{mg} / \mathrm{dl}(p<0,001)$ entre la 


\section{RESULTADOS}

situación basal y el alta tras el trasplante. Asimismo, se observa una disminución de 7,27 $\mathrm{mg} / \mathrm{dl}(\mathrm{p}<0,001)$ si comparamos la situación basal con la revisión actual. Finalmente se comprueba también un descenso de las cifras de creatinina sérica entre el momento del alta y la revisión actual de 0,64 mg/dl $(p=0,002)$.

A lo largo del seguimiento se observa una disminución progresiva de la desviación estándar relativa a los niveles plasmáticos de creatinina.
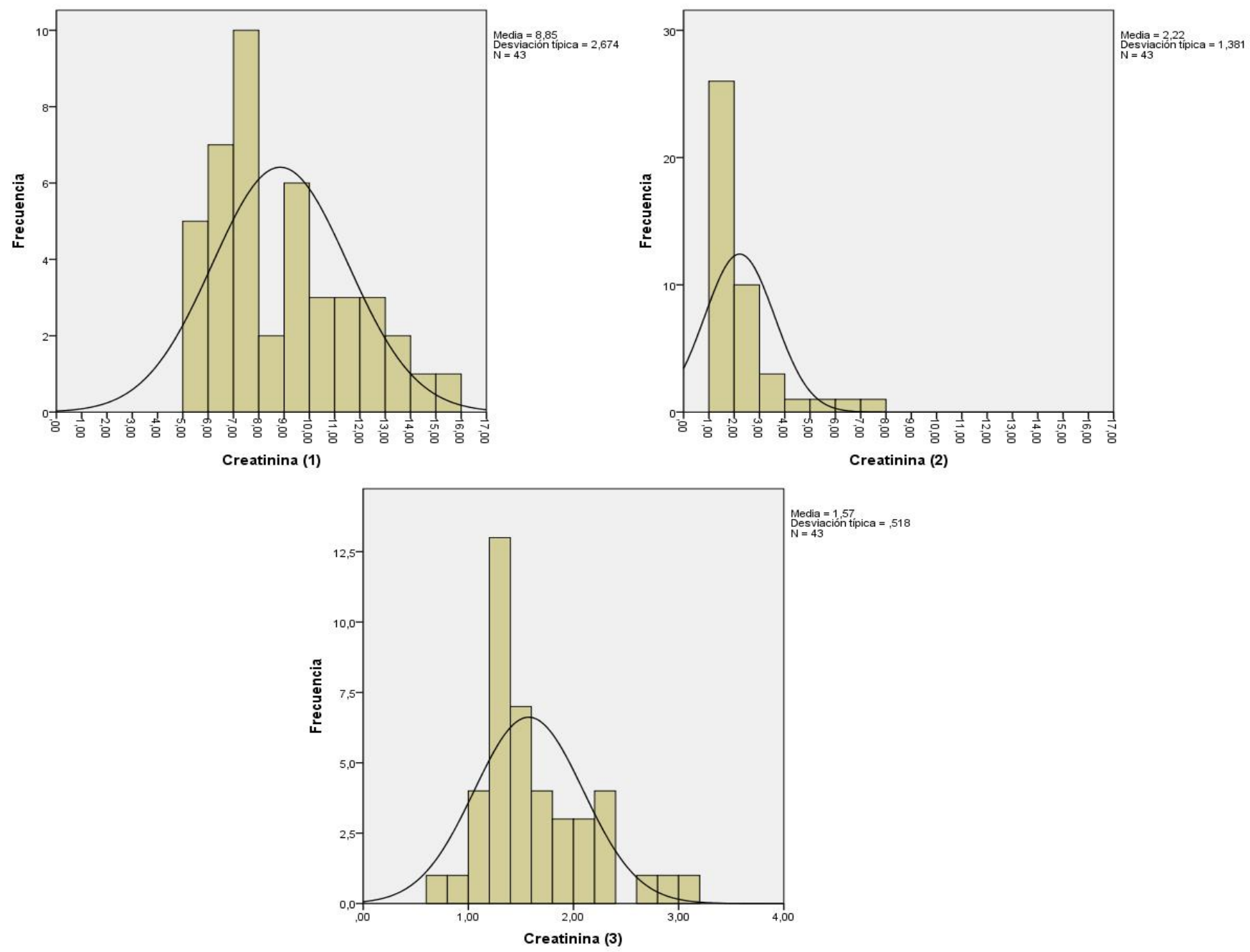

Figura 17: Histograma de distribución de la creatinina sérica a lo largo del seguimiento.

(1) Pretrasplante. (2) Alta tras el trasplante. (3) Revisión actual. 


\section{RESULTADOS}

\section{Aclaramiento de Cr estimado mediante la ecuación Cockroft Gault.}

Se comprueba un incremento en el aclaramiento de creatinina calculado mediante la fórmula de Cockroft Gault en estos enfermos en la revisión actual, tanto frente a la situación basal pretrasplante como respecto a los valores presentes en el momento del alta post-trasplante.

\begin{tabular}{|l|l|l|l|l|}
\hline & Media* & DS* & MAX* & MIN* \\
\hline C.Gault (1) & 10,33 & 3,67 & 22,17 & 5,25 \\
\hline C.Gault (2) & 44,57 & 15,26 & 76,37 & 10,78 \\
\hline C.Gault (3) & 59,96 & 24,44 & 138,43 & 21,87 \\
\hline
\end{tabular}

Tabla 40: Evolución del aclaramiento de creatinina estimado mediante la fórmula de Cockroft-Gault. ${ }^{*} \mathrm{ml} / \mathrm{min} 1,73 \mathrm{~m}^{2}$. (1) Pretrasplante. (2) Alta de trasplante. (3) Revisión actual.

El aclaramiento de creatinina estimado mediante la ecuación de Cockroft Gault presenta un aumento significativo tras la realización del trasplante. Dicho aumento es de 34,23 $\mathrm{ml} / \mathrm{min} 1,73 \mathrm{~m}^{2}(\mathrm{p}<0,001)$ entre la situación basal y el alta tras el trasplante. Asimismo, se observa un incremento de 49,63 $\mathrm{ml} / \mathrm{min} 1,73 \mathrm{~m}^{2}(p<0,001)$ si comparamos la situación basal con la revisión actual.

Finalmente se comprueba también un ascenso del aclaramiento calculado mediante Cockroft Gault entre el momento del alta y la revisión actual de 15,39 ml/min $(p<0,001)$.

A lo largo del seguimiento se observa un aumento progresivo de la desviación estándar relativa al aclaramiento de creatinina calculado mediante Cockroft Gault. 


\section{RESULTADOS}

Tasa de filtrado glomerular estimada por la ecuación MDRD-4.

Se observa un incremento en la tasa estimada de filtrado glomerular mediante la ecuación MDRD-4 en estos enfermos en la revisión actual, tanto frente a la situación basal pretrasplante como respecto a los valores presentes en el momento del alta hospitalaria tras la cirugía.

\begin{tabular}{|l|l|l|l|l|}
\hline & Media* & DS* & MAX* & MIN* \\
\hline MDRD4 (1) & 6,95 & 2,21 & 12,2 & 3,5 \\
\hline MDRD4 (2) & 40,35 & 17 & 73 & 7,34 \\
\hline MDRD4 (3) & 51,29 & 18,07 & 94,14 & 20,74 \\
\hline
\end{tabular}

Tabla 41: Tasa estimada de filtrado glomerular calculada mediante la fórmula de MDRD.

${ }^{*} \mathrm{ml} / \mathrm{min} 1,73 \mathrm{~m}^{2}$. (1) Pretrasplante. (2) Alta de trasplante. (3) Revisión actual.

La tasa estimada de filtrado glomerular calculada mediante la ecuación MDRD-4 presenta un aumento significativo tras la realización del trasplante. Dicho aumento es de $33,4 \mathrm{ml} / \mathrm{min} 1,73 \mathrm{~m}^{2}(\mathrm{p}<0,001)$ entre la situación basal y el alta tras el trasplante. Asimismo, se observa un incremento de $44,33 \mathrm{ml} / \mathrm{min} 1,73 \mathrm{~m}^{2}(\mathrm{p}<0,001)$ si comparamos la situación basal con la revisión actual.

Se comprueba también un ascenso del aclaramiento calculado mediante MDRD-4 entre el momento del alta y la revisión actual de 10,93 $\mathrm{ml} / \mathrm{min}(\mathrm{p}<0,001)$.

A lo largo del seguimiento se observa un aumento progresivo de la desviación estándar relativa a la tasa estimada de filtrado glomerular calculada mediante la ecuación MDRD4. 


\section{RESULTADOS}

Tasa de filtrado glomerular estimada por la ecuación CKD-EPI.

Se objetiva un aumento en la tasa estimada de filtrado glomerular mediante la ecuación CKD-EPI en estos enfermos en la revisión actual, tanto frente a la situación pretrasplante como respecto a las cifras existentes en el momento del alta hospitalaria tras la cirugía.

\begin{tabular}{|l|l|l|l|l|}
\hline & Media* & DS* & MAX* & MIN* \\
\hline CKD-EPI (1) & 6,42 & 2,2 & 11,92 & 3,26 \\
\hline CKD-EPI (2) & 40,53 & 17,73 & 73,61 & 7,04 \\
\hline CKD-EPI (3) & 51,7 & 19,73 & 99,24 & 20,54 \\
\hline
\end{tabular}

Tabla 42: Tasa estimada de filtrado glomerular calculada mediante la fórmula de CKDEPI. *ml/min 1,73m². (1) Pretrasplante. (2) Alta de trasplante. (3) Revisión actual.

La tasa estimada de filtrado glomerular calculada mediante la ecuación CKD-EPI presenta un aumento significativo tras la realización del trasplante. Dicho aumento es de $34,4 \mathrm{ml} / \mathrm{min} 1,73 \mathrm{~m}^{2}(\mathrm{p}<0,001)$ entre la situación basal y el alta tras el trasplante. Asimismo, se observa un incremento de $45,27 \mathrm{ml} / \mathrm{min} 1,73 \mathrm{~m}^{2}(\mathrm{p}<0,001)$ si comparamos la situación basal con la revisión actual.

Se comprueba también un ascenso del aclaramiento calculado mediante CKD-EPI entre el momento del alta y la revisión actual de 11,16 $\mathrm{ml} / \mathrm{min}(\mathrm{p}<0,001)$.

A lo largo del seguimiento se observa un aumento progresivo de la desviación estándar relativa a la tasa estimada de filtrado glomerular calculada mediante la ecuación CKDEPI. 


\section{RESULTADOS}

Tasa de filtrado glomerular estimada por la ecuación Mayo Quadratic.

Se comprueba un incremento en la tasa estimada de filtrado glomerular mediante la ecuación Mayo Quadratic en estos enfermos en la revisión actual, tanto frente a la situación basal pretrasplante como respecto a los niveles observados en el momento del alta hospitalaria tras la cirugía.

\begin{tabular}{|l|l|l|l|l|}
\hline & Media* & DS* & MAX* & MIN* \\
\hline Mayo Qua. (1) & 9,13 & 1,95 & 14,38 & 6,39 \\
\hline Mayo Qua. (2) & 47,15 & 23,57 & 93,49 & 8,86 \\
\hline Mayo Qua. (3) & 61,85 & 25,65 & 113,29 & 19,42 \\
\hline
\end{tabular}

Tabla 43: Tasa estimada de filtrado glomerular calculada mediante la fórmula Mayo

Quadratic. ${ }^{*} \mathrm{ml} / \mathrm{min} 1,73 \mathrm{~m}^{2}$. (1) Pretrasplante. (2) Alta tras el trasplante. (3) Revisión actual.

La tasa estimada de filtrado glomerular calculada mediante la ecuación Mayo Quadratic presenta un aumento significativo tras la realización del trasplante. Dicho aumento es de $38,01 \mathrm{ml} / \mathrm{min} 1,73 \mathrm{~m}^{2}(p<0,001)$ entre la situación basal y el alta tras el trasplante. Asimismo, se observa un incremento de $52,71 \mathrm{ml} / \mathrm{min} 1,73 \mathrm{~m}^{2}(p<0,001)$ si comparamos la situación basal con la revisión actual.

Se comprueba también un ascenso del aclaramiento calculado mediante Mayo Quadratic entre el momento del alta y la revisión actual de 14,69 ml/min $(p<0,001)$.

A lo largo del seguimiento se observa un aumento progresivo de la desviación estándar relativa a la tasa estimada de filtrado glomerular calculada mediante la ecuación Mayo Quadratic. 


\section{RESULTADOS}

\section{Estabilidad de la función renal.}

La estabilidad de la función renal de los injertos renales, determinada por las cifras de creatinina sérica, entre el alta de trasplante y la revisión actual fue la siguiente:

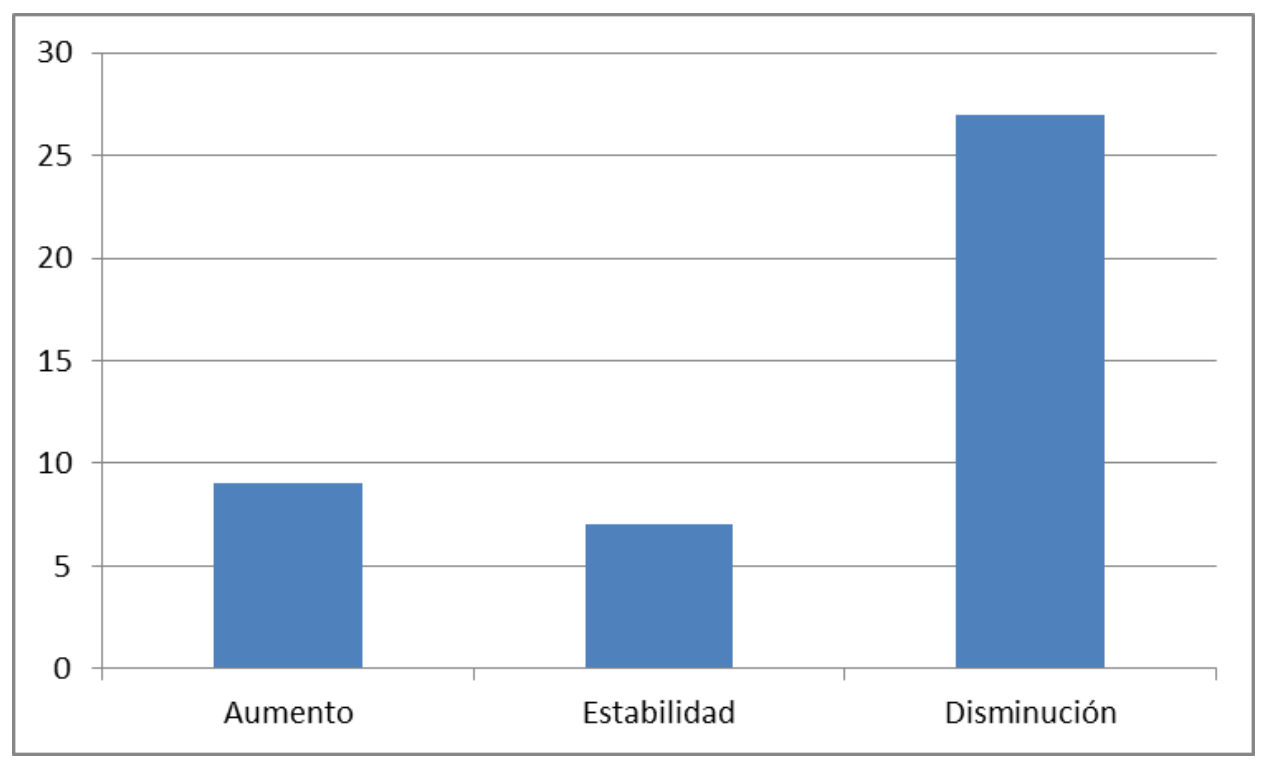

Figura 18: Estabilidad de la función renal (aumento, estabilidad o descenso en las cifras de creatinina sérica).

Un 62,79\% (27 pacientes) presentaron una mejoría de su función renal, representada por un descenso de la creatinina plasmática en la revisión actual respecto al alta tras el trasplante. La media del descenso observado fue de 1,11 $\pm 0,42 \mathrm{mg} / \mathrm{dl}$, mediana de 0,42 $\mathrm{mg} / \mathrm{dl}$ y rango intercuartílico $0,3 \mathrm{a} 1,2 \mathrm{mg} / \mathrm{dl}$.

Un 20,93\% (9 pacientes) sufrieron un deterioro de la función del injerto caracterizado por un aumento de la creatinina sérica. La media del aumento observado fue de 0,28 \pm $0,2 \mathrm{mg} / \mathrm{dl}$, mediana de $0,2 \mathrm{mg} / \mathrm{dl}$ y rango intercuartílico de 0,1 a $0,45 \mathrm{mg} / \mathrm{dl}$.

Un 16,27\% (7 pacientes) mostraron una función renal similar tras el trasplante a lo largo del seguimiento. 


\section{RESULTADOS}

\section{Estadios de enfermedad renal según las guías KDOQI}

Estratificamos a los pacientes siguiendo las directrices de las guías KDOQI (Kidney Disease Outcomes Quality Initiative of the National Kidney Foundation) (246), de acuerdo con la tasa de filtrado glomerular estimada por la ecuación MDRD-4, tanto a los 14 días tras el trasplante como en la revisión actual.

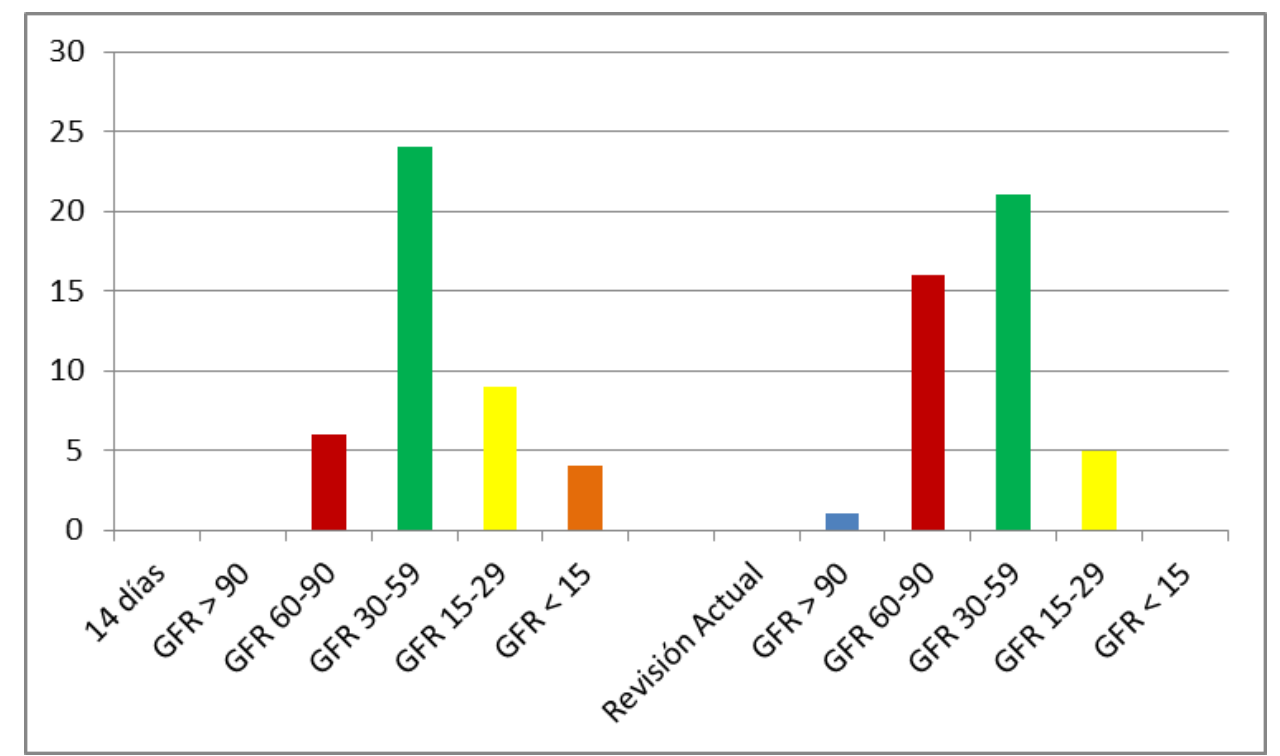

Figura 19: Estadios de la enfermedad renal según las guías KDOQI mediante MDRD-4 al alta de trasplante y en la revisión actual.

A los 14 días de la realización del trasplante un 14\% (6 pacientes) presentaban un estadio 2 de ERC, un 55,8\% (24 pacientes) un estadio 3, un 20,9\% (9 pacientes) un estadio 4, 9,3\% (4 pacientes) en estadio 5 .

En el momento actual un 2,3\% (un paciente) se encuentra en el estadio 1 de ERC, un $37,2 \%$ (16 pacientes) en el estadio 2 , un $48,8 \%$ ( 21 pacientes) en el estadio 3 , un $11,6 \%$ (5 pacientes) en el estadio 4 y ningún paciente presenta un estadio 5 de ERC.

Según la ecuación CKD-EPI, en el momento actual un 2,3\% (un paciente) presenta un estadio 1 de ERC, un 32,6\% (14 pacientes) en el estadio 2, un 53,5\% (23 pacientes) en el estadio 3 , un $11,6 \%$ (5 pacientes) en el estadio 4 y ningún paciente presenta un estadio 5 de ERC. 


\section{RESULTADOS}

Según la ecuación CG-BSA, en el momento actual un 11,6\% (5 pacientes) presentan un estadio 1 de ERC, un 30,2\% (13 pacientes) en el estadio 2, un 51,2\% (22 pacientes) en el estadio 3, un 7\% (3 pacientes) en el estadio 4 y ningún paciente presenta un estadio 5 de ERC.

Finalmente, según la ecuación Mayo Quadratic, en el momento actual un 16,3\% (7 pacientes) presentan un estadio 1 de ERC, un 34,9\% (15 pacientes) en el estadio 2, un $37,2 \%$ (16 pacientes) en el estadio 3 , un $11,6 \%$ (5 pacientes) en el estadio 4 y ningún paciente presenta un estadio 5 de ERC.
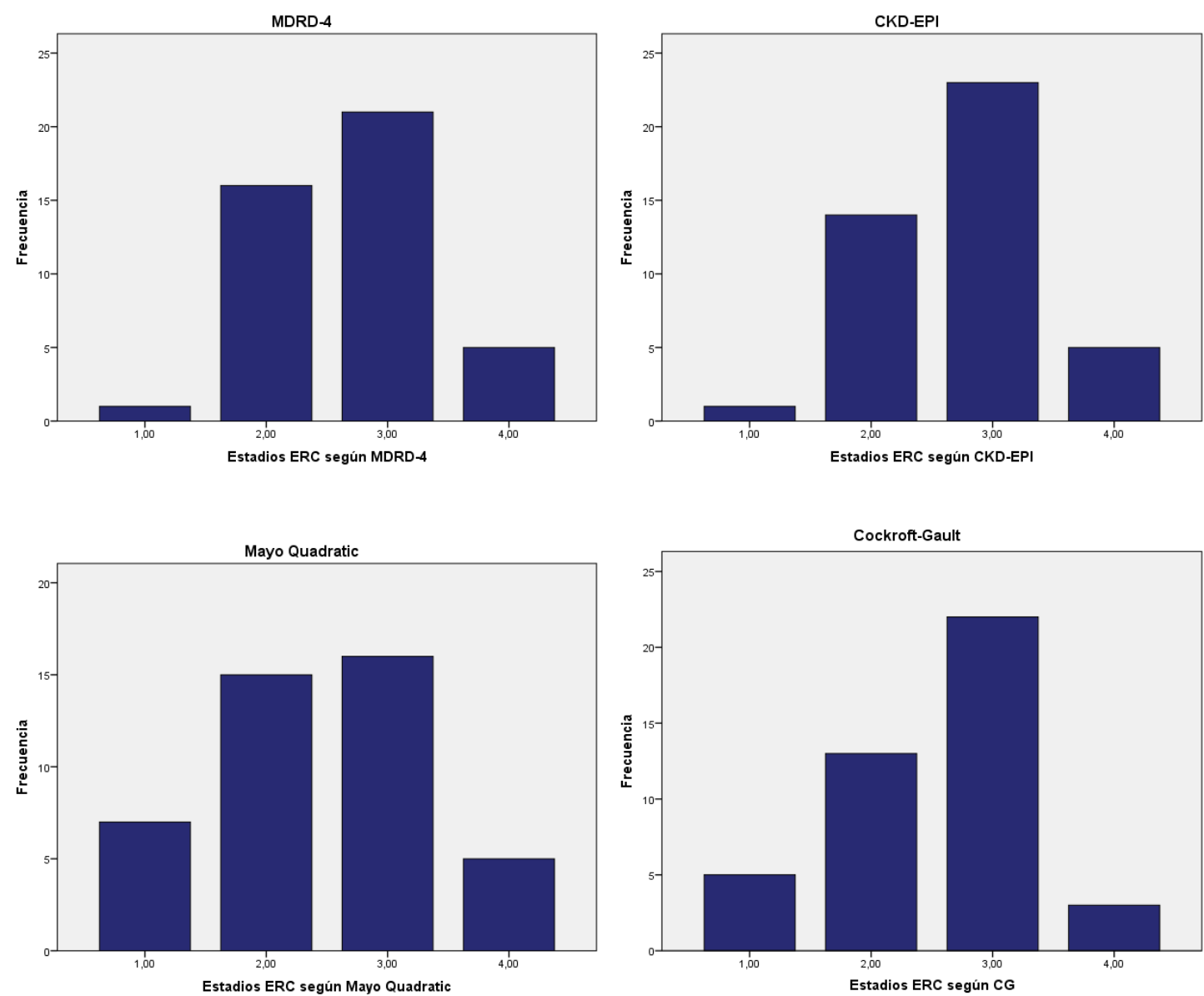

Figura 20: Distribución de los enfermos en los diferentes estadios ERC según las ecuaciones MDRD, CKD-EPI, Cockroft-Gault y MQ. 


\section{RESULTADOS}

\subsubsection{7: INMUNOSUPRESIÓN}

\section{Tratamiento inmunosupresor.}

Inducción de la inmunosupresión

Como tratamiento de inducción se empleó anticuerpos monoclonales anti CD25 (basiliximab) en la totalidad de los pacientes incluídos en el presente estudio.

\section{Corticoides}

Todos los pacientes recibieron corticoides durante el ingreso hospitalario posttrasplante. El porcentaje de pacientes que continuaron con corticoides como parte de su pauta habitual de tratamiento inmunosupresor y la dosis media recibida quedan recogidas en la siguientes tablas:

\begin{tabular}{|l|l|l|l|l|l|l|}
\hline & 10 año & 20 año & 30 año & 40 año & 50 año & 60 año \\
\hline Prednisona & $93 \%(40 p)$ & $41 \%(15 p)$ & $32 \%(8 p)$ & $35 \%(7 p)$ & $37,5 \%(6 p)$ & $25 \%(3 p)$ \\
\hline
\end{tabular}

Tabla 44: Porcentaje de individuos que recibían prednisona. 


\section{RESULTADOS}

\begin{tabular}{|l|l|l|l|l|}
\hline & Media & DS & MAX & MIN \\
\hline 1 año & 5,49 & 1,76 & 6,64 & 4,01 \\
\hline 20 año & 3,61 & 2,3 & 5 & 2,5 \\
\hline 3o año & 3,37 & 1,36 & 5 & 2,5 \\
\hline 40 año & 3,39 & 1,56 & 5 & 2,5 \\
\hline 5o año & 3,19 & 1,63 & 5,1 & 2,18 \\
\hline 60 año & 3,61 & 1,27 & 5 & 2,5 \\
\hline DT & 4,58 & 1,23 & 7,5 & 2,08 \\
\hline DA & 8,96 & 7,07 & 31,66 & 2,08 \\
\hline
\end{tabular}

Tabla 45: Dosis media (mg) de prednisona recibida. DT: Media aritmética de las dosis medias anuales recibidas mientras continuaba el tratamiento. DA: Producto de la DT por los años que recibió el tratamiento.

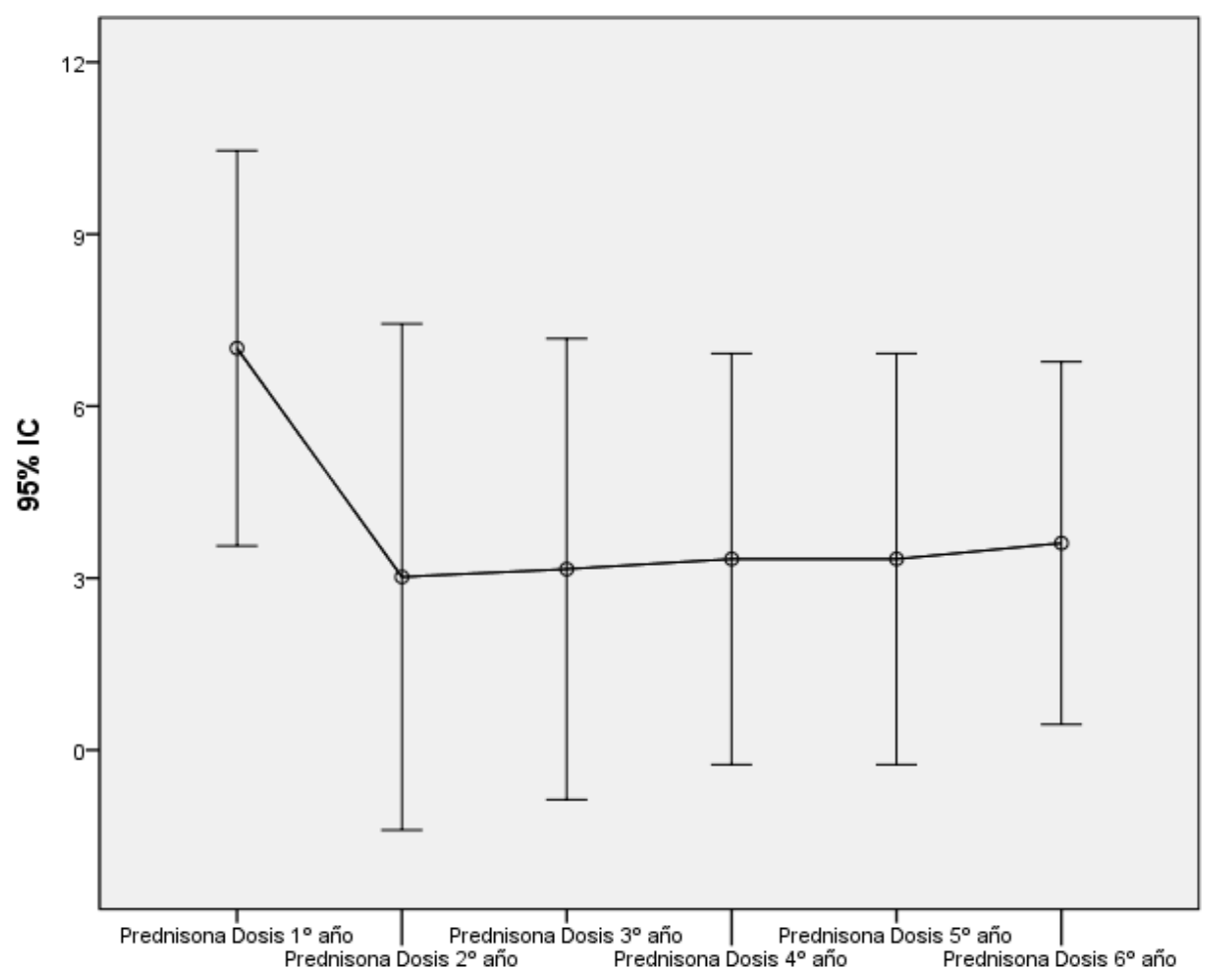

Figura 21: Evolución de la dosificación de prednisona a lo largo del seguimiento. 


\section{RESULTADOS}

\section{Tacrólimus}

Todos los pacientes recibieron tacrólimus durante el ingreso hospitalario posttrasplante. El porcentaje de pacientes que continuaron con corticoides como parte de su pauta habitual de tratamiento inmunosupresor y la dosis media recibida quedan recogidas en la siguientes tablas:

\begin{tabular}{|l|l|l|l|l|l|l|}
\hline & 10 año & 20 año & 3o año & 40 año & 5o año & 6o año \\
\hline Tacrólimus & $100 \%(43 p)$ & $91,6 \%(33 p)$ & $92 \%(23 p)$ & $85 \%(17 p)$ & $81 \%(13 p)$ & $66 \%(8 p)$ \\
\hline
\end{tabular}

Tabla 46: Porcentaje de individuos que recibían tacrólimus.

\begin{tabular}{|l|l|l|l|l|}
\hline & Media & DS & MAX & MIN \\
\hline 1 año & 6,79 & 3,02 & 14,13 & 2,42 \\
\hline 2o año & 4,27 & 2,18 & 9,5 & 1,5 \\
\hline 3o año & 4,41 & 3,2 & 15 & 1,16 \\
\hline 4 año & 3,64 & 2,42 & 10 & 1 \\
\hline 5o año & 3,88 & 2,73 & 10 & 1 \\
\hline 6o año & 3,8 & 3,02 & 10,9 & 1,14 \\
\hline DT & 5,5 & 2,71 & 13,3 & 1,51 \\
\hline DA & 16,02 & 12,09 & 57,7 & 3,79 \\
\hline
\end{tabular}

Tabla 47: Dosis media (mg) de tacrólimus recibida. DT: Media aritmética de las dosis medias anuales recibidas mientras continuaba el tratamiento. DA: Producto de la DT por los años durante los que recibió tratamiento. 


\section{RESULTADOS}

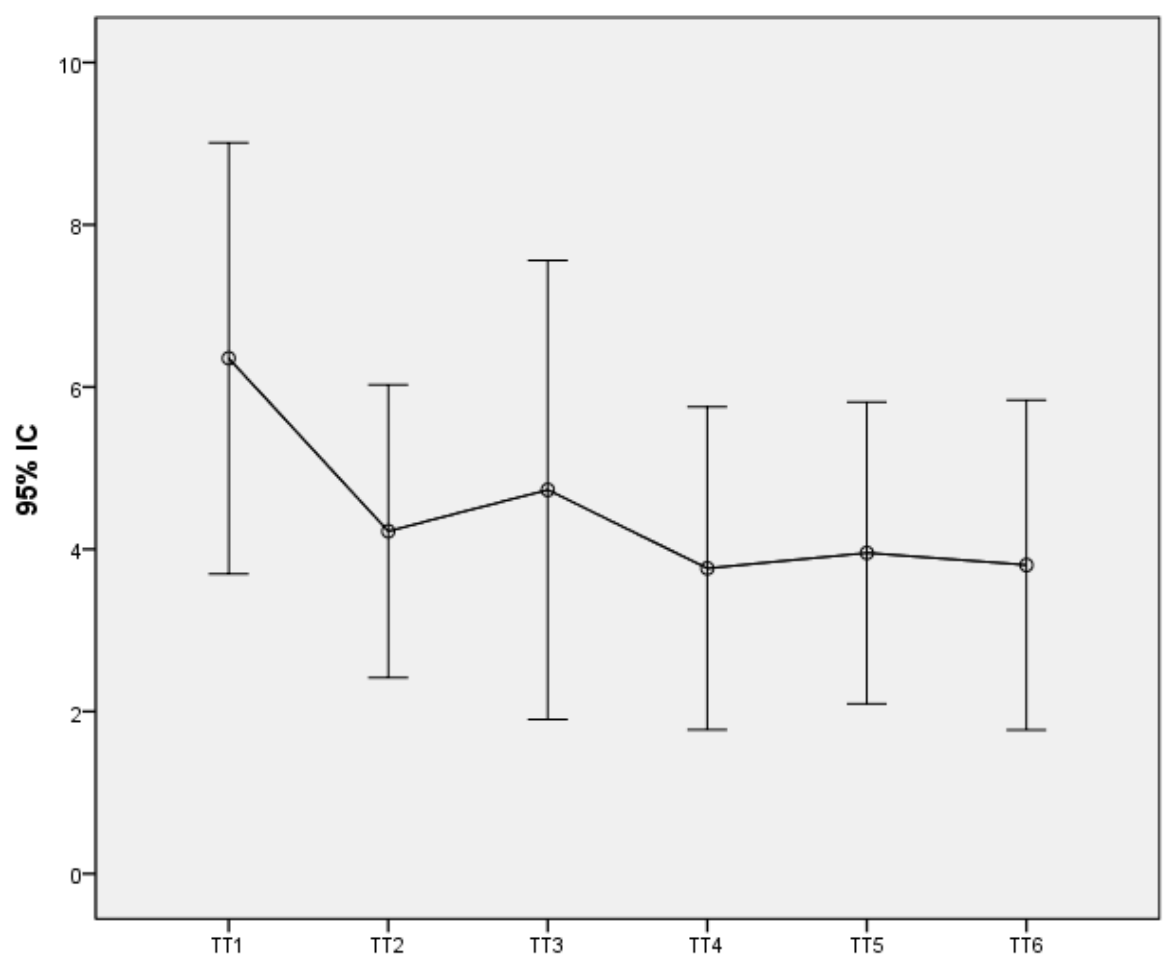

Figura 22: Evolución de la dosificación de tacrólimus a lo largo del seguimiento. TT: Dosis diaria total de tacrólimus.

\section{Sirólimus}

Ningún paciente recibió sirólimus durante el ingreso hospitalario post-trasplante. El porcentaje de pacientes que recibieron sirólimus como parte de su pauta habitual de tratamiento inmunosupresor y la dosis media recibida quedan recogidas en la siguientes tablas:

\begin{tabular}{|l|l|l|l|l|l|l|}
\hline & 10 año & 20 año & 30 año & 40 año & 5o año & 60 año \\
\hline Sirólimus & $6,9 \%(3 p)$ & $11 \%(4 p)$ & $16 \%(4 p)$ & $20 \%(4 p)$ & $25 \%(4 p)$ & $25 \%(3 p)$ \\
\hline
\end{tabular}

Tabla 48: Porcentaje de individuos que recibían sirólimus. 


\section{RESULTADOS}

\begin{tabular}{|l|l|l|l|l|}
\hline & Media & DS & MAX & MIN \\
\hline 1 año & 1,94 & 0,79 & 2,41 & 1,03 \\
\hline 20 año & 1,75 & 0,79 & 2,75 & 1 \\
\hline 3o año & 1,5 & 0,57 & 2 & 1 \\
\hline 4 año & 1,5 & 0,57 & 2 & 1 \\
\hline 50 año & 1,43 & 0,51 & 2 & 1 \\
\hline 60 año & 1,21 & 0,25 & 1,5 & 1 \\
\hline DT & 1,51 & 0,65 & 2,18 & 0,9 \\
\hline DA & 8,55 & 3,32 & 11,9 & 5,39 \\
\hline
\end{tabular}

Tabla 49: Dosis media (mg) de sirólimus recibida. DT: Media aritmética de las dosis medias anuales recibidas mientras continuaba el tratamiento. DA: Producto de la DT por los años durante los que recibió tratamiento.

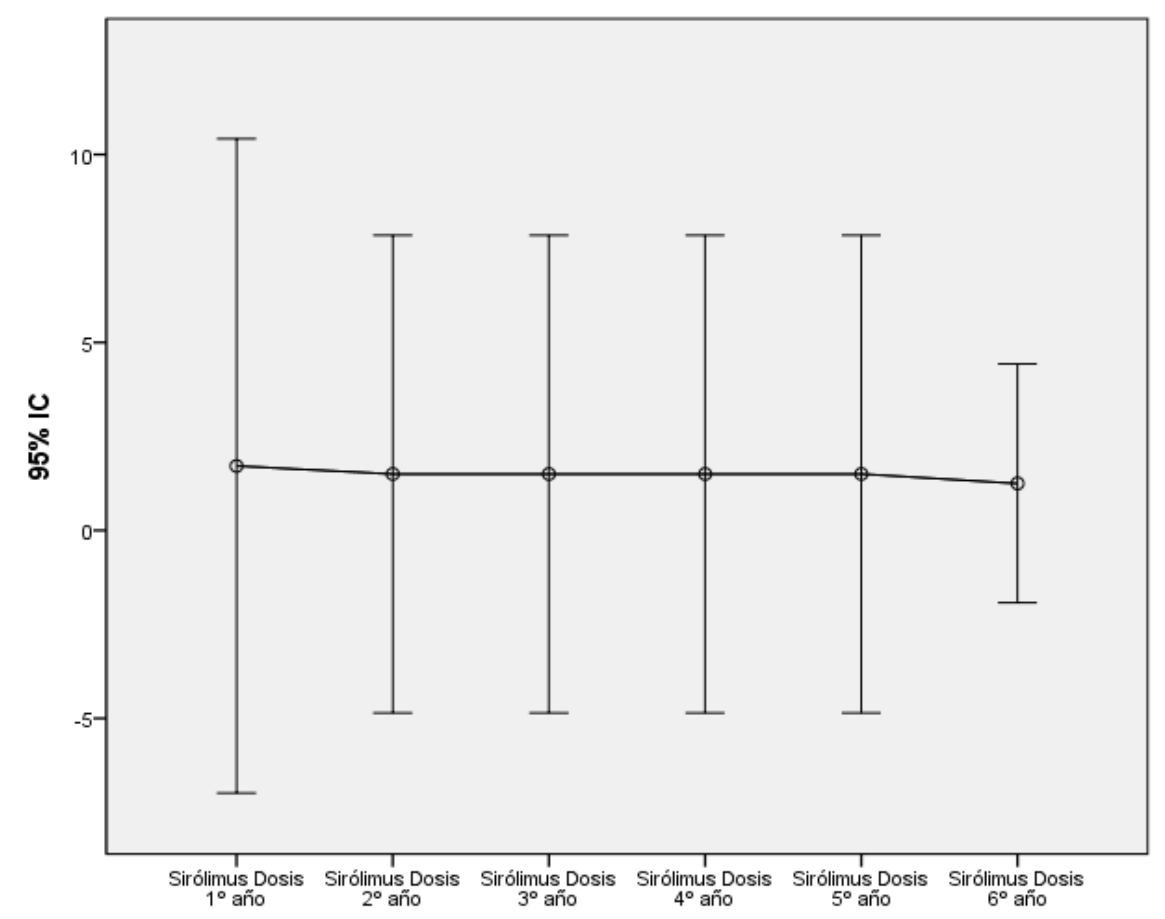

Figura 23: Evolución de la dosificación de sirólimus a lo largo del seguimiento. 


\section{RESULTADOS}

\section{Everólimus}

Ningún paciente recibió everólimus durante el ingreso hospitalario post-trasplante. El porcentaje de pacientes que continuaron con everólimus como parte de su pauta habiitual de tratamiento inmunosupresor y la dosis media recibida quedan recogidas en la siguientes tablas:

\begin{tabular}{|l|l|l|l|l|l|l|}
\hline & 10 año & 20 año & 3o año & 40 año & 50 año & 60 año \\
\hline Everólimus & $2,3 \%(1 p)$ & $2,7 \%(1 p)$ & $4 \%(1 p)$ & $10 \%(2 p)$ & $6,25 \%(1 p)$ & $8,3 \%(1 p)$ \\
\hline
\end{tabular}

Tabla 50: Porcentaje de individuos que recibían everólimus.

\begin{tabular}{|l|l|l|l|l|}
\hline & Media & DS & MAX & MIN \\
\hline 1 año & 2 & 0 & 2 & 2 \\
\hline 2o año & 2 & 0 & 2 & 2 \\
\hline 3 año & 3 & 0 & 3 & 3 \\
\hline 4 año & 2,34 & 2,02 & 3,78 & 0,91 \\
\hline 5o año & 1,5 & 0 & 1,5 & 1,5 \\
\hline 6o año & 3,03 & 0 & 3,03 & 3,03 \\
\hline DT & 1,91 & 0,96 & 2,83 & 0,91 \\
\hline DA & 5,4 & 5,34 & 11,31 & 0,91 \\
\hline
\end{tabular}

Tabla 51: Dosis media (mg) de everólimus recibida. DT: Media aritmética de las dosis medias anuales recibidas mientras continuaba el tratamiento. DA: Producto de la DT por los años durante los que recibió tratamiento.

\section{Ácido micofenólico.}

Un 79\% (34 pacientes) recibieron ácido micofenólico durante el ingreso hospitalario post-trasplante. El porcentaje de pacientes que continuaron con ácido micofenólico como parte de su pauta habitual de tratamiento inmunosupresor y la dosis media recibida quedan recogidas en la siguientes tablas: 


\section{RESULTADOS}

\begin{tabular}{|l|l|l|l|l|l|l|}
\hline & 10 año & 20 año & 3o año & 40 año & 5\% año & 6o año \\
\hline $\begin{array}{l}\text { Ac. } \\
\text { Micof. }\end{array}$ & $79 \%(34 p)$ & $72,2 \%(26 p)$ & $64 \%(16 p)$ & $60 \%(12 p)$ & $68,7 \%(11 p)$ & $67 \%(8 p)$ \\
\hline
\end{tabular}

Tabla 52: Porcentaje de individuos que recibían ácido micofenólico.

\begin{tabular}{|l|l|l|l|l|}
\hline & Media & DS & MAX & MIN \\
\hline 1 año & 1007,42 & 330,11 & 2000 & 333 \\
\hline 2o año & 992,54 & 374,65 & 2000 & 250 \\
\hline 3o año & 942,4 & 260,36 & 1583,3 & 312,5 \\
\hline 4o año & 930,5 & 177,07 & 1166,6 & 500 \\
\hline 5o año & 935,6 & 288,29 & 1500 & 291,67 \\
\hline 6o año & 843,75 & 229,03 & 1000 & 500 \\
\hline DT & 928,8 & 250,35 & 1650 & 333 \\
\hline DA & 2924,44 & 2071,48 & 8249,9 & 333 \\
\hline
\end{tabular}

Tabla 53: Dosis media (mg) de ácido micofenólico recibida. DT: Media aritmética de las dosis medias anuales recibidas mientras continuaba el tratamiento. DA: Producto de la DT por los años durante los que recibió tratamiento.

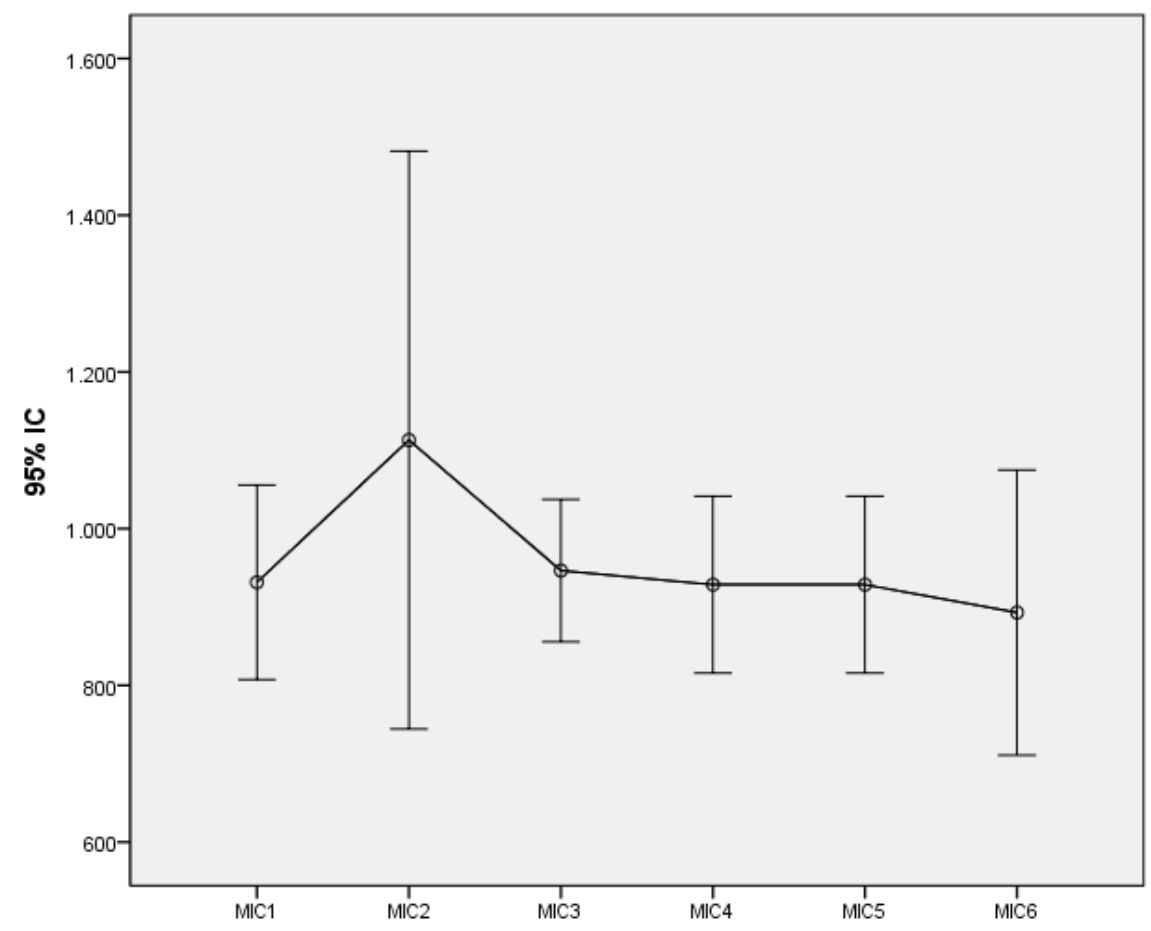

Figura 24: Evolución de la dosificación de ácido micofenólico a lo largo del seguimiento. 


\section{RESULTADOS}

Pautas de inmunosupresión.

\section{Tacrólimus, prednisona y ácido micofenólico.}

La combinación de un inhibidor de la calcineurina (tacrólimus) con corticoides y ácido micofenólico fue la pauta inmunosupresora más utilizada durante el primer año tras el trasplante. El número de pacientes que continuaron con esta pauta a lo largo del seguimiento queda recogido en la siguiente tabla:

\begin{tabular}{|l|l|l|l|l|l|l|}
\hline & 10 año & 20 año & 30 año & 40 año & 5o año & 60 año \\
\hline T+P+AM & $67 \%(29 p)$ & $28 \%(10 p)$ & $16 \%(4 p)$ & $15 \%(3 p)$ & $12,5 \%(2 p)$ & $8,3 \%(1 p)$ \\
\hline
\end{tabular}

Tabla 54: Porcentaje de pacientes que recibieron una combinación de tacrólimus, prednisona y ácido micofenólico a lo largo del seguimiento.

\section{Tacrólimus y ácido micofenólico.}

La combinación de un inhibidor de la calcineurina (tacrólimus) con ácido micofenólico fue la pauta inmunosupresora más empleada a partir del segundo año tras el trasplante. El número de pacientes que continuaron con esta pauta a lo largo del seguimiento queda recogido en la siguiente tabla:

\begin{tabular}{|l|l|l|l|l|l|l|}
\hline & 10 año & 20 año & 3o año & 40 año & 5o año & 60 año \\
\hline T+AM & $6,97 \%(3 p)$ & $36 \%(13 p)$ & $40 \%(10 p)$ & $30 \%(6 p)$ & $37,5 \%(6 p)$ & $41,6 \%(5 p)$ \\
\hline
\end{tabular}

Tabla 55: Porcentaje de pacientes que recibieron una combinación de tacrólimus y ácido micofenólico a lo largo del seguimiento. 


\section{RESULTADOS}

\section{Tacrólimus y prednisona.}

La combinación de un inhibidor de la calcineurina (tacrólimus) con corticoides fue la segunda pauta inmunosupresora más utilizada durante el primer año tras el trasplante. El número de pacientes que continuaron con esta pauta a lo largo del seguimiento queda recogido en la siguiente tabla:

\begin{tabular}{|l|l|l|l|l|l|l|}
\hline & 10 año & 20 año & 30 año & 40 año & 5o año & 60 año \\
\hline $\mathbf{T + P}$ & $16,3 \%(7 p)$ & $8,3 \%(3 p)$ & $8 \%(2 p)$ & $10 \%(2 p)$ & $12,5 \%(2 p)$ & $8,3 \%(1 p)$ \\
\hline
\end{tabular}

Tabla 56: Porcentaje de pacientes que recibieron una combinación de tacrólimus y prednisona a lo largo del seguimiento.

\section{Tacrólimus en monoterapia.}

La monoterapia con un inhibidor de la calcineurina (tacrólimus) no fue utilizada en ningún caso durante el primer año tras el trasplante. El número de pacientes que continuaron con esta pauta a lo largo del seguimiento queda recogido en la siguiente tabla:

\begin{tabular}{|l|l|l|l|l|l|l|}
\hline & 10 año & 20 año & 3o año & 40 año & 5o año & 60 año \\
\hline $\mathbf{T}$ & $0 \%$ & $13,8 \%(5 p)$ & $16 \%(4 p)$ & $15 \%(3 p)$ & $6,25 \%(1 p)$ & $8,3 \%(1 p)$ \\
\hline
\end{tabular}

Tabla 57: Porcentaje de pacientes que recibieron monoterapia con tacrólimus a lo largo del seguimiento. 


\section{RESULTADOS}

\section{Otras pautas.}

La utilización de sirólimus durante el primer año post-trasplante se limitó al 6,97\% (3 pacientes). No se utilizó everólimus durante el primer año tras el trasplante. El número de pacientes que continuaron con las siguientes pautas a lo largo del seguimiento queda recogido en la siguiente tabla:

\begin{tabular}{|c|c|c|c|c|c|c|}
\hline & 10 año & 20 año & 3o año & 40 año & 50 año & 60 año \\
\hline $\mathrm{T}+\mathrm{S}+\mathrm{P}+\mathrm{AM}$ & 2,32\%(1p.) & $0 \%$ & $0 \%$ & $0 \%$ & $0 \%$ & $0 \%$ \\
\hline$T+S+P$ & $4,65 \%(2 p)$. & $0 \%$ & $4 \%$ (1p.) & $5 \%$ (1p.) & 6,25\%(1p.) & $\begin{array}{l}8,3 \% \\
\text { (1p.) }\end{array}$ \\
\hline$T+S$ & $0 \%$ & $\begin{array}{l}5,5 \% \\
\text { (2p.) }\end{array}$ & $4 \%$ (1p.) & $5 \%$ (1p.) & 6,25\%(1p.) & $\begin{array}{l}\text { 8,3\% } \\
\text { (1p.) }\end{array}$ \\
\hline$T+P+E+A M$ & 2,32\%(1p.) & $0 \%$ & $0 \%$ & $0 \%$ & $0 \%$ & $0 \%$ \\
\hline$T+E+A M$ & $0 \%$ & $0 \%$ & $4 \%$ (1p.) & $0 \%$ & $0 \%$ & $0 \%$ \\
\hline $\mathrm{T}+\mathrm{E}$ & $0 \%$ & $0 \%$ & $0 \%$ & 5\% (1p.) & $0 \%$ & $0 \%$ \\
\hline S+P+AM & $0 \%$ & $\begin{array}{l}5,5 \% \\
\text { (2p.) }\end{array}$ & $4 \%$ (1p.) & 5\% (1p.) & 6,25\%(1p.) & $0 \%$ \\
\hline S+AM & $0 \%$ & $0 \%$ & $4 \%$ (1p.) & $5 \%$ (1p.) & 6,25\%(1p.) & $\begin{array}{l}8,3 \% \\
\text { (1p.) }\end{array}$ \\
\hline$E+A M$ & $0 \%$ & $\begin{array}{l}2,7 \% \\
\text { (1p.) }\end{array}$ & $0 \%$ & $5 \%$ (1p.) & 6,25\%(1p.) & $\begin{array}{l}8,3 \% \\
\text { (1p.) }\end{array}$ \\
\hline
\end{tabular}

Tabla 58: Porcentaje de pacientes que recibieron cada pauta a lo largo del seguimiento.

T: Tacrólimus. S: Sirólimus. E: Everólimus. P: Prednisona. AM: Ácido micofenólico. 


\section{RESULTADOS}

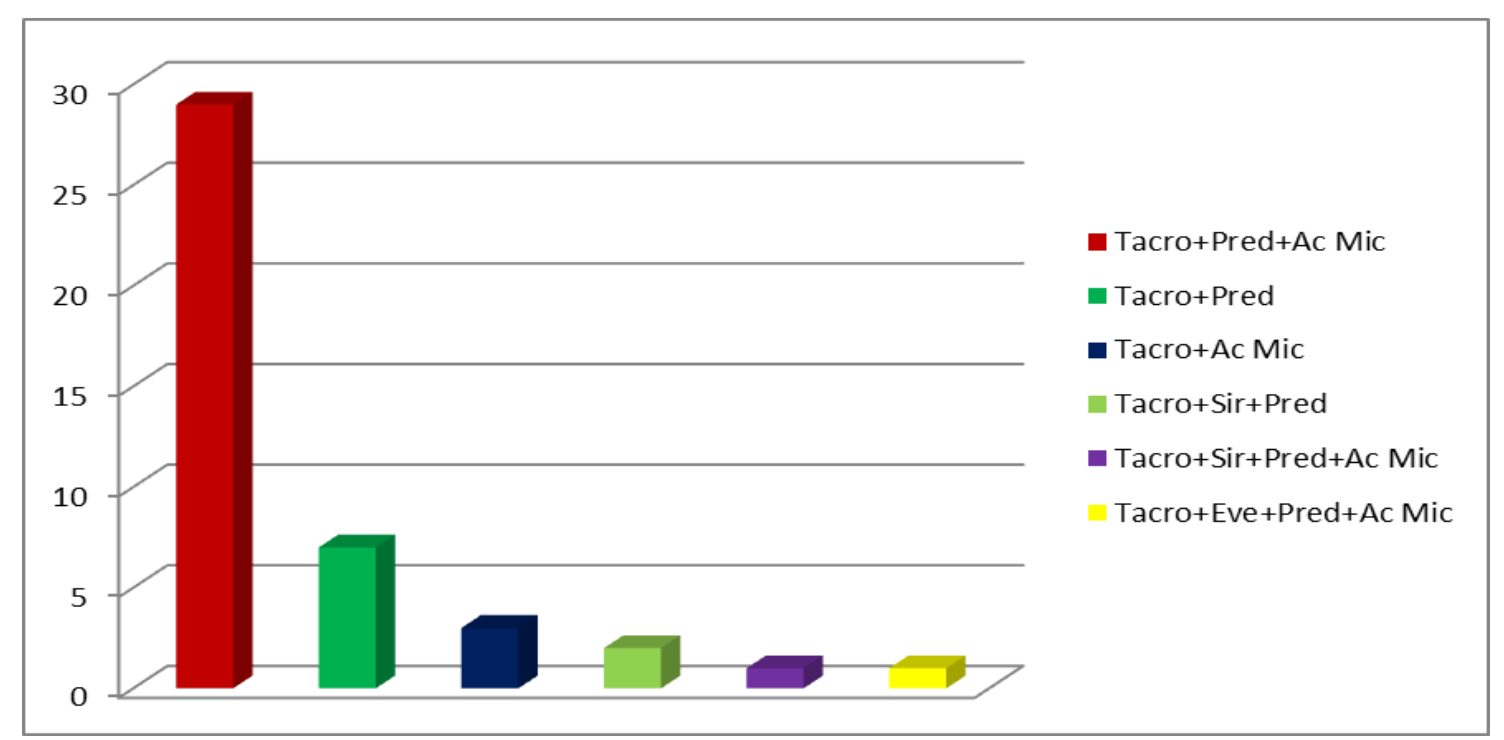

Figura 25: Tratamiento inmunosupresor al alta.

\section{2: EVALUACIÓN DE LA ACTIVIDAD FÍSICA}

Todos los pacientes que participaron en el estudio cumplimentaron un cuestionario abreviado IPAQ sobre actividad física. La media de METs semanales consumidos por los pacientes fue de 7640,23 $\pm 3977,9$ (máx: 21840, mín: 1080).

No hubo diferencias respecto al grado de actividad física entre hombres y mujeres. De igual manera, no se encontraron diferencias significativas en el nivel de METs semanales consumidos entre pacientes cuya edad era menor de 60 años respecto a aquellos de edad $\geq 60$ años, ni tampoco entre pacientes con una tasa estimada de filtrado glomerular calculada mediante la ecuación MDRD-4 superior a $60 \mathrm{ml} / \mathrm{min}$ frente a aquellos con MDRD-4 $<60 \mathrm{ml} / \mathrm{min}$. 


\section{3: EVALUACIÓN DEL GRADO DE CALCIFICACIÓN VASCULAR Y ÓSEA}

\subsection{1: CUANTIFICACIÓN DEL CALCIO EN ARTERIAS CORONARIAS}

El índice de calcificación de las arterias coronarias de los 43 receptores de trasplante renal se situó entre 0 y 36503 HU (Tabla 59).

El valor del score de Agatston y del percentil de calcio coronario obtenidos tras la realización del estudio de la muestra se recoge en la siguiente tabla:

\begin{tabular}{|l|l|l|l|l|l|l|}
\hline & Media & Mediana & MAX & MIN & R. Interq. & DS \\
\hline S.Agatston & 1532,7 & 64 & 36503 & 0 & $4-1009$ & 5655,5 \\
\hline Percentil & 66,27 & 80 & 90 & 10 & $40-90$ & 30,7 \\
\hline
\end{tabular}

Tabla 59: Estadísticos descriptivos del score de Agatston y del percentil de calcio coronario observados en la muestra.

La distribución de los pacientes estudiados según la puntuación del score de Agatston y siguiendo la subdivision de Rumberger (285) fue la siguiente:

\begin{tabular}{|l|l|l|l|}
\hline S. Agatston & Estrato & Recuento & Porcentaje \\
\hline$<\mathbf{1 0}$ & Normal/Leve & 11 & $25,6 \%$ \\
\hline $\mathbf{1 1 - 1 0 0}$ & Moderado & 13 & $30,2 \%$ \\
\hline $\mathbf{1 0 1 - 4 0 0}$ & Grave & 4 & $9,3 \%$ \\
\hline$>\mathbf{4 0 0}$ & Muy grave & 15 & $34,9 \%$ \\
\hline
\end{tabular}

Tabla 60: Distribución de los pacientes según el grado de CAC. 


\section{RESULTADOS}

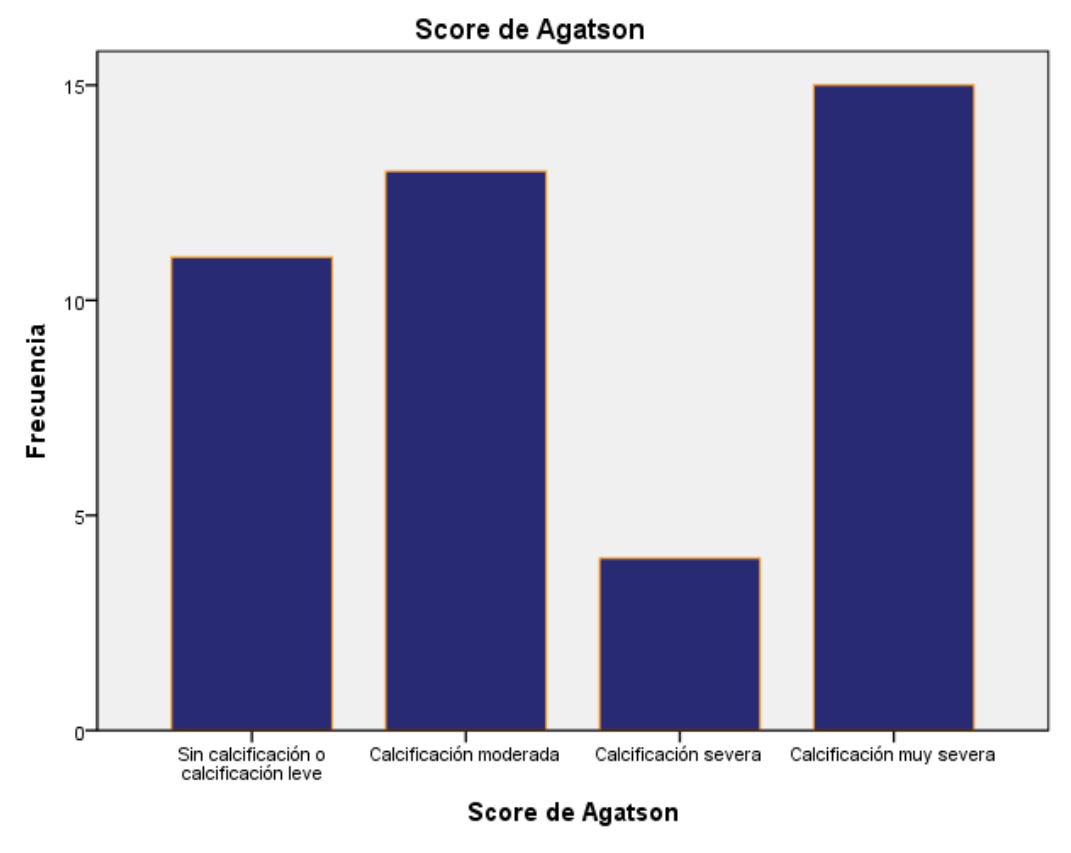

Figura 26: Distribución de los pacientes respecto al score de Agatston.

Para analizar la asociación observada entre las diferentes variables categóricas y cuantitativas y el score de Agatston se crearon dos conjuntos de pacientes según esta última variable, agrupándolos según presentasen un score de Agatston $<100$ HU o $\geq 100$ HU. Un 55,8\% (24 pacientes) de los pacientes presentaron un score de Agatston $<100$ HU.

En el análisis de las variables categóricas se ha empleado el test Chi-cuadrado de asociación entre variables medidas en escala nominal, realizando una aproximación al cálculo del tamaño del efecto.

Los resultados se resumen en la tabla 28. Se han observado las siguientes asociaciones:

- Sexo $(P<.05)$. Existe un porcentaje mayor de hombres en el grupo de pacientes con un score de Agatston igual o superior a $100 \mathrm{HU}$, con un efecto leve (.119).

- Modalidad de diálisis $(P<.05)$. Los pacientes que recibieron hemodiálisis presentan con un score de Agatston más elevado, con un efecto leve (.101).

- Diabetes $(P<.05)$. El grupo de pacientes con un score de Agatston $\geq 100 \mathrm{HU}$ presentan un mayor porcentaje de diabetes, con un efecto moderado bajo (.159) 


\section{RESULTADOS}

No se hallaron diferencias significativas en el porcentaje de pacientes con hipertensión arterial, dislipemia, sobrepeso o consumo de tabaco entre los pacientes con score de Agatston $<100 \mathrm{HU}$ y el resto de pacientes. Tampoco se hallaron diferencias relativas a la enfermedad renal de base.

Tabla 61: Test Chi-cuadrado. Asociación de Score de Agatston con variables categóricas -1-

\begin{tabular}{|c|c|c|c|c|c|c|c|}
\hline \multirow[b]{2}{*}{ Variable } & \multirow[b]{2}{*}{ Categoría } & \multicolumn{2}{|c|}{ Agatston \% (n) } & \multirow{2}{*}{$\mathrm{Chi}^{2}$} & \multirow{2}{*}{$\mathrm{Gl}$} & \multirow{2}{*}{ P } & \multirow{2}{*}{$\begin{array}{l}\text { Tam. } \\
\text { Efecto } \\
\text { aprox. }\end{array}$} \\
\hline & & Inferior & Igual o superior & & & & \\
\hline \multirow[t]{2}{*}{ Sexo } & Mujer & $41.7 \%(10)$ & $10.5 \%(2)$ & 5.11 & 1 & $.024 *$ & .119 \\
\hline & Hombre & $58.3 \%(14)$ & $89.5 \%(17)$ & & & & \\
\hline \multirow[t]{6}{*}{ Enf. renal de base } & $\begin{array}{l}\text { Neopatía túbulo- } \\
\text { intersticial }\end{array}$ & $25.0 \%(6)$ & $21.1 \%(4)$ & & & & \\
\hline & Glomerulonefritis & $20.8 \%(5)$ & $21.1 \%(4)$ & & & & \\
\hline & Poliquistosis renal & $25.0 \%(6)$ & $15.8 \%(3)$ & 5.56 & 5 & $.351^{\mathrm{NS}}$ & .094 \\
\hline & Nefropatía diabética & -- & $15.8 \%(3)$ & & & & \\
\hline & Nefroangioesclerosis & $8.3 \%(2)$ & $5.3 \%(1)$ & & & & \\
\hline & No filiada & $20.8 \%(5)$ & $21.1 \%(4)$ & & & & \\
\hline \multirow[t]{2}{*}{ Mod. Diálisis } & $\mathrm{HD}$ & $54.2 \%(13)$ & $84.2 \%(16)$ & 4.36 & 1 & $.037 *$ & .101 \\
\hline & DP & $45.8 \%(11)$ & $15.8 \%(3)$ & & & & \\
\hline \multirow[t]{3}{*}{ Acceso Vascular } & FAVI & $45.8 \%(11)$ & $73.7 \%(14)$ & & & & \\
\hline & Catéter peritoneal & $45.8 \%(11)$ & $15.8 \%(3)$ & 4.64 & 2 & $.098^{N S}$ & .093 \\
\hline & Catéter vascular & $8.3 \%(2)$ & $10.5 \%(2)$ & & & & \\
\hline HTA & $\mathrm{Si}$ & $79.2 \%(19)$ & $100 \%(19)$ & 2.68 & 1 & .102 NS & .094 \\
\hline Diabetes & $\mathrm{Si}$ & $4.2 \%(1)$ & $31.6 \%(6)$ & 4.10 & 1 & $.045 *$ & .159 \\
\hline Dislipemia & $\mathrm{Si}$ & $33.3 \%(8)$ & $57.9 \%(11)$ & 1.69 & 1 & .193 NS & .057 \\
\hline Card. Isquémica & $\mathrm{Si}$ & -- & $10.5 \%(2)$ & -- & -- & -- & -- \\
\hline Tabaquismo & $\mathrm{Si}$ & $16.7 \%(4)$ & $26.3 \%(5)$ & 0.16 & 1 & $.693^{\text {NS }}$ & .014 \\
\hline \multirow[t]{3}{*}{ Ecocard. Pre-Tx } & HVI leve & $70.0 \%$ (7) & $50.0 \%(7)$ & & & & \\
\hline & HVI moderada & $20.0 \%(2)$ & $50.0 \%(7)$ & 3.66 & 2 & $.161^{\mathrm{NS}}$ & .118 \\
\hline & HVI grave & $10.0 \%(1)$ & -- & & & & \\
\hline
\end{tabular}

Los pacientes que presentan un score de Agatston < $100 \mathrm{HU}$ son más jóvenes que presentan un score de Agatston mayor, tanto en el momento del trasplante como en la revisión, con un tamaño elevado del efecto (.316 y .292) (tabla 62). 


\section{RESULTADOS}

Se aprecia además que los pacientes con un score de Agatston $\geq 100$ HU presentan un tiempo medio en diálisis mayor que aquellos que presentan un score $<100 \mathrm{HU}$ (25.83 vs $54.95)$ de forma significativa $(P<.01)$. En este caso se tiene en cuenta el test de MannWhitney debido a la contrastada asimetría de la variable.

Tabla 62: Test de diferencia entre dos medias. Asociación de Score de Agatsotn con variables categóricas -2

\begin{tabular}{|c|c|c|c|c|c|c|c|c|c|c|c|}
\hline \multirow{2}{*}{ Variable / } & \multirow{2}{*}{ Agatston } & \multirow{2}{*}{$\mathrm{N}$} & \multirow{2}{*}{ Media } & \multirow{2}{*}{ D.E. } & \multicolumn{3}{|c|}{ T Student } & \multirow{2}{*}{$\begin{array}{c}\text { IC } 95 \% \text { para la } \\
\text { diferenc. absoluta }\end{array}$} & \multirow{2}{*}{$\begin{array}{l}\text { Efecto } \\
\mathrm{R}^{2}\end{array}$} & \multicolumn{2}{|c|}{ Test Mann-Whitney } \\
\hline & & & & & $\mathrm{T}$ & $\mathrm{gl}$ & $P$ & & & /Z/ & $P$ \\
\hline \multirow{3}{*}{$\begin{array}{l}\text { Edad al } \\
\text { trasplante }\end{array}$} & Inferior & 24 & 43.79 & 10.38 & & & & & & & \\
\hline & & & & & -4.35 & 41 & $.000 * *$ & $7.33-20.04$ & .316 & 3.73 & $.000 * *$ \\
\hline & Igual/Superior & 19 & 57.47 & 10.07 & & & & & & & \\
\hline \multirow{3}{*}{$\begin{array}{l}\text { Edad en la } \\
\text { revisión }\end{array}$} & Inferior & 24 & 48.04 & 10.89 & & & & & & & \\
\hline & & & & & -4.11 & 41 & $.000 * *$ & $6.73-19.71$ & .292 & 3.49 & $.000 * *$ \\
\hline & Igual/Superior & 19 & 61.26 & 9.90 & & & & & & & \\
\hline \multirow[t]{3}{*}{ Meses de diálisis } & Inferior & 24 & 25.83 & 30.43 & & & & & & & \\
\hline & & & & & -1.78 & 41 & $.083^{\mathrm{NS}}$ & N.S. & .072 & 3.11 & $.002 * *$ \\
\hline & Igual/Superior & 19 & 54.95 & 72.73 & & & & & & & \\
\hline \multirow{3}{*}{$\begin{array}{l}\text { Meses desde el } \\
\text { trasplante }\end{array}$} & Inferior & 24 & 49.79 & 29.12 & & & & & & & \\
\hline & & & & & 0.35 & 41 & $.724^{N S}$ & N.S. & .003 & 0.34 & .732 NS \\
\hline & Igual/Superior & 19 & 46.68 & 27.71 & & & & & & & \\
\hline \multirow{2}{*}{$\begin{array}{l}\text { Fracción de } \\
\text { eyección }\end{array}$} & Inferior & 18 & 67.25 & 5.98 & & & & & & & \\
\hline & Igual/Superior & 17 & 64.71 & 6.85 & 1.17 & 33 & $.250 \mathrm{NS}$ & N.S. & .040 & 1.09 & $.275 \mathrm{NS}$ \\
\hline
\end{tabular}

N.S. $=$ NO significativo $(P>.05) \quad * *=$ Altamente significativo al $1 \%(P<.01)$

Respecto a las variables cuantitativas, los resultados de las pruebas paramétricas y sus alternativas no-paramétricas son muy similares, por lo que la falta de normalidad de algunas de las variables no tiene consecuencias. En el primer grupo de variables contrastadas (tabla 63) solamente se han encontrado diferencias estadísticamente significativas (al menos $\mathrm{P}<.05$ ) indicativas de asociación, en tres de ellas:

- Volumen de diuresis ( $\mathrm{P}<.001)$. La media de los pacientes con score de Agatston < $100 \mathrm{HU}$ tienen una media más elevada (1429.17 vs 501.05) de manera que el tamaño del efecto (.222) es casi elevado.

- Hemoglobina $(\mathrm{P}<.05)$. Los pacientes con score de Agatston < $100 \mathrm{HU}$ tienen una media más alta (13.19 vs 11.93) siendo el tamaño del efecto moderado (.147).

- Hematocrito $(P<.05)$. Los pacientes con un score de Agatston < 100 HU presentan una media más alta (39.84 vs 35.92), con un efecto moderado (.147). 


\section{RESULTADOS}

En el resto de variables, las diferencias no alcanzan significación estadística ( $P>.05)$

Tabla 63: Test de diferencia entre 2 medias. Asociación de Score de Agatston con diversas variables antropométricas y de la analítica previa al trasplante -1-

\begin{tabular}{|c|c|c|c|c|c|c|c|c|c|c|c|}
\hline \multirow{2}{*}{ Variable } & \multirow{2}{*}{ Agatston } & \multirow{2}{*}{$\mathrm{N}$} & \multirow{2}{*}{ Media } & \multirow{2}{*}{ D.E. } & \multicolumn{3}{|c|}{ T Student } & \multirow{2}{*}{$\begin{array}{l}\text { IC 95\% para la } \\
\text { diferenc. absoluta }\end{array}$} & \multirow{2}{*}{$\begin{array}{c}\text { Efecto } \\
\mathrm{R}^{2}\end{array}$} & \multicolumn{2}{|c|}{ Test Mann-Whitney } \\
\hline & & & & & T & $\mathrm{Gl}$ & $\mathrm{P}$ & & & /Z/ & $P$ \\
\hline \multirow[t]{3}{*}{ Altura } & Inferior & 24 & 168.88 & 9.56 & & & & & & & \\
\hline & & & & & 0.53 & 41 & .601 Ns & N.S. & .007 & 0.53 & $.565^{\mathrm{NS}}$ \\
\hline & Igual/Superior & 19 & 167.39 & 8.57 & & & & & & & \\
\hline \multirow[t]{3}{*}{ Peso } & Inferior & 24 & 71.43 & 12.09 & & & & & & & \\
\hline & & & & & 0.34 & 41 & .737 Ns & N.S. & .003 & 0.33 & $.741 \mathrm{Ns}$ \\
\hline & Igual/Superior & 19 & 70.20 & 11.52 & & & & & & & \\
\hline \multirow[t]{3}{*}{ IMC } & Inferior & 24 & 24.97 & 3.12 & & & & & & & \\
\hline & & & & & 0.03 & 41 & .972 NS & N.S. & .000 & 0.12 & .903 Ns \\
\hline & Igual/Superior & 19 & 24.94 & 2.84 & & & & & & & \\
\hline \multirow[t]{3}{*}{ TAS } & Inferior & 24 & 140.75 & 22.61 & & & & & & & \\
\hline & & & & & -1.58 & 41 & .121 Ns & N.S. & .058 & 1.63 & $.103^{\mathrm{NS}}$ \\
\hline & Igual/Superior & 19 & 152.95 & 27.95 & & & & & & & \\
\hline \multirow[t]{3}{*}{ TAD } & Inferior & 24 & 83.13 & 12.75 & & & & & & & \\
\hline & & & & & -0.59 & 41 & $.558^{\mathrm{NS}}$ & N.S. & .008 & 0.48 & $.632 \mathrm{NS}$ \\
\hline & Igual/Superior & 19 & 85.47 & 13.24 & & & & & & & \\
\hline \multirow[t]{3}{*}{ Diuresis } & Inferior & 24 & 1429.17 & 1007.57 & & & & & & & \\
\hline & & & & & 3.42 & 41 & $.001 * *$ & $379.73-1476.50$ & .222 & 3.60 & $.000 * *$ \\
\hline & Igual/Superior & 19 & 501.05 & 695.60 & & & & & & & \\
\hline \multirow[t]{3}{*}{ Hemoglobina } & Inferior & 24 & 13.19 & 1.58 & & & & & & & \\
\hline & & & & & 2.66 & 41 & $.011^{*}$ & $0.30-2.22$ & .147 & 2.30 & $.021 *$ \\
\hline & Igual/Superior & 19 & 11.93 & 1.50 & & & & & & & \\
\hline \multirow[t]{3}{*}{ Hematocrito } & Inferior & 24 & 39.84 & 5.11 & & & & & & & \\
\hline & & & & & 2.66 & 41 & $.011 *$ & $0.95-6.90$ & 147 & 2.41 & $.016^{*}$ \\
\hline & Igual/Superior & 19 & 35.92 & 4.37 & & & & & & & \\
\hline \multirow[t]{3}{*}{ Leucocitos } & Inferior & 24 & 6675.82 & 1717.31 & & & & & & & \\
\hline & & & & & -0.15 & 41 & .879 NS & N.S. & .001 & 0.23 & $.816^{\mathrm{NS}}$ \\
\hline & Igual/Superior & 19 & 6753.68 & 1562.93 & & & & & & & \\
\hline \multirow[t]{2}{*}{ Plaquetas } & Inferior & 24 & 185666.67 & 62416.32 & & & & & & & \\
\hline & Igual/Superior & 19 & 192473.68 & 78227.14 & -0.32 & 41 & .752 NS & N.S. & .002 & 0.44 & $.660^{\mathrm{NS}}$ \\
\hline
\end{tabular}

N.S. $=$ NO significativo $(\mathrm{P}>.05) \quad *=$ Significativo al $5 \%(\mathrm{P}<.05) \quad * *=$ Altamente significativo al $1 \%(\mathrm{P}<.01)$

En el siguiente grupo de variables (tabla 64) correspondientes a la analítica previa al trasplante, solamente aparece significación en una de las variables.

- Colesterol total $(P<.01)$. Los pacientes del grupo con score de Agatston $<100 \mathrm{HU}$ presentan una media de colesterol total más alta que el resto (188.50 vs 144.11), con un tamaño del efecto moderado-alto (.185). 


\section{RESULTADOS}

En el resto de variables no se observa asociación significativa ( $P>.05)$.

Tabla 64: Test de diferencia entre dos medias. Asociación de Score de Agatston con diversas variables de la analítica previa al trasplante -2-

\begin{tabular}{|c|c|c|c|c|c|c|c|c|c|c|c|}
\hline \multirow{2}{*}{ Variable / } & \multirow{2}{*}{ Agatston } & \multirow{2}{*}{ N } & \multirow{2}{*}{ Media } & \multirow{2}{*}{ D.E. } & \multicolumn{3}{|c|}{ T Student } & \multirow{2}{*}{$\begin{array}{l}\text { IC } 95 \% \text { para la } \\
\text { diferenc. absoluta }\end{array}$} & \multirow{2}{*}{$\begin{array}{c}\text { Efecto } \\
\mathrm{R}^{2}\end{array}$} & \multicolumn{2}{|c|}{ Test Mann-Whitney } \\
\hline & & & & & T & gl & $\mathrm{P}$ & & & /Z/ & $P$ \\
\hline \multirow[t]{3}{*}{ Urea } & Inferior & 24 & 139.79 & 35.29 & & & & & & & \\
\hline & & & & & -1.04 & 41 & $.305^{N S}$ & N.S. & .026 & 1.03 & .304 NS \\
\hline & Igual/Superior & 19 & 150.89 & 34.12 & & & & & & & \\
\hline \multirow[t]{3}{*}{ Glucosa } & Inferior & 24 & 89.92 & 9.63 & & & & & & & \\
\hline & & & & & -1.69 & 41 & .099 NS & N.S. & .065 & 0.59 & $.557^{\mathrm{NS}}$ \\
\hline & Igual/Superior & 19 & 101.63 & 32.28 & & & & & & & \\
\hline \multirow[t]{3}{*}{ Creatinina } & Inferior & 24 & 8.54 & 2.72 & & & & & & & \\
\hline & & & & & -0.84 & 41 & $.405^{\text {NS }}$ & N.S. & 0.17 & 1.10 & $.271 \mathrm{NS}$ \\
\hline & Igual/Superior & 19 & 9.23 & 2.63 & & & & & & & \\
\hline \multirow[t]{3}{*}{ Triglicéridos } & Inferior & 24 & 112.58 & 33.09 & & & & & & & \\
\hline & & & & & -0.81 & 41 & $.421^{\mathrm{NS}}$ & N.S. & .016 & 0.87 & .385 NS \\
\hline & Igual/Superior & 19 & 122.89 & 49.88 & & & & & & & \\
\hline \multirow[t]{3}{*}{ Colesterol total } & Inferior & 24 & 188.50 & 49.25 & & & & & & & \\
\hline & & & & & 3.05 & 41 & $.004 * *$ & $14.99-73.80$ & .185 & 2.85 & $.004^{* *}$ \\
\hline & Igual/Superior & 19 & 144.11 & 44.98 & & & & & & & \\
\hline \multirow[t]{3}{*}{ Proteínas totales } & Inferior & 24 & 6.78 & 0.56 & & & & & & & \\
\hline & & & & & -1.61 & 41 & $.116^{\mathrm{NS}}$ & N.S. & .059 & 1.30 & .194 NS \\
\hline & Igual/Superior & 19 & 7.05 & 0.52 & & & & & & & \\
\hline \multirow[t]{3}{*}{ Calcio } & Inferior & 24 & 9.18 & 0.97 & & & & & & & \\
\hline & & & & & -0.73 & 41 & $.471^{\mathrm{NS}}$ & N.S. & .013 & 0.49 & .624 NS \\
\hline & Igual/Superior & 19 & 9.38 & 0.72 & & & & & & & \\
\hline \multirow[t]{3}{*}{ Calcio correg. } & Inferior & 24 & 9.54 & 1.01 & & & & & & & \\
\hline & & & & & -0.22 & 41 & .827 NS & N.S. & .001 & 0.21 & .835 NS \\
\hline & Igual/Superior & 19 & 9.60 & 0.70 & & & & & & & \\
\hline \multirow[t]{2}{*}{ Prod. Calc/Fósf. } & Inferior & 24 & 46.01 & 10.35 & & & & & & & \\
\hline & Igual/Superior & 19 & 46.87 & 10.88 & -0.27 & 41 & .792 NS & N.S. & .002 & 0.22 & .826 NS \\
\hline
\end{tabular}

En el siguiente bloque de variables (tabla 65) solamente aparecen diferencias que sean estadísticamente significativas en una variable:

- Fosfatasa alcalina $(\mathrm{P}<.01)$. Los pacientes con score de Agatston $<100 \mathrm{HU}$ presentan un valor menor de fosfatasa alcalina (78.88 vs 128.95$)$ que la de los demás pacientes. El tamaño de este efecto es moderado (.162). 


\section{RESULTADOS}

- Cockcroft Gault presenta una casi significación $(P<.100)$. Los resultados indican que los pacientes con un score de Agatston $<100 \mathrm{HU}$ tienen medias más altas (11.31 vs 9.11) si bien el tamaño del efecto sería bajo.

Tabla 65: Test de diferencia entre dos medias. Asociación de Score de Agatston con diversas variables de la analítica previa al trasplante.-3-

\begin{tabular}{|c|c|c|c|c|c|c|c|c|c|c|c|}
\hline \multirow{2}{*}{ Variable } & \multirow{2}{*}{ Agatston } & \multirow{2}{*}{$\mathrm{N}$} & \multirow{2}{*}{ Media } & \multirow{2}{*}{ D.E. } & \multicolumn{3}{|c|}{ T Student } & \multirow{2}{*}{$\begin{array}{l}\text { IC } 95 \% \text { para la } \\
\text { diferenc. absoluta }\end{array}$} & \multirow{2}{*}{$\begin{array}{c}\text { Efecto } \\
\mathrm{R}^{2}\end{array}$} & \multicolumn{2}{|c|}{ Test Mann-Whitney } \\
\hline & & & & & $T$ & $\mathrm{gl}$ & $\mathrm{P}$ & & & /Z/ & $\mathrm{P}$ \\
\hline \multirow[t]{3}{*}{ Fósforo } & Inferior & 24 & 5.01 & 1.09 & & & & & & & \\
\hline & & & & & 0.06 & 41 & .954 Ns & N.S. & .000 & 0.45 & .651 NS \\
\hline & Igual/Superior & 19 & 4.99 & 1.05 & & & & & & & \\
\hline \multirow[t]{3}{*}{ Fosfata Alcalina } & Inferior & 24 & 78.88 & 35.95 & & & & & & & \\
\hline & & & & & -2.82 & 41 & $.007^{* *}$ & $14.21-85.93$ & .162 & 2.88 & $.004 * *$ \\
\hline & Igual/Superior & 19 & 128.95 & 77.23 & & & & & & & \\
\hline \multirow[t]{3}{*}{ H. Paratiroidea } & Inferior & 24 & 313.51 & 341.70 & & & & & & & \\
\hline & & & & & -0.85 & 40 & $.398^{\mathrm{NS}}$ & N.S. & .018 & 0.41 & $.684^{\mathrm{NS}}$ \\
\hline & Igual/Superior & 18 & 416.29 & 438.42 & & & & & & & \\
\hline \multirow[t]{3}{*}{$\mathrm{pH}$} & Inferior & 24 & 7.37 & 0.06 & & & & & & & \\
\hline & & & & & -0.46 & 41 & $.646^{\mathrm{NS}}$ & N.S. & .005 & 0.38 & .704 Ns \\
\hline & Igual/Superior & 19 & 7.37 & 0.05 & & & & & & & \\
\hline \multirow[t]{3}{*}{ Bicarbonato } & Inferior & 24 & 24.03 & 2.88 & & & & & & & \\
\hline & & & & & 0.92 & 41 & $.363^{\mathrm{NS}}$ & N.S. & .020 & 0.78 & .434 Ns \\
\hline & Igual/Superior & 19 & 23.24 & 2.71 & & & & & & & \\
\hline \multirow[t]{3}{*}{ MDRDa } & Inferior & 24 & 7.16 & 2.31 & & & & & & & \\
\hline & & & & & 0.69 & 41 & .491 NS & N.S. & .012 & 0.66 & .509 NS \\
\hline & Igual/Superior & 19 & 6.69 & 2.13 & & & & & & & \\
\hline \multirow[t]{3}{*}{ C. Gault } & Inferior & 24 & 11.31 & 4.00 & & & & & & & \\
\hline & & & & & 2.00 & 41 & $.053^{\mathrm{NS}}$ & N.S. & .090 & 1.86 & $.063^{\mathrm{NS}}$ \\
\hline & Igual/Superior & 19 & 9.11 & 2.86 & & & & & & & \\
\hline \multirow[t]{3}{*}{ Mayo Quadr. } & Inferior & 24 & 9.56 & 2.08 & & & & & & & \\
\hline & & & & & 1.63 & 41 & $.111^{\mathrm{NS}}$ & N.S. & .061 & 1.59 & .112 Ns \\
\hline & Igual/Superior & 19 & 8.60 & 1.69 & & & & & & & \\
\hline \multirow[t]{2}{*}{ CKD-EPI } & Inferior & 24 & 6.74 & 2.33 & & & & & & & \\
\hline & Igual/Superior & 19 & 6.02 & 2.03 & 1.07 & 41 & $.293^{\mathrm{NS}}$ & N.S. & 0.27 & 0.95 & $.340^{\mathrm{NS}}$ \\
\hline
\end{tabular}

N.S. $=$ NO significativo $(P>05) \quad * *=$ Altamente significativo al $1 \%(P<.01)$

En este grupo (tabla 66) no se ha encontrado ninguna asociación que se pueda considerar como estadísticamente significativa ( $P>.05)$. 


\section{RESULTADOS}

Tabla 66: Test de diferencia entre dos medias. Asociación de Score de Agatston con diversas variables antropométricas y de la analítica al alta tras el trasplante.-1-

\begin{tabular}{|c|c|c|c|c|c|c|c|c|c|c|c|}
\hline \multirow{2}{*}{ Variable } & \multirow{2}{*}{ Agatston } & \multirow{2}{*}{$\mathrm{N}$} & \multirow{2}{*}{ Media } & \multirow{2}{*}{ D.E. } & \multicolumn{3}{|c|}{ T Student } & \multirow{2}{*}{$\begin{array}{l}\text { IC } 95 \% \text { para la } \\
\text { diferenc. absoluta }\end{array}$} & \multirow{2}{*}{$\begin{array}{c}\text { Efecto } \\
\mathrm{R}^{2}\end{array}$} & \multicolumn{2}{|c|}{ Test Mann-Whitney } \\
\hline & & & & & T & $\mathrm{gl}$ & $\mathrm{P}$ & & & /Z/ & $P$ \\
\hline \multirow[t]{3}{*}{ Peso } & Inferior & 24 & 69.98 & 12.26 & & & & & & & \\
\hline & & & & & 0.43 & 41 & .670 Ns & N.S. & .004 & 0.59 & .557 NS \\
\hline & Igual/Superior & 19 & 68.43 & 10.96 & & & & & & & \\
\hline \multirow[t]{3}{*}{ IMC } & Inferior & 24 & 24.48 & 3.46 & & & & & & & \\
\hline & & & & & 0.11 & 41 & .914 NS & N.S. & .000 & 0.00 & .999 NS \\
\hline & Igual/Superior & 19 & 24.37 & 3.08 & & & & & & & \\
\hline \multirow[t]{3}{*}{ TAS } & Inferior & 24 & 137.63 & 24.10 & & & & & & & \\
\hline & & & & & -0.04 & 41 & .971 Ns & N.S. & .000 & 0.28 & .778 NS \\
\hline & Igual/Superior & 19 & 137.89 & 23.61 & & & & & & & \\
\hline \multirow[t]{3}{*}{ TAD } & Inferior & 24 & 78.79 & 13.99 & & & & & & & \\
\hline & & & & & 0.16 & 41 & .873 Ns & N.S. & .001 & 0.15 & $.883^{\mathrm{NS}}$ \\
\hline & Igual/Superior & 19 & 78.11 & 13.72 & & & & & & & \\
\hline \multirow[t]{3}{*}{ Diuresis } & Inferior & 24 & 2541.67 & 931.92 & & & & & & & \\
\hline & & & & & 0.97 & 41 & .336 Ns & N.S. & .023 & 0.16 & $.874^{\mathrm{NS}}$ \\
\hline & Igual/Superior & 19 & 2308.16 & 529.71 & & & & & & & \\
\hline \multirow[t]{3}{*}{ Hemoglobina } & Inferior & 24 & 10.98 & 1.23 & & & & & & & \\
\hline & & & & & 1.44 & 41 & .156 NS & N.S. & .048 & 1.75 & .080 NS \\
\hline & Igual/Superior & 19 & 10.39 & 1.40 & & & & & & & \\
\hline \multirow[t]{3}{*}{ Hematocrito } & Inferior & 24 & 33.42 & 3.74 & & & & & & & \\
\hline & & & & & 1.32 & 41 & .195 NS & N.S. & .041 & 1.75 & .080 NS \\
\hline & Igual/Superior & 19 & 31.82 & 4.21 & & & & & & & \\
\hline \multirow[t]{3}{*}{ Leucocitos } & Inferior & 24 & 10207.92 & 3740.50 & & & & & & & \\
\hline & & & & & 1.47 & 41 & .149 Ns & N.S. & .050 & 1.74 & .082 Ns \\
\hline & Igual/Superior & 19 & 8546.84 & 3588.97 & & & & & & & \\
\hline \multirow[t]{3}{*}{ Plaquetas } & Inferior & 24 & 252583.33 & 108880.44 & & & & & & & \\
\hline & & & & & 0.12 & 41 & $.905^{\mathrm{NS}}$ & N.S. & .000 & 0.66 & .509 NS \\
\hline & Igual/Superior & 19 & 258263.16 & 126553.39 & & & & & & & \\
\hline \multirow[t]{2}{*}{ VSG } & Inferior & 24 & 33.58 & 29.00 & & & & & & & \\
\hline & Igual/Superior & 19 & 35.89 & 27.68 & -0.26 & 41 & .793 NS & N.S. & .002 & 0.51 & $.607^{\mathrm{NS}}$ \\
\hline
\end{tabular}

N.S. = NO significativo $(P>05)$

Al contrastar el siguiente bloque de variables (tabla 67) se han encontrado diferencias significativas en tres variables de la analítica al alta tras el trasplante:

- Glucosa $(P<.05)$. Los pacientes con score de Agatston $<100 \mathrm{HU}$ presentan un valor medio de glucosa plasmática al alta tras el trasplante menor que los demás pacientes (93.50 vs 115.63), con un efecto moderado (.124). 


\section{RESULTADOS}

- Producto cálcio-fósforo ( $\mathrm{P}<.01)$. Los pacientes con score de Agatston < $100 \mathrm{HU}$ tienen un producto calcio-fósforo medio más elevado que el resto (34.01 vs 25.99 ) de nuevo con tamaño del efecto moderado (.160)

- Fósforo $(\mathrm{P}<.05)$. Los pacientes del grupo con score de Agatston $<100 \mathrm{HU}$ tienen un valor medio de fósforo sérico más elevado (3.49 vs 2.79 ) que el resto, con un efecto moderado (.114).

Tabla 67: Test de diferencia entre dos medias. Asociación de Score de Agatston con diversas variables de la analítica al alta tras el trasplante.-2-

\begin{tabular}{|c|c|c|c|c|c|c|c|c|c|c|c|}
\hline \multirow{2}{*}{ Variable / } & \multirow{2}{*}{ Agatston } & \multirow{2}{*}{$\mathrm{N}$} & \multirow{2}{*}{ Media } & \multirow{2}{*}{ D.E. } & \multicolumn{3}{|c|}{ T Student } & \multirow{2}{*}{$\begin{array}{c}\text { IC } 95 \% \text { para la } \\
\text { diferenc. absoluta }\end{array}$} & \multirow{2}{*}{$\begin{array}{l}\text { Efecto } \\
\qquad R^{2}\end{array}$} & \multicolumn{2}{|c|}{ Test Mann-Whitney } \\
\hline & & & & & $\mathrm{T}$ & $\mathrm{gl}$ & $\mathrm{P}$ & & & /Z/ & $P$ \\
\hline \multirow[t]{3}{*}{ Urea } & Inferior & 24 & 90.42 & 47.10 & & & & & & & \\
\hline & & & & & 0.31 & 41 & .760 NS & N.S. & .002 & 0.39 & .695 NS \\
\hline & Igual/Superior & 19 & 86.79 & 24.77 & & & & & & & \\
\hline \multirow[t]{3}{*}{ Glucosa } & Inferior & 24 & 93.50 & 12.99 & & & & & & & \\
\hline & & & & & -2.41 & 41 & $.020 *$ & $3.60-40.66$ & .124 & 2.25 & $.024 *$ \\
\hline & Igual/Superior & 19 & 115.63 & 42.64 & & & & & & & \\
\hline \multirow[t]{3}{*}{ Creatinina } & Inferior & 24 & 2.48 & 1.68 & & & & & & & \\
\hline & & & & & 1.44 & 41 & $.157^{\mathrm{NS}}$ & N.S. & .048 & 0.72 & .469 NS \\
\hline & Igual/Superior & 19 & 1.88 & 0.79 & & & & & & & \\
\hline \multirow[t]{3}{*}{ Triglicéridos } & Inferior & 24 & 129.71 & 45.68 & & & & & & & \\
\hline & & & & & -1.81 & 41 & $.078^{N S}$ & N.S. & .074 & 1.20 & $.231 \mathrm{NS}$ \\
\hline & Igual/Superior & 19 & 166.84 & 86.88 & & & & & & & \\
\hline \multirow[t]{3}{*}{ Colesterol total } & Inferior & 24 & 196.08 & 53.01 & & & & & & & \\
\hline & & & & & 1.72 & 41 & .094 NS & N.S. & .067 & 1.53 & .126 NS \\
\hline & Igual/Superior & 19 & 170.32 & 43.13 & & & & & & & \\
\hline \multirow[t]{3}{*}{ Proteínas totales } & Inferior & 24 & 6.31 & 0.44 & & & & & & & \\
\hline & & & & & 1.49 & 41 & .144 NS & N.S. & .051 & 1.56 & .119 NS \\
\hline & Igual/Superior & 19 & 6.05 & 0.68 & & & & & & & \\
\hline \multirow[t]{3}{*}{ Calcio } & Inferior & 24 & 9.78 & 0.91 & & & & & & & \\
\hline & & & & & 1.67 & 41 & $.103^{\text {NS }}$ & N.S. & .063 & 1.31 & .190 NS \\
\hline & Igual/Superior & 19 & 9.34 & 0.77 & & & & & & & \\
\hline \multirow[t]{3}{*}{ Calcio correg. } & Inferior & 24 & 10.38 & 0.87 & & & & & & & \\
\hline & & & & & 1.26 & 41 & $.215^{\mathrm{NS}}$ & N.S. & .037 & 1.04 & $.298 \mathrm{NS}$ \\
\hline & Igual/Superior & 19 & 10.07 & 0.70 & & & & & & & \\
\hline \multirow[t]{3}{*}{ Prod. Calc/Fósf. } & Inferior & 24 & 34.01 & 11.20 & & & & & & & \\
\hline & & & & & 2.79 & 41 & $.008 * *$ & $2.22-13.82$ & .160 & 3.13 & $.002^{* *}$ \\
\hline & Igual/Superior & 19 & 25.99 & 6.27 & & & & & & & \\
\hline \multirow[t]{2}{*}{ Fósforo } & Inferior & 24 & 3.49 & 1.18 & & & & & & & \\
\hline & Igual/Superior & 19 & 2.79 & 0.67 & 2.29 & 41 & $.027 *$ & $0.08-1.31$ & .114 & 2.31 & $.021 *$ \\
\hline
\end{tabular}




\section{RESULTADOS}

En este último bloque de resultados analíticos relativos al alta tras el trasplante (tabla

68) solamente se detectan diferencias significativas $(P<.05)$ en una variable.

- Bicarbonato sódico $(\mathrm{P}<.05)$. Los sujetos con score de Agatston < $100 \mathrm{HU}$ presentan de media un valor inferior de bicarbonato sódico (20.22 vs 22.15), si bien equivale a un tamaño del efecto bajo. La alternativa no paramétrica de Mann-Whitney no es capaz de confirmar esta significación ( $P>.05)$ aunque podría hablarse de una casi significación $(P<.100)$. No hay suficientes evidencias estadísticas de asociación en este caso.

Tabla 68: Test de diferencia entre dos medias. Asociación de Score de Agatston con diversas variables de la analítica al alta tras el trasplante.-3-

\begin{tabular}{|c|c|c|c|c|c|c|c|c|c|c|c|}
\hline \multirow{2}{*}{ Variable / } & \multirow{2}{*}{ Agatston } & \multirow{2}{*}{$\mathrm{N}$} & \multirow{2}{*}{ Media } & \multirow{2}{*}{ D.E. } & \multicolumn{3}{|c|}{ T Student } & \multirow{2}{*}{$\begin{array}{c}\text { IC } 95 \% \text { para la } \\
\text { diferenc. Absoluta }\end{array}$} & \multirow{2}{*}{$\begin{array}{l}\text { Efecto } \\
\mathrm{R}^{2}\end{array}$} & \multicolumn{2}{|c|}{ Test Mann-Whitney } \\
\hline & & & & & $\mathrm{T}$ & gl & $P$ & & & |ZI & $P$ \\
\hline \multirow[t]{3}{*}{ Magnesio } & Inferior & 24 & 1.65 & 0.26 & & & & & & & \\
\hline & & & & & -0.64 & 41 & .523 NS & N.S. & .010 & 0.02 & .980 NS \\
\hline & Igual/Superior & 19 & 1.71 & 0.39 & & & & & & & \\
\hline \multirow[t]{3}{*}{ Fosfata Alcalina } & Inferior & 24 & 78.00 & 29.25 & & & & & & & \\
\hline & & & & & -1.26 & 41 & $.217^{\text {NS }}$ & N.S. & .037 & 1.01 & $.310^{\mathrm{NS}}$ \\
\hline & Igual/Superior & 19 & 98.11 & 71.45 & & & & & & & \\
\hline \multirow[t]{3}{*}{ Urea en orina } & Inferior & 24 & 1198.48 & 497.36 & & & & & & & \\
\hline & & & & & -0.19 & 41 & $.847^{\mathrm{NS}}$ & N.S. & .001 & 0.68 & .493 NS \\
\hline & Igual/Superior & 19 & 1223.58 & 297.76 & & & & & & & \\
\hline \multirow[t]{3}{*}{ Creat. en orina } & Inferior & 24 & 62.42 & 28.22 & & & & & & & \\
\hline & & & & & 1.44 & 41 & .158 NS & N.S. & .048 & 1.04 & $299 \mathrm{NS}$ \\
\hline & Igual/Superior & 19 & 51.54 & 19.08 & & & & & & & \\
\hline \multirow[t]{3}{*}{$\mathrm{pH}$} & Inferior & 24 & 7.35 & 0.05 & & & & & & & \\
\hline & & & & & -0.08 & 41 & .937 Ns & N.S. & .000 & 0.28 & .777 NS \\
\hline & Igual/Superior & 19 & 7.35 & 0.04 & & & & & & & \\
\hline \multirow[t]{3}{*}{ Bicarbonato } & Inferior & 24 & 20.22 & 3.04 & & & & & & & \\
\hline & & & & & -2.07 & 41 & $.045 *$ & $0.05-3.81$ & .095 & 1.90 & .058 Ns \\
\hline & Igual/Superior & 19 & 22.15 & 3.02 & & & & & & & \\
\hline \multirow[t]{3}{*}{ MDRDa } & Inferior & 24 & 37.27 & 17.45 & & & & & & & \\
\hline & & & & & -1.35 & 41 & $.185^{\mathrm{NS}}$ & N.S. & .043 & 1.39 & .163 Ns \\
\hline & Igual/Superior & 19 & 44.25 & 16.04 & & & & & & & \\
\hline \multirow[t]{3}{*}{ Cock. Gault } & Inferior & 24 & 44.59 & 17.69 & & & & & & & \\
\hline & & & & & 0.01 & 41 & .996 NS & N.S. & .000 & 0.20 & $.845^{\mathrm{NS}}$ \\
\hline & Igual/Superior & 19 & 44.56 & 11.99 & & & & & & & \\
\hline \multirow[t]{3}{*}{ Mayo Quadr. } & Inferior & 24 & 44.77 & 24.58 & & & & & & & \\
\hline & & & & & -0.74 & 41 & .463 NS & N.S. & .013 & 0.71 & .478 Ns \\
\hline & Igual/Superior & 19 & 50.16 & 22.54 & & & & & & & \\
\hline \multirow[t]{2}{*}{ CKD-EPI } & Inferior & 24 & 38.04 & 18.63 & & & & & & & \\
\hline & Igual/Superior & 19 & 43.69 & 16.48 & -1.04 & 41 & $.305^{N S}$ & N.S. & .026 & 1.03 & .304 NS \\
\hline
\end{tabular}

N.S. $=$ NO significativo $(P>05) \quad *=$ Significativo al $5 \%(P<.05)$ 


\section{RESULTADOS}

Al analizar las variables analíticas recogidas en el momento de la revisión, se ha encontrado que en este primer grupo (tabla 69) se mantiene ausencia de significación con estos parámetros ( $\mathrm{P}>$.05) que ya aparecía en el momento del alta.

Tabla 69: Test de diferencia entre dos medias. Asociación de Score de Agatston con diversas variables antropométricas y de la analítica en la revisión.-1-

\begin{tabular}{|c|c|c|c|c|c|c|c|c|c|c|c|}
\hline \multirow{2}{*}{ Variable / } & \multirow{2}{*}{ Agatston } & \multirow{2}{*}{$\mathrm{N}$} & \multirow{2}{*}{ Media } & \multirow{2}{*}{ D.E. } & \multicolumn{3}{|c|}{ T Student } & \multirow{2}{*}{$\begin{array}{c}\text { IC 95\% para la } \\
\text { diferenc. absoluta }\end{array}$} & \multirow{2}{*}{$\begin{array}{l}\text { Efecto } \\
\qquad \mathrm{R}^{2}\end{array}$} & \multicolumn{2}{|c|}{ Test Mann-Whitney } \\
\hline & & & & & $\mathrm{T}$ & $\mathrm{gl}$ & $P$ & & & /Z/ & $P$ \\
\hline \multirow[t]{3}{*}{ Peso } & Inferior & 24 & 75.37 & 15.01 & & & & & & & \\
\hline & & & & & 0.41 & 41 & .687 NS & N.S. & .001 & 0.43 & .669 NS \\
\hline & Igual/Superior & 19 & 73.71 & 10.85 & & & & & & & \\
\hline \multirow[t]{3}{*}{ IMC } & Inferior & 24 & 26.31 & 3.92 & & & & & & & \\
\hline & & & & & 0.04 & 41 & $.971^{\mathrm{NS}}$ & N.S. & .000 & 0.64 & .525 NS \\
\hline & Igual/Superior & 19 & 26.27 & 2.99 & & & & & & & \\
\hline \multirow[t]{3}{*}{ TAS } & Inferior & 24 & 145.13 & 17.37 & & & & & & & \\
\hline & & & & & 0.31 & 41 & $.761^{\mathrm{NS}}$ & N.S. & .002 & 0.26 & $.797^{\text {NS }}$ \\
\hline & Igual/Superior & 19 & 143.42 & 19.07 & & & & & & & \\
\hline \multirow[t]{3}{*}{ TAD } & Inferior & 24 & 86.00 & 8.83 & & & & & & & \\
\hline & & & & & 1.04 & 41 & $.302^{N S}$ & N.S. & .026 & 0.84 & $.398^{\mathrm{NS}}$ \\
\hline & Igual/Superior & 19 & 83.16 & 8.91 & & & & & & & \\
\hline \multirow[t]{3}{*}{ Diuresis } & Inferior & 24 & 2432.08 & 821.43 & & & & & & & \\
\hline & & & & & -1.52 & 41 & $.136^{\mathrm{NS}}$ & N.S. & .053 & 1.60 & $.109^{\text {NS }}$ \\
\hline & Igual/Superior & 19 & 2800.00 & 744.61 & & & & & & & \\
\hline \multirow[t]{3}{*}{ Hemoglobina } & Inferior & 24 & 13.59 & 2.28 & & & & & & & \\
\hline & & & & & 0.91 & 41 & $.371^{N S}$ & N.S. & .020 & 0.86 & .391 NS \\
\hline & Igual/Superior & 19 & 13.05 & 1.33 & & & & & & & \\
\hline \multirow[t]{3}{*}{ Hematocrito } & Inferior & 24 & 40.90 & 6.04 & & & & & & & \\
\hline & & & & & 0.98 & 41 & $.334^{\mathrm{NS}}$ & N.S. & .023 & 1.36 & $.175^{\mathrm{NS}}$ \\
\hline & Igual/Superior & 19 & 39.34 & 3.87 & & & & & & & \\
\hline \multirow[t]{3}{*}{ Leucocitos } & Inferior & 24 & 6770.00 & 2154.23 & & & & & & & \\
\hline & & & & & -0.32 & 41 & .750 NS & N.S. & .002 & 0.20 & $.845^{\text {NS }}$ \\
\hline & Igual/Superior & 19 & 6982.11 & 2159.14 & & & & & & & \\
\hline \multirow[t]{3}{*}{ Plaquetas } & Inferior & 24 & 197375.00 & 52885.28 & & & & & & & \\
\hline & & & & & 0.84 & 41 & .407 NS & N.S. & .017 & 1.02 & .310 NS \\
\hline & Igual/Superior & 19 & 182263.16 & 65572.56 & & & & & & & \\
\hline \multirow[t]{2}{*}{ VSG } & Inferior & 24 & 13.05 & 11.75 & & & & & & & \\
\hline & Igual/Superior & 19 & 20.84 & 16.80 & -1.79 & 41 & $.081^{\mathrm{NS}}$ & N.S. & .072 & 1.62 & $.106^{\text {NS }}$ \\
\hline
\end{tabular}

N.S. $=$ NO significativo $(P>05)$ 


\section{RESULTADOS}

En el siguiente bloque (tabla 70) han aparecido algunas significaciones:

- Urea $(\mathrm{P}<.01)$. Los pacientes con score de Agatston $<100 \mathrm{HU}$ presentan una media de urea sérica más baja (56.25 vs 84.00 ) que la de los demás casos, con un tamaño del efecto cerca de ser elevado (.224).

- Glucosa. El test de Student determina la existencia de significación $(P<.05)$ aunque con tamaño del efecto bajo (.096), según la cual los pacientes con score de Agatston < $100 \mathrm{HU}$ presentan una media de glucosa sérica menor (94.67 vs 114.26 ) que el resto. Sin embargo, la alternativa de Mann-Whitney no detecta esta significación aunque se podría hablar de una casi significación $(P<.100)$. Por tanto el resultado no es totalmente concluyente, si bien hay una sospecha de asociación que de confirmarse sería leve.

- Ácido úrico. Mientras que el test de Student no consigue detectar la significación ( $P>$.05) la alternativa de Mann-Whitney sí que lo hace y además de forma sólida $(P<.01)$. A la vista de la marcada asimetría de esta variable durante el análisis descriptivo (tabla 21) éste último resultado debe ser considerado en cuenta. Los datos indican que los enfermos con score de Agatston $<100 \mathrm{HU}$ tendrían valores de ácido úrico inferiores que el resto de los pacientes. 


\section{RESULTADOS}

Tabla 70: Test de diferencia entre 2 medias. Asociación de Score de Agatston con diversas variables de la analítica en la revisión.-2-

\begin{tabular}{|c|c|c|c|c|c|c|c|c|c|c|c|}
\hline \multirow{2}{*}{ Variable / } & \multirow{2}{*}{ Agatston } & \multirow{2}{*}{$\mathrm{N}$} & \multirow{2}{*}{ Media } & \multirow{2}{*}{ D.E. } & \multicolumn{3}{|c|}{ T Student } & \multirow{2}{*}{$\begin{array}{c}\text { IC } 95 \% \text { para la } \\
\text { diferenc. absoluta }\end{array}$} & \multirow{2}{*}{$\begin{array}{l}\text { Efecto } \\
\mathrm{R}^{2}\end{array}$} & \multicolumn{2}{|c|}{ Test Mann-Whitney } \\
\hline & & & & & $\mathrm{T}$ & gl & $\mathrm{P}$ & & & /Z/ & $P$ \\
\hline \multirow[t]{3}{*}{ Urea } & Inferior & 24 & 56.25 & 19.77 & & & & & & & \\
\hline & & & & & -.344 & 41 & $.001^{* *}$ & $11.45-44.05$ & .224 & 3.12 & $.002 * *$ \\
\hline & Igual/Superior & 19 & 84.00 & 32.76 & & & & & & & \\
\hline \multirow[t]{3}{*}{ Glucosa } & Inferior & 24 & 94.67 & 9.84 & & & & & & & \\
\hline & & & & & -2.08 & 41 & $.043 *$ & $0.60-38.59$ & .096 & 1.71 & $.087^{\mathrm{NS}}$ \\
\hline & Igual/Superior & 19 & 114.26 & 44.87 & & & & & & & \\
\hline \multirow[t]{3}{*}{ Creatinina } & Inferior & 24 & 1.50 & 0.54 & & & & & & & \\
\hline & & & & & -1.12 & 41 & $.269 \mathrm{NS}$ & N.S. & .030 & 1.51 & $.130 \mathrm{NS}$ \\
\hline & Igual/Superior & 19 & 1.67 & 0.49 & & & & & & & \\
\hline \multirow[t]{3}{*}{ Ácido úrico } & Inferior & 24 & 6.52 & 1.47 & & & & & & & \\
\hline & & & & & -1.40 & 41 & .169 NS & N.S. & .046 & 2.61 & $.009 * *$ \\
\hline & Igual/Superior & 19 & 11.62 & 17.82 & & & & & & & \\
\hline \multirow[t]{3}{*}{ Triglicéridos } & Inferior & 24 & 104.04 & 39.25 & & & & & & & \\
\hline & & & & & -2.19 & 41 & $.034 *$ & N.S. & .105 & 1.64 & .101 NS \\
\hline & Igual/Superior & 19 & 145.16 & 80.89 & & & & & & & \\
\hline \multirow[t]{3}{*}{ Colesterol total } & Inferior & 24 & 193.75 & 37.97 & & & & & & & \\
\hline & & & & & 1.85 & 41 & $.071^{\mathrm{NS}}$ & N.S. & .077 & 1.59 & $.112^{\mathrm{NS}}$ \\
\hline & Igual/Superior & 19 & 171.79 & 39.39 & & & & & & & \\
\hline \multirow[t]{3}{*}{ Proteínas totales } & Inferior & 24 & 6.83 & 0.47 & & & & & & & \\
\hline & & & & & 0.26 & 41 & $.795^{\mathrm{NS}}$ & N.S. & .002 & 0.58 & $.564 \mathrm{NS}$ \\
\hline & Igual/Superior & 19 & 6.79 & 0.52 & & & & & & & \\
\hline \multirow[t]{3}{*}{ Calcio } & Inferior & 24 & 9.55 & 0.67 & & & & & & & \\
\hline & & & & & -0.61 & 41 & .544 NS & N.S. & .009 & 0.37 & $.712 \mathrm{NS}$ \\
\hline & Igual/Superior & 19 & 9.66 & 0.44 & & & & & & & \\
\hline \multirow[t]{3}{*}{ Calcio correg. } & Inferior & 24 & 9.89 & 0.56 & & & & & & & \\
\hline & & & & & -0.80 & 41 & $.427^{N S}$ & N.S. & .015 & 0.66 & .509 NS \\
\hline & Igual/Superior & 19 & 10.02 & 0.47 & & & & & & & \\
\hline \multirow[t]{3}{*}{ Prod. Calc/Fósf. } & Inferior & 24 & 31.56 & 6.30 & & & & & & & \\
\hline & & & & & 1.15 & 41 & $.257^{N S}$ & N.S. & .031 & 1.09 & $.276 \mathrm{NS}$ \\
\hline & Igual/Superior & 19 & 29.43 & 5.63 & & & & & & & \\
\hline \multirow[t]{2}{*}{ Fósforo } & Inferior & 24 & 3.32 & 0.70 & & & & & & & \\
\hline & Igual/Superior & 19 & 3.05 & 0.61 & 1.30 & 41 & $.201^{\mathrm{NS}}$ & N.S. & .039 & 1.12 & $.264 \mathrm{NS}$ \\
\hline
\end{tabular}

En el siguiente bloque (tabla 71) solamente se ha encontrado diferencias significativas $(P<.01)$ en una variable:

- Hemoglobina glicosilada $(P<.01)$. La media de los pacientes con score de Agatston < $100 \mathrm{HU}$ tienen un valor medio de hemoglobina glicosilada más baja (5.63 vs 6.35) que el resto de casos, siendo el efecto moderado (.160). 


\section{RESULTADOS}

- Colesterol sérico, colesterol HDL y colesterol LDL $(\mathrm{P}<.100)$. En los tres casos se puede hablar de una casi significación, donde los casos con score de Agatston < $100 \mathrm{HU}$ muestran valores más altos de colesterol total, HDL y LDL, si bien el tamaño del efecto indicaría una asociación leve.

Tabla 71: Test de diferencia entre dos medias. Asociación de Score de Agatston con diversas variables de la analítica en la revisión.-3-

\begin{tabular}{|c|c|c|c|c|c|c|c|c|c|c|c|}
\hline \multirow{2}{*}{ Variable } & \multirow{2}{*}{ Agatston } & \multirow{2}{*}{$\mathrm{N}$} & \multirow{2}{*}{ Media } & \multirow{2}{*}{ D.E. } & \multicolumn{3}{|c|}{ T Student } & \multirow{2}{*}{$\begin{array}{c}\text { IC 95\% para la } \\
\text { diferenc. absoluta }\end{array}$} & \multirow{2}{*}{$\begin{array}{l}\text { Efecto } \\
\mathrm{R}^{2}\end{array}$} & \multicolumn{2}{|c|}{ Test Mann-Whitney } \\
\hline & & & & & T & $\mathrm{gl}$ & $P$ & & & /Z/ & $P$ \\
\hline \multirow[t]{3}{*}{ Magnesio } & Inferior & 24 & 1.84 & 0.27 & & & & & & & \\
\hline & & & & & -0.01 & 41 & .996 NS & N.S. & .000 & 0.26 & .795 NS \\
\hline & Igual/Superior & 19 & 1.84 & 0.29 & & & & & & & \\
\hline \multirow[t]{3}{*}{ Fosfata Alcalina } & Inferior & 24 & 71.54 & 15.73 & & & & & & & \\
\hline & & & & & -.156 & 41 & $.126^{\mathrm{NS}}$ & N.S. & .056 & 1.08 & $.282 \mathrm{NS}$ \\
\hline & Igual/Superior & 19 & 83.84 & 34.34 & & & & & & & \\
\hline \multirow[t]{3}{*}{ Clacio iónico } & Inferior & 24 & 1.26 & 0.07 & & & & & & & \\
\hline & & & & & -0.78 & 41 & .439 NS & N.S. & .015 & 0.44 & 659 NS \\
\hline & Igual/Superior & 19 & 1.27 & 0.06 & & & & & & & \\
\hline \multirow[t]{3}{*}{ PCR } & Inferior & 24 & 3.04 & 3.04 & & & & & & & \\
\hline & & & & & -0.28 & 41 & .782 NS & N.S. & .002 & 0.66 & .510 NS \\
\hline & Igual/Superior & 19 & 3.32 & 3.42 & & & & & & & \\
\hline \multirow[t]{3}{*}{ Interleukina } & Inferior & 24 & 8.85 & 24.06 & & & & & & & \\
\hline & & & & & 0.72 & 41 & .477 NS & N.S. & .012 & 1.44 & .150 NS \\
\hline & Igual/Superior & 19 & 4.85 & 3.46 & & & & & & & \\
\hline \multirow[t]{3}{*}{ PTH } & Inferior & 24 & 98.77 & 40.64 & & & & & & & \\
\hline & & & & & -1.17 & 41 & $.248^{\mathrm{NS}}$ & N.S. & .032 & 0.59 & $.557^{N S}$ \\
\hline & Igual/Superior & 19 & 118.83 & 70.50 & & & & & & & \\
\hline \multirow[t]{3}{*}{ Hemog. glicos. } & Inferior & 24 & 5.63 & 0.34 & & & & & & & \\
\hline & & & & & -2.79 & 41 & $.008^{* *}$ & $0.20-1.24$ & .160 & 2.57 & $.009 * *$ \\
\hline & Igual/Superior & 19 & 6.35 & 1.21 & & & & & & & \\
\hline \multirow[t]{3}{*}{ Vitamina D } & Inferior & 24 & 18.97 & 10.98 & & & & & & & \\
\hline & & & & & 0.34 & 41 & .739 NS & N.S. & .003 & 0.28 & $.778^{N S}$ \\
\hline & Igual/Superior & 19 & 17.89 & 9.85 & & & & & & & \\
\hline \multirow[t]{3}{*}{ Colest. HDL } & Inferior & 24 & 63.75 & 20.24 & & & & & & & \\
\hline & & & & & 2.00 & 41 & $.053^{\mathrm{NS}}$ & N.S. & .090 & 1.78 & .074 NS \\
\hline & Igual/Superior & 19 & 52.63 & 14.50 & & & & & & & \\
\hline \multirow[t]{2}{*}{ Colest. LDL } & Inferior & 24 & 108.48 & 34.42 & & & & & & & \\
\hline & Igual/Superior & 19 & 90.07 & 30.10 & 1.91 & 41 & $.063 \mathrm{Ns}$ & N.S. & .082 & 1.72 & .085 NS \\
\hline
\end{tabular}

N.S. $=$ NO significativo $(P>.05) \quad *=$ Significativo al $5 \%(P<.05)$

En el último grupo de variables analíticas en la revisión (tabla 72) apenas aparecen significaciones. Es necesario comentar las siguientes variables: 


\section{RESULTADOS}

- Microalbuminuria. El test de Student no alcanza a probar significación ( $P>.05$ ) a pesar de la elevada diferencia que se aprecia entre las medias. Sin embargo la alternativa de Mann-Whitney sí que la prueba $(P<.05)$ aunque parece que con un efecto pequeño. Los datos podrían indicar que los sujetos del grupo con Agatston < $100 \mathrm{HU}$ tienen valores menores de microalbuminuria (44.16 vs 105.79) que el resto de casos.

- Cockroft Gault $(\mathrm{P}<.05)$. Los pacientes con score de Agatston $<100 \mathrm{HU}$ tienen un valor medio más alto de aclaramiento de creatinina medido por la ecuación de CockroftGault (67.06 vs 51.01) que el resto de pacientes, con un tamaño del efecto moderadobajo (.109).

Tabla 72: Test de diferencia entre 2 medias. Asociación de Score de Agatston con diversas variables -4- de la analítica en la revisión.

\begin{tabular}{|c|c|c|c|c|c|c|c|c|c|c|c|}
\hline \multirow{2}{*}{ Variable } & \multirow{2}{*}{ Agatston } & \multirow{2}{*}{$\mathrm{N}$} & \multirow{2}{*}{ Media } & \multirow{2}{*}{ D.E. } & \multicolumn{3}{|c|}{ T Student } & \multirow{2}{*}{$\begin{array}{c}\text { IC 95\% para la } \\
\text { diferenc. absoluta }\end{array}$} & \multirow{2}{*}{$\begin{array}{l}\text { Efecto } \\
\mathrm{R}^{2}\end{array}$} & \multicolumn{2}{|c|}{ Test Mann-Whitney } \\
\hline & & & & & $T$ & $\mathrm{gl}$ & $\mathrm{P}$ & & & /Z/ & $\mathrm{P}$ \\
\hline \multirow[t]{3}{*}{$\mathrm{pH}$} & Inferior & 24 & 7.33 & 0.04 & & & & & & & \\
\hline & & & & & 0.04 & 41 & $.965^{\text {NS }}$ & N.S. & .000 & 0.27 & .787 Ns \\
\hline & Igual/Superior & 19 & 7.33 & 0.04 & & & & & & & \\
\hline \multirow[t]{3}{*}{ Bicarbonato } & Inferior & 24 & 22.65 & 2.32 & & & & & & & \\
\hline & & & & & 0.73 & 41 & .471 NS & N.S. & .013 & 0.66 & .509 Ns \\
\hline & Igual/Superior & 19 & 22.07 & 2.91 & & & & & & & \\
\hline \multirow[t]{3}{*}{ Microalbumin. } & Inferior & 24 & 44.16 & 100.63 & & & & & & & \\
\hline & & & & & -1.43 & 41 & .161 NS & N.S. & .047 & 2.39 & $.017^{*}$ \\
\hline & Igual/Superior & 19 & 105.79 & 179.24 & & & & & & & \\
\hline \multirow[t]{3}{*}{ MDRDa } & Inferior & 24 & 54.11 & 19.93 & & & & & & & \\
\hline & & & & & 1.16 & 41 & $.255^{\mathrm{NS}}$ & N.S. & .032 & 1.08 & .282 Ns \\
\hline & Igual/Superior & 19 & 47.72 & 15.20 & & & & & & & \\
\hline \multirow[t]{3}{*}{ Cock. Gault } & Inferior & 24 & 67.06 & 27.53 & & & & & & & \\
\hline & & & & & 2.24 & 41 & $.031 *$ & $1.56-30.53$ & .109 & 2.00 & $.045 *$ \\
\hline & Igual/Superior & 19 & 51.01 & 16.54 & & & & & & & \\
\hline \multirow[t]{3}{*}{ Mayo Quadr. } & Inferior & 24 & 67.53 & 27.45 & & & & & & & \\
\hline & & & & & 1.67 & 41 & .103 NS & N.S. & .063 & 1.64 & .101 Ns \\
\hline & Igual/Superior & 19 & 54.68 & 21.80 & & & & & & & \\
\hline \multirow[t]{3}{*}{ CKD-EPI } & Inferior & 24 & 55.68 & 21.99 & & & & & & & \\
\hline & & & & & 1.51 & 41 & .139 NS & N.S. & .053 & 1.44 & .149 Ns \\
\hline & Igual/Superior & 19 & 46.68 & 15.60 & & & & & & & \\
\hline \multirow[t]{2}{*}{ FGF-23 } & Inferior & 24 & 6.94 & 16.59 & & & & & & & \\
\hline & Igual/Superior & 19 & 2.64 & 5.88 & 1.07 & 41 & .289 NS & N.S. & .027 & 0.46 & .648 Ns \\
\hline
\end{tabular}

Tras los contrastes anteriores, quedan por analizar la asociación con la farmacología. Se realizaron test no paramétricos, siendo los valores de $P$ siempre $>.05$ por lo que se 


\section{RESULTADOS}

concluye que no hay relación alguna entre el score de Agatston y el tratamiento farmacológico recibido, tanto previo al trasplante como relativo a la inmunosupresión (considerando tanto la dosis recibida durante el primer año como la dosis total acumulada).

Finalmente se muestra el valor del score de Agatston estratificando a los pacientes según la edad y los resultados de diversas variables tanto analíticas como relativas ala historia clínica del enfermo.

Las Figuras $\mathbf{2 7}$ y $\mathbf{2 8}$ muestran el resultado del índice de CAC en diferentes variables tras estratificar según la edad actual del paciente:

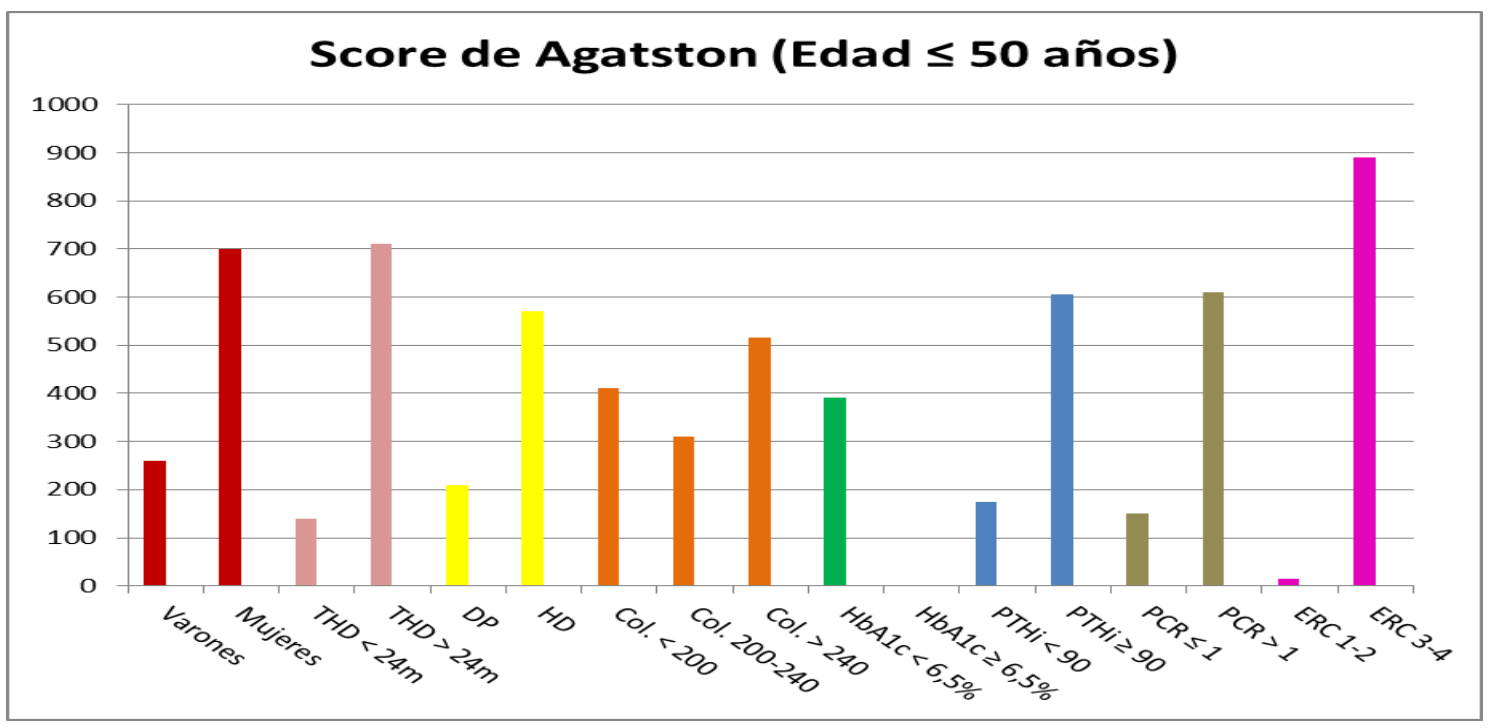

Figura 27: Diferencias en el grado de CAC según diversas variables en pacientes de edad $\leq 50$ años. THD: Tiempo en diálisis. Col.: Colesterol (mg/dl). PTHi: Hormona paratiroidea intacta $(\mathrm{pg} / \mathrm{ml})$.

Se observa un mayor score de Agatston dentro de este rango de edad en mujeres, pacientes con un mayor tiempo en diálisis o cuyo tratamiento renal sustitutivo de elección fue la hemodiálisis, enfermos con una peor función del injerto, con colesterol total $<200$ o $>240 \mathrm{mg} / \mathrm{dl}$ o aquellos con una mayor concentración sérica de PTHi o PCR. En este grupo de edad no hay individuos con concentración de hemoglobina glicosilada igual o superior al 6,5\%. 


\section{RESULTADOS}

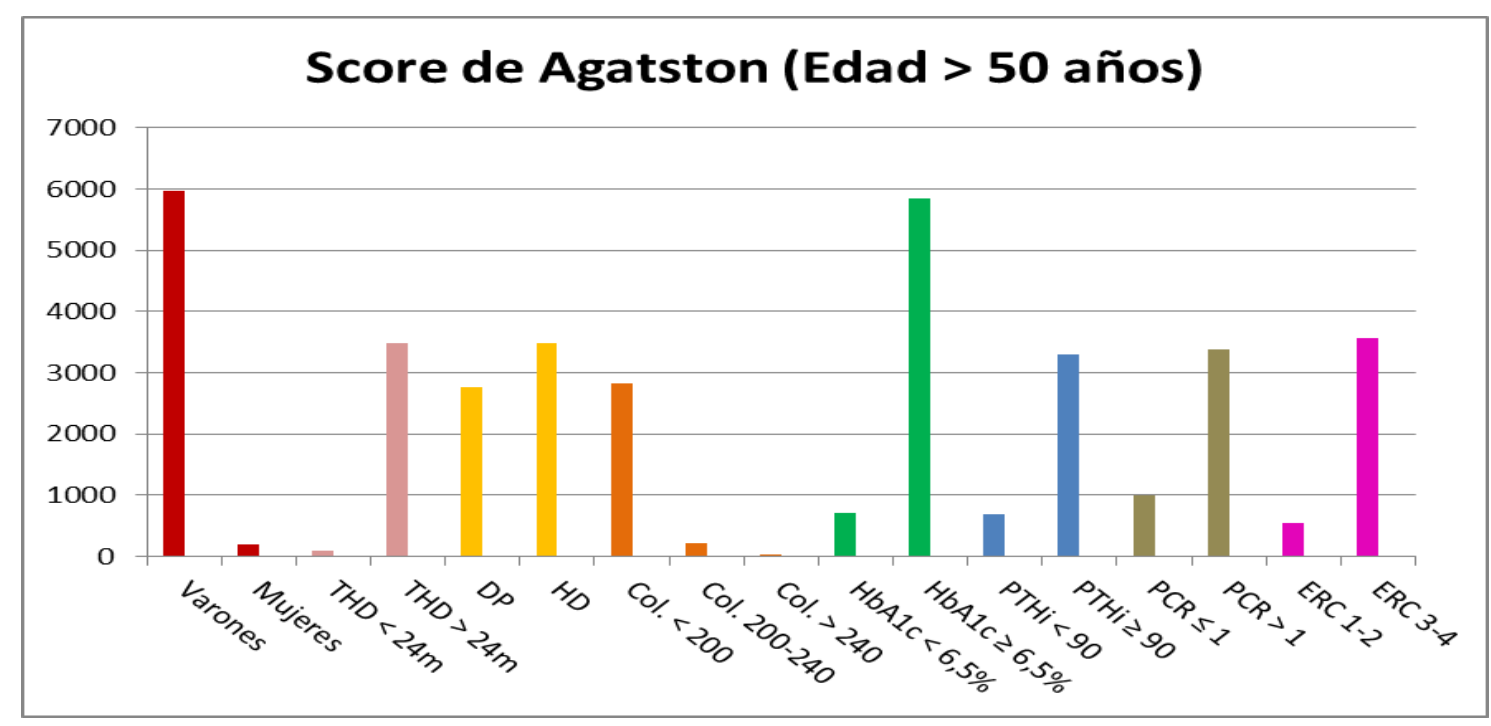

Figura 28: Diferencias en el grado de CAC según diversas variables en pacientes de edad $>50$ años. THD: Tiempo en diálisis. Col.: Colesterol (mg/dl). PTHi: Hormona paratiroidea intacta $(\mathrm{pg} / \mathrm{ml})$.

En este grupo de edad se comprueba un mayor score de Agatston entre los varones, así como una modificación de la "curva" observada en la puntuación del score en relación con el colesterol sérico. El resto de parámetros se comportan de forma similar en ambos grupos.

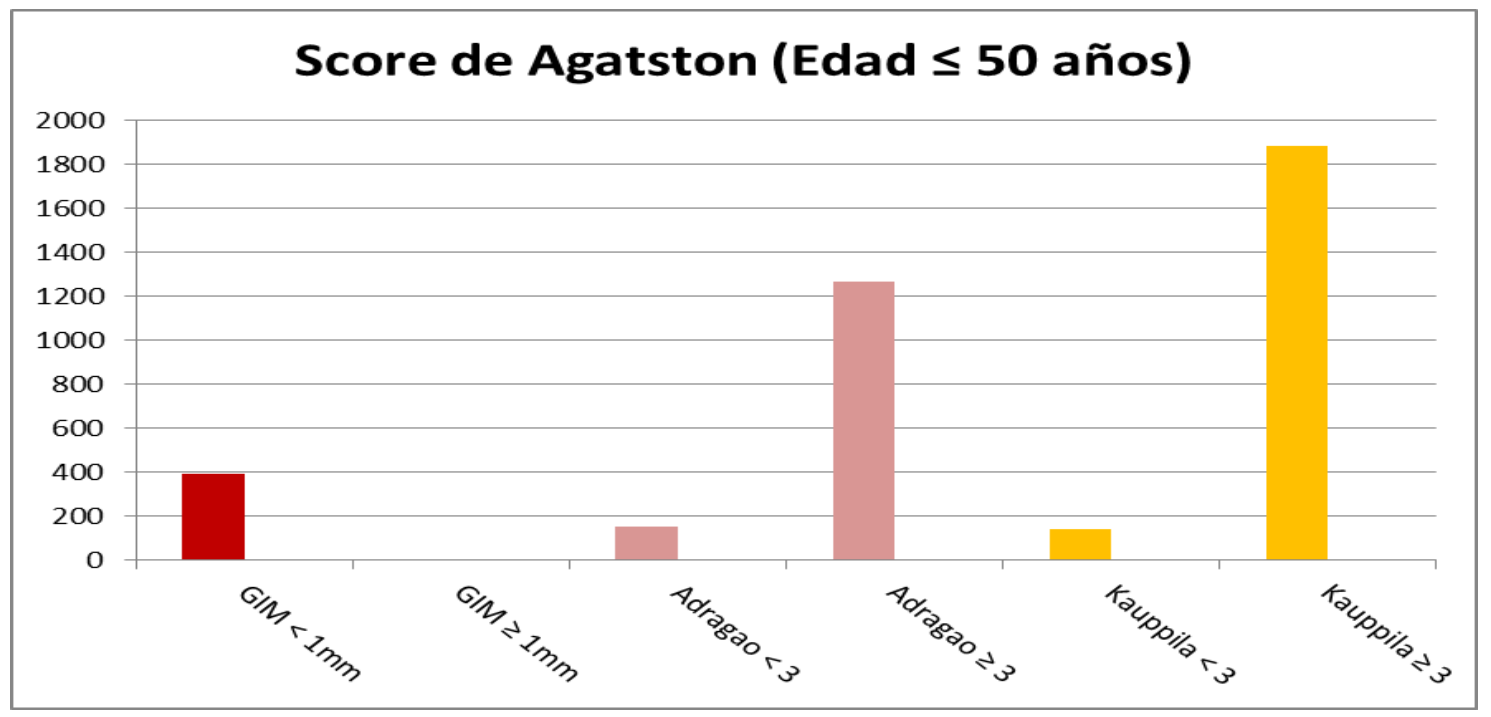

Figura 29: Diferencias en el grado de CAC según el resto de pruebas para valorar la calcificación vascular en pacientes de edad $\leq 50$ años.

La muestra no dispone de pacientes menores de 50 años que presenten un GIM igual o superior a $1 \mathrm{~mm}$. 


\section{RESULTADOS}

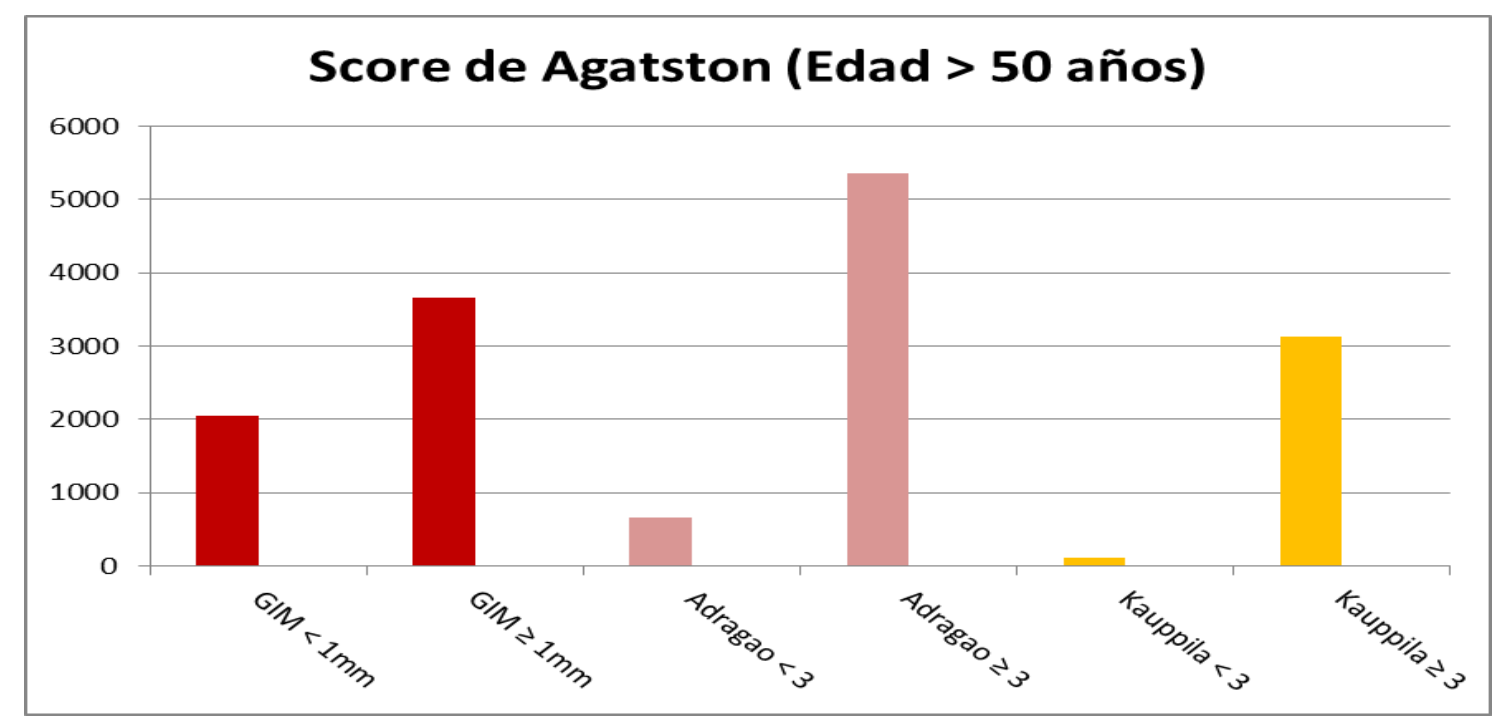

Figura 30: Diferencias en el grado de CAC según el resto de pruebas para valorar la calcificación vascular en pacientes de edad > 50 años. 


\section{RESULTADOS}

\subsection{2: GROSOR ÍNTIMA-MEDIA EN ARTERIA CARÓTIDA}

El grado de engrosamiento de las capas íntima y media de la pared de las arterias carótidas de los 43 receptores de trasplante renal se situó entre 0,56 y 1,18 mm (Tabla 73).

El valor del GIM obtenido tras la valoración de las ecografías carotideas realizadas en el estudio de la muestra se recoge en la siguiente tabla:

\begin{tabular}{|l|l|l|l|l|l|l|}
\hline & Media & Mediana & MAX & MIN & R. Interq. & DS \\
\hline GIM & 0,76 & 0,75 & 1,18 & 0,56 & $0,67-0,83$ & 0,13 \\
\hline
\end{tabular}

Tabla 73: Estadísticos descriptivos del GIM observados en la muestra. Unidad: mm.

La distribución de los pacientes estudiados según el valor del GIM fue la siguiente:

\begin{tabular}{|l|l|l|l|}
\hline GIM & Estrato & Recuento & Porcentaje \\
\hline$<\mathbf{1}$ & Normal & 40 & $93 \%$ \\
\hline $\mathbf{1}-\mathbf{1 , 4 9}$ & Moderado & 3 & $\mathbf{7} \%$ \\
\hline $\mathbf{2 1 , 5}$ & Grave & 0 & $0 \%$ \\
\hline
\end{tabular}

Tabla 74: Distribución de los pacientes de acuerdo a su GIM. 


\section{RESULTADOS}

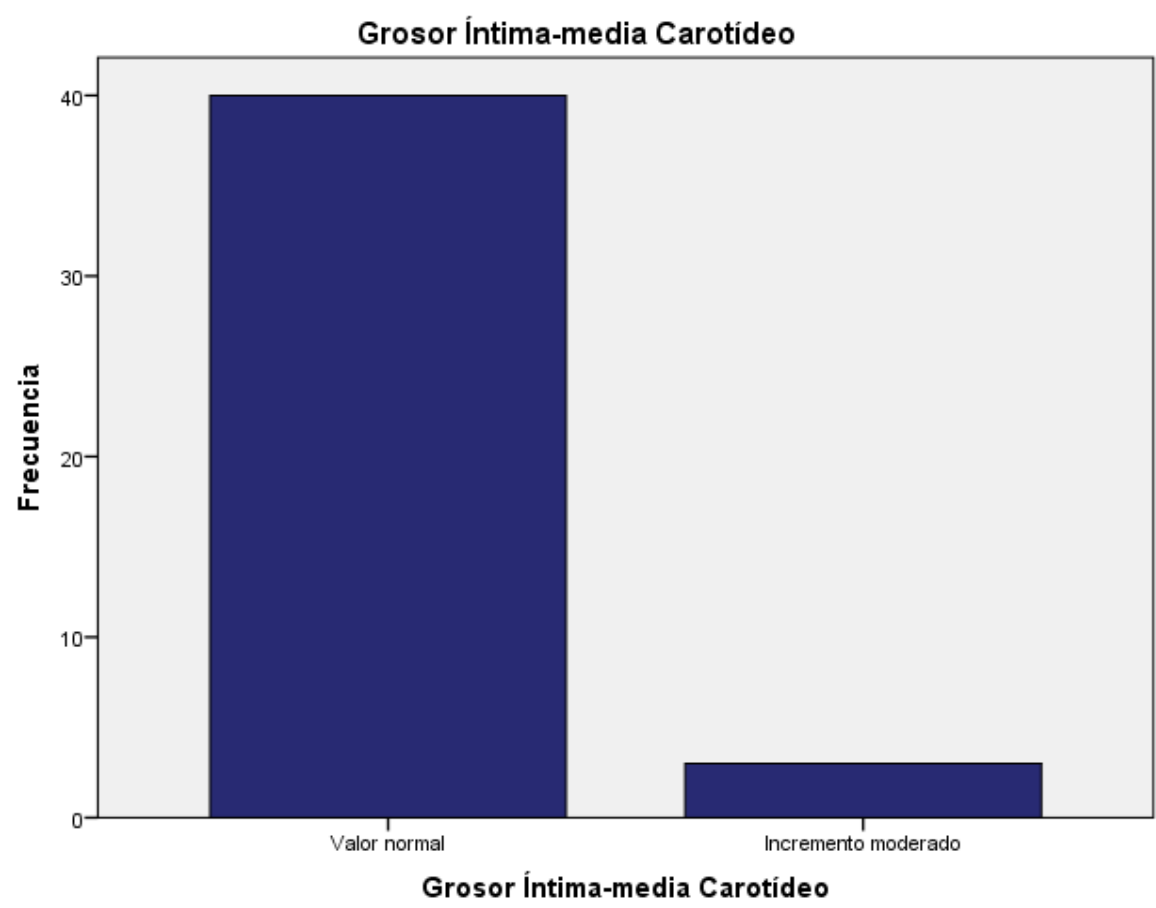

Figura 31: Distribución de los pacientes respecto al GIM.

Para analizar la asociación observada entre las diferentes variables categóricas y cuantitativas y el GIM se crearon dos conjuntos de pacientes según esta última variable, agrupándolos según presentasen un GIM $<0.75$ o $\geq 0.75 \mathrm{~mm}$. Un 48,8\% (21 pacientes) de los pacientes presentaron un GIM carotideo medio $<0.75 \mathrm{~mm}$. Un 51.2\% (22 pacientes) de los pacientes presentaron un GIM carotideo izquierdo o derecho $<0.75$ $\mathrm{mm}$.

En adelante se estudiaran las posibles asociaciones de las variables del estudio tanto con el GIM medio como con el GIM de arteria carótida común derecha e izquierda por separado.

En el análisis de las variables categóricas se ha empleado el test Chi-cuadrado de asociación entre variables medidas en escala nominal, realizando una aproximación al cálculo del tamaño del efecto mediante el cuadrado del valor del coeficiente Phi. 


\section{RESULTADOS}

En este grupo de variables categóricas asociadas al GIM medio (tabla 75) se observa:

- Diabetes $(\mathrm{P}<.05)$ : Todos los pacientes diabéticos presentan un $\mathrm{GIM}>0.75$, con una intensidad del efecto moderada (.156).

Tabla 75: Test Chi-cuadrado. Asociación de Índice de GIM carotideo con diversas variables categóricas -1-

\begin{tabular}{|c|c|c|c|c|c|c|c|}
\hline \multirow[b]{2}{*}{ Variable } & \multirow[b]{2}{*}{ Categoría } & \multicolumn{2}{|c|}{ GIM carotideo \% (n) } & \multirow{2}{*}{$\mathrm{Chi}^{2}$} & \multirow{2}{*}{$\mathrm{Gl}$} & \multirow{2}{*}{$\mathrm{P}$} & \multirow{2}{*}{$\begin{array}{l}\text { Tam. } \\
\text { Efecto } \\
\text { aprox }\end{array}$} \\
\hline & & Inferior & Igual o superior & & & & \\
\hline \multirow[t]{2}{*}{ Sexo } & Mujer & $28.6 \%(6)$ & $27.3 \%(6)$ & 0.00 & 1 & .924 NS & .000 \\
\hline & Hombre & $71.4 \%(15)$ & $72.7 \%(16)$ & & & & \\
\hline \multirow[t]{7}{*}{ Enf. renal de base } & Nefropatía túbulo-interst & $19.0 \%(4)$ & $27.3 \%(6)$ & & & & \\
\hline & Glomerulonefritis & $19.0 \%(4)$ & $22.7 \%(5)$ & & & & \\
\hline & Poliquistosis renal & $33.3 \%(7)$ & $9.1 \%(2)$ & & & & \\
\hline & & & & 8.04 & 5 & $.154^{\mathrm{NS}}$ & .134 \\
\hline & Nefropatía diabética & -- & $13.6 \%(3)$ & & & & \\
\hline & Nefroangioesclerosis & $4.8 \%(1)$ & $9.1 \%(2)$ & & & & \\
\hline & No filiada & $23.8 \%(5)$ & $18.2 \%(4)$ & & & & \\
\hline \multirow[t]{2}{*}{ Mod. Diálisis } & HD & $57.1 \%(12)$ & $77.3 \%(17)$ & 1.17 & 1 & .279 NS & .044 \\
\hline & DP & $42.9 \%(9)$ & $22.7 \%(5)$ & & & & \\
\hline \multirow[t]{3}{*}{ Acceso Vascular } & FAVI & $47.6 \%(10)$ & $68.2 \%(15)$ & & & & \\
\hline & Catéter peritoneal & $42.9 \%(9)$ & $22.7 \%(5)$ & 2.14 & 2 & $.343 \mathrm{Ns}$ & .047 \\
\hline & Catéter vascular & $9.5 \%(2)$ & $9.1 \%(2)$ & & & & \\
\hline HTA & $\mathrm{Si}$ & $85.7 \%(18)$ & $90.9 \%(20)$ & 0.00 & 1 & $.956^{\mathrm{NS}}$ & .006 \\
\hline Diabetes & $\mathrm{Si}$ & -- & $31.8 \%(7)$ & 5.82 & 1 & $.016 *$ & .156 \\
\hline Dislipemia & $\mathrm{Si}$ & $38.1 \%(8)$ & $50.0 \%(11)$ & 0.23 & 1 & .632 NS & .014 \\
\hline Card. Isquémica & $\mathrm{Si}$ & -- & $9.1 \%(2)$ & -- & -- & -- & -- \\
\hline Tabaquismo & $\mathrm{Si}$ & $9.5 \%(2)$ & $31.8 \%(7)$ & 2.02 & 1 & $.155^{\mathrm{NS}}$ & .070 \\
\hline \multirow[t]{3}{*}{ Ecocard. Pre-Tx } & HVI leve & $72.7 \%(8)$ & $46.2 \%(6)$ & & & & \\
\hline & HVI moderada & $27.3 \%$ (3) & $46.2 \%(6)$ & 2.53 & 2 & .283 NS & .082 \\
\hline & HVI grave & -- & $7.7 \%(1)$ & & & & \\
\hline
\end{tabular}

N.S. $=$ NO significativo $(P>$.05) 


\section{RESULTADOS}

En el segundo grupo de variables categóricas estudiadas (tabla 76) se observa:

- $\quad$ Edad ( $P<.05)$ : El grupo de pacientes con GIM medio < 0.75 son más jóvenes que el resto (46.1 vs 53.4), con un efecto bajo (.091).

- Meses en diálisis $(\mathrm{P}<.01)$ : El grupo de pacientes con GIM medio $<0.75$ han permanecido en diálisis un tiempo significativamente inferior (20.86 vs 55.73) siendo el efecto moderado-bajo.

Tabla 76: Test de diferencia entre dos medias. Asociación de Índice de GIM carotideo medio con diversas variables categóricas.2-

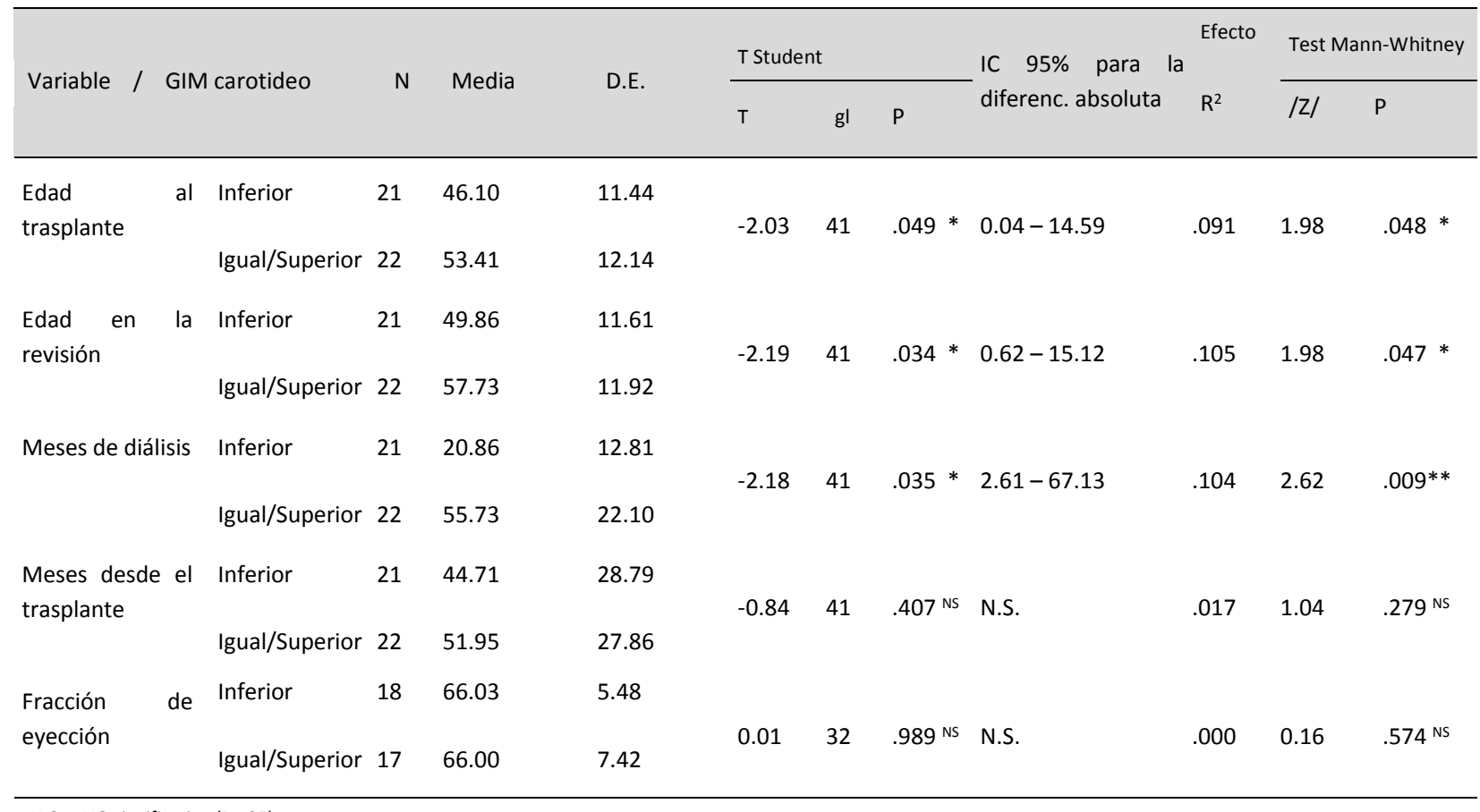

N.S. $=$ NO significativo $(P>05)$ 


\section{RESULTADOS}

En este primer bloque de variables categóricas asociadas al GIM derecho (tabla 77) se observa:

- Modalidad de diálisis $(\mathrm{P}<.05)$ : El grupo de pacientes con GIM medio $\geq 0.75$ recibieron con una mayor frecuencia hemodiálisis como tratamiento renal sustitutivo (85.7 vs 14.3). El efecto estimado indica una asociación moderada (.127).

- Diabetes $(P<.10)$ : El grupo de pacientes con GIM medio $<0.75$ presentan un menor porcentaje de diabetes que el resto ( $4.5 \%$ vs $28.6 \%)$, con una intensidad del efecto leve (.095).

Tabla 77: Test Chi-cuadrado. Asociación de Índice de GIM carótida derecha con diversas variables categóricas -1-

\begin{tabular}{|c|c|c|c|c|c|c|c|}
\hline \multirow[b]{2}{*}{ Variable } & \multirow[b]{2}{*}{ Categoría } & \multicolumn{2}{|c|}{ GIM carótida derecha $\%(n)$} & \multirow{2}{*}{$\mathrm{Chi}^{2}$} & \multirow{2}{*}{$\mathrm{Gl}$} & \multirow{2}{*}{$P$} & \multirow{2}{*}{$\begin{array}{l}\text { Tam. } \\
\text { Efecto } \\
\text { aprox. }\end{array}$} \\
\hline & & Inferior & Igual o superior & & & & \\
\hline \multirow[t]{2}{*}{ Sexo } & Mujer & $36.4 \%(8)$ & $19.0 \%(4)$ & 1.60 & 1 & $.206 \mathrm{NS}$ & .036 \\
\hline & Hombre & $63.6 \%(14)$ & $81.0 \%(17)$ & & & & \\
\hline \multirow[t]{7}{*}{ Enf. renal de base } & Nefropatía túbulo-interst. & $22.7 \%(5)$ & $23.8 \%(5)$ & & & & \\
\hline & Glomerulonefritis & $18.2 \%(4)$ & $23.8 \%(5)$ & & & & \\
\hline & Poliquistosis renal & $31.8 \%(7)$ & $9.5 \%(2)$ & & & & \\
\hline & & & & 7.64 & 5 & $.177^{N S}$ & .077 \\
\hline & Nefropatía diabética & -- & $14.3 \%(3)$ & & & & \\
\hline & Nefroangioesclerosis & $9.1 \%(2)$ & $4.8 \%(1)$ & & & & \\
\hline & No filiada & $18.2 \%(4)$ & $23.8 \%(5)$ & & & & \\
\hline \multirow[t]{2}{*}{ Mod. Diálisis } & $\mathrm{HD}$ & $50.0 \%(11)$ & $85.7 \%(18)$ & 6.24 & 1 & $.030 *$ & .127 \\
\hline & DP & $50.0 \%(11)$ & $14.3 \%(3)$ & & & & \\
\hline \multirow[t]{3}{*}{ Acceso Vascular } & FAVI & $36.4 \%(8)$ & $81.0 \%(17)$ & & & & \\
\hline & Catéter peritoneal & $50.0 \%(11)$ & $14.3 \%(3)$ & 9.20 & 2 & $.010 *$ & .170 \\
\hline & Catéter vascular & $13.6 \%(3)$ & $4.8 \%(1)$ & & & & \\
\hline HTA & $\mathrm{Si}$ & $90.9 \%(20)$ & $85.7 \%(18)$ & 0.00 & 1 & $.956 \mathrm{NS}$ & .006 \\
\hline Diabetes & $\mathrm{Si}$ & $4.5 \%(1)$ & $28.6 \%(6)$ & 2.96 & 1 & $.085^{\mathrm{NS}}$ & .095 \\
\hline Dislipemia & $\mathrm{Si}$ & $50.0 \%(11)$ & $38.1 \%(8)$ & 0.23 & 1 & .632 NS & .014 \\
\hline Card. Isquémica & $\mathrm{Si}$ & -- & $9.5 \%(2)$ & -- & -- & -- & -- \\
\hline Tabaquismo & $\mathrm{Si}$ & $9.1 \%(2)$ & $33.3 \%(7)$ & 2.49 & 1 & $.114 \mathrm{Ns}$ & .081 \\
\hline \multirow[t]{3}{*}{ Ecocard. Pre-Tx } & HVI leve & $72.7 \%(8)$ & $46.2 \%(6)$ & & & & \\
\hline & HVI moderada & $27.3 \%(3)$ & $46.2 \%(6)$ & 2.53 & 2 & $.283^{N S}$ & .082 \\
\hline & HVI grave & -- & $7.7 \%(1)$ & & & & \\
\hline
\end{tabular}




\section{RESULTADOS}

En el siguiente grupo de variables (tabla 78) observamos:

- $\quad$ Edad $(P<.05)$ : El grupo de pacientes con GIM medio < 0.75 son más jóvenes que el resto (45.8 vs 54.05) con tamaño del efecto moderado en este caso (.116).

- Meses en diálisis $(\mathrm{P}<.01)$ : El grupo de pacientes con GIM medio < 0.75 permanecieron menos tiempo en diálisis que el resto (33.41 vs 44.24$)$, aunque el efecto parece muy bajo.

Tabla 78: Test de diferencia entre dos medias. Asociación de Índice de GIM carótida derecha con diversas variables categóricas.$2-$

\begin{tabular}{|c|c|c|c|c|c|c|c|c|c|c|c|c|}
\hline \multirow{2}{*}{$\begin{array}{l}\text { Variable } \\
\text { derecha }\end{array}$} & \multirow{2}{*}{ / } & \multirow{2}{*}{ GIM carótida } & \multirow{2}{*}{$\mathrm{N}$} & \multirow{2}{*}{ Media } & \multirow{2}{*}{ D.E. } & \multicolumn{3}{|c|}{ T Student } & \multirow{2}{*}{$\begin{array}{l}\text { IC } 95 \% \text { para la } \\
\text { diferenc. absoluta }\end{array}$} & \multirow{2}{*}{$\begin{array}{l}\text { Efecto } \\
\mathrm{R}^{2}\end{array}$} & \multicolumn{2}{|c|}{ Test Mann-Whitney } \\
\hline & & & & & & T & gl & $\mathrm{P}$ & & & /Z/ & $P$ \\
\hline \multirow{3}{*}{$\begin{array}{l}\text { Edad } \\
\text { trasplante }\end{array}$} & al & Inferior & 22 & 45.82 & 11.37 & \multirow{3}{*}{-2.32} & \multirow{3}{*}{41} & \multirow{3}{*}{$.026 *$} & \multirow{3}{*}{$1.05-15.41$} & \multirow{3}{*}{.116} & \multirow{3}{*}{2.21} & \multirow{3}{*}{$.027 *$} \\
\hline & & & & & & & & & & & & \\
\hline & & Igual/Superior & 21 & 54.05 & 11.94 & & & & & & & \\
\hline \multirow{3}{*}{\multicolumn{2}{|c|}{$\begin{array}{l}\text { Edad en } \\
\text { revisión }\end{array}$}} & Inferior & 22 & 49.77 & 11.77 & \multirow{3}{*}{-2.36} & \multirow{3}{*}{41} & \multirow{3}{*}{$.023 *$} & \multirow{3}{*}{$1.23-15.61$} & \multirow{3}{*}{.120} & \multirow{3}{*}{2.30} & \multirow{3}{*}{$.022 *$} \\
\hline & & & & & & & & & & & & \\
\hline & & Igual/Superior & 21 & 58.19 & 11.57 & & & & & & & \\
\hline \multirow{3}{*}{\multicolumn{2}{|c|}{ Meses de diálisis }} & Inferior & 22 & 33.41 & 70.15 & \multirow{3}{*}{-0.64} & \multirow{3}{*}{41} & \multirow{3}{*}{.523 Ns } & \multirow{3}{*}{ N.S. } & \multirow{3}{*}{.010} & \multirow{3}{*}{2.30} & \multirow{3}{*}{$.003 * *$} \\
\hline & & & & & & & & & & & & \\
\hline & & Igual/Superior & 21 & 44.24 & 32.33 & & & & & & & \\
\hline \multirow{3}{*}{\multicolumn{2}{|c|}{$\begin{array}{l}\text { Meses desde el } \\
\text { trasplante }\end{array}$}} & Inferior & 22 & 46.00 & 30.56 & & & & & & & \\
\hline & & & & & & -0.57 & 41 & $.571^{\mathrm{NS}}$ & N.S. & .008 & 0.68 & .496 NS \\
\hline & & Igual/Superior & 21 & 50.95 & 26.04 & & & & & & & \\
\hline Fracción & de & Inferior & 19 & 65.08 & 6.12 & & & & & & & \\
\hline eyección & & Igual/Superior & 16 & 67.13 & 6.86 & -0.93 & 32 & $.358^{\mathrm{NS}}$ & N.S. & .026 & 1.03 & $.304^{\mathrm{NS}}$ \\
\hline
\end{tabular}




\section{RESULTADOS}

En este grupo de variables categóricas (tabla 79 ) no se ha encontrado ninguna significación estadística ( $P>.05$ ) en la búsqueda de asociaciones con el GIM en carótida izquierda.

Tabla 79: Test Chi-cuadrado. Asociación de Índice de GIM carótida izquierda con diversas variables categóricas -1-

\begin{tabular}{|c|c|c|c|c|c|c|c|}
\hline \multirow[b]{2}{*}{ Variable } & \multirow[b]{2}{*}{ Categoría } & \multicolumn{2}{|c|}{ GIM carótida izquierda $\%(n)$} & \multirow{2}{*}{$\mathrm{Chi}^{2}$} & \multirow{2}{*}{$\mathrm{Gl}$} & \multirow{2}{*}{$P$} & \multirow{2}{*}{$\begin{array}{l}\text { Tam. } \\
\text { Efecto } \\
\text { aprox. }\end{array}$} \\
\hline & & Inferior & Igual o superior & & & & \\
\hline \multirow[t]{2}{*}{ Sexo } & Mujer & $27.3 \% 6)$ & $28.6 \%(6)$ & 0.10 & 1 & $.924^{\mathrm{NS}}$ & .000 \\
\hline & Hombre & $72.7 \%(16)$ & $71.4 \%(15)$ & & & & \\
\hline \multirow[t]{7}{*}{ Enf. renal de base } & Nefropatía túbulo-interst. & $18.2 \%(4)$ & $28.6 \%(6)$ & & & & \\
\hline & Glomerulonefritis & $13.6 \%(3)$ & $28.6 \%(6)$ & & & & \\
\hline & Poliquistosis renal & $31.8 \%(7)$ & $9.5 \%(2)$ & & & & \\
\hline & & & & 6.04 & 5 & .302 Ns & .119 \\
\hline & Nefropatía diabética & $4.5 \%(1)$ & $9.5 \%(2)$ & & & & \\
\hline & Nefroangioesclerosis & $4.5 \%(1)$ & $9.5 \%(2)$ & & & & \\
\hline & No filiada & $27.3 \%(6)$ & $14.3 \%(3)$ & & & & \\
\hline \multirow[t]{2}{*}{ Mod. Diálisis } & $\mathrm{HD}$ & $63.6 \%(14)$ & $71.4 \%(15)$ & 0.05 & 1 & .826 NS & .006 \\
\hline & DP & $36.4 \%(8)$ & $28.6 \%(6)$ & & & & \\
\hline \multirow[t]{3}{*}{ Acceso Vascular } & FAVI & $54.5 \%(12)$ & $61.9 \%(13)$ & & & & \\
\hline & Catéter peritoneal & $36.4 \%(8)$ & $28.6 \%(6)$ & 0.30 & 2 & .859 NS & .006 \\
\hline & Catéter vascular & $9.1 \%(2)$ & $9.5 \%(2)$ & & & & \\
\hline HTA & $\mathrm{Si}$ & $90.9 \%(20)$ & $85.7 \%(18)$ & 0.00 & 1 & .956 NS & .006 \\
\hline Diabetes & $\mathrm{Si}$ & $9.1 \%(2)$ & $23.8 \%(5)$ & 0.80 & 1 & .372 NS & .038 \\
\hline Dislipemia & $\mathrm{Si}$ & $36.4 \%(8)$ & $52.4 \%(11)$ & 0.56 & 1 & $.453^{\mathrm{NS}}$ & .025 \\
\hline Card. Isquémica & $\mathrm{Si}$ & -- & $9.5 \%(2)$ & -- & -- & -- & -- \\
\hline Tabaquismo & $\mathrm{Si}$ & $9.1 \%(2)$ & $33.3 \%(7)$ & 2.49 & 1 & .114 Ns & .081 \\
\hline \multirow[t]{3}{*}{ Ecocard. Pre-Tx } & HVI leve & $66.7 \%(8)$ & $50.0 \%(6)$ & & & & \\
\hline & HVI moderada & $33.3 \%(4)$ & $41.7 \%(5)$ & 1.78 & 2 & $.410^{\mathrm{NS}}$ & .055 \\
\hline & HVI grave & -- & $8.3 \%(1)$ & & & & \\
\hline
\end{tabular}

N.S. = NO significativo $(P>05)$ 


\section{RESULTADOS}

Finalmente, para terminar con el análisis de la asociación de variables categóricas (tabla

80) es este último bloque tampoco aparece significación alguna ( $P>05)$.

Tabla 80: Test de diferencia entre 2 medias. Asociación de Índice de GIM carótida izquierda con variables categóricas.-2-

\begin{tabular}{|c|c|c|c|c|c|c|c|c|c|c|c|c|}
\hline \multirow{2}{*}{$\begin{array}{l}\text { Variable } \\
\text { izquierda }\end{array}$} & \multirow{2}{*}{ / } & \multirow{2}{*}{ GIM carótida } & \multirow{2}{*}{$\mathrm{N}$} & \multirow{2}{*}{ Media } & \multirow{2}{*}{ D.E. } & \multicolumn{3}{|c|}{ T Student } & \multirow{2}{*}{$\begin{array}{l}\text { IC } 95 \% \text { para la } \\
\text { diferenc. absoluta }\end{array}$} & \multirow{2}{*}{$\begin{array}{l}\text { Efecto } \\
\mathrm{R}^{2}\end{array}$} & \multicolumn{2}{|c|}{ Test Mann-Whitney } \\
\hline & & & & & & $\mathrm{T}$ & $\mathrm{gl}$ & $P$ & & & /Z/ & $P$ \\
\hline \multirow{3}{*}{\multicolumn{2}{|c|}{$\begin{array}{l}\text { Edad } \\
\text { trasplante }\end{array}$}} & Inferior & 22 & 48.73 & 14.08 & \multirow{3}{*}{-0.60} & \multirow{3}{*}{41} & \multirow{3}{*}{$.549 \mathrm{Ns}$} & \multirow{3}{*}{ N.S. } & \multirow{3}{*}{.009} & \multirow{3}{*}{0.92} & \multirow{3}{*}{$.356^{\mathrm{NS}}$} \\
\hline & & & & & & & & & & & & \\
\hline & & Igual/Superior & 21 & 51.00 & 10.18 & & & & & & & \\
\hline \multirow{3}{*}{\multicolumn{2}{|c|}{$\begin{array}{l}\text { Edad en } \\
\text { revisión }\end{array}$}} & Inferior & 22 & 52.45 & 14.19 & \multirow{3}{*}{-0.78} & \multirow{3}{*}{41} & \multirow{3}{*}{.442 Ns } & \multirow{3}{*}{ N.S. } & \multirow{3}{*}{.014} & \multirow{3}{*}{0.86} & \multirow{3}{*}{$.338^{\mathrm{NS}}$} \\
\hline & & & & & & & & & & & & \\
\hline & & Igual/Superior & 21 & 55.38 & 10.06 & & & & & & & \\
\hline \multirow{3}{*}{\multicolumn{2}{|c|}{ Meses de diálisis }} & Inferior & 22 & 25.50 & 18.47 & \multirow{3}{*}{-1.65} & \multirow{3}{*}{41} & \multirow{3}{*}{.106 Ns } & \multirow{3}{*}{ N.S. } & \multirow{3}{*}{.063} & \multirow{3}{*}{1.50} & \multirow{3}{*}{.135 NS } \\
\hline & & & & & & & & & & & & \\
\hline & & Igual/Superior & 21 & 52.52 & 74.33 & & & & & & & \\
\hline \multirow{3}{*}{\multicolumn{2}{|c|}{$\begin{array}{l}\text { Meses desde el } \\
\text { trasplante }\end{array}$}} & Inferior & 22 & 44.27 & 26.83 & & & & & & & \\
\hline & & & & & & -0.99 & 41 & .330 NS & N.S. & .023 & 1.08 & .279 NS \\
\hline & & Igual/Superior & 21 & 52.76 & 29.62 & & & & & & & \\
\hline Fracción & le & Inferior & 18 & 65.64 & 5.31 & & & & & & & \\
\hline eyección & & Igual/Superior & 17 & 66.41 & 7.63 & -0.35 & 32 & .729 NS & N.S. & .004 & 0.56 & .574 NS \\
\hline
\end{tabular}

N.S. $=$ NO significativo $(P>05)$

En adelante se analizarán las posibles asociaciones entre las variables cuantitativas incluidas en el estudio y el GIM, tanto medio como de arteria carótida derecha e izquierda (tabla 81). 


\section{RESULTADOS}

En el primer grupo de variables categóricas no aparece ninguna significación ( $P>.05)$.

Tabla 81: Test de diferencia entre dos medias. Asociación de Índice de GIM carotideo con diversas variables antropométricas y de la analítica previa al trasplante.-1-

\begin{tabular}{|c|c|c|c|c|c|c|c|c|c|c|c|}
\hline \multirow{2}{*}{ Variable / } & \multirow{2}{*}{ GIM carotideo } & \multirow{2}{*}{$\mathrm{N}$} & \multirow{2}{*}{ Media } & \multirow{2}{*}{ D.E. } & \multicolumn{3}{|c|}{ T Student } & \multirow{2}{*}{$\begin{array}{l}\text { IC } 95 \% \text { para la } \\
\text { diferenc. absoluta }\end{array}$} & \multirow{2}{*}{$\begin{array}{l}\text { Efecto } \\
\mathrm{R}^{2}\end{array}$} & \multicolumn{2}{|c|}{ Test Mann-Whitney } \\
\hline & & & & & $T$ & gl & $\mathrm{P}$ & & & |Z| & $P$ \\
\hline \multirow[t]{3}{*}{ Altura } & Inferior & 21 & 167.69 & 6.69 & & & & & & & \\
\hline & & & & & -0.37 & 41 & $.712^{\mathrm{NS}}$ & N.S. & .003 & 0.39 & $.697^{\text {NS }}$ \\
\hline & Igual/Superior & 22 & 168.73 & 8.61 & & & & & & & \\
\hline \multirow[t]{3}{*}{ Peso } & Inferior & 21 & 70.63 & 11.01 & & & & & & & \\
\hline & & & & & -0.14 & 41 & .892 NS & N.S. & .000 & 0.18 & $.855^{\mathrm{NS}}$ \\
\hline & Igual/Superior & 22 & 71.13 & 12.62 & & & & & & & \\
\hline \multirow[t]{3}{*}{ IMC } & Inferior & 21 & 25.09 & 3.23 & & & & & & & \\
\hline & & & & & 0.29 & 41 & .775 NS & N.S. & .002 & 0.32 & .752 Ns \\
\hline & Igual/Superior & 22 & 24.82 & 2.76 & & & & & & & \\
\hline \multirow[t]{3}{*}{ TAS } & Inferior & 21 & 144.57 & 24.55 & & & & & & & \\
\hline & & & & & -0.39 & 41 & $.699^{\mathrm{NS}}$ & N.S. & .004 & 0.44 & .661 Ns \\
\hline & Igual/Superior & 22 & 147.64 & 26.94 & & & & & & & \\
\hline \multirow[t]{3}{*}{ TAD } & Inferior & 21 & 86.43 & 12.57 & & & & & & & \\
\hline & & & & & 1.13 & 41 & .264 NS & N.S. & .030 & 1.13 & $.257^{\mathrm{NS}}$ \\
\hline & Igual/Superior & 22 & 82.00 & 13.05 & & & & & & & \\
\hline \multirow[t]{3}{*}{ Diuresis } & Inferior & 21 & 1269.05 & 1052.20 & & & & & & & \\
\hline & & & & & 1.65 & 41 & $.107^{\mathrm{NS}}$ & N.S. & .062 & 1.92 & $.055^{\mathrm{NS}}$ \\
\hline & Igual/Superior & 22 & 780.45 & 886.04 & & & & & & & \\
\hline \multirow[t]{3}{*}{ Hemoglobina } & Inferior & 21 & 12.68 & 1.74 & & & & & & & \\
\hline & & & & & 0.16 & 41 & $.875^{\mathrm{NS}}$ & N.S. & .001 & 0.29 & .770 NS \\
\hline & Igual/Superior & 22 & 12.60 & 1.61 & & & & & & & \\
\hline \multirow[t]{3}{*}{ Hematocrito } & Inferior & 21 & 38.12 & 5.13 & & & & & & & \\
\hline & & & & & 0.02 & 41 & .986 NS & N.S. & .000 & 0.21 & .836 NS \\
\hline & Igual/Superior & 22 & 38.09 & 5.26 & & & & & & & \\
\hline \multirow[t]{3}{*}{ Leucocitos } & Inferior & 21 & 6970.95 & 1934.44 & & & & & & & \\
\hline & & & & & 1.02 & 41 & .312 NS & N.S. & .025 & 1.21 & .224 NS \\
\hline & Igual/Superior & 22 & 6461.36 & 1276.78 & & & & & & & \\
\hline \multirow[t]{2}{*}{ Plaquetas } & Inferior & 21 & 196619.05 & 58523.91 & & & & & & & \\
\hline & Igual/Superior & 22 & 181090.91 & 78423.09 & 0.73 & 41 & .468 NS & N.S. & .013 & 1.02 & $.307^{\mathrm{NS}}$ \\
\hline
\end{tabular}

N.S. $=$ NO significativo $(\mathrm{P}>05) \quad * *=$ Altamente significativo al $1 \%(\mathrm{P}<.01)$ 


\section{RESULTADOS}

En el siguiente bloque (tabla 82) tampoco se han encontrado relaciones significativas $(\mathrm{P}>$.05).

Tabla 82: Test de diferencia entre dos medias. Asociación de Índice de GIM carotideo con diversas variables de la analítica previa al trasplante.-2-

\begin{tabular}{|c|c|c|c|c|c|c|c|c|c|c|c|}
\hline \multirow{2}{*}{ Variable / } & \multirow{2}{*}{ n carotideo } & \multirow{2}{*}{$\mathrm{N}$} & \multirow{2}{*}{ Media } & \multirow{2}{*}{ D.E. } & \multicolumn{3}{|c|}{ T Student } & \multirow{2}{*}{$\begin{array}{l}\text { IC } 95 \% \text { para la } \\
\text { diferenc. absoluta }\end{array}$} & \multirow{2}{*}{$\begin{array}{l}\text { Efecto } \\
\mathrm{R}^{2}\end{array}$} & \multicolumn{2}{|c|}{ Test Mann-Whitney } \\
\hline & & & & & $\mathrm{T}$ & $\mathrm{gl}$ & $P$ & & & /Z/ & $P$ \\
\hline \multirow[t]{3}{*}{ Urea } & Inferior & 21 & 151.76 & 38.41 & & & & & & & \\
\hline & & & & & 1.29 & 41 & .203 NS & N.S. & .039 & 1.08 & .129 NS \\
\hline & Igual/Superior & 22 & 138.05 & 30.40 & & & & & & & \\
\hline \multirow[t]{3}{*}{ Glucosa } & Inferior & 21 & 88.86 & 9.60 & & & & & & & \\
\hline & & & & & -1.78 & 41 & $.083^{\text {NS }}$ & N.S. & .071 & 1.32 & $.627^{\mathrm{NS}}$ \\
\hline & Igual/Superior & 22 & 101.05 & 30.00 & & & & & & & \\
\hline \multirow[t]{3}{*}{ Creatinina } & Inferior & 21 & 8.85 & 2.72 & & & & & & & \\
\hline & & & & & 0.00 & 41 & .998 NS & N.S. & .000 & 0.15 & $.210 \mathrm{NS}$ \\
\hline & Igual/Superior & 22 & 8.85 & 2.69 & & & & & & & \\
\hline \multirow[t]{3}{*}{ Triglicéridos } & Inferior & 21 & 108.29 & 35.76 & & & & & & & \\
\hline & & & & & -1.39 & 41 & $.171^{\text {NS }}$ & N.S. & .045 & 1.58 & .280 NS \\
\hline & Igual/Superior & 22 & 125.59 & 44.88 & & & & & & & \\
\hline \multirow[t]{3}{*}{ Colesterol total } & Inferior & 21 & 176.24 & 60.80 & & & & & & & \\
\hline & & & & & 0.91 & 41 & .370 NS & N.S. & .020 & 0.44 & .568 NS \\
\hline & Igual/Superior & 22 & 161.86 & 41.94 & & & & & & & \\
\hline \multirow[t]{3}{*}{ Proteínas totales } & Inferior & 21 & 6.79 & 0.54 & & & & & & & \\
\hline & & & & & -1.22 & 41 & $.230 \mathrm{NS}$ & N.S. & .035 & 1.04 & .584 NS \\
\hline & Igual/Superior & 22 & 7.00 & 0.56 & & & & & & & \\
\hline \multirow[t]{3}{*}{ Calcio } & Inferior & 21 & 9.27 & 0.98 & & & & & & & \\
\hline & & & & & 0.04 & 41 & .971 NS & N.S. & .000 & 0.63 & .349 NS \\
\hline & Igual/Superior & 22 & 9.26 & 0.77 & & & & & & & \\
\hline \multirow[t]{3}{*}{ Calcio correg. } & Inferior & 21 & 9.63 & 1.01 & & & & & & & \\
\hline & & & & & 0.41 & 41 & .681 NS & N.S. & .004 & 1.03 & .296 NS \\
\hline & Igual/Superior & 22 & 9.52 & 0.75 & & & & & & & \\
\hline \multirow[t]{2}{*}{ Prod. Calc/Fósf. } & Inferior & 21 & 46.26 & 10.62 & & & & & & & \\
\hline & Igual/Superior & 22 & 46.52 & 10.57 & -0.08 & 41 & .935 NS & N.S. & .000 & 0.35 & $.325^{\text {NS }}$ \\
\hline
\end{tabular}




\section{RESULTADOS}

En el bloque siguiente (tabla 83) no se encuentran diferencias significativas ( $P>.05$ )

Tabla 83: Test de diferencia entre dos medias. Asociación de Índice de GIM carotideo con diversas variables de la analítica previa al trasplante.-3-

\begin{tabular}{|c|c|c|c|c|c|c|c|c|c|c|c|}
\hline \multirow{2}{*}{ Variable } & \multirow{2}{*}{ carotideo } & \multirow{2}{*}{$\mathrm{N}$} & \multirow{2}{*}{ Media } & \multirow{2}{*}{ D.E. } & \multicolumn{3}{|c|}{ T Student } & \multirow{2}{*}{$\begin{array}{l}\text { IC } 95 \% \text { para la } \\
\text { diferenc. absoluta }\end{array}$} & \multirow{2}{*}{$\begin{array}{l}\text { Efecto } \\
\mathrm{R}^{2}\end{array}$} & \multicolumn{2}{|c|}{ Test Mann-Whitney } \\
\hline & & & & & $\mathrm{T}$ & gl & $P$ & & & /Z/ & $P$ \\
\hline \multirow[t]{3}{*}{ Fósforo } & Inferior & 21 & 4.98 & 0.98 & & & & & & & \\
\hline & & & & & -0.17 & 41 & $.868^{N S}$ & N.S. & .001 & 0.29 & .770 NS \\
\hline & Igual/Superior & 22 & 5.03 & 1.16 & & & & & & & \\
\hline \multirow[t]{3}{*}{ Fosfata Alcalina } & Inferior & 21 & 83.67 & 36.91 & & & & & & & \\
\hline & & & & & -1.83 & 41 & $.075^{\mathrm{NS}}$ & N.S. & .075 & 1.28 & .202 NS \\
\hline & Igual/Superior & 22 & 117.55 & 76.88 & & & & & & & \\
\hline \multirow[t]{3}{*}{ H. Paratiroidea } & Inferior & 22 & 327.56 & 366.67 & & & & & & & \\
\hline & & & & & -0.48 & 40 & $.636^{\mathrm{NS}}$ & N.S. & .006 & 0.18 & .860 NS \\
\hline & Igual/Superior & 22 & 384.83 & 406.67 & & & & & & & \\
\hline \multirow[t]{3}{*}{$\mathrm{Ph}$} & Inferior & 21 & 7.38 & 0.06 & & & & & & & \\
\hline & & & & & 1.09 & 41 & $.282^{\mathrm{NS}}$ & N.S. & .028 & 0.89 & $.374^{N S}$ \\
\hline & Igual/Superior & 22 & 7.36 & 0.04 & & & & & & & \\
\hline \multirow[t]{3}{*}{ Bicarbonato } & Inferior & 21 & 24.28 & 2.94 & & & & & & & \\
\hline & & & & & 1.38 & 41 & .174 NS & N.S. & .045 & 1.24 & $.215^{\mathrm{NS}}$ \\
\hline & Igual/Superior & 22 & 23.11 & 2.60 & & & & & & & \\
\hline \multirow[t]{3}{*}{ MDRDa } & Inferior & 21 & 7.06 & 2.35 & & & & & & & \\
\hline & & & & & 0.31 & 41 & $.758^{N S}$ & N.S. & .002 & 0.15 & $.884^{\mathrm{NS}}$ \\
\hline & Igual/Superior & 22 & 6.85 & 2.14 & & & & & & & \\
\hline \multirow[t]{3}{*}{ Cock. Gault } & Inferior & 21 & 10.89 & 4.40 & & & & & & & \\
\hline & & & & & 0.96 & 41 & $.343^{N S}$ & N.S. & .022 & 0.51 & $.610^{\mathrm{NS}}$ \\
\hline & Igual/Superior & 22 & 9.81 & 2.81 & & & & & & & \\
\hline \multirow[t]{3}{*}{ Mayo Quadr. } & Inferior & 21 & 9.40 & 2.17 & & & & & & & \\
\hline & & & & & 0.86 & 41 & .398 NS & N.S. & .018 & 0.61 & .544 NS \\
\hline & Igual/Superior & 22 & 8.89 & 1.74 & & & & & & & \\
\hline \multirow[t]{2}{*}{ CKD-EPI } & Inferior & 21 & 6.61 & 2.40 & & & & & & & \\
\hline & Igual/Superior & 22 & 6.24 & 2.04 & 0.54 & 41 & .594 NS & N.S. & .007 & 0.19 & .846 NS \\
\hline
\end{tabular}

N.S. $=$ NO significativo $(P>.05)$ 


\section{RESULTADOS}

En el siguiente grupo de variables (tabla 84) observamos:

- Leucocitos $(P<.05)$ : Los pacientes del grupo con GIM carotideo medio $<0.75$ tienen una media más elevada de leucocitos que el resto de casos (10747.14 vs 8258.64) siendo el tamaño del efecto moderado (.114).

Tabla 84: Test de diferencia entre dos medias. Asociación de Índice de GIM carotideo con diversas variables antropométricas y de la analítica al alta tras el trasplante.-1-

\begin{tabular}{|c|c|c|c|c|c|c|c|c|c|c|c|}
\hline \multirow{2}{*}{ Variable / } & \multirow{2}{*}{ GIM carotideo } & \multirow{2}{*}{$\mathrm{N}$} & \multirow{2}{*}{ Media } & \multirow{2}{*}{ D.E. } & \multicolumn{3}{|c|}{ T Student } & \multirow{2}{*}{$\begin{array}{l}\text { IC 95\% para la } \\
\text { diferenc. absoluta }\end{array}$} & \multirow{2}{*}{$\begin{array}{l}\text { Efecto } \\
\mathrm{R}^{2}\end{array}$} & \multicolumn{2}{|c|}{ Test Mann-Whitney } \\
\hline & & & & & $\mathrm{T}$ & $\mathrm{gl}$ & $P$ & & & /Z/ & $P$ \\
\hline \multirow[t]{3}{*}{ Peso } & Inferior & 21 & 69.51 & 11.68 & & & & & & & \\
\hline & & & & & 0.12 & 41 & .905 NS & N.S. & .000 & 0.51 & .610 NS \\
\hline & Igual/Superior & 22 & 69.08 & 11.78 & & & & & & & \\
\hline \multirow[t]{3}{*}{ IMC1 } & Inferior & 21 & 24.70 & 3.70 & & & & & & & \\
\hline & & & & & 0.53 & 41 & .599 NS & N.S. & .007 & 0.35 & .725 NS \\
\hline & Igual/Superior & 22 & 24.17 & 2.84 & & & & & & & \\
\hline \multirow[t]{3}{*}{ TAS } & Inferior & 21 & 136.38 & 24.18 & & & & & & & \\
\hline & & & & & -0.37 & 41 & $.716^{\mathrm{NS}}$ & N.S. & .003 & 0.63 & $.527^{\mathrm{NS}}$ \\
\hline & Igual/Superior & 22 & 139.05 & 23.53 & & & & & & & \\
\hline \multirow[t]{3}{*}{ TAD } & Inferior & 21 & 78.10 & 15.10 & & & & & & & \\
\hline & & & & & -0.18 & 41 & $.857^{\mathrm{NS}}$ & N.S. & .001 & 0.44 & .661 NS \\
\hline & Igual/Superior & 22 & 78.86 & 12.59 & & & & & & & \\
\hline \multirow[t]{3}{*}{ Diuresis } & Inferior & 21 & 2558.57 & 974.75 & & & & & & & \\
\hline & & & & & 0.98 & 41 & .330 NS & N.S. & .023 & 0.07 & .942 NS \\
\hline & Igual/Superior & 22 & 2323.86 & 534.94 & & & & & & & \\
\hline \multirow[t]{3}{*}{ Hemoglobina } & Inferior & 21 & 10.93 & 1.24 & & & & & & & \\
\hline & & & & & 1.01 & 41 & $.316^{\mathrm{NS}}$ & N.S. & .025 & 1.25 & $.210^{\mathrm{NS}}$ \\
\hline & Igual/Superior & 22 & 10.52 & 1.40 & & & & & & & \\
\hline \multirow[t]{3}{*}{ Hematocrito } & Inferior & 21 & 32.97 & 3.48 & & & & & & & \\
\hline & & & & & 0.41 & 41 & $.684^{\mathrm{NS}}$ & N.S. & .004 & 0.90 & .369 NS \\
\hline & Igual/Superior & 22 & 32.47 & 4.49 & & & & & & & \\
\hline \multirow[t]{3}{*}{ Leucocitos } & Inferior & 21 & 10747.14 & 3854.68 & & & & & & & \\
\hline & & & & & 2.30 & 41 & $.027 *$ & $301.96-4675.05$ & .114 & 2.06 & $.039 *$ \\
\hline & Igual/Superior & 22 & 8258.64 & 3230.86 & & & & & & & \\
\hline \multirow[t]{3}{*}{ Plaquetas } & Inferior & 21 & 281952.38 & 123658.59 & & & & & & & \\
\hline & & & & & 1.19 & 41 & .243 NS & N.S. & .033 & 1.32 & .185 NS \\
\hline & Igual/Superior & 22 & 240363.64 & 10617.41 & & & & & & & \\
\hline \multirow[t]{2}{*}{ VSG } & Inferior & 21 & 35.10 & 30.12 & & & & & & & \\
\hline & Igual/Superior & 22 & 34.14 & 26.76 & 0.11 & 41 & $.913^{N S}$ & N.S. & .000 & 0.04 & $.971^{\mathrm{NS}}$ \\
\hline
\end{tabular}




\section{RESULTADOS}

En el bloque que sigue (tabla 85) se observa:

- Triglicéridos ( $\mathrm{P}<.05)$ : El grupo de pacientes con GIM medio $<0.75$ presentan un valor menor que el resto de pacientes (124.14 vs 167.09) con un tamaño del efecto moderado bajo (.100).

Tabla 85: Test de diferencia entre dos medias. Asociación de Índice de GIM carotideo con diversas variables de la analítica al alta tras el trasplante.-2-

\begin{tabular}{|c|c|c|c|c|c|c|c|c|c|c|c|}
\hline \multirow{2}{*}{ Variable } & \multirow{2}{*}{1 carotideo } & \multirow{2}{*}{$\mathrm{N}$} & \multirow{2}{*}{ Media } & \multirow{2}{*}{ D.E. } & \multicolumn{3}{|c|}{ T Student } & \multirow{2}{*}{$\begin{array}{l}\text { IC 95\% para la } \\
\text { diferenc. absoluta }\end{array}$} & \multirow{2}{*}{$\begin{array}{l}\text { Efecto } \\
\mathrm{R}^{2}\end{array}$} & \multicolumn{2}{|c|}{ Test Mann-Whitney } \\
\hline & & & & & $\mathrm{T}$ & $\mathrm{gl}$ & $P$ & & & /Z/ & $P$ \\
\hline \multirow[t]{3}{*}{ Urea } & Inferior & 21 & 87.43 & 43.98 & & & & & & & \\
\hline & & & & & -0.23 & 41 & $.818^{\text {NS }}$ & N.S. & .001 & 0.85 & .395 NS \\
\hline & Igual/Superior & 22 & 90.18 & 33.41 & & & & & & & \\
\hline \multirow[t]{3}{*}{ Glucosa } & Inferior & 21 & 96.62 & 13.72 & & & & & & & \\
\hline & & & & & -1.37 & 41 & .179 NS & N.S. & .044 & 0.28 & $.780^{\mathrm{NS}}$ \\
\hline & Igual/Superior & 22 & 109.64 & 41.53 & & & & & & & \\
\hline \multirow[t]{3}{*}{ Creatinina } & Inferior & 21 & 2.43 & 1.65 & & & & & & & \\
\hline & & & & & 1.00 & 41 & .321 NS & N.S. & .024 & 0.60 & .551 NS \\
\hline & Igual/Superior & 22 & 2.01 & 1.06 & & & & & & & \\
\hline \multirow[t]{3}{*}{ Triglicéridos } & Inferior & 21 & 124.14 & 42.54 & & & & & & & \\
\hline & & & & & -2.13 & 41 & $.039 *$ & $2.27-83.62$ & .100 & 1.77 & .076 NS \\
\hline & Igual/Superior & 22 & 167.09 & 82.37 & & & & & & & \\
\hline \multirow[t]{3}{*}{ Colesterol total } & Inferior & 21 & 197.67 & 48.71 & & & & & & & \\
\hline & & & & & 1.70 & 41 & .097 NS & N.S. & .066 & 1.37 & $.170^{\mathrm{NS}}$ \\
\hline & Igual/Superior & 22 & 172.32 & 49.17 & & & & & & & \\
\hline \multirow[t]{3}{*}{ Proteínas totales } & Inferior & 21 & 6.31 & 0.49 & & & & & & & \\
\hline & & & & & 1.30 & 41 & $.201^{\mathrm{NS}}$ & N.S. & .040 & 1.51 & $.131^{\mathrm{NS}}$ \\
\hline & Igual/Superior & 22 & 6.09 & 0.63 & & & & & & & \\
\hline \multirow[t]{3}{*}{ Calcio } & Inferior & 21 & 9.84 & 0.92 & & & & & & & \\
\hline & & & & & 1.95 & 41 & $.058^{\mathrm{NS}}$ & N.S. & .085 & 1.80 & .072 NS \\
\hline & Igual/Superior & 22 & 9.34 & 0.77 & & & & & & & \\
\hline \multirow[t]{3}{*}{ Calcio correg. } & Inferior & 21 & 10.44 & 0.87 & & & & & & & \\
\hline & & & & & 1.62 & 41 & $.113^{\mathrm{NS}}$ & N.S. & .060 & 1.41 & .159 Ns \\
\hline & Igual/Superior & 22 & 10.05 & 0.71 & & & & & & & \\
\hline \multirow[t]{3}{*}{ Prod. Calc/Fósf. } & Inferior & 21 & 32.20 & 12.27 & & & & & & & \\
\hline & & & & & 1.11 & 41 & $.275^{\mathrm{NS}}$ & N.S. & .029 & 1.52 & .129 NS \\
\hline & Igual/Superior & 22 & 28.80 & 7.37 & & & & & & & \\
\hline \multirow[t]{2}{*}{ Fósforo } & Inferior & 21 & 3.27 & 1.27 & & & & & & & \\
\hline & Igual/Superior & 22 & 3.10 & 0.78 & 0.53 & 41 & $.596 \mathrm{NS}$ & N.S. & .007 & 0.41 & .679 Ns \\
\hline
\end{tabular}

N.S. $=$ NO significativo $(P>05)$ 


\section{RESULTADOS}

En este grupo (tabla 86) no se han detectado diferencias que tengan significación $(\mathrm{P}>$.05).

Tabla 86: Test de diferencia entre dos medias. Asociación de Índice de GIM carotideo con diversas variables de la analítica al alta tras el trasplante.-3-

\begin{tabular}{|c|c|c|c|c|c|c|c|c|c|c|c|}
\hline \multirow{2}{*}{ Variable / G } & \multirow{2}{*}{ И carotideo } & \multirow{2}{*}{$\mathrm{N}$} & \multirow{2}{*}{ Media } & \multirow{2}{*}{ D.E. } & \multicolumn{3}{|c|}{ T Student } & \multirow{2}{*}{$\begin{array}{l}\text { IC } 95 \% \text { para la } \\
\text { diferenc. absoluta }\end{array}$} & \multirow{2}{*}{$\begin{array}{l}\text { Efecto } \\
\mathrm{R}^{2}\end{array}$} & \multicolumn{2}{|c|}{ Test Mann-Whitney } \\
\hline & & & & & $\mathrm{T}$ & $\mathrm{gl}$ & $P$ & & & /Z/ & $P$ \\
\hline \multirow[t]{3}{*}{ Magnesio } & Inferior & 21 & 1.69 & 0.33 & & & & & & & \\
\hline & & & & & 0.31 & 41 & $.755^{\mathrm{NS}}$ & N.S. & .002 & 0.38 & $.704^{\mathrm{NS}}$ \\
\hline & Igual/Superior & 22 & 1.66 & 0.33 & & & & & & & \\
\hline \multirow[t]{3}{*}{ Fosfata Alcalina } & Inferior & 21 & 80.48 & 30.35 & & & & & & & \\
\hline & & & & & -0.78 & 41 & $.441^{\mathrm{NS}}$ & N.S. & .015 & 0.36 & $.715^{\mathrm{NS}}$ \\
\hline & Igual/Superior & 22 & 93.00 & 67.52 & & & & & & & \\
\hline \multirow[t]{3}{*}{ Urea en orina } & Inferior & 21 & 1214.31 & 496.24 & & & & & & & \\
\hline & & & & & 0.07 & 41 & .943 NS & N.S. & .000 & 0.66 & $.512 \mathrm{NS}$ \\
\hline & Igual/Superior & 22 & 1205.05 & 335.66 & & & & & & & \\
\hline \multirow[t]{3}{*}{ Creat. en orina } & Inferior & 21 & 60.16 & 26.23 & & & & & & & \\
\hline & & & & & 0.65 & 41 & .520 NS & N.S. & .010 & 0.29 & $.771^{N S}$ \\
\hline & Igual/Superior & 22 & 55.18 & 24.01 & & & & & & & \\
\hline \multirow[t]{3}{*}{$\mathrm{pH}$} & Inferior & 21 & 7.34 & 0.05 & & & & & & & \\
\hline & & & & & -0.31 & 41 & $.756^{\mathrm{NS}}$ & N.S. & .002 & 0.62 & $.533^{N S}$ \\
\hline & Igual/Superior & 22 & 7.35 & 0.05 & & & & & & & \\
\hline \multirow[t]{3}{*}{ Bicarbonato } & Inferior & 21 & 21.06 & 2.91 & & & & & & & \\
\hline & & & & & -0.04 & 41 & .969 NS & N.S. & .000 & 0.18 & $.855^{\text {NS }}$ \\
\hline & Igual/Superior & 22 & 21.10 & 3.43 & & & & & & & \\
\hline \multirow[t]{3}{*}{ MDRDa } & Inferior & 21 & 38.74 & 17.24 & & & & & & & \\
\hline & & & & & -0.60 & 41 & .550 NS & N.S. & .009 & 0.46 & .644 NS \\
\hline & Igual/Superior & 22 & 41.89 & 17.05 & & & & & & & \\
\hline \multirow[t]{3}{*}{ Cock. Gault } & Inferior & 21 & 44.83 & 17.76 & & & & & & & \\
\hline & & & & & 0.10 & 41 & $.917^{\text {NS }}$ & N.S. & .000 & 0.22 & $.827^{\mathrm{NS}}$ \\
\hline & Igual/Superior & 22 & 44.34 & 12.86 & & & & & & & \\
\hline \multirow[t]{3}{*}{ Mayo Quadr. } & Inferior & 21 & 45.48 & 24.00 & & & & & & & \\
\hline & & & & & -0.45 & 41 & $.655^{\mathrm{NS}}$ & N.S. & .005 & 0.39 & $.697^{\mathrm{NS}}$ \\
\hline & Igual/Superior & 22 & 48.75 & 23.62 & & & & & & & \\
\hline \multirow[t]{2}{*}{ CKD-EPI } & Inferior & 21 & 39.28 & 18.27 & & & & & & & \\
\hline & Igual/Superior & 22 & 41.73 & 17.55 & -0.45 & 41 & $.657^{\mathrm{NS}}$ & N.S. & .005 & 0.34 & $.734^{N S}$ \\
\hline
\end{tabular}




\section{RESULTADOS}

En el siguiente bloque (tabla 87) se observa:

- VSG $(\mathrm{P}<.05)$ : El grupo de pacientes con GIM medio $<0.75$ presentan un valor medio inferior al resto de pacientes (11.63 vs 21.14 ) con efecto moderado (.109).

Tabla 87: Test de diferencia entre dos medias. Asociación de Índice de GIM carotideo con diversas variables antropométricas y de la analítica en la revisión.-1-

\begin{tabular}{|c|c|c|c|c|c|c|c|c|c|c|c|}
\hline \multirow{2}{*}{ Variable / } & \multirow{2}{*}{ GIM carotideo } & \multirow{2}{*}{$\mathrm{N}$} & \multirow{2}{*}{ Media } & \multirow{2}{*}{ D.E. } & \multicolumn{3}{|c|}{ T Student } & \multirow{2}{*}{$\begin{array}{l}\text { IC } 95 \% \text { para la } \\
\text { diferenc. absoluta }\end{array}$} & \multirow{2}{*}{$\begin{array}{l}\text { Efecto } \\
\mathrm{R}^{2}\end{array}$} & \multicolumn{2}{|c|}{ Test Mann-Whitney } \\
\hline & & & & & $T$ & gl & $P$ & & & /Z/ & $P$ \\
\hline \multirow[t]{3}{*}{ Peso } & Inferior & 21 & 73.03 & 11.45 & & & & & & & \\
\hline & & & & & -0.77 & 41 & $.444^{\mathrm{NS}}$ & N.S. & .014 & 0.22 & $.827^{\mathrm{NS}}$ \\
\hline & Igual/Superior & 22 & 76.16 & 14.81 & & & & & & & \\
\hline \multirow[t]{3}{*}{ IMC } & Inferior & 21 & 25.93 & 3.28 & & & & & & & \\
\hline & & & & & -0.66 & 41 & .512 NS & N.S. & .011 & 0.46 & .644 Ns \\
\hline & Igual/Superior & 22 & 26.64 & 3.74 & & & & & & & \\
\hline \multirow[t]{3}{*}{ TAS } & Inferior & 21 & 142.19 & 15.61 & & & & & & & \\
\hline & & & & & -0.78 & 41 & .443 Ns & N.S. & .014 & 0.79 & .429 NS \\
\hline & Igual/Superior & 22 & 146.45 & 20.06 & & & & & & & \\
\hline \multirow[t]{3}{*}{ TAD } & Inferior & 21 & 85.14 & 8.34 & & & & & & & \\
\hline & & & & & 0.28 & 41 & $.777^{\mathrm{NS}}$ & N.S. & .002 & 0.18 & $.855^{\mathrm{NS}}$ \\
\hline & Igual/Superior & 22 & 84.36 & 9.53 & & & & & & & \\
\hline \multirow[t]{3}{*}{ Diuresis } & Inferior & 21 & 2560.48 & 859.74 & & & & & & & \\
\hline & & & & & -0.27 & 41 & $.788^{\mathrm{NS}}$ & N.S. & .002 & 0.47 & $.635^{\mathrm{NS}}$ \\
\hline & Igual/Superior & 22 & 2627.27 & 759.19 & & & & & & & \\
\hline \multirow[t]{3}{*}{ Hemoglobina } & Inferior & 21 & 13.46 & 2.01 & & & & & & & \\
\hline & & & & & 0.37 & 41 & .717 Ns & N.S. & .003 & 0.33 & .743 NS \\
\hline & Igual/Superior & 22 & 13.25 & 1.88 & & & & & & & \\
\hline \multirow[t]{3}{*}{ Hematocrito } & Inferior & 21 & 40.47 & 5.05 & & & & & & & \\
\hline & & & & & 0.31 & 41 & .760 NS & N.S. & .002 & 0.62 & $.535^{\mathrm{NS}}$ \\
\hline & Igual/Superior & 22 & 39.97 & 5.45 & & & & & & & \\
\hline \multirow[t]{3}{*}{ Leucocitos } & Inferior & 21 & 6759.05 & 2178.76 & & & & & & & \\
\hline & & & & & -0.31 & 41 & $.757^{\mathrm{NS}}$ & N.S. & .002 & 0.32 & $.752^{\mathrm{NS}}$ \\
\hline & Igual/Superior & 22 & 6963.04 & 2135.17 & & & & & & & \\
\hline \multirow[t]{3}{*}{ Plaquetas } & Inferior & 21 & 205380.95 & 57004.80 & & & & & & & \\
\hline & & & & & 1.64 & 41 & .109 NS & N.S. & .061 & 1.59 & $.111^{\mathrm{NS}}$ \\
\hline & Igual/Superior & 22 & 176681.82 & 57860.58 & & & & & & & \\
\hline \multirow[t]{2}{*}{ VSG } & Inferior & 21 & 11.63 & 9.46 & & & & & & & \\
\hline & Igual/Superior & 22 & 21.14 & 17.10 & -2.24 & 41 & $.031 *$ & $0.93-18.07$ & .109 & 2.04 & $.041 *$ \\
\hline
\end{tabular}

N.S. $=$ NO significativo $(P>05)$

En el siguiente grupo (tabla 88 ) se han encontrado algunas significaciones, en:

- Urea $(P<.05)$ : El grupo de pacientes con GIM medio $<0.75$ presentan un valor menor que la del resto (58.67 vs 77.91) con tamaño del efecto moderado-bajo. 


\section{RESULTADOS}

- Glucosa $(\mathrm{P}<.05)$ : El grupo de pacientes con GIM medio $<0.75$ presentan un valor menor que el resto de casos (94.29 vs 111.95), aunque el efecto parece pequeño.

- Ácido úrico $(\mathrm{P}<.05)$ : Los pacientes con GIM medio < 0.75 presentan un valor menor que el resto de casos (6.58 vs 10.87 ), pero con un efecto muy pequeño.

- Triglicéridos $(P<.01)$ : Los pacientes con GIM medio < 0.75 presentan un valor menor que el resto (94.95 vs 148.23) con un efecto moderado alto (.178).

Tabla 88: Test de diferencia entre dos medias. Asociación GIM carotideo con variables de la analítica en la revisión.-2-

\begin{tabular}{|c|c|c|c|c|c|c|c|c|c|c|c|}
\hline \multirow{2}{*}{ Variable / } & \multirow{2}{*}{ 1 carotideo } & \multirow{2}{*}{$\mathrm{N}$} & \multirow{2}{*}{ Media } & \multirow{2}{*}{ D.E. } & \multicolumn{3}{|c|}{ T Student } & \multirow{2}{*}{$\begin{array}{l}\text { IC } 95 \% \text { para la } \\
\text { diferenc. Absoluta }\end{array}$} & \multirow{2}{*}{$\begin{array}{l}\text { Efecto } \\
\mathrm{R}^{2}\end{array}$} & \multicolumn{2}{|c|}{ Test Mann-Whitney } \\
\hline & & & & & $\mathrm{T}$ & $\mathrm{Gl}$ & $P$ & & & /Z/ & $P$ \\
\hline \multirow[t]{3}{*}{ Urea } & Inferior & 21 & 58.67 & 22.87 & & & & & & & \\
\hline & & & & & -2.24 & 41 & $.031 *$ & $1.90-36.59$ & .109 & 2.13 & $.033 *$ \\
\hline & Igual/Superior & 22 & 77.91 & 32.39 & & & & & & & \\
\hline \multirow[t]{3}{*}{ Glucosa } & Inferior & 21 & 94.29 & 9.45 & & & & & & & \\
\hline & & & & & -1.87 & 41 & $.068^{N S}$ & N.S. & .079 & 2.27 & $.023 *$ \\
\hline & Igual/Superior & 22 & 111.95 & 42.20 & & & & & & & \\
\hline \multirow[t]{3}{*}{ Creatinina } & Inferior & 21 & 1.50 & 0.56 & & & & & & & \\
\hline & & & & & -0.98 & 41 & $.334^{\mathrm{NS}}$ & N.S. & .023 & 1.36 & $.175^{\text {NS }}$ \\
\hline & Igual/Superior & 22 & 1.65 & 0.48 & & & & & & & \\
\hline \multirow[t]{3}{*}{ Ácido úrico } & Inferior & 21 & 6.58 & 1.47 & & & & & & & \\
\hline & & & & & -1.18 & 41 & .245 NS & N.S. & .033 & 2.16 & $.031 *$ \\
\hline & Igual/Superior & 22 & 10.87 & 16.62 & & & & & & & \\
\hline \multirow[t]{3}{*}{ Triglicéridos } & Inferior & 21 & 94.95 & 31.62 & & & & & & & \\
\hline & & & & & -2.98 & 41 & $.005 * *$ & $17.19-89.36$ & .178 & 2.60 & $.009 * *$ \\
\hline & Igual/Superior & 22 & 148.23 & 75.80 & & & & & & & \\
\hline \multirow[t]{3}{*}{ Colesterol total } & Inferior & 21 & 193.33 & 32.18 & & & & & & & \\
\hline & & & & & 1.52 & 41 & $.136^{\mathrm{NS}}$ & N.S. & .053 & 1.50 & $.135^{N S}$ \\
\hline & Igual/Superior & 22 & 175.18 & 44.69 & & & & & & & \\
\hline \multirow[t]{3}{*}{ Proteínas totales } & Inferior & 21 & 6.74 & 0.53 & & & & & & & \\
\hline & & & & & -0.97 & 41 & .340 NS & N.S. & .022 & 0.85 & .393 NS \\
\hline & Igual/Superior & 22 & 6.88 & 0.44 & & & & & & & \\
\hline \multirow[t]{3}{*}{ Calcio } & Inferior & 21 & 9.58 & 0.57 & & & & & & & \\
\hline & & & & & -0.24 & 41 & .815 NS & N.S. & .001 & 0.09 & .932 NS \\
\hline & Igual/Superior & 22 & 9.62 & 0.59 & & & & & & & \\
\hline \multirow[t]{3}{*}{ Calcio correg. } & Inferior & 21 & 9.96 & 0.52 & & & & & & & \\
\hline & & & & & 0.19 & 41 & .853 NS & N.S. & .001 & 0.29 & $.770 \mathrm{NS}$ \\
\hline & Igual/Superior & 22 & 9.93 & 0.54 & & & & & & & \\
\hline \multirow[t]{3}{*}{ Prod. Calc/Fósf. } & Inferior & 21 & 30.62 & 7.01 & & & & & & & \\
\hline & & & & & 0.00 & 41 & $.997^{N S}$ & N.S. & .000 & 0.00 & .995 NS \\
\hline & Igual/Superior & 22 & 30.61 & 5.11 & & & & & & & \\
\hline \multirow[t]{2}{*}{ Fósforo } & Inferior & 21 & 3.20 & 0.76 & & & & & & & \\
\hline & Igual/Superior & 22 & 3.20 & 0.59 & 0.05 & 41 & $.964^{\mathrm{NS}}$ & N.S. & .000 & 0.05 & $.961 \mathrm{NS}$ \\
\hline
\end{tabular}

N.S. $=$ NO significativo $(P>05) \quad *=$ Significativo al $5 \%(P<.05)$ 


\section{RESULTADOS}

En el grupo que sigue (tabla 89 ) aparecen algunas significaciones:

- Hemoglobina glicosilada ( $P<.05)$ : Los casos con GIM carotideo inferior al corte tienen una media algo menor que el resto de pacientes (5.66 vs 6.23) de modo que el efecto es moderado-bajo.

- Colesterol LDL $(P<.05)$ : Los sujetos del grupo con GIM carotideo inferior al corte presentan un valor medio más elevado que el resto de pacientes (112.49 vs 88.76 ) siendo el tamaño del efecto moderado.

Tabla 89: Test de diferencia entre dos medias. Asociación de Índice de GIM carotideo con diversas variables de la analítica en la revisión.-3-

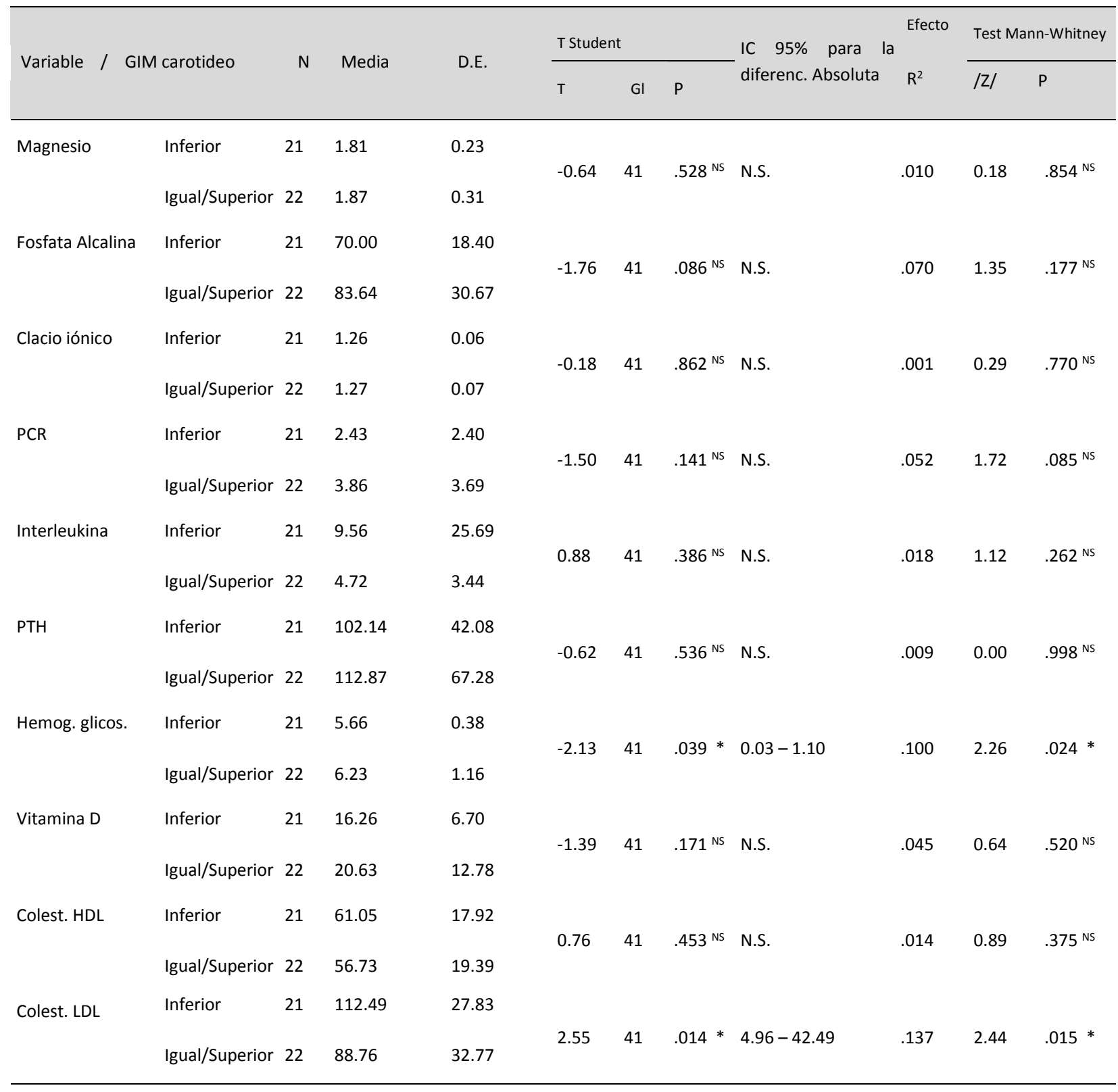

N.S. $=$ NO significativo $(P>05) \quad *=$ Significativo al $5 \%(P<.05)$ 


\section{RESULTADOS}

En este bloque (tabla 90) se observa:

- $\quad \mathrm{pH}(\mathrm{P}<.05)$ : Los pacientes con GIM carotideo inferior al corte tienen una media muy ligeramente superior al resto de casos (7.35 vs 7.32) aunque el tamaño del efecto es moderado.

Tabla 90: Test de diferencia entre 2 medias. Asociación de Índice de GIM carotideo con diversas variables de la analítica en la revisión.-4-

\begin{tabular}{|c|c|c|c|c|c|c|c|c|c|c|c|}
\hline \multirow{2}{*}{ Variable / C } & \multirow{2}{*}{ M carotideo } & \multirow{2}{*}{$\mathrm{N}$} & \multirow{2}{*}{ Media } & \multirow{2}{*}{ D.E. } & \multicolumn{3}{|c|}{ T Student } & \multirow{2}{*}{$\begin{array}{l}\text { IC } 95 \% \text { para la } \\
\text { diferenc. absoluta }\end{array}$} & \multirow{2}{*}{$\begin{array}{l}\text { Efecto } \\
\mathrm{R}^{2}\end{array}$} & \multicolumn{2}{|c|}{ Test Mann-Whitney } \\
\hline & & & & & T & $\mathrm{GI}$ & $P$ & & & /Z/ & $P$ \\
\hline \multirow[t]{3}{*}{ pH } & Inferior & 21 & 7.35 & 0.04 & & & & & & & \\
\hline & & & & & 2.43 & 41 & $.019 *$ & $0.00-0.05$ & 126 & 2.55 & $.011 *$ \\
\hline & Igual/Superior & 22 & 7.32 & 0.03 & & & & & & & \\
\hline \multirow[t]{3}{*}{ Bicarbonato } & Inferior & 21 & 23.00 & 2.02 & & & & & & & \\
\hline & & & & & 1.52 & 41 & $.137^{\mathrm{NS}}$ & N.S. & .053 & 1.54 & .123 NS \\
\hline & Igual/Superior & 22 & 21.82 & 2.96 & & & & & & & \\
\hline \multirow[t]{3}{*}{ Microalbumin. } & Inferior & 21 & 69.37 & 166.16 & & & & & & & \\
\hline & & & & & -0.09 & 41 & $.929^{\mathrm{NS}}$ & N.S. & .000 & 1.29 & $.198 \mathrm{NS}$ \\
\hline & Igual/Superior & 22 & 73.33 & 119.35 & & & & & & & \\
\hline \multirow[t]{3}{*}{ MDRDa } & Inferior & 21 & 56.15 & 20.14 & & & & & & & \\
\hline & & & & & 1.76 & 41 & $.085^{\mathrm{NS}}$ & N.S. & .070 & 1.58 & $.114^{\mathrm{NS}}$ \\
\hline & Igual/Superior & 22 & 46.66 & 14.87 & & & & & & & \\
\hline \multirow[t]{3}{*}{ Cock. Gault } & Inferior & 21 & 64.89 & 23.77 & & & & & & & \\
\hline & & & & & 1.30 & 41 & .201 NS & N.S. & 0.40 & 1.56 & .120 NS \\
\hline & Igual/Superior & 22 & 55.27 & 24.69 & & & & & & & \\
\hline \multirow[t]{3}{*}{ Mayo Quadr. } & Inferior & 21 & 68.95 & 28.10 & & & & & & & \\
\hline & & & & & 1.82 & 41 & $.076^{\mathrm{NS}}$ & N.S. & .075 & 1.75 & $.080^{\mathrm{NS}}$ \\
\hline & Igual/Superior & 22 & 55.07 & 21.58 & & & & & & & \\
\hline \multirow[t]{3}{*}{ CKD-EPI } & Inferior & 21 & 57.54 & 22.30 & & & & & & & \\
\hline & & & & & 1.96 & 41 & $.057^{\mathrm{NS}}$ & N.S. & .086 & 1.86 & .063 NS \\
\hline & Igual/Superior & 22 & 46.12 & 15.45 & & & & & & & \\
\hline \multirow[t]{2}{*}{ FGF-21 } & Inferior & 21 & 4.71 & 14.59 & & & & & & & \\
\hline & Igual/Superior & 22 & 5.36 & 11.73 & -0.16 & 41 & $.873^{\text {NS }}$ & N.S. & .001 & 0.95 & $.342^{\mathrm{NS}}$ \\
\hline
\end{tabular}

N.S. $=$ NO significativo $(P>.05)$ 


\section{RESULTADOS}

\section{GIM en arteria carótida derecha}

En el primer grupo de contrastes realizados entre variables cuantitativas y el GIM en carótida derecha (tabla 91) se observa:

- Volumen de diuresis ( $\mathrm{P}<.01)$ : Los pacientes del grupo con GIM carótida derecha inferior al corte, tienen una media más elevada que el resto (1404.55 vs 615.24) equivalente a un tamaño del efecto moderado (.162).

Tabla 91: Test de diferencia entre dos medias. Asociación de Índice de GIM carótida derecha con diversas variables antropométricas y de la analítica previa al trasplante.-1-

\begin{tabular}{|c|c|c|c|c|c|c|c|c|c|c|c|}
\hline \multirow{2}{*}{ Variable / G } & \multirow{2}{*}{ GIM carótida derecha } & \multirow{2}{*}{$\mathrm{N}$} & \multirow{2}{*}{ Media } & \multirow{2}{*}{ D.E. } & \multicolumn{3}{|c|}{ T Student } & \multirow{2}{*}{$\begin{array}{l}\text { IC 95\% para la } \\
\text { diferenc. absoluta }\end{array}$} & \multirow{2}{*}{$\begin{array}{l}\text { Efecto } \\
\mathrm{R}^{2}\end{array}$} & \multicolumn{2}{|c|}{ Test Mann-Whitney } \\
\hline & & & & & $\mathrm{T}$ & gl & $P$ & & & /Z/ & $P$ \\
\hline \multirow[t]{3}{*}{ Altura } & Inferior & 22 & 167.23 & 10.85 & & & & & & & \\
\hline & & & & & -0.73 & 41 & $.468^{\mathrm{NS}}$ & N.S. & .013 & 0.54 & .593 NS \\
\hline & Igual/Superior & 21 & 169.26 & 6.82 & & & & & & & \\
\hline \multirow[t]{3}{*}{ Peso } & Inferior & 22 & 70.81 & 11.36 & & & & & & & \\
\hline & & & & & -0.04 & 41 & $.968^{\mathrm{NS}}$ & N.S. & .000 & 0.79 & .430 NS \\
\hline & Igual/Superior & 21 & 70.96 & 12.36 & & & & & & & \\
\hline \multirow[t]{3}{*}{ IMC } & Inferior & 22 & 25.26 & 3.12 & & & & & & & \\
\hline & & & & & 0.69 & 41 & .495 NS & N.S. & .011 & 0.70 & .481 NS \\
\hline & Igual/Superior & 21 & 24.63 & 2.84 & & & & & & & \\
\hline \multirow[t]{3}{*}{ TAS } & Inferior & 22 & 142.86 & 19.91 & & & & & & & \\
\hline & & & & & -0.86 & 41 & .396 NS & N.S. & .018 & 0.57 & .567 Ns \\
\hline & Igual/Superior & 21 & 149.57 & 30.49 & & & & & & & \\
\hline \multirow[t]{3}{*}{ TAD } & Inferior & 22 & 85.00 & 10.76 & & & & & & & \\
\hline & & & & & 0.43 & 41 & .668 NS & N.S. & .005 & 0.93 & .354 NS \\
\hline & Igual/Superior & 21 & 83.29 & 14.98 & & & & & & & \\
\hline \multirow[t]{3}{*}{ Diuresis } & Inferior & 22 & 1404.55 & 1020.03 & & & & & & & \\
\hline & & & & & 2.82 & 41 & $.007 * *$ & $224.13-1354.48$ & .162 & 2.98 & $.003 * *$ \\
\hline & Igual/Superior & 21 & 615.24 & 795.32 & & & & & & & \\
\hline \multirow[t]{3}{*}{ Hemoglobina } & Inferior & 22 & 12.63 & 1.88 & & & & & & & \\
\hline & & & & & -0.01 & 41 & .990 NS & N.S. & .000 & 0.17 & .865 NS \\
\hline & Igual/Superior & 21 & 12.64 & 1.42 & & & & & & & \\
\hline \multirow[t]{3}{*}{ Hematocrito } & Inferior & 22 & 38.16 & 5.74 & & & & & & & \\
\hline & & & & & 0.07 & 41 & .944 NS & N.S. & .000 & 0.33 & .743 NS \\
\hline & Igual/Superior & 21 & 38.05 & 4.55 & & & & & & & \\
\hline \multirow[t]{3}{*}{ Leucocitos } & Inferior & 22 & 6964.55 & 1860.40 & & & & & & & \\
\hline & & & & & 1.05 & 41 & .301 NS & N.S. & .026 & 1.11 & .269 NS \\
\hline & Igual/Superior & 21 & 6443.81 & 1346.63 & & & & & & & \\
\hline \multirow[t]{2}{*}{ Plaquetas } & Inferior & 22 & 194227.27 & 58440.80 & & & & & & & \\
\hline & Igual/Superior & 21 & 182857.14 & 79729.09 & 0.54 & 41 & .595 NS & N.S. & .007 & 0.84 & .402 Ns \\
\hline
\end{tabular}

N.S. $=$ NO significativo $(P>.05) \quad * *=$ Altamente significativo al $1 \%(P<.01)$ 


\section{RESULTADOS}

En el siguiente grupo (tabla 92) no se han encontrado relaciones significativas ( $P>.05)$.

Tabla 92: Test de diferencia entre dos medias. Asociación de Índice de GIM carótida derecha con diversas variables de la analítica previa al trasplante.-2-

\begin{tabular}{|c|c|c|c|c|c|c|c|c|c|c|c|}
\hline \multirow{2}{*}{$\begin{array}{l}\text { Variable } \\
\text { derecha }\end{array}$} & \multirow{2}{*}{ GIM carótida } & \multirow{2}{*}{$\mathrm{N}$} & \multirow{2}{*}{ Media } & \multirow{2}{*}{ D.E. } & \multicolumn{3}{|c|}{ T Student } & \multirow{2}{*}{$\begin{array}{l}\text { IC 95\% para la } \\
\text { diferenc. absoluta }\end{array}$} & \multirow{2}{*}{$\begin{array}{l}\text { Efecto } \\
\mathrm{R}^{2}\end{array}$} & \multicolumn{2}{|c|}{ Test Mann-Whitney } \\
\hline & & & & & $\mathrm{T}$ & gl & $P$ & & & /Z/ & $P$ \\
\hline \multirow[t]{3}{*}{ Urea } & Inferior & 22 & 147.77 & 35.37 & & & & & & & \\
\hline & & & & & 0.59 & 41 & .560 NS & N.S. & .008 & .060 & $.552^{\mathrm{NS}}$ \\
\hline & Igual/Superior & 21 & 141.48 & 34.79 & & & & & & & \\
\hline \multirow[t]{3}{*}{ Glucosa } & Inferior & 22 & 89.59 & 9.62 & & & & & & & \\
\hline & & & & & -1.63 & 41 & $.110^{\mathrm{NS}}$ & N.S. & .061 & 0.79 & $.429^{N S}$ \\
\hline & Igual/Superior & 21 & 100.86 & 30.85 & & & & & & & \\
\hline \multirow[t]{3}{*}{ Creatinina } & Inferior & 22 & 8.86 & 2.74 & & & & & & & \\
\hline & & & & & 0.03 & 41 & .974 NS & N.S. & .000 & 0.17 & $.865^{\mathrm{NS}}$ \\
\hline & Igual/Superior & 21 & 8.83 & 2.67 & & & & & & & \\
\hline \multirow[t]{3}{*}{ Triglicéridos } & Inferior & 22 & 118.32 & 37.54 & & & & & & & \\
\hline & & & & & 0.19 & 41 & .850 NS & N.S. & .001 & 0.17 & $.865^{\mathrm{NS}}$ \\
\hline & Igual/Superior & 21 & 115.90 & 45.52 & & & & & & & \\
\hline \multirow[t]{3}{*}{ Colesterol total } & Inferior & 22 & 179.18 & 56.46 & & & & & & & \\
\hline & & & & & 1.34 & 41 & $.186^{\mathrm{NS}}$ & N.S. & .042 & 0.76 & $.444^{N S}$ \\
\hline & Igual/Superior & 21 & 158.10 & 45.48 & & & & & & & \\
\hline \multirow[t]{3}{*}{ Proteínas totales } & Inferior & 22 & 6.80 & 0.60 & & & & & & & \\
\hline & & & & & -1.20 & 41 & $.237^{\mathrm{NS}}$ & N.S. & .034 & 1.12 & $.263^{\mathrm{NS}}$ \\
\hline & Igual/Superior & 21 & 7.00 & 0.50 & & & & & & & \\
\hline \multirow[t]{3}{*}{ Calcio } & Inferior & 22 & 9.21 & 0.97 & & & & & & & \\
\hline & & & & & -0.42 & 41 & $.674^{N S}$ & N.S. & .004 & 0.05 & $.961^{\mathrm{NS}}$ \\
\hline & Igual/Superior & 21 & 9.33 & 0.76 & & & & & & & \\
\hline \multirow[t]{3}{*}{ Calcio correg. } & Inferior & 22 & 6.56 & 0.97 & & & & & & & \\
\hline & & & & & -0.04 & 41 & .965 NS & N.S. & .000 & 0.61 & .543 NS \\
\hline & Igual/Superior & 21 & 9.58 & 0.79 & & & & & & & \\
\hline \multirow[t]{2}{*}{ Prod. Calc/Fósf. } & Inferior & 22 & 46.04 & 9.31 & & & & & & & \\
\hline & Igual/Superior & 21 & 46.76 & 11.76 & -0.22 & 41 & .823 NS & N.S. & .001 & 0.42 & .671 NS \\
\hline
\end{tabular}

N.S. $=$ NO significativo $(P>05) \quad * *=$ Altamente significativo al $1 \%(P<.01)$ 


\section{RESULTADOS}

En este bloque (tabla 93) no se encuentran diferencias significativas ( $P>$.05)

Tabla 93: Test de diferencia entre dos medias. Asociación de Índice de GIM carótida derecha con diversas variables de la analítica previa al trasplante.-3-

\begin{tabular}{|c|c|c|c|c|c|c|c|c|c|c|c|}
\hline \multirow{2}{*}{$\begin{array}{l}\text { Variable } \\
\text { derecha }\end{array}$} & \multirow[t]{2}{*}{ GIM carótida } & \multirow{2}{*}{$\mathrm{N}$} & \multirow{2}{*}{ Media } & \multirow{2}{*}{ D.E. } & \multicolumn{3}{|c|}{ T Student } & \multirow{2}{*}{$\begin{array}{l}\text { IC } 95 \% \text { para la } \\
\text { diferenc. absoluta }\end{array}$} & \multirow{2}{*}{$\begin{array}{l}\text { Efecto } \\
\mathrm{R}^{2}\end{array}$} & \multicolumn{2}{|c|}{ Test Mann-Whitney } \\
\hline & & & & & $\mathrm{T}$ & gl & $P$ & & & /Z/ & $P$ \\
\hline \multirow[t]{3}{*}{ Fósforo } & Inferior & 22 & 4.99 & 0.90 & & & & & & & \\
\hline & & & & & -0.05 & 41 & $.957^{\mathrm{NS}}$ & N.S. & .000 & 0.10 & .923 NS \\
\hline & Igual/Superior & 21 & 5.01 & 1.23 & & & & & & & \\
\hline \multirow[t]{3}{*}{ Fosfata Alcalina } & Inferior & 22 & 92.86 & 52.40 & & & & & & & \\
\hline & & & & & -0.87 & 41 & $.388^{N S}$ & N.S. & .018 & 1.13 & $.258 \mathrm{Ns}$ \\
\hline & Igual/Superior & 21 & 109.52 & 71.78 & & & & & & & \\
\hline \multirow[t]{3}{*}{ H. Paratiroidea } & Inferior & 21 & 373.15 & 383.38 & & & & & & & \\
\hline & & & & & 0.26 & 40 & .796 NS & N.S. & .002 & 0.64 & $.521^{\mathrm{NS}}$ \\
\hline & Igual/Superior & 21 & 341.96 & 394.46 & & & & & & & \\
\hline \multirow[t]{3}{*}{$\mathrm{pH}$} & Inferior & 22 & 7.37 & 0.05 & & & & & & & \\
\hline & & & & & -0.45 & 41 & $.652^{\text {NS }}$ & N.S. & .005 & 0.68 & .495 NS \\
\hline & Igual/Superior & 21 & 7.37 & 0.05 & & & & & & & \\
\hline \multirow[t]{3}{*}{ Bicarbonato } & Inferior & 22 & 23.84 & 2.86 & & & & & & & \\
\hline & & & & & 0.37 & 41 & $.711^{\mathrm{NS}}$ & N.S. & .003 & 0.33 & .743 NS \\
\hline & Igual/Superior & 21 & 23.51 & 2.79 & & & & & & & \\
\hline \multirow[t]{3}{*}{ MDRDa } & Inferior & 22 & 6.92 & 2.38 & & & & & & & \\
\hline & & & & & -0.11 & 41 & $.916^{\mathrm{NS}}$ & N.S. & .000 & 0.36 & $.716^{\mathrm{NS}}$ \\
\hline & Igual/Superior & 21 & 6.99 & 2.09 & & & & & & & \\
\hline \multirow[t]{3}{*}{ Cock. Gault } & Inferior & 22 & 10.79 & 4.41 & & & & & & & \\
\hline & & & & & 0.82 & 41 & $.416^{\mathrm{NS}}$ & N.S. & .016 & 0.27 & .789 NS \\
\hline & Igual/Superior & 21 & 9.86 & 2.73 & & & & & & & \\
\hline \multirow[t]{3}{*}{ Mayo Quadr. } & Inferior & 22 & 9.26 & 2.21 & & & & & & & \\
\hline & & & & & 0.43 & 41 & .670 NS & N.S. & .004 & 0.10 & .923 NS \\
\hline & Igual/Superior & 21 & 9.01 & 1.70 & & & & & & & \\
\hline \multirow[t]{2}{*}{ CKD-EPI } & Inferior & 22 & 6.48 & 2.42 & & & & & & & \\
\hline & Igual/Superior & 21 & 6.37 & 2.01 & 0.16 & 41 & $.874^{N S}$ & N.S. & .001 & 0.19 & .846 Ns \\
\hline
\end{tabular}

N.S. $=$ NO significativo $(P>.05)$ 


\section{RESULTADOS}

En este bloque (tabla 94) solo aparece diferencia significativa en:

- Leucocitos $(P<.05)$ : Los casos del grupo con GIM carótida derecha inferior al corte, tienen una media más elevada que el resto de casos (10670.91 vs 8220.00) con un efecto moderado (.111).

Tabla 94: Test de diferencia entre dos medias. Asociación de Índice de GIM carótida derecha con diversas variables antropométricas y de la analítica al alta tras el trasplante.-1-

\begin{tabular}{|c|c|c|c|c|c|c|c|c|c|c|c|}
\hline \multirow{2}{*}{ Variable / c } & \multirow{2}{*}{ GIM carótida derecha } & \multirow{2}{*}{$\mathrm{N}$} & \multirow{2}{*}{ Media } & \multirow{2}{*}{ D.E. } & \multicolumn{3}{|c|}{ T Student } & \multirow{2}{*}{$\begin{array}{l}\text { IC } 95 \% \text { para la } \\
\text { diferenc. absoluta }\end{array}$} & \multirow{2}{*}{$\begin{array}{l}\text { Efecto } \\
\mathrm{R}^{2}\end{array}$} & \multicolumn{2}{|c|}{ Test Mann-Whitney } \\
\hline & & & & & $\mathrm{T}$ & gl & $P$ & & & /Z/ & $P$ \\
\hline \multirow[t]{3}{*}{ Peso } & Inferior & 22 & 69.83 & 11.30 & & & & & & & \\
\hline & & & & & 0.31 & 41 & $.762^{\mathrm{NS}}$ & N.S. & .002 & 0.85 & $.395^{N S}$ \\
\hline & Igual/Superior & 21 & 68.74 & 12.15 & & & & & & & \\
\hline \multirow[t]{3}{*}{ IMC } & Inferior & 22 & 24.95 & 3.40 & & & & & & & \\
\hline & & & & & 1.07 & 41 & $.290 \mathrm{NS}$ & N.S. & .027 & 1.06 & .291 NS \\
\hline & Igual/Superior & 21 & 23.89 & 3.08 & & & & & & & \\
\hline \multirow[t]{3}{*}{ TAS } & Inferior & 22 & 139.36 & 23.79 & & & & & & & \\
\hline & & & & & 0.46 & 41 & $.651^{\mathrm{NS}}$ & N.S. & .005 & 0.44 & $.661^{\mathrm{NS}}$ \\
\hline & Igual/Superior & 21 & 136.05 & 23.86 & & & & & & & \\
\hline \multirow[t]{3}{*}{ TAD } & Inferior & 22 & 80.36 & 14.80 & & & & & & & \\
\hline & & & & & 0.92 & 41 & $.365^{\mathrm{NS}}$ & N.S. & .020 & 0.84 & $.4011^{\text {NS }}$ \\
\hline & Igual/Superior & 21 & 76.52 & 12.53 & & & & & & & \\
\hline \multirow[t]{3}{*}{ Diuresis } & Inferior & 22 & 2549.09 & 957.29 & & & & & & & \\
\hline & & & & & 0.95 & 41 & .348 NS & N.S. & .022 & 0.01 & .990 NS \\
\hline & Igual/Superior & 21 & 2322.62 & 538.92 & & & & & & & \\
\hline \multirow[t]{3}{*}{ Hemoglobina } & Inferior & 22 & 10.81 & 1.23 & & & & & & & \\
\hline & & & & & 0.45 & 41 & .652 NS & N.S. & .005 & 0.82 & .415 NS \\
\hline & Igual/Superior & 21 & 10.62 & 1.44 & & & & & & & \\
\hline \multirow[t]{3}{*}{ Hematocrito } & Inferior & 22 & 32.68 & 3.53 & & & & & & & \\
\hline & & & & & -0.06 & 41 & .952 NS & N.S. & .000 & 0.23 & $.817^{\text {NS }}$ \\
\hline & Igual/Superior & 21 & 32.75 & 4.51 & & & & & & & \\
\hline \multirow[t]{3}{*}{ Leucocitos } & Inferior & 22 & 10670.91 & 3792.34 & & & & & & & \\
\hline & & & & & 2.26 & 41 & $.029 *$ & $260.14-4641.67$ & .111 & 2.06 & $.039 *$ \\
\hline & Igual/Superior & 21 & 8220.00 & 3289.04 & & & & & & & \\
\hline \multirow[t]{3}{*}{ Plaquetas } & Inferior & 22 & 279000.00 & 123077.99 & & & & & & & \\
\hline & & & & & 1.07 & 41 & .293 NS & N.S. & .027 & 1.08 & $.280 \mathrm{NS}$ \\
\hline & Igual/Superior & 21 & 241476.19 & 106748.59 & & & & & & & \\
\hline \multirow[t]{2}{*}{ VSG } & Inferior & 22 & 33.59 & 29.08 & & & & & & & \\
\hline & Igual/Superior & 21 & 35.67 & 27.74 & -0.24 & 41 & .812 NS & N.S. & .001 & 0.28 & $.780 \mathrm{NS}$ \\
\hline
\end{tabular}

En el siguiente bloque (tabla 95) han aparecido algunas significaciones que afectan a las siguientes variables: 


\section{RESULTADOS}

- Colesterol total $(P<.01)$ : Los pacientes del grupo de GIM carótida derecha inferior al corte presentan una media más elevada que el resto (206.05 vs 162.33 ) y que se corresponde con un tamaño del efecto moderado alto (muy cerca de .200).

- Calcio ( $\mathrm{P}<.01)$ : La media de los casos con GIM carótida derecha inferior, tienen una media más alta (9.93 vs 9.23) con tamaño del efecto moderado (.164).

- Calcio corregido ( $P<.01)$ : Los casos de GIM carótida derecha inferior, tienen una media mayor (10.54 vs 9.92) y tamaño del efecto moderado.

Tabla 95: Test de diferencia entre dos medias. Asociación de Índice de GIM carótida derecha con diversas variables de la analítica al alta tras el trasplante..2.

\begin{tabular}{|c|c|c|c|c|c|c|c|c|c|c|c|}
\hline \multirow{2}{*}{$\begin{array}{l}\text { Variable } \\
\text { derecha }\end{array}$} & \multirow{2}{*}{ GIM carótida } & \multirow{2}{*}{$\mathrm{N}$} & \multirow{2}{*}{ Media } & \multirow{2}{*}{ D.E. } & \multicolumn{3}{|c|}{ T Student } & \multirow{2}{*}{$\begin{array}{l}\text { IC } 95 \% \text { para la } \\
\text { diferenc. absoluta }\end{array}$} & \multirow{2}{*}{$\begin{array}{l}\text { Efecto } \\
\mathrm{R}^{2}\end{array}$} & \multicolumn{2}{|c|}{ Test Mann-Whitney } \\
\hline & & & & & T & gl & $\mathrm{P}$ & & & /Z/ & $P$ \\
\hline \multirow[t]{3}{*}{ Urea } & Inferior & 22 & 90.64 & 42.46 & & & & & & & \\
\hline & & & & & 0.31 & 41 & $.758^{\mathrm{NS}}$ & N.S. & .002 & 0.00 & .999 NS \\
\hline & Igual/Superior & 21 & 86.95 & 34.79 & & & & & & & \\
\hline \multirow[t]{3}{*}{ Glucosa } & Inferior & 22 & 98.00 & 14.75 & & & & & & & \\
\hline & & & & & -1.13 & 41 & $.266^{\mathrm{NS}}$ & N.S. & .030 & 0.08 & .932 NS \\
\hline & Igual/Superior & 21 & 108.81 & 42.42 & & & & & & & \\
\hline \multirow[t]{3}{*}{ Creatinina } & Inferior & 22 & 2.43 & 1.61 & & & & & & & \\
\hline & & & & & 1.02 & 41 & .312 NS & N.S. & .025 & 1.00 & $.318^{N S}$ \\
\hline & Igual/Superior & 21 & 2.00 & 1.09 & & & & & & & \\
\hline \multirow[t]{3}{*}{ Triglicéridos } & Inferior & 22 & 143.95 & 77.98 & & & & & & & \\
\hline & & & & & -0.21 & 41 & .836 NS & N.S. & .001 & 0.69 & .489 NS \\
\hline & Igual/Superior & 21 & 148.38 & 59.41 & & & & & & & \\
\hline \multirow[t]{3}{*}{ Colesterol total } & Inferior & 22 & 206.05 & 44.07 & & & & & & & \\
\hline & & & & & 3.15 & 41 & $.003^{* *}$ & $15.72-71.70$ & .195 & 2.78 & $.005^{* *}$ \\
\hline & Igual/Superior & 21 & 162.33 & 46.81 & & & & & & & \\
\hline \multirow[t]{3}{*}{ Proteínas totales } & Inferior & 22 & 6.27 & 0.45 & & & & & & & \\
\hline & & & & & 0.86 & 41 & .396 NS & N.S. & .018 & 0.78 & $.435^{\mathrm{NS}}$ \\
\hline & Igual/Superior & 21 & 6.12 & 0.68 & & & & & & & \\
\hline \multirow[t]{3}{*}{ Calcio } & Inferior & 22 & 9.93 & 0.86 & & & & & & & \\
\hline & & & & & 2.84 & 41 & $.007^{* *}$ & $0.20-1.20$ & .164 & 2.65 & $.008 * *$ \\
\hline & Igual/Superior & 21 & 9.23 & 0.75 & & & & & & & \\
\hline \multirow[t]{3}{*}{ Calcio correg. } & Inferior & 22 & 10.54 & 0.85 & & & & & & & \\
\hline & & & & & 2.73 & 41 & $.009 * *$ & $0.16-1.09$ & .154 & 2.66 & $.008^{* *}$ \\
\hline & Igual/Superior & 21 & 9.92 & 0.63 & & & & & & & \\
\hline \multirow[t]{3}{*}{ Prod. Calc/Fósf. } & Inferior & 22 & 32.73 & 11.80 & & & & & & & \\
\hline & & & & & 1.53 & 41 & $.133^{\mathrm{NS}}$ & N.S. & .054 & 1.48 & $.138^{\mathrm{NS}}$ \\
\hline & Igual/Superior & 21 & 28.09 & 7.48 & & & & & & & \\
\hline \multirow[t]{2}{*}{ Fósforo } & Inferior & 22 & 3.30 & 1.23 & & & & & & & \\
\hline & Igual/Superior & 21 & 3.05 & 0.80 & 0.81 & 41 & $.425^{N S}$ & N.S. & .016 & 0.56 & $.576^{\mathrm{NS}}$ \\
\hline
\end{tabular}

N.S. $=$ NO significativo $(P>$.05) 


\section{RESULTADOS}

\section{En el siguiente bloque (tabla 96) no se han detectado diferencias que tengan significación ( $\mathrm{P}>$.05).}

Tabla 96: Test de diferencia entre dos medias. Asociación de Índice de GIM carótida derecha con diversas variables de la analítica al alta tras el trasplante.-3-

\begin{tabular}{|c|c|c|c|c|c|c|c|c|c|c|c|}
\hline \multirow{2}{*}{$\begin{array}{l}\text { Variable } \\
\text { derecha }\end{array}$} & \multirow{2}{*}{ GIM carótida } & \multirow{2}{*}{$\mathrm{N}$} & \multirow{2}{*}{ Media } & \multirow{2}{*}{ D.E. } & \multicolumn{3}{|c|}{ T Student } & \multirow{2}{*}{$\begin{array}{l}\text { IC } 95 \% \text { para la } \\
\text { diferenc. absoluta }\end{array}$} & \multirow{2}{*}{$\begin{array}{l}\text { Efecto } \\
\mathrm{R}^{2}\end{array}$} & \multicolumn{2}{|c|}{ Test Mann-Whitney } \\
\hline & & & & & $\mathrm{T}$ & $\mathrm{gl}$ & $P$ & & & /Z/ & $P$ \\
\hline \multirow[t]{3}{*}{ Magnesio } & Inferior & 22 & 1.60 & 0.26 & & & & & & & \\
\hline & & & & & -1.57 & 41 & $.125^{\mathrm{NS}}$ & N.S. & .056 & 1.37 & .170 NS \\
\hline & Igual/Superior & 21 & 1.75 & 0.37 & & & & & & & \\
\hline \multirow[t]{3}{*}{ Fosfata Alcalina } & Inferior & 22 & 80.95 & 30.02 & & & & & & & \\
\hline & & & & & -0.75 & 41 & $.455^{\mathrm{NS}}$ & N.S. & .014 & 0.06 & .952 NS \\
\hline & Igual/Superior & 21 & 93.10 & 69.04 & & & & & & & \\
\hline \multirow[t]{3}{*}{ Urea en orina } & Inferior & 22 & 1232.85 & 496.12 & & & & & & & \\
\hline & & & & & 0.37 & 41 & $.713^{N S}$ & N.S. & .003 & 0.07 & .942 NS \\
\hline & Igual/Superior & 21 & 1185.19 & 323.94 & & & & & & & \\
\hline \multirow[t]{3}{*}{ Creat. en orina } & Inferior & 22 & 62.63 & 26.94 & & & & & & & \\
\hline & & & & & 1.36 & 41 & $.180^{\mathrm{NS}}$ & N.S. & .043 & 1.23 & $.220^{\mathrm{NS}}$ \\
\hline & Igual/Superior & 21 & 52.35 & 22.09 & & & & & & & \\
\hline \multirow[t]{3}{*}{$\mathrm{pH}$} & Inferior & 22 & 7.36 & 0.04 & & & & & & & \\
\hline & & & & & 1.25 & 41 & $.219^{\mathrm{NS}}$ & N.S. & .037 & 0.96 & $.334^{\mathrm{NS}}$ \\
\hline & Igual/Superior & 21 & 7.34 & 0.06 & & & & & & & \\
\hline \multirow[t]{3}{*}{ Bicarbonato } & Inferior & 22 & 21.37 & 2.61 & & & & & & & \\
\hline & & & & & 0.62 & 41 & $.541^{\mathrm{NS}}$ & N.S. & .009 & 0.46 & .644 NS \\
\hline & Igual/Superior & 21 & 20.77 & 3.67 & & & & & & & \\
\hline \multirow[t]{3}{*}{ MDRDa } & Inferior & 22 & 37.39 & 16.72 & & & & & & & \\
\hline & & & & & -1.17 & 41 & .247 NS & N.S. & .033 & 1.14 & .253 NS \\
\hline & Igual/Superior & 21 & 43.46 & 17.16 & & & & & & & \\
\hline \multirow[t]{3}{*}{ Cock. Gault } & Inferior & 22 & 44.51 & 18.24 & & & & & & & \\
\hline & & & & & -0.03 & 41 & .976 NS & N.S. & .000 & 0.19 & $.846^{\mathrm{NS}}$ \\
\hline & Igual/Superior & 21 & 44.65 & 11.82 & & & & & & & \\
\hline \multirow[t]{3}{*}{ Mayo Quadr. } & Inferior & 22 & 43.96 & 23.54 & & & & & & & \\
\hline & & & & & -0.91 & 41 & $.370^{N S}$ & N.S. & .020 & 0.88 & .382 NS \\
\hline & Igual/Superior & 21 & 50.50 & 23.73 & & & & & & & \\
\hline \multirow[t]{2}{*}{ CKD-EPI } & Inferior & 22 & 37.95 & 17.86 & & & & & & & \\
\hline & Igual/Superior & 21 & 43.25 & 17.61 & -0.98 & 41 & $.333^{N S}$ & N.S. & .023 & 0.85 & $.395^{N S}$ \\
\hline
\end{tabular}




\section{RESULTADOS}

En el siguiente bloque (tabla 97) una vez más no se han encontrado significaciones ( $P>$.05).

Tabla 97: Test de diferencia entre dos medias. Asociación de Índice de GIM carótida derecha con diversas variables antropométricas y de la analítica en la revisión.-1-

\begin{tabular}{|c|c|c|c|c|c|c|c|c|c|c|c|}
\hline \multirow{2}{*}{ Variable / G } & \multirow{2}{*}{ GIM carótida derecha } & \multirow{2}{*}{$N$} & \multirow{2}{*}{ Media } & \multirow{2}{*}{ D.E. } & \multicolumn{3}{|c|}{ T Student } & \multirow{2}{*}{$\begin{array}{l}\text { IC 95\% para la } \\
\text { diferenc. absoluta }\end{array}$} & \multirow{2}{*}{$\begin{array}{l}\text { Efecto } \\
\mathrm{R}^{2}\end{array}$} & \multicolumn{2}{|c|}{ Test Mann-Whitney } \\
\hline & & & & & $\mathrm{T}$ & gl & $P$ & & & /Z/ & $P$ \\
\hline \multirow[t]{3}{*}{ Peso } & Inferior & 22 & 73.87 & 11.78 & & & & & & & \\
\hline & & & & & -0.38 & 41 & $.704^{\mathrm{NS}}$ & N.S. & .004 & 0.28 & $.780^{\mathrm{NS}}$ \\
\hline & Igual/Superior & 21 & 75.43 & 14.82 & & & & & & & \\
\hline \multirow[t]{3}{*}{ IMC } & Inferior & 22 & 26.35 & 3.05 & & & & & & & \\
\hline & & & & & 0.11 & 41 & $.913^{N S}$ & N.S. & .000 & 0.34 & .734 NS \\
\hline & Igual/Superior & 21 & 26.23 & 4.00 & & & & & & & \\
\hline \multirow[t]{3}{*}{ TAS } & Inferior & 22 & 140.55 & 17.33 & & & & & & & \\
\hline & & & & & -1.45 & 41 & $.155^{N S}$ & N.S. & .049 & 1.16 & $.248^{\mathrm{NS}}$ \\
\hline & Igual/Superior & 21 & 148.38 & 18.09 & & & & & & & \\
\hline \multirow[t]{3}{*}{ TAD } & Inferior & 22 & 84.32 & 9.20 & & & & & & & \\
\hline & & & & & -0.32 & 41 & $.751^{\mathrm{NS}}$ & N.S. & .002 & 0.23 & $.817^{\mathrm{NS}}$ \\
\hline & Igual/Superior & 21 & 85.19 & 8.72 & & & & & & & \\
\hline \multirow[t]{3}{*}{ Diuresis } & Inferior & 22 & 2543.18 & 825.67 & & & & & & & \\
\hline & & & & & -0.43 & 41 & $.672^{\mathrm{NS}}$ & N.S. & .004 & 0.60 & .551 NS \\
\hline & Igual/Superior & 21 & 2648.57 & 790.53 & & & & & & & \\
\hline \multirow[t]{3}{*}{ Hemoglobina } & Inferior & 22 & 13.55 & 2.33 & & & & & & & \\
\hline & & & & & 0.71 & 41 & $.484^{N S}$ & N.S. & .012 & 0.45 & $.653^{\text {NS }}$ \\
\hline & Igual/Superior & 21 & 13.14 & 1.56 & & & & & & & \\
\hline \multirow[t]{3}{*}{ Hematocrito } & Inferior & 22 & 40.65 & 5.77 & & & & & & & \\
\hline & & & & & 0.56 & 41 & .576 NS & N.S. & .008 & 0.38 & .706 NS \\
\hline & Igual/Superior & 21 & 39.75 & 4.62 & & & & & & & \\
\hline \multirow[t]{3}{*}{ Leucocitos } & Inferior & 22 & 7200.00 & 2270.15 & & & & & & & \\
\hline & & & & & 1.06 & 41 & .296 NS & N.S. & .027 & 0.92 & $.356^{\mathrm{NS}}$ \\
\hline & Igual/Superior & 21 & 6511.43 & 1972.41 & & & & & & & \\
\hline \multirow[t]{3}{*}{ Plaquetas } & Inferior & 22 & 203318.18 & 56757.12 & & & & & & & \\
\hline & & & & & 1.47 & 41 & .150 NS & N.S. & .050 & 1.41 & .159 NS \\
\hline & Igual/Superior & 21 & 177476.19 & 58873.27 & & & & & & & \\
\hline \multirow[t]{2}{*}{ VSG } & Inferior & 22 & 13.51 & 13.17 & & & & & & & \\
\hline & Igual/Superior & 21 & 19.62 & 15.59 & -1.39 & 41 & $.172^{\text {NS }}$ & N.S. & .045 & 1.62 & $.062^{\mathrm{NS}}$ \\
\hline
\end{tabular}




\section{RESULTADOS}

En el siguiente grupo (tabla 98) observamos:

- Glucosa (P<.05): Los pacientes del grupo de GIM carótida derecha inferior al corte tienen una media menor que el resto de casos (92.21 vs 114.24) con efecto moderado.

- Colesterol total $(P<.10)$ : Los pacientes de GIM carótida derecha inferior, tienen valores más altos que los demás sujetos, si bien el efecto parece bajo.

Tabla 98: Test de diferencia entre dos medias. Asociación de Índice de GIM carótida derecha con diversas variables de la analítica en la revisión.

\begin{tabular}{|c|c|c|c|c|c|c|c|c|c|c|c|}
\hline \multirow{2}{*}{$\begin{array}{l}\text { Variable } \\
\text { derecha }\end{array}$} & \multirow{2}{*}{ GIM carótida } & \multirow{2}{*}{$\mathrm{N}$} & \multirow{2}{*}{ Media } & \multirow{2}{*}{ D.E. } & \multicolumn{3}{|c|}{ T Student } & \multirow{2}{*}{$\begin{array}{l}\text { IC } 95 \% \text { para la } \\
\text { diferenc. absoluta }\end{array}$} & \multirow{2}{*}{$\begin{array}{l}\text { Efecto } \\
\mathrm{R}^{2}\end{array}$} & \multicolumn{2}{|c|}{ Test Mann-Whitney } \\
\hline & & & & & $\mathrm{T}$ & gl & $P$ & & & /Z/ & $P$ \\
\hline \multirow[t]{3}{*}{ Urea } & Inferior & 22 & 63.27 & 25.75 & & & & & & & \\
\hline & & & & & -1.20 & 41 & .237 NS & N.S. & .034 & 1.24 & $.215^{\mathrm{NS}}$ \\
\hline & Igual/Superior & 21 & 74.00 & 32.65 & & & & & & & \\
\hline \multirow[t]{3}{*}{ Glucosa } & Inferior & 22 & 92.91 & 8.26 & & & & & & & \\
\hline & & & & & -2.31 & 41 & $.026 *$ & $2.66-40.00$ & .115 & 2.54 & $.011 *$ \\
\hline & Igual/Superior & 21 & 114.24 & 42.55 & & & & & & & \\
\hline \multirow[t]{3}{*}{ Creatinina } & Inferior & 22 & 1.60 & 0.54 & & & & & & & \\
\hline & & & & & 0.33 & 41 & $.745^{\mathrm{NS}}$ & N.S. & .003 & 0.17 & $.864^{\mathrm{NS}}$ \\
\hline & Igual/Superior & 21 & 1.55 & 0.51 & & & & & & & \\
\hline \multirow[t]{3}{*}{ Ácido úrico } & Inferior & 22 & 6.84 & 1.54 & & & & & & & \\
\hline & & & & & -1.08 & 41 & $.285^{\mathrm{NS}}$ & N.S. & .028 & 0.58 & $.560 \mathrm{NS}$ \\
\hline & Igual/Superior & 21 & 10.80 & 17.06 & & & & & & & \\
\hline \multirow[t]{3}{*}{ Triglicéridos } & Inferior & 22 & 110.41 & 58.70 & & & & & & & \\
\hline & & & & & -1.25 & 41 & .219 NS & N.S. & .037 & 1.22 & .224 NS \\
\hline & Igual/Superior & 21 & 134.57 & 68.01 & & & & & & & \\
\hline \multirow[t]{3}{*}{ Colesterol total } & Inferior & 22 & 195.41 & 34.26 & & & & & & & \\
\hline & & & & & 1.99 & 41 & $.054^{\mathrm{NS}}$ & N.S. & .088 & 1.93 & $.053^{\mathrm{NS}}$ \\
\hline & Igual/Superior & 21 & 172.14 & 42.27 & & & & & & & \\
\hline \multirow[t]{3}{*}{ Proteínas totales } & Inferior & 22 & 6.80 & 0.42 & & & & & & & \\
\hline & & & & & -0.10 & 41 & $.924^{\mathrm{NS}}$ & N.S. & .000 & 0.37 & $.714 *$ \\
\hline & Igual/Superior & 21 & 6.82 & 0.56 & & & & & & & \\
\hline \multirow[t]{3}{*}{ Calcio } & Inferior & 22 & 9.61 & 0.57 & & & & & & & \\
\hline & & & & & 0.13 & 41 & $.897^{\mathrm{NS}}$ & N.S. & .000 & 0.42 & $.678^{\mathrm{NS}}$ \\
\hline & Igual/Superior & 21 & 9.59 & 0.59 & & & & & & & \\
\hline \multirow[t]{3}{*}{ Calcio correg. } & Inferior & 22 & 9.96 & 0.50 & & & & & & & \\
\hline & & & & & 0.19 & 41 & .851 NS & N.S. & .001 & 0.28 & $.780^{\mathrm{NS}}$ \\
\hline & Igual/Superior & 21 & 9.93 & 0.55 & & & & & & & \\
\hline \multirow[t]{3}{*}{ Prod. Calc/Fósf. } & Inferior & 22 & 31.80 & 6.47 & & & & & & & \\
\hline & & & & & 1.32 & 41 & .193 NS & N.S. & .041 & 1.25 & $.211^{\mathrm{NS}}$ \\
\hline & Igual/Superior & 21 & 29.38 & 5.42 & & & & & & & \\
\hline \multirow[t]{2}{*}{ Fósforo } & Inferior & 22 & 3.32 & 0.71 & & & & & & & \\
\hline & Igual/Superior & 21 & 3.08 & 0.62 & 1.19 & 41 & .239 NS & N.S. & .034 & 1.07 & .283 NS \\
\hline
\end{tabular}

N.S. $=$ NO significativo $(P>.05) \quad *=$ Significativo al $5 \%(P<.05)$ 


\section{RESULTADOS}

En el este bloque (tabla 99) se observa:

- Hemoglobina glicosilada ( $P<.05)$ : Los sujetos del grupo con GIM carótida derecha inferior tienen una media menor que el resto de casos (5.63 vs 6.29) con un tamaño del efecto moderado.

- Colesterol LDL $(\mathrm{P}<.05)$ : Los casos con GIM carótida derecha inferior, tienen una media mayor (111.19 vs 88.99) con efecto moderado.

Tabla 99: Test de diferencia entre dos medias. Asociación de Índice de GIM carótida derecha con diversas variables de la analítica en la revisión.-3-

\begin{tabular}{|c|c|c|c|c|c|c|c|c|c|c|c|}
\hline \multirow{2}{*}{$\begin{array}{l}\text { Variable } \\
\text { derecha }\end{array}$} & \multirow{2}{*}{ GIM carótida } & \multirow{2}{*}{$\mathrm{N}$} & \multirow{2}{*}{ Media } & \multirow{2}{*}{ D.E. } & \multicolumn{3}{|c|}{ T Student } & \multirow{2}{*}{$\begin{array}{l}\text { IC } 95 \% \text { para la } \\
\text { diferenc. absoluta }\end{array}$} & \multirow{2}{*}{$\begin{array}{l}\text { Efecto } \\
\mathrm{R}^{2}\end{array}$} & \multicolumn{2}{|c|}{ Test Mann-Whitney } \\
\hline & & & & & T & gl & $P$ & & & /Z/ & $P$ \\
\hline \multirow[t]{3}{*}{ Magnesio } & Inferior & 22 & 1.77 & 0.25 & & & & & & & \\
\hline & & & & & -1.72 & 41 & $.092^{\mathrm{NS}}$ & N.S. & .068 & 1.56 & $.119^{\mathrm{NS}}$ \\
\hline & Igual/Superior & 21 & 1.91 & 0.29 & & & & & & & \\
\hline \multirow[t]{3}{*}{ Fosfata Alcalina } & Inferior & 22 & 72.91 & 16.44 & & & & & & & \\
\hline & & & & & -1.05 & 41 & $.300^{\mathrm{NS}}$ & N.S. & .026 & 0.21 & $.836^{\mathrm{NS}}$ \\
\hline & Igual/Superior & 21 & 81.24 & 33.24 & & & & & & & \\
\hline \multirow[t]{3}{*}{ Clacio iónico } & Inferior & 22 & 1.27 & 0.06 & & & & & & & \\
\hline & & & & & 0.32 & 41 & $.753^{N S}$ & N.S. & .002 & 0.44 & .661 NS \\
\hline & Igual/Superior & 21 & 1.26 & 0.07 & & & & & & & \\
\hline \multirow[t]{3}{*}{ PCR } & Inferior & 22 & 2.55 & 2.61 & & & & & & & \\
\hline & & & & & -1.32 & 41 & .196 NS & N.S. & .041 & 1.53 & $.127^{\text {NS }}$ \\
\hline & Igual/Superior & 21 & 3.81 & 3.63 & & & & & & & \\
\hline \multirow[t]{3}{*}{ Interleukina } & Inferior & 22 & 9.46 & 25.12 & & & & & & & \\
\hline & & & & & 0.88 & 41 & .382 NS & N.S. & .019 & 1.47 & .143 NS \\
\hline & Igual/Superior & 21 & 4.59 & 3.13 & & & & & & & \\
\hline \multirow[t]{3}{*}{ PTH } & Inferior & 22 & 108.08 & 51.72 & & & & & & & \\
\hline & & & & & 0.05 & 41 & $.958^{\mathrm{NS}}$ & N.S. & .000 & 0.24 & $.808^{\text {NS }}$ \\
\hline & Igual/Superior & 21 & 107.16 & 61.46 & & & & & & & \\
\hline \multirow[t]{3}{*}{ Hemog. glicos. } & Inferior & 22 & 5.63 & 0.35 & & & & & & & \\
\hline & & & & & -2.56 & 41 & $.014 *$ & $0.14-1.19$ & .138 & 2.86 & $.004 * *$ \\
\hline & Igual/Superior & 21 & 6.29 & 1.16 & & & & & & & \\
\hline \multirow[t]{3}{*}{ Vitamina D } & Inferior & 22 & 20.21 & 11.29 & & & & & & & \\
\hline & & & & & 1.11 & 41 & $.274^{\mathrm{NS}}$ & N.S. & .029 & 1.42 & $.155^{N S}$ \\
\hline & Igual/Superior & 21 & 16.70 & 9.29 & & & & & & & \\
\hline \multirow[t]{3}{*}{ Colest. HDL } & Inferior & 22 & 61.36 & 17.88 & & & & & & & \\
\hline & & & & & 0.91 & 41 & $.368^{\mathrm{NS}}$ & N.S. & .020 & 1.09 & $.274^{\mathrm{NS}}$ \\
\hline & Igual/Superior & 21 & 56.19 & 19.39 & & & & & & & \\
\hline \multirow[t]{2}{*}{ Colest. LDL } & Inferior & 22 & 111.19 & 39.94 & & & & & & & \\
\hline & Igual/Superior & 21 & 88.99 & 31.59 & 2.37 & 41 & $.023 *$ & $3.25-41.15$ & .120 & 2.50 & $.012 *$ \\
\hline
\end{tabular}

N.S. $=$ NO significativo $(P>.05) \quad *=$ Significativo al $5 \%(P<.05)$ 


\section{RESULTADOS}

En este bloque (tabla 100) no aparecen significaciones ( $P>.05)$ aunque se podría admitir una casi significación $(\mathrm{P}<.100)$ en la variable $\mathrm{pH}$, donde podría concluirse que los casos del grupo con GIM carótida derecha inferior al corte tienen valores más altos, aunque el efecto sería bajo.

Tabla 100: Test de diferencia entre dos medias. Asociación de Índice de GIM carótida derecha con diversas variables de la analítica en la revisión.-4-

\begin{tabular}{|c|c|c|c|c|c|c|c|c|c|c|c|}
\hline \multirow{2}{*}{$\begin{array}{l}\text { Variable } \\
\text { derecha }\end{array}$} & \multirow{2}{*}{ GIM carótida } & \multirow{2}{*}{$\mathrm{N}$} & \multirow{2}{*}{ Media } & \multirow{2}{*}{ D.E. } & \multicolumn{3}{|c|}{ T Student } & \multirow{2}{*}{$\begin{array}{l}\text { IC } 95 \% \text { para la } \\
\text { diferenc. absoluta }\end{array}$} & \multirow{2}{*}{$\begin{array}{l}\text { Efecto } \\
\mathrm{R}^{2}\end{array}$} & \multicolumn{2}{|c|}{ Test Mann-Whitney } \\
\hline & & & & & T & gl & $P$ & & & /Z/ & $P$ \\
\hline \multirow[t]{3}{*}{$\mathrm{pH}$} & Inferior & 22 & 7.34 & 0.04 & & & & & & & \\
\hline & & & & & 1.94 & 41 & $.060^{\mathrm{NS}}$ & N.S. & .084 & 1.82 & $.069 \mathrm{Ns}$ \\
\hline & Igual/Superior & 21 & 7.32 & 0.03 & & & & & & & \\
\hline \multirow[t]{3}{*}{ Bicarbonato } & Inferior & 22 & 22.77 & 2.19 & & & & & & & \\
\hline & & & & & 0.97 & 41 & $.336^{\mathrm{NS}}$ & N.S. & .023 & 0.96 & $.337^{\mathrm{NS}}$ \\
\hline & Igual/Superior & 21 & 22.00 & 2.95 & & & & & & & \\
\hline \multirow[t]{3}{*}{ Microalbumin. } & Inferior & 22 & 46.01 & 60.00 & & & & & & & \\
\hline & & & & & -1.20 & 41 & $.236 \mathrm{NS}$ & N.S. & .034 & 0.94 & $.346^{\mathrm{NS}}$ \\
\hline & Igual/Superior & 21 & 97.99 & 193.24 & & & & & & & \\
\hline \multirow[t]{3}{*}{ MDRDa } & Inferior & 22 & 50.50 & 19.30 & & & & & & & \\
\hline & & & & & -0.29 & 41 & .773 NS & N.S. & .002 & 0.24 & $.808^{\mathrm{NS}}$ \\
\hline & Igual/Superior & 21 & 52.12 & 17.15 & & & & & & & \\
\hline \multirow[t]{3}{*}{ Cock. Gault } & Inferior & 22 & 61.04 & 24.78 & & & & & & & \\
\hline & & & & & 0.29 & 41 & .773 NS & N.S. & .002 & 0.44 & .662 NS \\
\hline & Igual/Superior & 21 & 58.85 & 24.64 & & & & & & & \\
\hline \multirow[t]{3}{*}{ Mayo Quadr. } & Inferior & 22 & 62.81 & 28.87 & & & & & & & \\
\hline & & & & & 0.25 & 41 & $.805^{\mathrm{NS}}$ & N.S. & .002 & 0.22 & $.827^{\text {Ns }}$ \\
\hline & Igual/Superior & 21 & 60.84 & 22.47 & & & & & & & \\
\hline \multirow[t]{3}{*}{ CKD-EPI } & Inferior & 22 & 51.61 & 21.36 & & & & & & & \\
\hline & & & & & -0.03 & 41 & .976 NS & N.S. & .000 & 0.08 & .932 NS \\
\hline & Igual/Superior & 21 & 51.79 & 18.41 & & & & & & & \\
\hline \multirow[t]{2}{*}{ FGF-22 } & Inferior & 22 & 5.01 & 14.21 & & & & & & & \\
\hline & Igual/Superior & 21 & 5.08 & 12.07 & -0.02 & 41 & .985 Ns & N.S. & .000 & 0.00 & .999 NS \\
\hline
\end{tabular}

N.S. $=$ NO significativo $(P>05)$ 


\section{RESULTADOS}

\section{GIM en arteria carótida izquierda}

En el este primer bloque de variables contrastadas no aparece ninguna significación $(P>.05)$.

Tabla 101: Test de diferencia entre dos medias. Asociación de Índice de GIM carótida izquierda con diversas variables antropométricas y de la analítica previa al trasplante.-1-

\begin{tabular}{|c|c|c|c|c|c|c|c|c|c|c|c|}
\hline \multirow{2}{*}{$\begin{array}{l}\text { Variable } \\
\text { izquierda }\end{array}$} & \multirow{2}{*}{ GIM carótida } & \multirow{2}{*}{$\mathrm{N}$} & \multirow{2}{*}{ Media } & \multirow{2}{*}{ D.E. } & \multicolumn{3}{|c|}{ T Student } & \multirow{2}{*}{$\begin{array}{l}\text { IC } 95 \% \text { para la } \\
\text { diferenc. absoluta }\end{array}$} & \multirow{2}{*}{$\begin{array}{l}\text { Efecto } \\
\mathrm{R}^{2}\end{array}$} & \multicolumn{2}{|c|}{ Test Mann-Whitney } \\
\hline & & & & & $\mathrm{T}$ & gl & $P$ & & & /Z/ & $P$ \\
\hline \multirow[t]{3}{*}{ Altura } & Inferior & 22 & 167.89 & 9.38 & & & & & & & \\
\hline & & & & & -0.25 & 41 & $.808^{\mathrm{NS}}$ & N.S. & .001 & 0.20 & $.846^{\mathrm{NS}}$ \\
\hline & Igual/Superior & 21 & 168.57 & 8.93 & & & & & & & \\
\hline \multirow[t]{3}{*}{ Peso } & Inferior & 22 & 70.19 & 11.18 & & & & & & & \\
\hline & & & & & -0.39 & 41 & $.696^{\mathrm{NS}}$ & N.S. & .004 & 0.12 & $.903^{N S}$ \\
\hline & Igual/Superior & 21 & 71.61 & 12.49 & & & & & & & \\
\hline \multirow[t]{3}{*}{ IMC } & Inferior & 22 & 24.84 & 3.08 & & & & & & & \\
\hline & & & & & -0.24 & 41 & $.809^{N S}$ & N.S. & .001 & 0.10 & $.923^{\mathrm{NS}}$ \\
\hline & Igual/Superior & 21 & 25.07 & 2.92 & & & & & & & \\
\hline \multirow[t]{3}{*}{ TAS } & Inferior & 22 & 147.59 & 24.06 & & & & & & & \\
\hline & & & & & 0.38 & 41 & $.708^{N S}$ & N.S. & .003 & 0.56 & .576 NS \\
\hline & Igual/Superior & 21 & 144.62 & 27.51 & & & & & & & \\
\hline \multirow[t]{3}{*}{ TAD } & Inferior & 22 & 84.68 & 13.16 & & & & & & & \\
\hline & & & & & 0.27 & 41 & .790 NS & N.S. & .002 & 0.02 & $.981^{\mathrm{NS}}$ \\
\hline & Igual/Superior & 21 & 83.62 & 12.84 & & & & & & & \\
\hline \multirow[t]{3}{*}{ Diuresis } & Inferior & 22 & 1215.91 & 1058.01 & & & & & & & \\
\hline & & & & & 1.35 & 41 & $.185^{\mathrm{NS}}$ & N.S. & .042 & 1.50 & $.133^{\mathrm{NS}}$ \\
\hline & Igual/Superior & 21 & 812.86 & 892.79 & & & & & & & \\
\hline \multirow[t]{3}{*}{ Hemoglobina } & Inferior & 22 & 12.70 & 1.50 & & & & & & & \\
\hline & & & & & 0.26 & 41 & .795 NS & N.S. & .002 & 0.22 & .827 NS \\
\hline & Igual/Superior & 21 & 12.57 & 1.83 & & & & & & & \\
\hline \multirow[t]{3}{*}{ Hematocrito } & Inferior & 22 & 38.17 & 4.59 & & & & & & & \\
\hline & & & & & 0.09 & 41 & $.930^{\mathrm{NS}}$ & N.S. & .000 & 0.11 & $.913^{\mathrm{NS}}$ \\
\hline & Igual/Superior & 21 & 38.03 & 5.77 & & & & & & & \\
\hline \multirow[t]{3}{*}{ Leucocitos } & Inferior & 22 & 6689.09 & 1550.73 & & & & & & & \\
\hline & & & & & -0.09 & 41 & .932 NS & N.S. & .000 & 0.55 & $.585^{N S}$ \\
\hline & Igual/Superior & 21 & 6732.38 & 1751.34 & & & & & & & \\
\hline \multirow[t]{2}{*}{ Plaquetas } & Inferior & 22 & 196772.73 & 58008.97 & & & & & & & \\
\hline & Igual/Superior & 21 & 180190.48 & 79569.23 & 0.78 & 41 & $.438^{N S}$ & N.S. & .015 & 1.13 & .259 NS \\
\hline
\end{tabular}

N.S. $=$ NO significativo $(P>.05) \quad * *=$ Altamente significativo al $1 \%(P<.01)$ 


\section{RESULTADOS}

En el siguiente bloque (tabla 102) tampoco se han encontrado relaciones significativas (P>.05).

Tabla 102: Test de diferencia entre dos medias. Asociación de Índice de GIM carótida izquierda con diversas variables de la analítica previa al trasplante.-2-

\begin{tabular}{|c|c|c|c|c|c|c|c|c|c|c|c|}
\hline \multirow{2}{*}{$\begin{array}{l}\text { Variable } \\
\text { izquierda }\end{array}$} & \multirow{2}{*}{ GIM carótida } & \multirow{2}{*}{ N } & \multirow{2}{*}{ Media } & \multirow{2}{*}{ D.E. } & \multicolumn{3}{|c|}{ T Student } & \multirow{2}{*}{$\begin{array}{l}\text { IC } 95 \% \text { para la } \\
\text { diferenc. absoluta }\end{array}$} & \multirow{2}{*}{$\begin{array}{l}\text { Efecto } \\
\mathrm{R}^{2}\end{array}$} & \multicolumn{2}{|c|}{ Test Mann-Whitney } \\
\hline & & & & & $\mathrm{T}$ & gl & $\mathrm{P}$ & & & /Z/ & $P$ \\
\hline \multirow[t]{3}{*}{ Urea } & Inferior & 22 & 153.27 & 37.72 & & & & & & & \\
\hline & & & & & 1.69 & 41 & .099 NS & N.S. & .065 & 1.52 & .129 NS \\
\hline & Igual/Superior & 21 & 135.71 & 29.77 & & & & & & & \\
\hline \multirow[t]{3}{*}{ Glucosa } & Inferior & 22 & 96.09 & 28.15 & & & & & & & \\
\hline & & & & & 0.29 & 41 & $.775^{N S}$ & N.S. & .002 & 0.49 & $.627^{\text {NS }}$ \\
\hline & Igual/Superior & 21 & 94.05 & 16.82 & & & & & & & \\
\hline \multirow[t]{3}{*}{ Creatinina } & Inferior & 22 & 8.36 & 2.46 & & & & & & & \\
\hline & & & & & -1.23 & 41 & $.225^{N S}$ & N.S. & .036 & 1.23 & $.220 \mathrm{NS}$ \\
\hline & Igual/Superior & 21 & 9.36 & 2.86 & & & & & & & \\
\hline \multirow[t]{3}{*}{ Triglicéridos } & Inferior & 22 & 113.59 & 39.79 & & & & & & & \\
\hline & & & & & -0.57 & 41 & .569 NS & N.S. & .008 & 1.08 & $.280^{\mathrm{NS}}$ \\
\hline & Igual/Superior & 21 & 120.86 & 43.17 & & & & & & & \\
\hline \multirow[t]{3}{*}{ Colesterol total } & Inferior & 22 & 177.14 & 58.64 & & & & & & & \\
\hline & & & & & 1.07 & 41 & .291 NS & N.S. & .027 & 0.57 & $.568^{N S}$ \\
\hline & Igual/Superior & 21 & 160.24 & 43.48 & & & & & & & \\
\hline \multirow[t]{3}{*}{ Proteínas totales } & Inferior & 22 & 6.84 & 0.59 & & & & & & & \\
\hline & & & & & -0.62 & 41 & $.538^{\mathrm{NS}}$ & N.S. & .009 & 0.55 & .584 NS \\
\hline & Igual/Superior & 21 & 6.95 & 0.52 & & & & & & & \\
\hline \multirow[t]{3}{*}{ Calcio } & Inferior & 22 & 9.29 & 0.98 & & & & & & & \\
\hline & & & & & 0.15 & 41 & .880 NS & N.S. & .001 & 0.94 & .349 NS \\
\hline & Igual/Superior & 21 & 9.25 & 0.74 & & & & & & & \\
\hline \multirow[t]{3}{*}{ Calcio correg. } & Inferior & 22 & 9.62 & 1.00 & & & & & & & \\
\hline & & & & & 0.35 & 41 & .732 NS & N.S. & .003 & 1.05 & .296 NS \\
\hline & Igual/Superior & 21 & 9.52 & 0.75 & & & & & & & \\
\hline \multirow[t]{2}{*}{ Prod. Calc/Fósf. } & Inferior & 22 & 45.52 & 10.41 & & & & & & & \\
\hline & Igual/Superior & 21 & 47.31 & 10.70 & -0.55 & 41 & $.582 \mathrm{NS}$ & N.S. & .007 & 0.98 & $.325^{\mathrm{NS}}$ \\
\hline
\end{tabular}




\section{RESULTADOS}

En el grupo que sigue (tabla 103) tampoco se encuentran diferencias significativas $(P>.05)$

Tabla 103: Test de diferencia entre dos medias. Asociación de Índice de GIM carótida izquierda con diversas variables de la analítica previa al trasplante.-3-

\begin{tabular}{|c|c|c|c|c|c|c|c|c|c|c|c|}
\hline \multirow{2}{*}{$\begin{array}{l}\text { Variable } \\
\text { izquierda }\end{array}$} & \multirow[t]{2}{*}{ GIM carótida } & \multirow{2}{*}{$\mathrm{N}$} & \multirow{2}{*}{ Media } & \multirow{2}{*}{ D.E. } & \multicolumn{3}{|c|}{ T Student } & \multirow{2}{*}{$\begin{array}{l}\text { IC } 95 \% \text { para la } \\
\text { diferenc. absoluta }\end{array}$} & \multirow{2}{*}{$\begin{array}{l}\text { Efecto } \\
\mathrm{R}^{2}\end{array}$} & \multicolumn{2}{|c|}{ Test Mann-Whitney } \\
\hline & & & & & $\mathrm{T}$ & gl & $P$ & & & /Z/ & $P$ \\
\hline \multirow[t]{3}{*}{ Fósforo } & Inferior & 22 & 4.89 & 0.94 & & & & & & & \\
\hline & & & & & -0.73 & 41 & .469 NS & N.S. & .013 & 0.78 & .436 NS \\
\hline & Igual/Superior & 21 & 5.12 & 1.18 & & & & & & & \\
\hline \multirow[t]{3}{*}{ Fosfata Alcalina } & Inferior & 22 & 85.00 & 36.34 & & & & & & & \\
\hline & & & & & -1.76 & 41 & $.085^{\mathrm{NS}}$ & N.S. & .070 & 1.02 & $.307^{N S}$ \\
\hline & Igual/Superior & 21 & 117.76 & 78.88 & & & & & & & \\
\hline \multirow[t]{3}{*}{ H. Paratiroidea } & Inferior & 21 & 339.84 & 360.92 & & & & & & & \\
\hline & & & & & -0.30 & 40 & .769 NS & N.S. & .002 & 0.14 & .890 NS \\
\hline & Igual/Superior & 21 & 375.27 & 414.93 & & & & & & & \\
\hline \multirow[t]{3}{*}{$\mathrm{pH}$} & Inferior & 22 & 7.37 & 0.06 & & & & & & & \\
\hline & & & & & 0.11 & 41 & $.912^{\mathrm{NS}}$ & N.S. & .000 & 0.18 & $.855^{\mathrm{NS}}$ \\
\hline & Igual/Superior & 21 & 7.37 & 0.04 & & & & & & & \\
\hline \multirow[t]{3}{*}{ Bicarbonato } & Inferior & 22 & 24.29 & 2.73 & & & & & & & \\
\hline & & & & & 1.48 & 41 & $.147^{\mathrm{NS}}$ & N.S. & .051 & 1.23 & $.220^{\mathrm{NS}}$ \\
\hline & Igual/Superior & 21 & 23.04 & 2.79 & & & & & & & \\
\hline \multirow[t]{3}{*}{ MDRDa } & Inferior & 22 & 7.41 & 2.30 & & & & & & & \\
\hline & & & & & 1.40 & 41 & .169 NS & N.S. & .046 & 1.29 & .198 NS \\
\hline & Igual/Superior & 21 & 6.48 & 2.08 & & & & & & & \\
\hline \multirow[t]{3}{*}{ Cock. Gault } & Inferior & 22 & 11.00 & 4.30 & & & & & & & \\
\hline & & & & & 1.22 & 41 & .229 NS & N.S. & .035 & 0.85 & .395 NS \\
\hline & Igual/Superior & 21 & 9.64 & 2.82 & & & & & & & \\
\hline \multirow[t]{3}{*}{ Mayo Quadr. } & Inferior & 22 & 9.56 & 2.18 & & & & & & & \\
\hline & & & & & 1.46 & 41 & $.153^{\mathrm{NS}}$ & N.S. & .049 & 1.17 & $.244^{\mathrm{NS}}$ \\
\hline & Igual/Superior & 21 & 8.70 & 1.62 & & & & & & & \\
\hline \multirow[t]{2}{*}{ CKD-EPI } & Inferior & 22 & 6.89 & 2.36 & & & & & & & \\
\hline & Igual/Superior & 21 & 5.93 & 1.96 & 1.44 & 41 & .156 NS & N.S. & .048 & 1.24 & $.215^{\mathrm{NS}}$ \\
\hline
\end{tabular}

N.S. $=$ NO significativo $(P>.05)$ 


\section{RESULTADOS}

En este bloque (tabla 104) de nuevo no se encuentran diferencias significativas ( $P>.05)$.

Tabla 104: Test de diferencia entre dos medias. Asociación de Índice de GIM carótida izquierda con diversas variables antropométricas y de la analítica al alta tras el trasplante.-1-

\begin{tabular}{|c|c|c|c|c|c|c|c|c|c|c|c|}
\hline \multirow{2}{*}{$\begin{array}{l}\text { Variable } \\
\text { izquierda }\end{array}$} & \multirow{2}{*}{ GIM carótida } & \multirow{2}{*}{$\mathrm{N}$} & \multirow{2}{*}{ Media } & \multirow{2}{*}{ D.E. } & \multicolumn{3}{|c|}{ T Student } & \multirow{2}{*}{$\begin{array}{l}\text { IC } 95 \% \text { para la } \\
\text { diferenc. absoluta }\end{array}$} & \multirow{2}{*}{$\begin{array}{l}\text { Efecto } \\
\mathrm{R}^{2}\end{array}$} & \multicolumn{2}{|c|}{ Test Mann-Whitney } \\
\hline & & & & & $\mathrm{T}$ & $\mathrm{gl}$ & $P$ & & & |Z/ & $P$ \\
\hline \multirow[t]{3}{*}{ Peso } & Inferior & 22 & 69.35 & 11.98 & & & & & & & \\
\hline & & & & & 0.03 & 41 & $.973^{\text {NS }}$ & N.S. & .000 & 0.29 & .771 NS \\
\hline & Igual/Superior & 21 & 69.23 & 11.47 & & & & & & & \\
\hline \multirow[t]{3}{*}{ IMC } & Inferior & 22 & 24.56 & 3.61 & & & & & & & \\
\hline & & & & & 0.26 & 41 & $.794^{\text {NS }}$ & N.S. & .002 & 0.16 & $.875^{\text {NS }}$ \\
\hline & Igual/Superior & 21 & 24.30 & 2.93 & & & & & & & \\
\hline \multirow[t]{3}{*}{ TAS } & Inferior & 22 & 136.77 & 24.13 & & & & & & & \\
\hline & & & & & -027 & 41 & .786 NS & N.S. & .002 & 0.54 & .592 NS \\
\hline & Igual/Superior & 21 & 138.76 & 23.58 & & & & & & & \\
\hline \multirow[t]{3}{*}{ TAD } & Inferior & 22 & 75.45 & 14.94 & & & & & & & \\
\hline & & & & & -1.51 & 41 & .139 NS & N.S. & .053 & 1.63 & $.103^{N S}$ \\
\hline & Igual/Superior & 21 & 81.67 & 11.82 & & & & & & & \\
\hline \multirow[t]{3}{*}{ Diuresis } & Inferior & 22 & 2508.18 & 964.02 & & & & & & & \\
\hline & & & & & 0.59 & 41 & $.555^{\mathrm{NS}}$ & N.S. & .009 & 0.50 & $.618^{\mathrm{NS}}$ \\
\hline & Igual/Superior & 21 & 2365.48 & 541.73 & & & & & & & \\
\hline \multirow[t]{3}{*}{ Hemoglobina } & Inferior & 22 & 10.81 & 1.26 & & & & & & & \\
\hline & & & & & 0.45 & 41 & .652 NS & N.S. & .005 & 0.66 & $.511^{\mathrm{NS}}$ \\
\hline & Igual/Superior & 21 & 10.62 & 1.42 & & & & & & & \\
\hline \multirow[t]{3}{*}{ Hematocrito } & Inferior & 22 & 32.60 & 3.59 & & & & & & & \\
\hline & & & & & -0.18 & 41 & $.857^{\mathrm{NS}}$ & N.S. & .001 & 0.23 & $.817^{\mathrm{NS}}$ \\
\hline & Igual/Superior & 21 & 32.83 & 4.45 & & & & & & & \\
\hline \multirow[t]{3}{*}{ Leucocitos } & Inferior & 22 & 10057.73 & 3563.58 & & & & & & & \\
\hline & & & & & 1.05 & 41 & .298 NS & N.S. & .026 & 1.09 & .274 NS \\
\hline & Igual/Superior & 21 & 8862.38 & 3878.66 & & & & & & & \\
\hline \multirow[t]{3}{*}{ Plaquetas } & Inferior & 22 & 273818.18 & 116501.64 & & & & & & & \\
\hline & & & & & 0.76 & 41 & .452 NS & N.S. & .014 & 0.98 & .325 NS \\
\hline & Igual/Superior & 21 & 246904.76 & 115831.30 & & & & & & & \\
\hline \multirow[t]{2}{*}{ VSG } & Inferior & 22 & 37.95 & 29.78 & & & & & & & \\
\hline & Igual/Superior & 21 & 31.10 & 26.52 & 0.80 & 41 & .430 NS & N.S. & .015 & 0.67 & .504 NS \\
\hline
\end{tabular}

N.S. $=$ NO significativo $(\mathrm{P}>$.05) $\quad *=$ Significativo al $5 \%(\mathrm{P}<.05) \quad * *=$ Altamente significativo al $1 \%(\mathrm{P}<.01)$ 


\section{RESULTADOS}

En el siguiente bloque no se observa significación en el contraste con ninguna de las variables representadas en los contrastes de las variables con respecto a esta prueba (tabla 105).

Tabla 105: Test de diferencia entre dos medias. Asociación de Índice de GIM carótida izquierda con diversas variables de la analítica al alta tras el trasplante.-2-

\begin{tabular}{|c|c|c|c|c|c|c|c|c|c|c|c|}
\hline \multirow{2}{*}{$\begin{array}{l}\text { Variable } \\
\text { izquierda }\end{array}$} & \multirow{2}{*}{ GIM carótida } & \multirow{2}{*}{$\mathrm{N}$} & \multirow{2}{*}{ Media } & \multirow{2}{*}{ D.E. } & \multicolumn{3}{|c|}{ T Student } & \multirow{2}{*}{$\begin{array}{l}\text { IC 95\% para la } \\
\text { diferenc. absoluta }\end{array}$} & \multirow{2}{*}{$\begin{array}{l}\text { Efecto } \\
\mathrm{R}^{2}\end{array}$} & \multicolumn{2}{|c|}{ Test Mann-Whitney } \\
\hline & & & & & $\mathrm{T}$ & gl & $P$ & & & /Z/ & $P$ \\
\hline \multirow[t]{3}{*}{ Urea } & Inferior & 22 & 86.77 & 42.52 & & & & & & & \\
\hline & & & & & -0.36 & 41 & .723 NS & N.S. & .003 & 0.88 & .382 NS \\
\hline & Igual/Superior & 21 & 91.00 & 34.68 & & & & & & & \\
\hline \multirow[t]{3}{*}{ Glucosa } & Inferior & 22 & 102.05 & 23.30 & & & & & & & \\
\hline & & & & & -0.26 & 41 & .797 NS & N.S. & .002 & 0.42 & .671 NS \\
\hline & Igual/Superior & 21 & 104.57 & 38.95 & & & & & & & \\
\hline \multirow[t]{3}{*}{ Creatinina } & Inferior & 22 & 2.35 & 1.62 & & & & & & & \\
\hline & & & & & 0.62 & 41 & $.538^{\mathrm{NS}}$ & N.S. & .009 & 0.21 & $.836^{\mathrm{NS}}$ \\
\hline & Igual/Superior & 21 & 2.08 & 1.10 & & & & & & & \\
\hline \multirow[t]{3}{*}{ Triglicéridos } & Inferior & 22 & 130.36 & 45.65 & & & & & & & \\
\hline & & & & & -1.56 & 41 & $.125^{\mathrm{NS}}$ & N.S. & .056 & 1.17 & $.243^{N S}$ \\
\hline & Igual/Superior & 21 & 162.62 & 84.72 & & & & & & & \\
\hline \multirow[t]{3}{*}{ Colesterol total } & Inferior & 22 & 192.59 & 52.61 & & & & & & & \\
\hline & & & & & 1.06 & 41 & $.295^{\mathrm{NS}}$ & N.S. & .027 & 0.78 & .437 NS \\
\hline & Igual/Superior & 21 & 176.43 & 47.01 & & & & & & & \\
\hline \multirow[t]{3}{*}{ Proteínas totales } & Inferior & 22 & 6.24 & 0.48 & & & & & & & \\
\hline & & & & & 0.53 & 41 & $.596 \mathrm{NS}$ & N.S. & .007 & 0.52 & .600 NS \\
\hline & Igual/Superior & 21 & 6.15 & 0.65 & & & & & & & \\
\hline \multirow[t]{3}{*}{ Calcio } & Inferior & 22 & 9.64 & 1.03 & & & & & & & \\
\hline & & & & & 0.38 & 41 & $.704^{\mathrm{NS}}$ & N.S. & .004 & 0.16 & .874 NS \\
\hline & Igual/Superior & 21 & 9.53 & 0.70 & & & & & & & \\
\hline \multirow[t]{3}{*}{ Calcio correg. } & Inferior & 22 & 10.27 & 0.97 & & & & & & & \\
\hline & & & & & 0.23 & 41 & $.821^{\mathrm{NS}}$ & N.S. & .001 & 0.11 & $.913^{\mathrm{NS}}$ \\
\hline & Igual/Superior & 21 & 10.21 & 0.61 & & & & & & & \\
\hline \multirow[t]{3}{*}{ Prod. Calc/Fósf. } & Inferior & 22 & 31.04 & 12.41 & & & & & & & \\
\hline & & & & & 0.38 & 41 & $.708^{N S}$ & N.S. & .003 & 0.30 & .761 NS \\
\hline & Igual/Superior & 21 & 29.86 & 7.16 & & & & & & & \\
\hline \multirow[t]{2}{*}{ Fósforo } & Inferior & 22 & 3.21 & 1.26 & & & & & & & \\
\hline & Igual/Superior & 21 & 3.15 & 0.77 & 0.19 & 41 & .849 NS & N.S. & .001 & 0.16 & .874 NS \\
\hline
\end{tabular}

N.S. $=$ NO significativo $(P>05)$ 


\section{RESULTADOS}

En este bloque (tabla 106) no se han detectado diferencias que tengan significación ( $P>.05)$.

Tabla 106: Test de diferencia entre dos medias. Asociación de Índice de GIM carótida izquierda con diversas variables de la analítica al alta tras el trasplante.-3-

\begin{tabular}{|c|c|c|c|c|c|c|c|c|c|c|c|}
\hline \multirow{2}{*}{$\begin{array}{l}\text { Variable } \\
\text { izquierda }\end{array}$} & \multirow{2}{*}{ GIM carótida } & \multirow{2}{*}{$\mathrm{N}$} & \multirow{2}{*}{ Media } & \multirow{2}{*}{ D.E. } & \multicolumn{3}{|c|}{ T Student } & \multirow{2}{*}{$\begin{array}{l}\text { IC 95\% para la } \\
\text { diferenc. absoluta }\end{array}$} & \multirow{2}{*}{$\begin{array}{l}\text { Efecto } \\
\mathrm{R}^{2}\end{array}$} & \multicolumn{2}{|c|}{ Test Mann-Whitney } \\
\hline & & & & & $\mathrm{T}$ & gl & $P$ & & & /Z/ & $P$ \\
\hline \multirow[t]{3}{*}{ Magnesio } & Inferior & 22 & 1.75 & 0.38 & & & & & & & \\
\hline & & & & & 1.69 & 41 & $.098^{\mathrm{NS}}$ & N.S. & .065 & 1.40 & $.163^{\mathrm{NS}}$ \\
\hline & Igual/Superior & 21 & 1.59 & 0.23 & & & & & & & \\
\hline \multirow[t]{3}{*}{ Fosfata Alcalina } & Inferior & 22 & 79.86 & 29.79 & & & & & & & \\
\hline & & & & & -0.89 & 41 & $.376^{\mathrm{NS}}$ & N.S. & .019 & 0.60 & .551 NS \\
\hline & Igual/Superior & 21 & 94.24 & 68.92 & & & & & & & \\
\hline \multirow[t]{3}{*}{ Urea en orina } & Inferior & 22 & 1205.57 & 487.48 & & & & & & & \\
\hline & & & & & -0.06 & 41 & .950 NS & N.S. & .000 & 0.90 & .369 NS \\
\hline & Igual/Superior & 21 & 1213.76 & 339.18 & & & & & & & \\
\hline \multirow[t]{3}{*}{ Creat. en orina } & Inferior & 22 & 59.00 & 24.66 & & & & & & & \\
\hline & & & & & 0.37 & 41 & $.713^{\mathrm{NS}}$ & N.S. & .003 & 0.15 & $.884^{\mathrm{NS}}$ \\
\hline & Igual/Superior & 21 & 56.16 & 25.76 & & & & & & & \\
\hline \multirow[t]{3}{*}{$\mathrm{pH}$} & Inferior & 22 & 7.35 & 0.04 & & & & & & & \\
\hline & & & & & -0.11 & 41 & .910 NS & N.S. & .000 & 0.40 & $.687^{\mathrm{NS}}$ \\
\hline & Igual/Superior & 21 & 7.35 & 0.06 & & & & & & & \\
\hline \multirow[t]{3}{*}{ Bicarbonato } & Inferior & 22 & 21.06 & 2.92 & & & & & & & \\
\hline & & & & & -0.03 & 41 & $.978^{N S}$ & N.S. & .000 & 0.18 & $.855^{\mathrm{NS}}$ \\
\hline & Igual/Superior & 21 & 21.09 & 3.44 & & & & & & & \\
\hline \multirow[t]{3}{*}{ MDRDa } & Inferior & 22 & 39.72 & 16.82 & & & & & & & \\
\hline & & & & & -0.25 & 41 & .805 NS & N.S. & .001 & 0.02 & .981 NS \\
\hline & Igual/Superior & 21 & 41.02 & 17.60 & & & & & & & \\
\hline \multirow[t]{3}{*}{ Cock. Gault } & Inferior & 22 & 44.73 & 15.58 & & & & & & & \\
\hline & & & & & 0.07 & 41 & .948 NS & N.S. & .000 & 0.17 & .865 NS \\
\hline & Igual/Superior & 21 & 44.42 & 12.83 & & & & & & & \\
\hline \multirow[t]{3}{*}{ Mayo Quadr. } & Inferior & 22 & 46.44 & 23.43 & & & & & & & \\
\hline & & & & & -0.20 & 41 & $.843^{N S}$ & N.S. & .001 & 0.12 & .903 NS \\
\hline & Igual/Superior & 21 & 47.89 & 24.29 & & & & & & & \\
\hline \multirow[t]{2}{*}{ CKD-EPI } & Inferior & 22 & 40.04 & 17.94 & & & & & & & \\
\hline & Igual/Superior & 21 & 41.06 & 17.94 & -0.19 & 41 & $.853^{N S}$ & N.S. & .001 & 0.05 & $.961^{\mathrm{NS}}$ \\
\hline
\end{tabular}




\section{RESULTADOS}

No se han encontrado significaciones $(P>.05)$ entre las siguientes variables (tabla 107).

Tabla 107: Test de diferencia entre dos medias. Asociación de Índice de GIM carótida izquierda con diversas variables antropométricas y de la analítica en la revisión.-1-

\begin{tabular}{|c|c|c|c|c|c|c|c|c|c|c|c|}
\hline \multirow{2}{*}{$\begin{array}{l}\text { Variable } \\
\text { izquierda }\end{array}$} & \multirow[t]{2}{*}{ GIM carótida } & \multirow{2}{*}{$\mathrm{N}$} & \multirow{2}{*}{ Media } & \multirow{2}{*}{ D.E. } & \multicolumn{3}{|c|}{ T Student } & \multirow{2}{*}{$\begin{array}{l}\text { IC } 95 \% \text { para la } \\
\text { diferenc. absoluta }\end{array}$} & \multirow{2}{*}{$\begin{array}{l}\text { Efecto } \\
\mathrm{R}^{2}\end{array}$} & \multicolumn{2}{|c|}{ Test Mann-Whitney } \\
\hline & & & & & $\mathrm{T}$ & gl & $P$ & & & /Z/ & $P$ \\
\hline \multirow[t]{3}{*}{ Peso } & Inferior & 22 & 72.38 & 12.11 & & & & & & & \\
\hline & & & & & -1.15 & 41 & $.257^{\mathrm{NS}}$ & N.S. & .031 & 0.67 & $.504^{\mathrm{NS}}$ \\
\hline & Igual/Superior & 21 & 77.00 & 14.19 & & & & & & & \\
\hline \multirow[t]{3}{*}{ IMC } & Inferior & 22 & 25.61 & 3.41 & & & & & & & \\
\hline & & & & & -1.31 & 41 & .199 NS & N.S. & . 040 & 0.95 & $.343^{\mathrm{NS}}$ \\
\hline & Igual/Superior & 21 & 27.00 & 3.54 & & & & & & & \\
\hline \multirow[t]{3}{*}{ TAS } & Inferior & 22 & 143.18 & 17.12 & & & & & & & \\
\hline & & & & & -0.44 & 41 & .662 NS & N.S. & . 005 & 0.67 & $.504^{\mathrm{NS}}$ \\
\hline & Igual/Superior & 21 & 145.62 & 19.10 & & & & & & & \\
\hline \multirow[t]{3}{*}{ TAD } & Inferior & 22 & 85.00 & 8.71 & & & & & & & \\
\hline & & & & & 0.19 & 41 & .849 NS & N.S. & .001 & 0.00 & .998 Ns \\
\hline & Igual/Superior & 21 & 84.48 & 9.24 & & & & & & & \\
\hline \multirow[t]{3}{*}{ Diuresis } & Inferior & 22 & 2535.00 & 803.06 & & & & & & & \\
\hline & & & & & -0.50 & 41 & $.623^{\mathrm{NS}}$ & N.S. & .006 & 0.67 & $.504^{\mathrm{NS}}$ \\
\hline & Igual/Superior & 21 & 2657.14 & 813.37 & & & & & & & \\
\hline \multirow[t]{3}{*}{ Hemoglobina } & Inferior & 22 & 13.34 & 1.96 & & & & & & & \\
\hline & & & & & -0.05 & 41 & .959 NS & N.S. & .000 & 0.08 & .932 NS \\
\hline & Igual/Superior & 21 & 13.37 & 1.93 & & & & & & & \\
\hline \multirow[t]{3}{*}{ Hematocrito } & Inferior & 22 & 40.14 & 4.92 & & & & & & & \\
\hline & & & & & -0.10 & 41 & .922 NS & N.S. & .000 & 0.13 & $.894^{\mathrm{NS}}$ \\
\hline & Igual/Superior & 21 & 40.30 & 5.60 & & & & & & & \\
\hline \multirow[t]{3}{*}{ Leucocitos } & Inferior & 22 & 6640.00 & 2111.35 & & & & & & & \\
\hline & & & & & -0.70 & 41 & .488 NS & N.S. & .012 & 0.66 & $.512 \mathrm{NS}$ \\
\hline & Igual/Superior & 21 & 7098.10 & 2182.42 & & & & & & & \\
\hline \multirow[t]{3}{*}{ Plaquetas } & Inferior & 22 & 202045.45 & 53715.72 & & & & & & & \\
\hline & & & & & 1.31 & 41 & .197 NS & N.S. & .040 & 1.42 & $.155^{\text {NS }}$ \\
\hline & Igual/Superior & 21 & 178809.52 & 62350.32 & & & & & & & \\
\hline \multirow[t]{2}{*}{ VSG } & Inferior & 22 & 14.33 & 11.12 & & & & & & & \\
\hline & Igual/Superior & 21 & 18.76 & 17.46 & -1.00 & 41 & $.324 \mathrm{Ns}$ & N.S. & .024 & 0.75 & $.451^{\mathrm{NS}}$ \\
\hline
\end{tabular}

N.S. $=$ NO significativo $(P>05)$ 


\section{RESULTADOS}

En el siguiente grupo (tabla 108) se observa:

- Triglicéridos $(\mathrm{P}<.01)$ : Los casos con GIM carótida izquierda inferior al corte, tienen una media menor que el resto de pacientes (95.68 vs 150.00) equivalente a un tamaño del efecto moderado.

- Ácido úrico ( $\mathrm{P}<.05)$ : Los pacientes del grupo con GIM carótida izquierda inferior al corte parecen tener valores menores que el resto de casos, aunque el efecto parece ser muy pequeño.

Tabla 108: Test de diferencia entre dos medias. Asociación de Índice de GIM carótida izquierda con diversas variables de la analítica en la revisión.-2-

\begin{tabular}{|c|c|c|c|c|c|c|c|c|c|c|c|}
\hline \multirow{2}{*}{$\begin{array}{l}\text { Variable } \\
\text { izquierda }\end{array}$} & \multirow[t]{2}{*}{ GIM carótida } & \multirow{2}{*}{$\mathrm{N}$} & \multirow{2}{*}{ Media } & \multirow{2}{*}{ D.E. } & \multicolumn{3}{|c|}{ T Student } & \multirow{2}{*}{$\begin{array}{l}\text { IC } 95 \% \text { para la } \\
\text { diferenc. absoluta }\end{array}$} & \multirow{2}{*}{$\begin{array}{l}\text { Efecto } \\
\mathrm{R}^{2}\end{array}$} & \multicolumn{2}{|c|}{ Test Mann-Whitney } \\
\hline & & & & & $\mathrm{T}$ & gl & $P$ & & & /Z/ & $P$ \\
\hline \multirow[t]{3}{*}{ Urea } & Inferior & 22 & 63.45 & 25.30 & & & & & & & \\
\hline & & & & & -1.16 & 41 & $.254^{\mathrm{NS}}$ & N.S. & .032 & 1.02 & $.307^{\mathrm{NS}}$ \\
\hline & Igual/Superior & 21 & 73.81 & 33.08 & & & & & & & \\
\hline \multirow[t]{3}{*}{ Glucosa } & Inferior & 22 & 103.14 & 36.04 & & & & & & & \\
\hline & & & & & -0.04 & 41 & $.969 \mathrm{NS}$ & N.S. & .000 & 1.22 & $.224^{\mathrm{NS}}$ \\
\hline & Igual/Superior & 21 & 103.52 & 27.61 & & & & & & & \\
\hline \multirow[t]{3}{*}{ Creatinina } & Inferior & 22 & 1.51 & 0.56 & & & & & & & \\
\hline & & & & & -0.78 & 41 & .438 NS & N.S. & .015 & 1.20 & $.231 \mathrm{Ns}$ \\
\hline & Igual/Superior & 21 & 1.64 & 0.47 & & & & & & & \\
\hline \multirow[t]{3}{*}{ Ácido úrico } & Inferior & 22 & 6.61 & 1.55 & & & & & & & \\
\hline & & & & & -1.22 & 41 & .231 NS & N.S. & .035 & 2.20 & $.028 *$ \\
\hline & Igual/Superior & 21 & 11.04 & 17.00 & & & & & & & \\
\hline \multirow[t]{3}{*}{ Triglicéridos } & Inferior & 22 & 95.68 & 35.16 & & & & & & & \\
\hline & & & & & -3.05 & 41 & $.004^{* *}$ & $18.39-90.25$ & .185 & 2.78 & $.005^{* *}$ \\
\hline & Igual/Superior & 21 & 150.00 & 75.33 & & & & & & & \\
\hline \multirow[t]{3}{*}{ Colesterol total } & Inferior & 22 & 188.91 & 35.30 & & & & & & & \\
\hline & & & & & 0.82 & 41 & $.418^{\mathrm{NS}}$ & N.S. & .016 & 0.75 & $.451^{\mathrm{NS}}$ \\
\hline & Igual/Superior & 21 & 178.95 & 44.14 & & & & & & & \\
\hline \multirow[t]{3}{*}{ Proteínas totales } & Inferior & 22 & 6.79 & 0.56 & & & & & & & \\
\hline & & & & & -0.34 & 41 & .733 NS & N.S. & .003 & 0.32 & $.751^{\mathrm{NS}}$ \\
\hline & Igual/Superior & 21 & 6.84 & 0.41 & & & & & & & \\
\hline \multirow[t]{3}{*}{ Calcio } & Inferior & 22 & 9.58 & 0.56 & & & & & & & \\
\hline & & & & & -0.24 & 41 & .814 NS & N.S. & .001 & 0.05 & .961 Ns \\
\hline & Igual/Superior & 21 & 9.62 & 0.60 & & & & & & & \\
\hline \multirow[t]{3}{*}{ Calcio correg. } & Inferior & 22 & 9.94 & 0.54 & & & & & & & \\
\hline & & & & & -0.10 & 41 & $.921^{\text {NS }}$ & N.S. & .000 & 0.10 & .923 NS \\
\hline & Igual/Superior & 21 & 9.95 & 0.52 & & & & & & & \\
\hline \multirow[t]{3}{*}{ Prod. Calc/Fósf. } & Inferior & 22 & 31.22 & 6.68 & & & & & & & \\
\hline & & & & & 0.66 & 41 & $.513^{\mathrm{NS}}$ & N.S. & .011 & 0.70 & $.481^{\mathrm{NS}}$ \\
\hline & Igual/Superior & 21 & 29.99 & 5.38 & & & & & & & \\
\hline \multirow[t]{2}{*}{ Fósforo } & Inferior & 22 & 3.27 & 0.73 & & & & & & & \\
\hline & Igual/Superior & 21 & 3.13 & 0.61 & 0.68 & 41 & .500 NS & N.S. & .011 & 0.72 & .472 NS \\
\hline
\end{tabular}

N.S. $=$ NO significativo $(P>05) \quad *=$ Significativo al $5 \%(P<.05)$ 


\section{RESULTADOS}

En el siguiente grupo (tabla 109) de nuevo no se encuentran significaciones estadísticas (P>.05).

Tabla 109: Test de diferencia entre dos medias. Asociación de Índice de GIM carótida izquierda con diversas variables de la analítica en la revisión.-3-

\begin{tabular}{|c|c|c|c|c|c|c|c|c|c|c|c|}
\hline \multirow{2}{*}{$\begin{array}{l}\text { Variable } \\
\text { izquierda }\end{array}$} & \multirow{2}{*}{ GIM carótida } & \multirow{2}{*}{$\mathrm{N}$} & \multirow{2}{*}{ Media } & \multirow{2}{*}{ D.E. } & \multicolumn{3}{|c|}{ T Student } & \multirow{2}{*}{$\begin{array}{l}\text { IC } 95 \% \text { para la } \\
\text { diferenc. absoluta }\end{array}$} & \multirow{2}{*}{$\begin{array}{l}\text { Efecto } \\
\mathrm{R}^{2}\end{array}$} & \multicolumn{2}{|c|}{ Test Mann-Whitney } \\
\hline & & & & & $\mathrm{T}$ & $\mathrm{gl}$ & $P$ & & & /Z/ & $P$ \\
\hline \multirow[t]{3}{*}{ Magnesio } & Inferior & 22 & 1.87 & 0.30 & & & & & & & \\
\hline & & & & & 0.64 & 41 & $.528^{N S}$ & N.S. & .010 & 0.63 & .531 NS \\
\hline & Igual/Superior & 21 & 1.81 & 0.26 & & & & & & & \\
\hline \multirow[t]{3}{*}{ Fosfata Alcalina } & Inferior & 22 & 69.77 & 17.31 & & & & & & & \\
\hline & & & & & -1.91 & 41 & $.063^{\mathrm{NS}}$ & N.S. & .082 & 1.37 & $.170^{\mathrm{NS}}$ \\
\hline & Igual/Superior & 21 & 84.52 & 31.54 & & & & & & & \\
\hline \multirow[t]{3}{*}{ Clacio iónico } & Inferior & 22 & 1.26 & 0.06 & & & & & & & \\
\hline & & & & & -0.25 & 41 & $.805^{N S}$ & N.S. & .002 & 0.16 & .874 NS \\
\hline & Igual/Superior & 21 & 1.27 & 0.07 & & & & & & & \\
\hline \multirow[t]{3}{*}{ PCR } & Inferior & 22 & 2.41 & 2.34 & & & & & & & \\
\hline & & & & & -1.62 & 41 & $.112^{\mathrm{NS}}$ & N.S. & .060 & 1.68 & .093 NS \\
\hline & Igual/Superior & 21 & 3.95 & 3.76 & & & & & & & \\
\hline \multirow[t]{3}{*}{ Interleukina } & Inferior & 22 & 9.24 & 25.12 & & & & & & & \\
\hline & & & & & 0.80 & 41 & $.429^{N S}$ & N.S. & .015 & 1.05 & $.295^{\mathrm{NS}}$ \\
\hline & Igual/Superior & 21 & 4.82 & 3.50 & & & & & & & \\
\hline \multirow[t]{3}{*}{ PTH } & Inferior & 22 & 106.02 & 60.92 & & & & & & & \\
\hline & & & & & -0.19 & 41 & .849 NS & N.S. & .001 & 0.02 & $.981^{N S}$ \\
\hline & Igual/Superior & 21 & 109.32 & 51.81 & & & & & & & \\
\hline \multirow[t]{3}{*}{ Hemog. glicos. } & Inferior & 22 & 5.97 & 1.14 & & & & & & & \\
\hline & & & & & 0.12 & 41 & .901 NS & N.S. & .000 & 0.93 & .353 NS \\
\hline & Igual/Superior & 21 & 5.93 & 0.60 & & & & & & & \\
\hline \multirow[t]{3}{*}{ Vitamina D } & Inferior & 22 & 15.44 & 6.84 & & & & & & & \\
\hline & & & & & -1.95 & 41 & .098 NS & N.S. & .093 & 1.53 & $.126^{\mathrm{NS}}$ \\
\hline & Igual/Superior & 21 & 21.70 & 12.51 & & & & & & & \\
\hline \multirow[t]{3}{*}{ Colest. HDL } & Inferior & 22 & 62.36 & 17.50 & & & & & & & \\
\hline & & & & & 1.28 & 41 & $.207^{\mathrm{NS}}$ & N.S. & .039 & 1.44 & .151 NS \\
\hline & Igual/Superior & 21 & 55.14 & 19.40 & & & & & & & \\
\hline \multirow[t]{2}{*}{ Colest. LDL } & Inferior & 22 & 106.64 & 31.45 & & & & & & & \\
\hline & Igual/Superior & 21 & 93.76 & 32.81 & 1.31 & 41 & .196 NS & N.S. & .040 & 1.32 & $.185^{N S}$ \\
\hline
\end{tabular}




\section{RESULTADOS}

En este grupo de contrastes (tabla 110) se observa:

- $\quad \mathrm{pH}(\mathrm{P}<.05)$ : Los casos del grupo con GIM carótida izquierda inferior al corte tienen una media ligeramente más alta que el resto de casos, de modo que el tamaño del efecto es bajo.

Tabla 110: Test de diferencia entre dos medias. Asociación de Índice de GIM carótida izquierda con diversas variables de la analítica en la revisión.-4-

\begin{tabular}{|c|c|c|c|c|c|c|c|c|c|c|c|}
\hline \multirow{2}{*}{$\begin{array}{l}\text { Variable } \\
\text { izquierda }\end{array}$} & \multirow{2}{*}{ GIM carótida } & \multirow{2}{*}{ N } & \multirow{2}{*}{ Media } & \multirow{2}{*}{ D.E. } & \multicolumn{3}{|c|}{ T Student } & \multirow{2}{*}{$\begin{array}{l}\text { IC } 95 \% \text { para la } \\
\text { diferenc. absoluta }\end{array}$} & \multirow{2}{*}{$\begin{array}{l}\text { Efecto } \\
\mathrm{R}^{2}\end{array}$} & \multicolumn{2}{|c|}{ Test Mann-Whitney } \\
\hline & & & & & T & $\mathrm{gl}$ & $P$ & & & /Z/ & $P$ \\
\hline \multirow[t]{3}{*}{$\mathrm{pH}$} & Inferior & 22 & 7.34 & 0.04 & & & & & & & \\
\hline & & & & & 2.03 & 41 & $.049 *$ & $0.00-0.04$ & .091 & 2.31 & $.021 *$ \\
\hline & Igual/Superior & 21 & 7.32 & 0.03 & & & & & & & \\
\hline \multirow[t]{3}{*}{ Bicarbonato } & Inferior & 22 & 22.95 & 2.27 & & & & & & & \\
\hline & & & & & 1.44 & 41 & $.157^{\text {NS }}$ & N.S. & .048 & 1.47 & $.141^{\mathrm{NS}}$ \\
\hline & Igual/Superior & 21 & 21.82 & 2.82 & & & & & & & \\
\hline \multirow[t]{3}{*}{ Microalbumin. } & Inferior & 22 & 72.11 & 163.55 & & & & & & & \\
\hline & & & & & 0.03 & 41 & .974 NS & N.S. & .000 & 0.67 & $.333^{\mathrm{NS}}$ \\
\hline & Igual/Superior & 21 & 70.64 & 120.36 & & & & & & & \\
\hline \multirow[t]{3}{*}{ MDRDa } & Inferior & 22 & 55.30 & 20.34 & & & & & & & \\
\hline & & & & & 1.51 & 41 & .138 NS & N.S. & .053 & 1.31 & .190 NS \\
\hline & Igual/Superior & 21 & 47.09 & 14.68 & & & & & & & \\
\hline \multirow[t]{3}{*}{ Cock. Gault } & Inferior & 22 & 62.03 & 24.75 & & & & & & & \\
\hline & & & & & 0.56 & 41 & .578 NS & N.S. & .008 & 0.46 & $.644^{\mathrm{NS}}$ \\
\hline & Igual/Superior & 21 & 57.81 & 24.53 & & & & & & & \\
\hline \multirow[t]{3}{*}{ Mayo Quadr. } & Inferior & 22 & 67.41 & 28.81 & & & & & & & \\
\hline & & & & & 1.47 & 41 & .148 NS & N.S. & .050 & 1.38 & .166 NS \\
\hline & Igual/Superior & 21 & 56.03 & 21.00 & & & & & & & \\
\hline \multirow[t]{3}{*}{ CKD-EPI } & Inferior & 22 & 56.29 & 22.74 & & & & & & & \\
\hline & & & & & 1.59 & 41 & .120 NS & N.S. & .058 & 1.46 & .145 NS \\
\hline & Igual/Superior & 21 & 46.90 & 15.08 & & & & & & & \\
\hline \multirow[t]{2}{*}{ FGF-22 } & Inferior & 22 & 4.50 & 14.27 & & & & & & & \\
\hline & Igual/Superior & 21 & 5.62 & 11.96 & -0.28 & 41 & .783 NS & N.S. & .002 & 1.18 & .237 Ns \\
\hline
\end{tabular}

N.S. $=$ NO significativo $(P>.05)$ 


\section{RESULTADOS}

Las siguientes gráficas muestran los resultados del GIM medio estratificados según diferentes variables y agrupados según la edad de los pacientes.

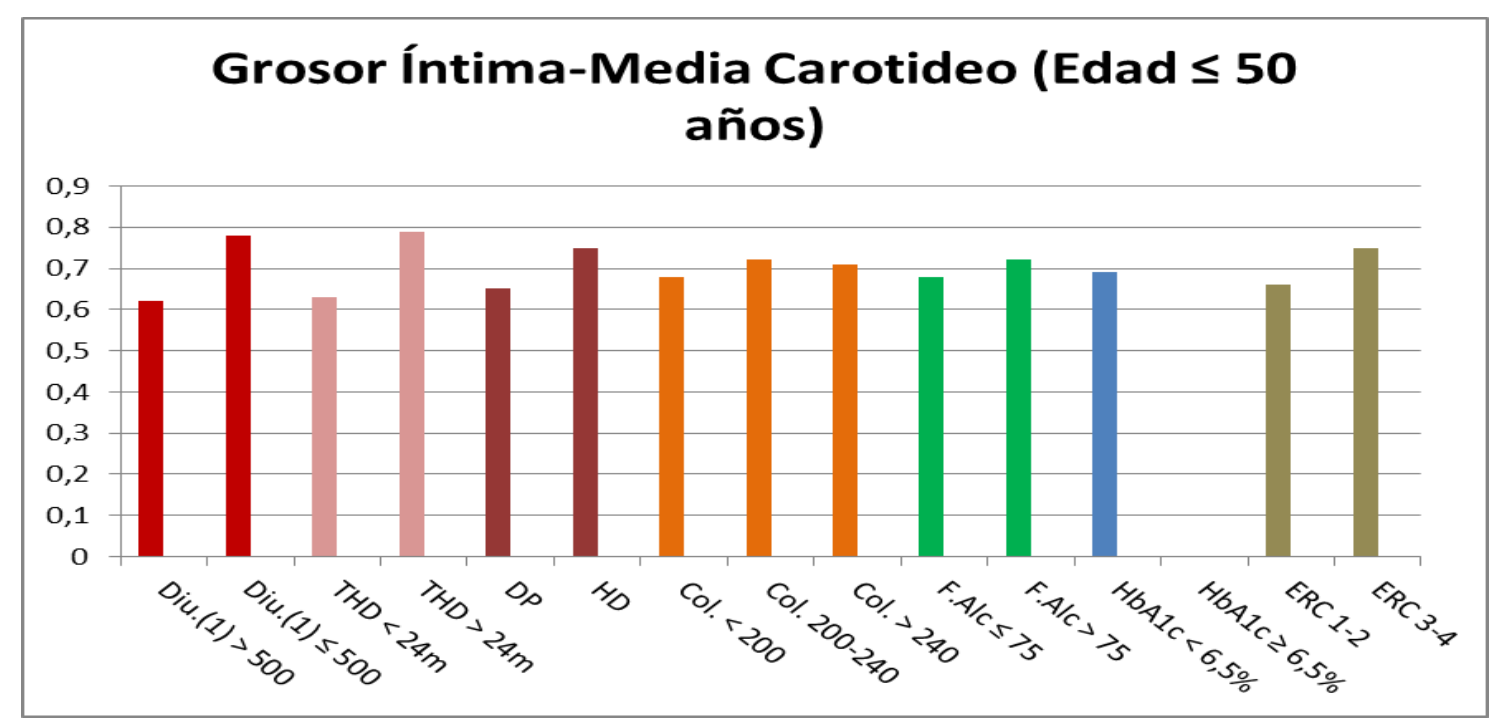

Figura 32: Diferencias en el grado de GIM según diversas variables en pacientes de edad $\leq 50$ años.

Se comprobó como en pacientes de edad igual o inferior a los 50 años presentaban un mayor GIM aquellos pacientes con menor diuresis residual pretrasplante, mayor tiempo de permanencia en TRS o con peor función del injerto.

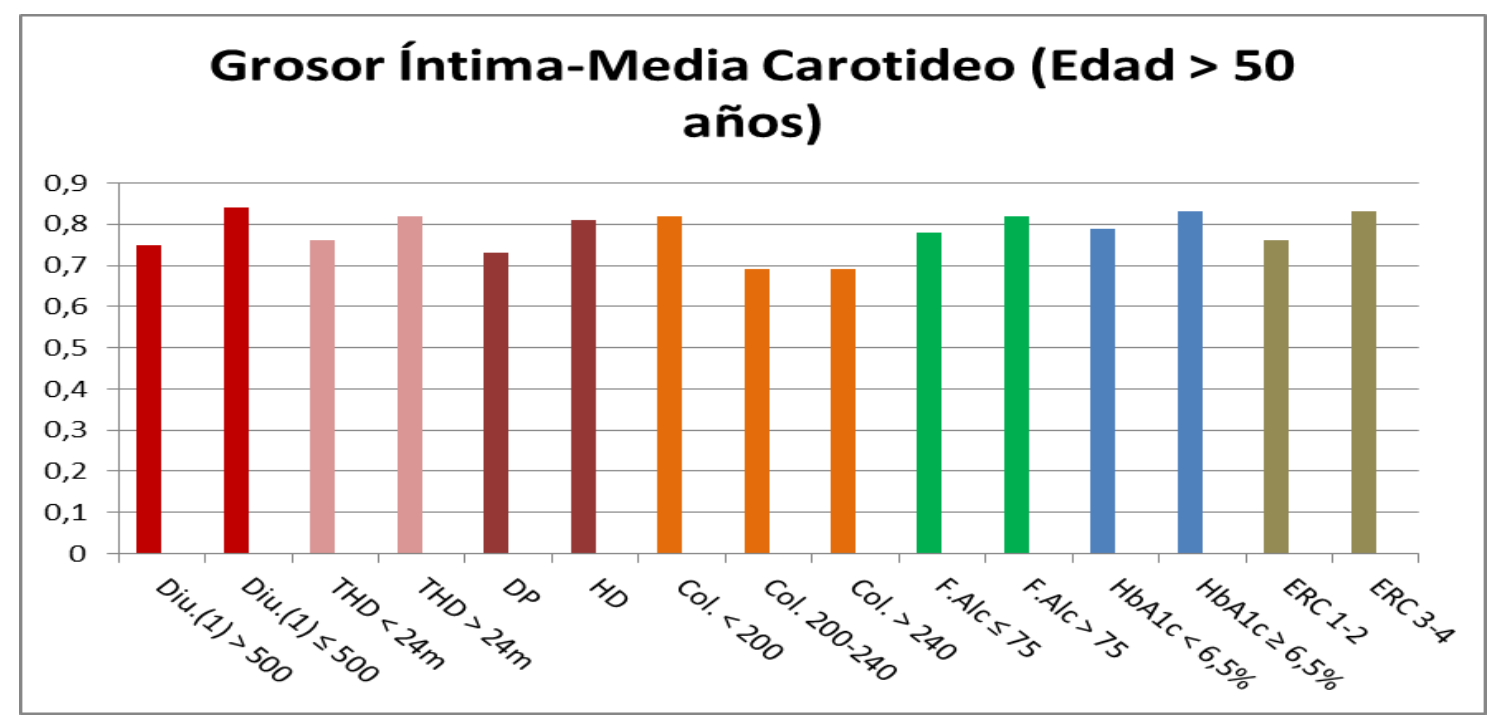

Figura 33: Diferencias en el grado de GIM según el resto de pruebas para valorar la calcificación vascular en pacientes de edad > 50 años. 


\section{RESULTADOS}

Existe un número reducido de individuos con colesterol elevado en el grupo de más edad, lo que provoca que los valores elevados de GIM que comporta una edad más avanzada se asocien a unas concentraciones de colesterol inferiores, por lo que parece que existe una asociación entre colesterol y calcificaciones menores ficticia.

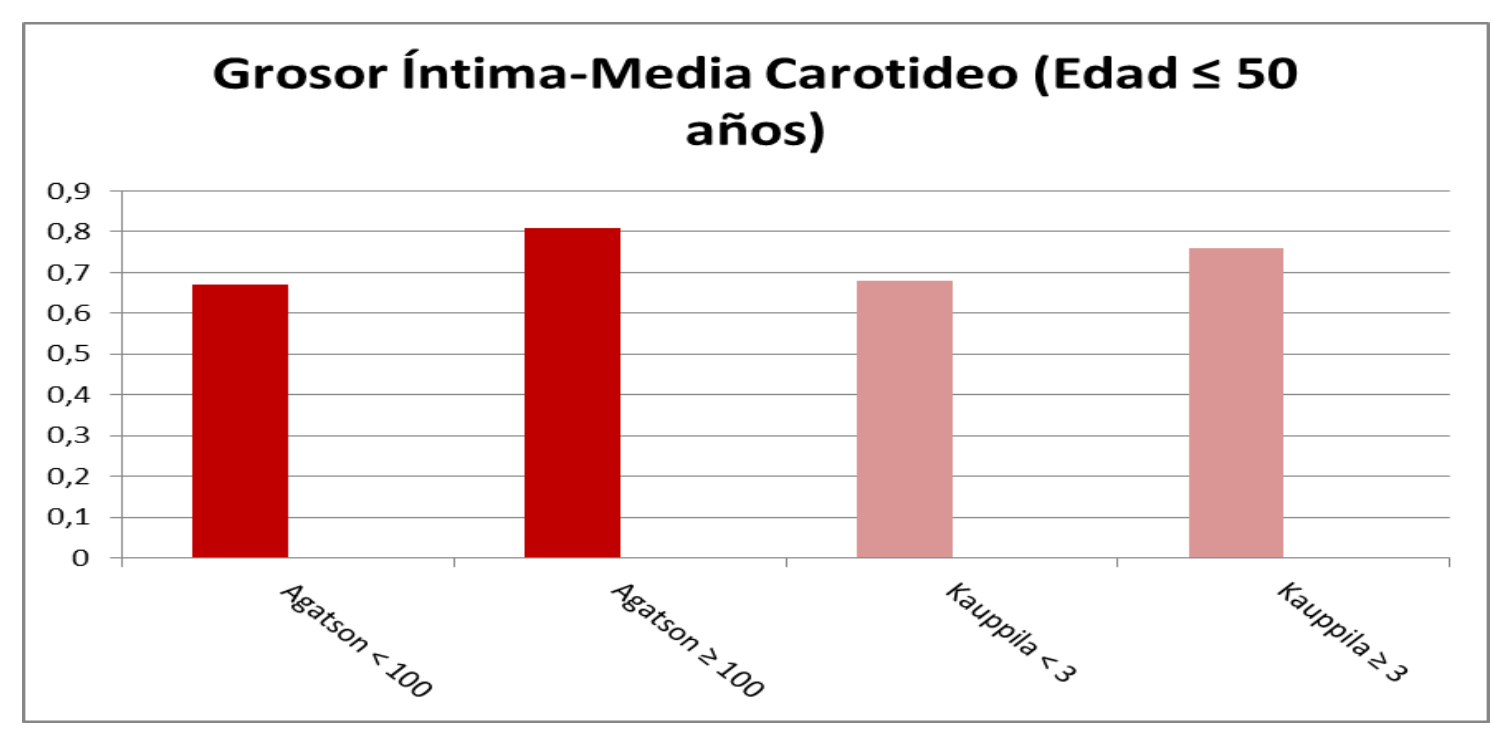

Figura 34: Diferencias en el grado de GIM según diversas variables en pacientes de edad $\leq 50$ años.

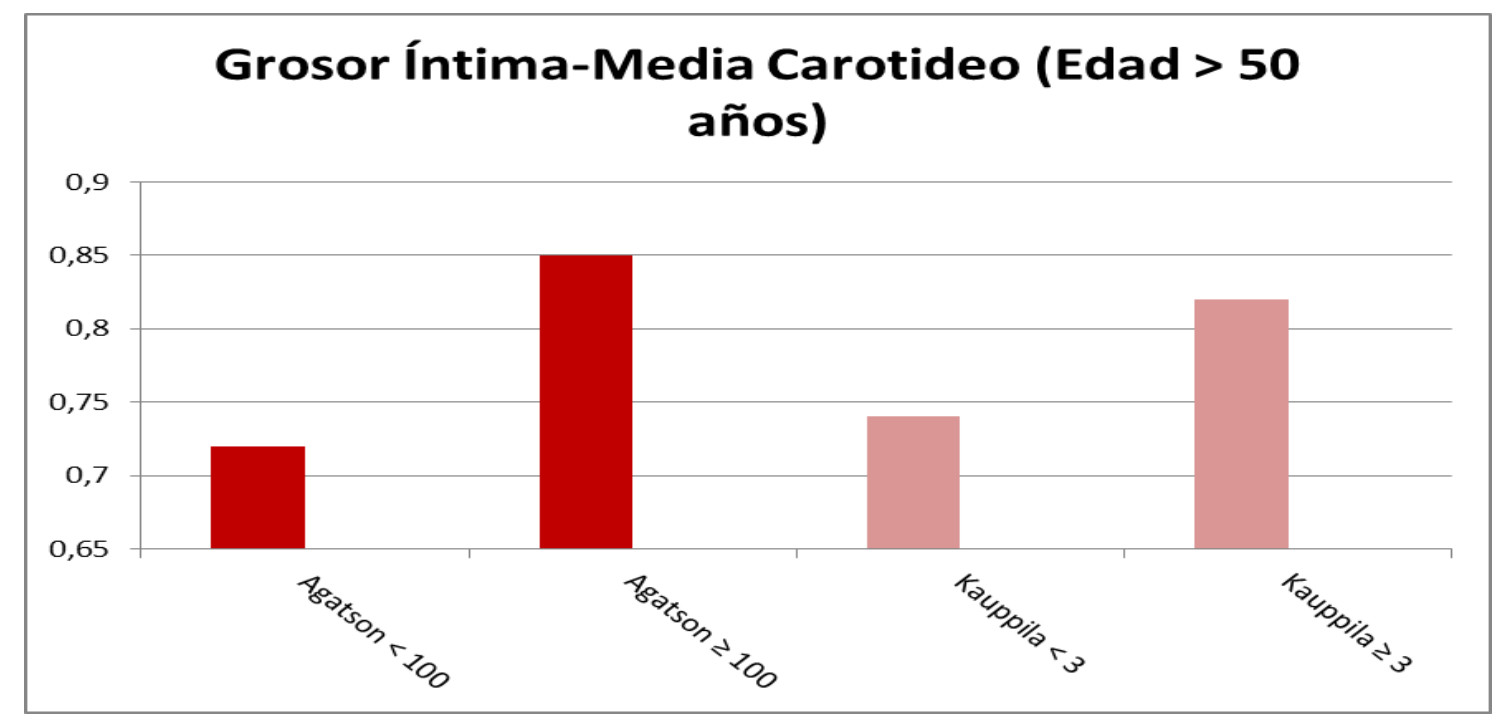

Figura 35: Diferencias en el grado de GIM según el resto de pruebas para valorar la calcificación vascular en pacientes de edad > 50 años. 


\section{RESULTADOS}

\subsection{4: ÍNDICE DE ADRAGAO}

El grado de calcificación de las arterias de mediano y gran calibre de los 43 receptores de trasplante renal se situó entre 0 y 8 (Tabla 111). El valor del índice de Adragao obtenidos tras la valoración de las radiografías de pelvis y manos realizadas en el estudio de la muestra se recoge en la siguiente tabla:

\begin{tabular}{|l|l|l|l|l|l|l|}
\hline & Media & Mediana & MAX & MIN & R. Interq. & DS \\
\hline Adragao & 1,74 & 0 & 8 & 0 & $0-4$ & 2,7 \\
\hline
\end{tabular}

Tabla 111: Estadísticos descriptivos del índice de Adragao observados en la muestra.

La distribución de los pacientes estudiados según la puntuación del índice de Adragao fue la siguiente:

\begin{tabular}{|l|l|l|l|}
\hline I. Adragao & Estrato & Recuento & Porcentaje \\
\hline$<\mathbf{3}$ & Normal & 31 & $72,1 \%$ \\
\hline $\mathbf{3 - 5}$ & Moderado & $\mathbf{5}$ & $11,6 \%$ \\
\hline $\mathbf{6 - 8}$ & Grave & 7 & $16,3 \%$ \\
\hline
\end{tabular}

Tabla 112: Distribución de los pacientes estudiados de acuerdo a la severidad del índice de Adragao. 


\section{RESULTADOS}

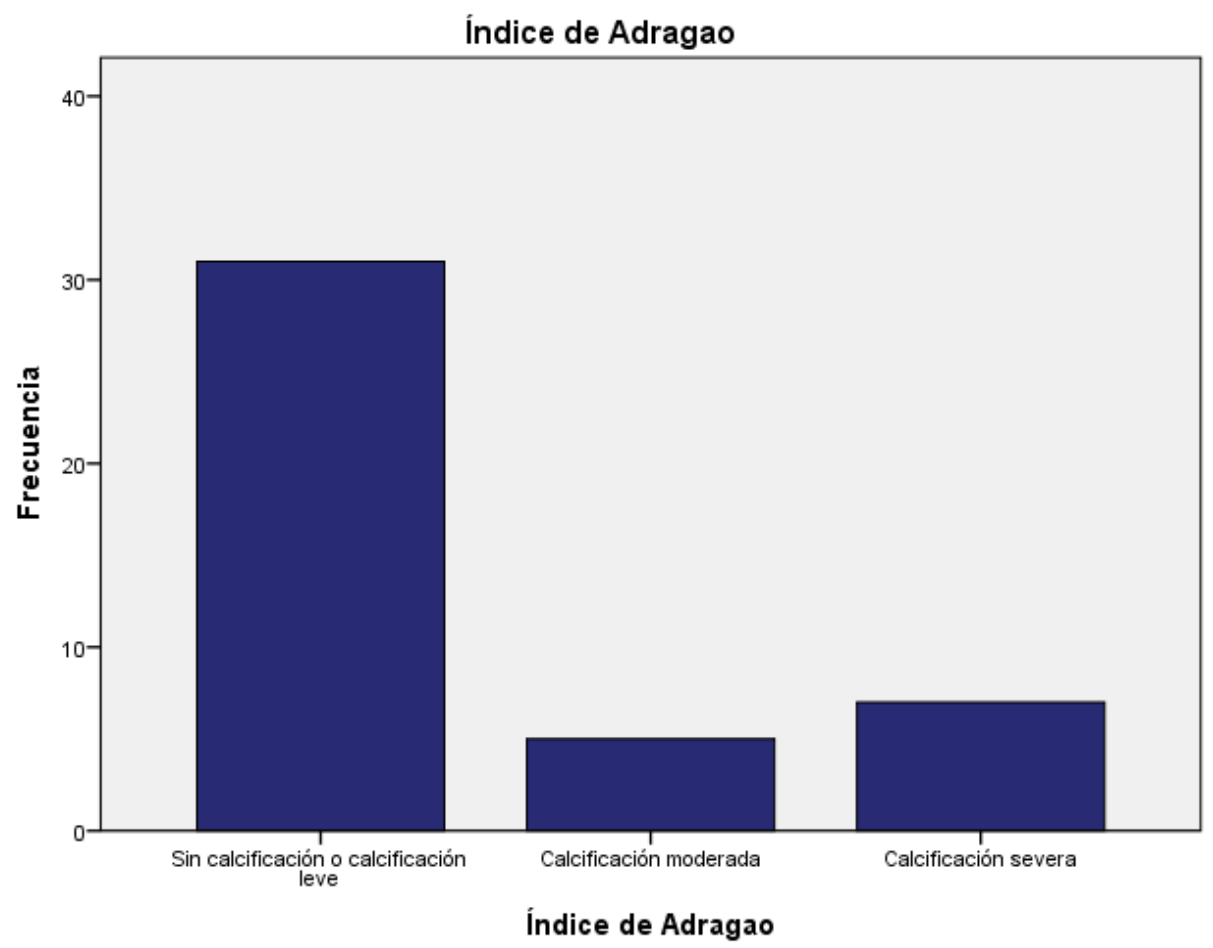

Figura 41: Distribución de los pacientes respecto al índice de Adragao.

Para analizar la asociación observada entre las diferentes variables categóricas y cuantitativas y el índice de Adragao se crearon dos conjuntos de pacientes según esta última variable, agrupándolos según presentasen un índice de Adragao $<20 \geq 2$. Un 69.8\% (30 pacientes) de los pacientes presentaron un índice de Adragao $<2$.

En el análisis de las variables categóricas se ha empleado el test Chi-cuadrado de asociación entre variables medidas en escala nominal, realizando una aproximación al cálculo del tamaño del efecto mediante el cuadrado del valor del coeficiente Phi.

En el cruce de las variables categóricas (tabla 113) se han encontrado algunas significaciones:

- Enfermedad renal de base $(P<.01)$ : Ningún paciente con poliquistosis renal como causa de su enfermedad renal presenta un índice de Adragao $\geq 2$ (30\% vs 0\%). De la misma forma, todos los pacientes con nefropatía diabética presentan un índice de Adragao $\geq 2$ ( $23.1 \%$ vs $0 \%$ ) en tanto que existe un mayor porcentaje de pacientes con nefroangioesclerosis en el grupo de individuos con índice de 


\section{RESULTADOS}

Adragao $\geq 2$ (15.4\% vs 3.3\%). La relación puede ser de intensidad moderada alta a la vista de la aproximación del valor de tamaño del efecto.

- Modalidad de diálisis ( $P<.05)$ : El grupo con un índice de Adragao $\geq 2$ presenta un mayor porcentaje de pacientes que recibieron hemodiálisis como terapia renal sustitutiva ( $92.3 \%$ vs $50 \%)$.

- Diabetes $(\mathrm{P}<.05)$ : El grupo con un índice de Adragao $\geq 2$ presenta un mayor porcentaje de pacientes diabéticos (46.2\% vs 3.3\%).

Tabla 113: Test Chi-cuadrado. Asociación de Índice de Adragao con diversas variables categóricas -1-

\begin{tabular}{|c|c|c|c|c|c|c|c|}
\hline \multirow[b]{2}{*}{ Variable } & \multirow[b]{2}{*}{ Categoría } & \multicolumn{2}{|c|}{ Adragao \% (n) } & \multirow{2}{*}{$\mathrm{Chi}^{2}$} & \multirow{2}{*}{$\mathrm{Gl}$} & \multirow{2}{*}{$\mathrm{P}$} & \multirow{2}{*}{$\begin{array}{l}\text { Tam. } \\
\text { Efecto } \\
\text { aprox. }\end{array}$} \\
\hline & & Inferior & Igual o superior & & & & \\
\hline \multirow[t]{2}{*}{ Sexo } & Mujer & $36.7 \%(11)$ & $7.7 \%(1)$ & 2.48 & 1 & $.115^{\text {NS }}$ & .081 \\
\hline & Hombre & $63.3 \%(19)$ & $92.3 \%(12)$ & & & & \\
\hline \multirow[t]{7}{*}{ Enf. renal de base } & Nefropatía túbulo-inter.I & $23.3 \%(7)$ & $23.1 \%(3)$ & & & & \\
\hline & Glomerulonefritis & $20.0 \%(6)$ & $23.1 \%(3)$ & & & & \\
\hline & Poliquistosis renal & $30.0 \%$ (9) & -- & & & & \\
\hline & & & & 15.67 & 5 & $.008^{* *}$ & .232 \\
\hline & Nefropatía diabética & -- & $23.1 \%(3)$ & & & & \\
\hline & Nefroangioesclerosis & $3.3 \%(1)$ & $15.4 \%(2)$ & & & & \\
\hline & No filiada & $23.3 \%(7)$ & $15.4 \%(2)$ & & & & \\
\hline \multirow[t]{2}{*}{ Mod. Diálisis } & Hemodiálisis & $56.7 \%(17)$ & $92.3 \%(12)$ & 2.52 & 1 & $.022 *$ & .122 \\
\hline & Diálisis Peritoneal & $43.3 \%(13)$ & $7.7 \%(1)$ & & & & \\
\hline \multirow[t]{3}{*}{ Acceso Vascular } & FAVI & $50.0 \%(15)$ & $76.9 \%(10)$ & & & & \\
\hline & Catéter peritoneal & $43.3 \%(13)$ & $7.7 \%(1)$ & 6.30 & 2 & $.043 *$ & .112 \\
\hline & Catéter venoso central & $6.7 \%(2)$ & $15.4 \%(2)$ & & & & \\
\hline HTA & $\mathrm{Si}$ & $83.3 \%(25)$ & $100 \%(13)$ & 1.10 & 1 & .117 Ns & .054 \\
\hline Diabetes & $\mathrm{Si}$ & $3.3 \%(1)$ & $46.2 \%(6)$ & 9.26 & 1 & $.002^{* *}$ & .284 \\
\hline Dislipemia & $\mathrm{Si}$ & $36.7 \%(11)$ & $61.5 \%(8)$ & 1.38 & 1 & .240 Ns & .053 \\
\hline Card. Isquémica & $\mathrm{Si}$ & -- & $15.4 \%(2)$ & -- & -- & -- & -- \\
\hline Tabaquismo & $\mathrm{Si}$ & $23.3 \%(7)$ & $15.4 \%(2)$ & 0.03 & 1 & $.857^{\mathrm{NS}}$ & .008 \\
\hline \multirow[t]{3}{*}{ Ecocard. Pre-Tx } & HVI leve & $69.2 \%$ (9) & $45.5 \%(5)$ & & & & \\
\hline & HVI moderada & $30.8 \%(4)$ & $45.5 \%(5)$ & 1.86 & 2 & .288 NS & .081 \\
\hline & HVI grave & -- & $9.1 \%(1)$ & & & & \\
\hline
\end{tabular}

N.S. $=$ NO significativo $(P>05) \quad *$ S Significativo al $5 \%(P<.05) \quad * *=$ Altamente significativo al $1 \%(P<.01)$ 


\section{RESULTADOS}

En la siguiente tabla de variables (tabla 114) en el último grupo de variables, no aparece ninguna posible asociación que se puede juzgar como significativa ( $P>.05)$.

Tabla 114: Test de diferencia entre dos medias. Asociación de Índice de Adragao con diversas variables antropométricas y relativas a los antecedentes personales.

\begin{tabular}{|c|c|c|c|c|c|c|c|c|c|c|c|}
\hline \multirow{2}{*}{ Variable / } & \multirow{2}{*}{ / Adragao } & \multirow{2}{*}{$\mathrm{N}$} & \multirow{2}{*}{ Media } & \multirow{2}{*}{ D.E. } & \multicolumn{3}{|c|}{ T Student } & \multirow{2}{*}{$\begin{array}{c}\text { IC } 95 \% \text { para la } \\
\text { diferenc. absoluta }\end{array}$} & \multirow{2}{*}{$\begin{array}{l}\text { Efecto } \\
\mathrm{R}^{2}\end{array}$} & \multicolumn{2}{|c|}{ Test Mann-Whitney } \\
\hline & & & & & $T$ & $\mathrm{gl}$ & $P$ & & & /Z/ & $P$ \\
\hline \multirow{3}{*}{$\begin{array}{l}\text { Edad al } \\
\text { trasplante }\end{array}$} & Inferior & 30 & 48.17 & 11.95 & & & & & & & \\
\hline & & & & & -1.37 & 41 & $.177^{\mathrm{NS}}$ & N.S. & .044 & 1.43 & $.153^{\mathrm{Ns}}$ \\
\hline & Igual/Superior & 13 & 53.69 & 12.49 & & & & & & & \\
\hline \multirow{3}{*}{$\begin{array}{l}\text { Edad en la } \\
\text { revisión }\end{array}$} & Inferior & 30 & 52.20 & 12.01 & & & & & & & \\
\hline & & & & & -1.38 & 41 & $.175^{\text {NS }}$ & N.S. & .044 & 1.48 & $.138^{\mathrm{Ns}}$ \\
\hline & Igual/Superior & 13 & 57.77 & 12.52 & & & & & & & \\
\hline \multirow[t]{3}{*}{ Meses de diálisis } & Inferior & 30 & 31.37 & 30.89 & & & & & & & \\
\hline & & & & & -1.35 & 41 & .185 NS & N.S. & .042 & 1.51 & .132 Ns \\
\hline & Igual/Superior & 13 & 55.62 & 87.80 & & & & & & & \\
\hline \multirow{3}{*}{$\begin{array}{l}\text { Meses desde el } \\
\text { trasplante }\end{array}$} & Inferior & 30 & 48.13 & 28.68 & & & & & & & \\
\hline & & & & & -0.10 & 41 & .921 Ns & N.S. & .000 & 0.30 & .761 Ns \\
\hline & Igual/Superior & 13 & 49.08 & 28.24 & & & & & & & \\
\hline \multirow{2}{*}{$\begin{array}{l}\text { Fracción de } \\
\text { eyección }\end{array}$} & Inferior & 24 & 66.35 & 6.66 & & & & & & & \\
\hline & Igual/Superior & 11 & 65.27 & 6.21 & 0.45 & 33 & .652 Ns & N.S. & .006 & 0.37 & .709 Ns \\
\hline
\end{tabular}

N.S. $=$ NO significativo $(P>05) \quad * *=$ Altamente significativo al $1 \%(P<.01)$

En el primer grupo de variables cuantitativas (tabla 115) correspondientes a la analítica previa se han encontrado diferencias estadísticamente significativas en las siguientes:

- $\quad$ TAS $(P<.01)$ : El grupo con un índice de Adragao $<2$ presenta un valor medio de TAS antes del trasplante inferior al resto (139.03 vs 162.54) siendo el tamaño del efecto moderado (.183).

- Volumen de diuresis $(\mathrm{P}<.05)$ : El grupo con un índice de Adragao $<2$ presenta un valor medio de volumen de diuresis residual más alto que el resto (1264.00 vs 453.85), con un tamaño del efecto moderado (.145).

- Hemoglobina $(\mathrm{P}<.05)$ : El grupo con un índice de Adragao < 2 presenta un valor medio de más alto (13.03 vs 11.72), correspondiente a un tamaño del efecto moderado (.138).

- Hematocrito $(\mathrm{P}<.05)$ : El grupo con un índice de Adragao $<2$ presenta un valor medio más elevado (39.29 vs 35.36), con un efecto moderado (.127) 


\section{RESULTADOS}

Tabla 115: Test de diferencia entre dos medias. Asociación de Índice de Adragao con diversas variables antropométricas y de la analítica previa al trasplante -1-

\begin{tabular}{|c|c|c|c|c|c|c|c|c|c|c|c|}
\hline \multirow{2}{*}{ Variable } & \multirow{2}{*}{ Adragao } & \multirow{2}{*}{$\mathrm{N}$} & \multirow{2}{*}{ Media } & \multirow{2}{*}{ D.E. } & \multicolumn{3}{|c|}{ T Student } & \multirow{2}{*}{$\begin{array}{l}\text { IC } 95 \% \text { para la } \\
\text { diferenc. absoluta }\end{array}$} & \multirow{2}{*}{$\begin{array}{c}\text { Efecto } \\
\mathrm{R}^{2}\end{array}$} & \multicolumn{2}{|c|}{ Test Mann-Whitney } \\
\hline & & & & & T & $\mathrm{Gl}$ & $\mathrm{P}$ & & & /Z/ & $P$ \\
\hline \multirow[t]{3}{*}{ Altura } & Inferior & 30 & 168.67 & 9.31 & & & & & & & \\
\hline & & & & & 0.49 & 41 & .630 Ns & N.S. & .006 & 0.45 & .653 NS \\
\hline & Igual/Superior & 13 & 167.19 & 8.73 & & & & & & & \\
\hline \multirow[t]{3}{*}{ Peso } & Inferior & 30 & 72.39 & 11.88 & & & & & & & \\
\hline & & & & & 1.29 & 41 & $.206 \mathrm{NS}$ & N.S. & .039 & 1.34 & .182 NS \\
\hline & Igual/Superior & 13 & 67.42 & 11.01 & & & & & & & \\
\hline \multirow[t]{3}{*}{ IMC } & Inferior & 30 & 25.36 & 2.97 & & & & & & & \\
\hline & & & & & 1.37 & 41 & .179 NS & N.S. & .044 & 1.45 & $.146^{\mathrm{NS}}$ \\
\hline & Igual/Superior & 13 & 24.02 & 2.85 & & & & & & & \\
\hline \multirow[t]{3}{*}{ TAS } & Inferior & 30 & 139.03 & 22.45 & & & & & & & \\
\hline & & & & & -3.03 & 41 & $.004 * *$ & $7.84-39.17$ & 183 & 2.75 & $.006^{* *}$ \\
\hline & Igual/Superior & 13 & 162.54 & 25.45 & & & & & & & \\
\hline \multirow[t]{3}{*}{ TAD } & Inferior & 30 & 83.38 & 13.33 & & & & & & & \\
\hline & & & & & -.061 & 41 & .544 NS & N.S. & .009 & 1.19 & .232 NS \\
\hline & Igual/Superior & 13 & 86.00 & 12.01 & & & & & & & \\
\hline \multirow[t]{3}{*}{ Diuresis } & Inferior & 30 & 1264.00 & 1050.26 & & & & & & & \\
\hline & & & & & 2.63 & 41 & $.012 *$ & $188.45-14.31 .86$ & .145 & 2.38 & $.017 *$ \\
\hline & Igual/Superior & 13 & 453.85 & 520.60 & & & & & & & \\
\hline \multirow[t]{3}{*}{ Hemoglobina } & Inferior & 30 & 13.03 & 1.52 & & & & & & & \\
\hline & & & & & 2.56 & 41 & $.014 *$ & $0.28-2.36$ & .138 & 2.34 & $.019 *$ \\
\hline & Igual/Superior & 13 & 11.72 & 1.64 & & & & & & & \\
\hline \multirow[t]{3}{*}{ Hematocrito } & Inferior & 30 & 39.29 & 5.00 & & & & & & & \\
\hline & & & & & 2.44 & 41 & $.019 *$ & $0.68-7.19$ & .127 & 2.29 & $.022 *$ \\
\hline & Igual/Superior & 13 & 35.36 & 4.50 & & & & & & & \\
\hline \multirow[t]{3}{*}{ Leucocitos } & Inferior & 30 & 6623.00 & 1551.86 & & & & & & & \\
\hline & & & & & -0.53 & 41 & .600 Ns & N.S. & .007 & 0.45 & $.653^{\mathrm{NS}}$ \\
\hline & Igual/Superior & 13 & 6911.54 & 1854.49 & & & & & & & \\
\hline \multirow[t]{2}{*}{ Plaquetas } & Inferior & 30 & 177733.33 & 50706.00 & & & & & & & \\
\hline & Igual/Superior & 13 & 213923.08 & 97384.51 & -1.61 & 41 & .116 NS & N.S. & .059 & 0.69 & .492 NS \\
\hline
\end{tabular}

En el siguiente grupo (tabla 116) se observan las siguientes significaciones:

- Colesterol total $(\mathrm{P}<.05)$ : El grupo con un índice de Adragao $<2$ presenta un valor medio de colesterol total previo al trasplante más elevado que el resto de individuos (185.87 vs 129.69), con un tamaño del efecto moderado (.253).

- Glucosa $(P<.05)$ : El test de Student detecta una diferencia significativa $(P<.05)$ según la cual el grupo con un índice de Adragao $<2$ presenta un valor medio glucosa menor (90.13 vs 106.54$)$ que el resto de pacientes, aunque con tamaño 


\section{RESULTADOS}

del efecto bajo. Esta significación no es corroborada por el test de Mann-

Whitney.

Tabla 116: Test de diferencia entre dos medias. Asociación de Índice de Adragao con diversas variables de la analítica previa al trasplante -2-

\begin{tabular}{|c|c|c|c|c|c|c|c|c|c|c|c|}
\hline \multirow{2}{*}{ Variable / } & \multirow{2}{*}{ Adragao } & \multirow{2}{*}{$\mathrm{N}$} & \multirow{2}{*}{ Media } & \multirow{2}{*}{ D.E. } & \multicolumn{3}{|c|}{ T Student } & \multirow{2}{*}{$\begin{array}{c}\text { IC 95\% para la } \\
\text { diferenc. absoluta }\end{array}$} & \multirow{2}{*}{$\begin{array}{l}\text { Efecto } \\
\mathrm{R}^{2}\end{array}$} & \multicolumn{2}{|c|}{ Test Mann-Whitney } \\
\hline & & & & & $\mathrm{T}$ & Gl & $P$ & & & /Z/ & $P$ \\
\hline \multirow[t]{3}{*}{ Urea } & Inferior & 30 & 145.13 & 33.53 & & & & & & & \\
\hline & & & & & 0.12 & 41 & .903 NS & N.S. & .000 & 0.16 & $.874^{N S}$ \\
\hline & Igual/Superior & 13 & 143.69 & 39.05 & & & & & & & \\
\hline \multirow[t]{3}{*}{ Glucosa } & Inferior & 30 & 90.13 & 8.57 & & & & & & & \\
\hline & & & & & -2.24 & 41 & $.030 *$ & $1.63-31.18$ & .109 & 0.60 & $.552^{\mathrm{NS}}$ \\
\hline & Igual/Superior & 13 & 106.54 & 38.48 & & & & & & & \\
\hline \multirow[t]{3}{*}{ Creatinina } & Inferior & 30 & 8.67 & 2.55 & & & & & & & \\
\hline & & & & & -0.65 & 41 & $.516^{\mathrm{NS}}$ & N.S. & .010 & 0.53 & .597 NS \\
\hline & Igual/Superior & 13 & 9.26 & 3.00 & & & & & & & \\
\hline \multirow[t]{3}{*}{ Triglicéridos } & Inferior & 30 & 119.77 & 37.04 & & & & & & & \\
\hline & & & & & 0.63 & 41 & $.531^{\mathrm{NS}}$ & N.S. & .010 & 0.45 & $.653^{\mathrm{NS}}$ \\
\hline & Igual/Superior & 13 & 111.08 & 50.52 & & & & & & & \\
\hline \multirow[t]{3}{*}{ Colesterol total } & Inferior & 30 & 185.87 & 47.76 & & & & & & & \\
\hline & & & & & 3.73 & 41 & $.001^{* *}$ & $25.74-86.61$ & .253 & 3.36 & $.001 * *$ \\
\hline & Igual/Superior & 13 & 129.69 & 39.09 & & & & & & & \\
\hline \multirow[t]{3}{*}{ Proteínas totales } & Inferior & 30 & 6.82 & 0.53 & & & & & & & \\
\hline & & & & & -1.41 & 41 & $.167^{N S}$ & N.S. & .046 & 1.21 & $.228 \mathrm{NS}$ \\
\hline & Igual/Superior & 13 & 7.07 & 0.58 & & & & & & & \\
\hline \multirow[t]{3}{*}{ Calcio } & Inferior & 30 & 9.31 & 0.95 & & & & & & & \\
\hline & & & & & 0.51 & 41 & .615 NS & N.S. & .006 & 0.94 & .347 NS \\
\hline & Igual/Superior & 13 & 9.17 & 0.65 & & & & & & & \\
\hline \multirow[t]{3}{*}{ Calcio correg. } & Inferior & 30 & 9.65 & 0.97 & & & & & & & \\
\hline & & & & & 0.94 & 41 & .352 NS & N.S. & .021 & 1.34 & $.181^{\mathrm{NS}}$ \\
\hline & Igual/Superior & 13 & 9.38 & 0.60 & & & & & & & \\
\hline \multirow[t]{2}{*}{ Prod. Calc/Fósf. } & Inferior & 30 & 47.18 & 11.58 & & & & & & & \\
\hline & Igual/Superior & 13 & 44.56 & 7.35 & 0.75 & 41 & $.458^{\mathrm{NS}}$ & N.S. & .014 & 1.07 & $.284^{\mathrm{NS}}$ \\
\hline
\end{tabular}

N.S. $=$ NO significativo $(P>.05) \quad * *=$ Altamente significativo al $1 \%(P<.01)$

En el siguiente bloque (tabla 117) solo se ha encontrado una diferencia que sea estadísticamente significativas:

- Fosfatasa alcalina $(\mathrm{P}<.05)$ : El grupo con un índice de Adragao $<2$ presenta un valor medio de menor de fosfatasa alcalina previo al trasplante que el resto de los enfermos (87.60 vs 131.92), con un tamaño del efecto moderado bajo (.109). 


\section{RESULTADOS}

Tabla 117: Test de diferencia entre dos medias. Asociación de Índice de Adragao con diversas variables de la analítica previa al trasplante.-3-

\begin{tabular}{|c|c|c|c|c|c|c|c|c|c|c|c|}
\hline \multirow{2}{*}{ Variable / } & \multirow{2}{*}{ / Adragao } & \multirow{2}{*}{$\mathrm{N}$} & \multirow{2}{*}{ Media } & \multirow{2}{*}{ D.E. } & \multicolumn{3}{|c|}{ T Student } & \multirow{2}{*}{$\begin{array}{c}\text { IC } 95 \% \text { para la } \\
\text { diferenc. absoluta }\end{array}$} & \multirow{2}{*}{$\begin{array}{l}\text { Efecto } \\
\mathrm{R}^{2}\end{array}$} & \multicolumn{2}{|c|}{ Test Mann-Whitney } \\
\hline & & & & & $\mathrm{T}$ & $\mathrm{Gl}$ & $P$ & & & /Z/ & $P$ \\
\hline \multirow[t]{3}{*}{ Fósforo } & Inferior & 30 & 5.06 & 1.14 & & & & & & & \\
\hline & & & & & 0.51 & 41 & $.615^{\mathrm{NS}}$ & N.S. & .006 & 0.64 & $.525 \mathrm{NS}$ \\
\hline & Igual/Superior & 13 & 4.88 & 0.87 & & & & & & & \\
\hline \multirow[t]{3}{*}{ Fosf Alcalina } & Inferior & 30 & 87.60 & 48.66 & & & & & & & \\
\hline & & & & & -2.24 & 41 & $.031 *$ & $4.32-84.32$ & .109 & 2.32 & $.021 *$ \\
\hline & Igual/Superior & 13 & 131.92 & 80.21 & & & & & & & \\
\hline \multirow[t]{3}{*}{ H. Paratiroidea } & Inferior & 29 & 293.78 & 325.63 & & & & & & & \\
\hline & & & & & -1.64 & 40 & .109 NS & N.S. & .063 & 0.99 & $.321^{\mathrm{NS}}$ \\
\hline & Igual/Superior & 13 & 499.82 & 475.38 & & & & & & & \\
\hline \multirow[t]{3}{*}{$\mathrm{pH}$} & Inferior & 30 & 7.37 & 0.05 & & & & & & & \\
\hline & & & & & -0.27 & 41 & $.788^{N S}$ & N.S. & .002 & 0.16 & .874 NS \\
\hline & Igual/Superior & 13 & 7.37 & 0.06 & & & & & & & \\
\hline \multirow[t]{3}{*}{ Bicarbonato } & Inferior & 30 & 24.03 & 2.53 & & & & & & & \\
\hline & & & & & 1.26 & 41 & $.215^{\mathrm{NS}}$ & N.S. & .037 & 0.94 & $.348^{\mathrm{NS}}$ \\
\hline & Igual/Superior & 13 & 22.87 & 3.31 & & & & & & & \\
\hline \multirow[t]{3}{*}{ MDRDa } & Inferior & 30 & 6.93 & 2.13 & & & & & & & \\
\hline & & & & & -0.09 & 41 & $.931^{\mathrm{NS}}$ & N.S. & .000 & 0.11 & .916 NS \\
\hline & Igual/Superior & 13 & 7.00 & 2.50 & & & & & & & \\
\hline \multirow[t]{3}{*}{ Cock. Gault } & Inferior & 30 & 10.76 & 3.78 & & & & & & & \\
\hline & & & & & 1.15 & 41 & $.258^{\mathrm{NS}}$ & N.S. & .031 & 1.11 & .267 NS \\
\hline & Igual/Superior & 13 & 9.37 & 3.35 & & & & & & & \\
\hline \multirow[t]{3}{*}{ Mayo Quadr. } & Inferior & 30 & 9.18 & 1.93 & & & & & & & \\
\hline & & & & & 0.23 & 41 & .816 NS & N.S. & .001 & 0.50 & .615 NS \\
\hline & Igual/Superior & 13 & 9.03 & 2.08 & & & & & & & \\
\hline \multirow[t]{2}{*}{ CKD-EPI } & Inferior & 30 & 6.44 & 2.14 & & & & & & & \\
\hline & Igual/Superior & 13 & 6.39 & 2.44 & 0.06 & 41 & .952 NS & N.S. & .000 & 0.08 & $.937^{\text {NS }}$ \\
\hline
\end{tabular}

N.S. $=$ NO significativo $(P>05) \quad * *=$ Altamente significativo al $1 \%(P<.01)$ 


\section{RESULTADOS}

En el siguiente bloque (tabla 118) no se detecta ninguna asociación que se pueda considerar como estadísticamente significativa ( $P>.05)$.

Tabla 118: Test de diferencia entre dos medias. Asociación de Índice de Adragao con diversas variables antropométricas y de la analítica al alta tras el trasplante.-1-

\begin{tabular}{|c|c|c|c|c|c|c|c|c|c|c|c|}
\hline \multirow{2}{*}{ Variable } & \multirow{2}{*}{ Adragao } & \multirow{2}{*}{$\mathrm{N}$} & \multirow{2}{*}{ Media } & \multirow{2}{*}{ D.E. } & \multicolumn{3}{|c|}{ T Student } & \multirow{2}{*}{$\begin{array}{c}\text { IC 95\% para la } \\
\text { diferenc. Absoluta }\end{array}$} & \multirow{2}{*}{$\begin{array}{l}\text { Efecto } \\
\mathrm{R}^{2}\end{array}$} & \multicolumn{2}{|c|}{ Test Mann-Whitney } \\
\hline & & & & & T & $\mathrm{Gl}$ & $\mathrm{P}$ & & & /Z/ & $P$ \\
\hline \multirow[t]{3}{*}{ Peso } & Inferior & 30 & 71.07 & 12.23 & & & & & & & \\
\hline & & & & & 1.55 & 41 & .129 NS & N.S. & .055 & 1.67 & .096 NS \\
\hline & Igual/Superior & 13 & 65.20 & 9.13 & & & & & & & \\
\hline \multirow[t]{3}{*}{ IMC } & Inferior & 30 & 24.91 & 3.32 & & & & & & & \\
\hline & & & & & 1.47 & 41 & .149 NS & N.S. & .050 & 1.61 & .107 Ns \\
\hline & Igual/Superior & 13 & 23.34 & 2.93 & & & & & & & \\
\hline \multirow[t]{3}{*}{ TAS } & Inferior & 30 & 136.57 & 22.93 & & & & & & & \\
\hline & & & & & -0.49 & 41 & .625 NS & N.S. & .006 & 0.70 & .483 NS \\
\hline & Igual/Superior & 13 & 140.46 & 25.84 & & & & & & & \\
\hline \multirow[t]{3}{*}{ TAD } & Inferior & 30 & 78.87 & 13.52 & & & & & & & \\
\hline & & & & & 0.27 & 41 & $.787^{\mathrm{NS}}$ & N.S. & .002 & 0.41 & .681 NS \\
\hline & Igual/Superior & 13 & 77.62 & 14.67 & & & & & & & \\
\hline \multirow[t]{3}{*}{ Diuresis } & Inferior & 30 & 2462.83 & 907.13 & & & & & & & \\
\hline & & & & & 0.31 & 41 & .760 Ns & N.S. & .002 & 0.38 & .701 Ns \\
\hline & Igual/Superior & 13 & 2382.31 & 374.37 & & & & & & & \\
\hline \multirow[t]{3}{*}{ Hemoglobina } & Inferior & 30 & 10.80 & 1.23 & & & & & & & \\
\hline & & & & & 0.63 & 41 & .531 Ns & N.S. & .010 & 0.98 & $.327^{N S}$ \\
\hline & Igual/Superior & 13 & 10.52 & 1.56 & & & & & & & \\
\hline \multirow[t]{3}{*}{ Hematocrito } & Inferior & 30 & 32.82 & 3.57 & & & & & & & \\
\hline & & & & & 0.25 & 41 & .801 NS & N.S. & .002 & 0.73 & .467 NS \\
\hline & Igual/Superior & 13 & 32.48 & 4.98 & & & & & & & \\
\hline \multirow[t]{3}{*}{ Leucocitos } & Inferior & 30 & 9566.33 & 3710.82 & & & & & & & \\
\hline & & & & & 0.24 & 41 & $.808^{\mathrm{NS}}$ & N.S. & .001 & 0.45 & .653 Ns \\
\hline & Igual/Superior & 13 & 9260.77 & 3902.26 & & & & & & & \\
\hline \multirow[t]{3}{*}{ Plaquetas } & Inferior & 30 & 248500.00 & 101489.17 & & & & & & & \\
\hline & & & & & -1.05 & 41 & .300 NS & N.S. & .026 & 0.57 & .570 NS \\
\hline & Igual/Superior & 13 & 288769.23 & 143682.61 & & & & & & & \\
\hline \multirow[t]{2}{*}{ VSG } & Inferior & 30 & 33.27 & 29.49 & & & & & & & \\
\hline & Igual/Superior & 13 & 27.69 & 25.48 & -0.47 & 41 & .641 Ns & N.S. & .005 & 1.06 & .290 NS \\
\hline
\end{tabular}

En el siguiente grupo de variables contrastadas (tabla 119) aparecen diferencias significativas en:

- Glucosa $(P<.05)$ : El grupo con un índice de Adragao $<2$ presenta un valor medio menor que el resto de enfermos (95.60 vs 121.00 ) y equivalente a un tamaño del efecto moderado (.140). Pero sin embargo el test alternativo de Mann-Whitney no confirma esa significación ( $\mathrm{P}>$.05) dejando alguna duda acerca de este resultado. 


\section{RESULTADOS}

- Producto cálcio-fósforo $(\mathrm{P}<.05)$ : El grupo con un índice de Adragao $<2$ presenta un valor medio mayor de producto calcio-fósforo en el momento del alta tras el trasplante (32.60 vs 25.54$)$ con tamaño del efecto moderado (.106)

- Fósforo: El test de Student no detecta significación ( $P>.05)$ aunque se podría hablar de una casi significación $(P<.100)$, en tanto que en la alternativa de Mann-Whitney sí que aparece $(P<.05)$ lo que podría indicar una cierta tendencia a que el grupo con un índice de Adragao < 2 presente un valor medio de fósforo mayor (3.37 vs 2.73).

Tabla 119: Test de diferencia entre dos medias. Asociación de Índice de Adragao con diversas variables de la analítica al alta tras el trasplante.-2-

\begin{tabular}{|c|c|c|c|c|c|c|c|c|c|c|c|}
\hline \multirow{2}{*}{ Variable / } & \multirow{2}{*}{ Adragao } & \multirow{2}{*}{$\mathrm{N}$} & \multirow{2}{*}{ Media } & \multirow{2}{*}{ D.E. } & \multicolumn{3}{|c|}{ T Student } & \multirow{2}{*}{$\begin{array}{l}\text { IC 95\% para la } \\
\text { diferenc. absoluta }\end{array}$} & \multirow{2}{*}{$\begin{array}{c}\text { Efecto } \\
\mathrm{R}^{2}\end{array}$} & \multicolumn{2}{|c|}{ Test Mann-Whitney } \\
\hline & & & & & T & $\mathrm{Gl}$ & P & & & /Z/ & $\mathrm{P}$ \\
\hline \multirow[t]{3}{*}{ Urea } & Inferior & 30 & 91.50 & 43.96 & & & & & & & \\
\hline & & & & & 0.68 & 41 & .497 NS & N.S. & .011 & 0.01 & .989 NS \\
\hline & Igual/Superior & 13 & 82.69 & 21.34 & & & & & & & \\
\hline \multirow[t]{3}{*}{ Glucosa } & Inferior & 30 & 95.60 & 13.82 & & & & & & & \\
\hline & & & & & -2.58 & 41 & $.013 *$ & $5.54-45.26$ & .140 & 1.56 & .119 NS \\
\hline & Igual/Superior & 13 & 121.00 & 50.35 & & & & & & & \\
\hline \multirow[t]{3}{*}{ Creatinina } & Inferior & 30 & 2.45 & 1.57 & & & & & & & \\
\hline & & & & & 1.75 & 41 & $.087^{\mathrm{NS}}$ & N.S. & .070 & 1.72 & $.085^{N S}$ \\
\hline & Igual/Superior & 13 & 1.67 & 0.50 & & & & & & & \\
\hline \multirow[t]{3}{*}{ Triglicéridos } & Inferior & 30 & 143.20 & 60.24 & & & & & & & \\
\hline & & & & & -0.42 & 41 & $.678^{\mathrm{NS}}$ & N.S. & .004 & 0.04 & .968 NS \\
\hline & Igual/Superior & 13 & 152.85 & 87.76 & & & & & & & \\
\hline \multirow[t]{3}{*}{ Colesterol total } & Inferior & 30 & 192.57 & 53.39 & & & & & & & \\
\hline & & & & & 1.60 & 41 & $.118^{\mathrm{NS}}$ & N.S. & .058 & 1.55 & .122 NS \\
\hline & Igual/Superior & 13 & 166.54 & 36.90 & & & & & & & \\
\hline \multirow[t]{3}{*}{ Proteínas totales } & Inferior & 30 & 6.21 & 0.52 & & & & & & & \\
\hline & & & & & 0.25 & 41 & $.801^{\mathrm{NS}}$ & N.S. & .002 & 0.32 & .750 NS \\
\hline & Igual/Superior & 13 & 6.16 & 0.69 & & & & & & & \\
\hline \multirow[t]{3}{*}{ Calcio } & Inferior & 30 & 9.66 & 0.89 & & & & & & & \\
\hline & & & & & 0.84 & 41 & $.405^{\text {NS }}$ & N.S. & .017 & 0.45 & .652 NS \\
\hline & Igual/Superior & 13 & 9.42 & 0.83 & & & & & & & \\
\hline \multirow[t]{3}{*}{ Calcio correg. } & Inferior & 30 & 10.31 & 0.83 & & & & & & & \\
\hline & & & & & 0.82 & 41 & .416 NS & N.S. & .016 & 0.62 & .534 NS \\
\hline & Igual/Superior & 13 & 10.08 & 0.75 & & & & & & & \\
\hline \multirow[t]{3}{*}{ Prod. Calc/Fósf. } & Inferior & 30 & 32.60 & 11.18 & & & & & & & \\
\hline & & & & & 2.20 & 41 & $.033 *$ & $0.58-13.53$ & .106 & 2.76 & $.006 * *$ \\
\hline & Igual/Superior & 13 & 25.54 & 4.05 & & & & & & & \\
\hline \multirow[t]{2}{*}{ Fósforo } & Inferior & 30 & 3.37 & 1.16 & & & & & & & \\
\hline & Igual/Superior & 13 & 2.73 & 0.49 & 1.92 & 41 & .062 Ns & N.S. & .082 & 2.19 & $.029 *$ \\
\hline
\end{tabular}

N.S. $=$ NO significativo $(\mathrm{P}>05) \quad *=$ Significativo al $5 \%(\mathrm{P}<.05) \quad * *=$ Altamente significativo al $1 \%(\mathrm{P}<.01)$ 


\section{RESULTADOS}

En este grupo (tabla 120) se han encontrado diferencias significativas en:

- MDRDa $(\mathrm{P}<.05)$ : El grupo con un índice de Adragao $<2$ presenta un valor medio menor que el resto (36.28 vs 49.76$)$, que se corresponde con un tamaño del efecto moderado.

- Mayo Quadratic $(\mathrm{P}<.05)$ : El grupo con un índice de Adragao $<2$ presenta un valor medio menor que el resto (42.27 vs 58.42) siendo el tamaño del efecto moderado.

- CKD-EPI $(P<.05)$ : El grupo con un índice de Adragao $<2$ presenta un valor medio menor que el resto (36.45 vs 49.95), con tamaño del efecto moderado.

Tabla 120: Test de diferencia entre dos medias. Asociación de Índice de Adragao con diversas variables de la analítica al alta tras el trasplante.-3-

\begin{tabular}{|c|c|c|c|c|c|c|c|c|c|c|c|}
\hline \multirow{2}{*}{ Variable } & \multirow{2}{*}{ / Adragao } & \multirow{2}{*}{$\mathrm{N}$} & \multirow{2}{*}{ Media } & \multirow{2}{*}{ D.E. } & \multicolumn{3}{|c|}{ T Student } & \multirow{2}{*}{$\begin{array}{l}\text { IC } 95 \% \text { para la } \\
\text { diferenc. Absoluta }\end{array}$} & \multirow{2}{*}{$\begin{array}{c}\text { Efecto } \\
\mathrm{R}^{2}\end{array}$} & \multicolumn{2}{|c|}{ Test Mann-Whitne } \\
\hline & & & & & T & gl & $P$ & & & /Z/ & $P$ \\
\hline \multirow[t]{3}{*}{ Magnesio } & Inferior & 30 & 1.67 & 0.32 & & & & & & & \\
\hline & & & & & -0.13 & 41 & .894 NS & N.S. & .000 & 0.27 & $.804 \mathrm{NS}$ \\
\hline & Igual/Superior & 13 & 1.68 & 0.34 & & & & & & & \\
\hline \multirow[t]{3}{*}{ Fosfata Alcalina } & Inferior & 30 & 78.10 & 27.90 & & & & & & & \\
\hline & & & & & -1.70 & 41 & $.096^{\mathrm{NS}}$ & N.S. & .066 & 0.89 & $.375^{\mathrm{NS}}$ \\
\hline & Igual/Superior & 13 & 107.15 & 84.47 & & & & & & & \\
\hline \multirow[t]{3}{*}{ Urea en orina } & Inferior & 30 & 1195.09 & 473.24 & & & & & & & \\
\hline & & & & & -0.34 & 41 & $.734^{\mathrm{NS}}$ & N.S. & .003 & 0.74 & .459 NS \\
\hline & Igual/Superior & 13 & 1243.00 & 254.38 & & & & & & & \\
\hline \multirow[t]{3}{*}{ Creat. en orina } & Inferior & 30 & 59.18 & 26.09 & & & & & & & \\
\hline & & & & & 0.62 & 41 & $.537^{\mathrm{NS}}$ & N.S. & .009 & 0.77 & $.443^{\mathrm{NS}}$ \\
\hline & Igual/Superior & 13 & 53.98 & 22.63 & & & & & & & \\
\hline \multirow[t]{3}{*}{$\mathrm{pH}$} & Inferior & 30 & 7.34 & 0.05 & & & & & & & \\
\hline & & & & & -0.78 & 41 & .442 Ns & N.S. & .014 & 0.90 & .366 Ns \\
\hline & Igual/Superior & 13 & 7.36 & 0.05 & & & & & & & \\
\hline \multirow[t]{3}{*}{ Bicarbonato } & Inferior & 30 & 20.61 & 3.20 & & & & & & & \\
\hline & & & & & -1.50 & 41 & .141 Ns & N.S. & .052 & 1.43 & $.153^{\mathrm{NS}}$ \\
\hline & Igual/Superior & 13 & 22.15 & 2.84 & & & & & & & \\
\hline \multirow[t]{3}{*}{ MDRDa } & Inferior & 30 & 36.28 & 15.93 & & & & & & & \\
\hline & & & & & -2.54 & 41 & $.015^{*}$ & $2.75-24.22$ & .136 & 2.38 & $.017^{*}$ \\
\hline & Igual/Superior & 13 & 49.76 & 16.19 & & & & & & & \\
\hline \multirow[t]{3}{*}{ Cock. Gault } & Inferior & 30 & 42.69 & 15.88 & & & & & & & \\
\hline & & & & & -1.24 & 41 & .222 NS & N.S. & .036 & 1.06 & $.290 \mathrm{NS}$ \\
\hline & Igual/Superior & 13 & 48.93 & 13.27 & & & & & & & \\
\hline \multirow[t]{3}{*}{ Mayo Quadr. } & Inferior & 30 & 42.27 & 22.07 & & & & & & & \\
\hline & & & & & -2.15 & 41 & $.038^{*}$ & $0.98-31.32$ & .101 & 2.01 & $.044 *$ \\
\hline & Igual/Superior & 13 & 58.42 & 23.91 & & & & & & & \\
\hline \multirow[t]{2}{*}{ CKD-EPI } & Inferior & 30 & 36.45 & 16.59 & & & & & & & \\
\hline & Igual/Superior & 13 & 49.95 & 17.26 & -2.42 & 41 & $.020 *$ & $2.24-24.76$ & .125 & 2.30 & $.021 *$ \\
\hline
\end{tabular}

N.S. $=$ NO significativo $(\mathrm{P}>05) \quad *=$ Significativo al $5 \%(\mathrm{P}<.05)$ 


\section{RESULTADOS}

En el siguiente bloque (tabla 121) no se ha encontrado ninguna significación ( $\mathrm{P}>\mathbf{0 5})$.

Tabla 121: Test de diferencia entre dos medias. Asociación de Índice de Adragao con diversas variables antropométricas y de la analítica en la revisión.-1-

\begin{tabular}{|c|c|c|c|c|c|c|c|c|c|c|c|}
\hline \multirow{2}{*}{ Variable } & \multirow{2}{*}{ Adragao } & \multirow{2}{*}{$\mathrm{N}$} & \multirow{2}{*}{ Media } & \multirow{2}{*}{ D.E. } & \multicolumn{3}{|c|}{ T Student } & \multirow{2}{*}{$\begin{array}{l}\text { IC } 95 \% \text { para la } \\
\text { diferenc. Absoluta }\end{array}$} & \multirow{2}{*}{$\begin{array}{c}\text { Efecto } \\
\mathrm{R}^{2}\end{array}$} & \multicolumn{2}{|c|}{ Test Mann-Whitney } \\
\hline & & & & & T & $\mathrm{gl}$ & $\mathrm{P}$ & & & /Z/ & $P$ \\
\hline \multirow[t]{3}{*}{ Peso } & Inferior & 30 & 75.43 & 14.31 & & & & & & & \\
\hline & & & & & 0.59 & 41 & $.555^{\mathrm{NS}}$ & N.S. & .009 & 0.52 & $.610^{\mathrm{NS}}$ \\
\hline & Igual/Superior & 13 & 72.80 & 10.52 & & & & & & & \\
\hline \multirow[t]{3}{*}{ IMC } & Inferior & 30 & 26.38 & 3.57 & & & & & & & \\
\hline & & & & & 0.26 & 41 & .799 NS & N.S. & .002 & 0.19 & .865 NS \\
\hline & Igual/Superior & 13 & 26.08 & 3.46 & & & & & & & \\
\hline \multirow[t]{3}{*}{ TAS } & Inferior & 30 & 146.17 & 16.26 & & & & & & & \\
\hline & & & & & 1.00 & 41 & .325 NS & N.S. & .024 & 0.97 & .339 NS \\
\hline & Igual/Superior & 13 & 140.23 & 21.46 & & & & & & & \\
\hline \multirow[t]{3}{*}{ TAD } & Inferior & 30 & 86.27 & 8.50 & & & & & & & \\
\hline & & & & & 1.75 & 41 & .087 Ns & N.S. & .070 & 1.67 & .099 NS \\
\hline & Igual/Superior & 13 & 81.23 & 9.04 & & & & & & & \\
\hline \multirow[t]{3}{*}{ Diuresis } & Inferior & 30 & 2572.33 & 806.29 & & & & & & & \\
\hline & & & & & -0.27 & 41 & .785 Ns & N.S. & .002 & 0.38 & .701 Ns \\
\hline & Igual/Superior & 13 & 2646.15 & 818.14 & & & & & & & \\
\hline \multirow[t]{3}{*}{ Hemoglobina } & Inferior & 30 & 13.35 & 2.17 & & & & & & & \\
\hline & & & & & 0.01 & 41 & .991 NS & N.S. & .000 & 0.29 & .781 NS \\
\hline & Igual/Superior & 13 & 13.35 & 1.25 & & & & & & & \\
\hline \multirow[t]{3}{*}{ Hematocrito } & Inferior & 30 & 40.08 & 5.71 & & & & & & & \\
\hline & & & & & -0.26 & 41 & .796 NS & N.S. & .002 & 0.32 & .751 NS \\
\hline & Igual/Superior & 13 & 40.53 & 3.93 & & & & & & & \\
\hline \multirow[t]{3}{*}{ Leucocitos } & Inferior & 30 & 6561.33 & 1908.47 & & & & & & & \\
\hline & & & & & -1.43 & 41 & .160 NS & N.S. & .047 & 1.26 & .209 NS \\
\hline & Igual/Superior & 13 & 7561.54 & 2523.70 & & & & & & & \\
\hline \multirow[t]{3}{*}{ Plaquetas } & Inferior & 30 & 187133.33 & 52593.91 & & & & & & & \\
\hline & & & & & -0.60 & 41 & .551 Ns & N.S. & .009 & 0.11 & .916 NS \\
\hline & Igual/Superior & 13 & 198923.08 & 72265.09 & & & & & & & \\
\hline \multirow[t]{2}{*}{ VSG } & Inferior & 30 & 16.21 & 14.05 & & & & & & & \\
\hline & Igual/Superior & 13 & 17.15 & 16.25 & -0.19 & 41 & .848 NS & N.S. & .001 & 0.20 & $.843^{\text {NS }}$ \\
\hline
\end{tabular}

N.S. = NO significativo $(P>.05)$

En este grupo de variables (tabla 122) han aparecido diferencias significativas en:

- Glucosa $(\mathrm{P}<.05)$ : El grupo con un índice de Adragao $<2$ presenta un valor medio menor de glucemia sérica en la revisión actual que el resto (96.6577 vs 118.92), con tamaño del efecto moderado. Sin embargo, la alternativa de Mann-Whitney no detecta esta asociación de forma significativa $(P>.05)$. 


\section{RESULTADOS}

- Colesterol total $(P<.05)$ : El test de Student indica la existencia de diferencias significativas ( $P<.05$ y efecto bajo) pero la alternativa de Mann-Whitney no las encuentra $(P>.05)$ aunque se podría hablar de una casi significación $(P<.100)$ que según los datos, parece indicar una leve relación tal que el grupo con un índice de Adragao $<2$ presenta un valor medio de colesterol total en la revisión actual más elevado (192.10 vs 165.46$)$.

Tabla 122: Test de diferencia entre dos medias. Asociación de Índice de Adragao con diversas variables de la analítica en la revisión.-2-

\begin{tabular}{|c|c|c|c|c|c|c|c|c|c|c|c|}
\hline \multirow{2}{*}{ Variable / } & \multirow{2}{*}{ Adragao } & \multirow{2}{*}{$\mathrm{N}$} & \multirow{2}{*}{ Media } & \multirow{2}{*}{ D.E. } & \multicolumn{3}{|c|}{ T Student } & \multirow{2}{*}{$\begin{array}{l}\text { IC } 95 \% \text { para la } \\
\text { diferenc. absoluta }\end{array}$} & \multirow{2}{*}{$\begin{array}{l}\text { Efecto } \\
\mathrm{R}^{2}\end{array}$} & \multicolumn{2}{|c|}{ Test Mann-Whitney } \\
\hline & & & & & T & gl & $\mathrm{P}$ & & & /Z/ & $P$ \\
\hline \multirow[t]{3}{*}{ Urea } & Inferior & 30 & 65.43 & 28.78 & & & & & & & \\
\hline & & & & & -1.04 & 41 & .304 Ns & N.S. & .026 & 1.23 & .219 NS \\
\hline & Igual/Superior & 13 & 75.62 & 30.97 & & & & & & & \\
\hline \multirow[t]{3}{*}{ Glucosa } & Inferior & 30 & 96.57 & 10.07 & & & & & & & \\
\hline & & & & & -2.21 & 41 & $.033 *$ & $1.94-42.77$ & .107 & 0.40 & $.691^{\mathrm{NS}}$ \\
\hline & Igual/Superior & 13 & 118.92 & 54.05 & & & & & & & \\
\hline \multirow[t]{3}{*}{ Creatinina } & Inferior & 30 & 1.59 & 0.53 & & & & & & & \\
\hline & & & & & 0.36 & 41 & $.721^{\mathrm{NS}}$ & N.S. & .003 & 0.52 & $.604^{\mathrm{NS}}$ \\
\hline & Igual/Superior & 13 & 1.53 & 0.51 & & & & & & & \\
\hline \multirow[t]{3}{*}{ Ácido úrico } & Inferior & 30 & 6.83 & 1.59 & & & & & & & \\
\hline & & & & & -1.65 & 41 & $.106^{\mathrm{NS}}$ & N.S. & .062 & 1.44 & .149 NS \\
\hline & Igual/Superior & 13 & 13.27 & 21.58 & & & & & & & \\
\hline \multirow[t]{3}{*}{ Triglicéridos } & Inferior & 30 & 119.07 & 57.38 & & & & & & & \\
\hline & & & & & -0.49 & 41 & .630 NS & N.S. & .006 & 0.05 & .958 NS \\
\hline & Igual/Superior & 13 & 129.46 & 78.89 & & & & & & & \\
\hline \multirow[t]{3}{*}{ Colesterol total } & Inferior & 30 & 192.10 & 35.22 & & & & & & & \\
\hline & & & & & 2.10 & 41 & $.042 *$ & $1.04-52.24$ & .097 & 1.88 & $.060^{\mathrm{NS}}$ \\
\hline & Igual/Superior & 13 & 165.46 & 44.52 & & & & & & & \\
\hline \multirow[t]{3}{*}{ Proteínas totales } & Inferior & 30 & 6.73 & 0.51 & & & & & & & \\
\hline & & & & & -1.71 & 41 & $.096^{\mathrm{NS}}$ & N.S. & .066 & 1.36 & .175 Ns \\
\hline & Igual/Superior & 13 & 7.00 & 0.39 & & & & & & & \\
\hline \multirow[t]{3}{*}{ Calcio } & Inferior & 30 & 9.52 & 0.59 & & & & & & & \\
\hline & & & & & -1.38 & 41 & $.175^{\mathrm{NS}}$ & N.S. & .044 & 1.36 & $.175^{\text {NS }}$ \\
\hline & Igual/Superior & 13 & 9.78 & 0.52 & & & & & & & \\
\hline \multirow[t]{3}{*}{ Calcio correg. } & Inferior & 30 & 9.91 & 0.50 & & & & & & & \\
\hline & & & & & -0.73 & 41 & $.472^{\text {NS }}$ & N.S. & 0.13 & 0.70 & $.483^{\mathrm{NS}}$ \\
\hline & Igual/Superior & 13 & 10.03 & 0.57 & & & & & & & \\
\hline \multirow[t]{3}{*}{ Prod. Calc/Fósf. } & Inferior & 30 & 31.45 & 6.32 & & & & & & & \\
\hline & & & & & 1.39 & 41 & .172 NS & N.S. & .045 & 1.39 & .165 NS \\
\hline & Igual/Superior & 13 & 28.70 & 5.02 & & & & & & & \\
\hline \multirow[t]{2}{*}{ Fósforo } & Inferior & 30 & 3.31 & 0.70 & & & & & & & \\
\hline & Igual/Superior & 13 & 2.94 & 0.53 & 1.73 & 41 & $.091^{\mathrm{NS}}$ & N.S. & .068 & 1.62 & $.105^{\mathrm{NS}}$ \\
\hline
\end{tabular}

N.S. $=$ NO significativo $(\mathrm{P}>05) \quad *=$ Significativo al $5 \%(\mathrm{P}<.05) \quad * *=$ Altamente significativo al $1 \%(\mathrm{P}<.01)$ 


\section{RESULTADOS}

En este grupo (tabla 123) aparecen diferencias significativas en:

- Hemoglobina glicosilada $(P<.01)$ : El grupo con un índice de Adragao $<2$ presenta un valor medio más bajo de hemoglobina glicosilada (5.72 vs 6.48) que el resto de pacientes, con tamaño del efecto moderado.

- Colesterol HDL ( $\mathrm{P}<.05)$ : El grupo con un índice de Adragao $<2$ presenta un valor medio mayo (63.37 vs 43.38) que el resto; para un tamaño del efecto moderado del efecto.

Tabla 123: Test de diferencia entre dos medias. Asociación de Índice de Adragao con diversas variables de la analítica en la revisión.-3-

\begin{tabular}{|c|c|c|c|c|c|c|c|c|c|c|c|}
\hline \multirow{2}{*}{ Variable } & \multirow{2}{*}{ Adragao } & \multirow{2}{*}{$\mathrm{N}$} & \multirow{2}{*}{ Media } & \multirow{2}{*}{ D.E. } & \multicolumn{3}{|c|}{ T Student } & \multirow{2}{*}{$\begin{array}{c}\text { IC 95\% para la } \\
\text { diferenc. absoluta }\end{array}$} & \multirow{2}{*}{$\begin{array}{c}\text { Efecto } \\
\mathrm{R}^{2}\end{array}$} & \multicolumn{2}{|c|}{ Test Mann-Whitney } \\
\hline & & & & & $T$ & gl & $P$ & & & /Z/ & $P$ \\
\hline \multirow[t]{3}{*}{ Magnesio } & Inferior & 30 & 1.83 & 0.26 & & & & & & & \\
\hline & & & & & -0.55 & 41 & .589 NS & N.S. & .007 & 0.29 & .795 Ns \\
\hline & Igual/Superior & 13 & 1.88 & 0.32 & & & & & & & \\
\hline \multirow[t]{3}{*}{ Fosf Alcalina } & Inferior & 30 & 74.43 & 19.68 & & & & & & & \\
\hline & & & & & -0.97 & 41 & .337 NS & N.S. & .023 & 0.12 & $.282 \mathrm{NS}$ \\
\hline & Igual/Superior & 13 & 82.85 & 37.24 & & & & & & & \\
\hline \multirow[t]{3}{*}{ Clacio iónico } & Inferior & 30 & 1.26 & 0.06 & & & & & & & \\
\hline & & & & & -0.35 & 41 & $.731^{\mathrm{NS}}$ & N.S. & .003 & 0.03 & .659 NS \\
\hline & Igual/Superior & 13 & 1.27 & 0.07 & & & & & & & \\
\hline \multirow[t]{3}{*}{ PCR } & Inferior & 30 & 3.10 & 2.92 & & & & & & & \\
\hline & & & & & -0.19 & 41 & $.847^{\text {NS }}$ & N.S. & .001 & 0.10 & $.510^{\mathrm{NS}}$ \\
\hline & Igual/Superior & 13 & 3.31 & 3.84 & & & & & & & \\
\hline \multirow[t]{3}{*}{ Interleukina } & Inferior & 30 & 8.37 & 21.54 & & & & & & & \\
\hline & & & & & 0.71 & 41 & .483 NS & N.S. & .012 & 0.35 & .150 Ns \\
\hline & Igual/Superior & 13 & 4.10 & 2.66 & & & & & & & \\
\hline \multirow[t]{3}{*}{ PTH } & Inferior & 30 & 109.70 & 52.84 & & & & & & & \\
\hline & & & & & 0.36 & 41 & $.718^{\mathrm{NS}}$ & N.S. & .003 & 0.61 & .557 Ns \\
\hline & Igual/Superior & 13 & 102.86 & 64.75 & & & & & & & \\
\hline \multirow[t]{3}{*}{ Hemog. glicos. } & Inferior & 30 & 5.72 & 0.40 & & & & & & & \\
\hline & & & & & -2.74 & 41 & $.009 * *$ & $0.20-1.33$ & .154 & 1.81 & $.009 * *$ \\
\hline & Igual/Superior & 13 & 6.48 & 1.43 & & & & & & & \\
\hline \multirow[t]{3}{*}{ Vitamina D } & Inferior & 30 & 18.86 & 10.91 & & & & & & & \\
\hline & & & & & 0.34 & 41 & .734 NS & N.S. & .003 & 0.16 & .778 NS \\
\hline & Igual/Superior & 13 & 17.66 & 9.44 & & & & & & & \\
\hline \multirow[t]{3}{*}{ Colest. HDL } & Inferior & 30 & 63.37 & 19.17 & & & & & & & \\
\hline & & & & & 2.59 & 41 & $.013 *$ & $3.28-26.68$ & .140 & 2.45 & $.013 *$ \\
\hline & Igual/Superior & 13 & 43.38 & 12.35 & & & & & & & \\
\hline \multirow[t]{2}{*}{ Colest. LDL } & Inferior & 30 & 104.32 & 29.85 & & & & & & & \\
\hline & Igual/Superior & 13 & 91.18 & 37.29 & 1.23 & 41 & .226 NS & N.S. & .036 & 1.28 & $.085^{\mathrm{NS}}$ \\
\hline
\end{tabular}

N.S. $=$ NO significativo $(\mathrm{P}>05) \quad *=$ Significativo al $5 \%(\mathrm{P}<.05) \quad * *=$ Altamente significativo al $1 \%(\mathrm{P}<.01)$ 


\section{RESULTADOS}

En este bloque (tabla 124) no ha aparecido ninguna diferencia que pueda ser tomada como estadísticamente significativa ( $P>.05)$.

Tabla 124: Test de diferencia entre dos medias. Asociación de Índice de Adragao con diversas variables de la analítica en la revisión.-4-

\begin{tabular}{|c|c|c|c|c|c|c|c|c|c|c|c|}
\hline \multirow{2}{*}{ Variable } & \multirow{2}{*}{ Adragao } & \multirow{2}{*}{$\mathrm{N}$} & \multirow{2}{*}{ Media } & \multirow{2}{*}{ D.E. } & \multicolumn{3}{|c|}{ T Student } & \multirow{2}{*}{$\begin{array}{c}\text { IC 95\% para la } \\
\text { diferenc. absoluta }\end{array}$} & \multirow{2}{*}{$\begin{array}{l}\text { Efecto } \\
\mathrm{R}^{2}\end{array}$} & \multicolumn{2}{|c|}{ Test Mann-Whitney } \\
\hline & & & & & T & $\mathrm{gl}$ & $\mathrm{P}$ & & & /Z/ & $P$ \\
\hline \multirow[t]{3}{*}{$\mathrm{pH}$} & Inferior & 30 & 7.33 & 0.04 & & & & & & & \\
\hline & & & & & 0.30 & 41 & $.765 \mathrm{Ns}$ & N.S. & .022 & 0.21 & .832 Ns \\
\hline & Igual/Superior & 13 & 7.33 & 0.03 & & & & & & & \\
\hline \multirow[t]{3}{*}{ Bicarbonato } & Inferior & 30 & 22.54 & 2.37 & & & & & & & \\
\hline & & & & & 0.53 & 41 & $.598^{\mathrm{NS}}$ & N.S. & .007 & 0.45 & .653 Ns \\
\hline & Igual/Superior & 13 & 22.08 & 3.11 & & & & & & & \\
\hline \multirow[t]{3}{*}{ Microalbumin. } & Inferior & 30 & 70.39 & 159.10 & & & & & & & \\
\hline & & & & & -0.07 & 41 & .945 NS & N.S. & .000 & 1.45 & .146 Ns \\
\hline & Igual/Superior & 13 & 73.72 & 98.85 & & & & & & & \\
\hline \multirow[t]{3}{*}{ MDRDa } & Inferior & 30 & 49.96 & 18.56 & & & & & & & \\
\hline & & & & & -0.73 & 41 & .472 NS & N.S. & .013 & 0.85 & $.397^{\mathrm{NS}}$ \\
\hline & Igual/Superior & 13 & 54.35 & 17.23 & & & & & & & \\
\hline \multirow[t]{3}{*}{ Cock. Gault } & Inferior & 30 & 60.51 & 25.75 & & & & & & & \\
\hline & & & & & 0.22 & 41 & $.830^{\mathrm{NS}}$ & N.S. & .001 & 0.16 & $.874^{\mathrm{NS}}$ \\
\hline & Igual/Superior & 13 & 58.73 & 22.04 & & & & & & & \\
\hline \multirow[t]{3}{*}{ Mayo Quadr. } & Inferior & 30 & 60.39 & 25.80 & & & & & & & \\
\hline & & & & & -0.56 & 41 & $.577^{N S}$ & N.S. & .008 & 0.53 & $.597 \mathrm{Ns}$ \\
\hline & Igual/Superior & 13 & 65.22 & 26.02 & & & & & & & \\
\hline \multirow[t]{3}{*}{ CKD-EPI } & Inferior & 30 & 50.65 & 20.36 & & & & & & & \\
\hline & & & & & -0.53 & 41 & .600 NS & N.S. & .007 & 0.58 & .561 Ns \\
\hline & Igual/Superior & 13 & 54.14 & 18.77 & & & & & & & \\
\hline \multirow[t]{2}{*}{ FGF-23 } & Inferior & 30 & 7.02 & 15.26 & & & & & & & \\
\hline & Igual/Superior & 13 & 0.49 & 1.16 & 1.53 & 41 & $.134^{\mathrm{NS}}$ & N.S. & .054 & 1.86 & .063 Ns \\
\hline
\end{tabular}

N.S. = NO significativo $(P>.05)$

Tras los contrastes anteriores, quedan por analizar la asociación con la farmacología. Se realizaron test no paramétricos, siendo los valores de $\mathrm{P}$ siempre $>.05$ por lo que se concluye que no hay relación alguna entre el índice de Adragao y el tratamiento farmacológico recibido, tanto previo al trasplante como relativo a la inmunosupresión (considerando tanto la dosis recibida durante el primer año como la dosis total acumulada). 


\section{RESULTADOS}

Finalmente se muestra el valor del índice de Adragao estratificando a los pacientes según la edad y los resultados de diversas variables tanto analíticas como relativas ala historia clínica del enfermo.

Las Figuras 42 y 43 muestran el resultado del índice de Adragao estratificando a los pacientes según diferentes variables y en dos grupos de edad:

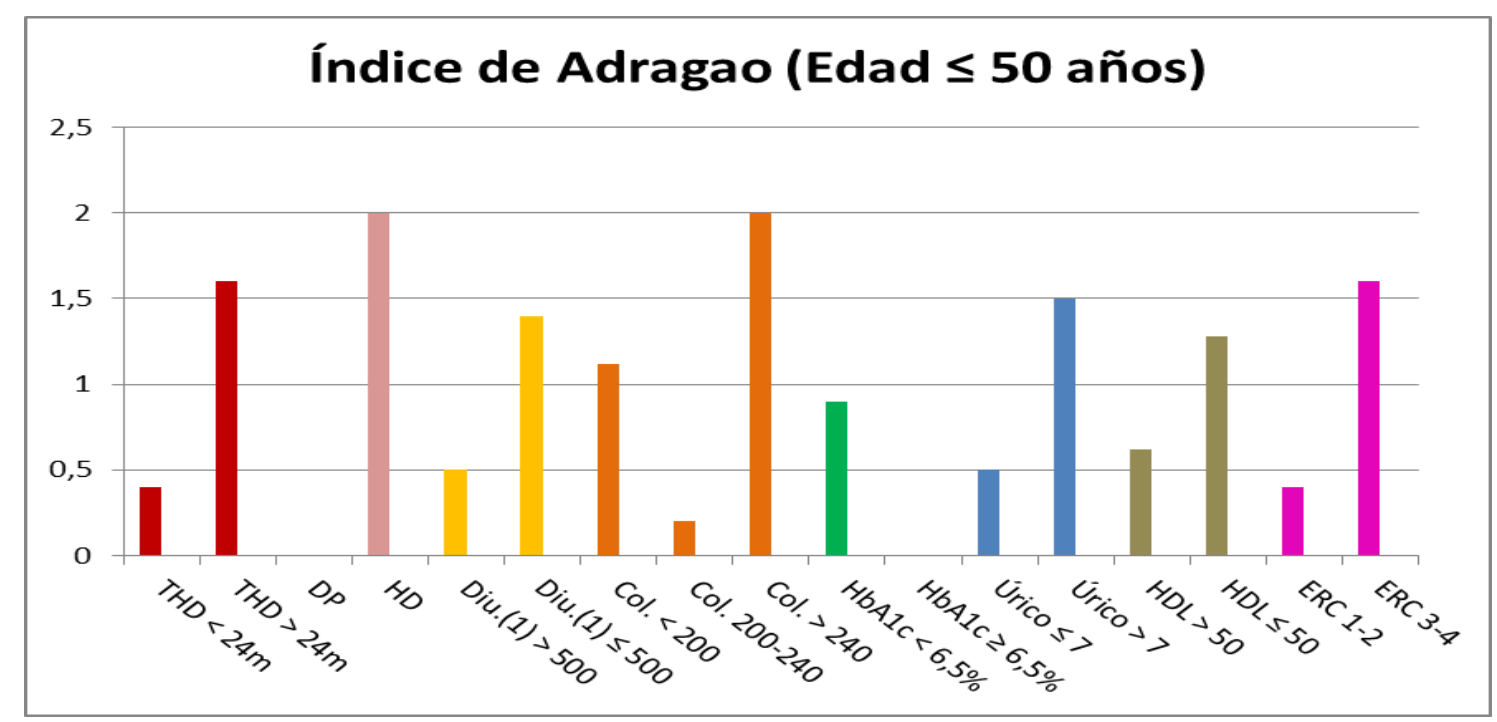

Figura 42: Diferencias en el índice de Adragao según diversas variables en pacientes de edad $\leq 50$ años.

El índice de Adragao de los pacientes revisados con edad igual o inferior a 50 años y que procedían de diálisis peritoneal es de 0 . No existen pacientes con edad $\leq 50$ años y con valores de hemoglobina glicosilada por encima de $6,5 \%$. 


\section{RESULTADOS}

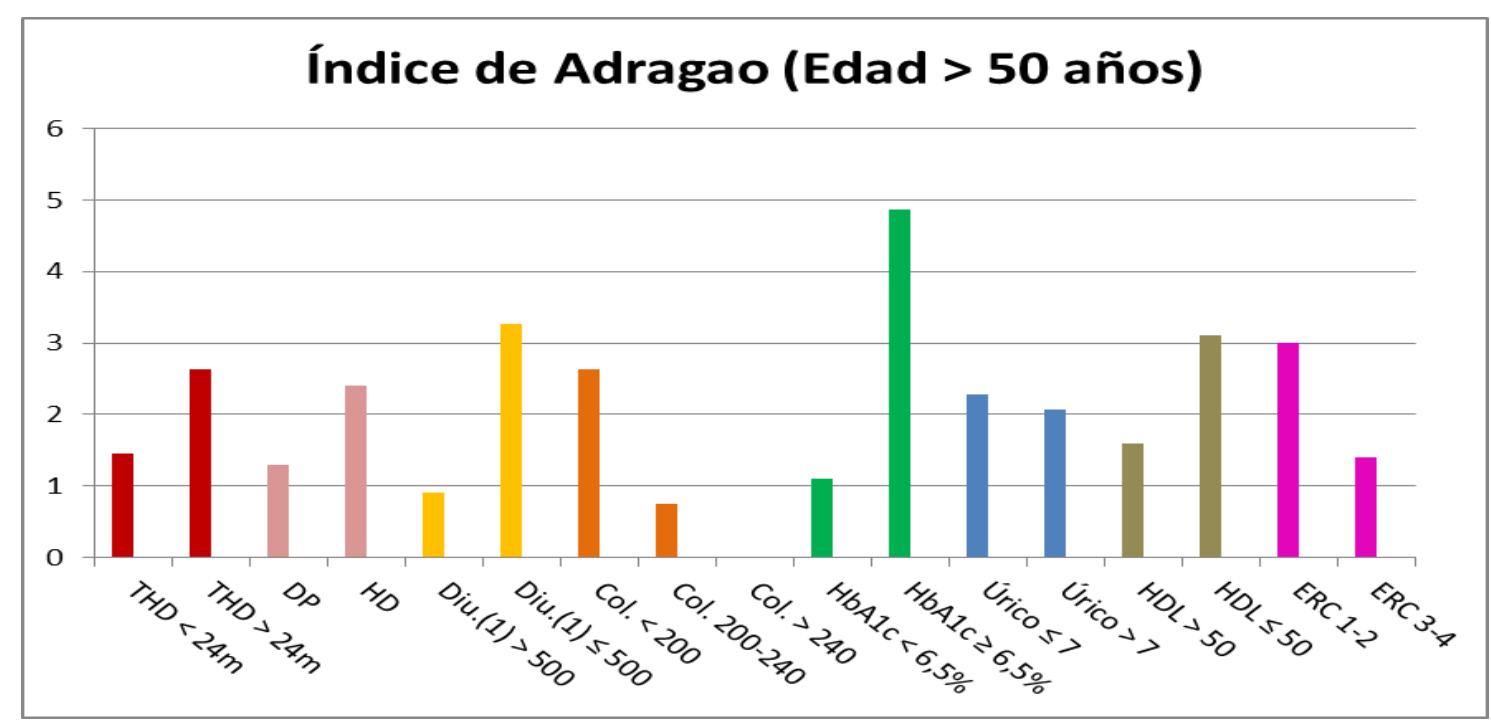

Figura 43: Diferencias en el índice de Adragao según diversas variables en pacientes de edad $>50$ años.

No existen pacientes de edad superior a 50 años con colesterol por encima de $240 \mathrm{mg} / \mathrm{dl}$. Asimismo, el número de pacientes en este rango de edad y con ERC 3-4 es muy reducido.

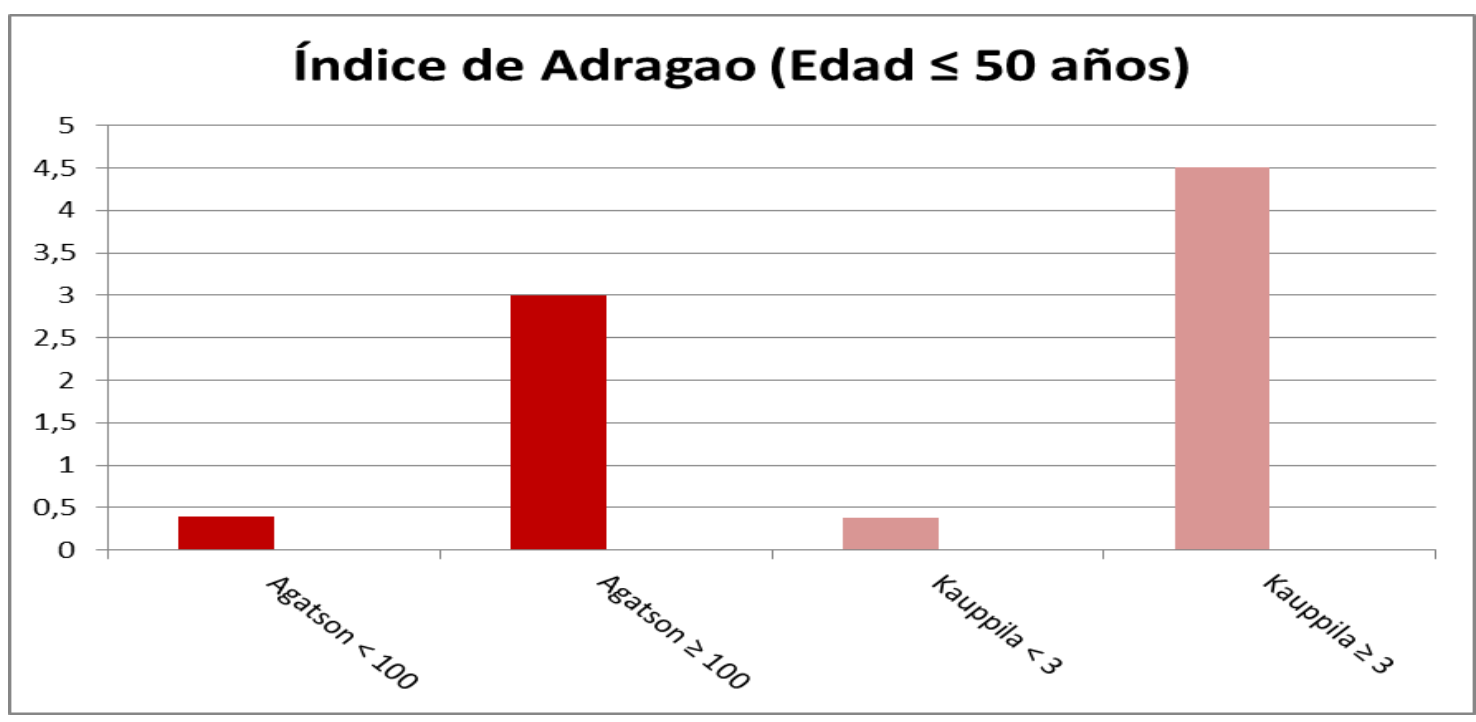

Figura 44: Diferencias en el índice de Adragao según el resto de pruebas para valorar la calcificación vascular en pacientes de edad $\leq 50$ años. 


\section{RESULTADOS}

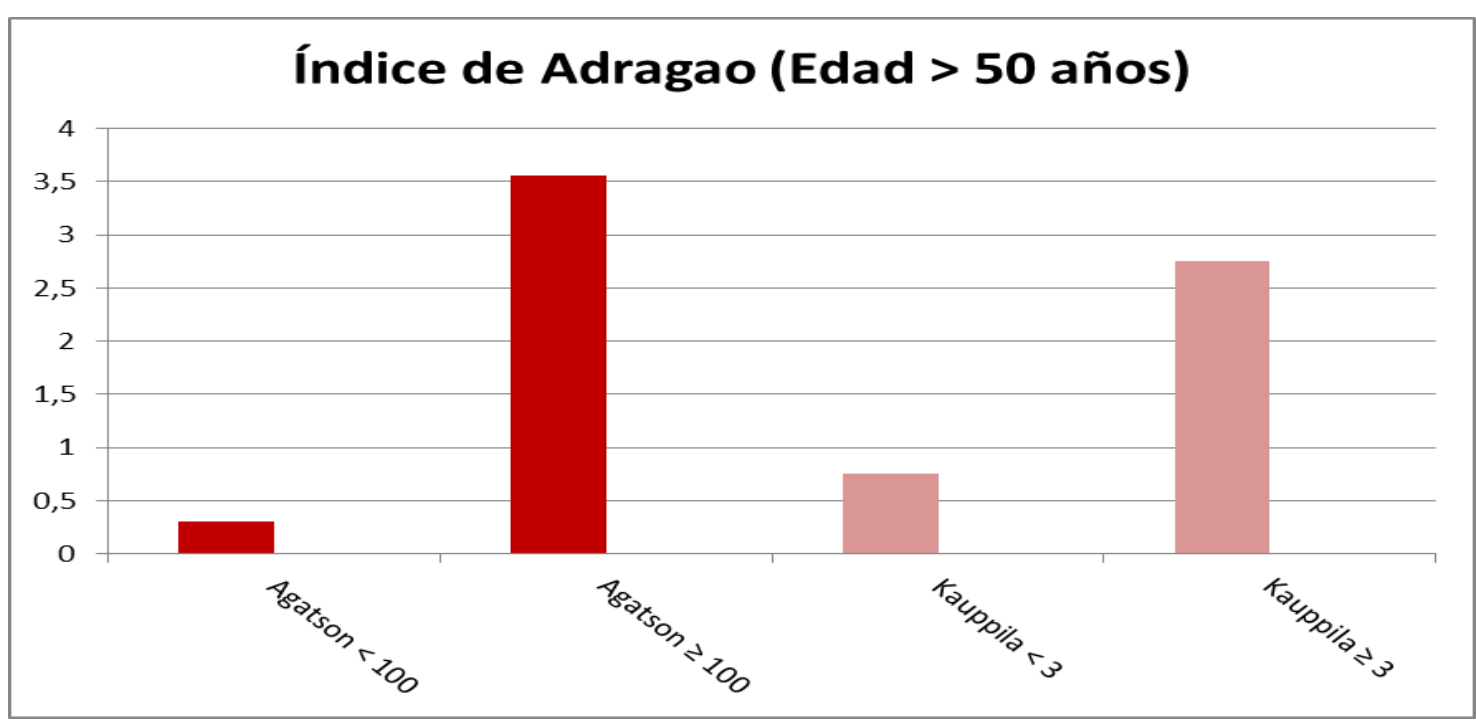

Figura 45: Diferencias en el índice de Adragao según el resto de pruebas para valorar la calcificación vascular en pacientes de edad > 50 años. 


\section{RESULTADOS}

\subsection{5: ÍNDICE DE KAUPPILA}

El grado de calcificación en arteria aorta lumbar de los 43 receptores de trasplante renal se situó entre 0 y 22 (Tabla 125).

El valor del índice de Kauppila obtenido tras la valoración de las radiografías de columna lumbar lateral realizadas en el estudio de la muestra se recoge en la siguiente tabla:

\begin{tabular}{|l|l|l|l|l|l|l|}
\hline & Media & Mediana & MAX & MIN & R. Interq. & DS \\
\hline Kauppila & 4,65 & 3 & 22 & 0 & $0-9$ & 5,97 \\
\hline
\end{tabular}

Tabla 125: Estadísticos descriptivos del índice de Kauppila observados en la muestra.

La distribución de los pacientes estudiados según la puntuación del índice de Kauppila fue la siguiente:

\begin{tabular}{|l|l|l|l|}
\hline I. Kauppila & Estrato & Recuento & Porcentaje \\
\hline$<\mathbf{2}$ & Normal & 21 & $48,8 \%$ \\
\hline $\mathbf{2}-\mathbf{3}$ & Leve & 2 & $4,7 \%$ \\
\hline $\mathbf{4 - 5}$ & Moderado & 6 & $14 \%$ \\
\hline $\mathbf{2 6}$ & Grave & 14 & $32,6 \%$ \\
\hline
\end{tabular}

Tabla 126: Distribución de los pacientes estudiados según el grado de severidad de las calcificaciones aórticas. 


\section{RESULTADOS}

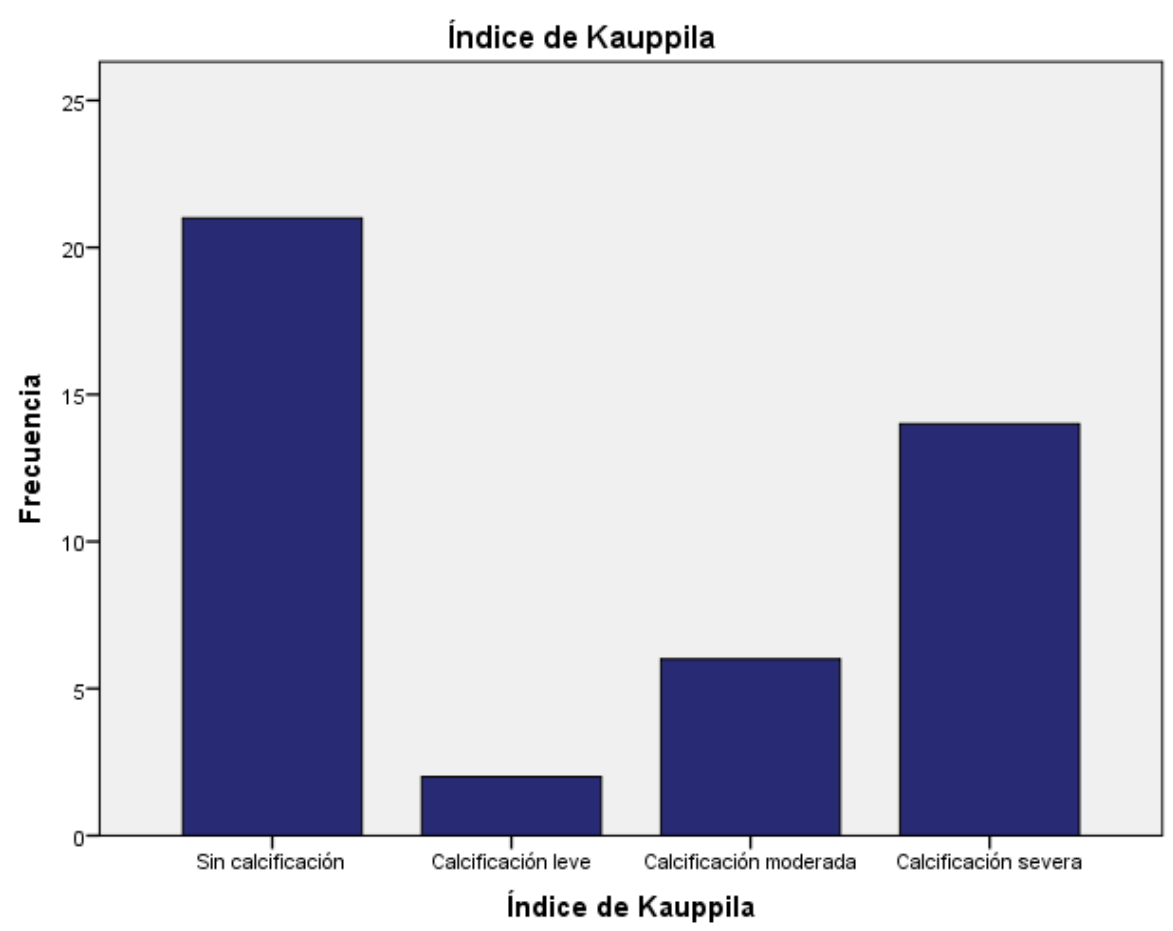

Figura 36: Distribución de los pacientes respecto al índice de Kauppila.

Para analizar la asociación observada entre las diferentes variables categóricas y cuantitativas y el índice de Kauppila se crearon dos conjuntos de pacientes según esta última variable, agrupándolos según presentasen un índice de Kauppila $<30 \geq 3$. Un 48,8\% (21 pacientes) de los pacientes presentaron un índice de Kauppila $<3$.

En el análisis de las variables categóricas se ha empleado el test Chi-cuadrado de asociación entre variables medidas en escala nominal, realizando una aproximación al cálculo del tamaño del efecto mediante el cuadrado del valor del coeficiente Phi.

En cuanto a las variables de tipo categórico (tabla 127) se observa:

- Sexo ( $\mathrm{P}<.05)$ : El sexo masculino parece asociar un índice de Kauppila más alto (86.4\% vs $13.6 \%$ ) aunque con una intensidad leve (.106).

- Modalidad de diálisis $(P<.10)$ : Los pacientes con un índice de Kauppila mayor recibieron en su mayoría hemodiálisis como tratamiento renal sustitutivo ( $81.8 \%$ vs $18.2 \%$ ), con una intensidad leve del efecto (.99) y sin llegar a alcanzar significación estadística en nuestra muestra. 


\section{RESULTADOS}

Tabla 127: Test Chi-cuadrado. Asociación de Índice de Kauppila con diversas variables categóricas -1-

\begin{tabular}{|c|c|c|c|c|c|c|c|}
\hline \multirow[b]{2}{*}{ Variable } & \multirow[b]{2}{*}{ Categoría } & \multicolumn{2}{|c|}{ Kauppila \% (n) } & \multirow{2}{*}{$\mathrm{Chi}^{2}$} & \multirow{2}{*}{$\mathrm{Gl}$} & \multirow{2}{*}{$P$} & \multirow{2}{*}{$\begin{array}{l}\text { Tam. } \\
\text { Efecto } \\
\text { aprox. }\end{array}$} \\
\hline & & Inferior & Igual o superior & & & & \\
\hline \multirow[t]{2}{*}{ Sexo } & Mujer & $42.9 \%(9)$ & $13.6 \%(3)$ & 4.56 & 1 & $.033^{*}$ & .106 \\
\hline & Hombre & $57.1 \%(12)$ & $86.4 \%(19)$ & & & & \\
\hline \multirow[t]{7}{*}{ Enf. renal de base } & Neopatía túbulo-intersticial & $33.3 \%(7)$ & $13.6 \%(3)$ & & & & \\
\hline & Glomerulonefritis & $14.3 \%(3)$ & $27.3 \%(6)$ & & & & \\
\hline & Poliquistosis renal & $28.6 \%(6)$ & $13.6 \%(3)$ & & & & \\
\hline & & & & 8.27 & 5 & .142 NS & .082 \\
\hline & Nefropatía diabética & -- & $13.6 \%(3)$ & & & & \\
\hline & Nefroangioesclerosis & $4.8 \%(1)$ & $9.1 \%(2)$ & & & & \\
\hline & No filiada & $19.0 \%(4)$ & $22.7 \%(5)$ & & & & \\
\hline \multirow[t]{2}{*}{ Mod. Diálisis } & $\mathrm{HD}$ & $52.4 \%(11)$ & $81.8 \%(18)$ & 3.01 & 1 & $.083^{\text {NS }}$ & . 099 \\
\hline & DP & $47.6 \%(10)$ & $18.2 \%(4)$ & & & & \\
\hline \multirow[t]{3}{*}{ Acceso Vascular } & FAVI & $42.9 \%(9)$ & $72.7 \%(16)$ & & & & \\
\hline & Catéter peritoneal & $47.6 \%(10)$ & $18.2 \%(4)$ & 4.62 & 2 & .099 Ns & .095 \\
\hline & Catéter vascular & $9.5 \%(2)$ & $9.1 \%(1)$ & & & & \\
\hline HTA & $\mathrm{Si}$ & $81.0 \%(17)$ & $95.5 \%(21)$ & 1.01 & 1 & .314 NS & .051 \\
\hline Diabetes & $\mathrm{Si}$ & $4.8 \%(1)$ & $27.3 \%(6)$ & 2.51 & 1 & .113 Ns & .085 \\
\hline Dislipemia & $\mathrm{Si}$ & $38.1 \%(8)$ & $50.0 \%(11)$ & 0.23 & 1 & .632 Ns & .014 \\
\hline Card. Isquémica & $\mathrm{Si}$ & -- & $9.1 \%(2)$ & -- & -- & -- & -- \\
\hline Tabaquismo & $\mathrm{Si}$ & $19.0 \%(4)$ & $22.7 \%(5)$ & 0.00 & 1 & $.999 \mathrm{Ns}$ & .002 \\
\hline \multirow[t]{3}{*}{ Ecocard. Pre-Tx } & HVI leve & $77.8 \%$ (7) & $46.7 \%(7)$ & & & & \\
\hline & HVI moderada & $22.2 \%(2)$ & $46.7 \%(7)$ & 2.81 & 2 & .245 Ns & .092 \\
\hline & HVI grave & -- & $6.7 \%(1)$ & & & & \\
\hline
\end{tabular}

N.S. $=$ NO significativo $(P>05) \quad *=$ Significativo al $5 \%(P<.05)$

Para terminar con el estudio asociativo de las variables de tipo categórico (tabla 128) observamos

- Edad $(\mathrm{P}<.01)$ : Los pacientes del grupo con un índice de Kauppila $<3$ son más jóvenes que el resto (43.52 vs 55.86) siendo el tamaño del efecto elevado (.260).

- Meses en diálisis $(P<.10)$ : El grupo de pacientes con un índice de Kauppila $<3$ presenta una duración menor de su estancia en diálisis que el resto (28.95 vs 48.00). 


\section{RESULTADOS}

Tabla 128: Test de diferencia entre dos medias. Asociación de Índice de Kauppila con diversas variables de la analítica en la revisión.-2-

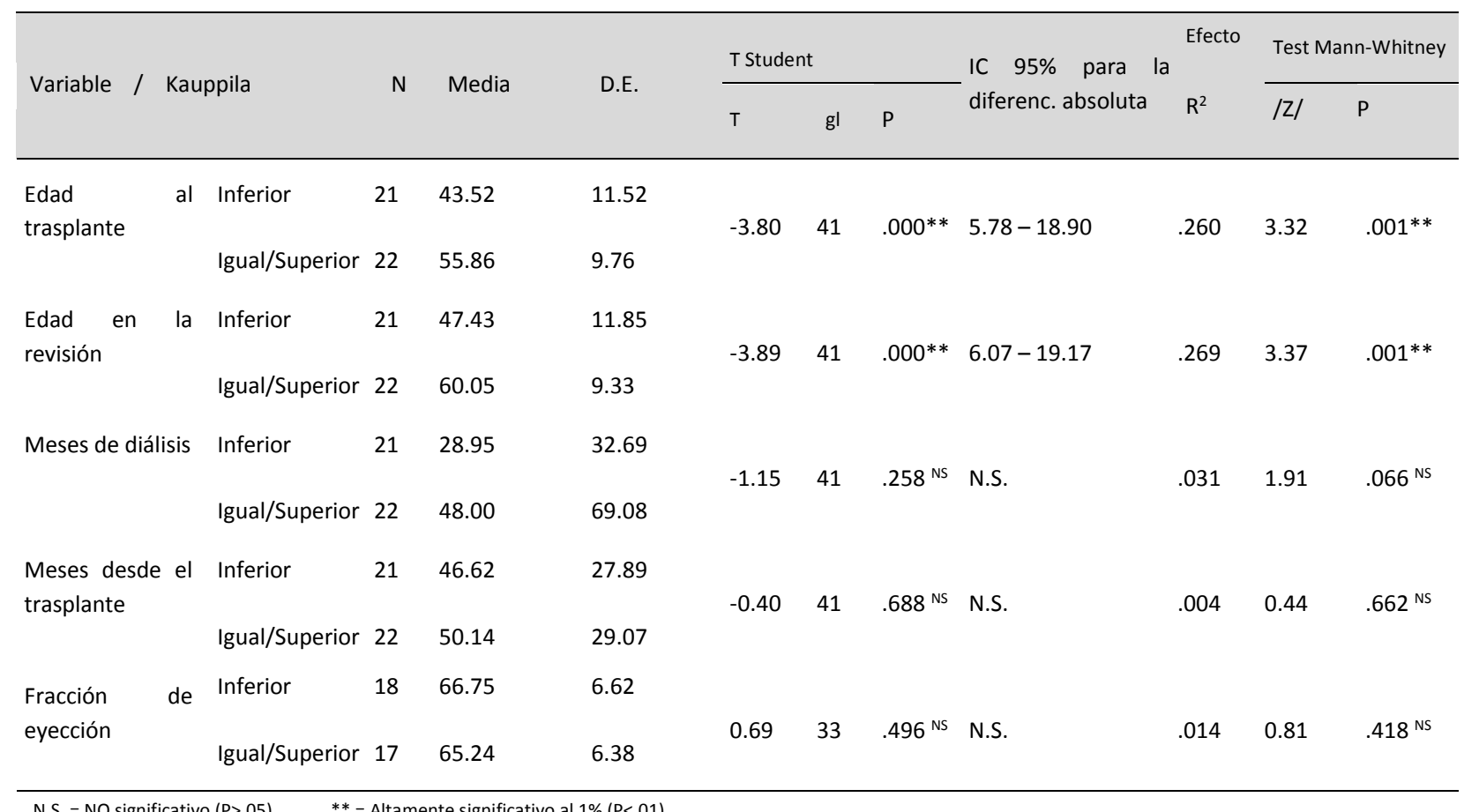

N.S. $=$ NO significativo $(P>05) \quad * *=$ Altamente significativo al $1 \%(P<.01)$ 


\section{RESULTADOS}

En el primer grupo de variables cuantitativas (tabla 129) observamos:

- Volumen de la Diuresis $(P<.01)$ : El grupo de pacientes con un índice de Kauppila $<3$ presenta un valor mayor de diuresis residual que el resto de los pacientes (1464.29 vs 594.09) siendo el tamaño del efecto moderado-alto (.198).

Tabla 129: Test de diferencia entre dos medias. Asociación de Índice de Kauppila con diversas variables antropométricas y de la analítica previa al trasplante.-1-

\begin{tabular}{|c|c|c|c|c|c|c|c|c|c|c|c|}
\hline \multirow{2}{*}{ Variable } & \multirow{2}{*}{ uppila } & \multirow{2}{*}{$\mathrm{N}$} & \multirow{2}{*}{ Media } & \multirow{2}{*}{ D.E. } & \multicolumn{3}{|c|}{ T Student } & \multirow{2}{*}{$\begin{array}{l}\text { IC } 95 \% \text { para la } \\
\text { diferenc. absoluta }\end{array}$} & \multirow{2}{*}{$\begin{array}{l}\text { Efecto } \\
\mathrm{R}^{2}\end{array}$} & \multicolumn{2}{|c|}{ Test Mann-Whitney } \\
\hline & & & & & $\mathrm{T}$ & $\mathrm{Gl}$ & $\mathrm{P}$ & & & /Z/ & $P$ \\
\hline \multirow[t]{3}{*}{ Altura } & Inferior & 21 & 167.88 & 8.53 & & & & & & & \\
\hline & & & & & -0.24 & 41 & $.813^{\mathrm{NS}}$ & N.S. & .001 & 0.34 & $.733^{N S}$ \\
\hline & Igual/Superior & 22 & 168.55 & 9.73 & & & & & & & \\
\hline \multirow[t]{3}{*}{ Peso } & Inferior & 21 & 72.03 & 11.16 & & & & & & & \\
\hline & & & & & 0.62 & 41 & $.537^{N S}$ & N.S. & .009 & 0.30 & $.304^{\mathrm{NS}}$ \\
\hline & Igual/Superior & 22 & 69.79 & 12.39 & & & & & & & \\
\hline \multirow[t]{3}{*}{ IMC } & Inferior & 21 & 25.55 & 3.18 & & & & & & & \\
\hline & & & & & 1.29 & 41 & $.205^{\mathrm{NS}}$ & N.S. & .039 & 1.19 & $.234^{\mathrm{NS}}$ \\
\hline & Igual/Superior & 22 & 24.39 & 2.70 & & & & & & & \\
\hline \multirow[t]{3}{*}{ TAS } & Inferior & 21 & 139.43 & 20.25 & & & & & & & \\
\hline & & & & & -1.72 & 41 & $.093^{\mathrm{NS}}$ & N.S. & .067 & 1.66 & $.098^{\text {NS }}$ \\
\hline & Igual/Superior & 22 & 152.55 & 28.74 & & & & & & & \\
\hline \multirow[t]{3}{*}{ TAD } & Inferior & 21 & 82.62 & 12.36 & & & & & & & \\
\hline & & & & & -0.77 & 41 & .449 NS & N.S. & .014 & 0.57 & .567 NS \\
\hline & Igual/Superior & 22 & 85.64 & 13.44 & & & & & & & \\
\hline \multirow[t]{3}{*}{ Diuresis } & Inferior & 21 & 1464.29 & 1059.62 & & & & & & & \\
\hline & & & & & 3.18 & 41 & $.003 * *$ & $316.96-1423.43$ & .198 & 2.89 & $.004^{* *}$ \\
\hline & Igual/Superior & 22 & 594.09 & 810.54 & & & & & & & \\
\hline \multirow[t]{3}{*}{ Hemoglobina } & Inferior & 21 & 12.96 & 1.77 & & & & & & & \\
\hline & & & & & 1.28 & 41 & $.208^{N S}$ & N.S. & .038 & 1.11 & $.269 \mathrm{NS}$ \\
\hline & Igual/Superior & 22 & 12.32 & 1.50 & & & & & & & \\
\hline \multirow[t]{3}{*}{ Hematocrito } & Inferior & 21 & 39.28 & 5.67 & & & & & & & \\
\hline & & & & & 1.49 & 41 & $.144^{N S}$ & N.S. & .051 & 1.28 & .202 NS \\
\hline & Igual/Superior & 22 & 36.98 & 4.41 & & & & & & & \\
\hline \multirow[t]{3}{*}{ Leucocitos } & Inferior & 21 & 6497.62 & 1651.37 & & & & & & & \\
\hline & & & & & -0.83 & 41 & .410 NS & N.S. & .017 & 0.64 & .520 NS \\
\hline & Igual/Superior & 22 & 6913.18 & 1625.22 & & & & & & & \\
\hline \multirow[t]{2}{*}{ Plaquetas } & Inferior & 21 & 185666.67 & 65018.72 & & & & & & & \\
\hline & Igual/Superior & 22 & 191545.45 & 74105.93 & -0.28 & 41 & .784 NS & N.S. & .002 & 0.19 & $.846^{\mathrm{NS}}$ \\
\hline
\end{tabular}

N.S. $=$ NO significativo $(P>05) \quad * *=$ Altamente significativo al $1 \%(P<.01)$ 


\section{RESULTADOS}

En este bloque de variables (tabla 130) se observa:

- Colesterol total $(\mathrm{P}<.01)$ : Los pacientes del grupo Kauppila $<3$ presentan una media más elevada de colesterol total previo al trasplante que los demás (191.19 vs 147.59$)$ con un tamaño del efecto moderado (.181).

Tabla 130: Test de diferencia entre dos medias. Asociación de Índice de Kauppila con diversas variables de la analítica previa al trasplante.-2-

\begin{tabular}{|c|c|c|c|c|c|c|c|c|c|c|c|}
\hline \multirow{2}{*}{\multicolumn{2}{|c|}{ Variable / Kauppila }} & \multirow{3}{*}{$\begin{array}{r}N \\
21\end{array}$} & \multirow{3}{*}{$\begin{array}{l}\text { Media } \\
143.19\end{array}$} & \multirow{3}{*}{$\begin{array}{l}\text { D.E. } \\
34.52\end{array}$} & \multirow{2}{*}{\multicolumn{3}{|c|}{ T Student }} & \multirow{2}{*}{$\begin{array}{l}\text { IC } 95 \% \text { para la } \\
\text { diferenc. absoluta }\end{array}$} & \multirow{2}{*}{$\begin{array}{l}\text { Efecto } \\
\mathrm{R}^{2}\end{array}$} & \multirow{2}{*}{\multicolumn{2}{|c|}{ Test Mann-Whitney }} \\
\hline & & & & & & & & & & & \\
\hline \multirow[t]{3}{*}{ Urea } & Inferior & & & & & & & & & & \\
\hline & & & & & -0.27 & 41 & .785 Ns & N.S. & .002 & 0.26 & $.799 \mathrm{NS}$ \\
\hline & Igual/Superior & 22 & 146.14 & 35.85 & & & & & & & \\
\hline \multirow[t]{3}{*}{ Glucosa } & Inferior & 21 & 88.57 & 10.17 & & & & & & & \\
\hline & & & & & -1.86 & 41 & $.069 \mathrm{NS}$ & N.S. & .078 & 1.56 & .120 NS \\
\hline & Igual/Superior & 22 & 101.32 & 29.70 & & & & & & & \\
\hline \multirow[t]{3}{*}{ Creatinina } & Inferior & 21 & 8.60 & 2.62 & & & & & & & \\
\hline & & & & & -0.58 & 41 & $.563 \mathrm{NS}$ & N.S. & .008 & 0.72 & $.717^{\mathrm{NS}}$ \\
\hline & Igual/Superior & 22 & 9.08 & 2.76 & & & & & & & \\
\hline \multirow[t]{3}{*}{ Triglicéridos } & Inferior & 21 & 113.81 & 38.39 & & & & & & & \\
\hline & & & & & -0.51 & 41 & $.610^{\mathrm{NS}}$ & N.S. & .006 & 0.54 & $.535^{\mathrm{NS}}$ \\
\hline & Igual/Superior & 22 & 120.32 & 44.27 & & & & & & & \\
\hline \multirow[t]{3}{*}{ Colesterol total } & Inferior & 21 & 191.19 & 49.61 & & & & & & & \\
\hline & & & & & 3.01 & 41 & $.005 * *$ & $14.31-72.89$ & 181 & 2.72 & $.006 * *$ \\
\hline & Igual/Superior & 22 & 147.59 & 45.49 & & & & & & & \\
\hline \multirow[t]{3}{*}{ Proteínas totales } & Inferior & 21 & 6.82 & 0.45 & & & & & & & \\
\hline & & & & & -0.86 & 41 & .397 Ns & N.S. & .018 & 1.02 & .306 NS \\
\hline & Igual/Superior & 22 & 6.97 & 0.64 & & & & & & & \\
\hline \multirow[t]{3}{*}{ Calcio } & Inferior & 21 & 9.14 & 1.02 & & & & & & & \\
\hline & & & & & -0.97 & 41 & .337 Ns & N.S. & .023 & 0.67 & $.503^{N S}$ \\
\hline & Igual/Superior & 22 & 9.39 & 0.69 & & & & & & & \\
\hline \multirow[t]{3}{*}{ Calcio correg. } & Inferior & 21 & 9.48 & 0.97 & & & & & & & \\
\hline & & & & & -0.68 & 41 & $.500 \mathrm{Ns}$ & N.S. & .011 & 0.00 & .999 NS \\
\hline & Igual/Superior & 22 & 9.66 & 0.79 & & & & & & & \\
\hline \multirow[t]{2}{*}{ Prod. Calc/Fósf. } & Inferior & 21 & 45.69 & 11.82 & & & & & & & \\
\hline & Igual/Superior & 22 & 47.06 & 9.22 & -0.42 & 41 & .674 NS & N.S. & .004 & 0.00 & .999 NS \\
\hline
\end{tabular}




\section{RESULTADOS}

En este grupo de variables (tabla 131) no se ha encontrado ninguna diferencia significativa ( $P>05)$ que pueda indicar la existencia de alguna asociación.

Tabla 131: Test de diferencia entre dos medias. Asociación de Índice de Kauppila con diversas variables de la analítica previa al trasplante.-3-

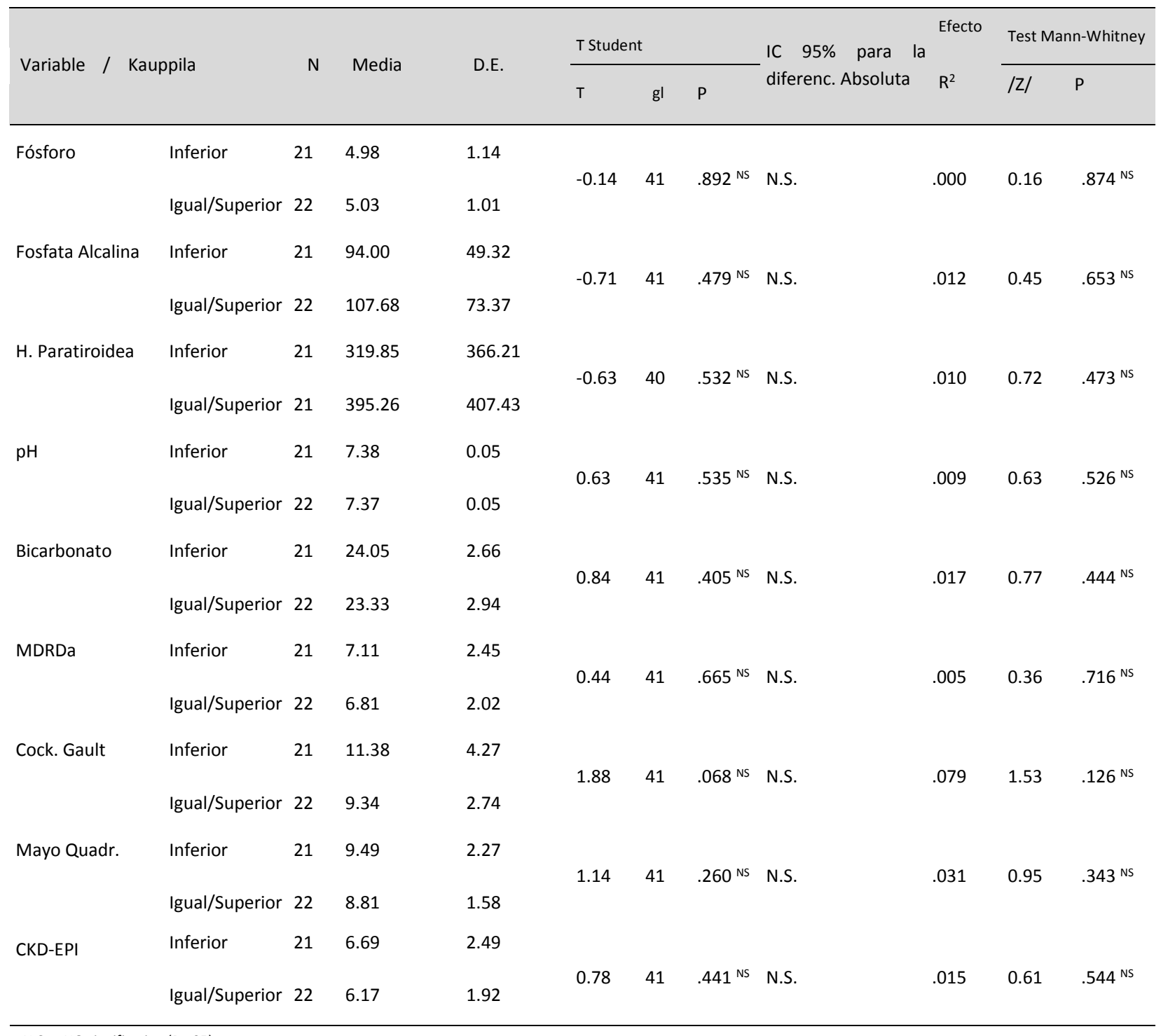

N.S. $=$ NO significativo $(P>05)$

En el siguiente bloque de variables (tabla 132) han aparecido varias significaciones:

- TAS $(\mathrm{P}<.05)$ : El grupo de pacientes con un índice de Kauppila $<3$ presenta un valor menor de TAS que el resto de casos (130.52 vs 144.64) si bien se corresponde con un tamaño del efecto bajo (.091).

- TAD ( $P<.10)$ : Se observa una casi significación en ambos test que podría estar indicando que los pacientes del grupo de Kauppila $<3$ tienen una media más baja que el resto (74.76 vs 82.05$)$. 


\section{RESULTADOS}

- Diuresis $(P<.01$ en test de Student y $P<.05$ en la alternativa de $M W)$ : Los pacientes con Kauppila < 3 tienen una media más elevada que el resto (2759.76 vs 2131.82) y equivalente a un tamaño del efecto moderado (.165).

Tabla 132: Test de diferencia entre dos medias. Asociación de Índice de Kauppila con diversas variables antropométricas y de la analítica al alta tras el trasplante.-1-

\begin{tabular}{|c|c|c|c|c|c|c|c|c|c|c|c|}
\hline \multirow{2}{*}{ Variable / } & \multirow{2}{*}{ ppila } & \multirow{2}{*}{$\mathrm{N}$} & \multirow{2}{*}{ Media } & \multirow{2}{*}{ D.E. } & \multicolumn{3}{|c|}{ T Student } & \multirow{2}{*}{$\begin{array}{l}\text { IC } 95 \% \text { para la } \\
\text { diferenc. absoluta }\end{array}$} & \multirow{2}{*}{$\begin{array}{l}\text { Efecto } \\
\mathrm{R}^{2}\end{array}$} & \multicolumn{2}{|c|}{ Test Mann-Whitney } \\
\hline & & & & & $\mathrm{T}$ & gl & $P$ & & & |Z/ & $\mathrm{P}$ \\
\hline \multirow[t]{3}{*}{ Peso } & Inferior & 21 & 70.02 & 11.32 & & & & & & & \\
\hline & & & & & 0.40 & 41 & .695 NS & N.S. & .004 & 0.07 & .942 NS \\
\hline & Igual/Superior & 22 & 68.60 & 12.08 & & & & & & & \\
\hline \multirow[t]{3}{*}{ IMC } & Inferior & 21 & 24.85 & 3.41 & & & & & & & \\
\hline & & & & & 0.81 & 41 & .423 NS & N.S. & .016 & 0.54 & .593 NS \\
\hline & Igual/Superior & 22 & 24.04 & 3.14 & & & & & & & \\
\hline \multirow[t]{3}{*}{ TAS } & Inferior & 21 & 130.52 & 22.74 & & & & & & & \\
\hline & & & & & -2.03 & 41 & $.049 *$ & $0.08-28.14$ & .091 & 2.16 & $.030 *$ \\
\hline & Igual/Superior & 22 & 144.64 & 22.80 & & & & & & & \\
\hline \multirow[t]{3}{*}{ TAD } & Inferior & 21 & 74.76 & 13.30 & & & & & & & \\
\hline & & & & & -1.79 & 41 & .081 NS & N.S. & .072 & 1.87 & .061 NS \\
\hline & Igual/Superior & 22 & 82.05 & 13.43 & & & & & & & \\
\hline \multirow[t]{3}{*}{ Diuresis } & Inferior & 21 & 2759.76 & 947.92 & & & & & & & \\
\hline & & & & & 2.85 & 41 & $.007^{* *}$ & $183.16-1072.73$ & .165 & 2.15 & $.031 *$ \\
\hline & Igual/Superior & 22 & 2131.82 & 402.17 & & & & & & & \\
\hline \multirow[t]{3}{*}{ Hemoglobina } & Inferior & 21 & 10.63 & 1.12 & & & & & & & \\
\hline & & & & & -0.43 & 41 & .669 NS & N.S. & .005 & 0.26 & .798 NS \\
\hline & Igual/Superior & 22 & 10.80 & 1.52 & & & & & & & \\
\hline \multirow[t]{3}{*}{ Hematocrito } & Inferior & 21 & 32.32 & 3.13 & & & & & & & \\
\hline & & & & & -0.63 & 41 & .532 NS & N.S. & .010 & 0.29 & $.771^{\mathrm{NS}}$ \\
\hline & Igual/Superior & 22 & 33.09 & 4.71 & & & & & & & \\
\hline \multirow[t]{3}{*}{ Leucocitos } & Inferior & 21 & 9788.10 & 4432.10 & & & & & & & \\
\hline & & & & & 0.54 & 41 & .595 NS & N.S. & .007 & 0.49 & $.627^{\mathrm{NS}}$ \\
\hline & Igual/Superior & 22 & 9174.09 & 2976.04 & & & & & & & \\
\hline \multirow[t]{3}{*}{ Plaquetas } & Inferior & 21 & 265282.71 & 127044.93 & & & & & & & \\
\hline & & & & & 0.25 & 41 & .802 NS & N.S. & .002 & 0.17 & .865 NS \\
\hline & Igual/Superior & 22 & 256272.73 & 106338.27 & & & & & & & \\
\hline \multirow[t]{2}{*}{ VSG } & Inferior & 21 & 36.48 & 27.78 & & & & & & & \\
\hline & Igual/Superior & 22 & 32.82 & 28.96 & 0.42 & 41 & $.675^{\text {NS }}$ & N.S. & .004 & 0.77 & $.444^{N S}$ \\
\hline
\end{tabular}




\section{RESULTADOS}

En el siguiente grupo de variables contrastadas (tabla 133) no se han encontrado diferencias significativas $(P>.05)$.

Tabla 133: Test de diferencia entre dos medias. Asociación de Índice de Kauppila con diversas variables de la analítica al alta tras el trasplante.-2-

\begin{tabular}{|c|c|c|c|c|c|c|c|c|c|c|c|}
\hline \multirow{2}{*}{ Variable / Ka } & \multirow{2}{*}{ uppila } & \multirow{2}{*}{$\mathrm{N}$} & \multirow{2}{*}{ Media } & \multirow{2}{*}{ D.E. } & \multicolumn{3}{|c|}{ T Student } & \multirow{2}{*}{$\begin{array}{l}\text { IC 95\% para la } \\
\text { diferenc. absoluta }\end{array}$} & \multirow{2}{*}{$\begin{array}{l}\text { Efecto } \\
\mathrm{R}^{2}\end{array}$} & \multicolumn{2}{|c|}{ Test Mann-Whitney } \\
\hline & & & & & $\mathrm{T}$ & $\mathrm{gl}$ & $P$ & & & /Z/ & $P$ \\
\hline \multirow[t]{3}{*}{ Urea } & Inferior & 21 & 95.81 & 46.98 & & & & & & & \\
\hline & & & & & 1.17 & 41 & $.251^{\mathrm{NS}}$ & N.S. & .032 & 0.61 & $.543^{\mathrm{NS}}$ \\
\hline & Igual/Superior & 22 & 82.18 & 27.67 & & & & & & & \\
\hline \multirow[t]{3}{*}{ Glucosa } & Inferior & 21 & 96.19 & 15.40 & & & & & & & \\
\hline & & & & & -1.46 & 41 & $.252^{\mathrm{NS}}$ & N.S. & .049 & 1.02 & $.307^{N S}$ \\
\hline & Igual/Superior & 22 & 110.05 & 40.83 & & & & & & & \\
\hline \multirow[t]{3}{*}{ Creatinina } & Inferior & 21 & 2.55 & 1.74 & & & & & & & \\
\hline & & & & & 1.56 & 41 & .126 NS & N.S. & .056 & 1.14 & $.252 \mathrm{NS}$ \\
\hline & Igual/Superior & 22 & 1.90 & 0.85 & & & & & & & \\
\hline \multirow[t]{3}{*}{ Triglicéridos } & Inferior & 21 & 136.90 & 62.41 & & & & & & & \\
\hline & & & & & -0.86 & 41 & .397 NS & N.S. & .018 & 0.88 & $.382^{\mathrm{NS}}$ \\
\hline & Igual/Superior & 22 & 154.91 & 74.68 & & & & & & & \\
\hline \multirow[t]{3}{*}{ Colesterol total } & Inferior & 21 & 195.10 & 54.79 & & & & & & & \\
\hline & & & & & 1.34 & 41 & $.186^{\mathrm{NS}}$ & N.S. & .042 & 1.15 & $.248^{N S}$ \\
\hline & Igual/Superior & 22 & 174.77 & 44.01 & & & & & & & \\
\hline \multirow[t]{3}{*}{ Proteínas totales } & Inferior & 21 & 6.17 & 0.49 & & & & & & & \\
\hline & & & & & -0.27 & 41 & .791 NS & N.S. & .002 & 0.34 & $.733^{N S}$ \\
\hline & Igual/Superior & 22 & 6.22 & 0.64 & & & & & & & \\
\hline \multirow[t]{3}{*}{ Calcio } & Inferior & 21 & 9.68 & 0.86 & & & & & & & \\
\hline & & & & & 0.69 & 41 & .492 NS & N.S. & .012 & 0.63 & .527 NS \\
\hline & Igual/Superior & 22 & 6.50 & 0.89 & & & & & & & \\
\hline \multirow[t]{3}{*}{ Calcio correg. } & Inferior & 21 & 10.35 & 0.82 & & & & & & & \\
\hline & & & & & 0.85 & 41 & .401 NS & N.S. & .017 & 0.98 & $.325^{N S}$ \\
\hline & Igual/Superior & 22 & 10.14 & 0.79 & & & & & & & \\
\hline \multirow[t]{3}{*}{ Prod. Calc/Fósf. } & Inferior & 21 & 33.43 & 11.77 & & & & & & & \\
\hline & & & & & 1.94 & 41 & $.059^{N S}$ & N.S. & .084 & 1.96 & $.051^{\mathrm{NS}}$ \\
\hline & Igual/Superior & 22 & 27.63 & 7.38 & & & & & & & \\
\hline \multirow[t]{2}{*}{ Fósforo } & Inferior & 21 & 3.46 & 1.25 & & & & & & & \\
\hline & Igual/Superior & 22 & 2.91 & 0.73 & 1.79 & 41 & .082 NS & N.S. & .072 & 1.75 & $.080^{N S}$ \\
\hline
\end{tabular}




\section{RESULTADOS}

En este bloque (tabla 134) no se han encontrado diferencia significativas ( $P>.05)$.

Tabla 134: Test de diferencia entre dos medias. Asociación de Índice de Kauppila con diversas variables de la analítica al alta tras el trasplante.-3-

\begin{tabular}{|c|c|c|c|c|c|c|c|c|c|c|c|}
\hline & & & & & T Stude & & & IC $95 \%$ para la & Efecto & Test N & nn-Whitney \\
\hline Variable / Ka & ppila & $\mathrm{N}$ & Media & D.E. & & & & 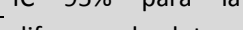 & & & \\
\hline Magnesio & Inferior & 21 & 1.63 & 0.27 & & & & & & & \\
\hline & & & & & -0.90 & 41 & .372 NS & N.S. & .020 & 0.43 & .668 NS \\
\hline & Igual/Superior & 22 & 1.72 & 0.37 & & & & & & & \\
\hline Fosfata Alcalina & Inferior & 21 & 85.10 & 38.21 & & & & & & & \\
\hline & & & & & -0.22 & 41 & $.830^{\mathrm{NS}}$ & N.S. & .001 & 0.10 & .923 NS \\
\hline & Igual/Superior & 22 & 88.59 & 64.19 & & & & & & & \\
\hline Urea en orina & Inferior & 21 & 1192.50 & 520.73 & & & & & & & \\
\hline & & & & & -0.26 & 41 & .797 NS & N.S. & .002 & 0.34 & .734 NS \\
\hline & Igual/Superior & 22 & 1225.86 & 297.36 & & & & & & & \\
\hline Creat. en orina & Inferior & 21 & 58.43 & 28.17 & & & & & & & \\
\hline & & & & & 0.21 & 41 & $.837^{\mathrm{NS}}$ & N.S. & .001 & 0.11 & .913 Ns \\
\hline & Igual/Superior & 22 & 56.83 & 22.08 & & & & & & & \\
\hline $\mathrm{pH}$ & Inferior & 21 & 7.34 & 0.05 & & & & & & & \\
\hline & & & & & -0.99 & 41 & $.326^{\mathrm{NS}}$ & N.S. & .024 & 0.89 & .372 NS \\
\hline & Igual/Superior & 22 & 7.35 & 0.04 & & & & & & & \\
\hline Bicarbonato & Inferior & 21 & 20.42 & 3.03 & & & & & & & \\
\hline & & & & & -1.34 & 41 & $.187^{\mathrm{NS}}$ & N.S. & .042 & 1.37 & $.170^{\mathrm{NS}}$ \\
\hline & Igual/Superior & 22 & 21.70 & 3.20 & & & & & & & \\
\hline MDRDa & Inferior & 21 & 35.84 & 16.29 & & & & & & & \\
\hline & & & & & -1.74 & 41 & .089 NS & N.S. & .069 & 1.75 & $.080^{\mathrm{NS}}$ \\
\hline & Igual/Superior & 22 & 44.66 & 16.92 & & & & & & & \\
\hline Cock. Gault & Inferior & 21 & 43.74 & 17.96 & & & & & & & \\
\hline & & & & & -0.35 & 41 & .730 NS & N.S. & .003 & 0.19 & .846 NS \\
\hline & Igual/Superior & 22 & 45.38 & 12.54 & & & & & & & \\
\hline Mayo Quadr. & Inferior & 21 & 42.37 & 22.01 & & & & & & & \\
\hline & & & & & -1.31 & 41 & $.197^{\text {NS }}$ & N.S. & .040 & 1.22 & .224 NS \\
\hline & Igual/Superior & 22 & 51.72 & 24.61 & & & & & & & \\
\hline CKD-EPI & Inferior & 21 & 36.50 & 17.45 & & & & & & & \\
\hline & Igual/Superior & 22 & 44.38 & 17.52 & -1.48 & 41 & $.147^{N S}$ & N.S. & .051 & 1.45 & $.145^{\mathrm{NS}}$ \\
\hline
\end{tabular}

N.S. $=$ NO significativo $(P>.05) \quad *=$ Significativo al $5 \%(P<.05)$ 


\section{RESULTADOS}

En el siguiente bloque (tabla 135) tampoco se ha encontrado ninguna significación $(\mathrm{P}>$.05).

Tabla 135: Test de diferencia entre dos medias. Asociación de Índice de Kauppila con diversas variables antropométricas y de la analítica en la revisión.-1-

\begin{tabular}{|c|c|c|c|c|c|c|c|c|c|c|c|}
\hline \multirow{2}{*}{ Variable / } & \multirow{2}{*}{ Kauppila } & \multirow{2}{*}{$\mathrm{N}$} & \multirow{2}{*}{ Media } & \multirow{2}{*}{ D.E. } & \multicolumn{3}{|c|}{ T Student } & \multirow{2}{*}{$\begin{array}{l}\text { IC } 95 \% \text { para la } \\
\text { diferenc. absoluta }\end{array}$} & \multirow{2}{*}{$\begin{array}{l}\text { Efecto } \\
\mathrm{R}^{2}\end{array}$} & \multicolumn{2}{|c|}{ Test Mann-Whitney } \\
\hline & & & & & $\mathrm{T}$ & gl & $P$ & & & /Z/ & $P$ \\
\hline \multirow[t]{3}{*}{ Peso } & Inferior & 21 & 74.71 & 14.05 & & & & & & & \\
\hline & & & & & 0.04 & 41 & $.972^{\text {NS }}$ & N.S. & .000 & 0.41 & $.680 \mathrm{NS}$ \\
\hline & Igual/Superior & 22 & 74.56 & 12.69 & & & & & & & \\
\hline \multirow[t]{3}{*}{ IMC } & Inferior & 21 & 26.42 & 3.58 & & & & & & & \\
\hline & & & & & 0.23 & 41 & $.819^{\text {NS }}$ & N.S. & .001 & 0.58 & $.560 \mathrm{NS}$ \\
\hline & Igual/Superior & 22 & 26.17 & 3.51 & & & & & & & \\
\hline \multirow[t]{3}{*}{ TAS } & Inferior & 21 & 144.33 & 15.58 & & & & & & & \\
\hline & & & & & -0.01 & 41 & .989 NS & N.S. & .000 & 0.32 & .752 NS \\
\hline & Igual/Superior & 22 & 114.41 & 20.31 & & & & & & & \\
\hline \multirow[t]{3}{*}{ TAD } & Inferior & 21 & 85.86 & 9.14 & & & & & & & \\
\hline & & & & & 0.80 & 41 & $.428^{\mathrm{NS}}$ & N.S. & .015 & 0.90 & $.368^{\mathrm{NS}}$ \\
\hline & Igual/Superior & 22 & 83.68 & 8.68 & & & & & & & \\
\hline \multirow[t]{3}{*}{ Diuresis } & Inferior & 21 & 2605.71 & 850.96 & & & & & & & \\
\hline & & & & & 0.09 & 41 & $.931^{\text {NS }}$ & N.S. & .000 & 0.08 & .932 NS \\
\hline & Igual/Superior & 22 & 2584.09 & 769.88 & & & & & & & \\
\hline \multirow[t]{3}{*}{ Hemoglobina } & Inferior & 21 & 13.40 & 2.38 & & & & & & & \\
\hline & & & & & 0.15 & 41 & $.885^{\text {NS }}$ & N.S. & .001 & 0.04 & .971 NS \\
\hline & Igual/Superior & 22 & 13.31 & 1.41 & & & & & & & \\
\hline \multirow[t]{3}{*}{ Hematocrito } & Inferior & 21 & 40.24 & 6.38 & & & & & & & \\
\hline & & & & & 0.04 & 41 & .972 NS & N.S. & .000 & 0.06 & .952 NS \\
\hline & Igual/Superior & 22 & 40.19 & 3.91 & & & & & & & \\
\hline \multirow[t]{3}{*}{ Leucocitos } & Inferior & 21 & 7094.76 & 1982.00 & & & & & & & \\
\hline & & & & & 0.69 & 41 & .494 NS & N.S. & .011 & 1.12 & $.264^{\mathrm{NS}}$ \\
\hline & Igual/Superior & 22 & 6643.18 & 2292.54 & & & & & & & \\
\hline \multirow[t]{3}{*}{ Plaquetas } & Inferior & 21 & 203380.95 & 63682.40 & & & & & & & \\
\hline & & & & & 1.40 & 41 & $.168^{\mathrm{NS}}$ & N.S. & .046 & 1.59 & $.111^{\mathrm{NS}}$ \\
\hline & Igual/Superior & 22 & 178590.91 & 51839.18 & & & & & & & \\
\hline \multirow[t]{2}{*}{ VSG } & Inferior & 21 & 16.71 & 15.45 & & & & & & & \\
\hline & Igual/Superior & 22 & 16.29 & 14.02 & 0.10 & 41 & $.925^{N S}$ & N.S. & .000 & 0.12 & .903 NS \\
\hline
\end{tabular}

En este grupo (tabla 136) observamos:

- $\quad$ Urea $(P<.10)$ : Mientras que el test de Student no alcanza significación $(P>.05)$ en ela alternativa de $\mathrm{MW}$ se puede hablar de una casi significación $(\mathrm{P}<.100)$ que podría indicar que los casos con un índice de Kauppila $<3$ tienen un valor menor de urea plasmática que el resto (61.29 vs 75.41$)$. 


\section{RESULTADOS}

- Glucosa $(\mathrm{P}<.05)$ : Los pacientes del grupo con índice de Kauppila $<3$ tienen un valor inferior de glucosa plasmática que el resto (93.67 vs 112.55), aunque con efecto bajo (.09).

- Fósforo $(\mathrm{P}<.05)$ : Los casos con índice de Kauppila $<3$ tienen una media más elevada que el resto (3.42.10 vs 2.99), con efecto moderado bajo (.105).

Tabla 136: Test de diferencia entre dos medias. Asociación de Índice de Kauppila con diversas variables de la analítica en la revisión.-2-

\begin{tabular}{|c|c|c|c|c|c|c|c|c|c|c|c|}
\hline \multirow{2}{*}{\multicolumn{2}{|c|}{ Variable / Kauppila }} & \multirow{2}{*}{$\mathrm{N}$} & \multirow{2}{*}{ Media } & \multirow{2}{*}{ D.E. } & \multicolumn{3}{|c|}{ T Student } & \multirow{2}{*}{$\begin{array}{l}\text { IC } 95 \% \text { para la } \\
\text { diferenc. absoluta }\end{array}$} & \multirow{2}{*}{$\begin{array}{l}\text { Efecto } \\
\mathrm{R}^{2}\end{array}$} & \multicolumn{2}{|c|}{ Test Mann-Whitney } \\
\hline & & & & & $T$ & gl & $P$ & & & /Z/ & $P$ \\
\hline \multirow[t]{3}{*}{ Urea } & Inferior & 21 & 61.29 & 28.08 & & & & & & & \\
\hline & & & & & -1.60 & 41 & .117 NS & N.S. & .059 & 1.91 & .056 NS \\
\hline & Igual/Superior & 22 & 75.41 & 29.73 & & & & & & & \\
\hline \multirow[t]{3}{*}{ Glucosa } & Inferior & 21 & 93.67 & 8.92 & & & & & & & \\
\hline & & & & & -2.01 & 41 & .051 NS & N.S. & .090 & 2.07 & $.039 *$ \\
\hline & Igual/Superior & 22 & 112.55 & 42.04 & & & & & & & \\
\hline \multirow[t]{3}{*}{ Creatinina } & Inferior & 21 & 1.50 & 0.48 & & & & & & & \\
\hline & & & & & -0.92 & 41 & .364 NS & N.S. & .020 & 0.71 & .479 NS \\
\hline & Igual/Superior & 22 & 1.65 & 0.56 & & & & & & & \\
\hline \multirow[t]{3}{*}{ Ácido úrico } & Inferior & 21 & 6.67 & 1.41 & & & & & & & \\
\hline & & & & & -1.13 & 41 & .265 NS & N.S. & .030 & 1.39 & $.166^{\mathrm{NS}}$ \\
\hline & Igual/Superior & 22 & 10.79 & 16.65 & & & & & & & \\
\hline \multirow[t]{3}{*}{ Triglicéridos } & Inferior & 21 & 114.38 & 57.28 & & & & & & & \\
\hline & & & & & -0.78 & 41 & .439 NS & N.S. & .015 & 0.73 & .466 NS \\
\hline & Igual/Superior & 22 & 129.68 & 70.03 & & & & & & & \\
\hline \multirow[t]{3}{*}{ Colesterol total } & Inferior & 21 & 193.90 & 36.73 & & & & & & & \\
\hline & & & & & 1.62 & 41 & $.113^{\mathrm{NS}}$ & N.S. & .060 & 1.58 & $.114^{\mathrm{NS}}$ \\
\hline & Igual/Superior & 22 & 174.64 & 40.95 & & & & & & & \\
\hline \multirow[t]{3}{*}{ Proteínas totales } & Inferior & 21 & 6.81 & 0.48 & & & & & & & \\
\hline & & & & & 0.03 & 41 & .973 NS & N.S. & .000 & 0.10 & .922 Ns \\
\hline & Igual/Superior & 22 & 6.81 & 0.51 & & & & & & & \\
\hline \multirow[t]{3}{*}{ Calcio } & Inferior & 21 & 9.52 & 0.63 & & & & & & & \\
\hline & & & & & -0.87 & 41 & .389 NS & N.S. & .018 & 0.44 & $.660^{\mathrm{NS}}$ \\
\hline & Igual/Superior & 22 & 9.68 & 0.52 & & & & & & & \\
\hline \multirow[t]{3}{*}{ Calcio correg. } & Inferior & 21 & 9.87 & 0.50 & & & & & & & \\
\hline & & & & & -0.98 & 41 & $.332 \mathrm{Ns}$ & N.S. & .023 & 0.74 & $.458^{\mathrm{NS}}$ \\
\hline & Igual/Superior & 22 & 10.02 & 0.54 & & & & & & & \\
\hline \multirow[t]{3}{*}{ Prod. Calc/Fósf. } & Inferior & 21 & 32.44 & 32.44 & & & & & & & \\
\hline & & & & & 2.00 & 41 & .052 NS & N.S. & .089 & 1.94 & .052 NS \\
\hline & Igual/Superior & 22 & 28.88 & 28.88 & & & & & & & \\
\hline \multirow[t]{2}{*}{ Fósforo } & Inferior & 21 & 3.42 & 3.42 & & & & & & & \\
\hline & Igual/Superior & 22 & 2.99 & 2.99 & 2.20 & 41 & $.034 *$ & $0.03-0.82$ & .105 & 2.12 & $.034 *$ \\
\hline
\end{tabular}

N.S. $=$ NO significativo $(P>.05) \quad *=$ Significativo al $5 \%(P<.05)$ 


\section{RESULTADOS}

En este bloque (tabla 137) se observa:

- Hemoglobina glicosilada $(P<.05)$ : Los casos con un índice de Kauppila $<3$ presentan una hemoglobina glicosilada inferior al resto de pacientes (5.65 vs 6.24) con tamaño del efecto moderado bajo.

Tabla 137: Test de diferencia entre dos medias. Asociación de Índice de Kauppila con diversas variables de la analítica en la revisión.-3-

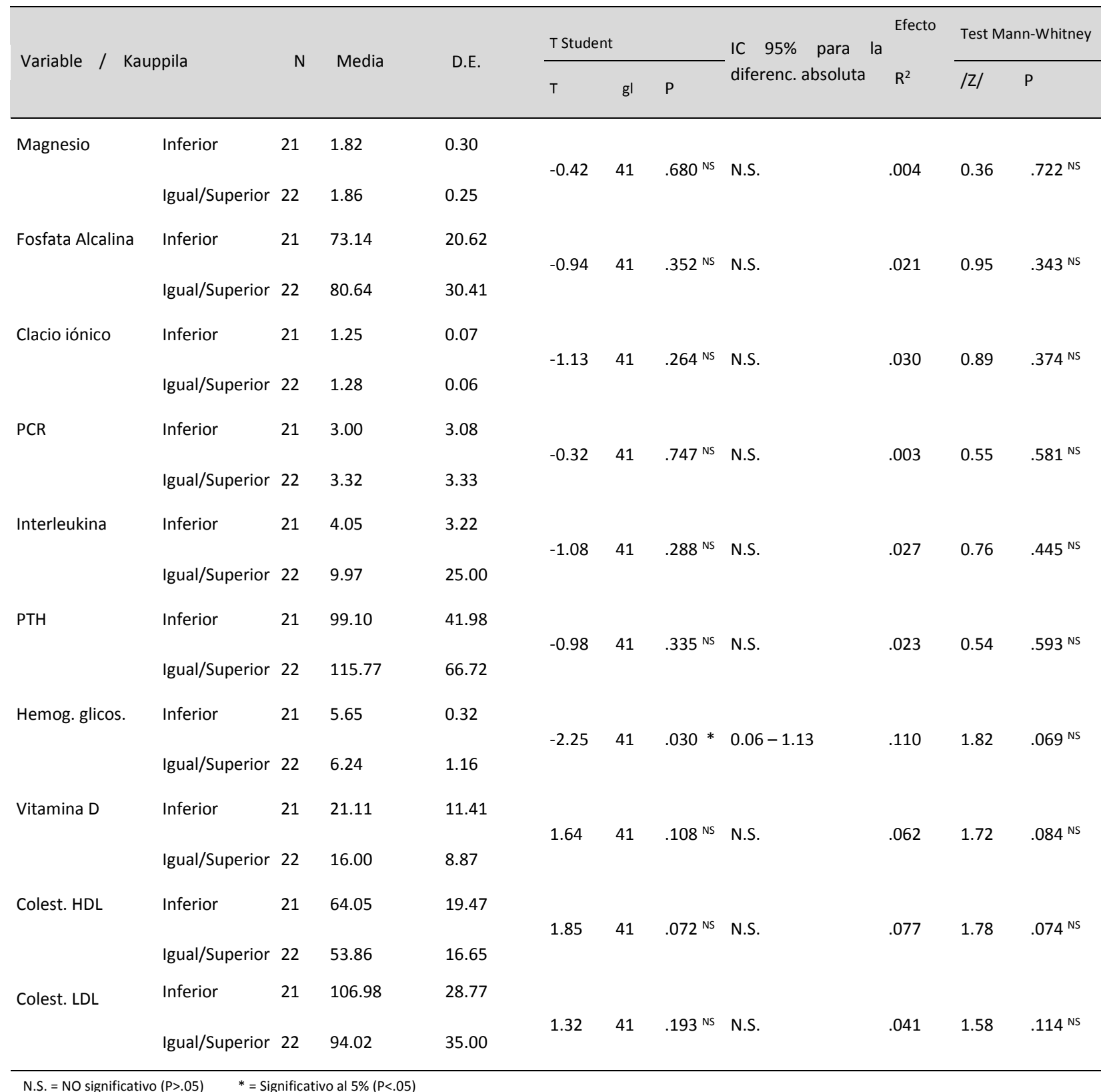




\section{RESULTADOS}

En este grupo (tabla 138) no ha aparecido ninguna diferencia estadísticamente significativa $(P>.05)$.

Tabla 138: Test de diferencia entre dos medias. Asociación de Índice de Kauppila con diversas variables de la analítica en la revisión.-4-

\begin{tabular}{|c|c|c|c|c|c|c|c|c|c|c|c|}
\hline \multirow{2}{*}{ Variable / } & \multirow{2}{*}{ Kauppila } & \multirow{2}{*}{$\mathrm{N}$} & \multirow{2}{*}{ Media } & \multirow{2}{*}{ D.E. } & \multicolumn{3}{|c|}{ T Student } & \multirow{2}{*}{$\begin{array}{l}\text { IC } 95 \% \text { para la } \\
\text { diferenc. absoluta }\end{array}$} & \multirow{2}{*}{$\begin{array}{l}\text { Efecto } \\
\mathrm{R}^{2}\end{array}$} & \multicolumn{2}{|c|}{ Test Mann-Whitney } \\
\hline & & & & & $\mathrm{T}$ & gl & $P$ & & & /Z/ & $P$ \\
\hline \multirow[t]{3}{*}{$\mathrm{pH}$} & Inferior & 21 & 7.34 & 0.03 & & & & & & & \\
\hline & & & & & 1.16 & 41 & $.253^{\mathrm{NS}}$ & N.S. & .032 & 1.54 & $.124^{\mathrm{NS}}$ \\
\hline & Igual/Superior & 22 & 7.33 & 0.04 & & & & & & & \\
\hline \multirow[t]{3}{*}{ Bicarbonato } & Inferior & 21 & 22.39 & 2.44 & & & & & & & \\
\hline & & & & & -0.03 & 41 & .977 NS & N.S. & .000 & 0.22 & $.827^{\text {NS }}$ \\
\hline & Igual/Superior & 22 & 22.41 & 2.77 & & & & & & & \\
\hline \multirow[t]{3}{*}{ Microalbumin. } & Inferior & 21 & 50.11 & 106.93 & & & & & & & \\
\hline & & & & & -0.96 & 41 & .344 NS & N.S. & .022 & 1.67 & .096 NS \\
\hline & Igual/Superior & 22 & 91.71 & 169.62 & & & & & & & \\
\hline \multirow[t]{3}{*}{ MDRDa } & Inferior & 21 & 53.67 & 20.64 & & & & & & & \\
\hline & & & & & 0.84 & 41 & $.405^{N S}$ & N.S. & .017 & 0.58 & $.560 \mathrm{NS}$ \\
\hline & Igual/Superior & 22 & 49.01 & 15.39 & & & & & & & \\
\hline \multirow[t]{3}{*}{ Cock. Gault } & Inferior & 21 & 67.31 & 29.45 & & & & & & & \\
\hline & & & & & 1.99 & 41 & $.053^{\mathrm{NS}}$ & N.S. & .088 & 1.72 & $.085^{N S}$ \\
\hline & Igual/Superior & 22 & 52.96 & 16.23 & & & & & & & \\
\hline \multirow[t]{3}{*}{ Mayo Quadr. } & Inferior & 21 & 66.48 & 27.58 & & & & & & & \\
\hline & & & & & 1.16 & 41 & $.253^{\mathrm{NS}}$ & N.S. & .032 & 1.07 & $.285^{N S}$ \\
\hline & Igual/Superior & 22 & 57.44 & 23.45 & & & & & & & \\
\hline \multirow[t]{3}{*}{ CKD-EPI } & Inferior & 21 & 55.30 & 22.82 & & & & & & & \\
\hline & & & & & 1.17 & 41 & .248 NS & N.S. & .032 & 0.91 & .362 NS \\
\hline & Igual/Superior & 22 & 48.27 & 16.05 & & & & & & & \\
\hline \multirow[t]{2}{*}{ FGF-23 } & Inferior & 21 & 7.99 & 17.50 & & & & & & & \\
\hline & Igual/Superior & 22 & 2.23 & 5.66 & 1.46 & 41 & $.151^{\mathrm{NS}}$ & N.S. & .050 & 1.29 & $.196^{\text {NS }}$ \\
\hline
\end{tabular}

N.S. = NO significativo $(P>.05)$ 


\section{RESULTADOS}

Las siguientes gráficas muestran el valor del índice de Kauppila al estratificar a los pacientes según diferentes variables y por grupos de edad:

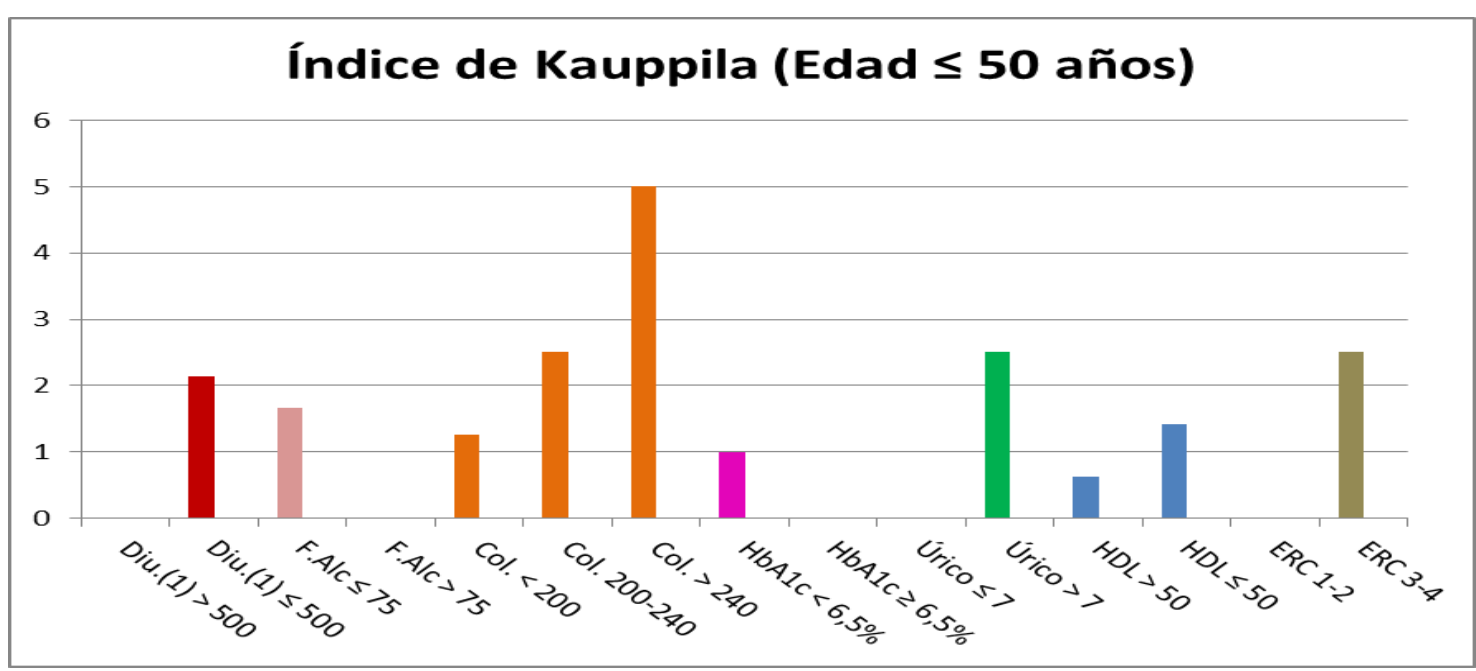

Figura 37: Diferencias en el índice de Kauppila según diversas variables en pacientes de edad $\leq 50$ años.

No existen pacientes en este rango de edad con $\mathrm{HbA1c}$ igual o superior a 6,5\%.

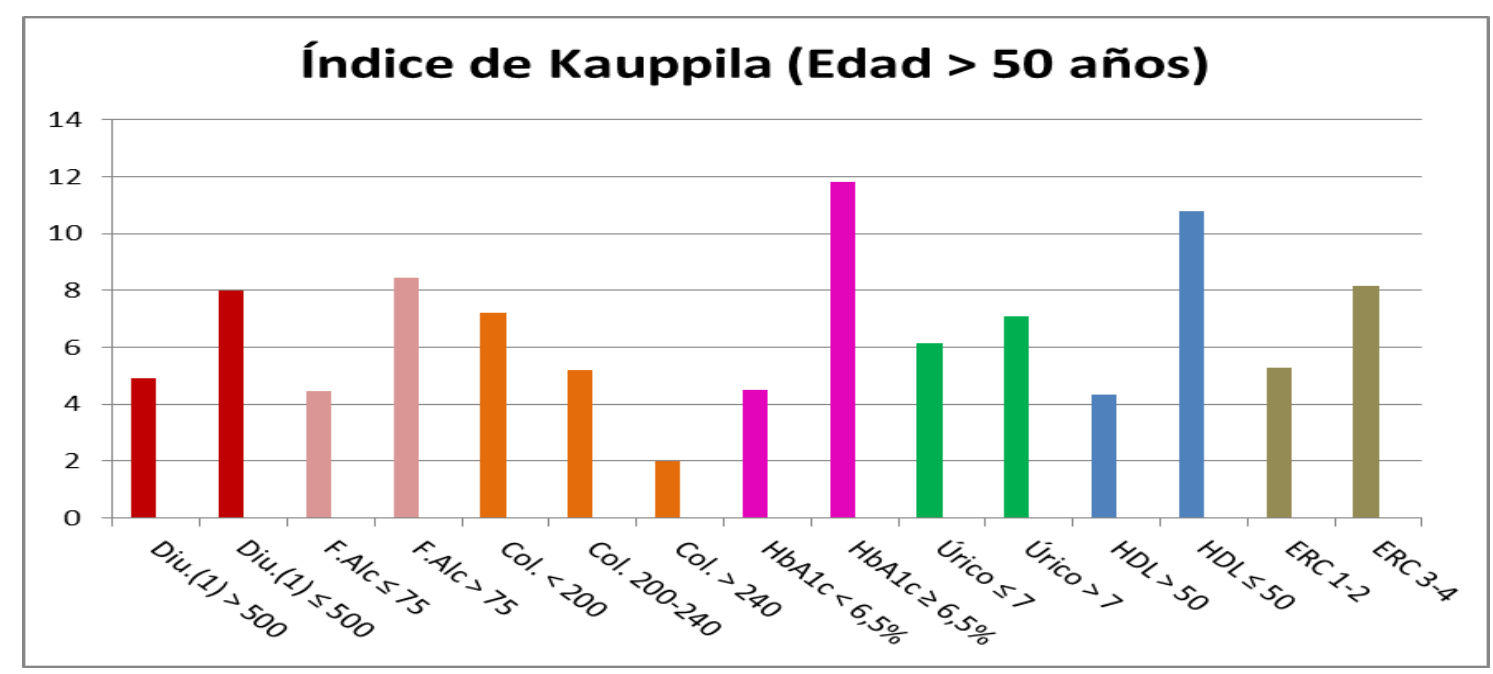

Figura 38: Diferencias en el índice de Kauppila según diversas variables en pacientes de edad $>50$ años. 


\section{RESULTADOS}

Sólo hay dos pacientes en el grupo de edad > 50 años con colesterol por encima de 240 $\mathrm{mg} / \mathrm{dl}$.

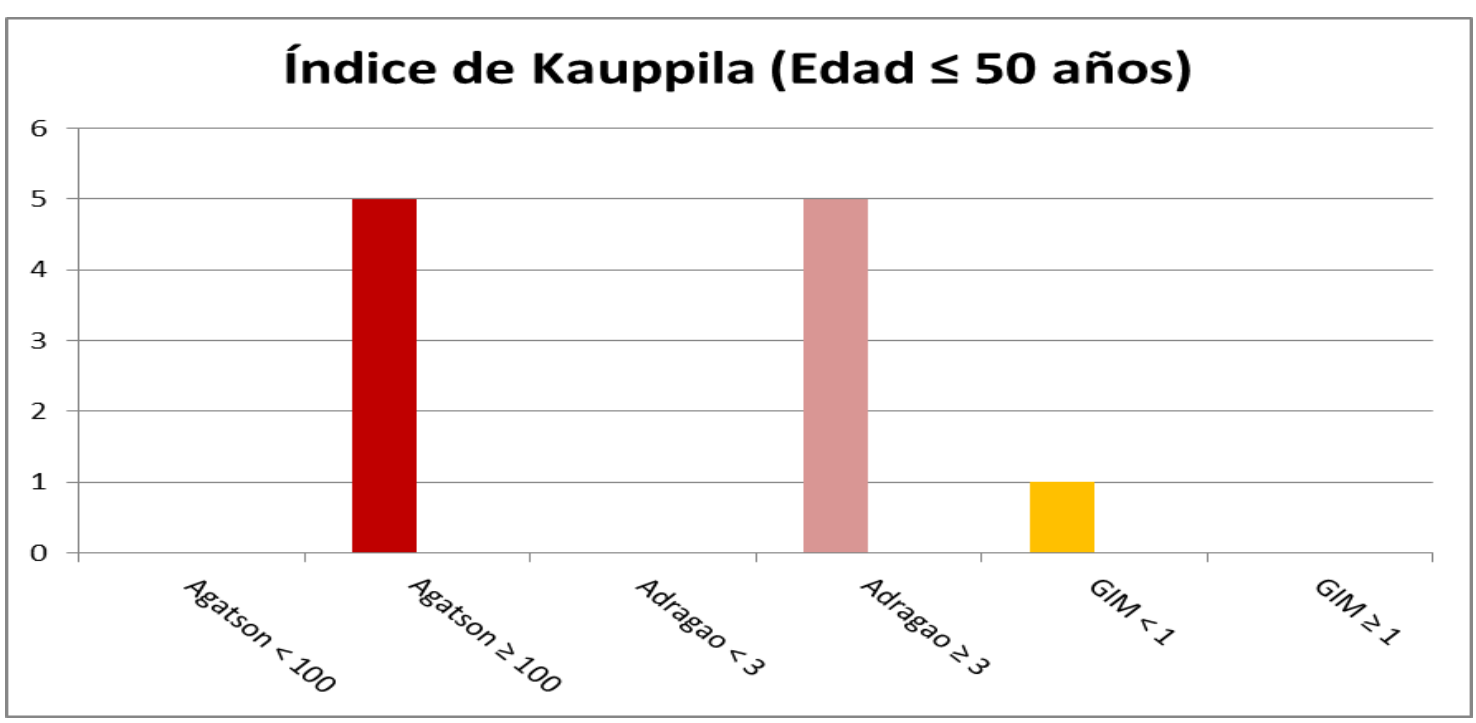

Figura 39: Diferencias en el índice de Kauppila según el resto de pruebas para valorar la calcificación vascular en pacientes de edad $\leq 50$ años.

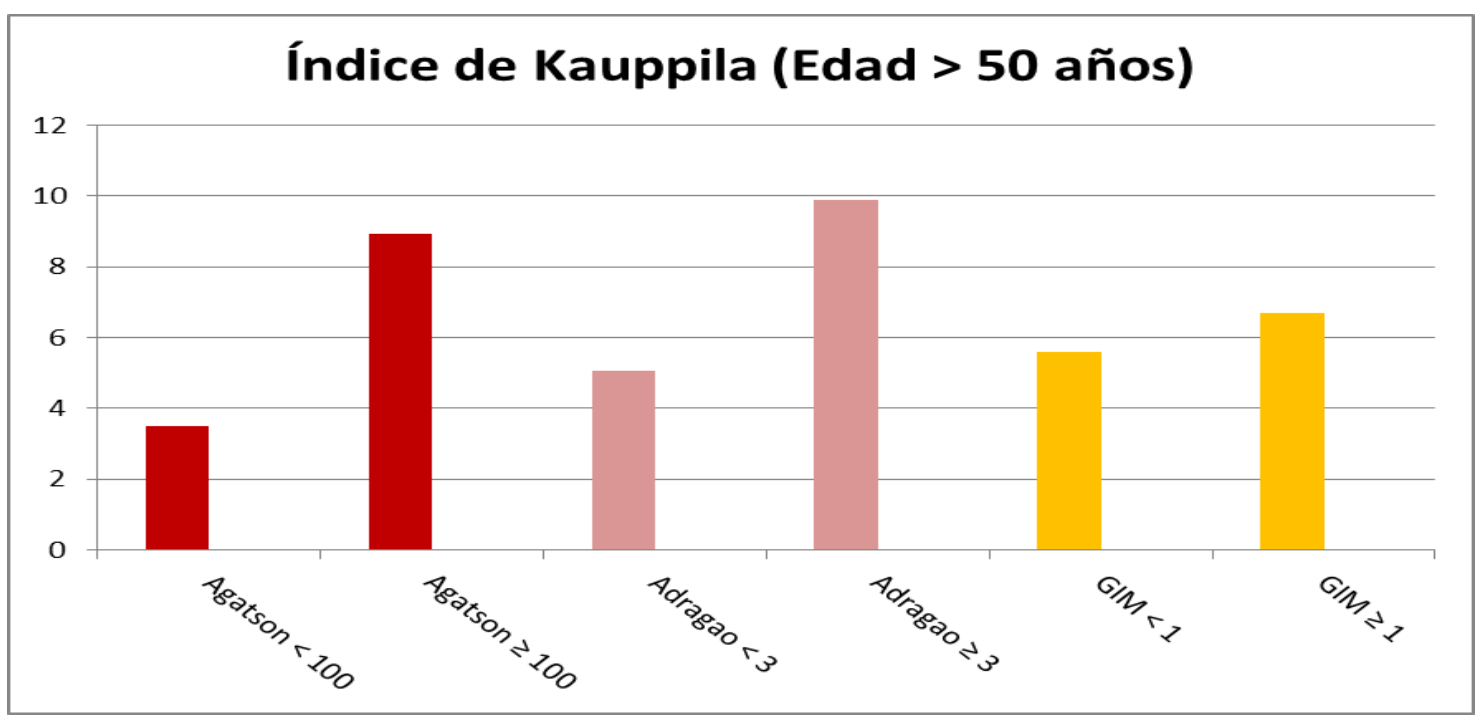

Figura 40: Diferencias en el índice de Kauppila según el resto de pruebas para valorar la calcificación vascular en pacientes de edad $\leq 50$ años. 


\section{RESULTADOS}

\subsection{6: DENSITOMETRÍA DEL CUELLO DEL FÉMUR}

El grado de densidad mineral-ósea (DMO) de los 43 receptores de trasplante renal se situó entre 0,31 y 1,07 (Tabla 139).

El valor de la DMO obtenido tras la valoración de las densitometrías del cuello del fémur realizadas en el estudio de la muestra se recoge en la siguiente tabla:

\begin{tabular}{|l|l|l|l|l|l|l|}
\hline & Media & Mediana & MAX & MIN & R. Interq. & DS \\
\hline DMO & 0,78 & 0,77 & 1,07 & 0,31 & $0,69-0,9$ & 0,14 \\
\hline
\end{tabular}

Tabla 139: Estadísticos descriptivos de la DMO observados en la muestra.

Se calculó asimismo el T-Score relativo a los resultados obtenidos en la densitometría del cuello del fémur. Este valor se situó entre -2,95 y 1,4 (Tabla 140).

El valor del T-Score obtenido tras la valoración de las densitometrías del cuello del fémur realizadas en el estudio de la muestra se recoge en la siguiente tabla:

\begin{tabular}{|l|l|l|l|l|l|l|}
\hline & Media & Mediana & MAX & MIN & R. Interq. & DS \\
\hline T-Score & $-0,86$ & $-1,23$ & 1,4 & $-2,95$ & $-1,6-0,05$ & 1,08 \\
\hline
\end{tabular}

Tabla 140: Estadísticos descriptivos del T-Score observados en la muestra.

La distribución de los pacientes estudiados según la DMO fue la siguiente:

\begin{tabular}{|l|l|l|l|}
\hline & Estrato & Recuento & Porcentaje \\
\hline$<0,97$ & Baja & 40 & $93 \%$ \\
\hline $\mathbf{2 0 , 9 7}$ & Normal & 3 & $7 \%$ \\
\hline
\end{tabular}

Tabla 141: Distribución de los pacientes estudiados según su DMO. 


\section{RESULTADOS}

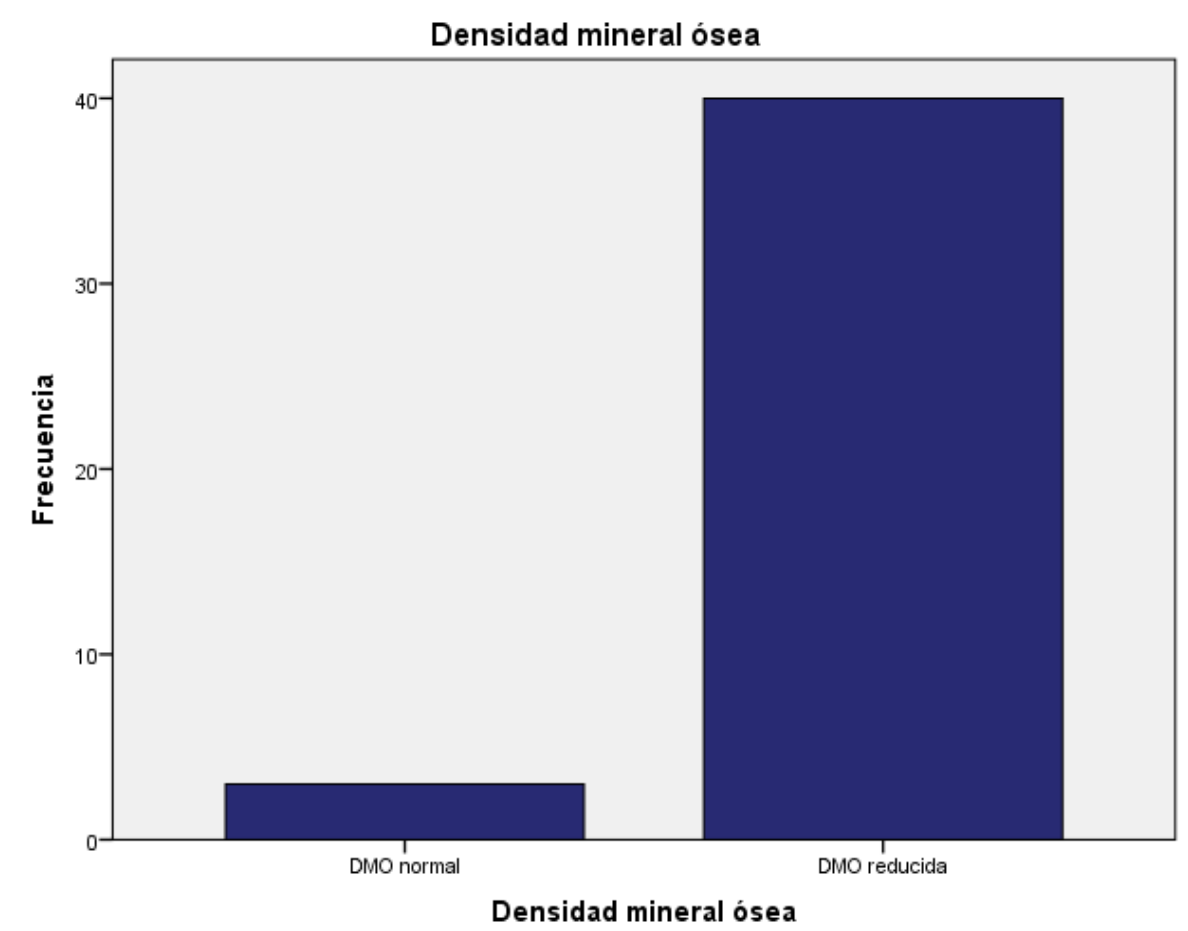

Figura 48: Distribución de los pacientes respecto a la DMO.

La distribución de los pacientes estudiados según el T-Score fue la siguiente:

\begin{tabular}{|l|l|l|l|}
\hline T-Score & Estrato & Recuento & Porcentaje \\
\hline $\mathbf{2 - 1}$ & Normal & 20 & $46,5 \%$ \\
\hline $\mathbf{- 2 , 5 - - 1}$ & Osteopenia & 22 & $51,2 \%$ \\
\hline $\mathbf{S - 2 , 5}$ & Osteoporosis & 1 & $3 \%$ \\
\hline
\end{tabular}

Tabla 142: Distribución de los pacientes estudiados de acuerdo con su T-Score. 


\section{RESULTADOS}

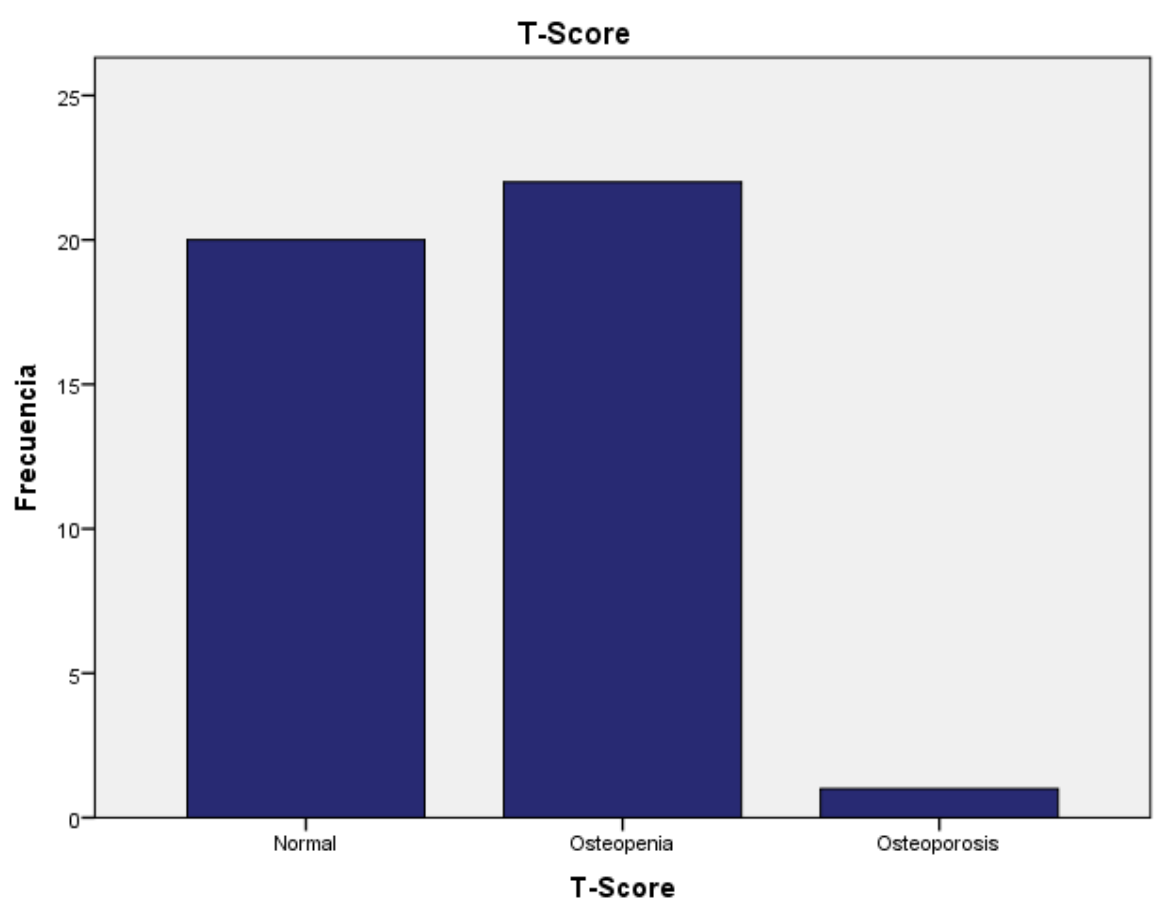

Figura 49: Distribución de los pacientes respecto al T-Score.

Debido a la asimetría existente en la distribución de los pacientes respecto al valor de densidad mineral ósea se decidió analizar únicamente la significación existente entre el T-Score y el resto de variables del estudio.

Para analizar la asociación observada entre las diferentes variables categóricas y cuantitativas y el T-Score se crearon dos conjuntos de pacientes según esta última variable, agrupándolos según presentasen un T-Score $<-10 \geq-1$. Un 54,8\% (23 pacientes, con una $\mathrm{N}$ válida de 42 ) de los pacientes presentaron un T-score medio en cuello femoral $<-1$.

En el análisis de las variables categóricas se ha empleado el test Chi-cuadrado de asociación entre variables medidas en escala nominal, realizando una aproximación al cálculo del tamaño del efecto mediante el cuadrado del valor del coeficiente Phi.

En el primer bloque de variables categóricas analizadas (tabla 143) no se ha encontrado ninguna relación que pueda ser considerara como estadísticamente significativa ( $P>.05)$. 


\section{RESULTADOS}

Tabla 143: Test Chi-cuadrado. Asociación de Índice de T-score del C.F. con diversas variables personales -1-

\begin{tabular}{|c|c|c|c|c|c|c|c|}
\hline \multirow[b]{2}{*}{ ariable } & \multirow[b]{2}{*}{ Categoría } & \multicolumn{2}{|c|}{ T-score del C.F. \% (n) } & \multirow{2}{*}{$\mathrm{Chi}^{2}$} & \multirow{2}{*}{$\mathrm{Gl}$} & \multirow{2}{*}{$P$} & \multirow{2}{*}{$\begin{array}{l}\text { Tam. } \\
\text { Efecto } \\
\text { aprox. }\end{array}$} \\
\hline & & Inferior & Igual o superior & & & & \\
\hline \multirow[t]{2}{*}{ Sexo } & Mujer & $21.7 \%(5)$ & $36.8 \%(7)$ & 1.16 & 1 & .281 NS & .028 \\
\hline & Hombre & $78.3 \%(18)$ & $63.2 \%(12)$ & & & & \\
\hline \multirow[t]{7}{*}{ Enf. renal de base } & Nefropatía túbulo-inters. & $17.4 \%(4)$ & $31.6 \%(6)$ & & & & \\
\hline & Glomerulonefritis & $30.4 \%(7)$ & $10.5 \%(2)$ & & & & \\
\hline & Poliquistosis renal & $174 \%(4)$ & $26.3 \%(5)$ & & & & \\
\hline & & & & 4.26 & 5 & .513 NS & .089 \\
\hline & Nefropatía diabética & $8.7 \%(2)$ & $5.3 \%(1)$ & & & & \\
\hline & Nefroangioesclerosis & $4.3 \%(1)$ & $10.5 \%(2)$ & & & & \\
\hline & No filiada & $21.7 \%(5)$ & $15.8 \%(3)$ & & & & \\
\hline \multirow[t]{2}{*}{ Mod. Diálisis } & $\mathrm{HD}$ & $73.9 \%(17)$ & $57.9 \%(11)$ & 1.20 & 1 & .273 NS & .028 \\
\hline & DP & $26.1 \%(6)$ & $42.1 \%(8)$ & & & & \\
\hline \multirow[t]{3}{*}{ Acceso Vascular } & FAVI & $69.6 \%(16)$ & $42.1 \%(8)$ & & & & \\
\hline & Catéter peritoneal & $26.1 \%(6)$ & $42.1 \%(8)$ & 3.60 & 2 & .165 Ns & .079 \\
\hline & Catéter vascular & $4.3 \%(1)$ & $15.8 \%(3)$ & & & & \\
\hline HTA & $\mathrm{Si}$ & $87.0 \%(20)$ & $89.5 \%(17)$ & 0.00 & 1 & .999 NS & .002 \\
\hline Diabetes & $\mathrm{Si}$ & $21.7 \%(5)$ & $5.3 \%(1)$ & 1.16 & 1 & .282 NS & .052 \\
\hline Dislipemia & $\mathrm{Si}$ & $43.5 \%(10)$ & $47.4 \%(9)$ & 0.00 & 1 & .999 NS & .002 \\
\hline Card. Isquémica & $\mathrm{Si}$ & $8.7 \%(2)$ & -- & -- & -- & -- & -- \\
\hline Tabaquismo & $\mathrm{Si}$ & $17.4 \%(4)$ & $26.3 \%(5)$ & 0.10 & 1 & .746 Ns & .012 \\
\hline \multirow[t]{3}{*}{ Ecocard. Pre-Tx } & HVI leve & $50.0 \%(6)$ & $72.7 \%(8)$ & & & & \\
\hline & HVI moderada & $41.7 \%(5)$ & $27.3 \%(3)$ & 2.13 & 2 & $.344^{\mathrm{NS}}$ & .071 \\
\hline & HVI grave & $8.3 \%(1)$ & -- & & & & \\
\hline
\end{tabular}

N.S. $=$ NO significativo $(P>.05) \quad *=$ Significativo al $5 \%(P<.05)$

En el segundo grupo de variables categóricas (tabla 144) se ha objetiva

- $\quad \operatorname{Edad}(\mathrm{P}<.01)$ : El grupo de pacientes con T-Score $\geq-1$ son más jóvenes que el resto (con una diferencia en torno a los 14 años) siendo el tamaño del efecto elevado (.343). 


\section{RESULTADOS}

En el resto de variables, no hay significación ( $P>.05)$.

Tabla 144: Test de diferencia entre dos medias. Asociación de Índice de T-score del C.F. con diversas variables categóricas.-2-

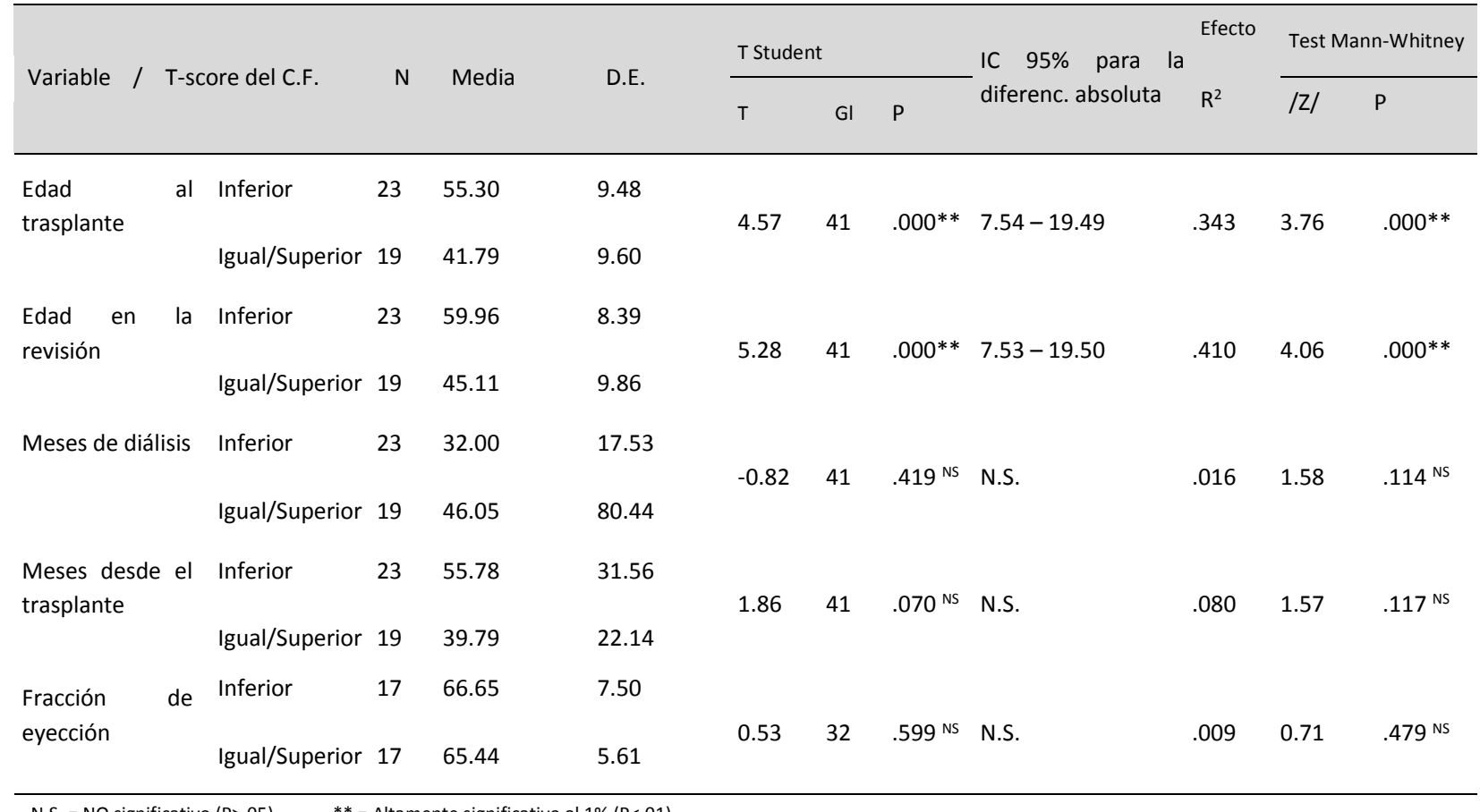

N.S. $=$ NO significativo $(P>$.05) $\quad * *=$ Altamente significativo al $1 \%(P<.01)$ 


\section{RESULTADOS}

En este primer bloque de variables cuantitativas (tabla 145) solo se ha encontrado una significación:

- Leucocitos $(\mathrm{P}<.05)$ : El grupo de pacientes con T-Score $<-1$ presenta un valor medio más alto que el resto (7125.65 vs 6116.84 ), con un tamaño del efecto bajo (.097). Esta asociación carece de significación al emplear el test de MannWhitney.

Tabla 145: Test de diferencia entre dos medias. Asociación de Índice de T-score del C.F. con diversas variables antropométricas y de la analítica previa al trasplante.-1-

\begin{tabular}{|c|c|c|c|c|c|c|c|c|c|c|c|}
\hline \multirow{2}{*}{ Variable / } & \multirow{2}{*}{ T-score del C.F. } & \multirow{2}{*}{$\mathrm{N}$} & \multirow{2}{*}{ Media } & \multirow{2}{*}{ D.E. } & \multicolumn{3}{|c|}{ T Student } & \multirow{2}{*}{$\begin{array}{l}\text { IC 95\% para la } \\
\text { diferenc. absoluta }\end{array}$} & \multirow{2}{*}{$\begin{array}{l}\text { Efecto } \\
\mathrm{R}^{2}\end{array}$} & \multicolumn{2}{|c|}{ Test Mann-Whitney } \\
\hline & & & & & $\mathrm{T}$ & $\mathrm{Gl}$ & $\mathrm{P}$ & & & /Z/ & $P$ \\
\hline \multirow[t]{3}{*}{ Altura } & Inferior & 23 & 168.09 & 8.99 & & & & & & & \\
\hline & & & & & -0.14 & 41 & $.887^{N S}$ & N.S. & .001 & 0.34 & $.733^{N S}$ \\
\hline & Igual/Superior & 19 & 168.50 & 9.62 & & & & & & & \\
\hline \multirow[t]{3}{*}{ Peso } & Inferior & 23 & 70.59 & 11.19 & & & & & & & \\
\hline & & & & & -0.17 & 41 & $.863^{\mathrm{NS}}$ & N.S. & .001 & 0.06 & .950 NS \\
\hline & Igual/Superior & 19 & 71.24 & 12.93 & & & & & & & \\
\hline \multirow[t]{3}{*}{ IMC } & Inferior & 23 & 24.90 & 2.89 & & & & & & & \\
\hline & & & & & -0.09 & 41 & .930 NS & N.S. & .000 & 0.01 & $.990 \mathrm{NS}$ \\
\hline & Igual/Superior & 19 & 24.98 & 3.21 & & & & & & & \\
\hline \multirow[t]{3}{*}{ TAS } & Inferior & 23 & 151.17 & 29.56 & & & & & & & \\
\hline & & & & & 1.41 & 41 & .166 NS & N.S. & .047 & 1.10 & $.271^{\mathrm{NS}}$ \\
\hline & Igual/Superior & 19 & 140.00 & 19.55 & & & & & & & \\
\hline \multirow[t]{3}{*}{ TAD } & Inferior & 23 & 85.13 & 14.33 & & & & & & & \\
\hline & & & & & 0.27 & 41 & $.787^{N S}$ & N.S. & .002 & 0.24 & $.810^{\mathrm{NS}}$ \\
\hline & Igual/Superior & 19 & 84.05 & 10.55 & & & & & & & \\
\hline \multirow[t]{3}{*}{ Diuresis } & Inferior & 23 & 792.17 & 783.23 & & & & & & & \\
\hline & & & & & -1.82 & 41 & $.077^{N S}$ & N.S. & .076 & 1.45 & $.147^{\mathrm{NS}}$ \\
\hline & Igual/Superior & 19 & 1336.84 & 1152.88 & & & & & & & \\
\hline \multirow[t]{3}{*}{ Hemoglobina } & Inferior & 23 & 12.74 & 1.56 & & & & & & & \\
\hline & & & & & 0.39 & 41 & $.701^{\mathrm{NS}}$ & N.S. & .004 & 0.64 & .519 NS \\
\hline & Igual/Superior & 19 & 12.54 & 1.83 & & & & & & & \\
\hline \multirow[t]{3}{*}{ Hematocrito } & Inferior & 23 & 38.43 & 4.84 & & & & & & & \\
\hline & & & & & 0.37 & 41 & $.710^{N S}$ & N.S. & .003 & 0.67 & $.503^{N S}$ \\
\hline & Igual/Superior & 19 & 37.83 & 5.69 & & & & & & & \\
\hline \multirow[t]{3}{*}{ Leucocitos } & Inferior & 23 & 7125.65 & 1698.30 & & & & & & & \\
\hline & & & & & 2.08 & 41 & $.044 *$ & $26.84-1990.78$ & .097 & 1.87 & $.061^{\mathrm{NS}}$ \\
\hline & Igual/Superior & 19 & 6116.84 & 1390.33 & & & & & & & \\
\hline \multirow[t]{2}{*}{ Plaquetas } & Inferior & 23 & 196652.17 & 71668.81 & & & & & & & \\
\hline & Igual/Superior & 19 & 178473.68 & 68189.58 & 0.84 & 41 & $.408^{\mathrm{NS}}$ & N.S. & .017 & 1.33 & $.185^{\mathrm{NS}}$ \\
\hline
\end{tabular}

N.S. $=$ NO significativo $(\mathrm{P}>$.05) $\quad * *=$ Altamente significativo al $1 \%(\mathrm{P}<.01)$ 


\section{RESULTADOS}

En el siguiente grupo (tabla 146) se observa significación en:

- Colesterol total $(\mathrm{P}<.01)$ : El grupo de pacientes con T-Score $<-1$ presenta un valor medio más bajo que los demás (150.43 vs 195.00) con un tamaño del efecto moderado alto (.192).

Tabla 146: Test de diferencia entre dos medias. Asociación de Índice de T-score del C.F. con diversas variables de la analítica previa al trasplante -2-

\begin{tabular}{|c|c|c|c|c|c|c|c|c|c|c|c|}
\hline \multirow{2}{*}{ Variable / T-s } & \multirow{2}{*}{ score del C.F. } & \multirow{2}{*}{ N } & \multirow{2}{*}{ Media } & \multirow{2}{*}{ D.E. } & \multicolumn{3}{|c|}{ T Student } & \multirow{2}{*}{$\begin{array}{l}\text { IC 95\% para la } \\
\text { diferenc. absoluta }\end{array}$} & \multirow{2}{*}{$\begin{array}{l}\text { Efecto } \\
\mathrm{R}^{2}\end{array}$} & \multicolumn{2}{|c|}{ Test Mann-Whitney } \\
\hline & & & & & $\mathrm{T}$ & gl & $P$ & & & /Z/ & $P$ \\
\hline \multirow[t]{3}{*}{ Urea } & Inferior & 23 & 144.52 & 33.63 & & & & & & & \\
\hline & & & & & 0.12 & 41 & $.901^{\mathrm{NS}}$ & N.S. & .000 & 0.09 & $.930 \mathrm{NS}$ \\
\hline & Igual/Superior & 19 & 143.16 & 37.17 & & & & & & & \\
\hline \multirow[t]{3}{*}{ Glucosa } & Inferior & 23 & 93.57 & 16.11 & & & & & & & \\
\hline & & & & & -0.17 & 41 & $.868^{\mathrm{NS}}$ & N.S. & .001 & 0.51 & $.613^{\mathrm{NS}}$ \\
\hline & Igual/Superior & 19 & 94.74 & 28.69 & & & & & & & \\
\hline \multirow[t]{3}{*}{ Creatinina } & Inferior & 23 & 8.85 & 2.61 & & & & & & & \\
\hline & & & & & 0.01 & 41 & .970 NS & N.S. & .000 & 0.24 & $.810^{\mathrm{NS}}$ \\
\hline & Igual/Superior & 19 & 8.82 & 2.89 & & & & & & & \\
\hline \multirow[t]{3}{*}{ Triglicéridos } & Inferior & 23 & 110.30 & 38.00 & & & & & & & \\
\hline & & & & & -1.19 & 41 & .240 NS & N.S. & .034 & 0.77 & $.441^{\mathrm{NS}}$ \\
\hline & Igual/Superior & 19 & 125.63 & 45.26 & & & & & & & \\
\hline \multirow[t]{3}{*}{ Colesterol total } & Inferior & 23 & 150.43 & 44.13 & & & & & & & \\
\hline & & & & & -3.08 & 41 & $.004 * *$ & $15.32-73.81$ & .192 & 2.70 & $.007 * *$ \\
\hline & Igual/Superior & 19 & 195.00 & 49.61 & & & & & & & \\
\hline \multirow[t]{3}{*}{ Proteínas totales } & Inferior & 23 & 6.99 & 0.55 & & & & & & & \\
\hline & & & & & 1.56 & 41 & .127 NS & N.S. & .057 & 1.87 & .061 Ns \\
\hline & Igual/Superior & 19 & 6.73 & 0.52 & & & & & & & \\
\hline \multirow[t]{3}{*}{ Calcio } & Inferior & 23 & 9.48 & 0.65 & & & & & & & \\
\hline & & & & & 1.89 & 41 & $.066^{\mathrm{NS}}$ & N.S. & .082 & 1.60 & .111 Ns \\
\hline & Igual/Superior & 19 & 8.98 & 1.03 & & & & & & & \\
\hline \multirow[t]{3}{*}{ Calcio correg. } & Inferior & 23 & 9.73 & 0.76 & & & & & & & \\
\hline & & & & & 1.34 & 41 & .189 NS & N.S. & .043 & 1.00 & $.318^{\mathrm{NS}}$ \\
\hline & Igual/Superior & 19 & 9.37 & 1.01 & & & & & & & \\
\hline \multirow[t]{2}{*}{ Prod. Calc/Fósf. } & Inferior & 23 & 48.55 & 9.92 & & & & & & & \\
\hline & Igual/Superior & 19 & 43.51 & 10.91 & 1.57 & 41 & .125 NS & N.S. & .058 & 1.28 & .202 Ns \\
\hline
\end{tabular}




\section{RESULTADOS}

En este bloque de variables (tabla 147) no aparecen diferencias significativas ( $P>.05)$.

Tabla 147: Test de diferencia entre dos medias. Asociación de Índice de T-score del C.F. con diversas variables de la analítica previa al trasplante.-3-

\begin{tabular}{|c|c|c|c|c|c|c|c|c|c|c|c|}
\hline \multirow{2}{*}{ Variable } & \multirow{2}{*}{ core del C.F. } & \multirow{2}{*}{$\mathrm{N}$} & \multirow{2}{*}{ Media } & \multirow{2}{*}{ D.E. } & \multicolumn{3}{|c|}{ T Student } & \multirow{2}{*}{$\begin{array}{l}\text { IC } 95 \% \text { para la } \\
\text { diferenc. absoluta }\end{array}$} & \multirow{2}{*}{$\begin{array}{l}\text { Efecto } \\
\mathrm{R}^{2}\end{array}$} & \multicolumn{2}{|c|}{ Test Mann-Whitney } \\
\hline & & & & & $\mathrm{T}$ & gl & $\mathrm{P}$ & & & |Z/ & $P$ \\
\hline \multirow[t]{3}{*}{ Fósforo } & Inferior & 23 & 5.13 & 1.01 & & & & & & & \\
\hline & & & & & 0.86 & 41 & $.397 \mathrm{Ns}$ & N.S. & 018 & 0.70 & .487 NS \\
\hline & Igual/Superior & 19 & 4.84 & 1.15 & & & & & & & \\
\hline \multirow[t]{3}{*}{ Fosfata Alcalina } & Inferior & 23 & 106.39 & 66.17 & & & & & & & \\
\hline & & & & & 0.55 & 41 & $.587^{\mathrm{NS}}$ & N.S. & .007 & 1.14 & $.255^{\mathrm{NS}}$ \\
\hline & Igual/Superior & 19 & 95.58 & 60.42 & & & & & & & \\
\hline \multirow[t]{3}{*}{ H. Paratiroidea } & Inferior & 22 & 293.02 & 234.57 & & & & & & & \\
\hline & & & & & -1.29 & 40 & $.205^{N S}$ & N.S. & .041 & 0.34 & .734 NS \\
\hline & Igual/Superior & 19 & 447.73 & 504.10 & & & & & & & \\
\hline \multirow[t]{3}{*}{$\mathrm{pH}$} & Inferior & 23 & 7.38 & 0.04 & & & & & & & \\
\hline & & & & & 1.45 & 41 & $.155^{\mathrm{NS}}$ & N.S. & .050 & 1.66 & $.097^{\mathrm{NS}}$ \\
\hline & Igual/Superior & 19 & 7.36 & 0.06 & & & & & & & \\
\hline \multirow[t]{3}{*}{ Bicarbonato } & Inferior & 23 & 24.02 & 2.97 & & & & & & & \\
\hline & & & & & 0.93 & 41 & .357 NS & N.S. & .021 & 1.11 & $.266 \mathrm{NS}$ \\
\hline & Igual/Superior & 19 & 23.20 & 2.64 & & & & & & & \\
\hline \multirow[t]{3}{*}{ MDRDa } & Inferior & 23 & 6.80 & 1.84 & & & & & & & \\
\hline & & & & & -0.57 & 41 & .570 NS & N.S. & .008 & 0.34 & .733 NS \\
\hline & Igual/Superior & 19 & 7.20 & 2.68 & & & & & & & \\
\hline \multirow[t]{3}{*}{ Cock. Gault } & Inferior & 23 & 9.59 & 2.60 & & & & & & & \\
\hline & & & & & -1.66 & 41 & $.104^{\mathrm{NS}}$ & N.S. & .065 & 1.15 & $.250 \mathrm{Ns}$ \\
\hline & Igual/Superior & 19 & 11.44 & 4.52 & & & & & & & \\
\hline \multirow[t]{3}{*}{ Mayo Quadr. } & Inferior & 23 & 8.81 & 1.51 & & & & & & & \\
\hline & & & & & -1.40 & 41 & $.168^{\mathrm{NS}}$ & N.S. & .047 & 1.02 & .306 NS \\
\hline & Igual/Superior & 19 & 9.65 & 2.35 & & & & & & & \\
\hline \multirow[t]{2}{*}{ CKD-EPI } & Inferior & 23 & 6.18 & 1.78 & & & & & & & \\
\hline & Igual/Superior & 19 & 6.80 & 2.66 & -0.89 & 41 & $.377^{N S}$ & N.S. & .020 & 0.57 & $.570^{\mathrm{NS}}$ \\
\hline
\end{tabular}

N.S. $=$ NO significativo $(P>.05)$

En el siguiente bloque (tabla 148) observamos:

- $\quad$ VSG $(P<.05)$ : El grupo de pacientes con T-Score < -1 presenta un valor medio más bajo (26.09 vs 44.05$)$ que el resto de pacientes, con un efecto moderado (.102).

- Volumen de diuresis (<.10): El grupo de pacientes con T-Score < -1 presenta un valor medio más bajo de diuresis en el momento del alta tras el trasplante (2246 vs 2688), con efecto bajo. 


\section{RESULTADOS}

Tabla 148: Test de diferencia entre dos medias. Asociación de Índice de T-score del C.F. con diversas variables antropométricas y de la analítica al alta tras el trasplante.-1-

\begin{tabular}{|c|c|c|c|c|c|c|c|c|c|c|c|}
\hline \multirow{2}{*}{ Variable } & \multirow{2}{*}{ T-score del C.F. } & \multirow{2}{*}{$\mathrm{N}$} & \multirow{2}{*}{ Media } & \multirow{2}{*}{ D.E. } & \multicolumn{3}{|c|}{ T Student } & \multirow{2}{*}{$\begin{array}{l}\text { IC 95\% para la } \\
\text { diferenc. absoluta }\end{array}$} & \multirow{2}{*}{$\begin{array}{l}\text { Efecto } \\
\mathrm{R}^{2}\end{array}$} & \multicolumn{2}{|c|}{ Test Mann-Whitney } \\
\hline & & & & & $\mathrm{T}$ & $\mathrm{gl}$ & $P$ & & & /Z/ & $P$ \\
\hline \multirow[t]{3}{*}{ Peso } & Inferior & 23 & 68.08 & 11.43 & & & & & & & \\
\hline & & & & & -0.63 & 41 & .531 NS & N.S. & .010 & 0.34 & $.733^{N S}$ \\
\hline & Igual/Superior & 19 & 70.38 & 12.16 & & & & & & & \\
\hline \multirow[t]{3}{*}{ IMC } & Inferior & 23 & 24.03 & 3.28 & & & & & & & \\
\hline & & & & & -0.71 & 41 & .484 NS & N.S. & .012 & 0.66 & $.511^{\mathrm{NS}}$ \\
\hline & Igual/Superior & 19 & 24.75 & 3.27 & & & & & & & \\
\hline \multirow[t]{3}{*}{ TAS } & Inferior & 23 & 137.52 & 22.44 & & & & & & & \\
\hline & & & & & -0.19 & 41 & .849 NS & N.S. & .001 & 0.08 & .939 NS \\
\hline & Igual/Superior & 19 & 138.95 & 25.79 & & & & & & & \\
\hline \multirow[t]{3}{*}{ TAD } & Inferior & 23 & 79.17 & 11.24 & & & & & & & \\
\hline & & & & & 0.00 & 41 & .997 NS & N.S. & .000 & 0.20 & .839 NS \\
\hline & Igual/Superior & 19 & 79.16 & 15.42 & & & & & & & \\
\hline \multirow[t]{3}{*}{ Diuresis } & Inferior & 23 & 2246.74 & 590.35 & & & & & & & \\
\hline & & & & & -1.86 & 41 & .070 NS & N.S. & .080 & 1.70 & .090 NS \\
\hline & Igual/Superior & 19 & 2688.42 & 936.60 & & & & & & & \\
\hline \multirow[t]{3}{*}{ Hemoglobina } & Inferior & 23 & 10.97 & 1.50 & & & & & & & \\
\hline & & & & & 1.19 & 41 & .242 NS & N.S. & .034 & 0.75 & $.455^{\mathrm{NS}}$ \\
\hline & Igual/Superior & 19 & 10.48 & 1.06 & & & & & & & \\
\hline \multirow[t]{3}{*}{ Hematocrito } & Inferior & 23 & 33.70 & 4.62 & & & & & & & \\
\hline & & & & & 1.61 & 41 & $.116^{\mathrm{NS}}$ & N.S. & .061 & 0.99 & $.324^{\mathrm{NS}}$ \\
\hline & Igual/Superior & 19 & 31.76 & 2.76 & & & & & & & \\
\hline \multirow[t]{3}{*}{ Leucocitos } & Inferior & 23 & 9552.61 & 3602.47 & & & & & & & \\
\hline & & & & & 0.13 & 41 & .895 NS & N.S. & .000 & 0.06 & .950 NS \\
\hline & Igual/Superior & 19 & 9395.26 & 4062.32 & & & & & & & \\
\hline \multirow[t]{3}{*}{ Plaquetas } & Inferior & 23 & 264434.78 & 112727.68 & & & & & & & \\
\hline & & & & & 0.17 & 41 & .867 NS & N.S. & .001 & 0.46 & .649 NS \\
\hline & Igual/Superior & 19 & 258263.16 & 124608.20 & & & & & & & \\
\hline \multirow[t]{2}{*}{ VSG } & Inferior & 23 & 26.09 & 20.66 & & & & & & & \\
\hline & Igual/Superior & 19 & 44.05 & 33.47 & -2.13 & 41 & $.039 *$ & $0.93-35.00$ & .102 & 1.98 &. $.048 *$ \\
\hline
\end{tabular}




\section{RESULTADOS}

En el siguiente grupo de variables relativas al momento del alta tras el trasplante (tabla 149) no se han encontrado diferencias significativas ( $P>.05)$.

Tabla 149: Test de diferencia entre medias. Asociación de Índice de T-score del C.F. con diversas variables de la analítica al alta tras el trasplante.-2-

\begin{tabular}{|c|c|c|c|c|c|c|c|c|c|c|c|}
\hline \multirow{2}{*}{ Variable } & \multirow{2}{*}{ core del C.F. } & \multirow{2}{*}{$\mathrm{N}$} & \multirow{2}{*}{ Media } & \multirow{2}{*}{ D.E. } & \multicolumn{3}{|c|}{ T Student } & \multirow{2}{*}{$\begin{array}{l}\text { IC } 95 \% \text { para la } \\
\text { diferenc. absoluta }\end{array}$} & \multirow{2}{*}{$\begin{array}{l}\text { Efecto } \\
\mathrm{R}^{2}\end{array}$} & \multicolumn{2}{|c|}{ Test Mann-Whitney } \\
\hline & & & & & $\mathrm{T}$ & gl & $P$ & & & /Z/ & $P$ \\
\hline \multirow[t]{3}{*}{ Urea } & Inferior & 23 & 79.70 & 29.63 & & & & & & & \\
\hline & & & & & -1.71 & 41 & $.096^{\mathrm{NS}}$ & N.S. & .068 & 1.53 & $.126^{\mathrm{NS}}$ \\
\hline & Igual/Superior & 19 & 99.84 & 46.35 & & & & & & & \\
\hline \multirow[t]{3}{*}{ Glucosa } & Inferior & 23 & 105.48 & 37.14 & & & & & & & \\
\hline & & & & & 0.74 & 41 & .465 NS & N.S. & .013 & 0.66 & $.511^{\mathrm{NS}}$ \\
\hline & Igual/Superior & 19 & 98.32 & 22.33 & & & & & & & \\
\hline \multirow[t]{3}{*}{ Creatinina } & Inferior & 23 & 1.90 & 0.84 & & & & & & & \\
\hline & & & & & -1.59 & 41 & .120 NS & N.S. & .059 & 1.17 & $.244 \mathrm{NS}$ \\
\hline & Igual/Superior & 19 & 2.57 & 1.82 & & & & & & & \\
\hline \multirow[t]{3}{*}{ Triglicéridos } & Inferior & 23 & 136.78 & 53.68 & & & & & & & \\
\hline & & & & & -0.88 & 41 & .382 NS & N.S. & .019 & 0.34 & $.733^{N S}$ \\
\hline & Igual/Superior & 19 & 155.84 & 85.12 & & & & & & & \\
\hline \multirow[t]{3}{*}{ Colesterol total } & Inferior & 23 & 180.65 & 42.91 & & & & & & & \\
\hline & & & & & -0.86 & 41 & $.397^{N S}$ & N.S. & .018 & 0.83 & $.404^{N S}$ \\
\hline & Igual/Superior & 19 & 193.74 & 56.03 & & & & & & & \\
\hline \multirow[t]{3}{*}{ Proteínas totales } & Inferior & 23 & 6.20 & 0.44 & & & & & & & \\
\hline & & & & & 0.09 & 41 & $.931^{\mathrm{NS}}$ & N.S. & .000 & 0.51 & .612 NS \\
\hline & Igual/Superior & 19 & 6.18 & 0.47 & & & & & & & \\
\hline \multirow[t]{3}{*}{ Calcio } & Inferior & 23 & 9.84 & 0.94 & & & & & & & \\
\hline & & & & & 1.93 & 41 & .060 NS & N.S. & .085 & 1.86 & .063 NS \\
\hline & Igual/Superior & 19 & 9.35 & 0.66 & & & & & & & \\
\hline \multirow[t]{3}{*}{ Calcio correg. } & Inferior & 23 & 10.49 & 0.84 & & & & & & & \\
\hline & & & & & 1.95 & 41 & $.056^{\mathrm{NS}}$ & N.S. & .090 & 1.83 & $.067^{N S}$ \\
\hline & Igual/Superior & 19 & 10.01 & 0.63 & & & & & & & \\
\hline \multirow[t]{3}{*}{ Prod. Calc/Fósf. } & Inferior & 23 & 29.07 & 8.40 & & & & & & & \\
\hline & & & & & -0.99 & 41 & $.329^{N S}$ & N.S. & .024 & 0.62 & $.536^{\mathrm{NS}}$ \\
\hline & Igual/Superior & 19 & 32.20 & 12.06 & & & & & & & \\
\hline \multirow[t]{2}{*}{ Fósforo } & Inferior & 23 & 2.94 & 0.76 & & & & & & & \\
\hline & Igual/Superior & 19 & 3.45 & 1.29 & -1.59 & 41 & .120 NS & N.S. & .059 & 1.40 & .160 NS \\
\hline
\end{tabular}




\section{RESULTADOS}

En el siguiente grupo (tabla 150) no se han encontrado diferencia significativas ( $P>.05)$.

Tabla 150: Test de diferencia entre dos medias. Asociación de Índice de T-score del C.F. con diversas variables de la analítica al alta tras el trasplante.-3-

\begin{tabular}{|c|c|c|c|c|c|c|c|c|c|c|c|}
\hline \multirow{2}{*}{ Variable / } & \multirow{2}{*}{ core del C.F. } & \multirow{2}{*}{$\mathrm{N}$} & \multirow{2}{*}{ Media } & \multirow{2}{*}{ D.E. } & \multicolumn{3}{|c|}{ T Student } & \multirow{2}{*}{$\begin{array}{l}\text { IC } 95 \% \text { para la } \\
\text { diferenc. absoluta }\end{array}$} & \multirow{2}{*}{$\begin{array}{l}\text { Efecto } \\
\mathrm{R}^{2}\end{array}$} & \multicolumn{2}{|c|}{ Test Mann-Whitney } \\
\hline & & & & & $\mathrm{T}$ & gl & $P$ & & & /Z/ & $P$ \\
\hline \multirow[t]{3}{*}{ Magnesio } & Inferior & 23 & 1.66 & 0.32 & & & & & & & \\
\hline & & & & & -0.17 & 41 & $.866^{\mathrm{NS}}$ & N.S. & .001 & 0.22 & $.829^{N S}$ \\
\hline & Igual/Superior & 19 & 1.67 & 0.34 & & & & & & & \\
\hline \multirow[t]{3}{*}{ Fosfata Alcalina } & Inferior & 23 & 96.48 & 65.06 & & & & & & & \\
\hline & & & & & 1.24 & 41 & $.223^{\mathrm{NS}}$ & N.S. & .037 & 1.79 & $.073^{\mathrm{NS}}$ \\
\hline & Igual/Superior & 19 & 72.26 & 31.73 & & & & & & & \\
\hline \multirow[t]{3}{*}{ Urea en orina } & Inferior & 23 & 1202.74 & 327.97 & & & & & & & \\
\hline & & & & & -0.18 & 41 & $.859^{\mathrm{NS}}$ & N.S. & .001 & 0.11 & .909 NS \\
\hline & Igual/Superior & 19 & 1226.40 & 521.36 & & & & & & & \\
\hline \multirow[t]{3}{*}{ Creat. en orina } & Inferior & 23 & 54.19 & 20.54 & & & & & & & \\
\hline & & & & & -1.04 & 41 & $.306^{\mathrm{NS}}$ & N.S. & .026 & 0.76 & $.448^{\mathrm{NS}}$ \\
\hline & Igual/Superior & 19 & 62.28 & 29.87 & & & & & & & \\
\hline \multirow[t]{3}{*}{$\mathrm{pH}$} & Inferior & 23 & 7.35 & 0.05 & & & & & & & \\
\hline & & & & & 0.32 & 41 & $.750 \mathrm{NS}$ & N.S. & .003 & 0.05 & .959 NS \\
\hline & Igual/Superior & 19 & 7.34 & 0.06 & & & & & & & \\
\hline \multirow[t]{3}{*}{ Bicarbonato } & Inferior & 23 & 21.44 & 2.96 & & & & & & & \\
\hline & & & & & 0.81 & 41 & $.421^{\mathrm{NS}}$ & N.S. & .016 & 0.64 & $.519^{\mathrm{NS}}$ \\
\hline & Igual/Superior & 19 & 20.64 & 3.47 & & & & & & & \\
\hline \multirow[t]{3}{*}{ MDRDa } & Inferior & 23 & 43.81 & 16.77 & & & & & & & \\
\hline & & & & & 1.30 & 41 & $.202^{\mathrm{NS}}$ & N.S. & .040 & 1.12 & .261 NS \\
\hline & Igual/Superior & 19 & 37.01 & 17.04 & & & & & & & \\
\hline \multirow[t]{3}{*}{ Cock. Gault } & Inferior & 23 & 44.91 & 12.42 & & & & & & & \\
\hline & & & & & -0.06 & 41 & .950 NS & N.S. & .000 & 0.19 & .850 NS \\
\hline & Igual/Superior & 19 & 45.21 & 18.24 & & & & & & & \\
\hline \multirow[t]{3}{*}{ Mayo Quadr. } & Inferior & 23 & 51.27 & 24.57 & & & & & & & \\
\hline & & & & & 1.06 & 41 & .295 NS & N.S. & .027 & 0.87 & .383 NS \\
\hline & Igual/Superior & 19 & 43.55 & 22.04 & & & & & & & \\
\hline \multirow[t]{2}{*}{ CKD-EPI } & Inferior & 23 & 43.62 & 17.37 & & & & & & & \\
\hline & Igual/Superior & 19 & 37.79 & 18.03 & 1.06 & 41 & $.294^{N S}$ & N.S. & .027 & 0.85 & $.397^{\text {NS }}$ \\
\hline
\end{tabular}

N.S. $=$ NO significativo $(P>.05) \quad *=$ Significativo al $5 \%(P<.05)$ 


\section{RESULTADOS}

En el siguiente bloque (tabla 151) tampoco se han encontrado significaciones ( $P>.05)$.

Tabla 151: Test de diferencia entre dos medias. Asociación de Índice de T-score del C.F. con diversas variables antropométricas y de la analítica en la revisión.-1-

\begin{tabular}{|c|c|c|c|c|c|c|c|c|c|c|c|}
\hline \multirow{2}{*}{ Variable / T } & \multirow{2}{*}{ T-score del C.F. } & \multirow{2}{*}{$\mathrm{N}$} & \multirow{2}{*}{ Media } & \multirow{2}{*}{ D.E. } & \multicolumn{3}{|c|}{ T Student } & \multirow{2}{*}{$\begin{array}{l}\text { IC } 95 \% \text { para la } \\
\text { diferenc. absoluta }\end{array}$} & \multirow{2}{*}{$\begin{array}{l}\text { Efecto } \\
\mathrm{R}^{2}\end{array}$} & \multicolumn{2}{|c|}{ Test Mann-Whitney } \\
\hline & & & & & $T$ & gl & $\mathrm{P}$ & & & |Z| & $P$ \\
\hline \multirow[t]{3}{*}{ Peso } & Inferior & 23 & 73.40 & 11.67 & & & & & & & \\
\hline & & & & & -0.66 & 41 & $.510^{\mathrm{NS}}$ & N.S. & .011 & 0.24 & $.510^{\mathrm{NS}}$ \\
\hline & Igual/Superior & 19 & 76.17 & 15.38 & & & & & & & \\
\hline \multirow[t]{3}{*}{ IMC } & Inferior & 23 & 25.93 & 3.46 & & & & & & & \\
\hline & & & & & -0.69 & 41 & $.494^{\mathrm{NS}}$ & N.S. & .012 & 0.54 & .494 NS \\
\hline & Igual/Superior & 19 & 26.69 & 3.69 & & & & & & & \\
\hline \multirow[t]{3}{*}{ TAS } & Inferior & 23 & 147.74 & 18.65 & & & & & & & \\
\hline & & & & & 1.27 & 41 & $.210 \mathrm{NS}$ & N.S. & .039 & 0.94 & $.210^{\mathrm{NS}}$ \\
\hline & Igual/Superior & 19 & 140.63 & 17.15 & & & & & & & \\
\hline \multirow[t]{3}{*}{ TAD } & Inferior & 23 & 85.65 & 8.40 & & & & & & & \\
\hline & & & & & 0.63 & 41 & $.533^{\mathrm{NS}}$ & N.S. & .010 & 0.67 & .533 NS \\
\hline & Igual/Superior & 19 & 83.89 & 9.72 & & & & & & & \\
\hline \multirow[t]{3}{*}{ Diuresis } & Inferior & 23 & 2794.35 & 786.02 & & & & & & & \\
\hline & & & & & 1.78 & 41 & .082 NS & N.S. & .074 & 1.68 & .082 NS \\
\hline & Igual/Superior & 19 & 2357.89 & 794.12 & & & & & & & \\
\hline \multirow[t]{3}{*}{ Hemoglobina } & Inferior & 23 & 13.25 & 1.95 & & & & & & & \\
\hline & & & & & -0.39 & 41 & .699 NS & N.S. & .004 & 0.52 & .699 NS \\
\hline & Igual/Superior & 19 & 13.49 & 1.97 & & & & & & & \\
\hline \multirow[t]{3}{*}{ Hematocrito } & Inferior & 23 & 40.00 & 5.46 & & & & & & & \\
\hline & & & & & -0.27 & 41 & $.788^{N S}$ & N.S. & .002 & 0.58 & $.788^{\mathrm{NS}}$ \\
\hline & Igual/Superior & 19 & 40.45 & 5.14 & & & & & & & \\
\hline \multirow[t]{3}{*}{ Leucocitos } & Inferior & 23 & 6722.17 & 2048.33 & & & & & & & \\
\hline & & & & & -0.45 & 41 & .652 NS & N.S. & .005 & 0.67 & .652 NS \\
\hline & Igual/Superior & 19 & 7028.95 & 2331.31 & & & & & & & \\
\hline \multirow[t]{3}{*}{ Plaquetas } & Inferior & 23 & 183391.30 & 59002.11 & & & & & & & \\
\hline & & & & & -1.00 & 41 & .323 NS & N.S. & .024 & 0.92 & .323 NS \\
\hline & Igual/Superior & 19 & 201684.21 & 58869.02 & & & & & & & \\
\hline \multirow[t]{2}{*}{ VSG } & Inferior & 23 & 17.19 & 16.11 & & & & & & & \\
\hline & Igual/Superior & 19 & 15.53 & 13.24 & 0.36 & 41 & .721 Ns & N.S. & .003 & 0.13 & $.721^{\mathrm{NS}}$ \\
\hline
\end{tabular}

N.S. $=$ NO significativo $(P>$.05)

En el grupo que sigue (tabla 152) se observa:

- Proteinas totales $(\mathrm{P}<.05)$ : Según el test de Mann-Whitney los pacientes del grupo de T-score $<-1$ tienen un valor medio de proteínas totales en el momento del alta tras el trasplante menor que el resto de casos $(6,67$ vs 6,94$)$, aunque el efecto parece bajo. 


\section{RESULTADOS}

Tabla 152: Test de diferencia entre 2 medias. Asociación de Índice de T-score del C.F. con diversas variables -2- de la analítica en la revisión.

\begin{tabular}{|c|c|c|c|c|c|c|c|c|c|c|c|}
\hline \multirow{2}{*}{ Variable / T-s } & \multirow{2}{*}{ score del C.F. } & \multirow{2}{*}{$\mathrm{N}$} & \multirow{2}{*}{ Media } & \multirow{2}{*}{ D.E. } & \multicolumn{3}{|c|}{ T Student } & \multirow{2}{*}{$\begin{array}{l}\text { IC } 95 \% \text { para la } \\
\text { diferenc. absoluta }\end{array}$} & \multirow{2}{*}{$\begin{array}{l}\text { Efecto } \\
\mathrm{R}^{2}\end{array}$} & \multicolumn{2}{|c|}{ Test Mann-Whitney } \\
\hline & & & & & T & gl & $P$ & & & /Z/ & $P$ \\
\hline \multirow[t]{3}{*}{ Urea } & Inferior & 23 & 74.65 & 35.80 & & & & & & & \\
\hline & & & & & 1.58 & 41 & .121 NS & N.S. & .059 & 1.09 & .277 Ns \\
\hline & Igual/Superior & 19 & 60.32 & 18.14 & & & & & & & \\
\hline \multirow[t]{3}{*}{ Glucosa } & Inferior & 23 & 101.70 & 27.14 & & & & & & & \\
\hline & & & & & -0.23 & 41 & $.815^{\mathrm{NS}}$ & N.S. & .001 & 0.28 & .781 NS \\
\hline & Igual/Superior & 19 & 104.05 & 37.78 & & & & & & & \\
\hline \multirow[t]{3}{*}{ Creatinina } & Inferior & 23 & 1.64 & 0.60 & & & & & & & \\
\hline & & & & & 0.89 & 41 & $.381^{\mathrm{NS}}$ & N.S. & .019 & 0.76 & $.446^{\mathrm{NS}}$ \\
\hline & Igual/Superior & 19 & 1.49 & 0.42 & & & & & & & \\
\hline \multirow[t]{3}{*}{ Ácido úrico } & Inferior & 23 & 10.65 & 16.30 & & & & & & & \\
\hline & & & & & 1.09 & 41 & .281 NS & N.S. & .029 & 1.58 & .114 NS \\
\hline & Igual/Superior & 19 & 6.55 & 1.06 & & & & & & & \\
\hline \multirow[t]{3}{*}{ Triglicéridos } & Inferior & 23 & 118.13 & 53.19 & & & & & & & \\
\hline & & & & & -0.59 & 41 & $.556^{\mathrm{NS}}$ & N.S. & .009 & 0.16 & .869 NS \\
\hline & Igual/Superior & 19 & 130.00 & 76.17 & & & & & & & \\
\hline \multirow[t]{3}{*}{ Colesterol total } & Inferior & 23 & 178.87 & 39.66 & & & & & & & \\
\hline & & & & & -1.21 & 41 & $.2344^{\mathrm{NS}}$ & N.S. & .035 & 1.16 & .245 NS \\
\hline & Igual/Superior & 19 & 193.42 & 37.87 & & & & & & & \\
\hline \multirow[t]{3}{*}{ Proteínas totales } & Inferior & 23 & 6.67 & 0.50 & & & & & & & \\
\hline & & & & & -1.95 & 41 & $.058^{\mathrm{NS}}$ & N.S. & .087 & 2.34 & $.019^{*}$ \\
\hline & Igual/Superior & 19 & 6.94 & 0.41 & & & & & & & \\
\hline \multirow[t]{3}{*}{ Calcio } & Inferior & 23 & 9.54 & 0.63 & & & & & & & \\
\hline & & & & & -0.89 & 41 & .377 NS & N.S. & .020 & 0.12 & .115 NS \\
\hline & Igual/Superior & 19 & 9.70 & 0.51 & & & & & & & \\
\hline \multirow[t]{3}{*}{ Calcio correg. } & Inferior & 23 & 9.96 & 0.57 & & & & & & & \\
\hline & & & & & -0.14 & 41 & .889 NS & N.S. & .000 & 0.63 & $.527^{\mathrm{NS}}$ \\
\hline & Igual/Superior & 19 & 9.98 & 0.45 & & & & & & & \\
\hline \multirow[t]{3}{*}{ Prod. Calc/Fósf. } & Inferior & 23 & 29.14 & 6.05 & & & & & & & \\
\hline & & & & & -1.63 & 41 & .111 NS & N.S. & .062 & 1.63 & .103 NS \\
\hline & Igual/Superior & 19 & 32.14 & 5.79 & & & & & & & \\
\hline \multirow[t]{2}{*}{ Fósforo } & Inferior & 23 & 3.06 & 0.65 & & & & & & & \\
\hline & Igual/Superior & 19 & 3.33 & 0.67 & -1.32 & 41 & $.194 *$ & N.S. & .042 & 1.24 & .214 NS \\
\hline
\end{tabular}

En el siguiente bloque que analiza variables relativas a la revisión actual (tabla 153) se observa:

- PTH $(\mathrm{P}<.05)$ : Los sujetos del grupo con T-score del C.F. $<-1$ tienen una media más elevada que el resto de casos (127.31 vs 89.41) con un tamaño del efecto moderado (.124). 


\section{RESULTADOS}

- PCR $(P<.10)$ : Existe una diferencia casi significativa $(P<.100$ en ambos test) que parece estar indicando que los casos con T-score $<-1$, tienen un valor medio de PCR mayor aunque con efecto pequeño.

- Interleukina-6 ( $\mathrm{P}<.01)$ : Los pacientes con T-score inferior al corte, presentan una media más elevada que el resto (11.18 vs 2.37 ) aunque el efecto parece muy pequeño.

Tabla 153: Test de diferencia entre dos medias. Asociación de Índice de T-score del C.F. con diversas variables de la analítica en la revisión.-3-

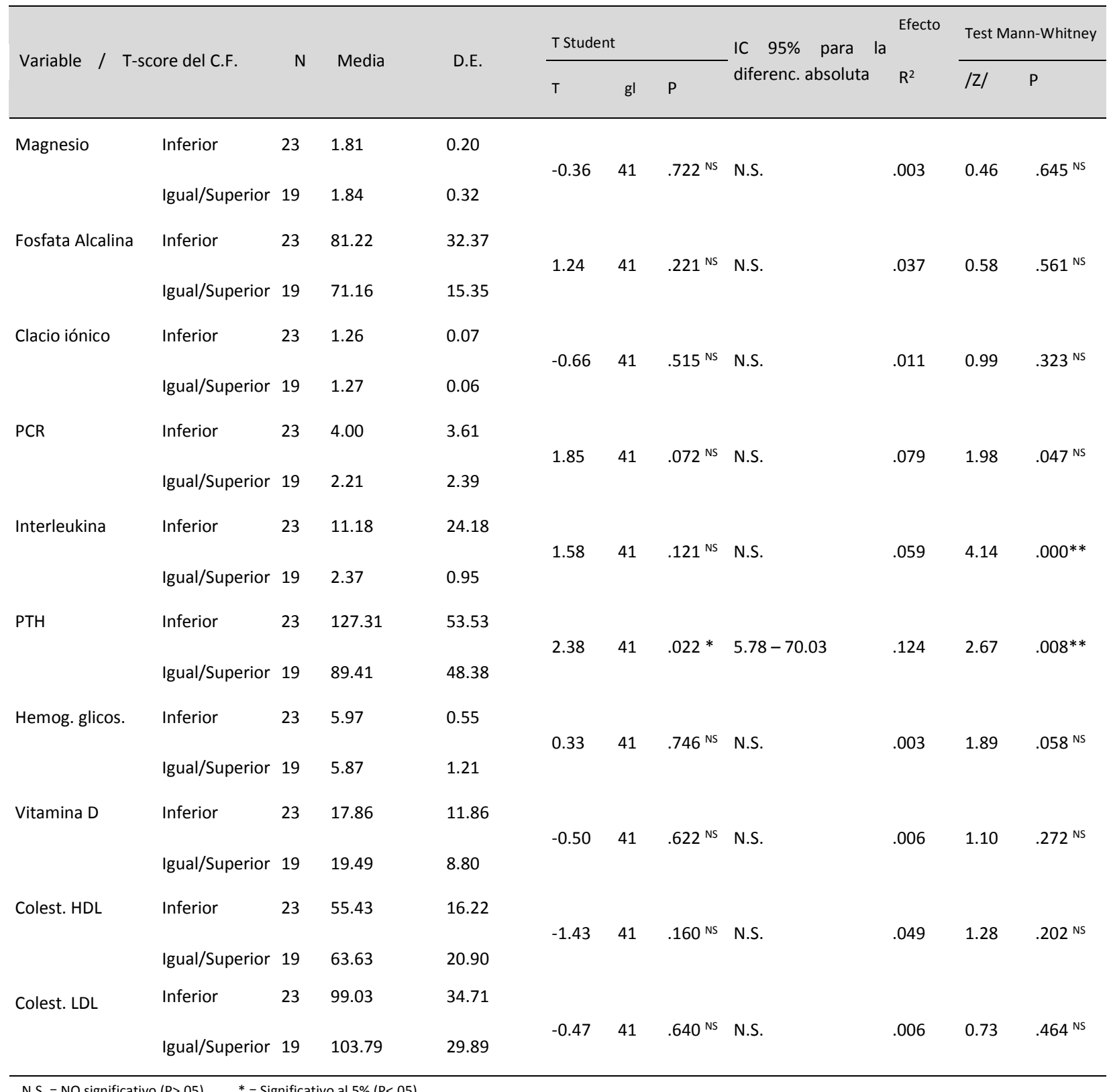

N.S. $=$ NO significativo $(P>05) \quad *=$ Significativo al $5 \%(P<.05)$ 


\section{RESULTADOS}

\section{En este grupo (tabla 154) se observa}

- Cockroft-Gault $(\mathrm{P}<.05)$ : El grupo de pacientes con T-Score < -1 presenta un valor medio más bajo el resto (53.34 vs 69.16 ) con efecto moderado, aunque es cierto que la alternativa de Mann-Whitney solo indica que la diferencia es casi significativa $(P<.100)$.

Tabla 154: Test de diferencia entre dos medias. Asociación de Índice de T-score del C.F. con diversas variables de la analítica en la revisión.-4-

\begin{tabular}{|c|c|c|c|c|c|c|c|c|c|c|c|}
\hline \multirow{2}{*}{ Variable / $\mathrm{T}$} & \multirow{2}{*}{ T-score del C.F. } & \multirow{2}{*}{$\mathrm{N}$} & \multirow{2}{*}{ Media } & \multirow{2}{*}{ D.E. } & \multicolumn{3}{|c|}{ T Student } & \multirow{2}{*}{$\begin{array}{l}\text { IC } 95 \% \text { para la } \\
\text { diferenc. absoluta }\end{array}$} & \multirow{2}{*}{$\begin{array}{l}\text { Efecto } \\
\mathrm{R}^{2}\end{array}$} & \multicolumn{2}{|c|}{ Test Mann-Whitney } \\
\hline & & & & & $\mathrm{T}$ & gl & $\mathrm{P}$ & & & /Z/ & $P$ \\
\hline \multirow[t]{3}{*}{$\mathrm{pH}$} & Inferior & 23 & 7.34 & 0.04 & & & & & & & \\
\hline & & & & & 0.67 & 41 & .508 NS & N.S. & .011 & 0.32 & .751 Ns \\
\hline & Igual/Superior & 19 & 7.33 & 0.03 & & & & & & & \\
\hline \multirow[t]{3}{*}{ Bicarbonato } & Inferior & 23 & 22.27 & 2.71 & & & & & & & \\
\hline & & & & & -0.30 & 41 & .769 NS & N.S. & .002 & 0.33 & .742 NS \\
\hline & Igual/Superior & 19 & 25.52 & 2.56 & & & & & & & \\
\hline \multirow[t]{3}{*}{ Microalbumin. } & Inferior & 23 & 79.99 & 165.56 & & & & & & & \\
\hline & & & & & 0.54 & 41 & .595 NS & N.S. & .007 & 1.54 & .123 NS \\
\hline & Igual/Superior & 19 & 55.99 & 113.84 & & & & & & & \\
\hline \multirow[t]{3}{*}{ MDRDa } & Inferior & 23 & 49.68 & 18.69 & & & & & & & \\
\hline & & & & & -0.69 & 41 & .495 Ns & N.S. & .012 & 0.62 & $.536^{\mathrm{NS}}$ \\
\hline & Igual/Superior & 19 & 53.61 & 18.01 & & & & & & & \\
\hline \multirow[t]{3}{*}{ Cock. Gault } & Inferior & 23 & 53.34 & 18.46 & & & & & & & \\
\hline & & & & & -2.18 & 41 & $.035 *$ & $1.14-30.52$ & .106 & 1.86 & .063 NS \\
\hline & Igual/Superior & 19 & 69.16 & 28.37 & & & & & & & \\
\hline \multirow[t]{3}{*}{ Mayo Quadr. } & Inferior & 23 & 57.47 & 25.19 & & & & & & & \\
\hline & & & & & -1.33 & 41 & .191 NS & N.S. & .042 & 1.12 & $.261^{\mathrm{NS}}$ \\
\hline & Igual/Superior & 19 & 68.03 & 26.08 & & & & & & & \\
\hline \multirow[t]{3}{*}{ CKD-EPI } & Inferior & 23 & 49.21 & 19.95 & & & & & & & \\
\hline & & & & & -1.00 & 41 & .325 NS & N.S. & .024 & 1.04 & .300 NS \\
\hline & Igual/Superior & 19 & 55.35 & 19.81 & & & & & & & \\
\hline \multirow[t]{2}{*}{ FGF-23 } & Inferior & 23 & 4.01 & 11.58 & & & & & & & \\
\hline & Igual/Superior & 19 & 6.56 & 15.10 & -0.62 & 41 & .538 NS & N.S. & .010 & 1.49 & .135 Ns \\
\hline
\end{tabular}




\section{RESULTADOS}

\section{4: ANÁLISIS CORRELACIONAL}

El análisis correlacional de las variables que corresponden a los resultados de las pruebas diagnósticas se puede abordar desde dos perspectivas. Por un lado, puesto que son de tipo cuantitativo se pueden relacionar mediante el habitual coeficiente de Pearson. Las asimetrías de algunas de las variables pueden ser un obstáculo para la detección de asociación con este método, por lo que en su lugar se puede emplear el coeficiente noparamétrico de Spearman que es más resistente a este tipo de desvíos de las variables con respecto al modelo de la normal gaussiana.

Por otro lado puesto que las variables tienen un punto de corte por el que se las ha dicotomizado, también se puede estudiar su relación mediante el test Chi-cuadrado de asociación entre variables categóricas.

Ante estas posibilidades, se ha optado por utilizar los tres procedimientos.

En primer lugar, en la tabla $\mathbf{1 5 5}$ se presenta el resumen de los valores de los coeficientes de Pearson y Spearman, junto a los valores $\mathrm{P}$ de significación respectivos. Cada casilla representa el cruce de la variable de fila con la variable de columna. En la mitad superior a la diagonal principal (en blanco) aparecen los valores de Pearson y en la mitad inferior bajo la citada diagonal se han incluido los valores del coeficiente de Spearman. Se marcan en negrita los significativos para más claridad en su lectura.

Se ha observado relación significativa y con muy elevada entre:

- Score de Agatston y:

○ Índice de Adragao (0.555; $\mathrm{P}<.001)$.

○ Índice de Kauppila $(0.633 ; \mathrm{P}<.001)$.

○ GIM carotideo medio $(0.618 ; \mathrm{P}<.001)$.

○ $\operatorname{GIM}$ carotideo derecho $(0.557 ; \mathrm{P}<.001)$.

- GIM carotideo medio y:

○ GIM carotideo derecho $(0.891 ;(P<.001)$.

○ GIM carotideo izquierdo (0.714; $\mathrm{P}<.001)$ 


\section{RESULTADOS}

- DMO media del cuello femoral y:

○ T-score del cuello femoral $(0.934 ; \mathrm{P}<.001)$.

Se ha encontrado relaciones significativas y de intensidad alta, o al menos moderada alta, entre:

- Score de Agatston y:

○ GIM carótida izquierda $(0.379 ; \mathrm{P}<.01)$.

- Índice de Adragao y:

○ Índice de Kauppila $(0.486 ; \mathrm{P}<.001)$.

- Índice de Kauppila y:

○ $\operatorname{GIM}$ carotideo $(0.408 ; \mathrm{P}<.01)$.

○ GIM carótida derecha: $(0.366 ; \mathrm{P}<.01)$.

- GIM carótida derecha e izquierda $(0.437 ; \mathrm{P}<.01)$.

Se ha encontrado relaciones significativas, aunque moderadas o leves, entre:

- Índice de Adragao y:

○ $\operatorname{GIM}$ carotideo $(0.351 ; \mathrm{P}<.05)$.

○ GIM carótida derecha $(0.347 ; \mathrm{P}<.05)$.

- Índice de Kauppila y:

○ GIM carótida derecha $(0.366 ; \mathrm{P}<.05)$.

○ GIM carótida izquierda $(0.320 ; \mathrm{P}<.05)$.

Algunas asociaciones se quedan al borde de la significación $(P<.100)$ :

- Score de Agatston y:

○ $\operatorname{DMO}(-0.226 ; \mathrm{P}=.075)$.

○ T-score $(-0.230 ; P=.071)$.

- Índice de Adragao y:

○ GIM carotideo izquierdo (0.247; P=.055).

- Índice de Kauppila y:

○ $\operatorname{DMO}(-0.207 ; \mathrm{P}=.094)$.

○ T-score (-0.252; $\mathrm{P}=.054)$. 


\section{RESULTADOS}

Tabla 155: Coeficientes de correlación: Pearson y Spearman. Asociación entre pruebas diagnósticas.

\begin{tabular}{|c|c|c|c|c|c|c|c|c|}
\hline $\begin{array}{l}\text { Pearson } \\
\text { ( } P-s i g) \\
\text { Spearman } \\
(P-s i g)\end{array}$ & $\begin{array}{l}\text { Score } \\
\text { Agatston }\end{array}$ & $\begin{array}{l}\text { Índice } \\
\text { Adragao }\end{array}$ & $\begin{array}{l}\text { Índice } \\
\text { Kauppila }\end{array}$ & $\begin{array}{l}\text { DMO } \\
\text { media } \\
\text { del C.F. }\end{array}$ & $\begin{array}{l}\text { T-score } \\
\text { C.F }\end{array}$ & $\begin{array}{l}\text { GIM } \\
\text { carot. } \\
\text { derecha }\end{array}$ & $\begin{array}{l}\text { GIM } \\
\text { carot. } \\
\text { izquierda }\end{array}$ & $\begin{array}{l}\text { GIM } \\
\text { carotideo }\end{array}$ \\
\hline \multirow[t]{2}{*}{ Score Agatston } & & 0.351 & 0.343 & -0.118 & -0.065 & 0.217 & 0.071 & 0.294 \\
\hline & & $.011^{*}$ & $.012 *$ & $.228^{\mathrm{NS}}$ & $.342 \mathrm{NS}$ & $.081^{\mathrm{NS}}$ & $.326^{\mathrm{Ns}}$ & $.028^{*}$ \\
\hline \multirow[t]{2}{*}{ Índice Adragao } & 0.555 & & 0.524 & -0.055 & -0.176 & 0.237 & 0.093 & 0.215 \\
\hline & $.000^{* *}$ & - & $.000 * *$ & .365 Ns & $.133^{\mathrm{NS}}$ & .063 Ns & $.276 \mathrm{NS}$ & $.083^{\mathrm{NS}}$ \\
\hline \multirow[t]{2}{*}{ Índice Kauppila } & 0.633 & 0.486 & & -0.087 & -0.169 & 0.286 & 0.222 & 0.350 \\
\hline & $.000^{* *}$ & $.000^{* *}$ & & $.293 \mathrm{NS}$ & $.142 \mathrm{Ns}$ & $.032 *$ & $.076 \mathrm{Ns}$ & $.011 *$ \\
\hline \multirow{3}{*}{$\begin{array}{l}\text { DMO media del } \\
\text { C.F. }\end{array}$} & -0.226 & -0.021 & -0.207 & & 0.853 & -0.223 & 0.314 & -0.229 \\
\hline & & & & - & & & & \\
\hline & $.075^{\mathrm{NS}}$ & .447 Ns & .094 NS & & $.000 * *$ & $.078^{\mathrm{NS}}$ & $.021 *$ & .072 Ns \\
\hline \multirow[t]{2}{*}{ T-score C.F } & -0.230 & -0.120 & -0.252 & 0.934 & & -0.127 & -0.030 & -0.128 \\
\hline & .071 Ns & .225 Ns & .054 Ns & $.000^{* *}$ & & $.212 \mathrm{NS}$ & .424 Ns & $.209 \mathrm{Ns}$ \\
\hline \multirow{2}{*}{$\begin{array}{l}\text { GIM } \\
\text { derecha }\end{array}$} & 0.557 & 0.347 & 0.366 & -0.130 & -0.059 & & 0.094 & 0.939 \\
\hline & $.000^{* *}$ & $.011 *$ & $.008^{* *}$ & $.207 \mathrm{Ns}$ & .355 Ns & & .273 Ns & $.000^{* *}$ \\
\hline \multirow{3}{*}{$\begin{array}{l}\text { GIM } \\
\text { izquierda }\end{array}$} & 0.379 & 0.247 & 0.320 & -0.023 & -0.108 & 0.437 & & 0.279 \\
\hline & & & & & & & - & \\
\hline & $.006 * *$ & .055 Ns & $.018^{*}$ & .442 Ns & $.248 \mathrm{NS}$ & $.002 * *$ & & $.035 *$ \\
\hline \multirow[t]{2}{*}{ GIM carotideo } & 0.618 & 0.351 & 0.408 & -0.144 & -0.090 & 0.891 & 0.714 & \\
\hline & $.000^{* *}$ & $.011^{*}$ & $.003 * *$ & $.181^{\text {NS }}$ & .285 NS & $.000^{* *}$ & $.000^{* *}$ & - \\
\hline
\end{tabular}

A continuación se exponen las mismas relaciones entre pares de variables, mediante el método de chi-cuadrado y considerándolas desde su perspectiva como categóricas (Según los puntos de corte considerados previamente). Cada una de las tablas que siguen, se corresponde con una columna de la tabla anterior. En la primera de ellas, se muestra el Score de Agatston con todas las demás y así sucesivamente. 


\section{RESULTADOS}

En la tabla 156, se comprueba como el Score de Agatston está altamente asociado de forma significativa $(P<.01)$ con:

- Índice de Adragao, de forma directa.

- Índice de Kauppila, de forma directa.

- GIM carotideo medio, de forma directa.

- GIM carotideo derecho, de forma directa.

- GIM carotideo izquiedo, de forma indirecta, aunque con menor intensidad $(\mathrm{P}<.05)$.

- T-score del cuello femoral, de forma inversa.

Tabla 156: Test Chi-cuadrado de asociación entre variables. Score de Agatston

\begin{tabular}{|c|c|c|c|c|c|c|}
\hline & & \multicolumn{2}{|c|}{ Score Agatston } & \multirow{2}{*}{$\mathrm{Chi}^{2}$} & \multirow{2}{*}{ gl } & \multirow{2}{*}{ P } \\
\hline & & $<100$ & $=>100$ & & & \\
\hline \multirow[t]{2}{*}{ Índice Adragao } & $<2$ & $51.2 \%(22)$ & $18.6 \%(8)$ & 12.35 & 1 & $.000^{* *}$ \\
\hline & $=>2$ & $4.7 \%(2)$ & $25.6 \%(11)$ & & & \\
\hline \multirow[t]{2}{*}{ Índice Kauppila } & $<3$ & $41.9 \%$ (18) & $7.0 \%(3)$ & 14.88 & 1 & $.000^{* *}$ \\
\hline & $=>3$ & $14.0 \%(6)$ & $37.2 \%(16)$ & & & \\
\hline \multirow[t]{2}{*}{ DMO media CF } & $<0.97$ & $52.4 \%(22)$ & $40.5 \%(17)$ & 0.12 & 1 & $.729 \mathrm{Ns}$ \\
\hline & $=>0.97$ & $4.8 \%(2)$ & $2.4 \%(1)$ & & & \\
\hline \multirow[t]{2}{*}{ T-score CF } & $<-1.0$ & $21.4 \%(9)$ & $33.3 \%(14)$ & 6.74 & 1 & $.009 * *$ \\
\hline & $=>-1.0$ & $35.7 \%(15)$ & $9.5 \%(4)$ & & & \\
\hline \multirow[t]{2}{*}{ GIM carot. dcha } & $<0.75$ & $39.5 \%$ (17) & $11.6 \%(5)$ & 8.41 & 1 & $.004^{* *}$ \\
\hline & $=>0.75$ & $16.3 \%(7)$ & $32.6 \%(14)$ & & & \\
\hline \multirow[t]{2}{*}{ GIM carot. izqda } & $<0.75$ & $37.2 \%(16)$ & $14.0 \%(6)$ & 5.22 & 1 & $.022 *$ \\
\hline & $=>0.75$ & $18.6 \%(8)$ & $30.2 \%(13)$ & & & \\
\hline \multirow[t]{2}{*}{ GIM carotideo } & $<0.75$ & $39.5 \%$ (17) & $9.3 \%(4)$ & 10.52 & 1 & $.001^{* *}$ \\
\hline & $=>0.75$ & $16.3 \%(7)$ & $34.9 \%(15)$ & & & \\
\hline
\end{tabular}

En la tabla 157 se incluye la relación del índice de Adragao con las otras pruebas restantes. Se aprecia relación significativa entre este índice y

- Índice de Kauppila $(P<.01)$, de forma directa.

- $\quad$ GIM carotideo medio (P>.05), de forma directa. 


\section{RESULTADOS}

Así mismo hay casi significación con otras dos pruebas:

- GIM carotideo derecho $(P<.100)$, de forma directa.

- $\quad$ GIM carotideo izquierdo $(P<.100)$, de forma directa.

Tabla 157: Test Chi-cuadrado de asociación entre variables. Índice de Adragao

\begin{tabular}{|c|c|c|c|c|c|c|}
\hline & & \multicolumn{2}{|c|}{ Índice Adragao } & \multirow{2}{*}{$\mathrm{Chi}^{2}$} & \multirow{2}{*}{ gl } & \multirow{2}{*}{$P$} \\
\hline & & $<2$ & $=>2$ & & & \\
\hline \multirow[t]{2}{*}{ Índice Kauppila } & $<3$ & $44.2 \%$ (19) & $4.7 \%(2)$ & 8.34 & 1 & $.004^{* *}$ \\
\hline & $=>3$ & $25.6 \%(11)$ & $25.6 \%(11)$ & & & \\
\hline \multirow[t]{2}{*}{ DMO media CF } & $<0.97$ & $64.3 \%(27)$ & $28,6 \%(12)$ & 1.29 & 1 & .256 NS \\
\hline & $=>0.97$ & $7.1 \%(3)$ & -- & & & \\
\hline \multirow[t]{2}{*}{ T-score CF } & $<-1.0$ & $35.7 \%(15)$ & $19.0 \%(8)$ & 0.96 & 1 & $.327^{\mathrm{NS}}$ \\
\hline & $=>-1.0$ & $35.7 \%(15)$ & $9.5 \%(4)$ & & & \\
\hline \multirow[t]{2}{*}{ GIM carot. dcha } & $<0.75$ & $41.9 \%(18)$ & $9.3 \%(4)$ & 3.10 & 1 & .078 NS \\
\hline & $=>0.75$ & $27.9 \%(12)$ & $20.9 \%$ (9) & & & \\
\hline \multirow[t]{2}{*}{ GIM carot. izqda } & $<0.75$ & $41.9 \%(18)$ & $9.3 \%(4)$ & 3.10 & 1 & .078 NS \\
\hline & $=>0.75$ & $27.9 \%(12)$ & $20.9 \%(9)$ & & & \\
\hline \multirow[t]{2}{*}{ GIM carotideo } & $<0.75$ & $41.9 \%(18)$ & $7.0 \%(3)$ & 4.95 & 1 & $.026 *$ \\
\hline & $=>0.75$ & $27.9 \%(12)$ & $23.3 \%(10)$ & & & \\
\hline
\end{tabular}

N.S. $=$ NO significativo $(\mathrm{P}>05) \quad *=$ Significativo al $5 \%(\mathrm{P}<.05) \quad * *=$ Altamente significativo al $1 \%(\mathrm{P}<.01)$

En negrita las casillas cuyos porcentajes de coincidencia, determinan la significación 


\section{RESULTADOS}

En la tabla 158, se puede verificar como el índice de Kauppila, además de las asociaciones antes comentadas, también está relacionado de forma significativa

- $\quad$-score $(P<.01)$, de forma inversa.

- $\quad$ GIM carotideo medio $(P<.05)$, de forma directa.

- GIM carotideo derecho $(P<.01)$, de forma directa.

Tabla 158: Test Chi-cuadrado de asociación entre variables. Índice de Kauppila

\begin{tabular}{|c|c|c|c|c|c|c|}
\hline & & \multicolumn{2}{|c|}{ Índice Kauppila } & \multirow{2}{*}{$\mathrm{Chi}^{2}$} & \multirow{2}{*}{$\mathrm{Gl}$} & \multirow{2}{*}{$P$} \\
\hline & & $<3$ & $=>3$ & & & \\
\hline \multirow[t]{2}{*}{ DMO media CF } & $<0.97$ & $45.2 \%$ (19) & $47.6 \%(20)$ & 0.36 & 1 & .549 Ns \\
\hline & $=>0.97$ & $4.8 \%(2)$ & $2.4 \%(1)$ & & & \\
\hline \multirow[t]{2}{*}{ T-score CF } & $<-1.0$ & $16.7 \%(7)$ & $38.1 \%(16)$ & 7.78 & 1 & $.005^{* *}$ \\
\hline & $=>-1.0$ & $33.3 \%(14)$ & $11.9 \%(5)$ & & & \\
\hline \multirow[t]{2}{*}{ GIM carot. dcha } & $<0.75$ & $34.9 \%(15)$ & $16.3 \%(7)$ & 6.74 & 1 & $.009^{* *}$ \\
\hline & $=>0.75$ & $14.0 \%(6)$ & $34.9 \%$ (15) & & & \\
\hline \multirow[t]{2}{*}{ GIM carot. izqda } & $<0.75$ & $30.2 \%(13)$ & $20.9 \%(9)$ & 1.90 & 1 & .169 Ns \\
\hline & $=>0.75$ & $18.6 \%(8)$ & $30.2 \%(13)$ & & & \\
\hline \multirow[t]{2}{*}{ GIM carotideo } & $<0.75$ & $32.6 \%(14)$ & $16.3 \%(7)$ & 2.55 & 1 & $.022 *$ \\
\hline & $=>0.75$ & $16.3 \%(7)$ & $34.9 \%(15)$ & & & \\
\hline
\end{tabular}

La tabla 159, muestra que la prueba DMO media del cuello femoral presenta las siguientes asociaciones:

- $\quad$-score $(P<.05)$, de forma directa.

Tabla 159: Test Chi-cuadrado de asociación entre variables. DMO media del cuello del fémur.

\begin{tabular}{|c|c|c|c|c|c|c|}
\hline & & \multicolumn{2}{|c|}{ DMO media CF } & \multirow{2}{*}{$\mathrm{Chi}^{2}$} & \multirow{2}{*}{$\mathrm{Gl}$} & \multirow{2}{*}{$P$} \\
\hline & & $<0.97$ & $=>0.97$ & & & \\
\hline \multirow[t]{2}{*}{ T-score CF } & $<-1.0$ & $54.8 \%(23)$ & -- & 3.91 & 1 & $.048 *$ \\
\hline & $=>-1.0$ & $38.1 \%(16)$ & $7.1 \%(3)$ & & & \\
\hline \multirow[t]{2}{*}{ GIM carot. dcha } & $<0.75$ & $52.4 \%(22)$ & -- & 3.55 & 1 & .059 NS \\
\hline & $=>0.75$ & $40.5 \%$ (17) & $7.1 \%(3)$ & & & \\
\hline \multirow[t]{2}{*}{ GIM carot. izqda } & $<0.75$ & $50.0 \%(21)$ & -- & 3.23 & 1 & .072 NS \\
\hline & $=>0.75$ & $42.9 \%(18)$ & $7.1 \%(3)$ & & & \\
\hline \multirow[t]{2}{*}{ GIM carotideo } & $<0.75$ & $50.0 \%(21)$ & -- & 3.23 & 1 & .072 NS \\
\hline & $=>0.75$ & $42.9 \%(18)$ & $7.1 \%(3)$ & & & \\
\hline
\end{tabular}




\section{RESULTADOS}

Además de todo lo comentado antes, en tabla $\mathbf{1 6 0}$ se aprecia cómo T-score presenta asociación con:

- GIM carotideo derecho (P=.059), de forma inversa.

Tabla 160: Test Chi-cuadrado de asociación entre variables. T-score del cuello del fémur.

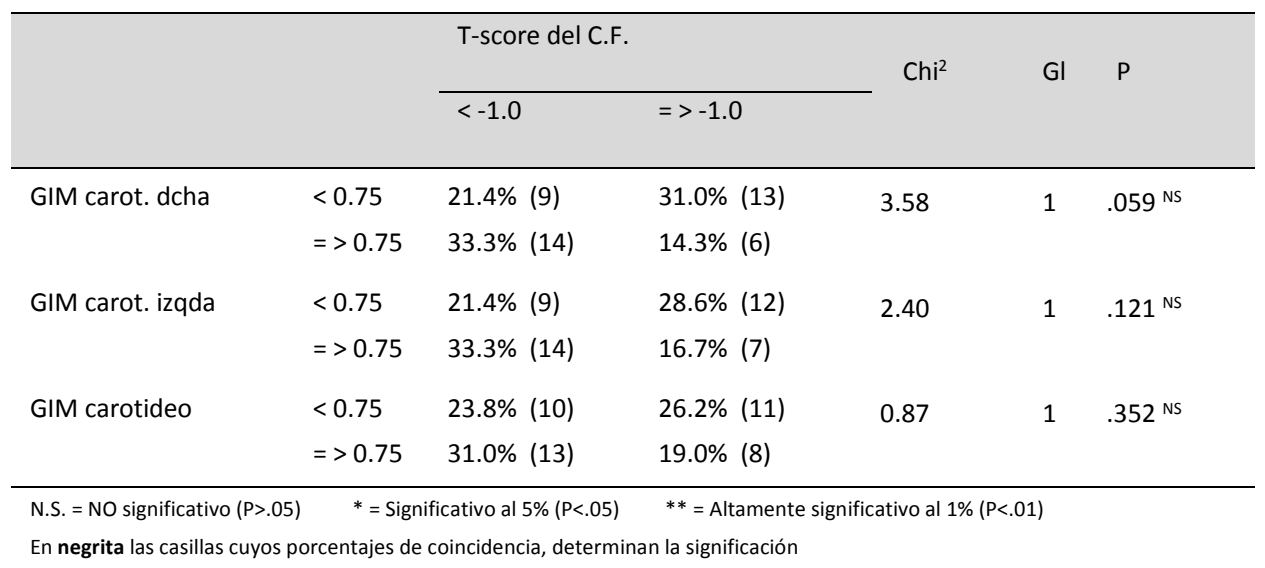

La tabla 161 presenta las relaciones de las pruebas GIM entre sí, quienes mantiene asociaciones altamente significativas $(\mathrm{P}<.001)$ y directas entre sí, como era de esperar.

Tabla 161: Test Chi-cuadrado de asociación entre variables. T-score del cuello del fémur.

\begin{tabular}{|c|c|c|c|c|c|c|}
\hline & & \multicolumn{2}{|c|}{ GIM carot. Dcha } & \multirow{2}{*}{$\mathrm{Chi}^{2}$} & \multirow{2}{*}{$\mathrm{Gl}$} & \multirow{2}{*}{$\mathrm{P}$} \\
\hline & & $<0.75$ & $=>0.75$ & & & \\
\hline \multirow[t]{2}{*}{ GIM carot. Izqda. } & $<0.75$ & $37.2 \%$ (16) & $14.0 \%(6)$ & 8.38 & 1 & $.004^{* *}$ \\
\hline & $=>0.75$ & $14.0 \%(6)$ & $34.9 \%$ (15) & & & \\
\hline \multirow[t]{4}{*}{ GIM carotideo } & $<0.75$ & $41.9 \%$ (18) & $7.0 \%(3)$ & 19.61 & 1 & $.000 * *$ \\
\hline & $=>0.75$ & $9.3 \%(4)$ & $41.9 \%$ (18) & & & \\
\hline & & \multicolumn{2}{|c|}{ GIM carot. Izqda. } & & & \\
\hline & & $<0.75$ & $=>0.75$ & & & \\
\hline \multirow[t]{2}{*}{ GIM carotideo } & $<0.75$ & $44.2 \%$ (19) & $4.7 \%(2)$ & 25.39 & 1 & $.000 * *$ \\
\hline & $=>0.75$ & $7.0 \%(3)$ & $44.2 \%$ (19) & & & \\
\hline
\end{tabular}




\section{RESULTADOS}

\section{5: ESTUDIO DE LA SENSIBILIDAD Y ESPECIFICIDAD DIAGNÓSTICA}

Para este análisis se considera a la prueba de Agatston como el gold standard de referencia. Con ella se contrastan resto de las pruebas diagnósticas y se han estimado los valores de: sensibilidad (tasa de enfermos bien diagnosticados), especificidad (tasa de sanos bien clasificados), valor predictivo positivo (tasa de aciertos entre los positivos de la prueba) y valor predictivo negativo (tasa de aciertos entre los negativos de la prueba). Como índice de coincidencia diagnóstica se ha empleado el coeficiente Kappa de Cohen que se acompaña de su P de significación. Los resultados se resumen en la tabla 109 que sigue.

Se ha objetivado que la prueba que mejor equilibra la sensibilidad (84.2\%) con la especificidad (72.7\%) es el índice de Kauppila (84.2\%) cuya validez diagnóstica es elevada (.583) y altamente significativa $(\mathrm{P}<.001)$. Otras pruebas como T-score y GIM carotideo tienen buena sensibilidad $(>77.0 \%)$ pero pierden especificidad $(<71.0 \%)$ alcanzado una alta validez $(>.400)$ y alta significación $(P<.001)$.

El índice de Adragao tiene una muy especificidad (91.7\%; la mejor de todas) pero baja de formar destacada en sensibilidad (57.9\%; la peor de todas). Aun así consigue alta coincidencia diagnóstica $(.512 ; \mathrm{P}<.001)$.

El GIM carotideo derecho e izquierdo se sitúan por detrás de las anteriores, pero equilibran bien la sensibilidad y la especificidad sobre el $70 \%$ lo que les permite tener validez diagnóstica significativa (al menos $\mathrm{p}<.05$ ).

Finalmente, la prueba DMO media de la CF, a pesar de su alta sensibilidad $(94.4 \%$ la mejor de todas) tiene muy mala especificidad (solo $8.3 \%$ ) que incide en una elevada tasa de falsos positivos (56.4\%). Como consecuencia no alcanza validez significativa ( $P>.05)$. 


\section{RESULTADOS}

Tabla 162: Estudio de la validez diagnóstica de las pruebas. Gold standard: Score de Agatston

\begin{tabular}{|c|c|c|c|c|c|c|c|c|}
\hline \multirow[b]{2}{*}{ Test } & \multicolumn{6}{|c|}{ Estadísticos (\%) } & \multirow{2}{*}{ Kappa } & \multirow{2}{*}{$P$} \\
\hline & S & $\mathrm{VP}+$ & $\mathrm{E}$ & VP- & $\mathrm{F+}$ & $\mathrm{F}_{-}$ & & \\
\hline Índice Adragao & 57.9 & 84.6 & 91.7 & 73.3 & 15.4 & 26.7 & .512 & $.000^{* *}$ \\
\hline Índice Kauppila & 84.2 & 72.7 & 75.0 & 85.7 & 27.3 & 14.3 & .583 & $.000^{* *}$ \\
\hline DMO media CF & 94.4 & 43.6 & 8.3 & 66.7 & 56.4 & 33.3 & .031 & $.729 \mathrm{Ns}$ \\
\hline T-score CF & 77.8 & 60.9 & 62.5 & 78.9 & 39.1 & 21.1 & .400 & $.009 * *$ \\
\hline GIM carot. Dcha & 73.7 & 66.7 & 70.8 & 77.3 & 33.3 & 22.7 & .440 & $.004 * *$ \\
\hline GIM carot. Izqda. & 68.4 & 61.9 & 66.7 & 72.7 & 38.1 & 27.3 & .347 & $.022 *$ \\
\hline GIM carotideo & 78.9 & 68.2 & 70.8 & 81.0 & 31.8 & 19.0 & .490 & $.001^{* *}$ \\
\hline & & & & & & .01) & & \\
\hline
\end{tabular}

\section{6: MODELO DE REGRESIÓN PARA PREDECIR EL GOLD}

\section{STANDARD}

Procederemos finalmente a construir un modelo predictivo de la variable Score de Agatston, tomada como gold standard. Aunque la naturaleza cuantitativa original de esta variable permitiría a priori la construcción del modelo mediante el método de regresión lineal, las asimetrías de algunas de las variables, junto a los buenos resultados obtenidos cuando la variable a predecir se ha dicotomizado, hacen recomendable emplear en su lugar el procedimiento de regresión logística binaria. Este método además permite obtener entre sus resultados el valor de la Odds Ratio (OR) que facilita la interpretación de las asociaciones.

Las variables que se van a emplear como posibles predictores son las pruebas que han aportado relación significativa con el gold standard. Todas las demás, al no tener una asociación estadísticamente significativa no van a tener suficiente capacidad predictiva como para formar parte de ningún modelo.

En primer lugar se realiza un estudio univariante, obteniendo los estadísticos que describen la asociación que tiene cada factor predictor, por sí solo, con respecto a la variable criterio que se pretende predecir. 


\section{RESULTADOS}

Como se puede comprobar en ella, algunos de los factores que tenían significación en el análisis bivariado ya no la presentan $(P>.05)$ desde la perspectiva de un modelo predictivo univariante: Glucosa, Triglicéridos y Albuminuria, todos ellos en la analítica realizada en la revisión actual.

Los factores con mayor potencia predictiva son, por este orden:

- Índice de Kaupilla $(P<.001): O R=16.00$ y efecto $\left(R^{2}\right)=.417$.

- Edad en el momento del trasplante $(P<.001)$ : OR= 1.14 por año y efecto: .413 (edad en la revisión tiene valores similares, pero no pueden ser utilizadas conjuntamente por colinealidad).

- Índice de Adragao ( $P<.001)$ : OR= 15.12 y efecto: .351 .

- Volumen Diuresis pre-trasplante $(P<.01)$ : $O R=0.99$ por unidad de media y efecto: .309 .

- GIM carotideo $(P<.01):$ OR= 9.11 y efecto .304.

- Urea en la revisión $(P<.01)$ : OR=1.04 por unidad de medida y efecto: 301 .

Los demás factores tienen peso significativo $(P<.05)$ y efectos menores a .300 (tabla 163). 


\section{RESULTADOS}

Tabla 163: Regresión logística univariante. Predicción del Score de Agatston; categoría criterio: valor >=100

\begin{tabular}{|c|c|c|c|c|c|c|c|}
\hline Factor predictor & Coeficiente B & E.T. (B) & OR & IC al $95 \%$ de OR & Wald & P-valor & $\mathrm{R}^{2}$ \\
\hline Índice Adragao (+) & 2.716 & 0.873 & 15.12 & $2.73-83.64$ & 9.69 & $.000 * *$ & .351 \\
\hline Índice Kauppila (+) & 2.773 & 0.786 & 16.00 & $3.43-74.70$ & 12.44 & $.000 * *$ & 417 \\
\hline T-score cuello fémur (+) & 1.764 & 0.707 & 5.83 & $1.46-23.30$ & 6.23 & $.013 *$ & .207 \\
\hline GIM carótida derecha (+) & 1.917 & 0.688 & 6.80 & $1.77-26.18$ & 7.77 & $.005^{* *}$ & .246 \\
\hline GIM carótida izquierda (+) & 1.466 & 0.657 & 4.33 & $1.20-15.69$ & 4.99 & $.026 *$ & .156 \\
\hline GIM carotideo $(+)$ & 2.209 & 0.720 & 9.11 & $2.22-37.34$ & 9.41 & $.002^{* *}$ & .304 \\
\hline Vol. Diuresis previo al traspl. & -0.001 & 0.000 & 0.99 & $0.99-0.99$ & 7.45 & $.006^{* *}$ & .309 \\
\hline Hemoglobina pre-trasplante & -0.535 & 0.227 & 0.58 & $0.37-0.91$ & 5.57 & $.018 *$ & .193 \\
\hline Hematocrito pre-trasplante & -0.177 & 0.075 & 0.84 & $0.72-0.97$ & 5.59 & $.018^{*}$ & .197 \\
\hline Colesterol total pre-trasplante & -0.022 & 0.009 & 0.98 & $0.96-0.99$ & 6.56 & $.010^{*}$ & .255 \\
\hline Fosfatasa alcalina pre-traspl. & 0.019 & 0.008 & 1.02 & $1.00-1.03$ & 5.18 & $.023 *$ & .231 \\
\hline Glucosa al alta & 0.031 & 0.016 & 1.03 & $1.00-1.06$ & 3.84 & $.049 *$ & .176 \\
\hline Prod. Calcio/Fósforo al alta & -0.131 & 0.054 & 0.88 & $0.79-0.98$ & 5.92 & $.015^{*}$ & .252 \\
\hline Fósforo al alta & -1.022 & 0.487 & 0.36 & $0.14-0.93$ & 4.41 & $.036 *$ & .181 \\
\hline Bicarbonato al alta & 0.217 & 0.111 & 1.24 & $1.00-1.54$ & 3.79 & $.050^{*}$ & .126 \\
\hline Urea en la revisión & 0.043 & 0.016 & 1.04 & $1.01-1.08$ & 7.49 & $.006 * *$ & .301 \\
\hline Glucosa en la revisión & 0.033 & 0.020 & 1.03 & $0.99-1.08$ & 2.66 & $.103^{\mathrm{NS}}$ & .150 \\
\hline Ácido úrico en la revisión & 0.533 & 0.259 & 1.70 & $1.03-2.83$ & 4.25 & $.039 *$ & .198 \\
\hline Triglicéridos en la revisión & 0.012 & 0.006 & 1.01 & $1.00-1.02$ & 3.70 & .054 Ns & .142 \\
\hline Hemoglob. glicosilada en la rev. & 1.989 & 0.782 & 7.31 & $1.58-33.82$ & 6.47 & $.011 *$ & .291 \\
\hline Microalbuminuria en la revisión & 0.004 & 0.003 & 1.00 & $0.99-1.01$ & 1.59 & $.207^{\mathrm{NS}}$ & .066 \\
\hline Cockroft Gault en la revisión & -0.033 & 0.016 & 0.97 & $0.94-0.99$ & 4.15 & $.042 *$ & .152 \\
\hline Sexo (masc.) & 1.804 & 0.855 & 6.07 & $1.14-32.41$ & 4.46 & $.035 *$ & .162 \\
\hline Edad en el trasplante & 0.132 & 0.042 & 1.14 & $1.05-1.24$ & 9.69 & $.002 * *$ & .413 \\
\hline Edad en la revisión & 0.125 & 0.042 & 1.13 & $1.04-1.23$ & 9.01 & $.003 * *$ & .387 \\
\hline Modalidad diálisis (HD) & 1.507 & 0.751 & 4.51 & $1.04-19.66$ & 4.03 & $.045^{*}$ & .136 \\
\hline Antecedente de Diabetes & 2.362 & 1.134 & 10.62 & $1-15-98-09$ & 4.34 & $.037^{*}$ & .180 \\
\hline
\end{tabular}

Tras esto se procedió a construir un modelo de regresión múltiple (análisis multivariante) que cuente con todos aquellos factores (de entre los significativos de la tabla anterior) que aporten una mejora en la capacidad predictiva del mismo. Para ello, el procedimiento que se ha seguido es incluir por orden de mayor a menor capacidad predictiva, los factores, añadiéndoles de uno en uno. Es el conocido como método de los pasos sucesivos. El procedimiento se detiene cuando ya no se encuentran factores que mejoren significativamente la capacidad predictiva del modelo del paso anterior. 


\section{RESULTADOS}

\section{Modelo 1}

El mejor de los modelos posibles, desde el punto de vista estadístico se resumen en la tabla 164. Este modelo es altamente significativo $(P<.001$ en el test Omnibus) y explica un elevado $81 \%$ de la variabilidad total del criterio a predecir. El test de bondad de ajuste de Hosmer-Lemeshow indica que no existen diferencias significativas ( $P>$.05) entre el estado real de los sujetos y aquel pronosticado con el modelo, logrando un $86 \%$ de casos correctamente clasificados ( $\mathrm{S}=84.2 \%$ y $E=87.5 \%)$, constituyendo un buen modelo predictivo.

Los factores que entran en dicho de forma significativa son:

- $\quad$ Edad en el momento del trasplante (OR=1.22 por año; $P<.05)$.

- Índice de Adragao (OR=37.45; $\mathrm{P}<.05)$.

- Urea en la revisión actual (OR=1.06 por unidad de medida; $P<.05)$.

- Volumen de diuresis residual previo al trasplante (OR=0.998; $\mathrm{P}<.05)$.

También se observa que la variable Triglicéridos en la revisión es casi significativa $(P<.100)$ y es posible que una muestra más grande pueda entrar en el modelo y mejorar aún más la capacidad predictiva del mismo. 


\section{RESULTADOS}

Tabla 164: Regresión logística Múltiple. Predicción del Score de Agatston; categoría criterio: valor >=100

\begin{tabular}{|c|c|c|c|c|c|c|c|c|c|c|}
\hline \multirow[b]{2}{*}{ Variables Incluidas } & \multicolumn{10}{|c|}{ Coeficientes del modelo de Regresión } \\
\hline & & & & $\mathrm{B}$ & E.T. (B) & Wald & P-sig & OR & IC 95 & $\%$ de la OR \\
\hline \multicolumn{4}{|c|}{ Edad en el momento del trasplante } & 0.201 & 0.081 & 6.17 & $.013^{*}$ & 1.22 & 1.04 & $4-1.43$ \\
\hline \multicolumn{4}{|l|}{ Test Adragao (+) } & 3.623 & 1.570 & 5.33 & $.021^{*}$ & 37.45 & 1.72 & $2-811.96$ \\
\hline \multicolumn{4}{|l|}{ Urea en la revisión } & 0.056 & 0.026 & 4.84 & $.028 *$ & 1.06 & 1.01 & $1-1.11$ \\
\hline \multicolumn{4}{|c|}{ Volumen Diuresis previo al trasplante } & -0.002 & 0.001 & 4.26 & $.039 *$ & 0.998 & 0.99 & $96-0.999$ \\
\hline \multicolumn{4}{|l|}{ Constante poblacional } & -17.255 & 6.024 & 8.21 & $.004^{* *}$ & - & - & \\
\hline & B & Wald & P-sig & \multicolumn{7}{|c|}{ Resumen del modelo final } \\
\hline Índice Kauppila (+) & 1.596 & 1.21 & .271 Ns & \multicolumn{4}{|c|}{ Test Ómnibus significación modelo: } & \multicolumn{3}{|c|}{$\mathrm{Chi}^{2}=39.85 ; \quad \mathrm{P}=.000^{* *}$} \\
\hline T-score cuello fémur (+) & 0.050 & 0.00 & $.971^{\mathrm{NS}}$ & \multicolumn{4}{|c|}{ Bondad de ajuste $(\mathrm{HL})$ : } & \multicolumn{3}{|c|}{$\mathrm{Chi}^{2}=4.49 ; \quad \mathrm{P}=.811 \mathrm{Ns}$} \\
\hline GIM carótida derecha (+) & 2.038 & 2.17 & $.141^{\mathrm{NS}}$ & \multicolumn{4}{|c|}{ Ajuste $\mathrm{R}^{2}$ Nagelkerke: } & \multicolumn{3}{|l|}{.809} \\
\hline GIM carótida izquierda (+) & 2.947 & 2.23 & .135 Ns & \multicolumn{4}{|c|}{ Porcentaje total clasificación correcta: } & \multicolumn{3}{|l|}{$86.0 \%$} \\
\hline GIM carotideo (+) & 3.180 & 2.42 & .120 NS & \multicolumn{4}{|c|}{ Sensibilidad: } & \multicolumn{3}{|l|}{$84.2 \%$} \\
\hline Hemoglobina pre-trasplante & -1.174 & 2.58 & $.108 \mathrm{NS}$ & \multicolumn{4}{|c|}{ Especificidad: } & \multicolumn{3}{|l|}{$87.5 \%$} \\
\hline Hematocrito pre-trasplante & -1.643 & 0.84 & .361 NS & & & & & & & \\
\hline Colesterol total pre-traspl. & 0.008 & 0.24 & .626 NS & & & & & & & \\
\hline Fosfatasa alcalina pre-traspl. & 0.014 & 1.41 & .235 NS & & & & & & & \\
\hline Glucosa al alta & 0.049 & 1.39 & $.238 \mathrm{NS}$ & & & & & & & \\
\hline Prod. Calcio/Fósforo al alta & -0.042 & 0.23 & $.633^{\mathrm{NS}}$ & & & & & & & \\
\hline Fósforo al alta & -0.122 & 0.02 & .889 NS & & & & & & & \\
\hline Bicarbonato al alta & 0.142 & 0.38 & $.536^{\mathrm{Ns}}$ & & & & & & & \\
\hline Glucosa en la revisión & 0.001 & 0.00 & $.980^{\mathrm{NS}}$ & & & & & & & \\
\hline Ácido úrico en la revisión & 0.644 & 1.27 & $.259 \mathrm{Ns}$ & & & & & & & \\
\hline Triglicéridos en la revisión & 0.036 & 2.99 & $.084^{\mathrm{NS}}$ & & & & & & & \\
\hline Hemoglob. Glicos. en la rev. & 0.749 & 0.34 & $.5611^{\mathrm{NS}}$ & & & & & & & \\
\hline Microalbuminuria en la rev, & 0.003 & 0.17 & $.683^{\mathrm{NS}}$ & & & & & & & \\
\hline Cockroft Gault en la revisión & 0.061 & 2.08 & .149 NS & & & & & & & \\
\hline Sexo (masc.) & 1.801 & 1.50 & $.221 \mathrm{Ns}$ & & & & & & & \\
\hline Modalidad diálisis (HD) & 1.193 & 0.60 & $.440 \mathrm{NS}$ & & & & & & & \\
\hline Antecedente de Diabetes & 4.335 & 0.90 & $.342^{\mathrm{NS}}$ & & & & & & & \\
\hline
\end{tabular}

\section{Modelo 2}

Es un modelo similar al anterior desde el punto de vista estadístico. También es altamente significativo ( $P<.001$ en el test Omnibus) y explica un $79 \%$ de la variabilidad total, algo menos que el anterior. Según el test Hosmer-Lemeshow no hay diferencias significativas ( $P>.05)$ entre el estado real de los sujetos y el pronosticado, alcanzando un $86 \%$ de casos correctamente clasificados ( $\mathrm{S}=83.3 \%$ y $\mathrm{E}=89.5 \%$ ) que son valores muy similares a los del modelo anterior. En consecuencia es muy buen modelo predictivo. Los factores significativos que los componen son: 


\section{RESULTADOS}

- $\quad$ Edad en el momento del trasplante (OR=1.39 por año; $\mathrm{P}<.05)$.

- $\quad$ GIM carotideo medio (OR=115.43; $P<.05)$.

- Volumen de diuresis previo al trasplante $(O R=0.997 ; P<.05)$

Este modelo incluye un predictor menos que el modelo 1.

Tabla 165: Regresión logística Múltiple. Predicción del Score de Agatston; categoría criterio: valor >=100

\begin{tabular}{|c|c|c|c|c|c|c|c|c|c|c|}
\hline \multirow[b]{2}{*}{ Variables Incluidas } & \multicolumn{10}{|c|}{ Coeficientes del modelo de Regresión } \\
\hline & & & & B & E.T. (B) & Wald & P-sig & $\mathrm{OR}$ & \multicolumn{2}{|c|}{ IC $95 \%$ de la OF } \\
\hline \multicolumn{4}{|c|}{ Edad en el momento del trasplante } & 0.326 & 0.127 & 6.56 & $.010 *$ & 1.39 & 1.08 & $8-1.78$ \\
\hline Test GIM carotideo (+) & & & & 4.7749 & 1.985 & 5.72 & $.017 *$ & 115.43 & 2.36 & $6-5649.82$ \\
\hline Volumen Diuresis previo al tra & plante & & & -0.003 & 0.001 & 5.39 & $.020 *$ & 0.997 & 0.99 & $94-0.999$ \\
\hline Constante poblacional & & & & -21.452 & 80.359 & 6.59 & $.010^{*}$ & - & - & \\
\hline & B & Wald & P-sig & \multicolumn{7}{|c|}{ Resumen del modelo final } \\
\hline Test de Adrago & 1.669 & 1.53 & $.216 \mathrm{NS}$ & \multicolumn{4}{|c|}{ Test Ómnibus significación modelo: } & \multicolumn{3}{|c|}{$\mathrm{Chi}^{2}=38.43 ; \quad \mathrm{P}=.000^{* *}$} \\
\hline Índice Kauppila (+) & 1.380 & 1.40 & $.237 \mathrm{Ns}$ & \multicolumn{4}{|c|}{ Bondad de ajuste $(\mathrm{HL})$ : } & \multicolumn{3}{|c|}{$\mathrm{Chi}^{2}=1.82 ; \quad \mathrm{P}=.986 \mathrm{Ns}$} \\
\hline T-score cuello fémur (+) & -2.480 & 1.50 & $.221 \mathrm{Ns}$ & \multicolumn{4}{|c|}{ Ajuste $R^{2}$ Nagelkerke: } & \multicolumn{3}{|l|}{.791} \\
\hline GIM carótida derecha (+) & -0.016 & 0.00 & $.990 \mathrm{NS}$ & \multicolumn{4}{|c|}{ Porcentaje total clasificación correcta: } & \multicolumn{3}{|l|}{$86.0 \%$} \\
\hline GIM carótida izquierda (+) & 1.119 & 0.25 & $.617^{\mathrm{NS}}$ & \multicolumn{4}{|c|}{ Sensibilidad: } & \multicolumn{3}{|l|}{$83.3 \%$} \\
\hline Hemoglobina pre-trasplante & -0.728 & 2.74 & .098 NS & \multicolumn{4}{|c|}{ Especificidad: } & \multicolumn{3}{|l|}{$89.5 \%$} \\
\hline Hematocrito pre-trasplante & -0.267 & 3.28 & $.070^{\mathrm{NS}}$ & & & & & & & \\
\hline Colesterol total pre-traspl. & -0.034 & 3.11 & .078 NS & & & & & & & \\
\hline Fosfatasa alcalina pre-traspl. & 0.019 & 1.30 & .254 NS & & & & & & & \\
\hline Glucosa al alta & 0.061 & 2.22 & .137 Ns & & & & & & & \\
\hline Prod. Calcio/Fósforo al alta & -0.087 & 0.93 & $.336 \mathrm{NS}$ & & & & & & & \\
\hline Fósforo al alta & -0.913 & 1.03 & $.311^{\mathrm{NS}}$ & & & & & & & \\
\hline Bicarbonato al alta & 0.304 & 1.79 & $.181^{\mathrm{Ns}}$ & & & & & & & \\
\hline Urea en la revisión & 0.025 & 1.07 & .301 NS & & & & & & & \\
\hline Glucosa en la revisión & -0.015 & 0.40 & $.524 \mathrm{NS}$ & & & & & & & \\
\hline Ácido úrico en la revisión & 0.952 & 2.36 & $.124^{\mathrm{NS}}$ & & & & & & & \\
\hline Triglicéridos en la revisión & 0.013 & 1.11 & $.291 \mathrm{NS}$ & & & & & & & \\
\hline Hemoglob. Glicos. en la rev. & 2.027 & 1.25 & .264 NS & & & & & & & \\
\hline Microalbuminuria en la rev, & 0.003 & 0.30 & $.587^{\mathrm{NS}}$ & & & & & & & \\
\hline Cockroft Gault en la revisión & 0.006 & 0.06 & $.803^{\mathrm{NS}}$ & & & & & & & \\
\hline Sexo (masc.) & 2.341 & 2.61 & $.106^{\mathrm{NS}}$ & & & & & & & \\
\hline Modalidad diálisis (HD) & 2.618 & 1.81 & $.178^{\mathrm{NS}}$ & & & & & & & \\
\hline Antecedente de Diabetes & 2.556 & 0.94 & .332 Ns & & & & & & & \\
\hline
\end{tabular}


DISCUSIÓN

DISCUSIÓN 


\section{DISCUSIÓN}

\section{1: INTRODUCCIÓN}

La enfermedad óseo-mineral constituye uno de los trastornos metabólicos más característicos de la enfermedad renal crónica. La disfunción del riñón induce una progresiva dificultad para eliminar fósforo del organismo. La pérdida de masa renal funcional provoca el descenso de los niveles plasmáticos de calcitriol, lo que facilita la aparición de hipocalcemia y de hiperparatiroidismo secundario al fallo renal. La hiperfunción paratiroidea induce cambios en el tejido óseo que se traducen en una disminución del hueso cortical y de la resistencia ósea, aumentando el riesgo de presentar fracturas.

El desajuste del metabolismo óseo-mineral propio de la enfermedad renal conlleva una serie de importantes consecuencias que afectan a múltiples órganos y tejidos. La hiperfosforemia, acompañada en ocasiones de elevaciones de la concentración sérica de calcio y el estrés oxidativo propio del estado urémico ocasionan cambios adaptativos en las células musculares lisas que componen la pared de los vasos. Dichos cambios incluyen la formación y el depósito de cristales de hidroxiapatita en el interior de las células, que modifican su fenotipo contráctil habitual por uno osteo/condrogénico (85). Estas células de fenotipo alterado se comportan como núcleos de osificación, pero la hiperfosforemia actúa también a otros niveles, facilitando el depósito de calcificaciones lineales en la capa elástica de la arteria $(\mathbf{8 2}, \mathbf{8 9 - 9 0 )}$. El desarrollo de calcificaciones vasculares es un proceso íntimamente ligado al avance de la aterosclerosis y conduce a un aumento de rigidez de los vasos lo que conlleva el desarrollo de un flujo deficiente a su través y a la aparición de complicaciones cardiovasculares.

El trasplante renal constituye actualmente el tratamiento renal sustitutivo de primera elección en todos aquellos pacientes en los que no exista una contraindicación para su ejecución. El trasplante renal permite la recuperación de la función renal y el incremento de la tasa de filtrado glomerular, corrigiendo completa o parcialmente muchos de los trastornos propios de la enfermedad renal. En los últimos años, el trasplante renal como 


\section{DISCUSIÓN}

tratamiento ha sido testigo de importantes mejoras, como la introducción en la práctica clínica de nuevos fármacos inmunosupresores de mayor eficacia y con un mejor perfil de seguridad.

Sin embargo y pese a la recuperación en la función renal, el riñón trasplantado no soluciona completamente los desajustes producidos en el metabolismo óseo-mineral y las lesiones presentes en el árbol vascular. Esto se debe a una combinación de factores propios del enfermo, como su evolución en diálisis o el grado de osteodistrofia renal previa al trasplante, como otros propios del mismo tratamiento renal sustitutivo, como una función renal del injerto deficiente o el efecto de la medicación inmunosupresora. La consecuencia más importante del mantenimiento del desequilibrio es el desarrollo de enfermedad cardiovascular. La enfermedad cardiovascular constituye actualmente la causa principal de mortalidad en la población receptora de trasplante renal y la causa más frecuente de pérdida de un injerto renal funcional.

Uno de los retos más importantes en la actualidad es el avance en el conocimiento de los mecanismos fisiopatológicos de la lesión cardiovascular en los receptores de trasplante renal, con el fin de incrementar la supervivencia a largo plazo tanto de paciente como del injerto. Para ello, es preciso profundizar en las bases bioquímicas del metabolismo óseo-mineral en todos los estadios de la enfermedad renal crónica, así como su interacción con otros factores de riesgo cardiovascular, tanto tradicionales como propios de la enfermedad renal crónica y del trasplante renal. De esta forma será posible actuar sobre los fundamentos de la lesión cardiovascular y mejorar el pronóstico y la supervivencia tanto del paciente como del injerto.

El objetivo de este estudio fue analizar el estado del metabolismo óseo-mineral en una muestra de pacientes trasplantados en el Servicio de Nefrología del Hospital Clínico Universitario de Valladolid. El objetivo de dicho análisis fue el de determinar el estado real de las alteraciones metabólicas tras la realización de un trasplante renal funcional, así como valorar el impacto de las mismas en el árbol cardiovascular de los enfermos y las consecuencias clínicas que comportan en los pacientes. Asimismo realizamos una comparación entre las diferentes pruebas diagnósticas que nos permiten valorar el 


\section{DISCUSIÓN}

estado del árbol cardiovascular de los pacientes con el fin de determinar la relación existente entre ellas y con diferentes parámetros antropométricos y analíticos propios de cada enfermo.

A continuación discutiremos las características socio-demográficas de la población objeto de este estudio, así como el estado del metabolismo óseo-mineral tanto previo al trasplante como en el momento actual y su relación con el desarrollo de lesiones cardiovasculares.

\section{2: DATOS DEL DONANTE}

En nuestra muestra la edad media de los donantes fue de $46,4 \pm 16$ años. Un $79 \%$ de los donantes fueron varones frente a un $21 \%$ de donantes mujeres.

La edad de los donantes de nuestra muestra es similar a la observada por otros autores en España, como Ballesteros en un trabajo previo realizado a partir de la misma población de base de pacientes trasplantados por el Servicio de Nefrología del Hospital Clínico de Valladolid (208), Miranda (286) o Serón (287). El envejecimiento progresivo de los donantes de riñón de cadáver es un fenómeno que se viene observando desde hace más de 15 años (288), debido a múltiples causas, como el aumento progresivo de pacientes en lista de espera para trasplante renal, lo que incrementa la demanda de órganos o la disminución del porcentaje de donaciones procedentes de fallecimientos debidos a traumatismos craneoencefálicos, aumentando la proporción de donaciones tras la muerte por accidente cerebro-vascular, más frecuente en población de edad avanzada.

Todo esto ha condicionado la necesidad de adaptar los criterios de aceptación de los donantes a la situación actual, especialmente respecto a su edad. Este incremento progresivo de la edad se comprueba revisando los datos publicados en la memoria de la ONT de 2012 (289), en la que la edad media de los donantes fue de 58,3 $\pm 18,4$ años, significativamente superior a la observada en nuestra muestra. En esta misma memoria 


\section{DISCUSIÓN}

se observa como en Castilla y León existe un amplio porcentaje de donantes de edad superior a 70 años (41,5\%), porcentaje sólo superado por Cantabria y La Rioja, debido al envejecimiento de la población general de dicho territorio.

Nuestra muestra presenta un mayor porcentaje de varones $(79,1 \%)$ respecto a la recogida por Ballesteros (64,8\%) (208). Estas diferencias se deben probablemente a que nuestra muestra presenta un tamaño inferior al estudiado por Ballesteros, que obtiene resultados muy similares a los registrados por Miranda (286). En 2012, un 61,8\% de los donantes españoles fueron varones, según los datos de la ONT (289).

\section{3: DATOS DEL RECEPTOR}

La edad media de los receptores que participaron en nuestra muestra en el momento del trasplante fue de 49,83 $\pm 12,23$ años en el momento de la realización del trasplante, siendo la franja de edad más frecuente la de 51-60 años.

Nuestros datos son similares a los obtenidos por Ballesteros, con una edad de $48,8 \pm$ 13,3 años (208) y por Serón dentro del Spanish Chronic Allograft Study Group, dónde registraron una media de edad del receptor de 47 años, a partir de una muestra de 3365 pacientes incluidos en el estudio (287). Actualmente la media de edad del paciente trasplantado renal se sitúa en los 50 años, con un 35\% superando los 55 años. Dicho envejecimiento constituye un importante factor de riesgo cardiovascular, especialmente en comunidades como Castilla y León que presentan una población general más envejecida.

Asimismo, un $72,1 \%$ de los pacientes de la muestra eran varones, frente a un $27,9 \%$ de mujeres. El porcentaje de varones es algo superior en nuestra muestra si lo comparamos con un 63,3\% de receptores varones observado por Ballesteros (208). La razón de dicha diferencia se fundamenta probablemente en las diferencias de tamaño muestral, mayor en el caso de Ballesteros y que obtiene un porcentaje más similar al ofrecido por la ONT en su memoria de 2012, con una proporción de un 61\% de receptores varones (289). 


\section{DISCUSIÓN}

Respecto a la enfermedad renal de base de los receptores, la nefropatía túbulointersticial $(23,3 \%)$ supuso la causa más frecuente de ERC terminal, seguida de las glomerulonefritis (20,9\%), la poliquistosis renal $(20,9 \%)$, la nefroangioesclerosis $(7 \%)$, la nefropatía diabética (7\%) y finalmente las nefropatías no filiadas (20,9\%). Los porcentajes difieren respecto a la muestra estudiada por Ballesteros, en la que la causa más común de ERC terminal fueron las glomerulonefritis (25,9\%), seguidas por las nefropatías no filiadas $(25,2 \%)$, la nefropatía túbulo-intersticial $(20,1 \%)$, la poliquistosis renal (12,9\%), la nefropatía diabética (5\%) y la nefroangioesclerosis (2,9\%). En ambas muestras destacan las glomerulonefritis y la NTI como origen de aproximadamente dos quintas partes de todos los casos de ERC terminal, junto con un bajo porcentaje de nefropatías secundarias a la diabetes mellitus y a la HTA y un amplio porcentaje de nefropatías no filiadas (208).

Dichos porcentajes establecen notables diferencias respecto a otros registros. El informe 2006 de diálisis y trasplante de la SEN notifica un $23,4 \%$ de pacientes con nefropatía diabética, constituyendo la causa más frecuente de ERC terminal y presentando además un $20,5 \%$ de nefropatías no filiadas (290). A nivel internacional, el Annual Report 2011 de la ERA-EDTA presenta las glomerulonefritis como la causa más común de ERC terminal, seguida de cerca por la nefropatía diabética y por las nefropatías de origen no filiado, aunque la prevalencia de cada una varía notablemente entre los países incluidos en la muestra (291).

El registro estadounidense USRDS presenta en sus resultados la nefropatía diabética como la primera causa de ERC terminal en población norteamericana, seguida por la nefroangioesclerosis y las glomerulonefritis (292). En esta muestra, el número de nefropatías no filiadas es considerablemente inferior. Como comparación, el registro USRDS informa de una prevalencia de ERC terminal secundaria a nefropatías no filiadas de 84,9 pmp, mientras que los resultados de Castilla y León recogidos en el Annual Report de la ERA-EDTA es de 300,1 pmp (291, 292). Sin embargo, McDonald y colaboradores notificaron en población australiana un porcentaje notablemente mayor de nefropatías no filiadas (43\%), con una distribución similar respecto a 


\section{DISCUSIÓN}

glomerulonefritis (22\%) y nefropatía diabética (18\%), mientras que la poliquistosis renal presentaba un porcentaje inferior (10\%) (293).

Las diferencias observadas relativas a la prevalencia de ERC secundaria a nefropatía diabética en nuestra muestra comparada con los registros USRDS, ERA-EDTA y ANZDATA, muy inferior en nuestros enfermos, se deben a que dichos registros analizan la prevalencia de las diferentes etiologías de la ERC en general, mientras que nuestro estudio se limita a una muestra de pacientes trasplantados. Dado que el padecimiento de diabetes mellitus condiciona un mayor riesgo cardiovascular y el desarrollo precoz de calcificaciones en el árbol vascular, que en muchas ocasiones contraindican la realización de un trasplante, es lógico encontrar diferencias en la prevalencia de nefropatía diabética en una muestra de pacientes trasplantados respecto a la población general de enfermos renales crónicos. La elevada prevalencia de NTI y glomerulonefritis en nuestra muestra se debe probablemente a que se trate de algunas de las causas más comunes de ERC terminal en pacientes jóvenes, con menor número de patologías concomitantes y por tanto, más aptos para recibir un trasplante renal. La prevalencia de ambas entidades, además, es elevada entre la población castellano-leonesa comparada con el resto del país (294).

Un $67,4 \%$ de los pacientes de la muestra recibieron hemodiálisis como terapia renal sustitutiva previa a la realización del trasplante renal, mientras que un 32,6\% recibieron diálisis peritoneal. La proporción de pacientes en diálisis peritoneal previa al trasplante fue superior al 22,3\% recogido por Ballesteros (208). El informe 2006 de la Sociedad Española de Nefrología notifica una prevalencia de pacientes en hemodiálisis de 458,6 pmp frente a una prevalencia de enfermos en diálisis peritoneal de 53,9 pmp (290). El Annual Report 2011 de la ERA-EDTA notifica una prevalencia de hemodiálisis variable entre 375,3 pmp en Reino Unido o 572,3 pmp en Francia frente a una prevalencia de diálisis peritoneal de 62,3 pmp y 43,2 pmp respectivamente en ambos países (291). Finalmente, el registro USRDS notifica una prevalencia de 1222,2 pmp en hemodiálisis frente a 98,8 pmp en diálisis peritoneal (292). 


\section{DISCUSIÓN}

Las diferencias observadas tanto en las causas de la ERC terminal como en la distribución de pacientes según su tratamiento renal sustitutivo se deben probablemente a que tanto los registros USRDS, ERA-EDTA y el informe de la SEN se refieren a prevalencia en población general de ERC, mientras que nuestro estudio está compuesto por una muestra de pacientes trasplantados. Dichos pacientes deben cumplir una serie de criterios definidos para ser admitidos en lista de espera de trasplante y se encuentran, por lo general, en mejores condiciones, con una edad inferior y más frecuentemente en diálisis peritoneal que el resto de pacientes en diálisis. Además, el padecimiento de ciertas enfermedades, como la diabetes mellitus de larga evolución, condiciona la aparición de calcificaciones a nivel cardiovascular y enfermedad coronaria, ambos criterios que dificultan la realización de un trasplante.

Un $88,4 \%$ de nuestros pacientes era portador de un primer trasplante, en un $7 \%$ de los casos se trataba de un segundo trasplante, mientras que en 4,7\% habían recibido tres trasplantes. Estos datos son similares a los recogidos por Ballesteros, con un 92,1\% de primeros trasplantes, un $7,2 \%$ de segundos trasplantes y un $0,7 \%$ de terceros trasplantes (208). En los últimos años, el porcentaje de segundos trasplantes se ha incrementado de un $5-10 \%$ a un $15-20 \%$ según datos de la Sociedad Española de Nefrología.

\subsection{1: ANTECEDENTES Y FACTORES DE RIESGO CARDIOVASCULAR}

\section{Antecedentes Cardiovasculares}

Un $4,7 \%$ de los pacientes incluidos en nuestro estudio presentaba antecedentes de cardiopatía isquémica previos a la realización del trasplante. Ningún paciente presentaba antecedentes de ictus o enfermedad arterial periférica.

Diversos autores han observado una prevalencia de enfermedad cardiovascular en población trasplantada significativamente mayor, como es el caso de Ballesteros, con un 


\section{DISCUSIÓN}

17,3\% (208), 11,7\% en el caso de Aker y cols (185), un 12,9\% en el caso de Marcén y cols (295), mientras que Kasiske y Valdés observaron unos porcentajes de incidencia de enfermedad cardiovascular del $21,3 \%$ y $22,2 \%$ respectivamente $(\mathbf{1 6 4}, \mathbf{1 8 3})$.

Ninguno de los pacientes que participaron en el estudio había requerido ingreso hospitalario por patología CV (ángor, cardiopatía isquémica, ictus o enfermedad arterial periférica) tras el trasplante. En la revisión actual se realizó un interrogatorio en busca de síntomas sugestivos de patología cardiovascular en los enfermos incluidos en el estudio de aparición posterior a la realización del trasplante; un 7\% refería haber presentado en alguna ocasión dolor torácico tipo ángor, un 4,7\% refería haber padecido algún episodio de disnea, de los cuales la mitad describía episodios de ortopnea, mientras que un 2,3\% refería claudicación intermitente a la marcha.

Las diferencias observadas entre nuestra muestra y el resto de estudios, en los que las tasas de prevalencia de enfermedad CV pretrasplante y de incidencia de enfermedad CV tras el trasplante son significativamente superiores, se deben a que nuestra muestra tiene un tamaño reducido comparado con el resto de estudios y en nuestro caso hemos considerado como antecedente de enfermedad cardiovascular únicamente aquellos casos en los que el paciente precisó ingreso hospitalario por enfermedad CV. Algunos de estos autores analizan enfermedad cardiovascular incidente tras el trasplante, con periodos de seguimiento considerablemente mayores que en nuestro caso, justificando una mayor incidencia de eventos $\mathrm{CV}$ en relación directa con la duración del trasplante.

La enfermedad cardiovascular supone la primera causa de muerte en pacientes trasplantados con injerto funcionante y la primera causa de pérdida del injerto en el momento actual $(\mathbf{1 8 3}, \mathbf{2 9 6 )}$. La prevalencia de enfermedad cardiovascular en el trasplantado se sitúa entre 2 y 5 veces la observada en población general, mientras que el riesgo relativo de muerte por enfermedad CV en pacientes trasplantados es 10 veces superior al que presentan individuos sanos (137). Algunos autores sitúan a la patología cardiovascular como responsable de un tercio de las muertes de pacientes trasplantados (296) mientras que otros estudios señalan que dicho porcentaje podría ascender a un 40-50\% (297). En una muestra de pacientes trasplantados en nuestro mismo centro, 


\section{DISCUSIÓN}

Ballesteros observó una incidencia de eventos CV del 12,94\% y una mortalidad del 6,5\% en un seguimiento de 5 años. La causa más frecuente de fallecimiento fue la enfermedad CV, responsable de un $44 \%$ de los éxitus (208).

\section{Prevalencia de Factores de Riesgo CV}

Un $88,4 \%$ de los pacientes estudiados padecían HTA.

Dicho porcentaje es algo superior al recogido por Ballesteros $(74,8 \%)$ (208) o por Holdaas, de aproximadamente un 75\% (298). Coresh y cols situaron la prevalencia de HTA en población trasplantada entre un 60 y un 90\% (137). La HTA constituye el factor de riesgo CV clásico más prevalente en población trasplantada, constituyendo un factor de riesgo de enfermedad cardiovascular tanto en población general como en trasplantados (299). En algunos estudios, el padecimiento de HTA se ha asociado a disfunción del injerto renal (208).

La prevalencia de diabetes mellitus en nuestra muestra pretrasplante fue del $16,3 \%$, con un solo caso de diabetes mellitus de novo tras el trasplante $(2,3 \%)$, ascendiendo el porcentaje de pacientes con diabetes en la revisión actual al 18,6\%.

Ballesteros recoge una prevalencia de diabetes pretrasplante algo inferior, del $11,5 \%$, con un mayor porcentaje de pacientes con diabetes de novo tras el trasplante, ascendiendo dicho porcentaje al $21,1 \%$ (208). Holdaas y cols describieron una prevalencia de diabetes de entre un 5 y un 20\% (298). La aparición de diabetes de novo tras el trasplante se relaciona con dosis altas de corticoides en el postrasplante precoz, junto con una mayor susceptibilidad individual de origen genético, dosis recibida de tacrólimus, edad del receptor, historia familiar y sobrepeso (208). El padecimiento de diabetes mellitus constituye un factor de riesgo independiente tanto para la supervivencia del injerto como para el desarrollo de enfermedad CV y de supervivencia del paciente, incrementando el riesgo de padecer un evento cardiovascular tanto fatal como no fatal entre 1,5 y 2,5 veces $(\mathbf{1 8 4}, \mathbf{2 0 8})$. La mayor incidencia de diabetes mellitus 


\section{DISCUSIÓN}

de novo tras el trasplante recogida por Ballesteros se debe probablemente a una dosis mayor de glucocorticoides recibida por los pacientes incluidos en la muestra de dicho estudio.

Nuestros pacientes presentan una prevalencia de dislipemia del $44 \%$. Esta cifra es inferior a la recogida por Coresh, situada entre un 60 y un 70\% (137) o la observada por Ballesteros, de un 57,8\% (208). La dislipemia en el trasplante renal se presenta habitualmente con cifras elevadas de colesterol total y colesterol LDL, niveles de triglicéridos normales o discretamente elevados y cifras de colesterol HDL dentro de la normalidad.

Las tasas de prevalencia de dislipemia en nuestra población probablemente se relacionen tanto al elevado porcentaje de pacientes trasplantados con sobrepeso y obesidad, porcentajes que se amplían tras el trasplante, como a la existencia de otros factores propios del trasplante como la medicación inmunosupresora que, pese a los avances en los últimos años, continúa favoreciendo la aparición de dislipemia. La dislipemia supone un importante factor de riesgo CV, incrementando el riesgo de padecer un evento CV 2,13 veces respecto a pacientes que no padezcan dicha enfermedad (208).

Respecto a la prevalencia de sobrepeso y obesidad, observamos un $46,5 \%$ de pacientes con sobrepeso y un $2,3 \%$ de pacientes obesos antes del trasplante. Dichos porcentajes aumentaron hasta alcanzar un $53,5 \%$ de pacientes con sobrepeso y un $9,3 \%$ de pacientes con obesidad en el momento actual.

El porcentaje de ganancia de peso en el momento actual respecto a la situación pretrasplante es del 5,7 $\pm 10,7 \%$, con una ganancia media en términos absolutos de 3,74 $\pm 7,49 \mathrm{~kg}$. Estas cifras son similares a las recogidas por Ballesteros, con una prevalencia de sobrepeso/obesidad del $48,9 \% / 10,1 \%$ antes del trasplante y del $57,8 \% / 24,8 \%$ transcurridos 5 años tras la realización de la cirugía (208). Cupples y cols describieron una ganancia de peso de un $6 \%$ transcurrido 6 meses tras el trasplante, sin aparente relación con edad, sexo, raza, dieta, actividad física o inmunosupresión (300). Entre los 


\section{DISCUSIÓN}

factores que favorecen la ganancia de peso tras el trasplante hay que destacar una mayor libertad dietética, así como el uso de inmunosupresión, especialmente los corticoides o la disfunción del injerto, en el contexto de una actividad física limitada (208).

La ganancia de peso presenta importantes efectos adversos a nivel cardiovascular, principalmente a través de su interacción con el metabolismo de los lípidos y el estímulo que ejerce sobre el desarrollo de placas de ateroma a nivel vascular.

Un $20,9 \%$ de nuestros pacientes se declaraban fumadores antes del trasplante. Se trata de un parámetro difícil de valorar ya que depende únicamente del testimonio del paciente. Esta cifra es similar a la prevalencia de tabaquismo del 17-19\% registrada por Holdaas (298), resultando inferior al porcentaje observado por Coresh (25\%) (137), Ballesteros (28,05\%) (208) o Lorenzetti (35,6\%) (301). Estas diferencias se deben probablemente a que nuestra población recibió su trasplante renal a lo largo de los 6 últimos años, recibiendo el beneficio de las numerosas campañas de concienciación para el abandono del hábito tabáquico realizadas por los Servicios de Salud Pública, así como diversas prohibiciones que han restringido el consumo de tabaco en lugares públicos. El abandono del hábito tabáquico tras el trasplante se sitúa en porcentajes entre el 15 y el $50 \%$ según diferentes autores. El consumo de tabaco es un importante factor de riesgo cardiovascular en población trasplantada, duplicando el riesgo de padecer un evento CV frente a individuos no fumadores.

Realizamos asimismo una evaluación del grado de actividad física de los pacientes evaluados. Para ello se utilizó el cuestionario IPAQ de actividad física en su versión corta. Los pacientes estudiados en nuestra muestra presentaron una cifra media de $7640 \pm$ 3977 mets-min/semana. Sólo un 7\% de los enfermos presentaba un nivel de actividad física bajo (inferior a 300 mets-min/semana). Sánchez y cols valoraron el nivel de actividad física de una muestra de 100 receptores de trasplante renal, de los que un $32 \%$ afirmaba realizar poca o nula actividad física, mientras que un $20 \%$ referían practicar ejercicio físico a menudo (302). 


\section{DISCUSIÓN}

El grado de actividad física que presentan los pacientes trasplantados depende de factores comunes con la población general como la edad o la situación clínica global y cardiovascular. Además, tras la realización del trasplante es frecuente que muchos enfermos continúen con las pautas de actividad física que arrastraban de su época en diálisis, mientras que en algunos casos los pacientes refieren temor a presentar complicaciones con el trasplante relacionadas con la realización de ejercicio físico.

\subsection{2: FUNCIÓN RENAL}

El desarrollo de enfermedad renal crónica es un importante factor de riesgo cardiovascular que condiciona la supervivencia del paciente a largo plazo $(303,304)$. La mejor forma de evaluar el filtrado glomerular en los pacientes renales ha sido objeto de debate. Durante muchos años el análisis de los niveles séricos de creatinina y el cálculo del aclaramiento convencional de creatinina han constituido las herramientas más empleadas en la práctica clínica para estimar el valor real de la tasa de filtrado glomerular. El estándar de oro para conocer dicho valor es, sin embargo, la utilización de marcadores no radiactivos como la inulina o estudios isotópicos, no empleados en la clínica habitual debido a la complicación técnica que requieren, la poca disponibilidad y el alto coste económico de dichas pruebas comparadas con el análisis de la creatinina sérica.

Actualmente existen diversas ecuaciones que nos permiten aproximar el valor real de la tasa de filtrado glomerular. La más utilizada actualmente de dichas ecuaciones es la fórmula procedente del estudio Modification of Diet in Renal Disease en su versión abreviada o MDRD-4, una ecuación desarrollada a partir de una amplia muestra de pacientes con enfermedad renal crónica y que constituye el método recomendado de evaluación de la función renal por la National Kidney Foundation K/DOQI y por las guías europeas (305).

Sin embargo, la fórmula MDRD presenta un serio inconveniente a la hora de aplicarla en población trasplantada. Debido a la población empleada como base a la hora de diseñar 


\section{DISCUSIÓN}

la ecuación, una muestra exclusivamente formada con pacientes enfermos renales crónicos, sin inclusión de sujetos sanos, la fórmula tiende a infraestimar la tasa de filtrado glomerular real en sujetos con función renal normal o estadios iniciales de ERC. Dicha fórmula no ha sido validada convenientemente para su uso en pacientes con fracaso renal agudo ni tampoco en pacientes trasplantados (272). Por ello decidimos calcular el aclaramiento de creatinina a través de la fórmula de Cockroft-Gault y la tasa estimada de filtrado glomerular mediante las ecuaciones MDRD-4, CKD-EPI y la ecuación cuadrática de la Clínica Mayo.

Todos los pacientes fueron evaluados previamente a su inclusión en lista de espera de trasplante renal. La cifra media de creatinina sérica en la evaluación pretrasplante en nuestra muestra fueron de $8,85 \pm 2,67 \mathrm{mg} / \mathrm{dl}$. El aclaramiento de creatinina calculado a través de la fórmula de Cockroft-Gault fue de 10,3 $\pm 3,6 \mathrm{ml} / \mathrm{min}$. La tasa estimada de filtrado glomerular media en la evaluación pretrasplante fue de 6,95 $\pm 2,21$ $\mathrm{ml} / \mathrm{min} / 1,73 \mathrm{~m}^{2}$ empleando la ecuación MDRD-4, de 6,42 $\pm 2,2 \mathrm{ml} / \mathrm{min} / 1,73 \mathrm{~m}^{2}$ mediante la ecuación CKD-EPI y de 9,13 \pm 1,95 ml/min $/ 1,73 \mathrm{~m}^{2}$ según la ecuación de la Clínica Mayo.

En el control analítico realizado en el momento del alta hospitalaria tras el trasplante el valor medio de creatinina plasmática fue de 2,22 $\pm 1,38 \mathrm{mg} / \mathrm{dl}$. El aclaramiento de creatinina calculado mediante la fórmula de Cockroft-Gault fue de 39,88 $\pm 15,26$ $\mathrm{ml} / \mathrm{min} / 1,73 \mathrm{~m}^{2}$. La tasa estimada de filtrado glomerular fue de 35,12 $\pm 17,01$ $\mathrm{ml} / \mathrm{min} / 1,73 \mathrm{~m}^{2}$ calculado mediante la aplicación de la ecuación MDRD-4, de 35,08 \pm $17,73 \mathrm{ml} / \mathrm{min} / 1,73 \mathrm{~m}^{2}$ mediante la ecuación CKD-EPI y de 39,9 $\pm 23,58 \mathrm{ml} / \mathrm{min} / 1,73 \mathrm{~m}^{2}$ mediante la ecuación de la Clínica Mayo.

En la revisión actual procedimos a estudiar de nuevo la función renal de los pacientes. El valor medio de creatinina plasmática actual fue de $1,57 \pm 0,52 \mathrm{mg} / \mathrm{dl}$. El aclaramiento de creatinina calculado mediante la fórmula de Cockroft-Gault fue de 59,9 $\pm 24,4$ $\mathrm{ml} / \mathrm{min} / 1,73 \mathrm{~m}^{2}$. La tasa estimada de filtrado glomerular fue de 51,29 $\pm 18,07$ $\mathrm{ml} / \mathrm{min} / 1,73 \mathrm{~m}^{2}$ calculado mediante la aplicación de la ecuación MDRD-4, de 51,7 — 19,73 


\section{DISCUSIÓN}

$\mathrm{ml} / \mathrm{min} / 1,73 \mathrm{~m}^{2}$ mediante la ecuación CKD-EPI y de 61,85 $\pm 25,65 \mathrm{ml} / \mathrm{min} / 1,73 \mathrm{~m}^{2}$ mediante la ecuación de la Clínica Mayo.

La diuresis residual de los pacientes antes del trasplante fue de 860,46 $\pm 814,2 \mathrm{ml} / \mathrm{día}$ (mediana $500 \mathrm{ml}$, rango 150-1500 ml, mínimo 0 ml, máximo $2500 \mathrm{ml}$ ). Un 53,48\% (23 pacientes) presentaban una diuresis residual de $500 \mathrm{ml} /$ día o inferior. En el momento del alta tras el trasplante, el volumen de diuresis fue de $2438,49 \pm 780,78 \mathrm{ml} / \mathrm{día}$ (mediana $2300 \mathrm{ml}$, rango 1930-2800 ml, mínimo $1050 \mathrm{ml}$, máximo $5350 \mathrm{ml}$ ) En la revisión actual el volumen medio de diuresis fue de 2594,6 \pm 800,8 ml/día (mediana 2500 ml, rango 2000-3100 ml, mínimo 1200 ml, máximo 4300 ml). Un 79\% (34 pacientes) presentaban un volumen de diuresis igual o superior a $2000 \mathrm{ml} / \mathrm{día}$.

El comportamiento de las ecuaciones a la hora de estimar la función renal viene siendo objeto de estudio y controversia desde hace años. La tasa estimada de filtrado glomerular permite realizar una aproximación más precisa a la función renal real del paciente que la obtenida mediante la valoración aislada de los niveles séricos de creatinina, pero continúa siendo un método de baja precisión y sujeto a ciertos sesgos. En un reciente análisis de 1067 pacientes sin enfermedad renal crónica conocida estudiamos el comportamiento de las ecuaciones de Cockroft-Gault, MDRD-4, CKD-EPI y la ecuación la Clínica Mayo (306). En dicho estudio se observó que MDRD-4 ofrecía los valores medios de estimación de filtrado glomerular más bajos de los cuatro métodos, seguida de CKD-EPI, Cockroft-Gault y por último la ecuación de la Clínica Mayo, que ofrecía la tasa estimada de filtrado glomerular más alta de entre las calculadas.

En nuestra muestra recogemos unos resultados comparables en población trasplantada. En la evaluación pretrasplante la ecuación CKD-EPI es la que ofrece un valor medio de FG más bajo, seguida de cerca por MDRD-4, mientras que la ecuación de la Clínica Mayo y Cockroft-Gault realizan una estimación más alta. En el momento actual, MDRD-4 ofrece la tasa estimada más baja de los cuatro métodos, seguida de cerca por CKD-EPI, mientras que Cockroft-Gault y especialmente la ecuación de la Clínica Mayo ofrecen una estimación del FG más alto. La mejoría en los resultados ofrecidos por las diferentes ecuaciones al comparar la situación pretrasplante con la evaluación actual sigue una 


\section{DISCUSIÓN}

distribución similar; MDRD-4 presenta una ganancia de 44,33 ml $/ \mathrm{min} / 1,73 \mathrm{~m}^{2}$, CKD-EPI de $45,27 \mathrm{ml} / \mathrm{min} / 1,73 \mathrm{~m}^{2}$, Cockroft-Gault de $49,63 \mathrm{ml} / \mathrm{min} / 1,73 \mathrm{~m}^{2}$ y la ecuación de la Clínica Mayo de 52,71 ml/min/1,73m².

Según la ecuación MDRD-4, en el momento actual un 60,4\% de los enfermos presentaría una ERC en estadios 3 o 4. La ecuación CKD-EPI clasifica como ERC estadios 3 y 4 al 65,1\% de los enfermos. La ecuación de Cockroft-Gault califica como ERC estadios 3-4 al 58,2\% de los pacientes, mientras que Mayo Quadratic clasificaría como tales al 48,8\% de los enfermos. El comportamiento de las ecuaciones varía según el estadio de función renal de los enfermos; para estadios avanzados (ERC estadio 4) tanto MDRD-4 como CKD-EPI y MQ ofrecen resultados similares, enmarcando en dicho estadio a 5 pacientes (11,62\%). Sin embargo, sus resultados difieren al analizar la distribución de los pacientes en los estadios 1, 2 y 3 de ERC, en los que MDRD-4 y CKD-EPI clasifican como ERC 1 y 2 a 17 $(39,53 \%)$ y 15 pacientes (34,88\%) mientras que Mayo Quadratic clasifica en dichos estadios a 22 pacientes (51,16\%), comprobando la tendencia de MDRD-4 de ofrecer cifras estimadas de FG más bajas que las calculadas por Mayo Quadratic en pacientes con ERC 1-3.

Los resultados obtenidos en nuestra muestra son similares a otros estudios realizados en pacientes trasplantados.

Ballesteros observó unas cifras medias de creatinina plasmática de 1,84 $\pm 1,85 \mathrm{mg} / \mathrm{dl}$ después de un seguimiento de 5 años tras el trasplante. El aclaramiento de creatinina mediante la ecuación de Cockroft-Gault fue de $64,57 \pm 26,41 \mathrm{ml} / \mathrm{min}$, mientras que la tasa estimada de FG mediante MDRD-4 fue de 55,08 $\pm 21,8 \mathrm{ml} / \mathrm{min}$ (208). Kasiske y cols estudiaron la evolución de la función del injerto en varias cohortes de pacientes trasplantados a lo largo de casi 20 años, obteniendo una tasa estimada de filtrado glomerular en la cohorte más reciente de $54.6 \pm 18.1 \mathrm{ml} / \mathrm{min}$ a los 6 meses del trasplante, de $53,7 \pm 17,6 \mathrm{ml} / \mathrm{min}$ a los 12 meses y de $51.8 \pm 18.4 \mathrm{ml} / \mathrm{min}$ a los 24 meses empleando la ecuación MDRD-4 (307). McDonald obtuvo una tasa estimada de FG en pacientes trasplantados algo inferior, de $49.2 \pm 17 \mathrm{ml} / \mathrm{min}$ a los 12 meses y de 50,6 \pm 17 $\mathrm{ml} / \mathrm{min}$ a los 36 meses, de nuevo utilizando la ecuación MDRD (293). Finalmente, 


\section{DISCUSIÓN}

Marcén y cols en una muestra de pacientes trasplantados durante una media de 12 meses en España obtuvieron una tasa estimada media de FG de 54,5 ml/min mediante la ecuación MDRD (308).

La función renal de los pacientes estudiados presenta una leve mejoría respecto a las cifras obtenidas 14 días después de la realización del trasplante. Un 62,79\% de los pacientes mostraron una mejoría de la función renal respecto a dichas cifras, un 16,27\% presentaron una función renal similar, mientras que el 20,93\% sufrieron un deterioro de la función del injerto. Ballesteros recogió en 5 años un 16,5\% de injertos con función estable, un $44 \%$ de injertos con una mejoría de función renal y un 38,5\% de injertos cuya función renal empeoró a lo largo del seguimiento (208). El mayor porcentaje de pacientes con un empeoramiento de función renal en el trabajo de Ballesteros se debe probablemente al mayor tiempo de seguimiento de este estudio y al deterioro progresivo dependiente del tiempo de duración del trasplante que presenta la función del injerto.

\subsection{3: INMUNOSUPRESIÓN}

Siguiendo el protocolo de inducción de la inmunosupresión empleado en la Unidad de Trasplante Renal del Hospital Clínico Universitario de Valladolid, el 100\% de los pacientes recibió basiliximab como terapia inductora.

La totalidad de los pacientes recibieron una pauta descendente de corticoides en su estancia hospitalaria tras el trasplante renal. Un 93\% de los enfermos continuaron con corticoides durante el primer año del trasplante. Dicho porcentaje se redujo en más de un $50 \%$ durante el segundo año tras el trasplante, recibiendo corticoides un $41 \%$ de los pacientes y disminuyendo esta proporción progresivamente a lo largo de los meses. La dosis de corticoides presentó una disminución significativa entre el primer y el segundo año tras el trasplante, permaneciendo estable posteriormente. 


\section{DISCUSIÓN}

Todos los pacientes estudiados recibieron tacrólimus dentro de la pauta inmunosupresora administrada en el post-trasplante inmediato. El porcentaje de pacientes de la muestra que recibieron tacrólimus se redujo desde un $100 \%$ el primer año tras el trasplante a un $66 \%$ transcurrido 6 años tras la cirugía, objetivándose asimismo una reducción paulatina de la dosis media anual recibida.

Ningún paciente recibió sirólimus en el post-trasplante inmediato, aumentando la proporción de pacientes con este macrólido de forma paralela a la disminución del número de enfermos con tacrólimus, ya que en muchos casos sirólimus se empleó en sustitución de tacrólimus. Las dosis del fármaco que recibieron los pacientes permanecieron estables a lo largo de todo el periodo de seguimiento tras el trasplante.

De forma similar al sirólimus, ningún paciente recibió everólimus como parte de su pauta inmunosupresora durante el post-trasplante inmediato, aumentando progresivamente dicho porcentaje con el paso de los meses. Las dosis empleadas de everólimus presentaban un ligero incremento con el paso del tiempo que careció de significación estadística.

Finalmente, un $79 \%$ de los pacientes recibieron ácido micofenólico como tratamiento inmunosupresor durante el primer año tras el trasplante. Estas cifras descendieron progresivamente hasta alcanzar un $67 \%$ a los 6 años. Las dosificaciones utilizadas de ácido micofenólico en los pacientes también mostraron un descenso lento y progresivo a lo largo del seguimiento.

En nuestros pacientes la triple terapia con corticoides, tacrólimus y ácido micofenólico es la pauta inmunosupresora más utilizada durante el primer año, con el objetivo de otorgar una adecuada cobertura inmunosupresora a pacientes que en un porcentaje importante de los casos presentan riñones procedentes de donantes con criterios expandidos o que, debido a la recepción previa de injertos renales no funcionales en la actualidad o secundaria a la realización de múltiples transfusiones durante su permanencia en diálisis presentan un grado importante de hiperinmunización. El 


\section{DISCUSIÓN}

objetivo de dicha pauta es prevenir, en la medida de lo posible, la aparición de rechazo agudo y minimizar el desarrollo de lesiones compatibles con rechazo crónico del injerto.

Desde 2004 se viene intentando reducir en la medida de lo posible las dosis de corticoides que recibe el receptor de trasplante renal (309), con el objetivo de disminuir la exposición de los pacientes a estos fármacos y con ella la incidencia de efectos adversos derivados de su uso. Ballesteros presenta en su muestra un uso más reducido de basiliximab (208), debido a que una parte de los individuos estudiados en dicho trabajo recibió su trasplante renal antes de 1999, fecha en la que comenzó a utilizarse basiliximab como terapia inductora en la unidad. El $100 \%$ de los pacientes recibieron inhibidores de la calcineurina, tanto en nuestro estudio como en el análisis de Ballesteros, aunque en este último la distribución era de un $51,1 \%$ de pacientes con ciclosporina y un $48,9 \%$ de pacientes con tacrólimus, frente al $100 \%$ de pacientes con tacrólimus de nuestra muestra. La sustitución de ciclosporina por tacrólimus en las pautas de inmunosupresión en pacientes trasplantados es un hecho que se viene comprobando desde 2001, impulsado por la mayor capacidad del tacrólimus de prevenir la incidencia de rechazo agudo del injerto y disminuir su severidad (310). Asimismo, el empleo de azatioprina recogido en el trabajo de Ballesteros (208) se ha visto reducido progresivamente a favor del uso de ácido micofenólico como antimetabolito coadyuvante con el tacrólimus como inmunosupresores.

Las tasas de empleo de sirólimus previas en nuestra unidad rondaban el 7,9\% (208), siendo algo menores en el momento actual. Shapiro y cols observaron un incremento progresivo en las tasas de utilización de sirólimus como inmunosupresor en el trasplante renal desde 1998 hasta 2000, momento en el cual se estancaron en torno al 20\% (311). Durante el primer año tras el trasplante sólo un 6,9\% de los enfermos recibieron sirólimus dentro de su pauta inmunosupresora, aumentando dicho porcentaje progresivamente a lo largo de los meses hasta alcanzar un $25 \%$ de aquellos pacientes con una duración del trasplante de al menos 5 años. Este aumento progresivo según transcurre el trasplante se debe probablemente a la aparición de efectos adversos relacionados con el tacrólimus, principalmente nefrotoxicidad y neurotoxicidad, provocando la sustitución de este inhibidor de la calcineurina por sirólimus. 


\section{DISCUSIÓN}

\section{4: METABOLISMO ÓSEO-MINERAL}

La evolución de las alteraciones relativas al metabolismo óseo-mineral en el posttrasplante depende del momento evolutivo del mismo (28). Los niveles de PTHi se mantienen por debajo de los existentes pretrasplante con un descenso que se sitúa entre un 19 y un 71\% según varios autores (29-33). La concentración sérica de la hormona tarda en estabilizarse, descendiendo de forma significativa durante los primeros 6 meses del post-trasplante para alcanzar valores estables que no suelen modificarse notablemente después $(\mathbf{3 4}, \mathbf{3 5})$.

Pese a este descenso, varios autores han notificado una persistencia de las cifras de PTHi sérica por encima de la normalidad en más del $50 \%$ de los pacientes trasplantados entre los 2 y los 5 años después del trasplante (36-38). Dichos valores dependen de la función del injerto, aunque casi la mitad de los trasplantados renales de larga evolución que mantienen cifras de creatinina sérica inferiores a $1,5 \mathrm{mg} / \mathrm{dl}$ presentan un hiperparatiroidismo según algunas series (39). El tiempo de permanencia en diálisis, el tamaño glandular y el desarrollo de hiperplasia nodular son algunos de los factores de riesgo más importantes para el desarrollo y mantenimiento del hiperparatiroidismo post-trasplante (40).

Las cifras de PTHi en nuestra muestra sufren un fuerte descenso tras el trasplante. Comprobamos un descenso de $251,05 \mathrm{pg} / \mathrm{ml}(\mathrm{p}<0,001)$ en las cifras de PTHi en la revisión actual respecto a la situación basal. Sin embargo y pese al descenso recogido y a la correción de los niveles séricos de calcio y fósforo, un importante porcentaje de pacientes mantiene cifras de PTHi elevadas de acuerdo con las recomendaciones de las guías SEN. El porcentaje de pacientes con cifras de PTHi elevadas para su estadio de ERC aumenta conforme se incrementa la gravedad de la ERC. De esta forma, en el momento actual un $64,7 \%$ de los pacientes con ERC estadio 2 presenta niveles de PTHi por encima de los recomendados, mientras que dicho porcentaje aumenta hasta un $77,27 \%$ en los pacientes con ERC estadio 3 y hasta alcanzar el 100\% en pacientes con ERC estadio 4. 


\section{DISCUSIÓN}

La concentración plasmática de FGF-23 presenta un descenso significativo durante el primer año tras el trasplante, llegando a reducirse en un $89 \%$ en los primeros días tras el trasplante (47). Barros y cols comprobaron un descenso pronunciado a lo largo del primer mes tras el trasplante (312). En esta muestra, que comprendía pacientes tanto procedentes de diálisis como enfermos que no habían llegado a precisar hasta el momento del trasplante tratamiento renal sustitutivo, se observó cómo los pacientes que habían llegado a recibir diálisis presentaban unos niveles basales y al primer mes tras el trasplante de FGF-23 mayores que el grupo de trasplantados que no habían recibido diálisis. Las cifras de fósforo sérico fueron menores tras el trasplante en el grupo de trasplantados procedentes de diálisis, siendo el mayor determinante de dicha concentración los niveles basales pretrasplante de FGF-23. Esta asociación se ha comprobado en estudios recientes (313).

En nuestra muestra únicamente se realizó una determinación plasmática de FGF-23 en la revisión actual, careciendo, por tanto de información relativa a la concentración del factor tanto antes del trasplante como en el post-trasplante inmediato. En dicha determinación obtuvimos una concentración media de FGF-23 de 5,04 \$13,05 pg/ml, con sólo un 4,7\% de los pacientes mostrando niveles de FGF-23 por encima de los 50 pg/ml.

Estas cifras son inferiores a las descritas por algunos autores. En población pediátrica con una mediana de 25 meses de duración del trasplante se observó una concentración sérica de FGF-23 de $146 \pm 30$ pg/ml (314). Sánchez Fructuoso y cols determinaron en pacientes adultos con una duración del trasplante inferior a 6 meses una mediana de concentración sérica de FGF-23 de 139 pg/ml (315). Sin embargo, la muestra estudiada por Madhumathi y cols mostró unos niveles de FGF-23 de 15.8 pg/ml (12.2-22.5 pg/ml), más reducidos y similares a los observados en nuestro estudio y con solo un $7 \%$ de pacientes con niveles por encima de $50 \mathrm{pg} / \mathrm{ml}$ (316). De forma similar, Malyszko y cols observaron unos niveles plasmáticos de FGF-23 de $16.7 \mathrm{pg} / \mathrm{ml}$ (13.8-21.2) en una muestra de 84 trasplantados renales con una mediana de duración del trasplante de 37 meses (316). Una de las diferencias fundamentales de estos dos últimos estudios y de nuestro análisis radica en la duración del trasplante, mayor tanto en nuestro caso como 


\section{DISCUSIÓN}

en el de Malyzsko y de Madhumathi (mediana de 12.8 meses (7.5-30.9)). Es posible que la curva descendente observada durante el post-trasplante inmediato en la concentración de FGF-23 se prolongue en el tiempo y explique los resultados recogidos tanto en el estudio de Madhumathi como en nuestro trabajo.

En nuestra muestra, la concentración de FGF-23 no mostró ningún tipo de asociación con los niveles de fósforo, PTHi, tiempo en diálisis, meses de duración del trasplante o tasa estimada de filtrado glomerular en el momento actual, aunque sí presentó una asociación directa con el producto calcio-fósforo (Rs=.301, P=.05) y con la concentración de $1,25-\mathrm{OH}$ Vitamina $\mathrm{D}(\mathrm{Rs}=.35, \mathrm{P}=.021)$ e inversa con los niveles de magnesio $(\mathrm{Rs}=-.33$, $\mathrm{P}=.031)$.

La asociación de FGF-23 con los diferentes parámetros relativos al metabolismo óseo.mineral en el paciente trasplantado no está del todo aclarada, especialmente en el post-trasplante tardío. En población pediátrica se ha observado como los niveles de FGF23 se asociaban tanto a la tasa estimada de filtrado glomerular como a los valores séricos de calcio, fósforo y PTHi (314). En el trabajo publicado por Sánchez-Fructuoso y cols (315) se observó una asociación entre la concentración de FGF-23 en los primeros 6 meses tras el trasplante y la tasa de reabsorción renal de fósforo, la concentración de 1,25-OH vitamina D, las cifras de PTHi o la tasa estimada de filtrado glomerular. En este estudio, sin embargo, no se describe asociación entre los niveles de FGF-23 y la concentración sérica de calcio, fósforo o magnesio. La correlación existente 1,25-OH vitamina D y FGF-23 ha sido descrita también en modelos animales (318). En el estudio realizado por Madhumathi (316) los niveles de FGF-23 se correlacionaron con las cifras de fósforo sérico, PTHi y con la duración del trasplante. En el estudio de Malyzsko y cols (317) los autores describen una asociación entre FGF-23 y la concentración sérica de fósforo, aunque no con los niveles de calcio.

Dichas asociaciones entre FGF-23 y la concentración de calcio, fósforo o PTHi no se observaron en nuestro análisis. La divergencia entre los datos recogidos por los diferentes estudios parece indicar que la asociación existente entre calcio, fósforo, PTHi y FGF-23 en el paciente trasplantado se encuentra bajo el efecto de otros factores no 


\section{DISCUSIÓN}

definidos adecuadamente hasta el momento y en parte diferentes a los encontrados en pacientes con ERC no trasplantados. La ausencia de asociación entre la concentración de PTHi, la tasa estimada de filtrado glomerular y los niveles séricos de calcio y fósforo descrita por otros autores (319) y que se constata también en nuestro análisis puede ser un indicativo de esta modificación. Uno de los factores implicados en esta modificación es el uso de inmunosupresores asociado al trasplante. En nuestro estudio no se encontró asociación entre la dosis acumulada de glucocorticoides, tacrólimus, sirólimus, everólimus y ácido micofenólico, pero esta ausencia de asociación puede deberse probablemente a la uniformidad de tratamiento inmunosupresor de los pacientes de nuestra muestra. Sin embargo, otros autores han descrito la correlación entre dosis acumulada creciente de glucocorticoides y unos niveles mayores de FGF-23, tanto en trasplantados adultos (320) como en población trasplantada pediátrica (321).

Malyszko y cols observaron asimismo una asociación entre los niveles séricos de FGF-23 y una batería de marcadores de disfunción endotelial como VCAM e Interleukina-6 en una muestra de trasplantados renales con una mediana de duración del trasplante de 37 meses (317). En nuestro estudio no encontramos ninguna correlación entre los niveles de FGF-23 y de PCR o Interleukina-6. Esta diferencia puede deberse en parte a una menor potencia de nuestro estudio, con un tamaño muestral más reducido que el empleado por Malyszko, ya que por lo demás se trata de dos muestras comparables tanto en edad como en duración del trasplante o en nefropatía de base.

En la mayoría de pacientes trasplantados las cifras de calcio sérico se mantienen en el límite alto de la normalidad $(33,34)$. La evolución de la concentración de calcio plasmático se compone de un descenso inicial durante las primeras dos semanas tras el trasplante para después aumentar progresivamente hasta la semana 26 y finalmente estabilizarse al alcanzar los 6 meses tras el trasplante (30). En adelante los niveles plasmáticos de calcio no presentan modificaciones de interés, con una tasa de variabilidad que suele situarse por debajo del $5 \%$ y que parece independiente de la función del injerto $(\mathbf{4 1}, \mathbf{4 2})$. 


\section{DISCUSIÓN}

En algunas series se han cuantificado porcentajes de pacientes con hipercalcemia durante los primeros tres meses que alcanzaban el 52\% (35). En nuestra muestra las cifras de calcio total en plasma aumentan tras el trasplante. Al alta se comprueba un aumento del calcio sérico de forma no significativa. En la revisión actual, las cifras de calcio total plasmático aumentan $0,34 \mathrm{mg} / \mathrm{dl}$ respecto a la situación basal $(p=0,034)$. El grado de cumplimiento de las guías SEN relativo a los niveles de calcio mejoró tras el trasplante desde un $32,6 \%$ antes de la cirugía a un $46,6 \%$ en el momento actual.

Las cifras de fósforo sérico descienden de forma importante tras el trasplante, hasta situarse en el límite bajo de la normalidad o incluso por debajo durante el primer mes tras el trasplante (34). Más adelante los niveles de fósforo se estabilizan, con cambios por debajo del $10 \%$ entre los meses 6 y 12 y por debajo del $2 \%$ entre los meses 12 y 24 . La incidencia de hipofosfatemia en los primeros meses tras la cirugía es importante, rondando entre el 1,6 y el $39 \%$ tras 6 meses $(34,44)$. La concentración de fósforo en plasma no parece depender de la función del injerto y su descenso de forma temprana tras el trasplante se debe al desarrollo de cierto grado de disfunción endotelial, la existencia de niveles elevados de FGF-23 y a la persistencia del hiperparatiroidismo (45).

Las cifras de fósforo plasmático se redujeron de forma significativa tras la realización del trasplante. En el momento del alta se comprueba un descenso de 1,82 mg/dl $(p<0,001)$. En la revisión actual, las cifras de calcio total plasmático muestran un descenso de 1,8 $\mathrm{mg} / \mathrm{dl}$ respecto a la situación basal $(p<0,001)$. El grado de cumplimiento de las guías SEN respecto a los niveles de fósforo se incrementó tras el trasplante. El porcentaje de pacientes con niveles elevados de fósforo pasó de un $67,4 \%$ en la evaluación pretrasplante a tan solo un $2,3 \%$ en el momento actual.

\section{5: CUANTIFICACIÓN DEL CALCIO CORONARIO}

El valor medio de la cuantificación de calcio coronario en los 43 pacientes estudiados fue de 1532,7 \pm 5655,5 $\mathrm{HU}$ (mediana $64 \mathrm{HU}$, rango 4-1009 HU). Un 44,2\% de los 


\section{DISCUSIÓN}

enfermos (19 pacientes), presentaron un grado de calcificación coronaria grave o muy grave.

Para analizar la relación existente entre las diferentes variables incluidas en el estudio y el score de Agatston decidimos estratificar los pacientes incluidos en dos grupos, según presentasen un score de Agatston inferior a $100 \mathrm{HU}$ o igual o superior a dicha cifra. Un $55,8 \%$ ( 24 pacientes) de los pacientes presentaron un score de Agatston $<100 \mathrm{HU}$.

Observamos que los pacientes con un score de Agatston igual o superior a $100 \mathrm{HU}$ presentaban una edad más avanzada, eran con mayor frecuencia varones, presentaban un mayor tiempo en diálisis previo al trasplante, habían recibido hemodiálisis con mayor frecuencia o que padecían diabetes mellitus más frecuentemente que el resto de enfermos. No se observaron diferencias respecto al padecimiento de HTA, sobrepeso y obesidad, dislipemia o tabaquismo entre los dos grupos de pacientes.

La diabetes mellitus constituye un importante factor de riesgo cardiovascular y actúa como un potente promotor sobre el desarrollo de calcificaciones vasculares.

La ausencia de influencia en nuestra muestra de la HTA sobre el grado de calcificación se debe probablemente a la elevada prevalencia de la enfermedad entre los pacientes estudiados, lo que dificulta enormemente la inclusión de receptores de trasplante renal normotensos para realizar una comparación adecuada entre grupos. De igual forma, el porcentaje de pacientes fumadores en la evaluación pretrasplante se limitaba a un 20,9\%, muchos de los cuales han abandonado el hábito tabáquico desde entonces, especialmente tras recibir un injerto renal, por lo que la muestra disponible de fumadores activos o que hayan abandonado recientemente el hábito tabáquico no es lo suficientemente grande como para poder encontrar una asociación significativa. En nuestra muestra no hallamos tampoco correlación entre el grado de calcificación de arterias coronarias y el padecimiento de dislipemia previa al trasplante, sobrepeso u obesidad. 


\section{DISCUSIÓN}

En el análisis realizado incluyendo parámetros antropométricos y analíticos observamos como los pacientes con un score de Agatston $<100 \mathrm{HU}$ presentan unos valores medios más reducidos de fosfatasa alcalina en el control previo al trasplante, glucosa plasmática en el momento del alta tras el trasplante y en la revisión actual, así como de la concentración en el momento actual de urea, ácido úrico, hemoglobina glicosilada y microalbuminuria.

De igual manera, los pacientes con un score de Agatston $<100 \mathrm{HU}$ presentaban un valor medio significativamente superior de diuresis residual previa al trasplante, un menor grado de anemia en su etapa en diálisis (definida por las cifras de hemoglobina y hematocrito en la evaluación pretrasplante), unas cifras de colesterol total previo al trasplante y en el momento actual más altas y un mayor aclaramiento de creatinina medido por la fórmula de Cockroft-Gault. Estos pacientes presentaban además un producto calcio-fósforo y un fósforo plasmático significativamente superior a los pacientes con un score de Agatston igual o superior a $100 \mathrm{HU}$.

Las cifras séricas de calcio y fósforo y el producto calcio-fósforo tanto pre trasplante como en la revisión actual, los niveles de vitamina $D$ actuales y la concentración de hormona paratiroidea, tanto previa al trasplante y en el momento actual no presentaron correlación alguna con el score de calcio coronario en nuestra muestra. Destaca sin embargo, cómo la concentración de fósforo sérico y el producto calcio-fósforo se encuentran en ambos casos significativamente más elevados en los pacientes con un score de Agatston menor en la analítica realizada inmediatamente tras el trasplante. Carecemos de información adicional relativa a elementos fundamentales del metabolismo óseo-mineral en dicho punto temporal en nuestra muestra, como son PTHi o FGF-23, pero la explicación más razonable para este hallazgo radica en la existencia de cifras más elevadas de FGF-23 en el post-trasplante inmediato descritas por algunos autores en pacientes procedentes de diálisis frente a pacientes en los que se realiza un trasplante renal previo a su entrada en un programa de diálisis $(312,313)$. El FGF-23 más elevado en esta población condiciona una mayor caída en la concentración sérica de fósforo en el post-trasplante inmediato $(312,313)$, siendo la concentración del FGF-23 


\section{DISCUSIÓN}

pretrasplante el mayor determinante de los niveles de fósforo en las primeras semanas tras la cirugía.

Por tanto, nuestra hipótesis para explicar la asociación entre un fósforo mayor en el post-trasplante inmediato y un menor score de Agatston radica en que en nuestra muestra un mayor tiempo en diálisis se asocia a un score de Agatston mayor, relación ya descrita por otros autores (239). Dichos pacientes deberían presentar unos niveles de FGF-23 más elevados debido a su mayor permanencia en diálisis, que condicionarían un mayor descenso de la concentración sérica de fósforo tras el trasplante. El tiempo en diálisis y los niveles pre trasplante de FGF-23 actuarían como nexo de unión el fósforo sérico y la calcificación coronaria.

El tratamiento farmacológico relativo al metabolismo óseo-mineral recibido antes del trasplante, así como la pauta de inmunosupresión seguida después de recibir el injerto no presentaron ninguna correlación con el grado de calcificación de arterias coronarias.

En nuestra muestra destaca el hecho de que el padecimiento de dislipemia previo al trasplante, el sobrepeso, la obesidad y las cifras de colesterol sérico no comporten un mayor grado de calcificación coronaria.

El comportamiento de la dislipemia en pacientes con ERC como factor de riesgo cardiovascular es diferente respecto a la población general. En estadios 3 y 4 de ERC, la dislipemia se caracteriza por una elevación de las cifras de triglicéridos y colesterol VLDL en plasma, concentración reducida de colesterol HDL y niveles normales o disminuidos de colesterol LDL (144). En aquellos pacientes que reciben diálisis, la asociación entre los niveles plasmáticos de colesterol y la mortalidad global y cardiovascular depende del grado de inflamación, definida por elevación de los niveles de proteína $\mathrm{C}$ reactiva e interleukina 6 y descenso de las cifras plasmáticas de albúmina. Mientras que en individuos sin elevación de parámetros inflamatorios existe una clara correlación entre los niveles séricos de colesterol y la mortalidad cardiovascular, en aquellos en los que existe evidencia de inflamación se comprueba como la concentración plasmática de colesterol presenta una relación en " $U$ " respecto a la mortalidad cardiovascular, 


\section{DISCUSIÓN}

entendiendo que cifras reducidas de colesterol sérico enmascaran estados de malnutrición e inflamación (145). Este fenómeno, descrito desde hace años en pacientes con enfermedad renal crónica terminal, ha recibido el calificativo de "epidemiología inversa" acuñado por Kalantar y cols en 2003 (322). Algunos autores apuntan, al igual que nuestro estudio, a esta relación "inversa" entre el colesterol y el desarrollo de calcificaciones. Shu y cols recogieron un score de Agatston superior a $10 \mathrm{HU}$ en el $60 \%$ de los pacientes incluidos en su estudio. La edad, el sexo masculino y el padecimiento de HTA supusieron factores asociados a un mayor grado de CAC, mientras que unos niveles superiores de colesterol HDL constituyeron un factor protector frente a la presencia de calcificaciones (240).

El ácido úrico constituye un foco de atención en el momento actual como uno de los posibles factores implicados en el desarrollo de la aterosclerosis. Algunos estudios sugieren que la hiperuricemia podría inducir el desarrollo de disfunción endotelial mediante la reducción de la biodisponibilidad del óxido nítrico. Mankovsky y cols (323) revisaron numerosos trabajos en los que se relaciona no sólo la hiperuricemia franca sino también los niveles en el límite alto de la normalidad de ácido úrico con una mayor incidencia de enfermedad coronaria, infarto, hipertensión arterial o síndrome metabólico. En nuestra muestra, la concentración plasmática de ácido úrico parece directamente relacionada con el grado de calcificación de las arterias coronarias. Krishnan y cols describieron una relación similar entre los niveles de ácido úrico y el score de calcio coronario en pacientes asintomáticos (324). Sin embargo, algunos autores no han sido capaces de comprobar dicha asociación; Neogi y cols describieron una asociación entre los niveles de ácido úrico y el grosor íntima-media carotideo (325), aunque no pudieron recoger esa misma asociación al comparar las cifras de ácido úrico con el índice de calcificación coronaria (326).

Nuestros resultados están en consonancia con los recogidos en la literatura disponible. Rosas y cols estudiaron 79 receptores de trasplante renal, en su mayoría (61\%) de cadáver. Dichos pacientes eran más jóvenes (47 \pm 12.1 años) y con un mayor porcentaje de mujeres (46\%). Obtuvieron un score de calcio coronario de $331.5 \pm 562.4 \mathrm{HU}$, encontrando como la edad, la diabetes, no haber recibido un trasplante renal previo a 


\section{DISCUSIÓN}

su entrada en diálisis y la hipercolesterolemia constituían factores de riesgo para el desarrollo de una mayor calcificación coronaria en el análisis univariante, mientras que la edad y el tiempo en diálisis constituyeron asimismo factores de riesgo independientes para el desarrollo de calcificaciones coronarias en el análisis multivariante (239). Los parámetros relacionados con el metabolismo óseo-mineral como calcio, fósforo o producto calcio-fósforo no presentaron asociación alguna con el grado de CAC.

La muestra estudiada por Rosas presenta un menor grado de calcificación arterial coronaria que el observado en nuestros enfermos. Esto se debe a la conjunción de varios factores; los pacientes incluidos en el estudio de Rosas eran significativamente más jóvenes, con un mayor porcentaje de mujeres y un menor tiempo en diálisis, llegando en algunos casos a recibir el trasplante sin haber alcanzado un estadio ERC terminal, por lo que es de esperar que obtuviesen un índice de CAC más bajo. En esta muestra además, constituyeron factores de riesgo para el desarrollo de CAC la edad, la diabetes y el tiempo en diálisis, al igual que en nuestra muestra.

Sin embargo, Rosas observó que la hipercolesterolemia actuaba como un factor favorecedor del desarrollo de CAC, resultado que no se ha repetido en nuestra muestra. Esto se debe probablemente a la influencia de la edad en ambas poblaciones. La muestra de Rosas es notablemente más joven y recibió en un importante porcentaje de los casos su trasplante renal de donante vivo y/o previo a su entrada en diálisis por lo que probablemente en estos pacientes la existencia de valores más bajos de colesterol sérico no se asocien con un peor estado nutricional y la relación entre la dislipemia y la enfermedad aterosclerótica sea más similar a la existente en población general. Sin embargo en nuestra muestra, la existencia de cifras más bajas de colesterol sérico parece ocultar un peor estado nutricional y un mayor grado de inflamación, constituyendo un caso de "epidemiología inversa" (322).

Schankel y cols publicaron en 2007 un análisis del grado de calcificación coronaria evaluado mediante tomografía computerizada de una muestra de 82 pacientes trasplantados renales. Dicho estudio se realizó a los 6 y 12 meses tras el trasplante. Los individuos estudiados eran más jóvenes (49,5 \pm 12,5 años), con un mayor porcentaje de 


\section{DISCUSIÓN}

mujeres (39\%) y con una pauta similar de inmunosupresión (242). En un 59,8\% de los casos se trataba de enfermos de raza caucásica y sólo el 62,2\% recibieron un trasplante renal de cadáver, con un $25,6 \%$ de pacientes que no llegaron a recibir diálisis, siendo trasplantados de forma precoz. La etiología de la enfermedad renal también es diferente en su muestra, con un porcentaje mucho más importante de nefropatía diabética (31\%), patología que probablemente constituya la razón del alto número de pacientes trasplantados antes de su llegada a diálisis, con el fin de minimizar en la medida de lo posible el desarrollo de calcificaciones vasculares asociado a la diabetes mellitus.

El score de calcio coronario recogido por Schankel fue de $392,4 \pm 747,9 \mathrm{HU}$ en el primer corte realizado tras una media de 2,6 \pm 1,9 meses tras el trasplante (34\% de pacientes por encima del percentil 90 de calcificación coronaria) y de $475,3 \pm 873,5 \mathrm{HU}$ en el segundo corte, realizado una media de 1,77 $\pm 0,57$ años tras el trasplante. Ambos resultados son inferiores a los recogidos en nuestra muestra, debido a varias razones. En primer lugar, ambas evaluaciones realizadas por Schankel se practicaron con pacientes con un seguimiento tras el trasplante menor que en nuestro caso, con una media de 48,41 meses de seguimiento, por lo que la probabilidad de presentar una función deteriorada del injerto es mayor en nuestra muestra. Su población es además más joven, con un mayor porcentaje de mujeres y con una amplia proporción de pacientes que recibieron el trasplante de forma precoz, lo que reduce enormemente el tiempo medio de permanencia en diálisis de la muestra, variable que influye especialmente en el desarrollo de las calcificaciones vasculares.

También hay que destacar que nuestra muestra está compuesta totalmente por individuos de raza caucásica, frente al 59,8\% del trabajo de Schankel. Según este autor, los individuos de raza caucásica presentaron en su muestra un patrón de progresión del grado de CAC significativamente mayor que los pacientes de otras razas (242). Schankel concluye que los individuos varones, con tasa estimada de filtrado glomerular por debajo de $60 \mathrm{ml} / \mathrm{min} / 1,73 \mathrm{~m}^{2}$ o que habían llegado a recibir diálisis presentan un nivel mayor de calcificación coronaria, resultados similares a los recogidos en nuestro análisis. Los resultados de Schankel sitúan la tasa de aumento anual de las calcificaciones coronarias en pacientes con lesiones preexistentes en un $10,7 \%$. 


\section{DISCUSIÓN}

La inflamación juega también un papel fundamental en la génesis y el desarrollo de calcificaciones vasculares. El grupo de Stompor analizó en 2003 el grado de calcificación coronaria existente en una muestra de 43 pacientes en diálisis peritoneal, observando como el depósito de calcio en dichas arterias se correlacionaba con la edad, el índice de masa corporal y los niveles séricos de leptina y PCR (327). Los pacientes con calcificaciones más severas mostraban cifras más elevadas de PCR, IL-6 y factor de crecimiento fibroblástico básico. En nuestro análisis la existencia de una mayor inflamación sistémica determinada por una mayor concentración de PCR se correlacionaba directamente con el grado de calcificación coronaria. Sin embargo, no comprobamos la misma asociación al analizar las cifras séricas de interleukina-6.

El grupo de Stompor estudió asimismo la diferente progresión en el grado de calcificación vascular observada entre pacientes en diálisis peritoneal que permanecían en la técnica transcurridos 12 meses y aquellos que recibían un trasplante renal. Los receptores de trasplante presentaban una estabilización en la CAC registrada, mientras que los que continuaban en DP sufrían una progresión en la afectación coronaria (327). Stompor concluía que dicho efecto se debía tanto al efecto del injerto renal como al hecho de que los pacientes que recibieron el trasplante presentaban, por lo general, una edad menor, una menor permanencia en diálisis, un menor grado de inflamación y un menor número de patologías concomitantes.

La influencia de la inflamación fue estudiada por Norby y cols en una muestra de 39 pacientes con lupus eritematoso sistémico que habían recibido un trasplante renal (328). En dicho estudio se observó una calcificación coronaria media de $894 \pm 1679 \mathrm{HU}$. La calcificación coronaria se correlacionaba en esta muestra con el índice de masa corporal, la velocidad de onda de pulso y el tiempo transcurrido desde el diagnóstico de LES. Sin embargo, este autor no encontró relación con la edad, la inflamación, la función renal, el tiempo en diálisis o los parámetros relativos al metabolismo óseo-mineral. Dichos resultados se deben probablemente a la interferencia ejercida por la enfermedad renal de base, que condiciona un estado basal inflamatorio muy alterado, que dificulta 


\section{DISCUSIÓN}

el hallazgo de asociación alguna entre PCR e IL-6 y las CAC. Además los pacientes habían permanecido de media un tiempo muy reducido en diálisis y eran más jóvenes.

Maréchal y cols publicaron en 2012 un estudio con 197 receptores de trasplante renal, realizando dos cortes (basal y una media de 3,5 años tras el trasplante). La muestra analizada presentaba un $98 \%$ de caucásicos, 57\% varones, con una edad de $52 \pm 12$ años, un seguimiento tras el trasplante de $93 \pm 78$ meses y una distribución respecto a la enfermedad renal de base similar a nuestro estudio (329). La valoración basal recogió una media del score de calcio coronario de $616 \pm 1164 \mathrm{HU}$, mientras que tras el seguimiento el índice se situó en $957 \pm 1941 \mathrm{HU}$. Marechal determinó que la edad, el sexo masculino, la diabetes, los niveles de homocisteína, PTHi y $25-\mathrm{OH}$ vitamina D constituían factores determinantes de la velocidad de progresión de las calcificaciones. Además, un $83,3 \%$ de los pacientes que presentaban un score de CAC de $0 \mathrm{HU}$ en la valoración basal no presentaban aumento en la valoración realizada tras el seguimiento.

Un análisis publicado en 2010 por Roe y cols (229), con una muestra de 112 receptores de trasplante renal de cadáver incidentes sin antecedentes de cardiopatía isquémica, estudió el grado de calcificación coronaria basal y tras un periodo de 1,7 años más tarde. La edad media fue de $48,8 \pm 12,5$ años, un $63 \%$ caucásicos, un $62 \%$ varones y en un $61 \%$ con donante cadáver. La enfermedad renal de base difiere considerablemente respecto a nuestro estudio, con un $54,5 \%$ de enfermos con nefroangioesclerosis y un $31,5 \%$ con nefropatía diabética. El tiempo medio de permanencia en diálisis fue de 2,7 años, con un $10 \%$ que recibieron el trasplante de forma precoz y un $74,1 \%$ de pacientes en hemodiálisis. El score de calcio coronario basal fue de $367,7 \pm 682,3 \mathrm{HU}$, con un $10,7 \%$ de pacientes con un score por encima de $1000 \mathrm{HU}$. La edad, el sexo masculino, el tiempo en diálisis, la diabetes, el índice de masa corporal, la donación de cadáver, la hipercolesterolemia y la hipertrigliceridemia constituyeron factores de riesgo para el desarrollo y la severidad de las CAC. En este estudio no se observó correlación entre las CAC y las cifras séricas de calcio y fósforo. Se comprobó asimismo como las calcificaciones coronarias constituyen un factor de riesgo para el desarrollo de eventos y mortalidad de tipo cardiovascular, con una supervivencia un $12,8 \%$ inferior a los dos años en pacientes con score de Agatston > $100 \mathrm{HU}$. 


\section{DISCUSIÓN}

Roe y cols no encontraron una asociación clara entre los indicadores de inflamación y el grado de progresión de la calcificación, mientras que el colesterol elevado sí supuso un factor de riesgo para el desarrollo de calcificaciones. Es probable que dichos resultados se deban al amplio porcentaje de pacientes con trasplante renal de donante vivo. Esto condiciona de media un menor tiempo en diálisis, un menor grado de inflamación que dificulta el hallazgo de asociación entre parámetros como PCR y CAC y a su vez, un mejor estado nutricional y por tanto una relación entre colesterol plasmático y CAC más similar a la observada en población general que a la específica de enfermos en diálisis.

De Paolis y cols analizaron una muestra de 45 receptores de trasplante renal, en su mayoría varones $(68,8 \%)$ con una edad de $48 \pm 14$ años, un tiempo en diálisis de $99 \pm$ 104 meses y un 100\% de los pacientes en hemodiálisis (330). Realizaron un corte basal y un segundo a los 12-16 meses tras el trasplante observando como la modificación del estado inflamatorio, determinado por las variaciones de PCR determinaba la progresión de las calcificaciones coronarias.

Abedi y cols analizaron un grupo de 31 pacientes en hemodiálisis que recibieron un trasplante renal y la evolución de sus CAC (331). Dicha cohorte estaba constituida por un $54 \%$ de varones, con una edad media de 38,08 $\pm 13,49$ años y con un tiempo en diálisis de $20 \pm 15,72$ meses. El grado de CAC en la evaluación pretrasplante fue de 39,82 $\pm 63,05 \mathrm{HU}$, mientras que tras el trasplante, las cifras medias del score de CAC fueron de 24,34 $\pm 39,55$ HU. Los autores describieron además una significativa reducción de la concentración sérica de PTHi y del producto calcio-fósforo en estos pacientes tras recibir el trasplante. Se evaluó además el grosor íntima-media carotideo tanto pretrasplante $(0,89 \pm 0,28 \mathrm{~mm})$ como tras el trasplante $(0,84 \pm 0,23)$. En esta muestra, el grado de CAC se correlacionaba de forma directa con la edad, las cifras de fósforo y PTHi séricas, el producto calcio-fósforo y el GIM. Estos resultados son comparables a los recogidos en nuestro estudio aunque en nuestro caso no encontramos asociación alguna entre los niveles séricos de fósforo o el producto calcio-fósforo, tanto pretrasplante como en la evaluación actual y el grado de CAC. El estudio de Abedi y colaboradores es uno de los 


\section{DISCUSIÓN}

pocos análisis en los que se ha descrito una correlación significativa entre las cifras de fósforo y producto calcio-fósforo y la calcificación coronaria.

El grado de calcificación en arterias de gran calibre comparado con arterias coronarias fue estudiado por Nguyen y cols en una muestra de 281 receptores de trasplante renal (231). Dicha muestra presentaba un porcentaje similar de pacientes varones (61\%), caucásicos en un $98 \%$ y con una prevalencia de diabetes entre los pacientes comparable a nuestro estudio (15\%). Otros datos de interés como la edad (53 \pm 13 años) y el tiempo en diálisis ( $28.8 \pm 28,8$ meses) fue similar, aunque nuestra muestra presentaba una permanencia en diálisis mayor. Los pacientes de Nguyen, por el contrario, presentaron una mayor prevalencia de patología cardiovascular (31\%). El índice de calcio coronario en este estudio se expresó en miligramos de hidroxiapatita, de modo que la comparación directa con nuestros resultados, expresados en unidades Hounsfield, no es factible. Los autores observaron que las CAC y la existencia de antecedentes cardiovasculares actuaban en esta muestra como un importante predictor de mortalidad y eventos cardiovasculares, mientras que los factores de riesgo cardiovascular clásicos como la edad, el sexo masculino, el perfil lipídico o la obesidad no fueron capaces en este estudio de predecir el desarrollo de eventos cardiovasculares. El nivel de calcificación de arterias coronarias fue uno de los predictores de mayor peso del avance de las mismas, así como la concentración plasmática de triglicéridos en el estudio de Seyahi y cols (332).

Pencak y colaboradores publicaron en 2013 un estudio con 104 pacientes en hemodiálisis con unas características similares a los pacientes trasplantados incluidos en nuestro análisis, comparados con un grupo control compuesto por individuos sanos (333). Los pacientes presentaban una media de edad de 53,6 años, un 53,8\% eran varones, con una media de permanencia en diálisis de 45 meses, un índice de masa corporal medio de 24,9 y un porcentaje de obesidad del $10,5 \%$. Un $84,5 \%$ de los enfermos eran hipertensos y un 18,3\% diabéticos, mientras que un $33,7 \%$ presentaban antecedentes de enfermedad coronaria. El estudio registró un $73,1 \%$ de los pacientes con algún grado de calcificación coronaria y un grado de calcificación con una mediana de 1196 HU (rango 720 - 1672 HU). La severidad de la calcificación coronaria se asociaba 


\section{DISCUSIÓN}

en este estudio con la edad, el tiempo de permanencia en diálisis, la duración de la terapia antihipertensiva recibida, el número de cigarrillos consumidos o niveles séricos más altos de osteoprotegerina. Se evaluó asimismo el nivel de calcificación aórtica, aunque en este caso dicha evaluación se realizó mediante tomografía computerizada de aorta torácica. El grado de calcificación en este caso se asociaba únicamente con la edad, el número de cigarrillos consumido y los niveles plasmáticos de osteoprotegerina, sin presentar relación aparente con el tiempo de permanencia en diálisis.

Kham y cols estudiaron la asociación del FGF-23 con las CAC, y su papel en la severidad y el desarrollo de las calcificaciones coronarias (334). Para ello analizaron una muestra de 99 pacientes en hemodiálisis, con una media de edad de $50 \pm 12,8$ años, un $68 \%$ varones, un $64 \%$ de raza afroamericana y con una alta prevalencia de diabetes (52\%) y sobrepeso (IMC $29 \pm 6$ ). Las cifras de FGF-23 se asociaron en esta muestra de pacientes en hemodiálisis no solo con el grado de calcificación de las arterias coronarias sino también con la progresión de las mismas. En nuestro estudio no hallamos correlación entre la calcificación de arterias coronarias y la concentración de FGF-23 en el momento actual. La razón de esta diferencia radicará probablemente en que los pacientes del análisis de Kham se encontraban en hemodiálisis, mientras que nuestra muestra incluye únicamente receptores de trasplante renal.

Krasniak y cols estudiaron el grado de calcificación de arterias coronarias mediante el score de Agatston en una muestra de 73 pacientes en hemodiálisis periódica (335). En dicha muestra se observó como el grado de calcificación se correlacionaba de forma positiva con la edad, el IMC, las cifras de PTHi, PCR, IL-6 y el grosor íntima-media carotideo, mientras que mostraba una correlación inversa con la 25-OH vitamina D, TGF$\beta$ y TGF- $\alpha$. No se observó correlación entre el grado de calcificación coronaria y las cifras de colesterol total, colesterol LDL, colesterol HDL, triglicéridos, homocisteína, calcio, fósforo o producto calcio-fósforo. En el análisis multivariante sólo la edad y el GIM constituyeron factores predictores independientes del grado de calcificación coronaria.

Existen diversos parámetros que constituyen factores de riesgo aparentemente consolidados para el desarrollo de calcificaciones coronarias en población trasplantada. 


\section{DISCUSIÓN}

En nuestro estudio constituyen factores asociados a un mayor grado de CAC la edad, el sexo masculino, un mayor tiempo de permanencia en diálisis, la hemodiálisis vs la diálisis peritoneal, la diabetes, las cifras de glucosa y hemoglobina glicosilada, la urea, el ácido úrico, la fosfatasa alcalina y la microalbuminuria. Asimismo, asocian un menor grado de CAC los pacientes con una mayor diuresis residual pretrasplante, mayores cifras de hemoglobina y hematocrito pretrasplante, una mayor concentración sérica de colesterol total y un mayor aclaramiento de creatinina.

La edad es uno de los factores que se asocian directamente a un mayor grado de CAC casi de forma universal, tanto en población general como en enfermos en prediálisis, en diálisis o trasplantados. El tiempo de permanencia en diálisis es otros de los factores con mayor peso a la hora de determinar la severidad de las calcificaciones coronarias. Su papel está especialmente definido en población en diálisis. Algunos estudios en trasplantados, sin embargo, no han alcanzado a comprobar dicha situación (242). Estos estudios se caracterizan habitualmente por presentar una muestra constituida por pacientes más jóvenes y con un alto porcentaje de donante vivo y/o trasplante previo a la diálisis, condicionando una menor exposición al tratamiento renal sustitutivo.

Nuestros resultados corroboran asimismo los hallazgos de múltiples estudios anteriores, en los que la diabetes mellitus constituye un importante factor de riesgo para el desarrollo de calcificaciones coronarias en receptores de trasplante renal $(\mathbf{2 3 9}, \mathbf{2 4 2})$. Un estudio reciente ha comparado el grado de calcificación coronaria existente en 341 enfermos en hemodiálisis, de los cuales 60 eran diabéticos (336). Los pacientes diabéticos presentaban de media una edad superior, un mayor tiempo en diálisis y una mayor prevalencia de HTA, con cifras más bajas de colesterol HDL y una mayor concentración de triglicéridos.

En este estudio se observó un mayor grado de calcificación coronaria en los enfermos diabéticos frente a los no diabéticos ( $478 \pm 590 \mathrm{HU}$ vs $336 \pm 627 \mathrm{HU}$ ), con un mayor porcentaje de enfermos con un score de CAC superior a $400 \mathrm{HU}$ ( $30 \%$ vs $18 \%$ ). Los parámetros relativos al metabolismo óseo-mineral y el resto de factores de riesgo cardiovascular clásicos no presentaron asociación con el grado de CAC. Este estudio 


\section{DISCUSIÓN}

señala un efecto promotor de las calcificaciones ejercido por la diabetes, tanto de forma directa sobre la pared de las arterias como de forma indirecta, favoreciendo el desarrollo de un perfil de dislipemia aterogénica y aumentando la prevalencia de otros factores de riesgo $\mathrm{CV}$.

El efecto lesivo sobre la pared de los vasos inducido por la diabetes parece regulado en parte tanto por el control glucémico conseguido con el tratamiento (323), como por la función renal del enfermo, aunque algunos autores han puesto en entredicho este último punto en una muestra de diabéticos tipo 2 asintomáticos (324).

La acción del trasplante renal sobre el proceso de calcificación vascular viene siendo objeto de debate desde hace algunos años. Moe y cols analizaron en 2003 dos cohortes de pacientes, 38 receptores de trasplante renal y 33 pacientes en diálisis (238). El grupo de pacientes trasplantados resultó ser más joven ( $45 \pm 13$ años vs a $55 \pm 11$ años), con un mayor porcentaje de varones (76,3\% vs $60.6 \%)$, con una menor permanencia en diálisis ( $25 \pm 19$ meses vs $77 \pm 68$ meses), un mayor porcentaje de pacientes en diálisis peritoneal y con un menor índice de masa corporal ( $25.2 \pm 4.4$ vs $26 \pm 8.1)$.

Los pacientes trasplantados presentaban una menor calcificación de arterias coronarias (314 \pm 728 HU vs $859 \pm 1654$ HU). En ambos grupos se comprobó como la edad y el tiempo en diálisis constituyeron importantes factores de riesgo que favorecían una mayor severidad en el grado de calcificación coronaria. Sin embargo Moe y cols no hallaron correlación entre las cifras séricas de calcio, fósforo, producto calcio-fósforo, PTHi, colesterol total o PCR y el grado de CAC. El carácter transversal del estudio, con dos muestras de pacientes con características basales diferentes hace imposible determinar en este estudio si la realización del trasplante tiene en la práctica un efecto beneficioso sobre la calcificación coronaria o si simplemente observamos en pacientes trasplantados un menor grado de calcificación debido a su menor edad y al mejor estado general que presentan de media frente a los enfermos en diálisis.

El papel de algunos factores no está del todo aclarado. El proceso aterosclerótico implica en su desarrollo diversos mecanismos inflamatorios. Varios intermediarios como la PCR, 


\section{DISCUSIÓN}

la lipoproteína A o las moléculas de adhesión ICAM constituyen nuevos factores de riesgo CV implicados en el desarrollo de esta patología. El recuento leucocitario plasmático se ha propuesto como marcador de riesgo CV independiente de otros factores de riesgo CV clásicos (337). Sin embargo, ni el estudio de Roe (229) ni nuestro análisis han sido capaces de objetivar una correlación entre el recuento leucocitario y las CAC.

La PCR constituye un importante marcador de inflamación y un predictor de mortalidad en enfermos en hemodiálisis. Sin embargo, su influencia sobre el desarrollo de CAC está en entredicho. Blacher y cols (228) encontraron una asociación entre los niveles de PCR y la calcificación vascular objetivada mediante ecografía en una muestra de pacientes en hemodiálisis. Esta relación ha sido descrita asimismo en pacientes en diálisis peritoneal (327) y en pacientes trasplantados (330) De la misma forma en nuestra muestra parece existir una relación directa entre las cifras de PCR y la severidad de las CAC. Varagunam y cols determinaron que la PCR pretrasplante constituía un importante factor predictor de eventos cardiovasculares y mortalidad en pacientes trasplantados (338).

Sin embargo, estos hallazgos no son universales. Russo y cols analizaron 85 pacientes con ERC en prediálisis y sin diabetes, sin encontrar relación entre las cifras de PCR y las CAC. De forma similar, Moe y cols estudiaron 71 pacientes en diálisis o trasplantados sin encontrar una asociación significativa entre estos parámetros (238). Roe y cols tampoco encontraron una asociación significativa entre los valores de PCR y el grado de progresión de las CAC, aunque sí con la severidad de las mismas, en una muestra de 112 trasplantados renales (229). Una de las diferencias que presenta nuestro estudio con algunos trabajos es que la determinación de PCR en nuestro caso es actual, mientras que en varios análisis se realizó antes del trasplante o en pacientes en diálisis de forma continuada. Además, nuestro análisis no determina si las cifras de PCR se relacionan con la progresión de la calcificación sino únicamente con su severidad en el único corte realizado en nuestro caso. 


\section{DISCUSIÓN}

El papel del colesterol en el desarrollo de CAC en esta subpoblación de pacientes no está completamente aclarado. En nuestra muestra cifras más altas de colesterol total tanto pretrasplante como en la revisión actual parecen otorgar cierto factor protector para el desarrollo de CAC, muy probablemente en relación con un fenómeno de "epidemiología inversa". Russo y cols (336) comprobaron una asociación similar entre el colesterol sérico y las CAC en una muestra de pacientes en diálisis. Sin embargo otros autores describen una correlación directa entre las cifras de colesterol sérico y las CAC (229). Estos trabajos se caracterizan por presentar muestras de menor edad, menor tiempo en diálisis y con mucha probabilidad un menor estado inflamatorio. En ninguno de los trabajos revisados en los que se describía una asociación directa entre colesterol y CAC se observaba simultáneamente la misma asociación entre CAC y parámetros inflamatorios. En resumen, es posible que en enfermos jóvenes, con poco tiempo en diálisis, bajo nivel de inflamación y un buen estado basal, el comportamiento del colesterol respecto a las CAC sea más similar a lo que sucede en población general, mientras que en pacientes de más edad, con patología concomitante, mayor tiempo de permanencia en diálisis y un mayor nivel de inflamación, el colesterol se comporte como un indicador de nutrición y debido a su asociación con un menor grado de inflamación asocie un menor grado de CAC y un mejor pronóstico global.

En nuestro análisis el ácido úrico sérico en el momento actual se correlaciona de forma directa con el índice de calcio coronario. Los niveles altos o en el límite alto de la normalidad se han correlacionado en diferentes trabajos con una mayor prevalencia de enfermedad coronaria, infarto agudo de miocardio e HTA. La correlación con el grado de calcificación coronaria no está clara. Nuestro estudio recoge dicha relación, al igual que Krishnan (324). Sin embargo, otros autores como Neogi (326) no han observado una asociación en la concentración sérica de úrico y el grado de CAC.

La concentración sérica de calcio y fósforo así como el producto calcio-fósforo y otros parámetros relativos al metabolismo óseo-mineral tanto pretrasplante como en el momento actual no presentan correlación con el grado de CAC. Otros factores que no tienen aparentemente influencia son la enfermedad renal de base excepto la diabetes, 


\section{DISCUSIÓN}

la actividad física, la inmunosupresión o el tratamiento relativo al metabolismo óseomineral recibido antes del trasplante.

\section{6: GROSOR ÍNTIMA-MEDIA CAROTIDEO}

El valor medio del grosor íntima-media carotideo en los 43 pacientes estudiados fue de 0,76 \pm 0,13 mm (mediana 0,75 mm, rango 0,67-0,83 mm). Un 93\% de los enfermos (40 pacientes), presentaron un GIM inferior a $1 \mathrm{~mm}$, un 7\% (3 pacientes) presentaron un GIM de entre 1 y 1,49 mm, mientras que ningún paciente presentó un GIM igual o superior a $1,5 \mathrm{~mm}$.

Para analizar la relación existente entre las diferentes variables incluidas en el estudio y el GIM carotideo medio, en carótida derecha e izquierda decidimos estratificar los pacientes incluidos en dos grupos, según presentasen un GIM inferior a $0.75 \mathrm{~mm}$ o igual o superior a dicha cifra. Un 48,8\% (21 pacientes) de los pacientes presentaron un GIM < $0.75 \mathrm{~mm}$.

Observamos que los pacientes con un GIM mayor presentaban con mayor frecuencia una edad más avanzada, un mayor tiempo en diálisis previo al trasplante, habían recibido hemodiálisis frente a diálisis peritoneal o padecían diabetes mellitus que el resto de enfermos. No se observaron diferencias entre grupos respecto al sexo de los pacientes o el padecimiento de HTA, sobrepeso y obesidad, dislipemia o tabaquismo.

La edad, el tiempo en diálisis y la indicación de hemodiálisis en lugar de diálisis peritoneal constituyen, al igual que en el caso de las calcificaciones coronarias, un importante factor de riesgo para el desarrollo de calcificaciones a nivel de las arterias carótidas. Sin embargo en nuestra muestra el sexo no parece presentar una asociación clara con el GIM, mientras que el sexo masculino sí constituye un factor de riesgo para el desarrollo de calcificaciones coronarias. 


\section{DISCUSIÓN}

De nuevo y al igual que se observó al analizar la relación entre las calcificaciones coronarias y los diferentes factores de riesgo cardiovascular clásicos recogidos, comprobamos en nuestro análisis como la diabetes constituye el único factor de riesgo que parece tener una influencia definida en el desarrollo de calcificaciones vasculares a nivel carotideo. La HTA no presentó asociación con el grado de afectación carotidea, muy probablemente debido a la elevada prevalencia de HTA en los enfermos renales crónicos, tanto en prediálisis como en diálisis o en trasplante renal, lo que dificulta la comparación con pacientes normotensos, mientras que la hipercolesterolemia presentó una relación paradójica, dónde cifras mayores de colesterol sérico asociaron un menor GIM en pacientes con un grado elevado de inflamación y una importante tendencia a la desnutrición como son los enfermos con ERC.

Comparamos asimismo el resto de variables antropométricas y analíticas incluidas en nuestro análisis en busca de la relación existente entre las mismas y el GIM. En nuestra muestra observamos como unos valores séricos mayores de fosfatasa alcalina pretrasplante (en el límite de la significación), triglicéridos en el momento del alta tras el trasplante y en la revisión actual, así como VSG, urea, glucosa sérica, ácido úrico y hemoglobina glicosilada en el momento actual se asocian de forma directa y significativa con un mayor GIM carotideo.

Observamos de igual forma que la existencia de un mayor volumen de diuresis residual previo al trasplante, un mayor recuento leucocitario en el momento del alta tras la cirugía, unas cifras de colesterol total tanto en el momento del alta tras el trasplante como actuales más altas y una mayor concentración de calcio en el momento del alta se correlacionan con un grosor íntima-media más reducido, una relación inversa con significación estadísticamente significativa en todos los casos. Pese a que los varones presentan un GIM más elevado que las mujeres en nuestra muestra ( 0.78 vs $0.72 \mathrm{~mm}$ ), dicha diferencia carece de significación en nuestro análisis.

Como en el caso de las calcificaciones coronarias, la edad, el tiempo en diálisis, la indicación de hemodiálisis, la diuresis residual pretrasplante, los niveles de ácido úrico, 


\section{DISCUSIÓN}

la diabetes y su control constituyen importantes factores que influyen en el desarrollo de lesiones a nivel de arterias carótidas.

En nuestra muestra el ácido úrico presenta una importante asociación con el GIM carotideo. Neogi y cols encontraron una asociación similar entre ambos parámetros en una muestra de 4866 pacientes sin factores de riesgo cardiovascular, especialmente entre individuos varones (325). D’Marco y cols estudiaron la relación entre las calcificaciones vasculares objetivadas mediante ecografía y el ácido úrico en una población con ERC, comprobando como un nivel elevado de ácido úrico comportaba un mayor riesgo de presentar calcificaciones y eventos cardiovasculares en los enfermos con ERC (337).

Sin embargo, estos hallazgos no son universales; De Luca y cols estudiaron la correlación entre las cifras de ácido úrico, el GIM carotideo y el grado de enfermedad arterial coronaria evaluado mediante angiografía sin encontrar una asociación definida entre las variables (339). Tanto PCR como IL-6 presentan una asociación directa con el valor del GIM, que no alcanza significación estadística. Sin embargo, niveles más altos tanto de colesterol total asocian un GIM más bajo, relación probablemente debida al mecanismo de "epidemiología inversa" mencionado anteriormente.

En el caso del GIM el sexo y los parámetros analíticos asociados al metabolismo óseomineral, tanto pretrasplante como en el momento actual e incluyendo las cifras de PTHi y fosfatasa alcalina no presentan asociación con la afectación carotidea. El tratamiento farmacológico relativo al metabolismo óseo-mineral recibido antes del trasplante, así como la pauta de inmunosupresión recibida después de recibir el injerto no presentaron ninguna correlación con el GIM.

El estudio del GIM en pacientes trasplantados y su asociación con otros indicadores de afectación vascular y cardiaca, así como su papel como factor pronóstico de eventos cardiovasculares vienen estudiándose desde hace años. Suwelack y cols publicaron en 1999 los resultados del análisis de 35 pacientes trasplantados renales asintomáticos y 29 controles sanos apareados por edad y sexo (340). La muestra de trasplantados 


\section{DISCUSIÓN}

presentaba una edad media de $45 \pm 2$ años, un porcentaje de varones del $25,7 \%$ y un IMC de $22 \pm 1$. En este estudio se comprobó cómo los receptores de trasplante renal presentaban un mayor $\operatorname{GIM}(1,21 \pm 0,08 \mathrm{~mm})$ y un mayor número de placas en carótidas que los controles. EI GIM mostraba en dicho estudio una clara asociación con la masa ventricular izquierda determinada por ecocardiografía. Sin embargo los autores no objetivaron en los trasplantados una asociación entre el GIM y diversos parámetros como la edad, la TA, el IMC, la creatinina sérica, el colesterol total o los niveles de lipoproteína A, mientras que en los controles el GIM sí se asociaba a la edad, aunque no a la masa ventricular izquierda determinada con ecocardiografía.

El estudio de Suwelack constituye una de las primeras valoraciones sobre las características del GIM en trasplantados renales y su asociación con diferentes parámetros analíticos y antropométricos. Este estudio está limitado debido al pequeño tamaño muestral o al alto porcentaje de mujeres, que no es representativo de la población trasplantada renal, con una mayor proporción de hombres. Paradójicamente, pese a que el grupo de trasplantados de Suwelack está formado principalmente por mujeres, a diferencia de la mayoría del resto de estudios, y con una edad significativamente menor, el valor del GIM recogido es mayor que el registrado en nuestro estudio y en la mayoría de análisis del GIM realizados en trasplantados.

Carecemos de información suficiente relativa a otros parámetros de interés, tanto relativa a la etapa pretrasplante (tiempo en diálisis, modalidad de diálisis recibida, diuresis residual) como relativa al tiempo trasplantado, la función del injerto, los niveles de ácido úrico o al padecimiento y control de la diabetes, todos ellos parámetros de especial relevancia a la hora de valorar el GIM en una población de especial riesgo como los receptores de trasplante renal, por lo que es difícil comparar los resultados de ambos estudios. Los avances introducidos desde entonces en el campo de la inmunosupresión y el mantenimiento del injerto han permitido aumentar la esperanza de vida del trasplante renal y reducir la incidencia de episodios de rechazo agudo, con lo que sería de esperar que, en el momento actual, la función media del injerto, un parámetro de especial relevancia en el desarrollo de calcificaciones vasculares, fuese mejor que en los pacientes incluidos en este estudio que fue publicado hace más de 14 años. 


\section{DISCUSIÓN}

Töz y cols estudiaron 102 receptores de trasplante renal con el objetivo de analizar el GIM y su asociación con diferentes factores de riesgo CV (341). La edad de los pacientes incluidos fue de $36 \pm 10$ años, con una media de permanencia en diálisis de $23 \pm 25$ meses, un tiempo trasplantados de $62 \pm 44$ meses y una creatinina sérica media de 1,67 $\pm 0,67 \mathrm{mg} / \mathrm{dl}$. En este estudio los autores describieron una asociación positiva entre el GIM y la edad, el tiempo en diálisis, las cifras plasmáticas de triglicéridos, al igual que en nuestra muestra, así como con una menor albúmina sérica y la existencia de antecedentes de enfermedad por citomegalovirus. Se observó como el GIM era mayor en pacientes diabéticos y con antecedentes de enfermedad CV. Este estudio, que relaciona directamente edad, tiempo en diálisis y la albúmina, como marcador nutricional con el GIM, ofrece unos resultados compatibles con nuestro análisis, pese a presentar una muestra significativamente más joven y con una permanencia en diálisis menor.

Schwenger y cols estudiaron el GIM en una muestra de 76 pacientes trasplantados renales con función renal estable (342). La edad de los pacientes fue de 49,9 9 14,6 años, con una media de permanencia en diálisis previa al trasplante de 39,48 $\pm 45,84$ meses. La tasa estimada de filtrado glomerular mediante la fórmula de Nankiwell fue de 65,9 \pm $23,3 \mathrm{ml} / \mathrm{min}$. El valor del GIM registrado en este estudio fue de 0,66 $\pm 0,13 \mathrm{~mm}$, algo inferior a nuestros resultados. Aunque el objetivo del estudio no era analizar los factores implicados en el desarrollo de un mayor GIM, sino correlacionar el grado de rigidez vascular con el índice de resistencia de la arteria renal del injerto, Schwenger sí observó como la edad era un parámetro con una fuerte influencia en el grado de rigidez arterial y más específicamente, con el GIM. Probablemente, las diferencias observadas entre ambas muestra respecto al GIM se deban, precisamente, a que nuestra muestra presenta una edad media más avanzada.

Otro trabajo, publicado por el grupo de Heine en 2005 (343) estudiaba una muestra de 105 receptores de trasplante renal, buscando de nuevo la correlación existente entre el índice de resistencia y parámetros que evalúan la rigidez arterial y el grado de afectación de la pared vascular como son el GIM y el índice tobillo-brazo. La edad media de los 


\section{DISCUSIÓN}

enfermos fue de $52.5 \pm 14.4$ años, con una creatinina sérica media de $1.7 \pm 0.7 \mathrm{mg} / \mathrm{dl}$. Un $25,71 \%$ de los enfermos padecían diabetes y un 43,8\% presentaban un elevado riesgo cardiovascular según el score de Framingham. El objetivo del estudio, a diferencia del nuestro, no fue analizar el GIM de los pacientes estudiados sino definir su asociación con el índice de resistencia de la arteria renal. Heine observó una asociación tanto del GIM como del ITB con dicho parámetro, en unos resultados compatibles con el trabajo de Schwenger.

Múltiples estudios han continuado ampliando el conocimiento existente hasta el momento actual sobre la influencia de diferentes factores clínicos y analíticos sobre el desarrollo de placas carotideas y aumento del GIM. Brzósko y cols observaron como en una muestra de 33 pacientes trasplantados comparada con 19 controles sanos, los receptores de trasplante presentaban un GIM más elevado y cifras más bajas de hemoglobina y hematocrito. En esta muestra el GIM se asociaba de forma significativa con el tiempo de permanencia en diálisis, la edad del enfermo y el valor de la hemoglobina y el hematocrito, constituyendo estos últimos tres parámetros factores pronósticos independientes (344). A diferencia de lo observado en el caso de las calcificaciones coronarias, y pese a que en los tres puntos temporales estudiados los pacientes con un GIM $<0.75 \mathrm{~mm}$ presentan cifras más altas de hemoglobina y hematocrito en nuestro análisis dichas diferencias carecen de significación.

De forma similar, Gungor y cols observaron como el GIM de una muestra de 98 pacientes se asociaba a la edad, el sexo masculino y la proteinuria (345). Este estudio recogió un valor de GIM de 0,62 $\pm 0,1 \mathrm{~mm}$ en una muestra de pacientes con edad media de 39,4 \pm 9,6 años y una prevalencia de diabetes del 10\%. A diferencia de nuestro estudio, tanto el sexo como la proteinuria supusieron un factor predictor para el GIM en este trabajo. En nuestro caso, existe una relación positiva entre el GIM y la microalbuminuria actual, pero dicha relación no alcanza significación estadística probablemente debido al pequeño tamaño muestral.

EI GIM también ha sido analizado en población trasplantada infantil y joven. Bilginer y cols publicaron en 2007 (346) un estudio con 24 pacientes receptores de trasplante 


\section{DISCUSIÓN}

renal, de edades comprendidas entre los 8 y los 25 años y 20 controles sanos. Un $66 \%$ de los enfermos había recibido diálisis peritoneal como tratamiento renal sustitutivo mientras que el $8 \%$ había recibido un trasplante renal previo a su entrada en diálisis. La mediana de estancia en diálisis resultó muy reducida, de 6,5 meses (rango 0-84 meses). EI GIM en esta población pediátrica resultó notablemente más reducido que en nuestra muestra (mediana $0.36 \mathrm{~mm}$, rango $0.16-0.48 \mathrm{~mm}$ ), fruto de la conjunción de múltiples factores relevantes como son una menor edad, un menor tiempo en diálisis, un mayor porcentaje de diálisis peritoneal y un menor número de enfermedades concomitantes. En esta muestra pediátrica no se encontró asociación entre el GIM y la procedencia del injerto (donante vivo vs cadáver), entre las diferentes causas de la enfermedad renal de base ni tampoco dependiendo de si padecían HTA o no o del grado de anemia o inflamación.

A diferencia de nuestros resultados la modalidad de diálisis recibida no asociaba diferencias significativas respecto al valor del GIM. El metabolismo lipídico tampoco presentaba una asociación con el GIM a diferencia de los pacientes adultos. Sin embargo las cifras de fósforo sérico en esta muestra, el producto calcio-fósforo y el tiempo en diálisis sí que presentaron una correlación estadísticamente significativa con el GIM. Estos resultados vienen a definir el tiempo en diálisis como uno de los factores de riesgo para el desarrollo de calcificaciones vasculares más importantes, independientemente de que se trate de población pediátrica o adulta.

El efecto deletéreo de la diabetes, incluso en sus estadios iniciales, fue estudiado en 2012 por Uchida y cols (347). En una muestra de 32 trasplantados renales se comprobó como la prevalencia de intolerancia oral a la glucosa asociaba un GIM mayor. Respecto al papel del colesterol Janda y cols encontraron una asociación positiva entre las concentraciones séricas de esta molécula y el valor del GIM en una muestra de 51 pacientes trasplantados (348). Este estudio presenta unos resultados contrarios a los recogidos en nuestra muestra pero de nuevo probablemente se deban a la edad de los pacientes analizados. En este caso, la edad media de los receptores de trasplante fue de 38,1 años y, como se ha postulado anteriormente, es posible que en población joven, con menor patología concomitante y muy probablemente un menor tiempo de 


\section{DISCUSIÓN}

permanencia en diálisis la hipercolesterolemia se comporte de forma más similar a la población general, mientras que en receptores añosos, con pluripatología y un mayor tiempo en diálisis el efecto de la hipercolesterolemia sobre el riesgo cardiovascular presente un perfil más parecido al existente en pacientes en diálisis.

Dos recientes estudios, publicados en 2013 y 2014, han indagado en la posible asociación entre el FGF-23 y el GIM en trasplante renal. Gungor y cols analizaron una muestra de 117 receptores de trasplante con edad media de 39,6 \pm 9,6 años, 51\% varones y un GIM medio de 0,62 £0,11 mm (349). Este grupo no fue capaz de objetivar asociación entre la concentración de FGF-23 y el valor del GIM en la muestra. Asicioglu y cols, en una reciente publicación analizaron un grupo de 46 trasplantados frente a 44 controles sanos. En este estudio se investigó la influencia de factores como el FGF-23, la concentración de triglicéridos, ácido úrico, PTHi o fosfatasa alcalina respecto al GIM. Sólo la creatinina y el ácido úrico séricos constituyeron predictores independientes de la gravedad del aumento del GIM (350).

Tanto en nuestro análisis como en varios de estos trabajos se ha definido al tiempo de permanencia de los pacientes en diálisis como uno de los factores determinantes de mayor peso a la hora de estimar el GIM. A este respecto Litwin y cols plantearon un estudio con 34 receptores de trasplante renal procedentes de una unidad pediátrica, 37 pacientes en diálisis, 55 enfermos en prediálisis y 270 controles sanos, con el objeto de analizar la influencia de los diferentes estadios de ERC en el desarrollo de calcificaciones vasculares a nivel carotideo en pacientes de edades comprendidas entre los 10 y los 20 años (351). La muestra de trasplantados presentaba una edad de $15 \pm 2,7$ años, una permanencia media en diálisis de $22 \pm 26$ meses, una creatinina sérica de 1,5 $\pm 0,9 \mathrm{mg} / \mathrm{dl}$ y un GIM de 0,43 $\pm 0,05 \mathrm{~mm}$, con un $75 \%$ de los enfermos por encima del percentil 95 de calcificación coronaria para su edad y sexo. El GIM se mostraba significativamente más elevado en el grupo de ERC frente a los controles. Dentro de los pacientes ERC, el grupo de pacientes en diálisis presentaba un GIM mayor que los pacientes en prediálisis o trasplantados. 


\section{DISCUSIÓN}

En los controles sanos se observó una correlación directa entre el GIM y el IMC y la presión de pulso e inversa con la concentración de colesterol HDL y apolipoproteína A. En los pacientes con ERC el GIM se correlacionaba con el producto calcio-fósforo pasado, la dosis acumulada de quelantes de fósforo, la dosis media previa de calcitriol y una concentración sérica de albúmina más baja. Asimismo el GIM presentaba en los pacientes con ERC una asociación con las cifras de TA sistólica, apolipoproteína A, apolipoproteína B y niveles de PCR. Sin embargo, no se observó asociación con la función renal, la duración de la enfermedad o el metabolismo óseo-mineral. En pacientes trasplantados, la dosis acumulada de corticoides y de quelantes de fósforo también se asociaba a un mayor GIM (351).

En nuestro estudio no se comprobó esta asociación entre el GIM y el tratamiento relativo al metabolismo óseo-mineral pretrasplante (calcitriol, paricalcitol, cinacalcet, quelantes de fósforo) ni respecto a la dosis acumulada de inmunosupresores (glucocorticoides, inhibidores de la calcineurina, ácido micofenólico, inhibidores de mtor). No hemos encontrado referencias a una influencia de dichos tratamientos sobre el GIM en los estudios sobre población trasplantada adulta que hemos revisado. Es posible que la sensibilidad del árbol vascular en pacientes pediátricos tanto a las alteraciones de la concentración plasmática de calcio y fósforo como a la acción de quelantes y glucocorticoides sea diferente a la presente en pacientes adultos.

El efecto de la pauta inmunosupresora sobre el GIM también ha sido analizado por algunos autores, con resultados compatibles con los observados en nuestra muestra. Mourer y cols estudiaron el efecto de la retirada tardía de los inhibidores de la calcineurina y el ácido micofenólico sobre las cifras de TA y el GIM en una muestra de 119 trasplantados (352). Se comprobó como la retirada de inmunosupresión favorecía un mejor control de las cifras tensionales, pero no tenía ningún impacto sobre el GIM.

El grupo de Oh y cols realizaron una comparación entre pacientes trasplantados y en hemodiálisis, estudiando su árbol vascular mediante el índice de CAC y el GIM (353). EI estudio incluyó 26 receptores de trasplante renal y 13 pacientes en diálisis. La edad media de los enfermos fue de $27,4 \pm 6,4$ años, un $69 \%$ varones. La media de permanencia 


\section{DISCUSIÓN}

en hemodiálisis de los pacientes trasplantados fue de $2,3 \pm 3,5$ años, significativamente inferior a la que presentaban los enfermos aún en hemodiálisis.

Un 92\% de los enfermos presentó algún grado de calcificación coronaria, siendo mayor de $400 \mathrm{HU}$ en un 5,1\% de los casos. Los pacientes trasplantados presentaron un índice de CAC inferior al recogido entre los enfermos en diálisis (mediana $60 \mathrm{HU}$, rango 23 103 HU vs mediana 156 HU, rango 46 - 226 HU) con una mayor proporción de lesiones moderadas o severas. En el modelo univariante, tanto la permanencia en diálisis como el valor medio de PTHi, la concentración acumulada de calcio y el producto calciofósforo y el valor actual de PCR y homocisteína se asociaban al índice de CAC. EI GIM se mostró significativamente más alto en pacientes en diálisis o trasplantados frente a los controles sanos, pero no presentaba variación significativa entre los dos primeros grupos. La edad mostraba una asociación con el GIM en los enfermos renales, mientras que dicha asociación no estaba presente en los controles. El valor del GIM se asoció en los pacientes al tiempo de permanencia en diálisis y a la concentración acumulada de calcio, fósforo y producto calcio-fósforo desde el inicio de la ERC.

El recuento leucocitario es otro de los parámetros que se ha visto asociado al desarrollo de aterosclerosis (354). El incremento en el recuento de leucocitos es un factor de riesgo independiente para el desarrollo de eventos cardiovasculares (355). Sin embargo, la relación existente entre el recuento leucocitario y el GIM no está completamente aclarada. Mientras que Kuo y cols no encontraron asociación entre el recuento leucocitario y el GIM en una muestra de sujetos asintomáticos de origen asiático (356), Matsumura y cols sí describieron una asociación directa entre el recuento leucocitario y el GIM en pacientes con diabetes mellitus tipo 2 y de origen asiático (357). No obstante, la asociación entre el recuento leucocitario y el GIM parece modificarse dependiendo de terceros factores, como puede ser la raza. Mitchell y cols describieron como la asociación entre recuento y GIM es particularmente fuerte en hispanos, intermedia en individuos de raza negra e inexistente en la muestra estudiada de caucásicos (358). En nuestro estudio, cuya muestra está compuesta al 100\% por individuos de raza caucásica, hemos observado una correlación inversa entre el recuento leucocitario, únicamente en la analítica realizada en el momento del alta tras el trasplante y el GIM actual. Dicho 


\section{DISCUSIÓN}

hallazgo contradice los resultados descritos en la literatura pero parece sujeto a varias posibles fuentes de sesgo. La asociación únicamente se observa en el momento inmediato al trasplante y que en dicha situación el recuento leucocitario puede estar sujeto a múltiples variables que lo modifiquen, como el uso de dosis elevadas de inmunosupresores como glucocorticoides, infecciones asociadas a la cirugía, complicaciones de tipo urológico, así como al empleo de sondajes urológicos o catéteres centrales.

El GIM evaluado en arterias carótidas comunes ha demostrado constituir un adecuado marcador de la presencia de aterosclerosis subclínica, así como de la velocidad de progresión de la misma en el individuo. En población general, el valor de GIM se asocia con el riesgo de presentar eventos cardiovasculares como infarto agudo de miocardio o ictus, así como de mortalidad cardiovascular.

La capacidad del GIM como factor pronóstico de eventos cardiovasculares ha sido analizada en población sin ERC pero con al menos un factor de riesgo cardiovascular clásico. Staub y cols, en una muestra de 146 pacientes con las mencionadas características observaron como el riesgo de presentar un evento cardiovascular a lo largo del seguimiento (mediana 36 meses) fue del 11,8\% para pacientes con un GIM inferior a 0,79 mm, mientras que se situó en el $25,6 \%$ en aquellos pacientes con un GIM igual o superior a 0,79 $\mathrm{mm}$ (359).

\section{7: CALCIFICACIÓN VASCULAR EVALUADA MEDIANTE ÍNDICES RADIOGRÁFICOS}

El grado de calcificación vascular fue evaluado en nuestra muestra mediante los índices radiográficos elaborados por Kauppila y Adragao. El índice de Kauppila valora el grado de calcificación existente en arteria aorta lumbar, mientras que el índice de Adragao evalúa el depósito de calcio en la pared de arterias iliacas, femorales, radiales e interdigitales, valorando vasos de un calibre menor. 


\section{DISCUSIÓN}

\subsection{1: INDICE DE ADRAGAO}

El valor medio del índice de Adragao en los 43 pacientes estudiados fue de 1,74 $\pm 2,7$ (mediana 0, rango 0-4). Un 27,9\% de los enfermos (12 pacientes), presentaron un grado de calcificación moderada o severa según este score (Adragao > 3).

Para analizar la relación existente entre las diferentes variables incluidas en el estudio y el índice de Adragao decidimos estratificar los pacientes incluidos en dos grupos, según presentasen un índice de Adragao inferior a 2 o igual o superior a dicha cifra. Un 69,8\% (30 pacientes) de los pacientes presentaron un índice de Adragao $<2$.

Observamos que los pacientes con un índice de Adragao $\geq 2$ son con mayor frecuencia diabéticos, procedentes de un programa de hemodiálisis y con cifras más altas de glucosa, fosfatasa alcalina y TA sistólica previas al trasplante. Los parámetros asociados a la diabetes mantienen esta asociación a lo largo de las revisiones; los pacientes con un mayor Adragao presentan cifras mayores de glucemia y de hemoglobina glicosilada en todos los controles realizados. Los pacientes con un índice de Adragao más alto tienen una edad más avanzada (53.69 vs 48.17) y con mayor frecuencia varones aunque dichas diferencias no alcanzan significación. En la revisión al alta tras el trasplante se observa una asociación directa entre una mayor tasa estimada de filtrado glomerular y un mayor índice de Adragao. Esta asociación se observa únicamente en este punto temporal, en el cual la función del injerto está sujeta a múltiples factores externos como nefrotoxicidad asociada al uso de tacrólimus o complicaciones urológicas y vasculares. El punto de corte utilizado para estratificar a los pacientes también modifica esta asociación ya que, si se toman tanto el valor de MDRD al alta tras el trasplante como el índice de Adragao como variables continuas la asociación entre ambas carece de significación ( $\mathrm{P}>$.05).

Los pacientes con un Adragao $<2$ presentan una mayor diuresis residual previa al trasplante y un valor mayor de hemoglobina y hematocrito pretrasplante. El colesterol total se encuentra más elevado en estos pacientes respecto al grupo con un índice de Adragao $\geq 2$, tanto antes del trasplante como en la revisión actual. Destaca además, 


\section{DISCUSIÓN}

como en el caso de las calcificaciones coronarias, como los pacientes con un índice de Adragao menor presentan un fósforo plasmático y un producto calcio-fósforo mayores en el momento del alta tras el trasplante, en probable relación con una menor alteración del metabolismo óseo-mineral previo al trasplante y como consecuencia una menor concentración de FGF-23 y una menor pérdida de fósforo en las primeras semanas tras el trasplante. El padecimiento de HTA, sobrepeso y obesidad, dislipemia o tabaquismo no asociaba diferencias en cuanto al índice de Adragao.

La diabetes mellitus y el tiempo en diálisis constituyen de nuevo importantes factores pronósticos sobre la calcificación vascular actuando como potentes promotores de las mismas. El grado de inflamación o la concentración de ácido úrico en plasma no presentaron correlación alguna con el índice de Adragao en nuestra muestra. Tampoco mostraron asociación alguna el tratamiento farmacológico relativo al metabolismo óseo-mineral recibido antes del trasplante ni tampoco la pauta de inmunosupresión seguida después de recibir el injerto.

El índice elaborado por Teresa Adragao se ideó como una forma de evaluar con una herramienta sencilla como es, en este caso, la radiografía simple de manos y pelvis, el grado de calcificación vascular existente en arterias de diferente calibre como son las iliacas, femorales, radiales o interdigitales. El estudio de Adragao y los subsecuentes análisis en los que se ha empleado este método de valoración se basan en muestras de enfermos en hemodiálisis, única población para la cual el índice ha sido validado de forma adecuada hasta el momento. Debido a este hecho, no hemos encontrado en la revisión de la literatura realizada previa a la elaboración de este trabajo ningún análisis que describa el comportamiento del índice de Adragao en pacientes trasplantados renales ni su correlación con los diferentes parámetros relativos a la enfermedad cardiovascular, la función del injerto o el metabolismo óseo-mineral en esta población.

Teresa Adragao publicó a este respecto en 2008 un estudio con 101 pacientes en hemodiálisis (252). Los pacientes eran en su mayoría varones (70\%), con una edad media de 58,9 $\pm 15,5$ años, un tiempo de permanencia en diálisis de 55, $8 \pm 54,8$ meses y una prevalencia de diabetes del $19 \%$. Un $58 \%$ de los pacientes de la muestra presentaban un 


\section{DISCUSIÓN}

índice de Adragao moderado o severo. Este resultado se asociaba en dicho estudio con la edad, el padecimiento de diabetes o enfermedad cardiovascular, la presión de pulso o la velocidad de onda de pulso y actuaba como un factor pronóstico en esta población de mortalidad. Los valores séricos de PCR o colesterol total no mostraron asociación con la calcificación vascular.

Los pacientes analizados por Adragao y cols en este estudio presentan varias diferencias significativas respecto a nuestra muestra: Los pacientes tenían una edad algo mayor, con una prevalencia de diabetes ligeramente más alta y un periodo de permanencia en diálisis significativamente más elevado que nuestros enfermos trasplantados. Las cifras de calcio sérico eran más altas en nuestra muestra $(9,6 \pm 0,57$ vs $9,3 \pm 0,9)$, mientras que el fósforo y la PTHi, como era de esperar, son significativamente más bajos en pacientes trasplantados respecto a aquellos aún en hemodiálisis $(3,2 \pm 0,66$ vs $5,2 \pm 1,4$ y 93,5 vs 476,4). Paradójicamente y al contrario de lo que cabría esperar, nuestros pacientes presentaron un mayor grado medio de inflamación representado mediante la concentración de PCR respecto a los enfermos estudiados por Adragao $(3,16 \pm 3,17$ vs $1,28 \pm 0,6)$.

El porcentaje de pacientes con un nivel moderado o severo de calcificación en nuestra muestra fue del 27,9\%, frente al 58\% del estudio de Adragao. La existencia de calcificaciones más extendidas en los pacientes en diálisis se debe, probablemente, al mayor tiempo de permanencia en diálisis de los pacientes frente a la muestra trasplantada.

Adragao y cols investigaron la utilidad del índice de Adragao y su correlación con los resultados obtenidos de un análisis densitométrico en una muestra de 70 pacientes en diálisis peritoneal (253). La edad media de los enfermos resultó ser de $52 \pm 14$ años, $52,85 \%$ varones, con una permanencia media en diálisis de $46 \pm 28$ meses y que presentaban una prevalencia de diabetes del $24,3 \%$. Un $61,42 \%$ de los enfermos presentaron algún grado de calcificación vascular. El mismo porcentaje de pacientes mostraba signos de osteopenia (T-score $<-1$ ) en el estudio densitométrico del cuello femoral. En este estudio, una menor densidad ósea en el cuello del fémur se asociaba a 


\section{DISCUSIÓN}

un mayor índice de calcificación vascular y a una mayor velocidad de onda de pulso. En esta muestra de pacientes en diálisis peritoneal, la densidad ósea a nivel del cuello del fémur se correlacionó negativamente con el grado de calcificación vascular y la prevalencia de enfermedad coronaria o arterial periférica.

El grupo de Adragao estudió la correlación entre la calcificación de aorta abdominal evaluada mediante el índice de Kauppila, el índice de calcificación vascular desarrollado por Teresa Adragao y el índice tobillo-brazo en una muestra de 219 pacientes en hemodiálisis (257). El 60\% de los pacientes estudiados fueron varones, con una edad media de $65 \pm 15$ años y una permanencia media en hemodiálisis de $82 \pm 74$ meses. La mediana del índice de Kauppila fue de 4 (rango intercuartílico de 9) y del índice de Adragao 3 (rango intercuartílico de 4). Un 41\% de los enfermos presentaron un ITB <0,9, un $40 \%$ mostraban un ITB entre 0,9 y 1,3 y un $19 \%$ un ITB $>1,3$.

El análisis de los datos de Adragao y cols mostró una asociación entre las calcificaciones vasculares en vasos de gran calibre (aorta lumbar, iliacas y femorales) con un ITB $<0,9$. La presencia de calcificaciones en arterias periféricas, tanto pélvicas como radiales e interdigitales se asociaba a un ITB > 1,3. Ambos índices de calcificación presentaban una puntuación mayor en aquellos enfermos con antecedentes de enfermedad arterial periférica. Un ITB < 0,9 también se asociaba a la existencia de antecedentes de enfermedad arterial periférica.

\subsection{2: ÍNDICE DE KAUPPILA}

El valor medio del índice de Kauppila en los 43 pacientes estudiados fue de 4,65 $\pm 5,97$ (mediana 3, rango 0-9). Un 46,6\% de los enfermos (20 pacientes), presentaron un grado de calcificación moderada o severa según este score (Kauppila > 4).

Para analizar la relación existente entre las diferentes variables incluidas en el estudio y el índice de Kauppila decidimos estratificar los pacientes incluidos en dos grupos, según 


\section{DISCUSIÓN}

presentasen un índice inferior a 3 o igual o superior a dicha cifra. Un 48,8\% (21 pacientes) de los pacientes presentaron un índice de Kauppila $<3$.

Observamos que los pacientes de edad más avanzada, varones, con un mayor tiempo en diálisis previo al trasplante o que habían recibido hemodiálisis frente a diálisis peritoneal presentaban con una frecuencia significativamente mayor un índice de Kauppila más elevado que el resto de enfermos. El padecimiento de HTA, sobrepeso y obesidad, dislipemia o tabaquismo no asociaba diferencias en cuanto al nivel de calcificación coronaria. La prevalencia de diabetes mellitus en el grupo de pacientes con un índice de Kauppila $\geq 3$ es mayor ( $27.3 \%$ vs $4.8 \%$ ). El hecho de que dicha diferencia no alcance significación se debe al punto de corte empleado al estratificar. Si calculamos la media del índice de Kauppila (considerada como variable continua) observada entre pacientes diabéticos y no diabéticos, la diferencia recogida entre ambas sí resulta estadísticamente significativa ( $10.85 \pm 8.25$ vs $3.44 \pm 4.69 ; P<.05)$.

En nuestra muestra observamos como aquellos pacientes con un score de Kauppila $\geq 3$ presentan una edad más avanzada, son con mayor frecuencia varones, han permanecido un mayor tiempo en diálisis, recibieron hemodiálisis como tratamiento renal sustitutivo y presentaban tanto una menor diuresis residual previa al trasplante como un volumen de diuresis en el momento del alta tras el trasplante más bajo.

A nivel analítico se observa una mayor concentración de colesterol total previa al trasplante en aquellos individuos con un índice de Kauppila $<3$, así como una menor concentración en la revisión actual de urea y glucosa. Destaca además en la revisión actual como los individuos menos calcificados según este índice presentan una mayor concentración sérica de fósforo (3.42 vs 2.99). Mientras que el valor medio de fósforo sérico en el grupo de pacientes con un índice de Kauppila $<3$ se encuentra en el rango de normalidad, la media en el grupo con un Kauppila $\geq 3$ se sitúa muy próxima al límite inferior de la normalidad. Es posible que la persistencia de una hipofosforemia relativa en este grupo sea consecuencia de un mayor desajuste del metabolismo óseo-mineral en la etapa previa al trasplante. En este sentido, los pacientes con un índice de Kauppila $<3$ presentan un nivel menor de PTHi y una concentración mayor de calcitriol. 


\section{DISCUSIÓN}

Los diversos factores clásicos de riesgo cardiovascular salvo la diabetes, la concentración de ácido úrico o el grado de inflamación no presentaron correlación alguna con el índice de Kauppila. El tratamiento farmacológico relativo al metabolismo óseo-mineral recibido antes del trasplante, así como la pauta de inmunosupresión seguida después de recibir el injerto no presentaron tampoco ninguna correlación con el grado de calcificación de aorta abdominal.

El grado de calcificación de aorta abdominal ha sido evaluado por varios autores en muestras de población trasplantada.

Chau y cols en un reciente estudio analizó 531 receptores de trasplante renal (69\%) y trasplante páncreas-riñón (31\%) (360). La mediana de edad de los pacientes fue de 41 años (rango 16-71), en un 58\% varones y con una mediana de permanencia en diálisis de 20 meses (rango 0-402 meses). La mediana de CAA fue de 6 (rango 1-24), con un 47\% de los enfermos que presentaban algún grado de calcificación en aorta abdominal. En esta muestra el grado de CAA se asociaba con la edad de los pacientes, el tiempo de permanencia en diálisis y la existencia de antecedentes cardiovasculares. Sin embargo, las CAA no se asociaron al sexo, el padecimiento de diabetes, el consumo de tabaco, el tipo de trasplante recibido (simple o combinado) o el Z-score evaluado mediante densitometría.

Meneghini y cols publicaron en 2013 los resultados de un análisis de 107 pacientes trasplantados renales comparados con 205 controles en diálisis (361). La edad media de los trasplantados incluidos fue de $47,96 \pm 11,1$ años, en un $51,4 \%$ varones. Un $67,28 \%$ recibieron hemodiálisis como tratamiento renal sustitutivo, presentando un tiempo medio de permanencia en diálisis de 56,43 meses. Un 10,28\% recibió el trasplante renal previo al comienzo de la diálisis. La pauta de inmunosupresión administrada fue muy similar (basiliximab, corticoides, tacrólimus y ácido micofenólico). Los autores realizaron una valoración basal del índice de calcio coronario mediante TC y del índice de Kauppila mediante radiografía lumbar lateral. El índice de Kauppila medio resultó ser de 5,32 (mediana 3, rango 0-22), mientras que el índice de CAC fue de 287,8 HU (mediana 40,15, 


\section{DISCUSIÓN}

rango 0-5744). Ambos parámetros presentaron una fuerte correlación en la muestra estudiada.

La calcificación aórtica observada un mes tras la realización del trasplante se asociaba positivamente con la edad del receptor y del donante, el tiempo de permanencia en diálisis, un fósforo sérico más bajo y unos niveles de osteoprotegerina más elevados. La función del injerto y el resto de parámetros relativos al metabolismo óseo-mineral no mostraron asociación alguna con el grado de calcificación aórtica. En la evaluación a los 12 meses del trasplante las asociaciones encontradas a los 30 días se mantenían, salvo en el caso del fósforo sérico.

En nuestro análisis tanto la edad como el tiempo en diálisis presentan una asociación positiva con la CAA. Sin embargo no hemos encontrado asociación entre la CAA y las cifras de fósforo sérico en la revisión realizada inmediatamente tras el trasplante. El grupo de pacientes con un menor grado de CAA presentan una concentración de fósforo plasmático, tanto en ese punto como en el momento actual mayor que los pacientes con más calcificación, aunque nunca por encima del rango de normalidad del parámetro. Es probable que dichas diferencias se deban también al punto de corte empleado para estratificar a los pacientes.

El estudio de Meneghini no fue capaz de encontrar relación alguna entre la CAA y la pauta de inmunosupresión empleada, la dosis acumulada de corticoides ni el número de pacientes que recibieron vitamina $\mathrm{D}$. Una peor función renal, que no mostraba influencia a la hora de determinar la severidad de las CAA, sí que se asociaba al grado de progresión de las mismas, así como cifras séricas mayores de calcio, fosfatasa alcalina y osteoprotegerina.

Otros autores han profundizado en el estudio de los posibles factores pronósticos de las calcificaciones aórticas en enfermos en diálisis y prediálisis.

Toussaint y cols estudiaron una muestra de 48 pacientes en hemodiálisis (362), con una edad media de 64,5 años (rango $26-80$ años), un 70,8\% de varones. La muestra estaba 


\section{DISCUSIÓN}

compuesta por caucásicos en un $89,6 \%$. Un $54,2 \%$ de los pacientes eran diabéticos, mientras que un 95,8\% padecían HTA. El método de valoración de las calcificaciones de aorta abdominal fue diferente, ya que se empleó un TAC abdominal para cuantificar el grado de calcificación vascular en unidades Hounsfield.

Las CAA se asociaron positivamente con la edad, la velocidad de onda del pulso y la concentración sérica de triglicéridos, mientras que presentaban una correlación inversa con la tasa de filtrado glomerular. No se observó asociación, sin embargo con variables como el sexo, el padecimiento de diabetes, la proteinuria o los niveles de PCR. Los autores realizaron asimismo un análisis densitométrico de los enfermos. La media de Tscore obtenido fue de $-1,31 \pm 1,17$, con una DMO de $0,86 \pm 0,17$. Un $47,9 \%$ de los enfermos presentaba osteopenia y un $13 \%$ osteoporosis en la valoración densitométrica del fémur. El grado de calcificación vascular presentó una asociación inversa con los valores de DMO y T-score registrados en cuello del fémur.

Paradójicamente, parecía existir una relación directa, presuntamente falsa según los autores, entre el grado de calcificación aórtica y el T-score vertebral. Es muy posible que dicha asociación se deba a una distinción errónea de las regiones óseas vertebrales y la pared adyacente aórtica, provocando que el sistema de análisis contabilizara como calcificación vascular regiones vertebrales o viceversa, lo que explicaría como los resultados ofrecen una correlación directa estadísticamente significativa.

La edad supone un factor de riesgo tanto en el estudio de Toussaint como en nuestro análisis. Sin embargo en nuestra muestra no hemos sido capaces de demostrar una asociación entre las CAA y la función del injerto o las concentraciones séricas de triglicéridos. Es posible que la diferencia existente entre los métodos empleados para valorar las calcificaciones aórticas esté detrás de dichas diferencias.

Nasrallah y cols publicaron en 2010 un estudio que ahondaba en la relación existente entre el FGF-23 y las CAA (116). Analizaron una muestra de 65 pacientes en hemodiálisis y 15 controles, con una edad de $50 \pm 15$ años, en un $43 \%$ varones, con unas cifras de calcio sérico $(8,9 \pm 1)$ inferiores a las observadas en nuestros pacientes, mientras que los 


\section{DISCUSIÓN}

niveles de $\mathrm{P}(6,8 \pm 2,7)$ y $\mathrm{PTHi}(314,7 \pm 368,2 \mathrm{pg} / \mathrm{ml})$ resultaron superiores. Los niveles de FGF-23 en los pacientes estudiados por Nasrallah y cols fueron de 4681,3 $\pm 3906,1$ $\mathrm{pg} / \mathrm{ml}$. En este estudio sobre una base de pacientes en hemodiálisis, los autores observaron como las cifras de FGF-23 y la TA sistólica constituyeron factores de riesgo independientes para la severidad de las CAA registradas. En nuestro análisis, la concentración actual de FGF-23 no se asoció de forma significativa a la existencia de CAA. Esta diferencia se debe seguramente a que el estudio de Nasrallah se basa en pacientes en hemodiálisis mientras que nuestra muestra está compuesta por receptores de trasplante renal.

En uno de los estudios de mayor tamaño realizados hasta el momento, el estudio CORD, Honkanen y cols analizaron 933 pacientes en diálisis (249). La edad media de los enfermos fue de 61,4 años (rango 19-89 años), en un 60,8\% varones. La terapia renal sustitutiva recibida fue en un $83,9 \%$ hemodiálisis y en un $16,1 \%$ diálisis peritoneal. Los pacientes padecían diabetes en un $22,9 \%$ y antecedentes cardiovasculares en un $43,7 \%$ de los casos. El índice de CAA en la muestra fue de 10,3 $\pm 0,3$. Dicho índice presentó asociación directa tanto con la edad como con el tiempo de permanencia en diálisis del paciente así como con la existencia de antecedentes cardiovasculares.

García Cantón y cols plantearon el estudio del grado de calcificación vascular en una muestra de enfermos en estadios de ERC 4 y 5 prediálisis (363). El estudio incluyo 210 pacientes con una edad media de $63,5 \pm 13$ años, en un $60,5 \%$ varones, con una tasa estimada de filtrado glomerular de $20,7 \pm 5 \mathrm{ml} / \mathrm{min}$ y una prevalencia de diabetes del $64,8 \%$ y de enfermedad cardiovascular del $47,1 \%$. Los resultados mostraron como el $54,28 \%$ de los enfermos presentaba un índice de Kauppila superior a 7 (con un 13,8\% de enfermos sin calcificaciones según el índice), mientras que el 57,4\% de los enfermos mostraba un índice de Adragao por encima de 3. El score de Kauppila se correlacionaba de forma directa con la edad, el padecimiento de diabetes y de enfermedad cardiovascular, los niveles séricos de triglicéridos y homocisteína, y de forma inversa con la concentración sérica de colesterol LDL y de 25-OH vitamina D. 


\section{DISCUSIÓN}

El índice de Kauppila se correlacionaba directamente con la edad, la diabetes, la enfermedad cardiovascular y cifras reducidas de $25-\mathrm{OH}$ vitamina $\mathrm{D}$. En nuestra muestra los niveles de $25-\mathrm{OH}$ vitamina D presentan una asociación inversa con el grado de calcificación vascular evaluado mediante ambos scores, que no alcanza significación estadística. Dado que en ambos estudios las cifras de $25-\mathrm{OH}$ vitamina D obtenidas son similares, en nuestro caso incluso con un menor porcentaje de pacientes con cifras dentro del rango de normalidad pese a tener un injerto renal funcional, esta diferencia probablemente se deba a una potencia insuficiente de nuestro estudio para concretar dicha relación.

El papel pronóstico que presentan las CAA fue recientemente analizado por Martino y cols en una muestra de 74 pacientes que recibían diálisis peritoneal (364). En este estudio, con una mediana de seguimiento de 30,5 meses, la edad, el volumen de diuresis residual y el grado de calcificación vascular medido a través del score de Kauppila se constituyeron como factores predictores de futuros eventos cardiovasculares. En el análisis multivariante, el índice de Kauppila analizado en terciles se constituyó como el único factor predictor independiente de eventos cardiovasculares.

\section{8: DENSITOMETRÍA ÓSEA}

Dentro de la evaluación pretrasplante se realizan por protocolo imágenes radiográficas simples de tórax y abdomen. A partir de dichas imágenes y de los informes remitidos por las unidades de referencia correspondientes pudimos establecer la prevalencia teórica de la osteoporosis previa al trasplante. Esta prevalencia se situó en nuestra muestra en un 9,3\%. Aunque los datos recogidos en la literatura son muy variables, con cifras de prevalencia de osteoporosis en ERC que van desde un 13 a un 80\% (365), nuestro valor con toda seguridad infraestima la prevalencia real de osteoporosis pretrasplante en la muestra, ya que el empleo de radiografías simples para valorar dicho parámetro no es el más adecuado. 


\section{DISCUSIÓN}

Para averiguar la densidad mineral ósea y el valor del T-score a nivel del cuello femoral en la muestra en el momento actual recurrimos a la realización de un estudio densitométrico. El valor medio de la DMO en cuello femoral en los 43 pacientes estudiados fue de $0,7 \pm 0,14 \mathrm{~g} / \mathrm{cm}^{2}$ (mediana $0,77 \mathrm{~g} / \mathrm{cm}^{2}$, rango 0,69-0,9 g/cm²). Un $93 \%$ de los enfermos (40 pacientes), presentaron un DMO reducida en el cuello del fémur (inferior a $0,97 \mathrm{~g} / \mathrm{cm}^{2}$ ).

El valor medio del T-score en cuello femoral en los 43 pacientes estudiados fue de $-0,86$ $\pm 1,08$ DS (mediana $-1,23$ DS, rango $-1,6-0,05$ DS). Un $51,2 \%$ de los enfermos (22 pacientes) presentaron osteopenia (T-Score inferior a -1 DS) de diverso grado a nivel del cuello femoral mientras que un $3 \%$ (un paciente) presentaba un T-Score compatible con osteoporosis (igual o inferior a -2,5 DS).

Debido a la asimetría existente en la distribución de los pacientes respecto al valor de densidad mineral ósea se decidió analizar únicamente la significación existente entre el T-Score y el resto de variables del estudio.

Para analizar la asociación observada entre las diferentes variables categóricas y cuantitativas y el T-Score se crearon dos conjuntos de pacientes según esta última variable, agrupándolos según presentasen un T-Score $<-10 \geq-1$. Un 54,8\% (23 pacientes, con una $\mathrm{N}$ válida de 42 ) de los pacientes presentaron un T-score medio en cuello femoral $<-1$.

Los pacientes con un T-Score $<-1$ presentaron una edad media más avanzada (55.3 vs 41.79) y un colesterol total más bajo previo al trasplante (150.4 vs 195). En el momento del alta tras el trasplante estos paciente muestran un valor medio de VSG menor (26.09 vs 44.05) así como un volumen de diuresis más bajo (2246 vs 2688) mientras que en la revisión actual se caracterizan por una concentración de proteínas totales más reducida (6.67 vs 6.94) así como unos niveles de PTHi mayores (127.3 vs 89.4), un menor aclaramiento de creatinina (53.3 vs 69.2) y un mayor grado de inflamación representado por la concentración sérica de PCR e interleukina-6. 


\section{DISCUSIÓN}

El T-Score supone, por tanto, el único parámetro estudiado que presenta una correlación estadísticamente significativa con el grado de inflamación en la revisión actual en nuestra muestra. La ausencia de correlación entre los parámetros asociados a la inflamación y los índices de calcificación se debe probablemente a que dichos índices suponen la representación en un punto temporal de un proceso desarrollado a lo largo de los años como es la calcificación vascular, mientras que la determinación analítica de forma aislada de PCR, IL-6 u otros factores asociados a la inflamación únicamente representan el grado de la misma en este momento en concreto, no siendo representativos del nivel de inflamación al que ha estado sometido el enfermo a lo largo de meses o años.

El sexo, el tiempo en diálisis, la modalidad de diálisis, el IMC, el padecimiento de HTA, sobrepeso y obesidad, diabetes, dislipemia o tabaquismo no asociaba diferencias en cuanto al T-Score.

La dosis de glucocorticoides acumulada total, el resto de terapia inmunosupresora o el tratamiento relativo a las alteraciones del metabolismo óseo-mineral no presentaron asociación con la DMO o el T-Score. Es probable que la ausencia de asociación entre la dosis de glucocorticoides y los parámetros densitométricos se deba a la uniformidad en la pauta de inmunosupresión recibida por los pacientes de nuestra muestra

La pérdida de masa ósea sufrida por los enfermos que reciben un injerto renal y el papel que juegan en el metabolismo óseo tanto la función renal recuperada como el tratamiento inmunosupresor administrado ha sido objeto de análisis por varios autores, con resultados dispares que no han permitido discernir claramente, hasta el momento, el peso que juegan los diferentes factores propios del trasplante renal en el mantenimiento de la DMO.

Akaberi y cols publicaron en 2008 un estudio que incluía 238 receptores de trasplante renal (366). La edad media de la muestra fue de 44 años (rango 4-73 años). Los pacientes eran varones en un $61 \%$, con un tiempo medio de permanencia en diálisis de 16,8 meses. Las principales causas de la ERC fueron las glomerulonefritis (26\%), la nefropatía 


\section{DISCUSIÓN}

diabética (18\%) y la nefropatía túbulo-intersticial (17\%). Un 98\% de los pacientes recibió glucocorticoides, un $82 \%$ ciclosporina, un $14 \%$ tacrólimus y un $1,7 \%$ rapamicina. El valor medio de PTHi fue de $68,6 \mathrm{pg} / \mathrm{ml}$. La DMO en cuello femoral recogida en la muestra fue de $0,9 \mathrm{~g} / \mathrm{cm}^{2}$ (rango 0,4-2 g/ $\mathrm{cm}^{2}$ ). El T-Score a nivel femoral fue de -0,9 DS (rango -4,77,4 DS).

Un $46 \%$ de los pacientes estudiados presentaban algún grado de osteopenia, mientras que un $13 \%$ presentaban una densitometría ósea compatible con osteoporosis. Estos resultados son relativos al análisis de cuello femoral, donde la afectación ósea era más frecuente. El estudio de Akaberi presenta una mayor prevalencia de osteoporosis (13\% vs $3 \%$ ) y una menor prevalencia de osteopenia ( $46 \%$ vs $51 \%$ ). El análisis de Akaberi también permitió definir como tanto la osteopenia como la osteoporosis y una DMO por debajo de la mediana a nivel del cuello del fémur constituyen factores de riesgo para el desarrollo de fracturas óseas en pacientes trasplantados renales. Sin embargo, mientras que la osteoporosis a nivel de columna lumbar sí presentaba una correlación con el desarrollo de fracturas óseas, la osteopenia a dicho nivel no mostraba esta asociación. Este trabajo correlaciona además el padecimiento de diabetes y el sexo femenino con un mayor riesgo de fracturas, mientras que la edad no parece constituir un factor de riesgo de las mismas en población trasplantada. Sin embargo, no entra a valorar la influencia que tienen dichos factores sobre los parámetros densitométricos utilizados.

Gupta y cols publicaron en 2012 un análisis con 389 receptores de trasplante renal a los que se les practicó un análisis densitométrico en columna lumbar, cadera y cuello femoral (367). La prevalencia de osteopenia y osteoporosis en las tres regiones presentó una importante correlación entre ellas. Sin embargo, la prevalencia de osteopenia/osteoporosis fue significativamente mayor en cuello femoral que en columna lumbar. La etiología de la ERC, el metabolismo lipídico o los niveles de PCR no presentaron ninguna correlación con los resultados densitométricos.

A nivel lumbar, una menor DMO se asoció a un IMC menor, unas cifras más altas de fosfatasa alcalina y una mayor prevalencia de diabetes post-trasplante. A nivel de la cadera una menor DMO se asoció a una mayor edad, menor IMC y cifras de fosfatasa 


\section{DISCUSIÓN}

alcalina mayores, mientras que a nivel del cuello femoral se observó una asociación entre una menor DMO y una edad mayor, una PTHi mayor, un IMC menor y la pertenencia a etnia asiática. En nuestra muestra la edad supuso un factor de riesgo para presentar una menor DMO a nivel del cuello del fémur. Sin embargo no encontramos asociación entre las cifras del IMC y la DMO a dicho nivel. Además, como en nuestro caso el $100 \%$ de la muestra está compuesta por caucásicos no hemos sido capaces de correlacionar las cifras de DMO con ninguna etnia en particular. La función del injerto, el padecimiento de diabetes previo al trasplante o los niveles de $25-\mathrm{OH}$ vitamina $\mathrm{D}$ no presentaron correlación con la DMO. En nuestro análisis no observamos asociación entre la dosis administrada de inmunosupresores y los parámetros densitométricos.

El estudio corrobora como la localización dónde se produce una disminución de la DMO de forma más significativa en los receptores de trasplante renal es la región del cuello femoral, aunque existe una notable correlación entre la existencia de osteopenia y osteoporosis en las diferentes regiones.

Luo y cols, en un estudio con 72 receptores de trasplante con una duración del trasplante superior a 5 meses encontró una prevalencia de osteopenia/osteoporosis del 27,7\% en la muestra. Los autores observaron como la prevalencia de osteopenia/osteoporosis resultó superior en el grupo de pacientes con niveles de tacrólimus más altos que en el resto de pacientes (45\% vs $20 \%$ ) (368). En nuestra muestra ni la dosis recibida en el primer año del trasplante ni la dosis media acumulada de tacrólimus recibida hasta el momento actual se correlacionan con los resultados densitométricos. Sin embargo, dado que no recogimos información relativa a los niveles séricos del fármaco, no podemos descartar la existencia de una relación semejante en nuestra muestra.

Huang y cols realizaron un análisis densitométrico sobre una muestra de 76 trasplantados renales buscando su correlación con diferentes parámetros analíticos y la influencia de la infección por el virus de la hepatitis C sobre el metabolismo óseo (369). El valor medio de la DMO fue de 0,68 $\pm 0,12 \mathrm{~g} / \mathrm{cm}^{2}$, mientras que el T-Score fue de $-2,45$ $\pm 0,6$ DS. Un $16,6 \%$ de los pacientes de la muestra presentaron resultados compatibles con la presencia de osteoporosis. 


\section{DISCUSIÓN}

Los resultados de la densitometría a nivel del cuello femoral se correlacionaban con la edad y el tiempo de trasplante en esta muestra, aunque sólo la edad constituyó un factor pronóstico independiente en el análisis multivariante. El estudio de Huang ofrece resultados compatibles con nuestro análisis e insiste de nuevo en la necesidad de valorar mediante densitometría de forma preferente la región del cuello femoral ya que es esta zona la que presenta con mayor frecuencia signos de osteopenia/osteoporosis en pacientes trasplantados.

Jeon y cols buscaron profundizar en el estudio del efecto de la terapia con vitamina D y bifosfonatos, de forma independiente o en combinación, en una muestra de 182 receptores de trasplante renal (370). La edad media de la muestra fue de $46,7 \pm 12,1$ años, con un $52,7 \%$ de varones. El T-Score en la muestra resultó ser de $-0,23 \pm 0,65$ DS, unos resultados algo mejores que los obtenidos en nuestra muestra, con mucha probabilidad debido a la menor edad de los enfermos incluidos. El objetivo del trabajo de Jeon fue, principalmente, analizar la eficacia de la terapia combinada con vitamina D y bifosfonatos a la hora de mejorar la densidad mineral ósea de los pacientes trasplantados, pauta que se mostró como la más efectiva a la hora de mejorar la DMO en estos pacientes.

Tutal y cols publicaron recientemente otro estudio con densitometría sobre enfermos trasplantados (371). Sobre una muestra de 107 pacientes se observó un porcentaje de osteoporosis notablemente mayor al recogido por otros autores (40,7\%). En este análisis se comprobó como una tasa superior de filtrado glomerular asociaba una menor PTHi y unas cifras mayores del T-Score. Como era de esperar, cifras más altas de PTHi se asociaban de forma inversa con el resultado del T-Score, al igual que en nuestro análisis. Sin embargo, dichos parámetros no presentaban correlación con la masa ósea. Los resultados de dicho estudio son difícilmente comparables con el resto de análisis, incluido el nuestro, ya que el análisis óseo no se realizó con densitometría sino mediante bioimpedancia. Esta diferencia puede residir en la base de la disparidad obtenida respecto al resto de estudios analizados. 


\section{DISCUSIÓN}

La DMO y el T-Score también han sido estudiados en receptores de donante vivo. Tokumoto y cols analizaron una muestra de 84 receptores de trasplante renal de donante vivo con una media de permanencia en diálisis de 40,3 meses (372). La pauta de inmunosupresión consistió en glucocorticoides, tacrólimus y ácido micofenólico. Se estudió la concentración sérica de FGF-23 que descendió a lo largo del seguimiento desde valores de $6304 \mathrm{pg} / \mathrm{ml}$ previos al trasplante hasta cifras de 37,3 pg/ml. Se observó cómo los pacientes que presentaban osteodistrofia renal aplásica mejoraban transcurridos 12 meses tras el trasplante aunque se desconoce el papel que juegan en dicha mejoría factores como el aumento del filtrado glomerular, la hipofosforemia o el descenso de las cifras de FGF-23. En nuestro estudio, dicho parámetro no guardó relación alguna con la densitometría ósea.

La evolución en población infantil de la DMO tras el trasplante también es objeto de debate en la actualidad. Derakhshan y cols analizaron los resultados de densitometría de 57 pacientes pediátricos con trasplante renal (373). La edad media de la muestra fue de $13 \pm 4,6$ años, en un $47,4 \%$ varones y con un $22,8 \%$ que recibieron el trasplante de forma previa a su entrada en diálisis. Según la densitometría de cadera, un 77,2\% de los enfermos presentaba osteopenia, con un Z-Score de $-1,64 \pm 0,89$ DS. El Z-Score no presentó correlación con las cifras de PTHi ni con la pauta de inmunosupresión en esta población pediátrica, correlacionándose negativamente tan sólo con la concentración sérica de fosfatasa alcalina. Es complicado extrapolar los resultados de un estudio densitométrico con población pediátrica a los adultos, ya que las características del metabolismo óseo durante la infancia son totalmente diferentes, pero sí se aprecia como la mayor parte de parámetros relacionados con el metabolismo óseo-mineral o la pauta inmunosupresora tampoco parecen tener relación con la DMO en esta población.

Finalmente, Adragao y cols publicaron en 2009 uno de los pocos estudios que combina el análisis densitométrico con la calcificación vascular, en este caso en una muestra de 38 pacientes en hemodiálisis (374). El análisis de esta muestra, elaborada tras excluir a los pacientes con diabetes, concluyó que la edad constituía un factor de riesgo para el desarrollo de calcificaciones coronarias evaluadas mediante el score de Agatston. Los autores observaron asimismo como un volumen óseo menor comportaba un mayor 


\section{DISCUSIÓN}

riesgo de presentar calcificaciones coronarias, de forma estadísticamente significativa. En nuestra muestra, se comprueba como aquellos pacientes con un score de Agatston igual o superior a $100 \mathrm{HU}$ presentan con mayor frecuencia un T-Score <-1, corroborando en trasplantados la asociación existente entre el desarrollo de calcificaciones vasculares y la pérdida de densidad mineral ósea descrita por Adragao en pacientes en hemodiálisis.

\section{9: COMPARACIÓN ENTRE PRUEBAS DIAGNÓSTICAS}

En nuestro análisis hemos observado como diversas variables presentan una fuerte correlación con varios de los métodos de valoración de las calcificaciones vasculares estudiados.

La edad supone uno de los factores de riesgo para el desarrollo de calcificaciones vasculares más conocido, tanto en población general, como en enfermos renales tanto en prediálisis como en diálisis y en trasplantados renales. En nuestro estudio comprobamos como una edad más avanzada se asociaba con una mayor calcificación coronaria, un mayor GIM carotideo y unas mayores calcificaciones aórticas, mientras que condicionaba una menor densidad mineral-ósea y un menor T-Score en cuello femoral.

El tiempo de permanencia en diálisis antes de recibir el trasplante es otro factor de suma importancia. Múltiples estudios corroboran nuestros resultados, que asocian dicha variable con el grado de CAC, el GIM y los índices de Adragao y Kauppila. De forma similar, la indicación de hemodiálisis frente a diálisis peritoneal como terapia renal sustitutiva recibida también comporta un aumento de los índices mencionados.

El metabolismo de los glúcidos es otro factor de gran impacto en el desarrollo de calcificaciones. En nuestro análisis hemos observado como en la muestra observada la existencia de antecedentes personales de diabetes mellitus se asocia a una mayor calcificación vascular, independientemente del territorio estudiado. De la misma forma, 


\section{DISCUSIÓN}

el grado de control de la diabetes, representado por la concentración sérica de hemoglobina glicosilada se asocia también con el grado de calcificación vascular a nivel coronario, carotideo, aórtico, iliaco, femoral, radial e interdigital.

Entre los factores que se asocian a un menor grado de calcificación vascular destacan por encima del resto la diuresis residual del enfermo y las concentraciones plasmáticas actuales de colesterol total. El grado de anemia previo al trasplante también se asocia de forma directa al grado de calcificación coronario y en arterias de mediano y gran calibre.

La diuresis residual es un factor cuyo efecto es de sobras conocido en los enfermos en diálisis, condicionando un menor número de complicaciones asociadas a la terapia y una mayor supervivencia tanto cardiovascular como global. En nuestro estudio, el mantenimiento de un volumen de diuresis residual superior a $500 \mathrm{ml} / 24 \mathrm{~h}$ condiciona una menor severidad de las calcificaciones vasculares independientemente de la herramienta empleada para cuantificarlas.

Las cifras actuales de colesterol se asocian de forma inversa con el grado de calcificación coronaria evaluado mediante cualquiera de los cuatro índices. Las concentraciones séricas de colesterol siguen probablemente en nuestra muestra un patrón en " $U$ " en el que cifras bajas asocian un mayor grado de desnutrición e inflamación, lo que conlleva una mayor severidad de las calcificaciones, mientras que cifras claramente por encima del límite superior de la normalidad asocian también un mayor grado de calcificación vascular y aterosclerosis. No ha sido posible estudiar la asociación específica entre niveles altos de colesterol total y el grado de calcificación vascular debido a que únicamente 8 pacientes presentaban un colesterol por encima de $220 \mathrm{mg} / \mathrm{dl}$, con tan sólo un enfermo por encima de $250 \mathrm{mg} / \mathrm{dl}$.

El grado de anemia previo al trasplante también parece influir en la severidad de las calcificaciones observadas. Una cifra mayor de hemoglobina y hematocrito previas al trasplante condiciona una menor calcificación a nivel coronario, iliaco, femoral, radial e interdigital. 


\section{DISCUSIÓN}

La inmunosupresión empleada y el tratamiento relativo al metabolismo óseo-mineral utilizado antes del trasplante no se asocian de forma alguna con los índices de calcificación empleados.

Las pruebas diagnósticas realizadas para evaluar el grado de calcificación vascular presentan una fuerte correlación entre sí. Dicha correlación es especialmente fuerte entre el score de Agatston y el resto de pruebas de imagen, así como entre los índices de Adragao y Kauppila. La asociación existente entre el GIM y los índices de Adragao y Kauppila presenta una intensidad alta.

Procedimos también a comparar el grado de calcificación vascular registrado mediante las cinco herramientas utilizadas con la DMO y el T-Score cuantificados mediante densitometría. Comprobamos como el score de Agatston, el GIM y el índice de Kauppila se asociaban de forma inversa con el T-Score en cuello femoral.

\subsection{0: MODELO PREDICTIVO DEL GRADO DE CALCIFICACIÓN CORONARIA}

La valoración del grado de calcificación vascular implica con frecuencia la realización de pruebas diagnósticas de imagen para poder estudiar de forma adecuada el estado del árbol arterial. El score de Agatston, la herramienta empleada en nuestro estudio para cuantificar el grado de calcificación existente en las arterias coronarias, constituye en el momento actual el estándar de oro para valorar este tipo de lesiones, ya que se trata de una prueba semi-automatizada en la cual se realiza una medición del grado de calcificación coronaria detectado por una tomografía axial computerizada empleado un software específico. El uso de un software para cuantificar el grado de calcificación reduce la variabilidad interobservador e intraobservador al dar un resultado numérico.

Sin embargo, esta herramienta no está disponible en todos los centros hospitalarios. Requiere de la participación de un cardiólogo y un radiólogo versados en su uso para 


\section{DISCUSIÓN}

conseguir una determinación fiable, además de un equipo costoso. En multitud de ocasiones, aquellos centros que cuentan con los dispositivos y el personal adecuado para la realización de la prueba sufren una enorme presión asistencial, teniendo que priorizar el uso de los recursos disponibles para valorar patología de una urgencia más inmediata. Finalmente, se trata de una prueba con un elevado coste económico, llegando a alcanzar los $650 €$ por exploración en el momento de la realización de este estudio y comporta una dosis de radiación significativamente superior a un estudio radiológico habitual, lo que limita las posibilidades de repetirla de forma programada para el seguimiento de las lesiones.

Ante la existencia de estos factores que dificultan su uso en la práctica clínica diaria nos planteamos la elaboración a partir de los resultados obtenidos de un modelo que nos permitiese aproximar, a partir de las diferentes variables analíticas, antropométricas y antecedentes personales del paciente, y los resultados del resto de pruebas de imagen, que cuentan con una disponibilidad significativamente superior y un precio mucho más reducido, los resultados que nos ofrecería la determinación de calcio coronario.

El índice de Kauppila supone, de forma aislada, la mejor prueba diagnóstica a la hora de contrastar los resultados obtenidos con el score de Agatston. El índice de Kauppila consigue una sensibilidad del $84.2 \%$ con una especificidad del $72,7 \%$, obteniendo una validez diagnóstica elevada $(.583, \mathrm{P}<.001)$.

En segundo lugar, procedimos a construir un modelo predictivo del score de Agatston, empleado un método de regresión logística binaria, aprovechando el punto de corte empleado en los análisis para dicotomizar la variable según el paciente presentase una ausencia de calcificación coronaria o calcificación coronaria leve (Score de Agatston < $100 \mathrm{HU}$ ) o un grado de calcificación coronaria moderado o severo (Score de Agatston $\geq$ $100 \mathrm{HU})$.

El mejor de los modelos posibles queda resumido en la tabla 164 e incluye los siguientes factores:

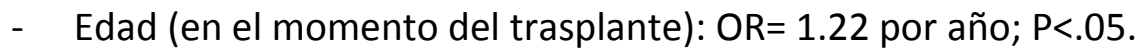




\section{DISCUSIÓN}

- Índice de Adragao: OR: 37.45; P<.05.

- $\quad$ Urea (revisión actual): OR: 1.06 por unidad; P<.05.

- Volumen de diuresis residual pretrasplante: OR: 0.998; $\mathrm{P}<.05$.

Dicho modelo resulta altamente significativo, obteniendo una $\mathrm{P}<.001$ en el test Omnibus. El modelo permite explicar un $81 \%$ de la variabilidad total observada en la variable objetivo (score de Agatston). El modelo consigue clasificar correctamente un $86 \%$ de los pacientes estudiados, con una sensibilidad de $84.2 \%$ y una especificidad de $87.5 \%$, constituyendo un buen modelo predictivo.

La aplicación de dicho modelo en la práctica clínica permitiría a partir de la siguiente ecuación estimar, con una prueba de imagen que implica la realización de dos imágenes radiográficas (pelvis y manos), un análisis bioquímico sencillo y la obtención de dos datos referentes a la historia clínica del enfermo, la existencia de un grado de calcificación coronaria moderado o severo.

La ecuación sería la siguiente:

$$
\begin{aligned}
& \operatorname{Pr}[Y=1] \\
& =\frac{1}{1+e^{(10,009-0,201 * \text { Edad-3,623*Adragao-0,056*UreaRev+0,002*VolDiurPrevio })}}
\end{aligned}
$$

Siendo para cada caso:

Edad $=$ número de años

Adragao $=1$ si es $\geq 2$ y 0 si es $<2$

UreaRev = valor de la urea en la revisión

VolDiurPrevio $=$ valor del volumen de la diuresis previo al trasplante

Y siendo: $\operatorname{Pr}[Y=1]$ la probabilidad de que un caso presente Agatson $>=100$

Así, por ejemplo: un paciente de 77 años de edad, con un índice de Adragao $\geq 2$, con una Urea plasmática en la revisión de $83 \mathrm{mg} / \mathrm{dl}$ y una diuresis residual previa al trasplante de 200 cc/24h, tiene esta predicción: 


\section{DISCUSIÓN}

$\operatorname{Pr}[Y=1]=\frac{1}{1+e^{10,009-(0,201 * 77)-(3,623 * 1)-(0,056 * 83)+(0,002 * 200)}}=0,9977$

Es decir una probabilidad del 99,77\% de tener una Agatson $>=100 \mathrm{HU}$.

\subsection{1: LIMITACIONES}

Nuestro estudio cuenta con varios aspectos positivos. Se trata del único estudio hasta el momento que analiza sobre una misma muestra de pacientes trasplantados renales el grado de calcificación vascular mediante cinco herramientas diagnósticas diferentes que combinan desde métodos sencillos como las pruebas de imagen radiográfica o ecografía hasta imagen mediante TAC. Nuestro análisis emplea además una herramienta diagnóstica, el índice de Adragao, que hasta el momento sólo había sido aplicada sobre población en hemodiálisis. El estudio se ha realizado en un corte transversal, simultáneando las diferentes pruebas diagnósticas en un corto periodo de tiempo. Además del análisis vascular nuestro estudio aporta también información acerca del grado de calcificación ósea, añadiendo un punto de vista combinado sobre los fenómenos de calcificación en diferentes territorios.

El estudio se realizó además sobre una muestra con una aceptable homogeneidad del tratamiento inmunosupresor administrado y se empleó en todas las valoraciones de las pruebas diagnósticas a un único observador para prescindir de un posible sesgo interobservador. Las determinaciones analíticas se realizaron en un mismo laboratorio de forma centralizada.

La mayor limitación del estudio deriva de su diseño transversal. El estudio transversal permite describir la situación clínica y analítica de los pacientes en un determinado momento del tiempo pero limita la posibilidad de establecer relaciones causa-efecto entre los diferentes parámetros y el proceso de calcificación vascular, especialmente en una población de riesgo como los receptores de trasplante renal. Al tratarse de un estudio observacional tampoco podemos determinar el efecto de la variación de los 


\section{DISCUSIÓN}

diferentes factores implicados en el proceso de calcificación vascular y desmineralización ósea.

La potencia estadística no es suficiente como para alcanzar significación estadística en ciertas determinaciones. Asimismo carecemos de una determinación basal de las diferentes pruebas de imagen, lo que nos permitiría definir de forma más precisa el grado de calcificación vascular previo al trasplante de los pacientes y su modificación a lo largo del tiempo. Hubiese sido deseable incluir ciertos parámetros analíticos como la osteoprotegerina o FGF-23 en todos los cortes ya que dichos parámetros cuentan con un papel demostrado en la génesis de las calcificaciones vasculares, pero dichas determinaciones no se incluyeron de serie al no pertenecer a la batería de pruebas disponibles en nuestro laboratorio, realizándose únicamente la determinación de FGF23 en el momento actual. Esto limita la capacidad de analizar la evolución del factor tras el trasplante y de poder extraer conclusiones acerca de su implicación en el desarrollo de calcificaciones vasculares en trasplantados renales. 


\section{DISCUSIÓN}


CONCLUSIONES

CONCLUSIONES 


\section{CONCLUSIONES}

1. Aproximadamente un $65 \%$ de los trasplantados con tasa estimada de filtrado glomerular $>60 \mathrm{ml} / \mathrm{min}$ padecen un hiperparatiroidismo. Más de la mitad de los enfermos estudiados presenta niveles de calcio fuera de los rangos recomendados para el control del MOM por las guías de la SEN. Sin embargo, un 86\% de los enfermos presenta cifras controladas de fósforo sérico, mejorando notablemente su regulación tras el trasplante.

2. El $44,2 \%$ de los enfermos mostró un grado de calcificación coronaria grave o muy grave. La edad, el sexo masculino, el tiempo en diálisis, la HD frente a la DP, un mayor grado de anemia previo al Tx, la existencia de una menor diuresis residual pre-Tx, la diabetes, la hiperuricemia y las cifras reducidas de colesterol total previo al trasplante $\mathrm{y}$ en el momento actual se asociaban de forma estadísticamente significativa a un mayor grado de calcificación del árbol coronario.

3. El $93 \%$ de los pacientes presentó un grosor íntima-media a nivel carotideo inferior a $1 \mathrm{~mm}$, con un 7\% de enfermos con un grosor íntima-media entre $1 \mathrm{~mm}$ y 1,49 mm. La edad, el tiempo en diálisis, el padecimiento de diabetes mellitus y su control actual determinado por la hemoglobina glicosilada, la hemodiálisis frente a la diálisis peritoneal, la concentración plasmática reducida de colesterol y la hiperuricemia presentan una asociación significativa con valores más elevados de GIM.

4. El $27,9 \%$ de los enfermos estudiados presentaron un grado de calcificación moderada o severa a nivel iliaco, femoral, radial e interdigital, según el índice de Adragao. Padecer diabetes, el control glucémico, la hemodiálisis frente a la diálisis peritoneal, la anemia pretrasplante, un menor volumen de diuresis residual, una concentración baja de colesterol plasmático y cifras elevadas de fosfatasa alcalina presentaron una asociación significativa con la calcificación descrita por este índice. 


\section{CONCLUSIONES}

5. El $46,6 \%$ de los pacientes estudiados presentaron un grado de calcificación en arteria aorta abdominal moderada o severa según el índice de Kauppila. La edad, el padecimiento de diabetes mellitus, una menor diuresis residual previa al trasplante, unas cifras reducidas de colesterol plasmático y una concentración sérica mayor de fosfatasa alcalina se asocian de forma estadísticamente significativa un mayor grado de calcificación en aorta abdominal.

6. El $93 \%$ de los pacientes estudiados presentaron una densidad mineral-ósea por debajo de la normalidad a nivel del cuello femoral. Un 51,2\% presentaron asimismo un T-Score compatible con osteopenia (T-Score <-1DS) mientras que un 3\% mostraba un T-Score compatible con osteoporosis (T-Score $<-2,5 \mathrm{DS}$ ). Ambas variables (DMO y T-Score) se asociaban negativamente con la edad, la concentración de PTHi en la actualidad y el grado de inflamación. El aclaramiento de creatinina actual y la concentración de colesterol total previa al trasplante así como el volumen de diuresis y la concentración de proteínas totales existente inmediatamente después del trasplante se asocian a un T-Score mayor.

7. La HTA, la dislipemia, el sobrepeso, la obesidad o el tabaquismo no mostraron asociación significativa con ninguna de las pruebas de evaluación de la calcificación vascular. Únicamente la edad y la diabetes constituyeron un factor de riesgo para el desarrollo de estas lesiones.

8. La inmunosupresión recibida y el tratamiento relativo al metabolismo óseomineral recibido previo al trasplante no presentan asociación significativa con el grado de calcificación vascular a ningún nivel.

9. Los resultados obtenidos confirman la correlación directa entre la calcificación coronaria, el grosor íntima-media carotideo y las calcificaciones aórticas, iliacas, femorales, radiales e interdigitales en pacientes trasplantados renales.

10. El desarrollo de calcificaciones vasculares se asocia a una disminución de la densidad mineral ósea y el T-Score a nivel de cuello femoral en la muestra estudiada. 
CONCLUSIONES 
BIBLIOGRAFÍA

\section{BIBLIOGRAFÍA}




\section{BIBLIOGRAFÍA}

1. Favus MJ. Primer on the metabolic bone diseases and disorders of mineral metabolism, 5aed. Washington: American Society for Bone and Mineral Research, 2003.

2. Harrison et al. Principios de Medicina Interna. Ediciones McGraw-Hill Interamericana; 2006.

3. Torregrosa et al. Patología óseo metabólica del trasplante renal. Ediciones Mayo; 2006.

4. Benoit St-Jacques et al. Indian hedgehog signaling regulates proliferation and differentiation of chondrocytes and is essential for bone formation. Genes Dev. (1999); 13(16): 2072-2086.

5. Aubin JE et al. Osteoprotegerin and its ligand: a new paradigm for the regulation of osteoclastogenesis and bone resorption. Osteoporos Int. (2000); 11: 905-913.

6. Suda $T$ et al. Modulation of osteoclast differentiation and function by the new members of the tumor necrosis factor receptor and ligand families. Endocr Rev. (1992); 20: $345-357$.

7. Lacey $\mathrm{DL}$ et al. Osteoprotegerin ligand is a cytokine that regulates osteoclast differentiation and activation. Cell. (1998); 93; 165-176.

8. Daugirdas JT et al. Manual de diálisis, 4ạ Edición. Wolters Kluwer; 2008.

9. Goldman L et al. Cecil Medicine. 23. Saunders Elsevier; 2007.

10. Cross HS et al. Mechanism and regulation of intestinal phosphate absorption. Miner Electrolyte Metab. (1990); 16: 115-124. 


\section{BIBLIOGRAFÍA}

11. Murer $\mathrm{H}$ et al.. Regulation of $\mathrm{Na} / \mathrm{Pi}$ transporter in the proximal tubule. Annu Rev Physiol. (2003); 65: 531-542.

12. Rodríguez $M$ et al. FGF23 and mineral metabolism, implications in CKD-MBD. Nefrologia (2012); 32(3): 275-8.

13. Carrillo-López $\mathrm{N}$ et al. Indirect regulation of PTH by estrogens may require FGF23. J Am Soc Nephrol (2009); 20: 2009-17.

14. Shimada T et al. FGF-23 is a potent regulator of vitamin D metabolism and phosphate homeostasis. J Bone Miner Res (2004);19:429-35.

15. Shimada $T$ et al. Vitamin D receptor-independent FGF23 actions in regulating phosphate and vitamin D metabolism. Am J Physiol Renal Physiol (2005);289:F1088F1095.

16. Ben Dov IZ et al. The parathyroid is a target organ for FGF23 in rats. J Clin Invest (2007); 117: 4003-8.

17. Krajisnik $T$ et al. Fibroblast growth factor-23 regulates parathyroid hormone and 1alpha-hydroxylase expression in cultured bovine parathyroid cells. J Endocrinol (2007); 195: 125-31.

18. Canalejo R et al. FGF23 fails to inhibit uremic parathyroid glands. J Am Soc Nephrol (2010); 21. 1125-35.

19. Torregrosa et al. Recomendaciones de la SEN para el manejo de las alteraciones del metabolismo óseo-mineral en los pacientes con enfermedad renal crónica. Nefrología (2011); 31 (Suppl.1): 3-32.

20. Cunningham J et al. Secondary hyperparathyroidism: Pathogenesis, disease progression, and therapeutic options. Clin J Am Soc Nephrol (2011); 6: 913-921. 


\section{BIBLIOGRAFÍA}

21. Ritter CS et al. Parathyroid hyperplasia in uremic rats precedes down-regulation of the calcium receptor. Kidney Int (2001); 60: 1737-1744.

22. Babinsky $V$ et al. Association Studies of Calcium-Sensing Receptor (CaSR) Polymorphisms with Serum Concentrations of Glucose and Phosphate, and Vascular Calcification in Renal Transplant Recipients. PLoS ONE (2015); 10(3): e0119459.

23. Taal et al. Brenner \& Rector's The Kidney. 9a Edición. Elsevier-Saunders; 2011.

24. Canalejo R et al. FGF23 fails to inhibit uremic parathyroid glands. J Am Soc Nephrol (2010); 21: 1125-1135.

25. Galitzer $\mathrm{H}$ et al. Parathyroid cell resistance to FGF23 in secondary hyperparathyroidism of CKD. Kidney Int 2010; 77: 211-218.

26. Vázquez MA. Chronic rejection of renal transplants: new clinical insights. Am J Med Sci (2000); 320: 43-58.

27. Sprague et al. Abnormal bone and mineral metabolism in kidney transplant patients - A review. Am J Nephrol (2008); 28: 246-253.

28. López Oliva MO et al. Alteraciones del metabolismo óseo mineral en la enfermedad renal crònica del paciente trasplantado renal. Nefrología (2009); 29(sup. 1): 31-37.

29. Bonnin MR et al. Changes in serum osteocalcin levels in the follow-up of kidney transplantation. Ann Clin Biochem (1997); 34: 651-655.

30. Claesson $\mathrm{K}$ et al. Prospective study of calcium homeostasis after renal transplantation. World J Surg (1998); 22: 635-641.

31. Mikuls TR et al. Bone mineral density changes within six months of renal transplantation. Transplantation (2003); 75: 49-54. 


\section{BIBLIOGRAFÍA}

32. Oschatz E et al. Changes of coronary calcification after kidney transplantation. Am J Kidney Dis (2006); 48: 307-313.

33. Suwelack B et al. Effect of parathyroid hormone levels on carotid intima-media thickness after renal transplantation. Am J Hypertens (2001); 14: 1012-1018.

34. De Sevaux RG et al. Abnormal vitamin $D$ metabolism and loss of bone mass after renal transplantation. Nephron Clin Pract (2003);93:C21-C28.

35. Reinhardt $W$ et al. Sequential changes of biochemical bone parameters after kidney transplantation. Nephrol Dial Transplant (1998);13:436-442.

36. Rubello $D$ et al. Secondary hyperparathyroidism is associated with vitamin $D$ receptor polymorphism and bone density after renal transplantation. Biomed Pharmacother (2005); 59: 402-407.

37. Kusec V et al. Determinants of reduced bone mineral density and increased bone turnover after kidney transplantation: cross-sectional study. Croat Med J (2000); 41: 396-400.

38. Giannini S et al. Persistently increased bone turnover and low bone density in longterm survivors to kidney transplantation. Clin Nephrol (2001); 56: 353-363.

39. Torres A et al. Optimum PTH levels before renal transplantation to prevent persistent hyperparathyroidism. J Am Soc Nephrol (1998) 9: 572A.

40. Koch PC et al. Evolution of secondary hyperparathyroidism after renal transplantation. Pediatr Nephrol (2000); 14: 342-346.

41. Al-Gabri S et al. Changes in bone mineral density and selected metabolic parameters over 24 months following renal transplantation. Transplant Proc (2005);37:1014-1019. 


\section{BIBLIOGRAFÍA}

42. Brandenburg VM et al. Development of lumbar bone mineral density in the late course after kidney transplantation. Am J Kidney Dis (2002);40:1066-1074.

43. Rodriguez $\mathrm{M}$ et al. Calcemic response to parathyroid hormone in renal failure: role of phosphorus and its effect on calcitriol. Kidney Int (1991) 40: 1055-1062.

44. Cayco AV et al. Posttransplant bone disease: evidence for a high bone resorption state. Transplantation (2000);70:1722-1728.

45. Rosenbaum RW et al. Decreased phosphate reabsorption after renal transplantation: Evidence for a mechanism independent of calcium and parathyroid hormone. Kidney Int (1981); 19: 568-578.

46. Moe SM et al. Mechanisms of Vascular Calcification in Chronic Kidney Disease. J Am Soc Nephrol (2008); 19(2): 213-216.

47. Pande $S$ et al. FGF-23 and SFRP-4 in Chronic Kidney Disease and Post-Renal Transplantation. Nephron Physiol (2006); 104:23-32.

48. Trombetti A et al. Early post-transplantation hypophosphatemia is associated with elevated FGF-23 levels. Eur J Endocrinol. (2011); 164(5): 839-47.

49. Evenepoel P et al. Recovery of hyperphosphatoninism and renal phosphorus wasting one year after successful renal transplantation. Clin J Am Soc Nephrol (2008); 3: 18291836.

50. Han SY et al. Elevated fibroblast growth factor 23 levels as a cause of early post-renal transplantation hypophosphatemia. Transplant Proc. 2012); 44(3): 657-660.

51. Soylemezoglu $O$ et al. Changes in bone mineral density, insulin-like growth factor-1 and insulin-like growth factor binding protein-3 in kidney transplant recipients. A longitudinal study. Nephron (2002);91:468-473. 


\section{BIBLIOGRAFÍA}

52. Saag KG. Glucocorticoid-induced osteoporosis. Endocrinol Metab Clin North Am. (2003); 32: 135-157.

53. Vidal NO et al. Osteoprotegerin mRNA is expressed in primary human osteoblast-like cells: Down-regulation by glucocorticoids. J. Endocrinol. (1998); 159: 191-195.

54. Clowes JA et al. Glucocorticoid induced osteoporosis. Endocrinol Metab Clin North Am. (2003); 32; 135-157.

55. Hsueh AJ et al. Glucocorticoid inhibition of $\mathrm{FSH}$-induced estrogen production in cultured rat granulosa cells. Steroids. (1978); 32; 639-648.

56. Caniggia A et al. Pathophysiology of the adverse events of glucoactive corticosteroids on calcium metabolism in man. J Steroid Biochem Mol Biol. (1981); 15: 153-161.

57. Walsh CT et al. Cyclosporin A, the cyclophilin class of peptidylprolyl isomerases, and blockade of T-cell signal transduction. J Biol Chem. (1992); 267: 13.115-13.118.

58. Shui $\mathrm{C}$ et al. The immunosuppressant rapamycin, alone or with transforming growth factor beta, enhances osteoclast differentiation of RAW264.7 monocyte-macrophage cells in the presence of RANK-ligand. Calcif Tissue Int. (2002); 71: 437-446.

59. Kneissel $\mathrm{M}$ et al. Everolimus suppresses cancellous bone loss, bone resorption, and cathepsin K expression by osteoclasts. Bone. (2004); 35: 1.144-1.156.

60. K/DOQI Clinical Practice Guidelines for Bone Metabolism and Disease in Chronic Kidney Disease. Am J Kidney Dis (2003); 42 (4): Suppl 3.

61. Schlieper $\mathrm{G}$ et al. Vascular calcification in chronic kidney disease: an update. Nephrol Dial Transplant (2015); 0: 1-9. 


\section{BIBLIOGRAFÍA}

62. Foley RN et al. Epidemiology of cardiovascular disease in chronic kidney disease. J Am Soc Nephrol. (1998); 9: S16-S23.

63. Schoppet $M$ et al. Exploring the biology of vascular calcification in chronic kidney disease: what's circulating? Kidney Int. (2008); 73(4):384-390.

64. Valdivielso JM. Calcificación Vascular: Tipos y mecanismos. Nefrología (2011); 31(2):142-147.

65. Bellasi A et al. How long is the warranty period for nil or low coronary artery calcium in patients new to hemodialysis? J Nephrol. (2009); 22: 255-262.

66. Giachelli CM. Vascular calcification mechanisms. J Am Soc Nephrol (2004); 15: 295964.

67. Burke AP et al. Coronary calcification: insights from sudden coronary death victims. Z Kardiol (2000);89(Suppl 2):49-53.

68. Edmonds ME et al. Medial arterial calcification and diabetic neuropathy. Br Med J (Clin Res Ed) (1982);284:928-30.

69. Coll B et al. Large Artery Calcification on Dialysis Patients Is Located in the Intima and Related to Atherosclerosis. Clin J Am Soc Nephrol (2011);6(2): 303-310.

70. London $\mathrm{G}$ et al. Arterial aging and arterial disease: interplay between central hemodynamics, cardiac work, and organ flow-implications for CKD and cardiovascular disease. Kidney Int Suppl (2011) 2011; 1: 10-12.

71. Tyralla K et al. Cardiovascular changes in renal failure. Blood Purif (2002); 20: 462465. 


\section{BIBLIOGRAFÍA}

72. Block GA et al. Re-evaluation of risks associated with hyperphosphatemia and hyperparathyroidism in dialysis patients: Recommendations for a change in management. Am J Kidney Dis (2000);35:1226-37.

73. Reynolds JL et al. Human vascular smooth muscle cells undergo vesicle-mediated calcification in response to changes in extracellular calcium and phosphate concentrations: A potential mechanism for accelerated vascular calcification in ESRD. J Am Soc Nephrol (2004);15:2857-67.

74. Moe SM et al. Mechanisms of Vascular Calcification in Chronic Kidney Disease. J Am Soc Nephrol (2008); 19(2): 213-216.

75. Catherine M. Shanahan et al. Arterial calcification in chronic kidney disease: key roles for calcium and phosphate. Circ Res. (2011); 109(6): 697-711.

76. Jono $S$ et al. Phosphate regulation of vascular smooth muscle cell calcification. Circ Res. (2000);87:E10-17.

77. Lomashvili KA et al. Vascular calcification is dependent on plasma levels of pyrophosphate. Kidney Int (2014); 85: 1351-1356.

78. Lomashvili KA et al. Phosphate-induced vascular calcification: role of pyrophosphate and osteopontin. J Am Soc Nephrol. (2004);15:1392-1401.

79. St Hilaire C et al. NT5E mutations and arterial calcifications. N Engl J Med (2011); 364: 432-442.

80. Basalyga DM et al. Elastin degradation and calcification in an abdominal aorta injury model: role of matrix metalloproteinases. Circulation (2004); 110: 3480-3487.

81. Hosaka $\mathrm{N}$ et al. Elastin degradation accelerates phosphate-induced mineralization of vascular smooth muscle cells. Calcif Tissue Int (2009); 85: 523-529. 


\section{BIBLIOGRAFÍA}

82. Pai $A$ et al. Elastin degradation and vascular smooth muscle cell phenotype change precede cell loss and arterial medial calcification in a uremic mouse model of chronic kidney disease. Am J Pathol (2011); 178: 764-773.

83. Schlieper $G$ et al. Ultrastructural analysis of vascular calcifications in uremia. J Am Soc Nephrol (2010); 21: 689-696.

84. Wada et al. Calcification of vascular smooth muscle cell cultures: inhibition by osteopontin. Circ Res. (1999);84(2):166-178.

85. Villa-Bellosta $\mathrm{R}$ et al. Role of calcium-phosphate deposition in vascular smooth muscle cell calcification. Am J Physiol Cell Physiol. (2011);300:C210-220.

86. Byon $\mathrm{CH}$ et al. Oxidative stress induces vascular calcification through modulation of the osteogenic transcription factor Runx2 by AKT signaling. J Biol Chem. (2008);283:15319-15327.

87. Son BK et al. Statins protect human aortic smooth muscle cells from inorganic phosphate-induced calcification by restoring Gas6-Axl survival pathway. Circ Res. (2006);98:1024-1031.

88. Son B et al. Gas6/Axl-PI3K/Akt pathway plays a central role in the effect of statins on inorganic phosphate-induced calcification of vascular smooth muscle cells. Eur J Pharmacol. (2007);556:1-8

89. El-Abbadi MM, Pai AS, Leaf EM, Yang HY, Bartley BA, Quan KK, Ingalls CM, Liao HW, Giachelli CM. Phosphate feeding induces arterial medial calcification in uremic mice: role of serum phosphorus, fibroblast growth factor-23, and osteopontin. Kidney Int. (2009);75:1297-1307. 


\section{BIBLIOGRAFÍA}

90. Shanahan $\mathrm{CM}$ et al. Medial localization of mineralization-regulating proteins in association with Monckeberg's sclerosis: evidence for smooth muscle cell-mediated vascular calcification. Circulation. (1999);100:2168-2176.

91. Rucker R. Calcium binding to elastin. Adv Exp Med Biol. (1974);48(0):185-209.

92. Kovesdy CP et al. Outcomes associated with serum calcium level in men with nondialysis-dependent chronic kidney disease. Clin J Am Soc Nephrol. 2010;5:468-476.

93. Yang $\mathrm{H}$ et al. Elevated extracellular calcium levels induce smooth muscle cell matrix mineralization in vitro. Kidney Int. (2004);66:2293-2299.

94. Reynolds JL et al. Human vascular smooth muscle cells undergo vesicle-mediated calcification in response to changes in extracellular calcium and phosphate concentrations: a potential mechanism for accelerated vascular calcification in ESRD. J Am Soc Nephrol. (2004);15:2857-2867.

95. Shroff RC et al. Chronic mineral dysregulation promotes vascular smooth muscle cell adaptation and extracellular matrix calcification. J Am Soc Nephrol. (2010);21:103-112.

96. Kapustin A et al. Calcium Regulates Key Components of Vascular Smooth Muscle CellDerived Matrix Vesicles to Enhance Mineralization. Circ Res. (2011);109:e1-e12.

97. Farzaneh-Far A et al. Matrix gla protein is regulated by a mechanism functionally related to the calcium-sensing receptor. Biochem Biophys Res Commun. (2000);277:736-740.

98. Tyson KL et al. Osteo/chondrocytic transcription factors and their target genes exhibit distinct patterns of expression in human arterial calcification. Arterioscler Thromb Vasc Biol (2003);23:489-94. 


\section{BIBLIOGRAFÍA}

99. Cardús A et al. Differential effects of vitamin D analogs on vascular calcification. J Bone Miner Res (2007); 22: 860-866.

100. Mizobuchi $M$ et al. Differential effects of vitamin D receptor activators on vascular calcification in uremic rats. Kidney Int (2007); 72: 709-715.

101. Lopez I et al. Calcimimetic R-568 decreases extra osseous calcifications in uremic rats treated with calcitriol. J Am Soc Nephrol (2006); 17: 795-804.

102. Shroff $R$ et al. A bimodal association of vitamin $D$ levels and vascular disease in children on dialysis. J Am Soc Nephrol (2008); 19: 1239-1246.

103. Moe SM et al. Uremia induces the osteoblast differentiation factor Cbfa1 in human blood vessels. Kidney Int (2003);63:1003-11.

104. Tintut $Y$ et al. Tumor necrosis factor-alpha promotes in vitro calcification of vascular cells via the cAMP pathway. Circulation (2000);102:2636-42.

105. Watson KE et al. Fibronectin and collagen I matrixes promote calcification of vascular cells in vitro, whereas collagen IV matrix is inhibitory. Arterioscler Thromb Vasc Biol (1998);18:1964-71.

106. Watson KE et al. TGF-beta 1 and 25-hydroxycholesterol stimulate osteoblast-like vascular cells to calcify. J Clin Invest (1994);93:2106-13.

107. Gutierrez $O$ et al. Fibroblast growth factor-23 mitigates hyperphosphatemia but accentuates calcitriol deficiency in chronic kidney disease. J Am Soc Nephrol (2005); $16: 2205-2215$.

108. Shimada $T$ et al. Transgenic mice expressing fibroblast growth factor 23 (FGF23) demonstrate hypophosphatemia with low serum 1,25-dihydroxyvitaminD [1,25(OH)2D] and rickets/osteomalacia. J Bone Miner Res (2001); 16:S151. 


\section{BIBLIOGRAFÍA}

109. Lim $\mathrm{K}$ et al. Vascular klotho deficiency potentiates the development of human artery calcification and mediates resistance to fibroblast growth factor 23.Circulation (2012); 125:2243-2255.

110. Dominguez JR. Fractional excretion of phosphorus modifies the association between fibroblast growth factor-23 and outcomes. J Am Soc Nephrol (2013); 24:647654.

111. Craver et al.: A low fractional excretion of Phosphate/Fgf23 ratio is associated with severe abdominal Aortic calcification in stage 3 and 4 kidney disease patients. BMC Nephrology (2013); 14:221.

112. Scialla JJ et al. Cardiovascular Events in CKD.J Am Soc Nephrol.(2014); 25(2):349-60.

113. Faul C et al.: FGF23 induces left ventricular hypertrophy. J Clin Invest (2011); 121:4393-4408.

114. Scialla JJ et al. Fibroblast growth factor 23 is not associated with and does not induce arterial calcification. Kidney Int. (2013); 83(6): 1159-1168.

115. Kitagawa $M$ et al. A Decreased Level of Serum Soluble Klotho Is an Independent Biomarker Associated with Arterial Stiffness in Patients with Chronic Kidney Disease. PLoS ONE (2013); 8(2): e56695. doi:10.1371/journal.pone.0056695.

116. Nasrallah $\mathrm{MM}$ et al. Fibroblast growth factor-23 (FGF-23) is independently correlated to aortic calcification in haemodialysis patients. Nephrol Dial Transplant (2010); 25:2679-2685.

117. Jean $\mathrm{G}$ et al. High levels of serum fibroblast growth factor (FGF)-23 are associated with increased mortality in long haemodialysis patients. Nephrol DialTransplant (2009); 24:2792-2796. 


\section{BIBLIOGRAFÍA}

118. Ozkok et al. FGF-23 associated with the progression of coronary artery calcification in hemodialysis patients. BMC Nephrology (2013); 14:241.

119. Lee $C$ et al. Type 3 cystatins; fetuins, kininogen and histidine-rich glycoprotein. Front Biosci (Landmark Ed) (2009); 14: 2911-2922.

120. Schäfer $C$ et al. The serum protein alpha 2 -Heremans-Schmid glycoprotein/fetuinA is a systemically acting inhibitor of ectopic calcification. J Clin Invest (2003); 112: 357366.

121. Westenfeld R et al. Fetuin-A protects against atherosclerotic calcification in CKD. J Am Soc Nephrol (2009); 20: 1264-1274.

122. Ketteler $M$ et al. Association of low fetuin-A (AHSG) concentrations in serum with cardiovascular mortality in patients on dialysis: a cross-sectional study. Lancet (2003); 361: 827-833.

123. Herrmann $M$ et al. Clearance of fetuin-A--containing calciprotein particles is mediated by scavenger receptor-A. Circ Res (2012); 111: 575-584.

124. Demetriou M et al. Fetuin/alpha2-HS glycoprotein is a transforming growth factorbeta type II receptor mimic and cytokine antagonist. J Biol Chem (1996); 271: 1275512761.

125. Hofbauer LC et al. Osteoprotegerin: a link between osteoporosis and arterial calcification? Lancet (2001); 358: 257-259.

126. Schurgers $\amalg$ et al. Vitamin K-dependent carboxylation of matrix Gla-protein: a crucial switch to control ectopic mineralization. Trends Mol Med (2013); 19: 217-226. 


\section{BIBLIOGRAFÍA}

127. Speer MY et al. Inactivation of the osteopontin gene enhances vascular calcification of matrix Gla protein-deficient mice: evidence for osteopontin as an inducible inhibitor of vascular calcification in vivo. J Exp Med (2002); 196: 1047-1055.

128. López Gómez JM et al. Factores de riesgo cardiovascular en la enfermedad renal crónica. Nefrología Vol XXII. Suplemento 1. 2002.

129. Marcén R et al. Enfermedades cardiovasculares en el trasplante renal. Nefrología (2001); 21: 104-114.

130. Arnlov, J. et al. Low-grade albuminuria and incidence of cardiovascular disease events in non hypertensive and non diabetic individuals: the Framingham Heart study. Circulation (2005) 112, 969-975.

131. Garg A. et al. Albuminuria and renal insufficiency prevalence guides population screening: results from the NHANes iii. Kidneylnt (2002); 61: 2165-2175.

132. Culleton BF et al: Cardiovascular disease and mortality in a community-based cohort with mild renal insufficiency. Kidney Int (1999); 56: 2214-2219.

133. Jungers $P$ et al. Incidence and risk factors of atherosclerotic cardiovascular accidents in predialysis chronic renal failure patients: a prospective study. Nephrol Dial Transpl (1997) 12: 2597-2602.

134. Longenecker JC et al. For the CHOICE study: Validation of comorbid conditions on the end-stage renal disease medical evidence report: the CHOICE study. J Am Soc Nephrol (2000) 11: 520-529.

135. Foley $\mathrm{RN}$ et al. Clinical epidemiology of cardiovascular disease in chronic renal disease. Am J KidneyDis (1998):; 32 (Suppl.3): S112-S119. 


\section{BIBLIOGRAFÍA}

136. Baigent $C$ et al. Premature cardiovascular disease in chronic renal failure. Lancet (2000) 356, 147-152.

137. Coresh J et al. Epidemiology of cardiovascular risk factors in chronic renal disease. J Am Soc Nephrol (1998); 9: S24-S30.

138. Ritz E et al. Atherogenesis and cardiac death: are they related to dialysis procedure and biocompatibility? Nephrol Dial Transplant (1994); 8 (Suppl. 2): 165-172.

139. Locatelli $F$ et al. Cardiovascular disease in chronic renal failure: the challenge continues. Nephrol Dial Transplant (2000); 15 (Supl. 5): 69-80.

140. Rucker $D$ et al. Cardiovascular risk and management in chronic kidney disease. Nat. Rev. Nephrol. (2009); 5: 287-296.

141. Muntner $P$ et al. Traditional and nontraditional risk factors predict coronary heart disease in chronic kidney disease: results from the atherosclerosis risk in communities study. J. Am. Soc. Nephrol.(2005); 16: 529-538.

142. Port $\mathrm{F}$ et al. Predialysis blood pressure and mortality risk in a national sample of maintenance hemodialysis patients. Am J Kidney Dis (1999); 33: 507-517.

143. Tonelli M. et al. effect of pravastatin in people with diabetes and chronic kidney disease. J Am Soc Nephrol (2005); 16: 3748-3754.

144. Kasiske, BL et al. Hyperlipidemia in patients with chronic renal disease. Am. J. Kidney Dis. (1998); 32: s142-s156.

145. Liu $Y$ et al. Association between cholesterol level and mortality in dialysis patients: role of inflammation and malnutrition. JAMA (2004) 291,451-459. 


\section{BIBLIOGRAFÍA}

146. Kalantar-Zadeh et al. Survival advantages of obesity in dialysis patients. Am. J. Clin. Nutr.(2005); 81: 543-554.

147. Block, GA et al. Association of serum phosphorus and calcium $\times$ phosphate product with mortality risk in chronic hemodialysis patients: a national study. Am. J. Kidney Dis. (1998); 31: 607-617.

148. London, GM et al. Arterial media calcification in end-stage renal disease: impact on all-cause and cardiovascular mortality. Nephrol. Dial. Transplant.(2003); 18: 17311740.

149. Collins, AJ et al. Impact of hematocrit on morbidity and mortality. Semin Nephrol (2000); 20: 345-349.

150. Shlipak, MG. et al. Cardiovascular mortality risk in chronic kidney disease: comparison of traditional and novel risk factors. JAMA (2005); 293: 1737-1745.

151. Pecoits -Filho, $R$ et al. Interleukin- 6 is an independent predictor of mortality in patients starting dialysis treatment. Nephrol.Dial. Transplant. (2002); 17: 1684-1688.

152. De Zeeuw, D. et al.Proteinuria, a target for reno protection in patients with type 2 diabetic nephropathy: lessons from RENAAL. Kidney Int. (2004); 65: 2309-2320.

153. Lucius, R et al. Beyond blood pressure: new roles for angiotensin II. Cell. Mol. Life Sci. (1999); 56: 1008-1019.

154. Ojo AO. Cardiovascular complications after renal transplantation and their prevention.Transplantation (2006); 82(5):603-11.

155. Brynger $\mathrm{H}$ et al. Combined report on regular dialysis and transplantation in Europe, X, 1979. Proc Eur Dial Transplant Ass (1980) 17: 2-87. 


\section{BIBLIOGRAFÍA}

156. Schweitzer EJ et al. Causes of renal allograft loss. Progress in the 1980 s, challenges for the 1990s. Ann Surg (1991) 214: 679-688.

157. Matas AJ et al. Half-life and risk factors for kidney transplant outcome-importance of death with function. Transplantation (1993) 55: 757-761.

158. Hill MN et al. Changes in causes of death after renal transplantation, 1966 to 1987. Am J Kidney Dis (1991) 17: 512-518.

159. Lindholm A et al. Ischemic heart disease-major cause of death and graft loss after renal transplantation in Scandinavia. Transplantation (1995) 60: 451-457.

160. Salama DS et al. Comparison of intima-media thickness of the common carotid artery in dialysis and kidney transplant recipient patients. Exp Clin Transplant. (2011) Feb; 9(1):26-31.

161. Stompór T et al. Changes in common carotid artery intima-media thickness over 1 year in patients on peritoneal dialysis. Nephrol Dial Transplant.(2005);20(2):404-412.

162. Surdacki $A$ et al. Effect of having a functioning cadaveric renal transplant on cardiovascular mortality risk in patients on renal replacement therapy. Nephrol Dial Transplant. 1995;10(7):1218-23.

163. Kasiske BL. Risk factors for accelerated atherosclerosis in renal transplant recipients. Am J Med. (1988);84(6):985-92.

164. Valdés F et al. Incidence of cardiovascular events in renal transplant recipients and clinical relevance of modifiable variables. Transplant Proc (2007); 39: 2239-41.

165. Jeloka TK et al. Renal transplant outcome in high-cardiovascular risk recipients. Clinical Transplantation (2007); 21:609-14. 


\section{BIBLIOGRAFÍA}

166. De Mattos AM et al. Left ventricular function is better than coronary anatomy to predict survival of renal transplant candidates. ATC (2007); 546.

167. Teruel JL et al. Regression of left ventricular hypertrophy after renal transplantation. Transplantation (1997) 43: 307-309.

168. Parfrey PS et al. Impact of renal transplantation on uremic cardiomyopathy. Transplantation (1996)60: 908-914.

169. Chapman J et al. Hypertension after renal transplantation. A comparison of cyclosporine and conventional immunosuppression. Transplantation (1987); 43: 860864.

170. Marcén R et al. Impairment of tubular secretion of urate in renal transplant patients. Nephron 70 (1995): 307-313.

171. Warholm C et al: Hypertension two years after renal transplantation: causes and consequences. Transpl Int (1995) 8: 286-292.

172. Budde $\mathrm{K}$ et al. Hypertension in patients after renal transplantation. Transplant Proc (1997) 29: 209-211.

173. Pérez Fontán $M$ et al. Early immunologic and non immunologic predictors of arterial hypertension after renal transplantation. Am J Kidney Dis (1999) 33: 21-28.

174. Peschke B et al. Hypertension is associated with hyperlipidemia, coronary heart disease and chronic graft failure in kidney transplant recipients. Clin Nephrol (1999) 51: 290-295.

175. Luke RG: Pathophysiology and treatment of post transplant hypertension. J Am Soc Nephrol 2 (Supl. 1): S37-S44, 1991. 


\section{BIBLIOGRAFÍA}

176. McHugh $\mathrm{Ml}$ et al. Hypertension following renal transplantation: therole of the host's kidneys. Quart J Med (1980)49: 395-403.

177. First MR et al. Hypertension after renal transplantation. J Am Soc Nephrol (1994); 4 Suppl: S30-S36.

178. Curtis JJ. Cyclosporine and post transplant hypertension. J Am Soc Nephrol (1992); 2 Suppl: S243-S245.

179. Kasiske BL et al. Recommendations for the outpatient surveillance of renal transplant recipients. J AmSoc Nephrol 11 (2000) (Suppl. 15): S1-S86.

180. Kasiske BL. Clinical practice guidelines for managing dyslipidemias in kidney transplant patients. Am J Transplant 5 (2005):1576.

181. Pham PT et al. Cardiovascular disease post transplant. Semin Nephrol (2007); 27: 430-444.

182. Kasiske BL: Risk factors for accelerated atherosclerosis in renal transplant recipients. Am J Med (1988) 84:985-992.

183. Kasiske BL et al. Cardiovascular disease after renal transplantation. J Am Soc Nephrol (1996) 7: 158-165.

184. Kasiske BL et al. Explained and unexplained ischemic heart disease risk after renal transplantation. J Am Soc Nephrol (2000)11: 1735-1743.

185. Aker $S$ et al. Cardiovascular complications after renal transplantation. Transplant Proc (1998) 30: 2039-2042.

186. Aakhus $S$ et al. Cardiovascular morbidity and risk factors in renal transplant patients. Nephrol Dial Transplant (1999) 14; 648-654. 


\section{BIBLIOGRAFÍA}

187. Cosio FG et al. Patient survival after renal transplantation: IV. Impact of posttransplant diabetes. Kidney Int (2002); 62: 1440-1446.

188. Kasiske BL et al. Diabetes mellitus after kidney transplantation in the United States. Am J Transplant (2003); 3: 178-185.

189. Lindholm A et al. Ischemic heart disease: Major cause of death and graft loss after renal transplantation in Scandinavia. Transplantation (1995); 60: 451-457.

190. Fernandez-Fresnedo $G$ et al. Post transplant diabetes is a cardiovascular risk factor in renal transplant patients. Transplant Proc (2003); 35: 700.

191. Reisaeter AV et al. Risk factors and incidence of post transplant diabetes mellitus. Transplant Proc 33 (2001); Suppl: 8S-18S.

192. Bloom RD et al. Association of hepatitis $C$ with post transplant diabetes in renal transplant patients on tacrolimus. J Am Soc Nephrol (2002); 13: 1374-1380.

193. Friedman AN et al. Demographics and trends in overweight and obesity inpatients at time of kidney transplantation. Am J Kidney Dis (2003); 41: 480-487.

194. Cheigh JS et al. Kidney transplant nephrotic syndrome: relationship between allograft histopathology and natural course. Kidney Int (1980) 18 (3): 358-365.

195. Fernandez-Fresnedo $G$ et al. Proteinuria: Anew marker of long-term graft and patient survival in kidney transplantation. Nephrol Dial Transplant (2004); 19: III47-III51.

196. Roodnat $\mathrm{Jl}$ et al. Proteinuria after renal transplantation affects not only graft survival but also patient survival. Transplantation (2001); 72: 438-444.

197. Yildiz A et al.The prognostic importance of severity and type of post-transplant proteinuria. Clin Transplant (1999) 13: 241-244. 


\section{BIBLIOGRAFÍA}

198. Bear RA et al. Proteinuria in renal transplant recipients: incidence, cause and prognostic importance. Transplant Proc (1988) 20: 1235-1236.

199. Grimm RH et al. Proteinuria is a risk factor for mortality over 10 years of follow up. Kidney Int 52 (1997) (Supl. 63): s10-s14.

200. G. Fernández Fresnedo et al. Factores de riesgo cardiovascular en el trasplante renal: marcadores clínicos. Nefrología (2002). Vol. XXII. Suppl 4.

201. Rigatto $C$ et al. Congestive heart failure in renal transplant recipients: Risk factors, outcomes, and relationship with ischemic heart disease. J Am Soc Nephrol (2002); 13: 1084-1090.

202. Rigatto $C$ et al: Electrocardiographic left ventricular hypertrophy in renal transplant recipients: Prognostic value and impact of blood pressure and anemia relationship with ischemic heart disease. J Am Soc Nephrol (2003); 14: 462-468.

203. Imoagene-Oyedeji $A E$ et al. Post transplantation anemia at 12 months in kidney recipients treated with mycophenolate mofetil: Risk factors and implications for mortality. J Am Soc Nephrol (2006); 17:3240-3247.

204. Chauveau $P$ et al. Hyperhomocysteinemia, a risk factor for atheroesclerosis in chronic uremic patients. Kidney Int (1993); 42 (Suppl. 43): S72-S77.

205. Arnadottir $M$ et al. Serum total homocysteine concentration before and after renal transplantation. Kidney Int (1998); 54: 1380-1384.

206. Ducloux D et al. Prevalence, determinants, and clinical significance of hyperhomocyst(e)inaemia in renal-transplant recipients. Nephrol Dial Transplant (1998) 13: $2890-2893$. 


\section{BIBLIOGRAFÍA}

207. Winkelmayer WC et al. C-reactive protein and body mass index independently predict mortality in kidney transplant recipients. Am J Transplant (2004); 4: 1148-1154.

208. Ballesteros S. Morbi-mortalidad del trasplante renal de cadáver. Seguimiento a cinco años. Universidad de Valladolid (2010).

209. Horber FF et al. Changes in bone mass early after kidney transplantation. J Bone Min Res (1994) 9: 1-9.

210. Torres $A$ et al. Influence of vitamin $D$ receptor genotype on bone mass changes after renal transplantation. Kidney Int (1996) 50:1726-1733.

211. Torres A et al. Calcium Metabolism and Skeletal Problems after Transplantation. J Am Soc Nephrol (2002) 13: 551-558.

212. Almond MK et al. Loss of regional bone mineral density in the first 12 months following renal transplantation. Nephron (1994) 66: 52-57.

213. Horber FF et al. Changes in bone mass early after kidney transplantation. J Bone Min Res (1994) 9: 1-9.

214. Grotz W.H. et al. Bone fracture and osteodensitometry with dual energy X-ray absorptiometry in kidney transplant recipients. Transplantation (1994) 58: 912-915.

215. Ramsey-Goldman R et al. Increased risk of fracture in patients receiving solid organ transplants. J Bone Miner Res (1999) 14: 456-463.

216. Julián BA et al. Rapid los of vertebral mineral density after renal transplantation. New Eng J Med (1991); 325: 544-550.

217. Schwarz S et al. Association of Disorders in Mineral Metabolism with Progression of Chronic Kidney Disease. Clin J Am Soc Nephrol (2006); 1( 4): 825-831. 


\section{BIBLIOGRAFÍA}

218. Ayús JC et al. Left ventricular hypertrophy: Is hyperphosphatemia among dialysis patients a risk factor? J Am Soc Nephrol (2006); 17: S255-S261.

219. Kestenbaum B et al. Serum phosphate levels and mortality risk among people with chronic kidney disease. J Am Soc Nephrol (2005); 16: 520-528.

220. Forman JP et al. Vitamin D and Risk of Hypertension Plasma 25-Hydroxyvitamin D Levels and Risk of Incident Hypertension. Hypertension (2007); 49: 1063-69.

221. Wang TJ et al. Vitamin D deficiency and risk of cardiovascular disease. Circulation (2008);117:503-11.

222. Rumberger JA et al. Coronary calcium, as determined by electron beamed computed tomography and coronary disease on arteriogram: effect of patient's sex on diagnosis. Circulation (1995); 91: 1363.

223. Haydar AA et al. Coronary artery calcification is related to coronary atherosclerosis in chronic renal disease patients: a study comparing EBCT-generated coronary artery calcium scores and coronary angiography. Nephrol Dial Transplant (2004); 19: 2307.

224. Rumberger JA et al. Electron beam computed tomographic coronary calcium scanning: a review and guidelines for use in asymptomatic persons. Mayo Clinic Proceedings.(1999);74:243-252.

225. Arad $Y$ et al. Prediction of coronary events with electron beam computed tomography. Journal of the American College of Cardiology (2000); 36: 1253-1260.

226. Raggi $P$ et al. Identification of patients at increased risk of first unheralded acute myocardial infarction by electron-beam computed tomography. Circulation (2000); 101: 850-855. 


\section{BIBLIOGRAFÍA}

227. Matsuoka $M$ et al. Impact of high coronary artery calcification score (CACS) on survival in patients on chronic hemodialysis. Clin Exp Nephrol (2004); 8: 54-58.

228. Blacher J et al. Arterial calcifications, arterial stiffness, and cardiovascular risk in end-stage renal disease. Hypertension (2001); 38: 938-942.

229. Roe $P$ et al. Inflammation, coronary artery calcification and cardiovascular events in incident renal transplant recipients. Atherosclerosis (2010) Oct; 2012(2): 589-594.

230. Liefeldt $L$ et al. Risk factors for cardiovascular disease in renal transplant recipients and strategies to minimize risk. Transplant Int (2010); 23: 1191-1204.

231. Nguyen PT et al. Coronary artery calcification: a strong predictor of cardiovascular events in renal transplant recipients. Nephrol Dial Transplant.(2010); 25(11): 3773-3778.

232 Stompor $T$ et al. Renal transplantation ameliorates the progression of arterial stiffness in patients treated with peritoneal dialysis. Perit Dial Int (2005); 25: 492-496.

233. Moe SM et al. Natural history of vascular calcification in dialysis and transplant patients. Nephrol Dial Transplant (2004); 19: 2387-2393.

234. Robinson J et al. Electron-Beam Computerized Tomography Correlates with Coronary Angiogram in Chronic Kidney Disease Patients. Am J Nephrol (2007);27:247252.

235. Przemysław P. et al. Calcification of coronary arteries and abdominal aorta in relation to traditional and novel risk factors of atherosclerosis in hemodialysis patients. BMC Nephrol.(2013); 14: 10.

236. Srivaths PR. et al. Elevated FGF 23 and phosphorus are associated with coronary calcification in hemodialysis patients. Pediatr Nephrol. (2011) Jun;26(6):945-51. 


\section{BIBLIOGRAFÍA}

237. Cianciolo G. et al. Coronary calcifications in end-stage renal disease patients: a new link between osteoprotegerin, diabetes and body mass index? Blood Purif (2010); 29(1): $13-22$.

238. Moe SM et al. Assessment of vascular calcification in ESRD patients using spiral CT. Nephrol Dial Transplant. (2003); 18: 1152-1158.

239. Rosas SE et al. Coronary artery calcification in renal transplant recipients. Am J Transplant.(2005);5:1942-1947.

240. Shu KH et al. Coronary artery calcification in kidney transplant recipients with longterm follow-up. Transplant Proc (2012); 44: 687-690.

241. Budoff MJ et al. Relationship of estimated GFR and coronary artery calcification in the CRIC (Chronic Renal Insufficiency Cohort) study. Am J Kidney Dis (2011); 58(4): 51926.

242. Schankel K et al. Determinants of coronary artery calcification progression in renal transplant recipients. Am J Transplant. (2007); 7: 2158-2164.

243. Bayés B. Complicaciones metabólicas tras el trasplante renal. Nefrología (2009); 29(Suppl. Ext. 5): 27-32.

244. Yilmaz Ml et al. Predictors of Carotid Artery Intima-Media Thickness in Chronic Kidney Disease and Kidney Transplant Patients without Overt Cardiovascular Disease. Am J Nephrol (2010); 31: 214-221

245. Augst $A D$ et al. Analysis of complex flow and the relationship between blood pressure, wall shear stress, and intima-media thickness in the human carotid artery. Am J Physiol Heart Circ Physiol (2007); 293: H1031-H1037. 


\section{BIBLIOGRAFÍA}

246. Bayés B et al. Ghrelin, glucose homeostasis, and carotid intima media thickness in kidney transplantation. Transplantation 2007; 84: 1248-54.

247. Burroughs TE et al. Diabetic complications associated with new-onset diabetes mellitus in renal transplant recipients. Transplantation 2007; 83: 1027-34.

248. Osorio JM, et al. SEN 2008 - oral 515.

249. Honkanen E. et al. Abdominal aortic calcification in dialysis patients: results of the CORD study. Nephrol Dial Transplant. (2008); 23(12): 4009-4015.

250. Yoon HE et al. Abdominal aortic calcification is associated with diastolic dysfunction, mortality, and nonfatal cardiovascular events in maintenance hemodialysis patients. J Korean Med Sci. (2012); 27(8): 870-5.

251. Adragao T et al. A simple vascular calcification score predicts cardiovascular risk in haemodialysis patients. Nephrol. Dial. Transplant. (2004) 19 (6): 1480-1488.

252. Adragao T et al. A plain X-ray vascular calcification score is associated with arterial stiffness and mortality in dialysis patients. Nephrol. Dial. Transplant. (2009) 24 (3): $997-$ 1002.

253. Adragao T et al. Bone Mineral Density, Vascular Calcifications, and Arterial Stiffness in Peritoneal Dialysis Patients. Perit Dial Int (2008); 28:668-672.

254. Ono $\mathrm{K}$ et al. Ankle-brachial blood pressure index predicts all-cause and cardiovascular mortality in hemodialysis patients. J Am Soc Nephrol (2003); 14: 15911598.

255. Chen SC et al. Ankle brachial index as a predictor for mortality in patients with chronic kidney disease and undergoing hemodialysis. Nephrology (Carlton) (2010); 15: 294-299. 


\section{BIBLIOGRAFÍA}

256. Liu JH et al. Subclinical peripheral artery disease in patients undergoing peritoneal dialysis: risk factors and outcome. Perit Dial Int (2009); 29: 64-71.

257. Adragao $T$ et al. Ankle-brachial index, vascular calcifications and mortality in dialysis patients. Nephrol. Dial. Transplant. (2012) 27 (1): 318-325.

258. Wu SW et al. Subclinical Peripheral Arterial Disease in Renal Transplantation. Am J Med Sci. (2013) Mar 14.

259. Marshall D et al. Meta-analysis of how well measures of bone mineral density predict occurrence of osteoporotic fractures. BMJ (1996). 312: 1254-1259.

260. Chamith R. et al. Micro-MR Imaging-based Computational Biomechanics Demonstrates Reduction in Cortical and Trabecular Bone Strength after Renal Transplantation. Radiology. (2012); 262(3): 912-920.

261. Durieux $S$ et al. Bone mineral density and fracture prevalence in long-term kidney graft recipients. Transplantation (2002) 27;74(4):496-500.

262. Kodras K et al. Effect of kidney transplantation on bone. Eur J Clin Invest (2006); 36 (Suppl.S2): 63-75.

263. Horber FF et al. Changes in bone mass early after kidney transplantation. J Bone Miner Res (1994);9:1-9.

264. Gorriz JL et al. Características del metabolismo óseo y-mineral en pacientes con ERC en estadios 3-5 no en diálisis: resultados del estudio OSERCE. Nefrología (2013); 33: 4660.

265. Gorriz JL et al. Impact of vascular calcification assessed by simple radiography in allcause and cardiovascular mortality of non-dialysis chronic kidney disease patients: 


\section{BIBLIOGRAFÍA}

Results of the 3-year observational OSERCE-II study. Nephrol Dial Transplant (2014); 29 (suppl 3): ii54-ii55.

266. Torres A et al. Situación de las alteraciones del metabolism óseo y mineral (MOM) en una muestra representativa de la población trasplantada española (estudio EMITRAL). XLII Congreso Nacional de la Sociedad Española de Nefrología (2012). Maspalomas, Gran Canaria.

267. Von Elm E et al. Declaración de la iniciativa STROBE: Directrices para la comunicación de estudios observacionales. Nefrología (2009); 29 (suppl.1): 11-16.

268. Von Elm E et al. The Strengthening the Reporting of Observational Studies in Epidemiology (STROBE) statement: guidelines for reporting observational studies. Lancet (2007); 370(9596): 1453-1457.

269. Cockcroft DW et al. Prediction of creatinine clearance from serum creatinine. Nephron (1976); 16 (1): 31-41.

270. Gault $\mathrm{MH}$ et al. Predicting glomerular function from adjusted serum creatinine. Nephron (1992); 62 (3): 249-56.

271. Levey AS et al. A more accurate method to estimate glomerular filtration rate from serum creatinine: a new prediction equation. Modification of Diet in Renal Disease Study Group. Annals of Internal Medicine (1999); 130 (6): 461-70.

272. Rule $A D$ et al. Using serum creatinine to estimate glomerular filtration rate: accuracy in good health and in chronic kidney disease. Ann Intern Med. (2004);141(12):929-37.

273. Levey AS et al. A new equation to estimate glomerular filtration rate. Annals of Internal Medicine (2009); 150 (9): 604-12. 


\section{BIBLIOGRAFÍA}

274. Eckardt KU et al. Definition and Classification of CKD: The Debate Should Be About Patient Prognosis-A Position Statement From KDOQI and KDIGO. American Journal of Kidney Diseases (2009); 53 (6): 915-920.

275. Achenbach $S$ et al. Variability of repeated coronary artery calcium measurements by electron beam tomography. Am J Cardiol (2001); 87: 210-213.

276. Hoffmann U. Cardiology patient page. Use of new imaging techniques to screen for coronary artery disease. Circulation (2003); 108 (8): e50-3.

277. Al-Qaisi et al. Ankle brachial pressure index (ABPI): An update for practitioners. Vascular health and risk management (2009); 5: 833-41.

278. Kiel DP et al. Bone loss and the progression of abdominal aortic calcification over a 25 year period: The Framingham Heart Study. Calcif Tissue Int (2001); 68: 271-276.

279. The Seventh Report of the Joint National Committee on Prevention, Detection, Evaluation, and Treatment of High Blood Pressure (JNC 7). Hypertension (2003); 42: 1206.

280. Standards of Medical Care in Diabetes2014. Diabetes Care (2014); 37: Suppl 1.

281. Third Report of the National Cholesterol Education Program (NCEP) Expert Panel on Detection, Evaluation, and Treatment of High Blood Cholesterol in Adults (Adult Treatment Panel III): Final Report. Bethesda, MD: National Heart, Lung, and Blood Institute. National Institutes of Health Publication (2002); 2: 5215.

282. Kliger AS et al. KDOQI US Commentary on the 2012 KDIGO Clinical Practice Guideline for Anemia in CKD. Am J Kid Dis (2013); 62(5): 849-859.

283. Prevention and management of osteoporosis. WHO Technical Report Series (2003); 921. 


\section{BIBLIOGRAFÍA}

284. Hinkle DE et al. Applied Statistics for the Behavioral Sciences. 5th ed. Boston: Houghton Mifflin; 2003.

285. Rumberger JA et al. Electron-beam computed tomographic coronary calcium scanning:a review and guidelines for use in asymptomatic persons. Mayo Clin Proc (1999); 74: 243-252.

286. Miranda B. et al. Donación y trasplante renal en España 1989-1999. Nefrología Vol.20 (2000), Supl. 5.

287. Serón D et al. The Spanish Chronic Allograft Study Group. Late renal allograft failure between 1990 and 1998 in Spain: a changing scenario. Transplatation (2003); 76 (11): 1588-1594.

288. Andrés A et al. Trasplante renal con donantes de edad avanzada. Nefrología (1998); Vol. 18: Suppl.4.

289. Memoria de Actividad. ONT 2012.

290.Informe 2006 de diálisis y trasplante renal en España. Nefrología (2009);29(6):525533.

291. ERA-EDTA Registry: ERA-EDTA Registry Annual Report 2011. Academic Medical Center, Department of Medical Informatics, Amsterdam, The Netherlands, 2013.

292. U.S. Renal Data System, USRDS 2013 Annual Data Report: Atlas of Chronic Kidney Disease and End-Stage Renal Disease in the United States, National Institutes of Health, National Institute of Diabetes and Digestive and Kidney Diseases, Bethesda, MD, 2013.

293. McDonald S. et al. Survival or recipients of cadaveric kidney transplants compared with those receiving dialysis treatment in Australia and New Zealand. Nephrol Dial Transplant (2004) 17(12) 2212-2219. 


\section{BIBLIOGRAFÍA}

294. Arrieta J et al. Informe de la situación de diálisis y trasplante en España en 2004. Nefrología (2007) 27; 3: 279-299.

295. Marcén R et al. Enfermedad cardiovascular en el trasplante renal. Nefrología (2001); 11 (2): 104-114.

296. Marcén R et al. Prevalencia de los factores tradicionales de riesgo cardiovascular en los receptores de trasplante renal. Nefrología (2004); 14 (1): 65-66.

297. Kasiske B. Epidemiology of cardiovascular disease after renal transplantation. Transplantation (2001); 72 (6 Suppl.): S5-S8.

298. Holdaas $\mathrm{H}$ et al. Assessment of LEscol in Renal Transplantation (ALERT) Study Investigators.Effect of fluvastatin in cardiac outcomes in renal transplant recipients: a mulcitcentre, randomized, placebo-controlled trial. Lancet (2003); 361(9374): 20242031.

299. Moreso F et al. Riesgo cardiovascular e hipertensión arterial postrasplante. Nefrología (2009); 29 (Suppl. Ext. 3): 11-15.

300. Cupples CK et al. Characterizing dietary intake and physical activity affecting weight gain in kidney transplant recipients. Prog Transplant. (2012); 22(1): 62-70.

301. Lorenzetti $\mathrm{M}$ et al. Risk factors of cardiovascular disease in patients with functioning kidney grafts. Transplant Proc (1998); 30 (5): 2049.

302. Sánchez ZV et al. Perceived barriers and facilitators to physical activity in kidney transplant recipients. Prog Transplant. (2007); 17(4): 324-31.

303. Sarnak MJ et al. Kidney disease as a risk factor for development of cardiovascular disease: a statement from the American Heart Association Councils on Kidney in 


\section{BIBLIOGRAFÍA}

Cardiovascular Disease, High Blood Pressure Research, Clinical Cardiology, and Epidemiology and Prevention. Hypertension.(2003);42(5):1050-65.

304. Sarnak MJ et al. Chronic Kidney Disease as a Risk Factor for Cardiovascular Disease and All-Cause Mortality: A Pooled Analysis of Community-Based Studies. J Am Soc Nephrol (2004); 15(5): 1307-1315.

305. European best practice guidelines for renal transplantation. Section IV: Long-term management of the transplant recipient. Nephrol Dial Transplant (2002); 17 (Suppl.4): 1-67.

306. Coca $A$ et al. Estimation of the prevalence of CKD in healthy subjects by four different equations. Nephrol Dial Transplant (2013); 28: S1.

307. Kasiske BL et al. Long term deterioration of kidney allograft function. Am J Transpl (2005); 5: 1405-1414.

308. Marcén $\mathrm{R}$ et al. Chronic kidney disease in renal transplant recipients. Transplant Proc (2005); 37 (9): 3718-3720.

309. Meir-Kriesche HU et al. Immunosuppression: evolution in practice trends 19942004. Am J Transplant (2006) 6; 5: 1111-1131.

310. Artz MA et al. Conversion from cyclosporine to tacrolimus improves quality-of-life indices, renal graft function and cardiovascular risk profile. Am J Transplant (2004);4 (6): 937-945.

311. Shapiro R et al. Immunosuppression: Evolution in practice trends 1993-2003. Am J Transplant (2005);5 (4): 874-886.

312. Barros $X$ et al. Earlier decrease of FGF-23 and less hypophosphatemia in preemptive kidney transplant recipients. Transplantation (2012); 94(8): 830-836. 


\section{BIBLIOGRAFÍA}

313. Tsujita $\mathrm{M}$ et al. Beneficial effects of preemptive kidney transplantation on calcium and phosphorus disorders in early post-transplant recipients. Clin Exp Nephrol. (2015); 19(2): 319-24.

314. Van Husen $M$ et al. Fibroblast growth factor 23 and calcium phosphate homeostasis after pediatric renal transplantation. Pediatric Transplantation (2012); 16(5): 443-450.

315. Sánchez Fructuoso A et al. Role of fibroblast growth factor 23 (FGF23) in the metabolism of phosphorus and calcium immediately after kidney transplantation. Transplant Proc. (2012); 44(9): 2551-4.

316. Madhumathi R et al. Fibroblast growth factor and mineral metabolism parameters among prevalent kidney transplant patients. Int J Nephrol. (2012); 2012: 490623.

317. Malyszko J et al. FGF23 and Klotho in relation to markers of endotelial dysfunction in kidney transplant recipients. Transplant Proc (2014); 46(8): 2647-2650.

318. Saito $\mathrm{H}$ et al. Circulating FGF-23 is regulated by $1 \alpha, 25$-Dihydroxyvitamin D3 and phosphorus in vivo. J Biol Chem (2004); 280: 2543-2549.

319. Rao et al. Fibroblast Growth Factor and Mineral Metabolism Parameters among Prevalent Kidney Transplant Patients. Int J Nephrol (2012); 490623.

320. Sánchez Fructuoso A et al. Serum level of fibroblast growth factor 23 in maintenance renal transplant patients. Nephrol Dial Transplant (2012); 27:4227-4235.

321. Bacchetta J et al. The influence of glomerular filtration rate and age on fibroblast growth factor 23 serum levels in pediatric chronic kidney disease. J Clin Endocrinol Metab (2010); 95:1741-1748.

322. Kalantar-Zadeh $\mathrm{K}$ et al. Reverse epidemiology of cardiovascular risk factors in maintenance dialysis patients. Kidney International (2003); 63: 793-808. 


\section{BIBLIOGRAFÍA}

323. Mankovsky $B$ et al. Is serum uric acid a risk factor for atherosclerotic cardiovascular disease? A review of the clinical evidence.Part 1, diabetes and metabolic syndrome. Clin Res Rev (2010); 4: 176-184.

324. Krishnan $E$ et al. Hyperuricemia and the risk for subclinical coronary atherosclerosis-data from a prospective observational cohort study. Arthritis Res Ther (2011); 13: R66.

325. Neogi T et al. Serum uric acid is associated with carotid plaques: the National Heart Lung, and Blood Institute Family Heart Study. J Rheumatol (2009); 36: 378-384.

326. Neogi T et al. Serum urate is not associated with coronary artery calcification: the NHLBI Family Heart Study. J Rheumatol (2011); 38: 111-117.

327. Stompor $\mathrm{T}$ et al. Trends in coronary artery calcification in peritoneal dialysis and transplant patients. Nephrol Dial Transplant.(2004);19(12):3205-6.

328. Norby GE et al. Prevalence and risk factors for coronary artery calcification following kidney transplantation for systemic lupus erythematosus. Rheumatology (Oxford) (2011); 50(9): 1659-64.

329. Maréchal $C$ et al. Progression of coronary artery calcification and thoracic aorta calcification in kidney transplant recipients. Am J Kidney Dis. (2012); 59(2):258-69.

330. De Paolis $P$ et al. Modifications of Coronary Artery Calcifications (CAC) and Correlations with C Reactive Protein (CRP) Levels in Renal Recipients after the First Year of Transplantation. Open Journal of Nephrology (2013); 3: 1-5.

331. Abedi SA et al. Effect of renal transplantation on coronary artery calcification in hemodialysis patients. Transplant Proc. (2009); 41(7): 2829-31. 


\section{BIBLIOGRAFÍA}

332. Seyahi $\mathrm{N}$ et al. Progression of coronary artery calcification in renal transplant recipients. Nephrol Dial Transplant (2012); 27: 2101-2107.

333. Pencak $P$ et al. Calcification of coronary arteries and abdominal aorta in relation to traditional and novel risk factors of atherosclerosis in hemodialysis patients. BMC Nephrol.(2013); 14: 10.

334. Khan AM et al. FGF-23 and the Progression of Coronary Arterial Calcification in Patients New to Dialysis. Clin J Am Soc Nephrol. (2012); 7(12): 2017-2022.

335. Krasniak A. et al. Factors involved in vascular calcification and atherosclerosis in maintenance haemodialysis patients. Nephrol Dial Transplant (2007) 22: 515-521.

336. Russo D et al. Coronary Artery Calcification and Outcomes in Diabetic Patients with and without Chronic Kidney Disease. Blood Purif (2013); 36: 17-20.

337. D'Marco $L$ et al. Uric acid, atherosclerosis and vascular calcifications in chronic kidney disease. Invest Clin (2012); 53(1): 52-9.

338. Varagunam $\mathrm{M}$ et al. Pretransplantation levels of $\mathrm{C}$-reactive protein predict all-cause and cardiovascular mortality, but not graft outcome, in kidney transplant recipients. Am J Kidney Dis. (2004); 43(3): 502-7.

339. De Luca G et al. Uric acid does not affect the prevalence and extent of coronary artery disease. Results from a prospective study. Nutr Metab Cardiovasc Dis. (2012); 22(5): 426-33.

340. Suwelack B et al. Studies on structural changes of the carotid arteries and the heart in asymptomatic renal transplant recipients. Nephrol Dial Transplant (1999); 14(1): 160165. 


\section{BIBLIOGRAFÍA}

341. Töz $\mathrm{H}$ et al. Intima media thickness as a predictor of atherosclerosis in renal transplantation. Transplantation Proceedings (2004); 36(1): 156-158.

342. Schwenger V et al. Color Doppler Indices of Renal Allografts Depend on Vascular Stiffness of the Transplant Recipients. Am J Transplant (2006); 6(11): 2721-24.

343. Heine $\mathrm{GH}$ et al. Renal Doppler resistance indices are associated with systemic atherosclerosis in kidney transplant. Kidney Int (2005); 68: 878-885.

344. Brzósko $S$ et al. Correlation between carotid intima-media thickness and hematocrit and hemoglobin values in renal transplant recipients. Clin Transplant. (2001); 15(5): 34953.

345. Gungor $O$ et al. The associations between serum paraoxonase 1 activity and carotid atherosclerosis in renal transplant patients. Clin Nephrol.(2013); 80(3): 198-202.

346. Bilginer $Y$ et al. Carotid intima-media thickness in children and young adults with renal transplant: Internal carotid artery vs. common carotid artery. Pediatr Transplant. (2007); 11(8): 888-94.

347. Uchida J et al. Glucose Intolerance Is Associated with Increased Intimal Medial Thickness of the Carotid Artery and Increased Pulse Wave Velocity in Renal Transplant Recipients. Transplantation (2012); 94(10S): 826.

348. Janda K et al. Influence of elevated homocystein level and selected lipid parameters in kidney transplant patients on the progression of atherosclerotic changes assessed by intima-media thickness index (CCA-IMT). Przegl Lek.(2012); 69(9): 670-4.

349. Gungor $O$ et al. The relationships between serum sTWEAK, FGF-23 levels, and carotid atherosclerosis in renal transplant patients. Ren Fail. (2013); 35(1): 77-81. 


\section{BIBLIOGRAFÍA}

350. Asicioglu $E$ et al. Fibroblast growth factor-23 levels are associated with uric Acid but not carotid intima media thickness in renal transplant recipients. Transplant Proc. (2014); 46(1): 180-183.

351. Litwin $\mathrm{M}$ et al. Altered Morphologic Properties of Large Arteries in Children with Chronic Renal Failure and after Renal Transplantation. J Am Soc Nephrol (2005); 16(5): 1494-1500.

352. Mourer JS et al. Impact of late calcineurin inhibitor withdrawal on ambulatory blood pressure and carotid intima media thickness in renal transplant recipients. Transplantation (2013); 96(1):49-57.

353. Oh J et al. Advanced coronary and carotid arteriopathy in young adults with childhood-onset chronic renal failure. Circulation (2002); 106: 100-105.

354. Ross R. Atherosclerosis: an inflammatory disease. N Engl J Med (1999); 340(2):11526.

355. Friedman GD et al. The leukocyte count as a predictor of myocardial infarction. N Engl J Med. (1974); 290(23):1275-1278.

356. Kuo WK et al. Correlation of hematologic factors to carotid intima-media thickness in men and women: a study of 2767 asymptomatic subjects of Taiwan. Acta Neurol Taiwan. (2012); 21(4):158-64.

357. Matsumura T et al. Association between circulating leukocyte subtype counts and carotid intima-media thickness in Japanese subjects with type 2 diabetes Cardiovasc Diabetol. 2013; 12: 177.

358. Mitchell S et al. Elevated white blood cell count and carotid plaque thickness. Stroke (2001); 32: 842-849. 


\section{BIBLIOGRAFÍA}

359. Staub D et al. Prediction of Cardiovascular Morbidity and Mortality Comparison of the Internal Carotid Artery Resistive Index With the Common Carotid Artery IntimaMedia Thickness. Stroke (2006); 37: 800-805.

360. Chau DK et al. Vascular calcification in patients undergoing kidney and simultaneous kidney pancreas transplantation. Nephrology (Carlton). (2014) doi: 10.1111/nep.12212.

361. Meneghini $M$ et al. Calcium and osteoprotegerin levels predict the progression of the abdominal aortic calcifications after kidney transplantation. Transplantation (2013); 96: 42-48.

362. Toussaint ND et al. Associations between vascular calcification, arterial stiffness and bone mineral density in chronic kidney disease. Nephrol Dial Transplant (2008); 23: 586-593.

363. García-Canton C et al. Vascular calcification and 25-hydroxyvitamin D levels in nondialysis patients with chronic kidney disease stages 4 and 5.Nephrol Dial Transplant. (2011); 26(7): 2250-6.

364. Martino $\mathrm{F}$ et al. Abdominal aortic calcification is an independent predictor of cardiovascular events in peritoneal dialysis patients. Ther Apher Dial. (2013); 17(4): 44853.

365. Vouri S et al. Bisphosphonate use in patients undergoing dialysis.Consult Pharm. (2013); 28(11): 738-741.

366. Akaberi $S$ et al. Can DXA Predict Fractures in Renal Transplant Patients? American Journal of Transplantation (2008); 8: 2647-2651.

367. Gupta AK et al. Determinants of bone mineral density in stable kidney transplant recipients. J Nephrol (2012); 25(03): 373-383. 


\section{BIBLIOGRAFÍA}

368. Luo L et al. Impact of tacrolimus on bone metabolism after kidney transplantation. Int Immunopharmacol.(2012); 13(1): 69-72.

369. Huang WH et al. Impact of Hepatitis C Virus Infection on Bone Mineral Density in Renal Transplant Recipients. PLoSONE (2013); 8(5): e63263.

370. Jeon $\mathrm{HJ}$ et al.Impact of vitamin $\mathrm{D}$, bisphosphonate, and combination therapy on bone mineral density in kidney transplant patients. Transplant Proc. (2013); 45(8): 29637.

371. Tutal E et al. Low graft function and ongoing hyperparathyroidism are closely related to post-transplantation osteoporosis. Transplant Proc. (2013); 45(4): 1562-6.

372. Tokumoto $T$ et al. Clinical outcomes of recipients with aplastic bone disease after renal transplantation. Transplant Proc. (2012); 44(3): 680-3.

373. Derakhshan A et al. Bone mineral disorders in pediatric and adolescent renal transplant recipients. Pediatr Transplant. (2011); 15(4): 367-75.

374. Adragao $\mathrm{T}$ et al. Low bone volume-A risk factor for coronary calcifications in hemodialysis patients. Clin J Am Soc Nephrol (2009); 4: 450-455. 